\title{
Theories of \\ Social and Economic Justice
}

Edited by

AJ van der Walt 
e 
A Research Project of the Stellenbosch Institute for Advanced Study

\section{stias}

The Stellenbosch Institute for Advanced Study (STIAS) is a high-level research institution dedicated to keep Africa at the forefront of international scientific developments. It facilitates innovative and interdisciplinary research on issues that are of special relevance to the continent. It does so by inviting leading researchers from all over the world to work in close interaction with their counterparts from Africa. By including younger researchers in its projects, it contributes to the development of a next generation of scholars.

Website: http://academic.sun.ac.za/stias/ 


\section{Theories of Social and Economic Justice}

edited by
AJ VAN DER WALT
Professor, Faculty of Law,
Stellenbosch University 
SUN PRESS is a division of AFRICAN SUN MeDIA, Stellenbosch University's publishing division. SUN PRESS publishes academic, professional and reference works in electronic and print format. This publication may be downloaded or ordered directly from www.sun-e-shop.co.za.

\section{Copyright permissions}

William Forbath 'A not so Simple Justice: Frank Michelman on Social Rights, 1969 - Present' first appeared in (2004) 39 Tulsa Law Review 597-638. () W Forbath and Tulsa Law Review. Reprinted here (with minor editorial changes) with the kind permission of W Forbath and Tulsa Law Review.

Sandra Liebenberg 'The Value of Human Dignity in Interpreting Socio-Economic Rights' first appeared in (2005) 21 South African Journal on Human Rights 1-31. () S Liebenberg and Juta \& Co, publishers of $S A J H R$. Reprinted here (with minor editorial changes) with the kind permission of S Liebenberg, I Currie (editor of $S A J H R$ ) and Juta \& Co.

Charles Ngwena 'The Historical Development of the Modern South African Health-Care System: From Privilege to Egalitarianism' first appeared in (2004) 37 De Jure 290-312. (C) C Ngwena. Reprinted here (with minor authorial and editorial changes) with the kind permission of C Ngwena and De Jure, the editor of De Jure and Lexis-Nexis Butterworths.

Theunis Roux 'Pro-Poor Court, Anti-Poor Outcomes: Explaining the Performance of the South African Land Claims Court' first appeared in (2004) 20 South African Journal on Human Rights 511-543. () T Roux and Juta \& Co, publishers of $S A J H R$. Reprinted here (with minor editorial changes) with the kind permission of T Roux, I Currie (editor of $S A J H R$ ) and Juta \& Co.

Lucy Williams 'Beyond Labour Law's Parochialism: A Re-Envisioning of the Discourse of Distribution' first appeared in J Conaghan, RM Fischl \& K Klare (eds) Labour Law in an Era of Globalization: Transformative Practices and Possibilities (2002) Oxford University Press 93-114. (C L Williams and Oxford University Press. Reprinted here (with minor editorial changes) with the kind permission of L Williams, J Conaghan, RM Fischl and K Klare and Oxford University Press.

Published by SUN PRESS,

a division of AFRICAN SUN MeDIA,

Victoria Street, Stellenbosch 7600, South Africa

www.africansunmedia.co.za

All rights reserved.

No part of this book may be reproduced or transmitted in any form or by any electronic, photographic or mechanical means, including photocopying and recording on record, tape or laser disk, on microfilm, via the Internet, by e-mail, or by any other information storage and retrieval system, without prior written permission by the publisher.

First edition 2005

ISBN: 978-1-919980-82-9 | e-ISBN: 978-1-919980-84-3 | DOI: 10.18820/9781919980843

Cover design by Laura Oliver

Typesetting by Felini Studio

Set in 10 on 12.5 pt Sabon

Printed and bound by US Printers, Ryneveld street, Stellenbosch 7600 


\section{Contents}

Preface

Gregory S Alexander

Socio-Economic Rights in American Perspective:

The Tradition of Anti-Paternalism in American

Constitutional Thought

DANIE BRAND

The 'Politics of Need Interpretation' and the Adjudication of Socio-Economic Rights Claims in South Africa

STAN A du Plessis

New Tools for the Constitutional Bench

FANIE DU TOIT

Social Justice and Theological Method

WiLliam Forbath

A not so Simple Justice: Frank Michelman on Social Rights,

1969 - Present

\section{Derik Gelderblom}

The Just Community: Emile Durkheim on Liberalism and Society

Nico N KoOpman

Theology and the Fulfilment of Social and Economic Rights:

Some Theoretical Considerations

SANDRA LiEBENBERG

The Value of Human Dignity in Interpreting Socio-Economic Rights

\section{Elsabe Loots}

The Fiscal Implications of Social and Economic Justice:

An Overview of the Changing Theoretical Framework

Charles Ngwena

The Historical Development of the Modern South African

Health-Care System: From Privilege to Egalitarianism 
Pro-Poor Court, Anti-Poor Outcomes:

Explaining the Performance of the South African

Land Claims Court

\section{DiRKIE J SMIT}

On Social and Economic Justice in South Africa Today:

A Theological Perspective on Theoretical Paradigms

LuCY A Williams

Beyond Labour Law's Parochialism:

A Re-Envisioning of the Discourse of Redistribution

Ross ZuCKer

Opening the Door to More Equality

BIBLIOGRAPHY

CASES

309

Legislation and Policy Documents

312

INDEX 


\section{Preface}

The bulk of the contributions that make up this book originated in a research project initiated by the Stellenbosch Institute for Advanced Study (STIAS) in 2002. The Director of the Institute, Bernard Lategan, asked me whether I would be interested in running a research project with STIAS; I proposed a project on Theories of Social and Economic Justice, which was accepted; and the result was that STIAS hosted a workshop in July 2004 in which researchers from Law, Economics, Theology and Sociology participated. One distinguished participant was a STIAS Research Fellow at the time, Gregory S Alexander (Cornell Law School). ${ }^{1}$ The contributions at the workshop were of such a standard and the debate so interesting that everybody agreed that it would be useful to publish some of the papers resulting from the presentations. Participants were therefore invited to submit papers for publication.

Johan van der Walt (University of Johannesburg) and Dr Tessa Marcus (National Research Foundation), both of whom attended the workshop, helped me decide which of the presentations were suitable for publication and made suggestions on possible amendments and revisions. The end result was a group of very interesting papers dealing with various theories of social and economic justice. However, because of the fairly rigorous review process the selected contributions were just not quite substantial enough for a full-scale publication and I had to either supplement the selected papers or abandon the publication project. One or two of the participants published extended versions of their workshop presentations or related work in peer-reviewed journals and agreed to these articles being re-published here. ${ }^{2}$ To flesh out the intended publication I also approached a number of colleagues, both in South Africa and abroad, who had not participated in the workshop but whose recently published work on social and economic justice fitted in with the project extremely well, and I asked them for permission to re-publish their articles and essays together with the ones selected from the workshop. They all graciously agreed, and the result is the book you have in your hands now. ${ }^{3}$

The idea for the STIAS project on Theories of Social and Economic Justice had its origin in an article I had written in 2002 for a collection of South African essays in honour of US scholar Frank I Michelman. ${ }^{4}$ In that article, I developed the thought that the attainment of greater social and economic justice, specifically in the South African context, was strongly influenced

1 Prof Alexander's work on social and economic justice includes GS Alexander 'The Concept of Property in Private and Constitutional Law: The Ideology of the Scientific Turn in Legal Analysis' (1982) 82 Columbia LR 1545-1599; GS Alexander Commodity \& Propriety: Competing Visions of Property in American Legal Thought 1776-1970 (1997).

2 Sandra Liebenberg 'The Value of Human Dignity in Interpreting Socio-Economic Rights' first appeared in (2005) 21 SAJHR 1-31; Theunis Roux 'Pro-Poor Court, Anti-Poor Outcomes: Explaining the Performance of the South African Land Claims Court' first appeared in (2004) 20 SAJHR 511-543.

3 William Forbath 'A not so Simple Justice: Frank Michelman on Social Rights, 1969 - Present' first appeared in (2004) 39 Tulsa Law Review 597-638; Charles Ngwena 'The Historical Development of the Modern South African Health-Care System: From Privilege to Egalitarianism' first appeared in (2004) 37 De Jure 290-312; Lucy Williams ‘Beyond Labour Law's Parochialism: A Re-Envisioning of the Discourse of Distribution' first appeared in J Conaghan, RM Fischl \& K Klare (eds) Labour Law in an Era of Globalization: Transformative Practices and Possibilities (2002) Oxford University Press 93-114. Ross Zucker kindly agreed to write a substantially new contribution for this volume, based on the theoretical worked that underlies his recently published book Democratic Distributive Justice (2002). 
by the implications and the coherence of various theories of social and economic justice. One of my central hypotheses in that article was borrowed from Frank Michelman, namely that my approach would be what Michelman described as 'provisional adoption, as inchoate legal doctrine, of a theory of social justice. ${ }^{5}$ In other words, I accepted that theory does make a difference on the struggle for greater social and economic justice, but nevertheless argued that the best approach was not to develop a single, coherent and all-encompassing grand theory but rather to uncover the strengths and the weaknesses of several theoretical approaches for different contexts and circumstances. ${ }^{6}$ In doing so I was aware of the danger of facile eclecticism and tried to avoid it - the fact that several theoretical approaches could have different benefits in various contexts does not mean that they are all relatively or equally useful or valid; in fact, several theories are subjected to strong criticism in the article. The 'new property' theories based on Charles Reich's work, ${ }^{7}$ for instance, are subjected to a critique that implies that these theories are not suitable for arguments in favour of state provision of access to social and economic benefits. ${ }^{8}$ Equally strong criticism is leveled at equality-based theories, partly relying on a critique developed by Michelman. ${ }^{9}$ On the other hand, however, equality-based theories have proven to be particularly useful and strong when attacking state provision of social and economic support on the basis of non-participation, lack of access or unfair denial and termination; just as the property-based theories are very useful when protecting already vested and acquired benefits from amendment or termination. In short, the article concluded that the promotion and protection of social and economic justice need to be approached from different theoretical perspectives when considering different practical circumstances, contexts and dilemmas. One theoretical size simply does not fit all, as far as social and economic justice is concerned.

In the process of developing and making this argument I concentrated quite strongly on the central distinction between rights-based and needs-based theories of social and economic justice, partly because of Michelman's pivotal role in emphasizing the distinction and the importance of the often ignored needs-based arguments. ${ }^{10}$ The theoretical arguments on either side of this divide have both weaknesses and strengths, which underlines the central finding that a variety of even seemingly contradictory theoretical approaches could offer useful insights when developing strategies for the promotion and protection of social and economic justice. Rights talk has serious shortcomings and has quite rightly been criticized very harshly; needs talk poses considerable theoretical and moral problems that detract from its intuitive appeal; but nevertheless the experience of the impoverished and the marginalised in post-apartheid South Africa has shown convincingly that both kinds of rhetoric may have their place in strategic thinking about social and economic transformation. When faced with the stark reality of the utterly and

4 The book was published as H Botha, A van der Walt \& J van der Walt (eds) Rights and Democracy in a Transformative Constitution (2003). My essay, entitled 'A South African Reading of Frank Michelman's Theory on Social Justice', appeared at 163-211. It was subsequently re-published in (2004) 19 SA Public Law 253-307. I refer to the original pagination in Botha, van der Walt \& van der Walt here.

5 Van der Walt (note 4 above) at 180, citing FI Michelman 'The Supreme Court 1968 Term - Foreword: On Protecting the Poor through the Fourteenth Amendment' (1969) 83 Harvard LR 7 at 10.

6 In van der Walt (note 4 above) at $204 \mathrm{ff}$ I described this process as 'twisting rope'.

7 C Reich 'The New Property' (1964) 73 Yale LJ 733; C Reich 'Individual Rights and Social Welfare: The Emerging Legal Issues' (1965) 74 Yale LJ 1245.

8 Van der Walt (note 4 above) at 168.

9 Van der Walt (note 4 above) at 174. 
hopelessly destitute, those who have lost even whatever access to rudimentary shelter and safety they had through natural disaster or social upheaval, there is just no place for a hard-nosed approach based on rights talk, and a different attitude is required. To their credit, the South African courts have shown a growing awareness of this need for different approaches in different circumstances, and they have been particularly successful in developing a context-sensitive and weakness-aware approach to the position of those who cannot claim anything within the parameters of a strictly rights-based discourse. ${ }^{11}$ However, in another context it is equally valid to abandon the softer approach of needs talk and resort to the harder, more self-confident rhetoric of rights when that is the best way of protecting rights already acquired. ${ }^{12}$

The article had three theoretically interesting implications that informed the STIAS project. Firstly, I concluded that 'theory matters'; in other words, theory makes a difference in the practical, legal and political struggle around social and economic justice. The struggle for social and economic justice was not theory-innocent, theory-neutral or theory-agnostic; in fact, it was very directly and clearly informed and influenced by theoretical assumptions, even when those assumptions were taken for granted and never questioned, discussed or even clearly articulated. Whenever a particular instance of legislative drafting, policy formulation, administrative action or judicial decision-making avoided or ignored theoretical arguments or approaches completely, the result was not that it was theory-neutral but rather that it simply accepted and confirmed the 'normality assumption',13 that set of theoretical assumptions accepted without thinking by the majority of a particular interpretive community at a certain time.

The second implication was, in the tone of a hypothesis, that theory had restraining as well as energizing effects on the promotion of social and economic justice, because the more or less automatic reliance of the 'normality assumption' or default position would usually resist change and affirm the status quo. Moreover, lack of theoretical development could result in a kind of 'theory drag' in the sense that practical political development could sometimes outstrip theoretical thinking, creating a vacuum of nonexistent theoretical explanation, justification and inspiration that could hold development back even when the political will to promote it is strong. This effect was clearly visible in the South African situation ever since the promulgation of the new democratic constitutions in 1993 and 1996: political development easily outpaced academic efforts to produce and develop suitable, useful theoretical work that could serve as inspiration and reflective material for policy making, and ever since academics have more or less been doing their utmost to catch up with - rather than prompt, inspire or challenge - policy making and legislative processes.

The third conclusion was already alluded to earlier: theoretical interest for and the effect of theory on the promotion of social and economic development reflect a wide range of different kinds and levels of theoretical thinking, ranging from legal doctrine through political philosophy to critical theory, from due process-based theories of political organization, division of powers and judicial law-making to social theories of individualism, community and the ethics

10 Van der Walt (note 4 above) at 196-204. In his contribution to this book Forbath analyses Michelman's contribution and arguments in depth.

11 Particularly in Government of the Republic of South Africa and Others v Grootboom and Others 2001 (1) SA 46 (CC); but see further in Port Elizabeth Municipality $v$ Various Occupiers 2005 (1) SA 217 (CC).

$12 \mathrm{E} g$ in Nhlabati and Others $v$ Fick 2003 (7) BCLR 806 (LCC).

13 A phrase coined by Rosemary Coombe "Same as it Ever Was": Rethinking the Politics of Legal Interpretation' 1989 McGill LJ 603-652. 
of care. Legal theory, political theory, social theory, economic theory, theological thinking and many other fields of theoretical endeavour could possibly cast useful light on the dynamics that either promote or inhibit the promotion of social and economic justice. The project therefore had to be a cross- or multi-disciplinary one. The question was: are there any benefits to be had from discussing social and economic justice from the perspective of these theoretical hypotheses in different disciplines? Is it worthwhile to investigate the notion that theoretical assumptions and paradigms affect the promotion of social and economic justice; or the idea that theory drag could inhibit social and economic development?

The participants in the STIAS workshop took on the challenge to discuss the ideas that 'theory matters' and of 'theory drag' and developed them in the fields of economic theory, social philosophy, theological thinking and legal theory. The range of theoretical approaches represented in this book exemplifies the success of their efforts, and the fact that it made more sense to arrange the contributions alphabetically rather than thematically is testimony to the truly cross- and multi-disciplinary nature of the contributions. The most obvious way of arranging the contributions, namely according to broad subject (law, economics, theology) was precluded by the fact that economists and theologians involved themselves deeply in legal theory (Stan du Plessis, Dirkie Smit, Fanie du Toit), just like lawyers, theologians and sociologists involved themselves deeply in economic theory (Ross Zucker, Derik Gelderblom and Fanie du Toit).

The range of theoretical approaches from which the importance and the potential effect of theory on social and economic justice are analysed in the contributions to this book is surprisingly wide, although there is a perhaps predictably strong interest in the conflicts between social and communitarian theories and individualist, liberal theoretical approaches (Smit, Koopman, Liebenberg, Brand, Roux, Gelderblom, Ngwena, Forbath, Alexander, Williams). Several contributors investigate different versions of what could be described as a dialogic or discursive theory of rights (Nico Koopman, Danie Brand), while others discuss different institutional theories of rights (Stan du Plessis, Theunis Roux, Ross Zucker). One of the fairly general conclusions that could be drawn from the contributions as a whole is that liberal, individualist theories could tend to inhibit the promotion of social and economic justice in so far as these theories rely strongly on individual rights, whereas social and economic justice at least sometimes requires state-sponsored actions that are not premised on the existence of such rights (Liebenberg, Roux, Brand, Ngwena). These general conclusions are supported by more detailed and contextual analyses of the promotion of social and economic justice in very specific areas such as labour (Williams), land reform (Roux), and health services (Ngwena), from which more general arguments about social and economic justice follow. The value of these analyses is enhanced by the comparative theoretical contributions from US scholars (Alexander, Forbath, Williams and Zucker) and by historical perspectives (Alexander, Forbath, Ngwena). In sum, these contributions constitute a valuable source of theoretical insight and argument about social and economic justice, particularly about the role of theory in either promoting or inhibiting the advancement of justice.

A number of people contributed to the success of the STIAS workshop and the resulting book. Bernard Lategan, the director of STIAS, provided continuing financial, intellectual and institutional support for the whole project. Johan van der Walt and Tessa Marcus contributed intellectual insight in and rigour to the evaluation and selection of presentations. Gerhard du Toit provided enthusiastic assistance with the editing of contributions and he also compiled the bibliography and index. All the participants in the STIAS workshop, both those who presented papers and the discussants, helped to generate valuable discussion and intellectual exchange from a variety of disciplines. The participants who submitted contributions to this book assist- 
ed in taking the discussion further and in developing the ideas and insights into something that can form the basis for continuing debate. Contributors who agreed to write new work or to republish their earlier work in the book made it possible to produce a more extensive and wideranging collection of readings. Journals, editors and publishers who agreed to re-publication graciously allowed us to produce this wider collection of contributions. STIAS and Sun Press generously agreed to assist in publishing what is an extremely interesting but in many respects probably not very profitable book. I would like to extend my warm and heartfelt gratitude to them all.

\author{
André van der Walt \\ Stellenbosch \\ May 2005
}




\title{
Socio-Economic Rights in American Perspective: The Tradition of Anti-Paternalism in American Constitutional Thought
}

\author{
- Gregory S AlexAnder \\ Robert Noll Professor of Law, \\ Cornell University, Ithaca, NY
}

\section{Introduction}

As many constitutional law scholars have noted, with respect to socio-economic rights, American constitutional law is an outlier. While many, perhaps even most, of the world's constitutions recognize at least some socio-economic rights, either textually or through judicial interpretations, the US Constitution does not. Individuals have no basis under the American constitution for asserting positive claims against the state for the provision of even the barest of necessities. Nor is there any basis for constitutional socio-economic rights even as aspirational goals.

Why is this the case? Why has American constitutional law never recognized socio-economic interests as rights that entitle individuals to substantive protection, even aspirationally? Professor Cass Sunstein has argued that the best explanation focuses on a particular historical moment when a change in the membership of the US Supreme Court undermined the only opportunity that has existed for the Court to recognize constitutional socio-economic rights. ${ }^{1}$ In making this argument, Sunstein rejects several other possible explanations, including explanations that look to American legal traditions and culture.

In this brief essay, I shall suggest that while Sunstein's self-styled 'Legal Realist' explanation is correct as far as it goes, it is incomplete. Sunstein too quickly rejects legal culture and tradition as the key to understanding why American constitutional jurisprudence has historically not given substantive protection to socio-economic interests. A deeper look at the traditions of American legal jurisprudence reveals that the continual presence of a distinctive social vision in constitutional thought that is fundamentally at odds with the idea of constitutional socio-economic rights. This social vision is that of anti-paternalism. Anti-paternalism has both framed the way in which American judges view socio-economic interests and created a strong presumption against any fullscale recognition of such interests as substantively-protectable constitutional rights throughout American constitutional history, though such rights certainly do exist as a statutory matter. The explanation for America's failure to recognize socio-economic rights at a constitutional level results, I will argue, from a combination of two factors: the legal-political culture of anti-paternalism and the institutional character of constitutional rights in the American political and legal sphere.

1 CR Sunstein The Second Bill of Rights: FDR's Unfinished Revolution and Why We Need It More than Ever (2004). 
In focusing on the culture of anti-paternalism, I am not proposing a monist theory. Anti-paternalism has not been the exclusive social vision throughout American history. Another social vision has also been available in American constitutional thought, and this alternative vision might have been exploited to support the recognition of constitutional socio-economic rights as compatible with the traditions of American constitutionalism. This is the social vision of civic republicanism. While civic republican ideas have not been ascendant in American constitutional jurisprudence since the 18th century, their presence has been felt at particular moments and may yet be felt again. Civic republicanism, however, is a recessive gene in American's constitutional genetic order. It seems highly unlikely to have the kind of strength necessary to generate the constitutional mutation that would yield a new species of individual rights in the American system. Moreover, there are substantive aspects of civic republicanism, particularly its historic hierarchical and exclusionary characteristics, that make it a weak candidate for supporting substantive socio-economic rights as a constitutional matter.

Before explaining why American constitutional law has never recognized socio-economic interests as basic rights, I need first to establish that in fact they have not, at least not overtly or robustly. I will then turn to the question of explanation and briefly sketch the anti-paternalist social vision that has made the idea of socio-economic interests as substantive constitutional rights seem uncongenial, if not anathema to the American legal mind.

\section{Socio-Economic Interests In American Constitutional Jurisprudence}

The appropriate starting place in any study of the status of socio-economic rights in American constitutional law is the familiar distinction in liberal thought between positive and negative rights. Positive rights, orthodox liberal thought tells us, impose affirmative obligations on the state to act on behalf of the individual. They compel the state to reach into its pocket to make provision for certain individual needs. They remove from the realm of governmental discretionary judgment the decision about whether to ensure that individual citizens enjoy the basic material conditions necessary for both civic participation and personal self-development. Negative rights, by contrast, restrain the state from acting, rather than requiring, as positive rights do, its affirmative action on behalf of individuals. They are 'checks,' that is, means of protecting individuals from governmental actions that unduly impinge on a sacred sphere of personal autonomy. Classical liberal legalism considers negative rights as real rights and positive rights as unpalatable pretenders.

This distinction between negative and positive rights is the appropriate starting place for understanding the place of socio-economic interests in American constitutionalism because American constitutional thought invariably labels socio-economic rights as positive rights and, as such, ersatz rights. The commonplace understanding in the United States is that constitutional rights are exclusively negative rights. Judge Richard Posner has pithily expressed what is in most American constitutional law circles regarded as bedrock truth: the American Constitution 'is a charter of negative rather than positive liberties.'2 Posner further explains, 'The men who wrote the Bill of Rights were not concerned that Government might do too little for the people, but that it might do too much to them.' What Posner is telling us is that there is no constitutional right to socioeconomic benefits, ${ }^{3}$ nor will such a right ever exist in the American constitutional scheme.

2 Jackson $v$ City of Joliet 715 F 2d 1200, 1203 (7th Cir) cert denied 465 US 1049 (1983).

3 DP Currie 'Positive and Negative Constitutional Rights' (1986) 53 Univ of Chicago LR at 864, 864. 
Posner's assessment is misleading in several respects. Consider first his unexamined reliance on the conventional distinction between negative and positive rights. The distinction between the two is less categorical than first meets the eye. A central insight of the American Legal Realists was that so-called negative rights are in fact interventionist in character. The exercise of such rights require government assistance, most conspicuously through enforcement. Indeed, Bentham pointed out that property rights would not exist in the absence of state power. The dependence of negative rights on affirmative state action makes the distinction between positive and negative rights much less clear than Posner and classical liberal theory recognize.

A second reason why Posner's dismissal of positive rights from the pantheon of American constitutional rights is inaccurate is the fact that although American constitutional rights traditionally have been negative in nature, positive rights are not entirely unknown in American constitutional jurisprudence. ${ }^{4}$ Many American state constitutions contain affirmative guarantees of specific socio-economic interests, such as education. ${ }^{5}$ The New Hampshire Constitution of 1784 even constitutionalized the Lockean social compact by conferring on every citizen 'the right to be protected . . in the enjoyment of his life, liberty, and property.' 6

More important perhaps, the American Supreme Court, while generally rebuffing efforts to recognize positive constitutional rights, has recognized positive rights in a few instances. In 1956, the Court held that the equal protection clause requires states to provide trial transcripts (or their equivalent) to poor people appealing their criminal convictions. ${ }^{7} \mathrm{~A}$ decade later, the Court held that state poll taxes violate the Constitution. The effect of that ruling was that states must provide the vote free of charge despite the fact that this imposes costs on the state. ${ }^{8}$ To some extent, then, it is inaccurate to say that the American Constitution does not recognize any positive socio-economic rights or rights that require the state to reach into its pocket.

Posner might object that the recognition of rights such as these does not prove very much with respect to socio-economic interests. In these cases the Court recognized positive rights only when the meaningful exercise of some independent and fundamental aspect of citizenship, such as the right to vote or to prove criminal innocence, required the provision of economic benefits by the state. That is not the case with respect to socio-economic rights.

It is worth pausing for a moment on just what we mean when we speak of 'socio-economic rights.' Liberals (classical liberals) consider socio-economic rights to be 'second-generation rights,' with the first generation being classical liberal negative rights. In modern times, they were first introduced into the American political and legal lexicon in a serious way in President Franklin D Roosevelt's famous Second Bill of Rights address to Congress. ${ }^{9}$ Roosevelt's Second Bill of Rights, which, along with the Universal Declaration of Human Rights, inspired the social rights provisions of many modern constitutions, ${ }^{10}$ included not only welfare rights but workrelated rights as well. Thus, among the rights Roosevelt specified were ' $[t]$ he right to earn enough to provide adequate food and clothing and recreation' and '[t]he right to a useful and remunerative job in the industries or shops or factories or mines of the Nation.' Roosevelt

4 See DP Currie The Constitution of the Federal Republic of Germany (1994) at 14.

5 See eg Ill Const Art X $\mathbb{} 1$.

6 NH Const Pt I Art 12 (1784).

7 Griffin v Illinois 351 US 12 (1956).

8 Harper $v$ Virginia Board of Elections 383 US 663 (1966).

9 FD Roosevelt 'Objectives of the Administration' (June 8, 1934) in The Public Papers and Addresses of Franklin D Roosevelt (1938) vol 3 at 291-92.

10 WE Forbath 'Not So Simple Justice: Frank Michelman on Social Rights 1969-Present' (2004) 39 Tulsa LR 597 at $598 \mathrm{fn} 7$. See reprint in this volume at 72 . 
grouped these rights together with welfare rights like '[t]he right of every family to a decent home,' 'the right to adequate medical care and the opportunity to achieve and enjoy good health,' and the right to 'social security.' Since Roosevelt's time, most of the attention in the US has been directed to welfare rights rather than work rights (though recently some progressive scholars have refocused attention on work rights ${ }^{11}$ ). Welfare rights are the sorts of rights that most proponents of constitutional socio-economic rights have in mind, and it is these sorts of rights that, as Judge Posner correctly suggests, have never been recognized in American constitutional law. ${ }^{12}$

The most sustained effort to gain constitutional recognition of welfare rights in the United States occurred during the late 1960s and early 1970s, the height of the War-on-Poverty era. The type of rights that activist lawyers urged the Court to recognize were welfare rights. The legal theory that many of these lawyers used was the so-called 'New Property' theory proposed by Yale law professor Charles Reich in a famous 1964 article by that name. Reich argued that what he called government 'largesse,' a broad collection of government benefits including both welfare transfer payments and employment-related licenses, should be constitutionally protected as property since in the modern welfare state they serve the same function as traditional forms of property. Welfare-rights lawyers gained some Supreme Court victories in the 1970s, but these victories do not contradict my claim that American constitutional jurisprudence has never recognized socio-economic interests as substantively-protected rights. While the 'New Property' cases do represent the highwater mark of the most serious effort to introduce socioeconomic interests into the realm of constitutionally-protected individual rights, they fell far short of the goal of entrenching personal economic welfare as substantive constitutional right.

In its broadest ruling on the 'New Property' theory, the Supreme Court in Goldberg v Kelly held that the Fourteenth Amendment's due process clause requires that a welfare recipient be given an evidentiary hearing prior to termination of benefits. Citing Reich's article, Justice Brennan wrote, 'It may be realistic today to regard welfare entitlements as more like 'property' than a 'gratuity.' Much of the existing wealth in this country takes the form of rights that do not fall within traditional common-law forms of property.' Brennan's opinion, however, said nothing to indicate that the Court was prepared to recognize a substantive right to welfare. Although so distinguished an academic commentator as Frank Michelman viewed the opinion as signaling a willingness to consider that a right to subsistence may legitimately be found in some provision of the Constitution, there was really nothing in the Court's opinion to suggest that the state was under a constitutional obligation to create any welfare program. ${ }^{13}$ Any possibility that the Court might so expand on its tenuous acceptance of Charles Reich's theory was soon dashed when the Court, in Dandridge $v$ Williams held that a state family-assistance law was valid even though its cap on maximum payments left many families living at state-recognized poverty levels. And just two year later, the Court, in upholding a state's summary eviction procedure, baldly stated that the 'Constitution does not provide judicial remedies for every social and economic ill.' The Constitution, said the Court, does not provide a 'guarantee of access to dwellings of a particular quality.' However slightly the door to judicial recognition of some kind of substantive constitutional right of welfare might have been opened by Goldberg $v$ Kelly, it was emphatically closed in these later cases. Since that time, the door has remained shut and securely locked.

11 See ibid.

12 See Currie (note 3 above) at 866.

13 See Currie (note 3 above) at 872 . 


\section{Sunstein's Explanation}

Why has this been our history? Why have American courts refused to read into the Constitution any sort of substantive right to even the barest of welfare needs? Professor Cass Sunstein has examined four possible explanations. Three are theories that other writers have offered to explain why socio-economic interests are not protected as constitutional rights in the American legal system. Rejecting all three of these, Sunstein proposes a fourth theory. It is worth a brief look at the first three because all have surface plausibility.

The first of these theories is a chronological theory. This theory points to the fact that the American Constitution is an 18th century document. At that time, constitutional rights, which were still in their infancy, simply weren't thought of as including social and economic guarantees. Created against the backdrop of monarchical governments, classical constitutional rights were barriers against abuses of state power. This was certainly the English tradition, and that tradition was the template for all constitutional bills of rights created during the classical era.

The difficulty with this explanation, Sunstein points out, is the American Constitution has hardly been a static document. It has been formally amended, sometimes in quite dramatic ways. Yet at no point in American history, not even the late 1960s or early 70s, has there ever been serious discussion of amending the Constitution to include substantive welfare rights. Moreover, the original meaning of the American Constitution has also been changed, sometimes quite sharply, through the process of judicial interpretation, yet never for the purpose of introducing socio-economic rights. Chronology alone cannot explain this fact.

The second theory that Sunstein considers and rejects is pragmatic and institutional. The basic argument is that American constitutional rights have been pragmatic rights, rights that are capable of being judicially enforced. They are not simply expressive of our deepest values. They may well have expressive content, but they are not solely expressive. The nearly-universal view of constitutional rights among American lawyers, scholars, and courts is that they are tools for implementing actual legal, political, and social change. Aspirational rights have had no place in our constitutional history, unlike that of many countries whose constitutions have recognized socio-economic rights.

This strongly pragmatic understanding of constitutional rights is closely related to the role of courts as interpreters of the Constitution. Judicial review has long been the central preoccupation in American constitutional thought and practice, and there is a widely-held view that a substantive constitutional right to social welfare cannot easily coexist with judicial review. Courts, many constitutionalists believe, are simply unable to enforce a constitutional provision mandating health care, housing, or even food. Such a constitutional provision would end up being an empty promise, mocking the very idea of what a constitutional right is supposed to be.

Sunstein perceptively points out the flaws in this explanation as well. For one thing, while the Federal Constitution lacks a constitutional right to social welfare, many state constitutions do not. The experience with those provision has been mixed, but at least in some of the states courts have been somewhat willing to enforce their social and economic rights. ${ }^{14}$ Moreover, as Sunstein points out, the fact that courts would be unable completely to enforce a constitutional guarantee regarding housing or employment would hardly be unique in our constitutional

14 See eg Tucker $v$ Toia 371 NE 2d 449 (NY 1977). 
experience. The same is true of our existing, negative rights. As he says, '[T]he prohibition on unreasonable searches and seizures [is] violated every day.' 15 What courts could do is to prompt legislatures to create programs aimed at fulfilling the constitutional guarantee or adequate housing or health care and to exercise at least a modicum of supervision over those programs. American federal courts have undertaken such supervisory functions in the context of other constitutional rights. While their performance in this capacity has perhaps been less than ideal, there is no evidence that the fact that they have fallen short of completely implementing the relevant constitutional right has undermined public confidence in the meaningfulness of the right itself. So, this pragmatic explanation, like the chronological explanation, is at best incomplete.

The third explanation that Sunstein examines is one that I think he dismisses too quickly. I will briefly mention it at this point and come back to it later to offer a variation on it. The explanation is cultural in nature. It is the familiar story of American exceptionalism. Specifically, the theory is that the absence of social welfare rights from the list of American constitutional rights can be traced to the absence of socialism in our political history. Since socialism has never been a significant force in American political ideology, the theory goes, it is hardly surprising that there has been a major effort to inject what are, after all, essentially socialiststyle rights in the Federal Constitution. Responding to this theory, Sunstein does not doubt that socialism has never played a major role in American politics, nor does he question the connection between social welfare rights and socialist forces in countries that have recognized constitutional socio-economic rights. He argues instead that a strong socialist movement is neither a necessary nor a sufficient condition for social and economic rights. ${ }^{16}$ There are example of countries with strong socialist movements but no constitutional socio-economic rights (Sunstein cites Canada and Israel), and he says one can easily imagine that a country without a socialist past might be inspired to give constitutional recognition to social welfare rights. After all, President Roosevelt, who despite some of his contemporary detractors was no socialist, did call on Congress to adopt his Second Bill of Rights as a legislative matter. Why not as a constitutional matter? The answer, Sunstein asserts, must lie elsewhere.

He finds the answer in his fourth theory, a theory that he labels 'Realist,' in a gesture to the American Legal Realists who contended that constitutional law, like all law, is a matter of concrete human actions and human personalities. ${ }^{17}$ Here, in a nutshell, is Sunstein's theory:

...The crucial development was [sic] the election of President Nixon in 1968 and his four appointments to the [Supreme] Court: Warren Burger in 1969, Harry Blackmun in 1970, and Lewis Powell and William Rehnquist in 1972. These appointees produced a stunning series of decisions, issued in amazingly rapid succession, which ... made it clear that for the most part, social and economic rights have no constitutional status... 18

The idea is that as of 1970, the Supreme Court was on the verge of reading some form of a right to social welfare into the Constitution through the Fourteenth Amendment due process clause or the equal protection clause but that the appointment of four moderate-to-conservative new justices to the Court closed the door to that opportunity. Had Hubert Humphrey, rather than

15 Sunstein (note 1 above) at 144 .

16 Ibid p 136-137.

17 This was hardly the emphasis of all, or even most, of the American Legal Realists. The one Realist whom this description best fits was J Frank Law and the Modern Mind (1930).

18 Sunstein (note 1 above) 163. 
Richard Nixon, been elected president in 1968, things would have turned out differently and the United States would have become another member of the club of countries whose constitutions recognize socio-economic rights.

While others have offered the same theory, ${ }^{19}$ it is less compelling than meets the eye. The claim that 1970, the year of Goldberg $v$ Kelly, was the golden-but-lost moment for a constitutional right to welfare relies on a more expansive reading of that case that is warranted. Scholars like Sunstein who read Goldberg as signaling the pre-Nixon Supreme Court's willingness to recognize a substantive right to welfare into the Constitution emphasize dicta in the Court's opinion that is promising but misleading. The Court stated, for example, 'From its founding the Nation's basic commitment has been to foster the dignity and well-being of all persons within its borders. We have come to recognize that forces not within the control of the poor contribute to their poverty.' 20 The Court went on to say

...Welfare, by meeting the basic needs of subsistence, can help bring within the reach of the poor the same opportunities that are available to others to participate meaningfully in the life of the community. ... Public assistance, then, is not mere charity, but a means to [quoting here from the Preamble to the US Constitution] 'promote the general Welfare, and secure the Blessings of Liberty to ourselves and our Posterity...21

The real meaning of the Court's high-flown rhetoric is grasped when we put it in the context of the legal issue before the Court. That issue, as I've already indicated, was whether, under the fourteenth amendment due process clause, recipients of government welfare assistance benefits are entitled to an evidentiary hearing prior to termination of benefits. The resolution of that issue turned on whether the recipient possessed a 'property' interest for procedural due process purposes. The government had argued that there was no right to receive welfare benefits, that such benefits were only a 'privilege.' It was this right/privilege distinction that the Court rejected. Citing Charles Reich, Justice Brennan wrote, 'It may be realistic today to regard welfare entitlements as more like "property" than a "gratuity".' But the determination that welfare recipients have a property interest was made only with respect to the question whether they have any procedural rights under the Constitution, not whether they have any sort of substantive right to receive those benefits. Thus, the case really does not provide clear evidence to support the contention that the Court was on the verge of recognizing something like a substantive constitutional right to minimum welfare. Perhaps in some future case the Court, had it not been reconstituted by Richard Nixon, might have headed in that direction, but that is sheer counterfactual speculation.

It is important to be careful about distinguishing statutory social welfare rights and a constitutional welfare right. There is no doubt that during the late 1960s, there was a major expansion of statutory welfare rights. Prodded by the steam-rolling exhortations of President Lyndon Johnson, Congress enacted program after program in an overt effort to eradicate poverty by meeting the minimum economic needs of all Americans, but no political leader at the time urged translating such statutory rights into a substantive constitutional right.

19 See WE Forbath (note 10 above) at 598 fn 7and 612-613; WE Forbath 'Lincoln, the Declaration, and the 'Grisly, Undying Corpse of States' Rights: History, Memory, and Imagination in the Constitution of a Southern Liberal' (2004) 92 Georgetown LJ 709 at 709.

20397 US at $264-265$.

21 Ibid at 265. 
So, if Professor Sunstein's Legal Realist theory does not provide a convincing explanation of why there are no constitutional socio-economic rights in the US, what is the reason? At least part of the explanation, I want to suggest, lies in American culture, but not the American exceptionalist culture that Sunstein described. It lies, rather, in a tradition of anti-paternalist ideology that has strongly influenced American jurisprudence, both public and private, at least since the second half of the 19th century. The idea of enshrining social welfare rights in the Ur-text of the American polity, I suggest, is fundamentally incompatible with the American legal culture of anti-paternalism.

\section{The Culture Of Anti-Paternalism In American Jurisprudence}

As a mode of legal thought and culture, anti-paternalism is closely related to two other cultural strands in American intellectual history. The first is Social Darwinism. In recent years there has been considerable discussion among American legal historians about the prevalence of Social Darwinist ideas in American legal thought since the second half of the nineteenth century. Revising the conventional account, which is usually attributed to the late Richard Hofstadter,22 that depicts Social Darwinism as dominant since 1870, the consensus among American historians now is that the Social Darwinism did not dominate American legal thought during the late nineteenth century. But Social Darwinism, though closely related to anti-paternalism, is not identical with it. Anti-paternalism, or anti-protectionism as it might also be called, is captured by Albert Venn Dicey's remark that 'protection invariably involves disability. ${ }^{23}$ It is primarily focused on the relationship between individuals and the state, viewing state measures to protect individuals from the hardships of life as inimical to the project of progressively developing a society of the fit. Social Darwinism, which reached its apogee in the United States during the Age of Enterprise, roughly from 1870 to 1900, tended to focus instead on the relationship between and the state and the market, as distinguished from society. Its thrust was certainly anti-protectionist, but its real attention was on the proper conditions of economic activity in a competitive market economy. To be sure, anti-paternalist rhetoric was often a surrogate for explicitly Social Darwinist rhetoric, ${ }^{24}$ but the forces opposing legal paternalism tended to be more preoccupied with social progress rather than economic progress. If Social Darwinism has not dominated American legal culture since the late 1800s, anti-paternalism has. The key to understanding why socio-economic rights have never been recognized in American constitutional jurisprudence lies, I contend, in this feature of American legal tradition and culture.

Assaults on legal paternalism have been a constant feature of American legal culture at least since the late 19th century. Today, anti-legal paternalism is often couched in the rhetoric of economics, but the American critique of legal paternalism is more than a matter of economic theory. It is based on a distinct social and, for many, moral vision, a vision that in some respects is an atavar of the 18th-century civic republican sociology of virtue, which taught that civic

22 See R Hofstadter Social Darwinism in American Thought (1955).

23 AV Dicey Lectures on Law and Public Opinion in England During the Nineteenth Century (1905) at 150 fn 1.

24 See A Soifer 'The Paradox of Paternalism and Laissez-Faire Constitutionalism: United Supreme Court, 1888-1921' (1987) 5 Law \& History Review 252. 
virtue was indispensable for a vigorous republic and that self-governance and economic independence were necessary conditions for civic virtue. In later incarnations, this vision emphasized personal independence and self-reliance above all else. Unless your status placed you in one of the categories of persons deemed incapable of looking out for themselves - categories that in the 19th and early 20th centuries included racial groups such as Native Americans and African-Americans - you were held responsible for the material conditions of your own life. No one owed you a duty, legal or moral, to protect you against financial misfortune or to bail you out of economic distress. If people were to become legally entitled to protection against either their own ill-considered decisions or the vagaries of the market's invisible hand, they would rapidly lose the very personal qualities necessary for the civicly proper moral and political personality carefulness, determination, honesty, and above all, energy. The virtuous citizen was one who earned his wealth, paid his own way, satisfied all his debts, and responded to adversity with renewed vigor. He was, in short, the self-sufficient, productive person of integrity.

The influence of this legal anti-paternalist thought on American constitutional jurisprudence during the period between 1870 and 1930 is well-known, ${ }^{25}$ for this was the heyday of what is commonly called laissez-faire constitutionalism. While the conventional view of judicial thought and practice during the era of laissez-faire constitutionalism has undergone a revision in recent years, with revisers softening the image of courts as intractably opposed to all and every form of interference with the workings of the market, there still remains little doubt that during this period courts tended to be hostile to legislation that they viewed as 'class' legislation. ${ }^{26}$ This was especially true of legislation aimed at protecting discrete categories of workers from harsh working conditions and unfair terms of employment. That the culture of anti-paternalism was doing the real work behind the mask of freedom of contract is indicated by the factual circumstances in which courts gave their constitutional approval to legislative regulations of the workplace. The best example is the famous 1908 case of Muller $v$ Oregon, ${ }^{27}$ where the Supreme Court upheld a state statute limiting the number of hours women could work in laundries. The Court's opinion rested squarely and explicitly on the factual assumption that women were naturally 'at a disadvantage in the race for subsistence. ${ }^{28}$ Women, along with children, Native Americans, and a few other social categories (such as 'idiots') were widely considered to be naturally in need of legal protection, ${ }^{29}$ so statutes of the sort involved in Muller did not run afoul of the consensus regarding anti-paternalism.

During the Great Depression, which lasted from 1929 to 1941, attitudes about need, selfsufficiency, and legal protection changed profoundly in many respects. The Depression made it abundantly clear to most Americans that even the most virtuous and productive person could find herself in desperate circumstances for reasons completely beyond her control. As one legal historian has written, 'The Great Depression sorely tested old assumptions . . that economic well-being flowed from personal virtue, and that government had a limited role in promoting the collective social welfare.' 30 Franklin Roosevelt's election to the Presidency was due in no small measure to this sea change in the economic conditions of many hard-working ordinary

\section{See ibid.}

26 See ML Benedict 'Laissez-Faire and Liberty: A Reevaluation of the Meaning and Origins of Laissez-Faire Constitutionalism' (1985) 3 Law \& History Review 293.

27208 US 412 (1908).

28 Ibid at 421.

29 See eg JC Gray Restraints on the Alienation of Property (1895) at 170.

30 KL Hall The Magic Mirror (1989) at 267. 
Americans. His New Deal legislative programmes were directly aimed at providing governmental assistance to a wide array of Americans, including groups, such as White males, that in anti-paternalist ideology were considered lacking any excuse for legal protection.

Yet even the Great Depression did not eradicate the culture of anti-paternalism. There was a change in attitude toward legal protectionism, to be sure, but that change had definite limits. While legal paternalism was accepted in the form of legislation, it was not accepted at a constitutional level. The New Deal introduced unprecedented legislation aimed at providing economic assistance to a broad cross-section of the American public, but at no point was there any serious discussion of a constitutional basis for governmental assistance to the poor, the sick, or the unemployed. Indeed, there was not even any proposal for a constitutional right to public assistance of any kind. Conspicuously, Franklin Roosevelt's own Second Bill of Rights never included a proposal for constitutional action. The President anticipated that his proposals would be implemented solely through legislation.

The same pattern existed during the next period of social-welfare activism, the era of the War on Poverty and the Great Society. Scholars have noted the ways in which the welfare-rights movement of the 1960s departed from prior social movements aimed at government assistance for the needy, notably by shifting from an emphasis on work to a focus on welfare. ${ }^{31}$ However, the two movements shared a common and exclusive method for implementing their vision of weaving socio-economic rights into the fabric of American law, and that exclusive method was legislation. As in the case of the New Deal, the welfare-rights activists of the 1960s, including Charles Reich, never proposed making social welfare a matter of constitutional right. There had been a shift away from the more robust version of anti-paternalist legal and political culture in the late 1960s, but that shift went only so far. The line between statutory and constitutional paternalism was not to be crossed.

Why was that the case? Once the culture of anti-paternalism was relaxed, why didn't it lead to constitutional action, either through constitutional amendment or through judicial interpretation? Here we have to turn our attention from culture to an institutional factor. That factor is the character of constitutional rights in the American legal system. Constitutional rights are different from their counterparts in many other countries. This is not the occasion for detailing all of these differences, but a few have to be noted to understand why the idea of statutory socio-economic rights has been accepted while a constitutional version of such rights has not.

One difference has already been noted: in American jurisprudence legal rights, but especially constitutional rights, are generally viewed as pragmatic tools rather than being purely expressive or aspirational. ${ }^{32}$ While statutory rights usually are viewed through the same pragmatic lens, there are instances in which statutes have been enacted despite substantial doubts about their judicial enforceability. In these instances lawmakers view the harm likely to result from the fact that a statute's failure to deliver its practical promise as outweighed by the benefit gained by the statute's expressive effect. This is not the case with respect to constitutional norms, however. The idea of a constitutional provision that lacks judicial enforceability is anathema to the American legal system. Legal unenforceability, real or projected, has both prevented adoption of constitutional amendments (as in the case of the Equal Rights Amendment) and prompted repeal of amendments already enacted (as in the case of the Eighteenth

31 Forbath (note 10 above) at 604.

32 For a discussion of the expression vs pragmatic character of American constitutional rights, see Sunstein (note 1 above) at 140-145 
Amendment, which prohibited the manufacture, sale, and transport of intoxicating liquor). A statute that doesn't do something is tolerable; a comparable constitutional right is not.

A related institutional factor is the importance in the American constitutional scheme of maintaining the realm of ordinary, ie majoritarian politics. A right that is strictly statutory does not remove the subject matter of the right from the realm of majoritarian politics. The matter is always on the political table, subject to legislative control and change through the processes of ordinary politics. Elevating a right to constitutional level, however, poses the counter-majoritarian difficulty. The right becomes a 'Super Right,' removed from the realm of ordinary politics and majoritarian control. In a country in which 'democracy' means majoritarian control, the decision to make an individual right a constitutional right is taken with great caution. Better to err on the side of leaving the matter subject to legislative control, the thought is. So, the default mode regarding constitutional revision of any sort is inaction.

This general hesitation regarding recognition of new constitutional rights, combined with the residual force of the culture of anti-paternalism, in my judgment, explains the absence of constitutional socio-economic rights better than Professor Sunstein's theory. Even in the absence of a change of membership of the Supreme Court in 1970, I think it highly unlikely that a substantive social welfare right would have been added to the constitutional roster. 


\title{
The 'Politics of Need Interpretation"" and the Adjudication of Socio-Economic Rights Claims in South Africa**
}

\author{
DANIE BRAND \\ Senior lecturer, Department of Public Law, \\ University of Pretoria
}

\section{Introduction}

Against the backdrop of a transformative constitution, writes Karl Klare, an important question to ask of the work product of judges is the extent to which it either erodes or reinforces discursive politics, opens up or limits space for political contestation, 'deepen[s] democratic culture' or ignores it. ${ }^{1}$ Judgments and interpretations that reinforce participatory politics advance the Constitution's transformative ethos, those that do the opposite, unconscious of their political role, frustrate it. ${ }^{2}$ Klare himself proposes one way in which judges can through their work deepen democratic culture. By being candid about the political nature of their work, by laying bare the extra-legal political concerns that influence their interpretations and decisions, they can render themselves accountable and so create space for political critique of their work product. ${ }^{3}$ But we know, as does Klare, that important as such candour might be, the difficulty facing judges in this respect is more complex than this, that the tension between rights and democracy is more intractable. ${ }^{4}$ The law, including adjudication, works in a variety of ways to destruct the societal structures necessary for politics, to close down space for political contestation. To work in a

* Nancy Fraser 'Talking about Needs: Interpretive Contests as Political Conflicts in Welfare-State Societies' (1989) 99 Ethics 291 at 292.

** My thanks to Beth Goldblatt, Sandra Liebenberg, André van der Walt, Johan van der Walt and Stuart Wilson for their comments when I presented earlier versions of this paper at the July 2004 South African Journal of Human Rights Conference in Johannesburg and the July 2004 Stellenbosch Institute for Advanced Studies seminar on theories of socio-economic rights in Stellenbosch, and to Karin van Marle and Stu Woolman for reading and commenting on various drafts. Mistakes are my own.

1 K Klare 'Legal Culture and Transformative Constitutionalism' (1998) 14 SAJHR 146 at 164-165 and 171. As the word and terms 'politics' or 'political contestation' and 'democracy' will often appear in this paper, I would do well at this stage already to say what I mean with them. I refer to politics in what Nancy Fraser 'Talking About Needs: Interpretive Contests as Political Conflicts in Welfare-State Societies' (1989) 99 Ethics 291 at 297 has described as a discursive sense - in this sense, 'something is "political" if it is contested across a range of different discursive arenas and among a range of different publics'. Politics in this sense is contrasted with politics in the institutional sense ('a matter is deemed political if it is handled directly in the institutions of the official governmental system, including parliaments, administrative apparatuses, and the like') and politics in the official sense ("what is "political" ... contrasts with what is handled in institutions like the "family" or the "economy", which are defined as outside the official-political system').

2 Ibid 165.

3 Ibid 164-165.

4 Ibid 171-172. 
transformative way, judges have to be aware of and attempt to take account of all of them.

In this paper, I focus on one way in which courts can close down space for politics that judges should be aware of: courts can erode participatory politics by invoking and therefore reinforcing in their judgments and interpretations certain rhetorical strategies that are used by participants in the political discourse around poverty and need in our new welfare state to depoliticise the terms of that debate. I analyse a number of the socio-economic rights cases that the Constitutional Court and Supreme Court of Appeal have decided to date - Soobramoney, ${ }^{5}$ Grootboom, ${ }^{6}$ Treatment Action Campaign ${ }^{7}$ Khosa, ${ }^{8}$ Port Elizabeth Municipality ${ }^{9}$ and Modderklip ${ }^{10}$ - and track the use by courts of this depoliticizing rhetoric. At the same time I identify from the cases countervailing trends that suggest ways in which courts can subvert or avoid this particular depoliticising effect of their work.

\section{Drawing the Limits of the Political}

Poverty and basic need - those social problems of hunger, homelessness and inadequate access to health care, social assistance and education that give rise to socio-economic rights litigation - are questions of major political concern. These issues occupy a significant part of the discourse in our formal political institutions. In the competitive environment of parliamentary politics, different understandings of, for example, the causes of HIV/Aids, of who bears responsibility for providing treatment for people living with HIV/Aids and of how best to treat them are centrally important subjects of political contestation and forms of political currency. These issues are also central to informal participatory forms of politics. An issue like inadequate access to basic services such as water and electricity gives rise to popular demonstrations and constitutes the raison d'être of informal social movements who engage in direct political action; uncertainty about the nature and extent and the causes of homelessness sustains political debates in the print and visual media; and questions about whether or not South Africa should extend its social assistance system occupy the discursive politics of social activists and academics. In sum, in South Africa 'talk about people's needs is an important species of political discourse', 'has been institutionalised as a major vocabulary of politic[s]' and is 'an idiom in which political conflict is played out and through which inequalities are symbolically elaborated and challenged'. 11

At the same time there is in the different political discourses about these questions a pervasive tendency toward their depoliticisation - that is, a tendency to talk about them in such a way that they are bracketed as non-political, not subject to or not capable of being subjected to political contestation. When Government publicly warns that further extension of the social assistance system would lead to the inculcation in poor people of a 'culture of dependency', ${ }^{12}$ the implication is that poor people somehow are themselves to blame for their predicament, that they are poor because they are lazy or lack entrepreneurial vigour. The political causes of their poverty are hidden, papered over. When ordinary people lament the enormity of poverty

5 Soobramoney v Minister of Health, KwaZulu-Natal 1998 (1) SA 765 (CC) (Soobramoney).

6 Government of the Republic of South Africa v Grootboom 2001 (1) SA 46 (CC) (Grootboom).

7 Minister of Health $v$ Treatment Action Campaign 2002 (5) SA 721 (CC) (Treatment Action Campaign).

8 Khosa $v$ Minister of Social Development 2004 (6) SA 505 (CC) (Khosa).

9 Port Elizabeth Municipality v Various Occupiers 2004 (12) BCLR 1268 (CC) (PE Municipality).

10 Modderfontein Squatters v Modderklip Boerdery (Pty) Ltd 2004 (6) SA 40 (SCA) (Modderklip).

11 Fraser (note 1 above) at 291.

12 See the remarks of government spokesperson Joel Netshitenze, in response to the proposal by the Taylor Commission of Inquiry into a Comprehensive System of Social Security for South Africa for a universal basic income grant, saying that it would amount to a 'handout' and would encourage a culture of entitlement. Netshitenze further indicated that the cabinet prefers a public works programme, because it believes 
in South Africa, pointing to the inexorable impact of a globalised economy, or an inadequate natural resource base as its cause, something similar happens. Poverty is attributed to forces over which we have no control, with which political engagement is impossible or futile. ${ }^{13}$

Against this background, Nancy Fraser describes what she calls the process of 'need interpretation' - of giving meaning to the concepts basic need and poverty, determining their causes, deciding which needs and which kinds or degrees of poverty merit state intervention and deciding what the best ways are to address instances of deprivation - as follows:

$[\mathrm{N}]$ eeds talk appears as a site of struggle where groups with unequal discursive (and non-discursive) resources compete to establish as hegemonic their respective interpretations of legitimate social needs. Dominant groups articulate need interpretations intended to exclude, defuse and/or co-opt counterinterpretations. Subordinate or oppositional groups, on the other hand, articulate need interpretations intended to challenge, displace, and/or modify dominant ones. 14

In short, the political discourse around issues of poverty and basic need is a process of politicisation, depoliticisation and repoliticisation of the issues at stake. Particular questions of deprivation - say inadequate access to anti-retroviral treatment for people living with HIV/AIDS, or insecurity of tenure for the propertyless - are inserted into political discourse, claimed as legitimate political concerns through the oppositional social action of social pressure groups or political movements. Dominant societal groups, intent on immunizing their privileged position as property owners or hiding their complicity in the suffering of people living with HIV/AIDS or justifying to themselves their position of relative privilege, attempt to remove these issues from the search light of robust political contestation, to depoliticise them. Subordinate groups - the people living with HIV/AIDS or the propertyless - in turn, intent on challenging their positions of relative deprivation and on claiming from society the assistance to which they feel entitled, work to retain these questions as issues of political concern, to politicise or repoliticise them.

In this political to-and-fro, this process of depoliticisation and repoliticisation, a set of stock depoliticizing rhetorical strategies are usually employed. The first of these strategies is to 'domesticate' issues of poverty and need - to describe them as issues that fall within the domestic rather than the political sphere. As such, these issues can be cast as private or familial issues rather than public or political. ${ }^{15}$ Martha Fineman describes the nature and effect of this domestication strategy as follows:

The private family is the social institution that is relied upon to raise children and care for the ill, the needy and the dependent. Ideally it performs these tasks as a selfcontained and self-sufficient unit without demanding public resources to do so. In the societal division of labor among institutions, the private family bears the burden of dependency, not the public state. Resort to the state is considered a failure. By according to the private family responsibility for inevitable dependency, society directs dependency away from the state and privatizes it. ${ }^{16}$

'able-bodied' South Africans should enjoy 'the opportunity, the dignity and rewards of work' (quoted in A Habib \& C Skinner 'The Poor Must Fend for Themselves' (04-08-2002) Sunday Times 14).

13 LA Williams 'Welfare and Legal Entitlements: The Social Roots of Poverty' in D Kairys (ed) The Politics of Law. A Progressive Critique (1998, 3d edition) 569 at 569.

14 Fraser (note 1 above) at 296.

15 Fraser (note 1 above) at 299.

16 MLA Fineman 'Masking Dependency: The Political Role of Family Rhetoric' (1995) 81 Virginia LR 2181 at 2205. 
In a patriarchal, capitalist society such as ours, the depoliticizing effect of the domestication of an issue is profound. One needs think only of how recently still forced sex within a marriage was in South Africa not regarded as rape but as a 'private matter' between husband and wife, to be reminded of how startlingly strong the perceived normative split between the public (political) and the private (personal) still is, or until recently was, in this respect.

The second common depoliticisation strategy employed by dominant groups is the personalisation of need and dependence - the status of poverty, of being dependent is attributed to the personal character traits, the failure, the abnormality of poor people themselves, rather than to the social, political and economic forces that actually shape it. Thomas Ross writes that this rhetorical process of personalisation of poverty takes place in two stages. The first rhetorical step is the creation of the "abstraction the "poor"' as a distinct class of people "who are them, not us'. ${ }^{17}$ This makes possible the second rhetorical move - the attribution to the poor of moral weakness. To describe the poor as morally weak, they first have to exist as a separate group. This creation of otherness has a further result: it makes it possible for the middle class and the affluent to proclaim not only the moral weakness of the poor, but also their deviance, their abnormality. ${ }^{18}$ In similar vein, Lucy Williams relates how popular understandings of poverty and dependence in the US distinguish between the 'deserving' and the 'undeserving' poor. Poverty or dependence that cannot be explained as the result of 'natural' factors such as natural disaster, physical or mental disability or age is undeserving of social assistance. Such 'undeserving' poverty, in the absence of a 'natural' cause, so the assumptions go, can only be explained by the personal degeneracy and deviance of the poor person, who is to blame for her own position and consequently doesn't deserve assistance. ${ }^{19}$ Perceptions or assumptions about the moral degeneracy of the poor and their consequent blameworthiness for their predicament are prevalent in South Africa. South Africa's social assistance system is built on a distinction between deserving and undeserving poor. It is almost wholly special needs based - regular grants are paid only to groups such as children, older people and the disabled, who cannot be blamed for the condition of poverty, while no provision is made for social assistance to people who are poor, but 'able bodied'. Government's reaction to the proposal made in 2002 by the Taylor Commission of Inquiry into a Comprehensive Social Security system for South Africa that a universal basic income grant should be introduced is illuminating in this respect. Government rejected the proposal and introduced instead an extended Public Works Programme. At the time, a government spokesperson explained this move as motivated by the fear that a basic income grant would breed in poor people a 'culture of entitlement' or dependency, and went on to say that a public works programme is apposite, as 'able-bodied' South Africans should enjoy 'the opportunity, the dignity and rewards of work'. ${ }^{20}$

A third rhetorical strategy employed by dominant groups within the political discourse about need and poverty to depoliticise the debate is the naturalisation of poverty. Poverty and deprivation is depoliticised by it being attributed to 'natural' causes, wholly outside of the control of society. This process of naturalisation can occur in two ways. The first is through the act of

17 Thomas Ross 'The Rhetoric of Poverty: Their Immorality, Our Helplessness' (1991) 79 Georgetown LJ 1499 at $1499-1500$.

18 Ibid 1500-1501.

19 Williams (note 13 above) at 569. See also Ross (note 17 above) at 1501-1502; and N Fraser \& L Gordon 'A Genealogy of Dependency: Tracing a Keyword of the US Welfare State' (1994) 19 Signs: Journal of Women in Culture and Society 309 (reproduced in LA Williams Welfare Law (2001) 47) at 323-324.

20 Joel Netshitenze, quoted by Habib \& Skinner (note 12 above). 
throwing one's hands in the air and succumbing to the enormity of the problem of poverty simply saying that there is so much of it that it will always be with us. The second is through the act of according causes to poverty, but then inexorable causes over which society has no control, for example the uncompromising, impersonal forces of the global market. Common to both these assertions is the idea that poverty is somehow 'naturally' part of the structure of our society, and will consequently always be there, whatever we do: 'The causes of poverty, we assume, are a product of a complex set of factors tied to politics, culture, history, psychology and philosophy. Thus, only in a radically different world might poverty cease to exist. And, whatever the extent of [our] ... powers ..., radically remaking the world is not one of them.' 21

The fourth and final depoliticizing rhetorical strategy employed in the political discourse about poverty is the process of instrumentalisation of needs-talk. ${ }^{22}$ The political discourse about poverty and need occurs in different discursive arenas - within informal social movements and pressure groups, more formal organs of civil society such as NGO's and academia and, finally, within official discursive arenas such as Parliament or specialist administrative agencies. ${ }^{23}$ These different discursive arenas occupy positions of relative power in the struggle to determine and fix meaning in the interpretation of questions of poverty and need. The descriptions given to poverty and need in the official discursive arenas such as Parliament and specialist administrative agencies are officially sanctioned. As such they exert an authoritative influence on the political discourse around poverty and need. At the same time the interpretation of poverty, need and deprivation that takes place in these official discursive arenas is explicitly depoliticizing. When Parliament, or a department of state speak about a particular need and engage in the interpretation of that need, they do so with a specific purpose. The need in question has been legitimized as deserving of state intervention and their purpose is to find the best way to satisfy it - they are in the process of 'translating politicized needs into administerable needs. ${ }^{24}$ As such, the previously politicized issues with which they are confronted become 'technical problems for managers and planners ... in contradistinction to political matters. 25 This process of translation depoliticises in two ways. First, it brackets the issues in question as technically complex issues with which ordinary, non-expert participants in the discourse on poverty cannot usefully engage. Second, the subordinate participants in the discourse are repositioned - whereas before they where active participants in the process of interpretation of their needs, engaged in political action, they now become the passive recipients of services - their predefined needs are administered to them through a process of therapeutic assistance. ${ }^{26}$ As a result, their political engagement is negated.

The different strategies of depoliticisation described above are politically motivated - they are used to further particular political agendas and are as such in themselves acutely political. ${ }^{27}$ Dependence and deprivation is attributed to the personality traits of poor people so that the complicity of the legal and political system in creating their predicament can be obscured and challenge to these systems can be avoided and so that positions of relative affluence can be jus-

21 Ross (note 17 above) at 1501.

22 Fraser (note 1 above) at 299.

23 Ibid 295.

24 Ibid 306.

25 Ibid 299. See also J Habermas 'Law as Medium and Law as Institution' in G Teubner (ed) Dilemmas of Law in the Welfare State (1986) 204 at 210.

26 Habermas (note 25 above) at 210; see also Fraser (note 1 above) at 307.

27 Fraser (note 1 above) at 298: '[O]ne of the primary stakes of social conflict in late-capitalist societies is precisely where the limits of the political will be drawn.' 
tified - it is the fault of poor people themselves that they are poor and of no one else. Poverty is described as inevitable, as a constant presence in society so that personal and collective inaction with respect to it can be justified - society can assert its helplessness in the face of 'natural' deprivation and so avoid having to do anything about it. In broad terms all these strategies of depoliticisation are aimed to preserve the status quo, both by immunizing it from attack by hiding its complicity in creating and maintaining poverty and by justifying inaction in the face of poverty and hardship. As such these acts of depoliticisation are cause for concern: they constitute attempts by society to assert its helplessness in the face of poverty, to get away with doing nothing about something that indeed is, at least to some extent, within its control. ${ }^{28}$

That the law is determinatively involved in the discourse about the political stakes of poverty and need is a point that hardly requires making. Precisely the social provisioning activities of the welfare state - state provision of housing, of health care services, of education and of other social services - are regulated by vast, complicated and ever-expanding networks of law, in the widest possible sense of that word: Formal legislation, administrative rules and decisions and, more recently, constitutional or statutory welfare rights elaborated in judgements by courts. The law in question is of a particular kind - its is 'regulatory', 'instrumentalised' law, aimed not, as law traditionally was, at resolving particular and discrete disputes, but at regulating, guiding, constituting and giving effect to the social provisioning programmes and goals of the state. As such it is part of and in certain respects constitutive of the political discourse around poverty and need. South Africa certainly also stands under the mark of this kind of, what has come to be called 'juridification'. ${ }^{29}$ Although the Apartheid-state already operated according to its fair share of regulatory law, South Africa has, post liberation, seen an explosion of law intended to control, guide and give effect to the 'societal guidance intentions' 30 of the new State. Courts' socio-economic rights judgements, and the doctrine established and elaborated in those judgements, form a significant part of our process of juridification.

The effects of juridification - the role of law in the welfare state, its impact and the consequences of its operation there - have for long attracted scholarly attention. Scholars have first analysed and questioned the effect of legal expansion on the law itself, arguing for instance that, because law is bound to fail in its social engineering role, juridification causes a crisis of credibility for law, ${ }^{31}$ and that the instrumentalisation of law for social purposes threatens its conceptual structures, ${ }^{32}$ rendering it internally incoherent and 'disintegrat[ing] basic legal values and the unity of the legal system.'33

More pertinently, juridification scholars have also devoted considerable attention to the effect of juridification on the areas of life and society into which law newly expands or in which

28 Ross (note 17 above) at 1509-1513.

29 'Juridification' is the term used to describe the phenomenon of growth of regulation or growth of law in the welfare state. See, for a good synopsis of both the phenomenon of juridification itself and the body of scholarship that has developed from the study of its nature, causes and effects, JWG van der Walt The Twilight of Legal Subjectivity: Towards a Deconstructive Republican Theory of Law (1995) unpublished LLD dissertation, Rand Afrikaans University at 319-326; see also the various contributions in G Teubner (ed) Dilemmas of Law in the Welfare State (1986) and Juridification of Social Spheres (1987).

30 G Teubner 'The Transformation of Law in the Welfare State' in G Teubner (ed) Dilemmas of Law in the Welfare State (1986) 3 (Teubner 'Transformation') at 3.

31 G Teubner 'Juridification Concepts, Aspects, Limits, Solutions' in G Teubner (ed) Juridification of Social Spheres (1987) (Teubner 'Concepts') at 6.

32 N Luhman 'The Self-Reproduction of Law and its Limits' in G Teubner (ed) Dilemmas of Law in the Welfare State (1986) 111, in general.

33 Teubner 'Transformation' (note 30 above) at 4. See also Van der Walt (note 29 above) at 324. 
existing regulation densifies. In this respect juridification commentators have explored and analysed a familiar tension: The tension between rights and democracy ${ }^{34}$ or the 'ambivalence of guarantees of and denials of freedom' 35 that is occasioned by the process of juridification the problem that, whilst juridification patently has an emancipatory intent (guaranteeing, for instance, access to basic social benefits to protect against the depredations of the market), it operates simultaneously in a repressive fashion in that it limits the potential for radical and critical political action. ${ }^{36}$

Juridification - including the work of courts in the process of interpreting and applying socio-economic rights - can exercise this stilling effect on radical and critical political action first by destructing or subverting the various forms of social organisation upon which such action depends. ${ }^{37}$ Johan van der Walt, for example, refers to the 'individualizing tendency' of juridification - rights and the individual entitlements emanating from them that are inserted into the social sphere through juridification 'take[ ] the place of spontaneous communal support in family as well as in local community life', so that collective organisation and collective political action is impaired, replaced by self-interest seeking action. ${ }^{38}$ This kind of 'privatisation of right' has been well documented in historical accounts of labour movements in Europe, where the creeping legalism of juridification has contributed to the transformation of these movements from collective bodies advocating the emancipation of workers as a class, to 'encorporated organisations' representing the individual consumer interests of their members. Membership of the group loses its political dimension, becoming instead an instrument for the furtherance of individual interests. 39

Juridification further works to 'gloss over' and 'pacify' political conflict and contestation. ${ }^{40}$ The intrusion of rights and the language of rights in the social sphere runs the risk of promoting 'a false expectation in disadvantaged individuals and groups that the pursuit of legal rights through the courts can effect lasting social change' whereas 'rights...operate instead to...channel potentially radical demands for change into legal claims which, by definition, will not be disruptive of the social and economic status quo.'41

But juridification can also diminish the potential for critical political action in another way. The law can, through the language it uses, through the interpretations of need and poverty that it authorizes, confirm and legitimate the depoliticizing strategies that participants in the political debate around need employ. Courts can play a particularly significant role in this respect.

34 See also in this respect the various contributions in H Botha, AJ van der Walt \& JWG van der Walt Rights and Democracy in a Transformative Constitution (2004).

35 Habermas (note 25 above) at 209.

36 Van der Walt (note 29 above) at 323 (juridification is aimed at 'serving the goal of social integration, yet ... merely contribute[s] to the process of social disintegration').

37 J Habermas (note 25 above) at 211: ' ... [W] [Wile the welfare state guarantees are intended to serve the goal of social integration, they nevertheless promote the disintegration of life relations.'

38 Van der Walt (note 29 above) at 324. See also AAG Peters 'Law as Critical Discussion' in G Teubner (ed) Dilemmas of Law in the Welfare State (1986) 250 at 276-277.

39 Peters (note 38 above) at 276. See also S Simitis 'Juridification of Labor Relations' in G Teubner (ed) Juridification of Social Spheres (1987) 113 at 132-134.

40 Van der Walt (note 29 above) at 324.

41 M Jackman 'Constitutional Rhetoric and Social Justice: Reflections on the Justiciability Debate' in J Bakan \& D Schneiderman (eds) Social Justice and the Constitution: Perspectives on a Social Union for Canada (1992) 17 at 22. See in this respect S Wilson 'Taming the Constitution: Rights and Reform in the South African Education System' (2004) 20 SAJHR 418 at 423-424, who points out how the Department of Education has effectively co-opted rights talk to 'provide ideological window-dressing for policies and practices, which actually countenance significant limits on the very rights they are supposed to advance' (at 424). 
The particular rhetorical power that their processes and their work-product enjoy in our democracy has been noted before - in Karl Klare's words, we may 'legitimately expect' adjudication 'to innovate and model intellectual and institutional practices' in our democracy. ${ }^{42}$ To some extent at least, and it might be to only a very small extent, ${ }^{43}$ but nevertheless, when courts speak, people listen and sometimes copy. When courts engage with issues of poverty and need in socio-economic rights cases they also engage with and participate in the political discourse around poverty and need referred to above. This happens in different ways. First, courts' adjudication of socio-economic rights claims becomes part of the political discourse, even a medium through which this discourse partly plays out. Civil society organisations and social movements regard and use socio-economic rights litigation as tools of political struggle not separate from, but as part of that struggle. ${ }^{44}$ Court judgments in these kinds of cases once handed down become rallying points, political currency in their struggles. Second, courts also occupy a symbolic, or perhaps more accurately, an exemplary role with respect to poverty and need discourses - their vocabulary, the conceptual structures they rely on, the rhetorical strategies they employ infiltrate and so influence and shape the political discourses around poverty and need. This is, despite its protestations to the contrary, ${ }^{45}$ particularly true of the Constitutional Court, because of its prominence and its symbolic significance - one can but think of the extent to which the 'reasonableness' test that the Court developed in Grootboom and Treatment Action Campaign with which to evaluate the state's social provisioning activities has shaped civil society monitoring of planning and delivery with respect to social services and the political advocacy informed by that monitoring. ${ }^{46}$

Now, as I pointed out at the start of this section, the political discourse about poverty and need in the welfare state in which law is a participant consists not only in a political process of the interpretation of need, but also in a political process of drawing the limits of the political, of determining which issues related to poverty and need are legitimately subject to political contestation. In the political struggle around issues of poverty and deprivation rhetorical strategies of domestication, personalisation, naturalisation and instrumentalisation are employed by usually the socially dominant participants to depoliticise issues in need-interpretation, to cast them as non-political, as falling outside the scope of legitimate political contestation. Were courts to invoke these rhetorical strategies in their interpretation and judgement when deciding socioeconomic rights cases, they could potentially exert a profound depoliticising influence on the

42 Klare (note 1 above) at 147.

43 Wilson (note 41 above) at 420-421.

44 See ibid 436-442 for an account of use of the right to education in this 'instrumental' sense by social movements and NGO's in struggles pertaining to basic education. With respect to the use of litigation in this sense, see M Heywood 'Preventing Mother-to-Child HIV Transmission in South Africa: Background, Strategies and Outcomes of the Treatment Action Campaign Case Against the Minister of Health' (2003) 19 SAJHR 278 at 314-315; and S Liebenberg 'South Africa's Evolving Jurisprudence on Socio-Economic Rights: An Effective Tool in Challenging Poverty?' (2002) 6 Law, Democracy and Development 159 at 159.

45 See eg Treatment Action Campaign (note 7 above) paras 20-21: '[T] he issue of HIV/AIDS has for some time been fraught with an unusual degree of political, ideological and emotional contention ... [S]ome of this contention and emotion has spilt over into this case ... Ultimately, however, we have found it possible to cut through the overlay of contention and arrive at a straightforward and unanimous conclusion.' For a discussions see H Botha 'Freedom and Constraint in Constitutional Adjudication' (2004) 20 SAJHR 249 at 249-250 and K Van Marle 'Revisiting the Politics of Post-Apartheid Constitutional Interpretation' (2003) TSAR 549 at 552-553.

46 See eg J Streak \& J Wehner 'Children's Socio-economic Rights in the South African Constitution: Towards a Framework for Monitoring Implementation' in E Coetzee \& J Streak (eds) Monitoring Child SocioEconomic Rights in South Africa: Achievements and Challenges (2004) 50 at 79. 
political discourse around poverty and need. Invoking such depoliticizing rhetorical strategies will in the first place significantly determine the outcomes of their decisions - courts, as do those in the political discourse, usually invoke such strategies so as to justify their avoidance of particular issues, to assert, as Thomas Ross has described it, their helplessness with respect to a particular aspect of poverty or deprivation. ${ }^{47}$ Not only does that mean that the court does not decide the issue in question. It also means that substantive political discussion of it in court is precluded. ${ }^{48}$ In the second place, invocation of these rhetorical strategies could also, because of the rhetorical power that the language of courts enjoy in our political discourse around poverty and need, influence and shape that discourse, contribute to drawing the limits of the political there.

To recapitulate: In this section I described ways in which courts can work to erode and limit political contestation. I focused on one particular such way: The invocation of courts in their interpretation and judgement in socio-economic rights cases of depoliticising rhetorical strategies of domestication, personalisation, naturalisation and instrumentalisation of issues of poverty and basic need. I pointed out that courts' reliance on these strategies could limit the transformative impact of their decisions and could work to depoliticize the political discourse around issues of poverty and basic need. In the following section, I proceed to analyse a number of judgements with a view to identifying courts' invocation of the depoliticising rhetorical strategies discussed above. In addition, I point to various countervailing strategies operating in these judgements that might aid courts in managing their impact on the space for political contestation.

\section{Depoliticisation and Repoliticisation in the Courts}

\section{(A) INTRODUCTION}

In my review of the case law to follow, I focus on a particular kind of socio-economic rights case: cases in which the enforcement of an affirmative constitutional duty - that is, a duty to do something rather than a negative duty to refrain from doing something 49 - was at issue. The Constitutional Court has to date decided four cases that were explicitly formulated as such. In Soobramoney $v$ Minister of Health, KwaZulu-Natal, 50 it denied an application for an order that a state hospital provide dialysis treatment to the applicant, finding that the guidelines according to which the hospital decided whether to provide the treatment were not unreasonable 51 and were applied rationally and in good faith to the applicant. ${ }^{52}$ As such, the Court held

47 Ross (note 17 above) at 1511

48 Ibid.

49 The distinction between affirmative and negative duties is of course empty - it is often impossible to distinguish between positive and negative constitutional duties and the strategic conclusions that are drawn on the basis of the distinction are false; see D Brand 'Introduction to Socio-Economic Rights in the South African Constitution' in D Brand \& CH Heyns (eds) Socio-economic Rights in South Africa (2005) 1 at 1012. Nevertheless, the Constitutional Court has adopted this distinction and has developed its doctrine with respect to the enforcement of socio-economic rights with it in mind.

50 Soobramoney (note 5 above).

51 Ibid paras 24-28.

52 Ibid para 29. 
that the denial of treatment did not breach the section 27(1) right of everyone to have access to health care services. ${ }^{53}$ In Government of the Republic of South Africa $v$ Grootboom, ${ }^{54}$ the Court heard a claim that the state was obliged to provide homeless people with shelter. It declared the state's housing programme inconsistent with section 26(1) of the Constitution. ${ }^{55}$ In Minister of Health $v$ Treatment Action Campaign, ${ }^{56}$ the Court held that the state's policy not to provide Nevirapine at all public health facilities to prevent the mother-to-child transmission (MTCT) of HIV at birth, as well as the general failure by the state to adopt an adequate plan to combat MTCT of HIV, breached section 27(1) of the Constitution. The Court held that the state's measures to prevent MTCT of HIV breached its duties in terms of section 27(1) of the Constitution, ${ }^{57}$ declared as much and directed the state to remedy its programme. ${ }^{58}$ In Khosa $v$ Minister of Social Development, ${ }^{59}$ the Court held sections of the Social Assistance Act 60 excluding permanent residents from access to social assistance grants inconsistent with section 9(3) (the prohibition on unfair discrimination) ${ }^{61}$ and section $27(1)$ (c) (the right to have access to social assistance) ${ }^{62}$ of the Constitution. The Court read words into the Act to remedy the constitutional defect. ${ }^{63}$ In addition to these four, I also consider two further cases, in which affirmative duties came into play indirectly. In Modderfontein Squatters $v$ Modderklip Boerdery (Pty) Ltd, ${ }^{64}$ the Supreme Court of Appeal was confronted with a claim brought by a private landowner that the state was constitutionally obliged to enforce and carry out an eviction order that he had obtained in terms of section 4 of the Prevention of Illegal Eviction from and Unlawful Occupation of Land Act (PIE) ${ }^{65}$ against squatters illegally occupying his land. The Court held that the state was indeed obliged to protect the claimant's right to property against invasion by unlawful occupiers. ${ }^{66}$ However, at the same time, the state was obliged to protect the right of the squatters to have access to adequate housing. ${ }^{67}$ The Court consequently ordered the state to pay damages to Modderklip to make good the breach of its right to property and the State's failure to protect against that breach, ${ }^{68}$ and to allow the squatters to remain on Modderklip's land until alternative land is made available to them by the state. ${ }^{69} \mathrm{In}$ effect, the

53 Ibid para 36. The application was argued around the sec $27(3)$ right not to be refused emergency medical treatment and on the right to life. The Court denied the application in these respects, holding that, because health care rights were explicitly protected in the Constitution, it was unnecessary to rely on the right to life (para 19) and that sec 27(3) did not apply to the applicant's case, because his was not an emergency situation (para 21) and sec 27(3) was a right not arbitrarily to be refused emergency medical treatment where it was available, instead of a positive right to make available emergency medical treatment where it was not (para 20). The Court on its own initiative proceeded to consider the claim on the basis of sec 27(1) (para 22).

54 Grootboom (note 6 above).

55 Ibid para 95.

56 Treatment Action Campaign (note 7 above).

57 Ibid para 95.

58 Ibid para 135.

59 Khosa (note 8 above).

60 Social Assistance Act 59 of 1992.

61 Khosa (note 8 above) para 77.

62 Ibid para 85.

63 Ibid paras $89 \& 98$.

64 Modderklip (note 10 above).

65 Prevention of Illegal Eviction from and Unlawful Occupation of Land Act 19 of 1998 (PIE).

66 Modderklip (note 10 above) para 21.

67 Ibid para 22.

68 Ibid paras $43 \& 52$.

69 Ibid paras $43 \& 52$. 
order required the state to buy the land so that the squatters could remain there, without continuing to infringe Modderklip Boerdery's property rights. ${ }^{70}$ In Port Elizabeth Municipality $v$ Various Occupiers, ${ }^{71}$ the state had applied for an order to evict illegal occupants from privately owned land in terms of section 6 of PIE. ${ }^{72}$ The Constitutional Court confirmed the Supreme Court of Appeal's decision denying the eviction order, in part because suitable alternative land was not available to the evictees. ${ }^{73}$

\section{(B) Soobramoney, Grootboom and Treatment Action Campaign: AN INSTITUTIONAL UNDERSTANDING OF DEMOCRACY}

Soobramoney, Grootboom and Treatment Action Campaign, although they exhibit instances of the Court resisting the depoliticizing strategies described above (the court resists the personalisation of poverty by emphasising the economic, political and social causes of poverty $)^{74}$ most prominently show pervasive strategies of depoliticization. The Court engages in both the domestication and the instrumentalisation of the issues before it.

The most striking example of domestication employed as a depoliticising rhetorical strategy comes from Sachs J's concurring opinion in Soobramoney. An inordinate portion of this opinion $^{75}$ is devoted to an explanation why the Court was unable to intervene on behalf of $\mathrm{Mr}$ Soobramoney - not why in a substantive sense his claim must fail, 76 but why the Court could not engage with the issues raised by his claim. Indeed the opinion can perhaps best be described as a decision not to decide - a rather extreme example of what Robert Cover has called 'the judicial can't'. ${ }^{77}$ Sachs J invokes the usual arguments of institutional incapacity and limited resources to justify his 'can't'. He argues, persuasively, that the issues with respect to Mr Soobramoney's medical treatment were technical medical questions that the court is not equipped to decide ${ }^{78}$ and 'toll[s] the bell of lack of resources', ${ }^{79}$ pointing out that 'if governments were unable to confer any benefit on any person unless it conferred an identical benefit on all, the only viable option would be to confer no benefit on anybody. ${ }^{\prime} 80$ But then he goes further still. Referring to US case

70 Although explicitly indicating that it would not be proper for it to order the state to expropriate the land in question (ibid para 41), the Court does point out that, in light of its order, it would be the sensible thing for the state to do, to expropriate the land (para 43). The state took Modderklip on appeal to the Constitutional Court. The Constitutional Court decision was reported on 16 May 2005; confirming the SCA decision in its effect, albeit for other reasons based on secs 1, 34 rather than 25, 26 of the Constitution.

71 PE Municipality (note 9 above).

72 PIE (note 64 above) sec 6(3)(c).

73 The Supreme Court of Appeal decision is reported as Baartman v Port Elizabeth Municipality 2004 (1) SA 560 (SCA).

74 See eg Grootboom (note 6 above) para 3 ('The ... people with whom we are concerned in these proceedings lived in appalling conditions, decided to move out and illegally occupied someone else's land. They were evicted and left homeless. The root cause of their problems is the intolerable conditions under which they were living while waiting in the queue for their turn to be allocated low-cost housing.').

758 of the 11 paragraphs; Soobramoney (note 5 above) paras 52-59.

76 Substantive engagement with the claim is limited to a single paragraph, in which Sachs J expressed his agreement with Chaskalson P's finding for the Court that Mr Soobramoney's condition was not an emergency medical condition and did not qualify him for the protection of section 27(3); ibid para 51.

77 R Cover Justice Accused: Anti-Slavery and the Judiciary Process (1975) at 119-120.

78 Soobramoney (note 5 above) para 58.

$79 R v$ Cambridge Health Authority, ex parte B [1995] 2 All ER 129 (CA) at 137c-d, quoted in Soobramoney (note 5 above) para 52.

80 Soobramoney (note 5 above) para 53. 
law dealing with the right to die, ${ }^{81}$ he concludes that '[c] ourts are not the proper place to resolve the agonising personal ... problems that underlie these issues' 82 (my emphasis) and that '[o]ur country's legal system simply "cannot replace the more intimate struggle that must be borne by the patient ... and those who care about the patient" 83 (my emphasis). The message seems clear: because issues surrounding a person's death are intensely personal, the court is powerless to address Mr Soobramoney's plight: '[C]onsiderations of the wisdom and utility of the actions that might have been taken are beside the point. Normative debate [about, for instance, whether or not the balance struck 'between the equally valid entitlements or expectations of a multitude of claimants' 84 that had resulted in $\mathrm{Mr}$ Soobramoney being denied the treatment he required, was appropriate] is not invited. 85 Questions of death are private, not political. What makes Sachs J's assertion of this rhetorical depoliticization strategy so startling, is that the US right to die case law he refers to so as to make his point is wholly inapposite. Certainly, when the question is whether or not the state should allow a person who does not want to live anymore to die, the issue whether or not or to what extent a court can prescribe the choice to a patient arises. But Mr Soobramoney was in the opposite position - he very much wanted to live, and the question in his case was whether or not the state is obliged to keep him alive. I fail to see how the issues that arise in determining that question are 'agonising personal problems' part of an 'intimate struggle' that Mr Soobramoney should be left to go through on his own - the essence of $\mathrm{Mr}$ Soobramoney's claim is after all that the state is obliged to get involved in his life and possible death. How does one make sense of this mistaken analogy? Sachs J could have made his point relying only on the institutional capacity arguments, without having to go any further. Thomas Ross has said that 'judges invoke the rhetoric of judicial helplessness most fervently when confronted with a problem of unjust and tragic dimensions' ${ }^{86}$ Perhaps it was precisely the acutely political nature of $\mathrm{Mr}$ Soobramoney's predicament - the tragic fact that his position is compared to that of others, and that the state makes a choice not to intervene in his - that prompted Sachs $\mathrm{J}$ to go to such tortuous lengths to justify his and the rest of the Court's inaction. As such this element of the opinion constitutes an extraordinary flight from politics.

A second example of the Constitutional Court's domestication of needs talk occurs in Grootboom. The Grootboom community's claim for shelter was partly based on children's section $28(1)$ (c) right to shelter. Although Yacoob J, for the Court, decided the case on the basis of the section 26(1) right of everyone to have access to adequate housing, he did provide an interpretation of section $28(1)(\mathrm{c})$. The linchpin of this interpretation is a conflation of section 28(1)(c) with section $28(1)(a)$, which proclaims children's right 'to family care or parental care, or to appropriate alternative care when removed from the family environment'. In Yacoob J's words:

[Sections 28(1)(b) and 28(1)(c)] must be read together. They ensure that children are properly cared for by their parents or families, and that they receive appropriate alternative care in the absence of parental or family care ... Subsection (1)(b) defines those responsible for giving care while ss (1)(c) lists various aspects of the care entitlement. ${ }^{87}$

81 Cruzan v Director, Missouri Department of Health, et al 497 US 261 (1990), quoted in Soobramoney (note 5 above) para 56.

82 Soobramoney (note 5 above) para 58.

83 In re Jobes 529 A2d 434 at 451 (NJ SCt, 1987), quoted in Soobramoney (note 5 above) para 58.

84 Soobramoney (note 5 above) para 54.

85 Ross (note 17 above) at 1511.

86 Ibid.

87 Grootboom (note 6 above) para 76. 
On this basis Yacoob J proceeds to argue that the state has only a residual duty to provide shelter to children - the primary duty to do so rests on parents and family and the state incurs the direct duty to do so only with respect to those children 'who are removed from their families' ${ }^{88}$ Where children are cared for by their parents or families (are still with their parents or families) the only duty the state carries with respect to them is 'to provide the legal and administrative infrastructure necessary to ensure that children are accorded the protection contemplated by s $28^{\prime} .{ }^{89}$ From this Yacoob J's conclusion follows ineluctably: ${ }^{90}$

It was not contended that the children who are respondents in this case should be provided with shelter apart from their parents. Those of the respondents in this case who are children are being cared for by their parents; they are not in the care of the State, in any alternative care, or abandoned. [T] herefore, there was no obligation upon the State to provide shelter to those of the respondents who were children.

Yacoob J's interpretative maneuvering clearly 'directs dependency away from the state [to the family] and [so] privatizes it'. ${ }^{91}$ The result is profoundly depoliticizing. It allows Yacoob J simply to ignore the social fact that often children who are 'properly' with their parents or family are worse of than those who find themselves in some form of alternative care, because their parents or family are simply too poor 'properly' to care for them. It also allows him to ignore the question whether or not the State has a duty, where children are with their parents or family but in a situation of indigence, to provide forms of material care directly to those children. Finally, it allows him to skirt the deeply political question whether or not, in the social provisioning activities of the state, children's needs should enjoy material priority over the needs of others. As with Sachs J's opinion in Soobramoney, what makes Yacoob J's depoliticising strategy in Grootboom all the more remarkable is that it was unnecessary - Yacoob J's interpretation of sections $28(1)(b)$ and (c) is certainly not the only interpretation possible, nor even the most obvious. There is no textual reason to subsume subsection (1)(c) into subsection (1)(b) as Yacoob J did - the various entitlements listed in the subsections of section 28(1) (there are nine - (a) to (i)) are connected to each other with an 'and' and seem to be intended as separate entitlements. It is also a plausible interpretation to say that subsection (1)(b) refers to the emotional and other non-material aspects of care, whilst subsection (1)(c) lists elements of material care. ${ }^{92}$ Yacoob J had to make a conscious choice to adopt the interpretation he did, it is not suggested by the text - and his employment of the depoliticizing strategy flowing from that interpretation was equally a conscious choice.

To some extent my use of these two examples of the domestication of needs talk by the Court is gratuitous. Yacoob J's interpretation of section 28(1)(c) in Grootboom was reversed in Treatment Action Campaign. The Court still employed Yacoob J's view that the primary duty to provide shelter, health care, nutrition and social services rests on parents and family, with only an alternative duty falling on the State, ${ }^{93}$ but extended the circumstances under which this alternative duty would kick in. As the mothers with which the case was concerned were 'for the most part indigent and unable to gain access to private medical treatment which is beyond their

88 Ibid para 77.

89 Ibid para 78.

90 Ibid para 79.

91 Fineman (note 16 above) at 2205.

92 See Jooste $v$ Botha 2002 (2) BCLR 187 (T).

93 Treatment Action Campaign (note 7 above) para 75. 
means' for them and their children, '[ $t$ ]hey and their children are in the main dependent upon the State to make health care services available to them. ${ }^{.94}$ As a result the state incurred a duty to provide health care services to their children, even though their children were still in their care. In addition, the two instances of domestication that I relate are isolated incidents and certainly cannot be used to indicate a trend. However, the depoliticizing bent of the Court is demonstrated much more clearly in Soobramoney, Grootboom and Treatment Action Campaign in the Court's use of the rhetorical strategy of instrumentalisation - here a trend can be ascertained, and it is this to which I now turn.

As could be expected, one of the major concerns of the Constitutional Court's thus far in its socio-economic rights cases has been to determine the scope of its review powers with respect to socio-economic rights. ${ }^{95}$ This was particularly so in its first three cases, Soobramoney, Grootboom, and Treatment Action Campaign. In these cases the Court struggled with basic questions such as which kinds of issues that arose in socio-economic rights cases it is competent to engage with at all, what its standard of scrutiny should be there where it does engage with the issues, and what the scope of its power is to provide relief there where it has exercised its review power and found a breach of a socio-economic right.

What is interesting is the idiom that the Court has employed to justify the choices it has made in this respect. In its first three cases, the Court has, when engaging with the different questions related to the nature and scope of its review powers, relied in the first place on 'institutional capacity' arguments. That is, what motivates the Court's decision to limit the scope of its review powers in a particular instance has been its perceived lack of the requisite technical expertise and institutional capacity properly to engage with the issues. The Court has utilized these institutional capacity arguments when seeking to justify its choice not to decide a particular question raised in the course of socio-economic rights litigation. In Treatment Action Campaign, for example, the Court explains its decision not to decide whether or not the State's constitutional duties in terms of section 27(1) requires it to provide formula feed to HIV-positive mothers to prevent the transmission of HIV to their children through breast feeding by saying that this question 'raises complex issues' that it does not have the capacity or information on the basis of which to decide. ${ }^{96}$ The Court's rejection of the 'minimum core content' approach to deciding claims for access to basic resources has equally been motivated with reference to its institutional incapacity to access and analyse the kind and quantity of information that would be required to determine what the minimum core of any given right in any given set of circumstances entails. ${ }^{97}$ Finally, the Court has justified its adoption of what it has

94 Ibid para 79.

95 As could be expected, because the debate about whether to include socio-economic rights in the 1996 Constitution (for a summary see S Liebenberg 'Interpretation of Socio-Economic Rights' in M Chaskalson, J Kentridge, J Klaaren, G Marcus, D Spitz, A Stein \& S Woolman (eds) Constitutional Law of South Africa (2nd edition OS, December 2003) chapter 33,3-4) was a debate about their justiciability and the proposals and counter-proposals made in this respect amounted to proposals about the manner in which courts could exercise their review powers with respect to these rights; see N Haysom 'Constitutionalism, Majoritarian Democracy and Socio-Economic Rights' (1992) 8 SAJHR 451; E Mureinik 'Beyond a Charter of Luxuries: Economic Rights in the Constitution' (1992) 8 SAJHR 464; and DM Davis 'The Case Against the Inclusion Of Socio-Economic Demands In a Bill of Rights Except as Directive Principles' (1992) 8 SAJHR 475. The subsequent academic debate has also focused the extent of courts' review power with respect to socio-economic rights; see eg CR Sunstein 'Social and Economic Rights? Lessons from South Africa' (2001) 11:4 Constitutional Forum 123; and T Roux 'Legitimating Transformation: Political Resource Allocation in the South African Constitutional Court' (2003) 10 Democratization 92.

96 Treatment Action Campaign (note 7 above) para 128.

97 Grootboom (note 6 above) para 33; Treatment Action Campaign (note 7 above) para 37. 
called a 'restrained role' in reviewing State conduct in light of socio-economic rights, embodied in its 'reasonableness review' approach, also with reference to its institutional incapacity. 98

The Court's reliance on these institutional capacity arguments in this respect is in itself uncontroversial. Certainly the Court, when it employs this rhetoric, enters into a depoliticizing discourse - it effectively instrumentalises the questions that it is considering, describing them as 'technical problems for managers and planners ... in contradistinction to political matters.' 99 However, although there is room for argument about the extent to which the Court is institutionally incapable in any given context, ${ }^{100}$ it cannot be denied that it is indeed institutionally constrained and that the depoliticisation that it engages in on that basis alone is to some extent inevitable. What does make the Court's use of this particular instance of 'instrumentalising' rhetoric problematic, or more problematic than it would otherwise be, is not so much the fact that it defers, but what it is that it defers to. Central to the Court's self-limitation of its powers of review and remedy in the three early cases is a second set of arguments: 'constitutional comity' arguments. Equally as concerned as the Court is about its institutional incapacity, it is concerned about its institutional illegitimacy. When the Court defers, declining to decide a particular issue, or to apply a stringent standard of scrutiny, or to impose an intrusive order, it defers not only to the complexity of the issues at hand, recognizing that it is incapable of deciding them. It also, more importantly, defers to, or defers in favour of the other branches of government - the executive, the legislature or the state administration - on the understanding that it is, in the context of institutional spheres of power, the inappropriate forum to decide them. In short, the problem with defining the nature and scope of its review powers for the Court 'comes down mainly, if not solely, to a matter of separation of powers'.101

This is true in all the contexts within which the Court has had occasion to describe the limits and nature of its powers. In Soobramoney, Chaskalson P justifies his choice not to engage with the decisions made with respect to the rationing of health care resources that led to $\mathrm{Mr}$ Soobramoney's exclusion from treatment as follows: 'These choices involve difficult decisions [here is the reference to institutional incapacity] to be taken at the political level in fixing the health budget, and at the functional level in deciding upon the priorities to be met. [here is the deference to the other branches of government] A court will be slow to interfere with rational decisions taken in good faith by the political organs and medical authorities whose responsibility it is to deal with such matters' 102 (my emphasis). In Grootboom Yacoob J, in describing the reasonableness review test that the Court fashioned in that case, emphasizes that 'a court considering reasonableness will not enquire whether other more desirable or favourable measures could have been adopted, or whether public money could have been better spent.' 103

98 Treatment Action Campaign (note 7 above) para 38: 'Courts are ill-suited to adjudicate upon issues where Court orders could have multiple social and economic consequences for the community.' See also the Court's justification for the lenient standard of scrutiny adopted in Soobramoney (note 5 above) para 29: 'A court will be slow to interfere with rational decisions taken in good faith by the political organs and medical authorities whose responsibility it is to deal with such matters'.

99 Fraser (note 1 above) at 299.

100 It has, for example, been pointed out that the Court is in fact capable of determining the minimum core with respect to a given right, despite its protestations to the contrary, provided that it understands correctly what the minimum core entails; D Bilchitz 'Giving Socio-Economic Rights Teeth: The Minimum Core and its Importance' (2002) 118 SALJ 484 at 487.

101 FI Michelman 'The Constitution, Social Rights, and Liberal Political Justification' (2003) 1 International Journal of Constitutional Law 13 at 15.

102 Soobramoney (note 5 above) para 29.

103 Grootboom (note 6 above) para 41. 
Instead, he proceeds, ' $[\mathrm{t}] \mathrm{he}$ precise contours and content of the measures to be adopted are primarily a matter for the legislature and the Executive'. ${ }^{104}$ Finally, in Treatment Action Campaign one of the primary motivations for the Court's decision not to impose structural injunctive relief on the government is its concern that in doing so it will have to prescribe particular policy and rationing choices to it, instead of determining only the contours of what is required and leaving the details of planning and implementation to government itself. 105

Certainly, one might argue in favour of the Court that at the heart of its concern with the constitutional comity of its engagement with socio-economic rights is a concern with democracy. The Court, acutely aware of its position as the least democratically accountable branch of government, defers to the other branches, because in doing so it believes it respects the democratic will of which the political branches are the repositories. ${ }^{106}$ But the conception of democracy, or of politics or the political that underlies this concern is a peculiarly limited one. The Court's concern with constitutional comity evinces what Nancy Fraser has described as an institutional understanding of politics and democracy, in terms of which 'a matter is deemed political if it is handled directly in the institutions of the official governmental system, including parliaments, administrative apparatuses, and the like'107 and in terms of which democracy occurs only within these institutions of the official governmental system. This understanding of democracy and politics stands in contrast to what Fraser describes as a discursive sense of politics, in which 'something is "political" if it is contested across a range of different discursive arenas and among a range of different publics' and in which democracy occurs not only in the institutions of the official governmental system, but in all of these (official and unofficial) 'discursive arenas' and 'publics'. Stated differently, the Court's stance reflects a dependent conception of democracy, according to which democracy takes place only in formally constituted democratic structures, where political questions of, for example, distribution of resources are decided for and the results presented to civil society. Again, this conception stands in contrast to a participatory model of democracy, in which the focus is on creating and maintaining structures for the democratic process 'which maximize the allocation of equal political power to the citizenry' across the board of the different (official and unofficial) discursive arenas. ${ }^{108}$

Against this background, it becomes clear that the Court's instrumentalising rhetoric that it employs to justify its choices with respect to self-limitation of its powers operates to depoliticise issues of poverty, need and social provisioning of the State in two respects. First, and most obviously, the Court's rhetoric depoliticises in that it describes the issues in question as of a technical rather than a political nature. As pointed out above, this can to some extent be seen as inevitable. However, second, the Court's rhetoric depoliticises in that it relegates the discourse about these issues, even in their technical sense, wholly to the formally constituted political branches of government 'whose responsibility [and right] it is to deal with such matters'. ${ }^{109}$

\section{Ibid.}

105 Treatment Action Campaign (note 7 above) paras 96-114 \& 129-133.

106 See Roux (note 95 above), who explores the currency that this concern with democratic legitimacy has in the Court's conception of its review powers, and praises the Court for the extent to which it manages to remain appropriately respectful of democratic prerogatives in this respect.

107 Fraser (note 1 above).

108 Davis (note 95 above) at 488-489. See also E Pieterse \& M van Donk 'The Politics of Socio-Economic Rights in South Africa. Ten Years after Apartheid' (2004) 5:5 ESR Review 12 at 13: 'The realisation of socio-economic rights is an inherently political process, which needs to involve rights-holders ... in determining the desired outcomes, objectives, strategies and acceptable trade-offs so that they are enabled to take control of their own destinies. This inevitably implies a political process of negotiation, disagreement, conflict, occasionally consensus, and, at a minimum, forms of mutual accommodation.'

109 Soobramoney (note 5 above) para 29. 
The message to those other, unofficial 'publics' (social movements, NGO's, ordinary people) who operate democratically in those other, unofficial 'discursive arenas' is therefore not only that the issues that they deal with are difficult ones in a technical sense, requiring of them sustained, informed engagement ${ }^{110}$ which they, like the Court, might not have the capacity for. It is also that the issues are, as with the Court, simply not their business. The Court's rhetoric casts them not as active participants in the process of interpretation of their needs, engaged in political action, but as the passive recipients of services - their needs, predefined by the political branches of government, are administered to them through a process of therapeutic assistance. ${ }^{111}$

\section{(C) Khosa, Modderklip and PE Municipality: TOWARd a DISCURSIVE UNDERSTANDING OF DEMOCRACY?}

In socio-economic rights decisions of the Constitutional Court and the Supreme Court of Appeal subsequent to Soobramoney, Grootboom and Treatment Action Campaign it is possible to see the beginnings of a countervailing trend in the Court's rhetoric that is more closely allied to a discursive or participatory conception of politics and democracy and that can in this respect be contrasted to the Constitutional Court's instrumentalising rhetoric in the earlier three cases.

In the first place, in the cases in question (Khosa, Modderklip and PE Municipality) the Constitutional Court and Supreme Court of Appeal have emphasised the political agency of the poor people involved vis-à-vis government by taking its operation into account in interpreting the rights in question. In Khosa Mokgoro J, for example, in finding that the State had a constitutional duty to provide social assistance to indigent (non-citizen) permanent residents in South Africa, placed great stock in the fact that permanent residents had through their conduct in effect thrown in their lot with South Africa. In this respect Mokgoro J points out that permanent residents intend to become South African citizens, that they have made their homes here and have brought their families here, that for many their children have been born here, that they owe a duty of allegiance to the State ${ }^{112}$ and that they pay taxes in South Africa. ${ }^{113}$ As a result, although not yet formally citizens, they have claimed their membership of our community through the exercise of their political agency and deserve to be treated equally as fully fledged such members. ${ }^{114}$ In Modderklip Harms J for the Supreme Court of Appeal equally emphasizes the role of the political agency of the property owner and the squatters in determining the resolution of the case. In this respect Harms J points out that the landowner had at all times acted within the law and had throughout sought to effect an amicable solution that would vindicate both his and the squatters' rights 115 and that the squatters had occupied the land without intending to force the hand of the state to provide them with land in preference to others and had also sought to reach an amicable solution both with the landowner and the state. ${ }^{116}$ These indications of an attitude of political engagement with each other and with the State play an important role in eventually

110 Wilson (note 41 above) at 447.

111 Habermas (note 25 above) at 210; see also Fraser (note 1 above) at 307.

112 Khosa (note 8 above) para 59.

113 Ibid para 74.

114 Ibid.

115 Modderklip (note 10 above) paras 33, $37 \& 38$.

116 Ibid para 25. 
persuading the Court to find in favour of both the landowner and the squatters against the State, who by contrast had failed diligently to pursue a settlement and had reneged on agreements reached, ${ }^{117}$ despite the fact that it had itself caused the predicament of the squatters and the landowner by previously evicting the squatters from state land without providing alternative accommodation. ${ }^{118}$ Similarly, in PE Municipality, the Constitutional Court emphasises the political agency of the group of squatters that the State sought to evict there. Again the fact that they had occupied the land in question not in order to force the municipality to provide to them, in preference to others, alternative land when they are eventually evicted, but because they had been evicted from elsewhere and had nowhere else to go ${ }^{119}$ and that they had attempted to negotiate with the property owners and the State whilst the municipality had made no serious effort to reach an amicable conclusion to the matter, but had rushed to apply for an eviction order and had acted unilaterally, ${ }^{120}$ partly drove the Court to the conclusion that an eviction order could not be granted unless suitable alternative land or accommodation was provided. Indeed, in PE Municipality these factors, together with others, were seen as so important that the Court took the surprisingly intrusive step of rejecting the municipality's offer of two possible alternative sites, finding that they were not suitable to the squatters' needs.

Certainly one has to sound a note of caution here. As with any form of community-oriented rhetoric, the Court's emphasis in these three cases on the 'proper' political action of the permanent residents, the property owner and the squatters runs the risk of being read in an exclusionary fashion. So, for example, Mokgoro J explicitly uses this rhetoric to distinguish permanent residents from other non-citizens in South Africa and then, on the basis of that distinction to deny other non-citizens membership of the South African community. ${ }^{121}$ Equally, the two courts' reference in both Modderklip and PE Municipality to the fact that the squatters in question had occupied land illegally not with the intention to 'jump' the housing queue by forcing government to provide them with alternative accommodation when they were evicted, effectively marks the conduct of squatters who have indeed acted with that purpose as 'improper' and excludes their conduct (certainly equally born of desperation) from the realm of 'proper' political action. In this respect the two courts run the risk of creating an idea of acceptable civic action that one has to comply with in order to form part of the South African political community, excluding other forms of political action. ${ }^{122}$ Nevertheless, this aspect of the cases is important because at least it casts the permanent residents, property owner and squatters in the role of political actors, actively (and legitimately) engaging in the interpretation of their needs together with the State, who is in turn cast as just one more (albeit particularly authoritative) such participant in the process of need interpretation. In this way it avoids the depoliticising instrumentalist effect of the Constitutional Court's earlier separation of powers rhetoric.

This new concern with participatory democracy and discursive politics shows also in the manner in which the Constitutional Court and the Supreme Court of Appeal exercised and described their remedial powers in the three later cases. This is evident first in Modderklip. Modderklip was presented by the State as an intractable situation. The State argued that it

117 Ibid paras 35-38.

118 Ibid para 35.

119 PE Municipality (note 9 above) paras $49 \& 55$.

120 Ibid paras 45, 55-57 \& 59 .

121 Khosa (note 8 above) para 59: 'For these reasons, I exclude temporary residents ...'.

122 See in this respect K van Marle 'Love, Law and the South African Community: Critical Reflections on "Suspect Intimacies" and "Immanent Subjectivity"' in H Botha, AJ van der Walt \& JWG van der Walt Rights and Democracy in a Transformative Constitution (2004) 231 at 245-246. 
could not enforce Modderklip's eviction order against the squatters, because it did not have the resources to do so, particularly as it would have to provide alternative land to the squatters were it to evict them. ${ }^{123}$ This it would not be able to do also because it did not have the requisite resources, but, more importantly, because to provide the squatters with alternative land would allow them to jump the housing queue, thus legitimating unacceptable social behaviour. 124 This stance of the State's is a particularly clear example of the strategy of naturalisation referred to above: The State throws its hands in the air, overwhelmed by the intractable nature of the problems facing it and so attempts to remove the issues in question from the arena of political contestation. Harms J is unambiguous in his rejection of this strategy. Holding that 'Courts [and by implication the State] should not be overawed by practical problems' but should instead 'mould an order that will provide effective relief to those affected by a constitutional breach'125 he proceeds to find a solution where the State said there was none, ordering the State to pay damages to the property owner and to allow the squatters to remain on the land in question until alternative accommodation is found. Harmse J's 'can do' rhetoric powerfully counteracts the State's attempts at depoliticisation and places the kinds of issues that were dealt with in the case (homelessness, land invasion and eviction) squarely back in the domain of political contestation. In addition, because it amounted to the implementation of a proposal that both the property owner and the squatters had made in the course of their attempted negotiations with the State, ${ }^{126}$ it emphasises the involvement of these non-official political actors in the process of defining their needs and finding ways to satisfy them. As such, it underscores a participatory understanding of democracy and a discursive understanding of politics and counteracts the idea that it is only the State who can engage politically with the issues and then hand down solutions from on high.

The repoliticising trend continues in the Constitutional Court's description of its remedial powers in PE Municipality. Both Grootboom and Treatment Action Campaign have been criticised for the Court's failure to employ structural injunctive relief. In Grootboom, the Court issued a simple declaratory order, leaving the remedy of the constitutional defect in its housing programme entirely to the state. ${ }^{127}$ In Treatment Action Campaign, the Court similarly issued a declarator, coupled with a mandatory order requiring the state to remedy the constitutional defect in its programme for prevention of MTCT of HIV. ${ }^{128}$ However, despite confirming that it did indeed have the power to do so, the Court again declined to issue a supervisory interdict, holding that there was no indication that the state would not implement its order properly. ${ }^{129}$ The critiques of the two cases in this respect have focused on the extent to which the failure to employ such structural relief trenched on the effectiveness of the Court's remedies. ${ }^{130}$ However, Dennis Davis has recently instead emphasised the role of such structural relief in promoting democratic accountability. To him, the failure of the Court to employ structural relief has caused it to miss an opportunity to allow those affected by its judgements to be involved in their implementation as active political agents and as such has undermined the idea of participatory democ-

123 Modderklip (note 10 above) para 13.

124 Ibid para 29.

125 Ibid para 42.

126 Ibid para 14.

127 Grootboom (note 6 above) para 99.

128 Treatment Action Campaign (note 7 above) para 135.

129 Ibid para 129.

130 See eg K Pillay 'Implementation of Grootboom: Implications for the Enforcement of Socio-Economic Rights' (2002) 6 Law, Democracy and Development 255. 
racy. ${ }^{131}$ In PE Municipality Sachs J seems to heed this call. Although in the event declining to do so, ${ }^{132}$ Sachs $\mathrm{J}$ raises the possibility that a court, in providing a remedy in an eviction case such as the one the Constitutional Court was faced with could order compulsory mediation between the parties. That is, a court could make a normative finding, in the sense of describing the outcomes that the constitutional and other legal duties at play in the case required, but could then order the parties to enter into a process of mediation in order to agree upon the most appropriate means with which to reach those outcomes. ${ }^{133}$ As Charles Sable and William Simon have pointed out, ${ }^{134}$ this kind of 'experimentalist' 135 structural injunctive relief combines the virtues of the Court requiring constitutional duties to be met in a practically effective way, whilst remaining respectful of its own institutional incapacity with respect to the substantive issues involved in the implementation of its normative findings. For my purposes it shows a further important virtue. Courts employing such relief would certainly, as Sable and Simon argue, remain appropriately respectful of their own institutional incapacity by deferring to another forum than themselves with respect to the implementation of their orders. However, they will defer in this respect not in favour of the political branches of government only, as the Constitutional Court has been wont to do, but to the political process in the wider, discursive sense of the word outlined above. In this way courts would be able to subvert the instrumentalising rhetoric that they seem inevitably to have to engage in when adjudicating socio-economic rights claims and give effect to a participatory, rather than institutional understanding of democracy.

\section{Conclusion}

At the outset of this paper I recalled Karl Klare's challenge to judges and lawyers: In order to give expression to the transformative ethos of the Constitution, they should attempt to work in such a way as to deepen democratic culture in South Africa. I then proceeded to discuss one way in which courts can do so - by avoiding in their socio-economic rights judgements the use and consequent confirmation of rhetorical strategies of depoliticisation commonly used in the political discourse around the interpretation of need and poverty. I pointed to various instances in which courts have used and so confirmed some of these strategies, but also detailed instances in which they subverted these processes of depoliticisation. The countervailing tendencies that I identified, although important, of course do not allow courts to escape or to mediate the tensions between rights and democracy that their work is inevitably caught up in - judges continue to operate under freedom and constraint, their work inevitably both guarantees and denies freedom, reinforces and destructs democracy. Nevertheless, the Supreme Court of Appeal and Constitutional Court's rehabilitation of discursive politics through its emphasis on political agency and use of inventive remedies in Khosa, Modderklip and PE Municipality constitutes an important moment in the 'deepening of democracy' that Klare requires.

131 DM Davis 'Socio-Economic Rights in South Africa. The Record of the Constitutional Court after Ten Years' (2004) 5:5 ESR Review 3 at 6-7.

132 PE Municipality (note 9 above) para 47.

133 Ibid para 39-46.

134 CF Sable \& WH Simon 'Destabilisation Rights: How Public Law Litigation Succeeds' (2004) 117 Harvard LR 1016 at 1019 \& 1053-1056.

135 As opposed to 'command-and-control' injunctive regulation; ibid 1019. 


\title{
New Tools for the Constitutional Bench
}

\author{
- STAN A DU Plessis 1 \\ Associate Professor, \\ Department of Economics, \\ Stellenbosch University
}

' $\ldots$ on those occasions when the legal process does establish that an infringement on an entrenched right has occurred... The courts have a particular responsibility in this regard and are obliged to "forge new tools" and shape innovative remedies, if needs be, to achieve this goal."2

\section{Introduction}

It is highly unlikely that Justice Ackerman referred to positive theories of social change when he called on courts in South Africa to forge new tools in their rights jurisprudence, but I will argue here that such an allusion would not have been amiss. Indeed, such tools are indispensable for a Constitutional Court seeking the realisation of social and economic rights ${ }^{3}$ as is the case in South Africa. 4

Though the argument of this chapter is formal, the intention is practical and constructed specifically to participate in the present debate on social and economic rights in South Africa. In short, I argue that a constitutional court such as South Africa's might have to acquire and use explicitly the tools of positive social science - notably of economics - to complement the normative and legal tools already at its disposal. Since the Constitutional Court is already applying social science implicitly, to the extent that it regards social and economic rights as partially justiciable, it would be advantageous not only academically, but even more so practical-

1 I wish to thank Ronelle Burger for helpful comments, Gerhard du Plessis for his help with the jurisprudence literature, Gerhard du Toit for considerable help with editing and Thinus Keefe for research assistance. The usual disclaimer applies.

2 Justice Ackerman for the South African Constitutional Court in Fose v Minister of Safety and Security 1997 (3) SA 786 (CC) para 69 (fn omitted).

3 The following sections of the South African Constitution pertain to social and economic rights: section 25(5) (the right to equitable access to land); section 26(1) (the right to adequate housing); section 27(1) (the right of access to health care, adequate food and water and social security and social assistance) and section 28(1) (the right of children to adequate food, shelter, health care and social services). This list is from A J van der Walt 'A South African Reading of Frank Michelman's Theory of Social Justice' in H Botha, AJ van der Walt and J van der Walt (eds) Rights and Democracy in a Transformative Constitution (2003) 163 fn 5.

4 Justice Moseneke argued along similar lines: 'The Constitution has reconfigured the way judges should do their work. It invites us into a new plane of jurisprudential creativity and self-reflection about legal method, analysis and reasoning consistent with its transformative roles'; see D Moseneke 'The Fourth Bram Fischer Memorial Lecture: Transformative Adjudication' (2002) 17 SAJHR 309 at 318. This volume explores various theoretical perspectives on Moseneke's 'new plane of jurisprudential creativity'. The intention of this chapter is to broaden this theoretical discussion beyond jurisprudence, as the wide-ranging scope of social and political rights calls the Justices of the Constitutional Court beyond the reach of jurisprudence. 
ly, if the social science of the Constitutional Court was explicit, open to scrutiny and, in that way, open to the possibility of improvement through critical discussion.

The first section of this chapter develops an argument for the use of positive theory by the Constitutional Court and contrasts such a theory with normative and legal theories of social and economic rights. However, to assist the practical deliberations of the Constitutional Court requires not only a case for positive theory, but an argument for a specific positive theory. To inform that choice the broad range of such theories is sketched in section III. The fourth section narrows the discussion to one particular theory, the so-called New Institutional Economics, which is a positive theory of the requisite kind and which is gaining widespread theoretical and empirical support in economics. Section V demonstrates how the New Institutional Economics could be used to inform the analysis and enforcement of social and economic rights in South Africa and how the use of such a positive theory often complements the other theoretical perspectives.

\section{Why the Constitutional Court should use Theories of Positive Social Science}

The explicit provision of social and economic rights in the Bill of Rights and various other articles of South Africa's 1996 Constitution is widely noted and often applauded. 5 South African legal scholars have argued (in this volume and elsewhere) that these rights are justiciable in a comparable manner to the civil and political rights (sometimes called 'first generation rights') in the Constitution. This interpretation has found support in the Constitutional Court, where it has been argued that social and economic rights are '.... at least to some extent, justiciable'. ${ }^{6}$

The project on 'Theories of Social Justice' that gave rise to this volume takes the above as given. In South Africa this understanding of justiciable social and economic rights have to be seen in the context of a developing country with deep poverty combined with unequal access to resources and opportunities that are to a considerable extent due to historical discrimination. Reading the arguments for justiciable social and economic rights in the light of these economic and social challenges facing contemporary South Africa resulted in the two hypotheses that informed this project.

The first hypothesis is that 'theory matters', since theory is likely to influence the jurisprudence of social and economic rights in South Africa, as elsewhere. The second hypothesis is that 'theoretical drag', or the possibility that theory that lagged behind the drive for transformation in South Africa and that theory might, in this way, be delaying material improvement for the most vulnerable sections of the South African population. Against this background, Justice Ackerman's call for 'new tools' (quoted above) is here understood to mean, inter alia, solutions to theoretical drag in the implementation of social and economic rights.

It is easy to conceive how theory might matter and to agree that theoretical drag should be avoided, but it is harder to discern the kind(s) of theory that is required. At this point the common ground between the legal and economic literature seems particularly barren, with economists emphasising sustained economic growth as a (perhaps the most) important factor in the progressive realisation of social and economic rights and proposing positive theories of social change to that end. I did not detect a comparable concern with positive theories of social change

5 For example CA Sunstein 'Social and Economic Rights? Lessons from South Africa' (2001) Chicago Law and Economics Working Paper no 124 at 4.

6 Ex Parte Chairperson of the Constitutional Assembly 1996 (4) SA 744 (CC) para 78. 
in the legal literature on social and economic rights in South Africa. ${ }^{7}$ Instead the latter contains a rich discussion of normative and legal theories underpinning social and economic rights, some of which have been repeated and extended in this volume. While legal scholars have apparently been concerned with theoretical drag in jurisprudence or ethics, economists have typically been concerned with the possibility of positive theoretical drag.

In the service of clarity it might be useful to state explicitly what an economist understands by the distinction between normative and legal theories of social and economic rights on the one hand and positive theories of social change on the other. In this chapter a positive theory of social change is understood to mean a set of arguments (with empirical content) referring to certain changes in society. ${ }^{8}$ Empirical content is central to that definition and is understood in the critical or Popperian tradition, that is: the empirical content of a theory is provided by potential falsification. Theories with high empirical content make bold statements about the world, and indeed it is the wide range of conceivable experience that might refute such theories that constitute their empirical content. In contrast, theories with low empirical content do not make statements at odds with possible experience. ${ }^{9}$ An example of a (highly specific) positive theory relevant to the topic under consideration is: rural South Africans would experience a sustained rise in average household income if the South African Constitutional Court enjoined the government to implement a basic income grant.

A normative theory is here understood to be a set of arguments about the desired relationships and/or behaviour between persons, or between persons and their environment (whether the material environment or a spiritual dimension). Whether observed behaviour is presently or conceivably at odds with the normative recommendation does not pose an insurmountable intellectual challenge to normative theories. A relevant example of such a normative theory is: South Africans should support the implementation of the Constitution produced by a democratically representative Constitutional Assembly.

Finally, a legal theory is a set of arguments about the nature of the law, acceptable interpretation of the law, or the rights and obligations which derive from the law. Legal theories build on a wide range of principles, of which some are particular to jurisprudence, while others overlap with ethics or even political theory. Liebenberg provides the following summary of an envisaged jurisprudence relevant to justiciable social and economic rights: 'The jurisprudence will define the nature of the state's obligations in relation to socio-economic rights, the conditions under which these rights can be claimed, and the nature of the relief that those who turn to the courts can expect'.10

Evidently, the consideration that 'theory matters' requires a preliminary answer to the question: 'what sort of theory'? If we restrict our attention for the time being to positive theories, then the questions arises: What arguments could be used to evaluate the hypothesis that 'positive theory matters' for the jurisprudence of social and economic rights? Perhaps it is easiest to answer

7 This is a vast and rapidly expanding literature, which is the despair of a non-specialist. There is a small overlap between the legal and economic disciplines domestically but the interdisciplinary discussion has been hampered by a sometimes overly rigid approach to the rights literature on the side of economists and a sometimes overly ideological approach on the side of legal scholars to what has been called neo-liberal economics.

8 Economists often insist that positive theory of this kind is value neutral; see RA Posner 'Values and Consequences: An Introduction to Economic Analysis of Law' (1998) Chicago Law \& Economics Working Paper no 53 at 3.

9 For an elaboration of these views see for example KR Popper The Logic of Science (1959) at 41.

10 S Liebenberg 'South Africa's Evolving Jurisprudence on Socio-Economic Rights: An Effective Tool in Challenging Poverty?’ (2002) 6 Law, Democracy and Development 159 at 160. 
this question in the negative, that is, to demonstrate the consequences of proceeding with the judicial implementation of social and economic rights without considering positive theory.

Two subdivisions of the academic literature in economics is highly relevant in this regard. First, the public choice literature provides ample theoretical and empirical reasons for doubting that the outcomes of (especially ambitious) social plans will necessarily match their intentions. ${ }^{11}$ Second, the development economic literature has analysed decades of disappointment with development plans. ${ }^{12}$

Giving particular content to 'social transformation' in South Africa is undoubtedly contentious, ${ }^{13}$ though it almost certainly entails a dimension of economic development. We are not only interested in equitable participation in the economy this year but also, and perhaps more so, we are interested in a sustained rise of the average income and in effective and sustained poverty alleviation. Such changes would be transforming in an economy that has known decades of stagnation and exclusion.

The record of frustrated development, especially in Africa, Latin America and South Asia, has provided important refutations of various positive theories of economic development. ${ }^{14}$ The Constitutional Court could guard against a repetition of similar mistakes by learning the negative lessons of these positive theories.

A similar argument could be made for learning the negative lessons recorded in the public choice literature. In the context of a discussion about the Constitutional Court's role in the transformation of society (via the interpretation and implementation of social and economic rights) it seems reasonable to assume that at least the behaviour of the Constitutional Court, but also that of government at all levels, has to be analysed. Most notably, any uncritical belief in the efficiency of government has to be tempered by the public choice analysis of 'government failures'. Indeed, the public choice literature has undermined the

11 See for example: V Tanzi 'The Changing Role of the State in the Economy' (1997) IMF Working Paper WP/97/114 passim; JM Buchanan 'Politics without Romance' in JM Buchanan (ed) The Collected Works of James Buchanan. Volume I. The Logical Foundations of Constitutional Liberty (1999) 45; JM Buchanan \& RA Musgrave Public Finance and Public Choice. Two Contrasting Visions of the State (2000) passim; V Tanzi 'The Role of the State and the Quality of the Public Sector' (2000) IMF Working Paper WP/00/36) passim.

12 See for example P Collier \& JW Gunning 'Explaining African Economic Performance' (1999) 37 Journal of Economic Literature 64-111; W Easterly The Elusive Quest for Growth (2001) at 23.

13 Moseneke (note 4 above) at 315 quotes Albertyn \& Goldblatt approvingly where they argued that transformation requires '.... complete reconstruction of the state and society...'. It is very difficult and perhaps impossible to pursue such a comprehensive vision with the tools of positive theory as is argued below and also by KR Popper The Poverty of Historicism (1961) at 69; KR Popper 'Towards a Rational Theory of Tradition' in KR Popper (ed) Conjectures and Refutations: The Growth of Scientific Knowledge (1992) 120 at 131. An example of the sober view presently ascendant in development economics is Easterly's conclusion that: 'the problem of making poor countries rich was more difficult than we thought...[and] the recommendations I have given are themselves no panacea - they will take patient incremental work and further money to implement': Easterly (note 12 above) at 291.

If we take the contextuality of all social relationships and hence all social science seriously, it precludes the possibility of discussing social relations in an as yet unknown society. We are left only with the possibility of piecemeal social policy - adjusting for specific problems here and there - and then learning from our mistakes as the unintended consequences of the policies unfold: Popper (note 13 above) at 70 . Arguments such as these explain much of the scepticism of Utopian schemes for social reform in economics and other positive social sciences, while such systematic visions of a better tomorrow might remain useful in a different theoretical setting.

14 The failure of foreign aid to boost economic growth and development in much of the developing world is an important example discussed in, for example, Easterly (note 12 above) at 43. 
presumption that a centralised solution exists for every decentralised failure in society. ${ }^{15}$

Returning to justiciable social and economic rights: the Constitutional Court could avoid a repetition of the unfortunate government failures of the last fifty years by learning the lessons of the positive theories of public choice with respect to the scope and limit for action by (i) the Constitutional Court itself, (ii) the national executive, and (iii) local government.

While the lessons from public choice and development economics mentioned in the last few paragraph have been essentially negative, there are also constructive reasons for recommending closer attention to positive theories of social change by the Constitutional Court. Assuming that the Constitutional Court wishes to contribute to particular changes in South African society, it stands to reason that the Court would need theories of how these changes might in reality occur. Furthermore, these theories must neither be restricted to the legal theories that inform the legitimate scope for their action, nor must it be restricted to moral theories of what goals and priorities the Constitutional Court ought to be pursuing.

Rather, the Constitutional Court has a need to understand whether - and if, then how - the intended consequences of a particular project are likely to arise and, perhaps more importantly, what the unintended consequences of the initiative might be. Such a focus on unintended consequences - and hence on the behavioural implications of incentives created by programmes under review - is central to the economic analysis of law which has gained credence in recent years. ${ }^{16}$

If positive theories of social science matter for social and economic rights, then it follows that 'theoretical drag' with respect to such positive theories might also hamper progress on the realisation of these rights. Accepting the case for a positive theory does not, however, determine the particular positive theory that should be used. The next section considers a range of positive theories relevant to the questions of transformation, economic development and social and economic rights.

\section{A Spectrum of Positive Theories}

The eagerly anticipated social transformation of South African society implies changes along two dimensions. The first dimension is economic growth and the economic development of society and the second dimension the degree of equality in the distribution of income and wealth. This project is concerned with the role of rights, notably social and economic rights, in the changes along these two dimensions.

In the previous section it was argued that positive theory was important in understanding the role that rights could play in this transformation. Economics is one of the social sciences that offers such positive theories of social change. Economists study decisions and the constraints on these decisions and it is therefore unsurprising that economic theory could provide a useful tool to analyse the role of rights in social change. But there is a broad range of positive theories about social change, and legal scholars and the Constitutional Court will face the difficult task of judging the relative merits of these theories in order to form a rational expectation of how social and economic rights might be connected with actual social change.

For the sake of analytical tractability two extreme views are presented here, though the work of leading theorists and econometricians are invariably more subtle, combining elements of

15 For an elaboration on the theory and support for public choice theory see for example Buchanan (note 11 above).

16 Posner (note 8 above) at 3 . 
both. The two ends of the spectrum are the decentralised theories of social change on the one hand and the centralised theories on the other. ${ }^{17}$

Centralised theories of social change are built around the vision of a centralised authority (usually the state) which takes the initiative and plays a leading role in the process of initiating and sustaining economic development. The theory of a developmental state (developed to explain the experience of notably Japan) is amongst the better known examples of this type, but this end of the spectrum reaches all the way to various forms of socialism. The intuitive appeal of the centralised theories are that they seem rational (at least in the sense of 'rational planning') and simple as the main requirements are apparently (i) sufficient resources and (ii) the legitimate authority to use these resources for the development plan. This simplicity improves transparency with the benefit of raising potential accountability for the planning authority.

Centralised theories of social change are relevant to the implementation of social and economic rights in two ways: first by the sometimes tacit assumption that combination of sufficient authority and sufficient resources would very likely lead to the desired social change; and second by various empirically testable hypotheses that can be deduced from the last century of centralised attempts at social change. Though the former of these is empirically empty, the latter is not and economists have checked its empirical record against expectations, with the sobering result summarised by Tanzi:

...We now have the reality of several decades of expanded state intervention so that expectations can be compared against the results. The results from this experience have been disappointing in many countries, especially in developing countries. There is now ample evidence that large state intervention has not improved the allocation of resources, has not promoted faster growth, has not brought about a better distribution of income, and has not provided a more stable economic environment... ${ }^{18}$

Despite their leading role in the development of centralised theories of change, economists have also developed decentralised theories of social change dating back to the Scottish Enlightenment. Since then economists have theorised about the combination of institutions that would yield a peaceful and progressive social order, without making exaggerated assumptions about the moral stature of the citizens or the skill and integrity of the authorities. It was a great discovery of the Scottish Enlightenment that a spontaneous social order, and not unavoidable chaos, could obtain in these circumstances. ${ }^{19}$

A decentralised economy works by allowing individuals to specialise on own initiative and then to provide for the remainder of their needs through exchange. However, decentralised

17 Neither of these theories can be associated with conservative or progressive views of social change as such. In a decentralised society social change can be rapid or slow, progressive or regressive, depending on the scope for decisions by individuals and the decisions they actually make. Likewise, a centralised society might experience progressive or regressive change, and this at a rapid or slow pace, depending on the scope and capacity of government, and the actual decisions taken by authorities. The point is not that economists are agnostic about the likelihood of (say) rapid progressive change in a society (more about that in section IV) but that neither of these theoretical extremes imply a particular type of change as such.

18 Tanzi (note 11 above) at 15.

19 The self-regulated order of a decentralised society has variously been called a 'spontaneous order': FA Hayek 'Individualism: True and False' in FA Hayek (ed) Individualism and Economic Order (1984) 1 at 7; 'ordered anarchy': Buchanan note 11 above or the 'invisible-hand order' (by Nozick). The common intuition in these terms is that the social order is not the result of conscious effort by any of its constituent parts. 
order requires, at a minimum, secure property rights and an extravagant amount of information. It was not in the tradition of the Scottish Enlightenment to solve this problem of information by assuming 'perfect' knowledge either for individuals or for some social planner. Rather, the emphasis was on people's epistemological limitations. For Hayek, this modest view of human capacity, or what he calls the '...constitutional limitations of man's knowledge and interests, the fact that he cannot know more than a tiny part of the whole society and that therefore all that can enter into his motives are the immediate effects which his actions will have in the sphere he knows...' is central to the solution suggested by Adam Smith and others. ${ }^{20}$

It is the price mechanism which, in a competitive market, solves this information problem to a satisfactory extent and provides the incentives for using that information. ${ }^{21} \mathrm{On}$ this view 'the market' is the institutional framework, or network of links, within which voluntary exchange manifests itself. Competition is the means by which information is acquired and disseminated along this network, creating in Hayek's words: '...the unity and coherence of the economic system which we presuppose when we think of it as one market. 22

Notwithstanding the power of this demonstration, it is - as described - only half a theory'. The efficacy of the price system to bring about spontaneous social order is conditional on the gains of specialisation and trade exceeding the costs of trade, and this cannot be assumed. Indeed, for much of history and in most societies, the cost of trading was exceedingly high and prevented the transition to modern decentralised production. The New Institutional Economists, especially Douglass North, have suggested that it is the political and economic institutions (as defined below) in an economy that form the link between the theory of production (by specialisation and exchange) and transaction costs that limit the extent of the market. ${ }^{23}$

This decentralised theory of society, anchored in the vision of material progress through specialisation and trade yields, empirically testable hypotheses about social change that can be tested with the data of the last two centuries. Of further interest to this particular project is that constitutions and the rights they define, protect and implement, play a crucial role in the decentralised theories of social change. In this way the decentralised theory offers an empirically testable tool for assessing the manner in which to realise, inter alia, social and economic rights.

With the benefit of hindsight, economists have come to judge decentralised theories of social change more favourably than centralised theories. This was an important consideration in my decision to focus on one of the decentralised theories of social change in the following section. The analytical scope in New Institutional Economics for analysing the role of rights was a further reason.

20 Hayek 'Individualism' (note 19 above) at 14.

21 Towards the end of his career Paul Samuelson tried to capture what economists had learnt from the lengthy debate between proponents of decentralised development and those who argued for the 'feasibility of socialist rational pricing' and his conclusion was both gracious (to Hayek, a long standing academic opponent) and modest (in its claims for the decentralised system). 'Hayek has been persuasive,' Samuelson admitted '...in arguing that experience suggests that only with heavy dependence on market pricing mechanisms can there be realised quasi-efficient and quasi-progressive organisation of societies involving humans as Darwinian history has bequeathed them': PA Samuelson 'Some Uneasiness with the Coase Theorem' (1993) 7 Japan and the World Economy 1 at 7. Efficiency (in the ultimate sense) never obtains, neither in the decentralised systems of present day market economies, nor in the unlamented socialist experiments of the twentieth century.

22 FA Hayek 'The Meaning of Competition' in FA Hayek (ed) Individualism and Economic Order (1984) 92 at 106.

23 DC North 'Institutions' (1991) 5 Journal of Economic Perspectives 97 at 102; DC North Institutions, Institutional Change, and Economic Performance (1990) at 27. 


\section{New Institutional Economics}

The vast differences in standard of living - however measured - between the richest and the poorest countries in the world today is mainly a result of differences in sustained economic growth over the last millennium, with a widening of the gap since the industrial revolution. ${ }^{24}$ Economists have shown that such differences cannot, in the words of Mancur Olson '.. be explained by differences in the ratio of population to land or natural resources, or by differences in the quality of marketable human capital or personal culture....'25

'The real secret of successful development is the performance of the people concerned,' as David Landes wrote '...but achievement must come from within....' ${ }^{26}$ In other words, the social change that is affected by economic development requires a certain kind of society; development requires a society where many (perhaps most) people can envisage a better future, not only for themselves, but especially for their children. But here is the crux: the path to this better future must pass through production, not predation; making new wealth, not merely diverting wealth from others. ${ }^{27}$ In such a society people change their behaviour, invest in their own human capital, change the size of their families and invest in the human capital of their children. ${ }^{28}$

It is this investment in human capital that unlocks the tremendous latent potential of hitherto poor societies, allowing them to experience catch-up growth as they apply the more recent vintages of knowledge and technology available in a globalising international economy. These technologies can be implemented in local conditions with the logic of trial and error, where potential return rewards risks taken and mistakes are eliminated by the material sanction of the market. $^{29}$

The process of development described above has an explicit time dimension. Economic development requires more than the efficient allocation of resources in every period, it requires additionally what North has called 'adaptive efficiency'; in his words:

... [adaptive efficiency] is concerned with the tolerance of a society to the acquisition of knowledge and learning; to a society's encouragement of innovation, risk-taking, and creative activities of all sorts. The encouragement, via the appropriate institutional framework, of trials, experiments, and innovation, is essential because in a world of uncertainty no one knows the 'correct' answer to the problems we confront... . ${ }^{30}$

24 A Maddison The World Economy: A Millennial Perspective (2002) passim; D Landes The Unbound Prometheus: Technological Change and Industrial Development in Western Europe from 1750 to the Present (2003) passim.

25 M Olson 'Big Bills left on the Sidewalk: Why Some Nations are Rich, and Others Poor' in S Knack (ed) Democracy, Governance and Growth (2003) 29 at 47.

26 D Landes The Wealth and Poverty of Nations. Why Some are so Rich and Some so Poor (1998) at 562.

27 S Knack 'Predation of Production? The Impact of Political, Legal and Social Institutions' in S Knack (ed) Democracy, Governance and Growth (2003) 1 at 1.

28 RJ Lucas Lectures on Growth Theory (2002) at v.

29 J Diamond Guns, Germs and Steel. The Fates of Human Societies (1997) passim; Landes (note 26 above) passim.

30 DC North 'On the Economic Role of the State: Comment' in A Heertje (ed) The Economic Role of the State (1989) 107 at 109. 
The concept of institutions has become central to economists' understanding of this dynamic process of change. Formally, institutions are '.... a set of constraints on behaviour in the form of rules and regulations; a set of procedures to detect deviations from the rules and regulations; and, finally, a set of moral, ethical behavioural norms which define the contours that constrain the way in which the rules and regulations are specified and enforcement is carried out...., 31 or in game-theoretic terms, the institutions are the 'rules of the game' of social interaction. ${ }^{32}$

Institutions can lower transaction costs, thereby facilitating specialisation and exchange, by rendering behaviour more stable and predictable, or in the words of Kasper and Streit: '...the key function of institutions is to facilitate order: a systematic, non-random and therefore comprehensible pattern of actions and events.... ${ }^{33}$ Institutions play this central role in the social order, since it is the combination of the formal and informal institutions with the standard constraints of economics that 'define the opportunity set of the economy', as North argued elsewhere. ${ }^{34}$

A complex network of institutions - called the institutional matrix - facilitates all social interaction. This matrix is composed of both formal rules (for example the legal code) and informal rules (for example customs and taboos) and is both political (for example proportional representation as a voting rule) and economic (for example tariffs).

This institutional matrix, including the formal rules set by government, and the informal rules that command broad adherence create and direct incentives either for productive activity or for rent seeking. Every society offers incentives for both productive activity and rent seeking, but economic historians such as North and development economists such as Easterly have argued that the relative weight taken by these two broad groups of incentives are a crucial factor in the long run prosperity of a society. ${ }^{35}$

'People respond to incentives', as William Easterly ${ }^{36}$ reminded us of the lesson of elementary economics, and that is the reason why the institutional matrix has such a profound effect on the dynamic efficiency of a society. This effect is mediated through the structure of industrial organisation encouraged, governance in the private and public sector, and flexibility in both public and private sectors. ${ }^{37}$ North identified two necessary conditions for adaptive efficiency: first, decentralised decision making and second, a feedback mechanism that eliminates errors more or less expeditiously.

It is only in adaptively efficient economies where the tremendous potential of specialisation and trade can be realised, as these rely on '...contracts across time and space and with unknown second parties.... 38 These contracts cannot exist without a favourable institutional framework, including formal rules such as property rights and a judicial system that enforces contract rights; nor could these contracts exist without informal rules, such as a high degree of trust and respect for the formal rules.

31 DC North 'Transaction Costs, Institutions, and Economic History' (1984) 140 Journal of Institutional and Theoretical Economics 7 at 7-8.

32 DC North (note 23 above) at 3

33 W Kasper \& M E Streit Institutional Economics: Social Order and Public Policy (1998) at 28.

34 DC North 'Five Propositions about Institutional Change' in J Knight \& I Sened (ed) Explaining Social Institutions (1995) 15 at 15.

35 North (note 34 above); Easterly (note 11 above) passim.

36 Easterly (note 11 above) at 177.

37 North (note 30 above) at 109.

38 North (note 30 above) at 109. 
Such an institutional approach accords an important role to the State. Kasper and Streit list a number of reasons why government enforcement of institutions are often desirable, including the state's comparative advantage in power; government's credibility; the potential ambiguity of internal rules; the ability of the state to implement rules dispassionately; free riding; the tragedy of the commons and finally, prisoner-dilemma type situations can often be resolved with credible external commitments. In the next section constitutional rights are regarded as important examples of such formal institutions.

Mancur Olsen has shown how the distribution of favourable institutions internationally helps us to untangle some of the puzzling stylised facts of economic growth, for example that poor countries would not, unconditionally, be catching up with the rich countries, but that some poor countries - those with favourable institutions, creating adaptive efficiency - would enjoy catch-up growth. 39

This is not a circular argument, with Olsen, North and others equating 'good institutions' ex post to those institutions found in rich or fast growing countries. On the contrary, it is a positive theory of social change that yields empirically testable hypotheses (using various measures of institutional quality). 40 There is an extensive literature that applies institutional economics to economic history. Douglass North and Mancur Olson have been seminal in this field. ${ }^{41}$ Other important contributions have been made inter alia by Baumol, Eggertsson, Grilli, Masciandaro and Tabellini, de Long and Shleifer and Acemoglu. ${ }^{42}$

More recently, the empirical importance of institutions has been investigated using formal econometric tests. Some of these use simple graphical correlations between various measures of 'good governance' and different dimensions of economic performance. ${ }^{43}$ More sophisticated econometric techniques were used by inter alia Knack and Keefer, Hall and Jones, Clague, Keefer, Knack and Olson, Acemoglu, Johnson and Robinson and Rodrik, Subramanian and Trebbi to investigate the importance of empirical relevance of institutions in economic growth. ${ }^{44}$ In summary, the positive analysis of economic growth (in a vast literature that has received considerable attention from economists over the last twenty years) has yielded the ten-

39 We know some institutional remedies that help matters, even if they are no panaceas. If only rule of law, democracy, independent central banks, independent finance ministers, and other good-quality institutions can be put in place, the endless cycle of bad policies and poor growth can come to an end': Easterly (note 11 above) at 279 .

40 A critical review of these attempts to quantify institutional quality is offered by $\mathrm{J}$ Aron 'Growth and Institutions: A Review of Evidence' (2000) 15(1) The World Bank Observer 99.

41 North (note 31 above) passim; North (note 30 above) passim; North (note 34 above) passim; Olsen 'The Rise and Decline of Nations: Economic Growth, Stagflation, and Social Rigidities' (1982) passim.

42 WJ Baumol. 'Entrepreneurship: Productive, Unproductive and Destructive' (1990) 89 Journal of Political Economy 893; T Eggertsson Economic Behaviour and Institutions (1990) passim; V Grilli, D Masciandaro et al 'Institutions and Policies' (1991) Economic Policy 341; JB de Long \& A Shleifer 'Princes and Merchants: European City Growth before the Industrial Revolution' (1993) 36 Journal of Law and Economics 671; D Acemoglu 'Root Causes. A Historical Approach to Assessing the Role of Institutions in Economic Development' (2003) 40 Finance and Development 27.

43 A typical example is the strong positive correlation between the number of procedures required for registering a new business and an index measuring corruption in the same economy. See World Bank World Development Report 2002. Building Institutions for Markets (2002) at 7.

44 S Knack \& P Keefer 'Institutions and Economic Performance: Cross Country Tests Using Alternative Institutional Measures' (1995) 7 Economics and Politics 207; R Hall \& CI Jones 'Why do Some Countries Produce so Much More Output per Worker than Others' (1999) 114 Quarterly Journal of Economics 83; Acemoglu (note 42 above); D Rodrik, A Subramanian et al 'Institutions Rule: The Primacy of Institutions over Geography and Integration in Economic Development' (2002) NBER Working Paper 9305. 
tative conclusion that institutions (as defined here) are amongst the most central determinants of long run growth and economic development. These institutions are also crucial for the sustained productivity growth which is the other major determinant of sustained technological growth. Taken together, the importance (even dominance) of institutions and technology growth undermine the sometimes intuitive view that economic development is mainly a matter of acquiring more resources. ${ }^{45}$

This result has an important implication for the progressive realisation of social and economic rights. It should shift the attention of government and the Constitutional Court from an exclusive concern with mobilising resources to a focus on the institutional matrix in society and the considerable role that government and the Constitutional Court play in the maintenance and evolution of that matrix. 46

The interest in this project lies beyond establishing the theoretical and empirical importance of institutions, though. At stake is the difficult issue of institutional change and specifically how the Constitutional Court might participate in the institutional change associated with the realisation of social and economic rights in South Africa. The institutional literature referred to above includes theories of social change which incorporates positive and negative rights as institutions and which explains the observed international distribution of material prosperity.

North derived two important implications of the theory of institutional change from this literature: firstly, that institutional change is likely to be incremental and secondly, that institutional change is likely to be path dependent. ${ }^{47}$ Both observations have interesting implications for the possibility of theoretical drag in the realisation of social and economic rights.

If institutional change is mostly gradual, as opposed to revolutionary, then we should adapt our expectations of the time horizon involved in the realisation of such change accordingly. This is not a defeatist attitude; rather it utilises the theoretical modelling of institutional change, and the historical record, to inform reasonable expectations. It is important for all the stakeholders in society, but especially for the Constitutional Court in this regard, to have reasonable expectations regarding the horizon over which institutional change occurs.

The importance of reasonable expectations is closely associated with the likely path dependence of institutional change. The latter means that changes to the institutional matrix (that will affect the relative incentives for productive activity and rent seeking) have to be approached very carefully, as the possibility of ending in an underdevelopment trap is not simply theoretical. Indeed, dozens of societies remain trapped in such circumstances today. ${ }^{48}$ It follows that the Constitutional Court should, as it wrestles with the interpretation and realisation of social and economic rights in South Africa, bear in mind the incremental character of institutional change and the path dependency which both raises the importance of moving forward in present circumstances and of avoiding injudicious moves down an ill-fated path where rent-seeking dominates productive choices.

45 Easterly (note 11 above) at 279.

46 The present literature on economic growth is, therefore, at odds with claims made in this regard by, for example, Chetty that 'the pace and extent of development is ultimately determined by the resource constraints'. See K Chetty 'The Public Finance Implications of Recent Socio-Economic Rights Judgments' (2002) 6 Law, Democracy and Development 231 at 234.

47 This emphasis on the slow moving and contextualised evolution of institutions reminds of Popper's case for piecemeal social reform mentioned above (note 13). See also North (note 34 above) at 15.

48 Easterly (note 11 above) at 163. 


\section{$V$ Rights as Institutions}

The New Institutional Economics provides an analytical framework for thinking about rights as an important subset of the institutional framework. Such a framework is useful to analyse both the role played by various rights in a given society and the role-players involved in securing and exercising the rights. Thinking about rights as institutions provides a perspective in the rights literature that is complementary to perspectives gained from the philosophical and legal literature. Of particular interest for the purposes of this project is that the perspective gained from the New Institutional Economics offers one bridge between normative theories and legal analysis of social and political rights on the one hand and positive theories of social change (in which these rights play a central role) on the other. 49

First generation human rights are often called negative freedoms as they require the protection of a private sphere of control. ${ }^{50}$ It is often advantageous for these rights to be defined and maintained by a state. The definition and maintenance of property rights is a typical - and for economists crucially important - example of an institution that lowers transaction costs as discussed above.

Second generation human rights, such as the right to health care, to education, to housing, employment and so on, are 'positive rights' in Berlin's terminology. ${ }^{51}$ In contrast with the private sphere of control created by the first generation rights, the second-generation rights are aimed at empowering people to participate in society by providing access to resources and by defining a certain minimum standard of living. ${ }^{52}$ These rights, and the manner of their realisation, also affect the incentives in society considerably. However their impact on incentives is not necessarily in the same manner as that of the first generation rights, nor necessarily even in the same direction.

Economists have studied the respective roles of positive and negative rights in the institutional matrix. Specifically, economists are concerned with the potential behavioural implications of different ways in which the realisation of rights could obtain. For example, economists are concerned with the intended but also with the unintended consequences of any intervention such as the definition of a minimum core for the concept of socio-economic rights by the Constitutional Court. To this end economists use their rational choice theory to trace the intended and unintended consequence of such institutional innovations..$^{53}$

In the modern economics literature such concerns have been formalised in the Lucas-critique, according to which policy authorities should realise that behaviour in society will not be invariant to policy interventions. ${ }^{54}$ Behaviour and policies interact in this dynamic manner since policies change the incentives of private and public decision makers. The same is true of social and

49 The New Institutional Economics analytical framework also provides alternative theories of the emergence of rights, but that falls beyond the scope of this project. I Sened 'The Emergence of Individual Rights' in J Knight \& I Sened (ed) Explaining Social Institutions (1995) 161, offers an interesting recent example.

50 For A Sen 'The Possibility of Social Choice' (1999) 89 American Economic Review 349 at 363, these negative liberties (or rights) constitute the 'process aspect' of liberty, that is the 'choices over private domains, no matter what we may or may not achieve'.

51 I Berlin 'Two Concepts of Liberty' in I Berlin Fours Essays on Liberty (1969) 118.

52 For Sen (note 50 above) at 363 these positive rights define the 'opportunity aspect' of liberty, that is they '...can help us to achieve what we would choose to achieve in our respective private domains.'

53 Posner (note 8 above) at 3.

54 RJ Lucas 'Econometric Policy Evaluation: A Critique' in K Brunner \& AH Meltzer (ed) The Phillips Curve and Labour Markets (1976) 19 at 25. 
economic (and indeed, civil and political) rights, as has been demonstrated by the New Institutional Literature referred to above.

The implication of the Lucas-critique for constitutional courts is similar to the implication for other policy authorities, that is: the Constitutional Court requires a fully articulated behavioural model (as opposed to broad stylised facts and general behavioural observations) before it can responsibly anticipate the outcomes of its decisions with respect to, inter alia, changes in the implementation of social and economic rights. In other words, the Constitutional Court requires a positive theory of behaviour in society, calibrated with the behavioural parameters of the actual society, in addition to the normative parameters of the society towards which the Court or anybody else may be striving. And the Court should not impose normative or ideological priors on the role of various rights in such a positive theory of behaviour and social change.

Though legal scholars have also been enthusiastic to attribute an important role to rights in their theory of social change, their analysis has often been strikingly different form that sketched in the preceding paragraphs. Scholars such as de Vos and Klare have drawn strong conclusions about the role of social and economic rights in support of the transformative character of the South African Constitution and the apparent impediment of negative rights in that regard. ${ }^{55}$ Many of these accounts share the assumption that South Africa's particular history required transformative social and economic rights to prevent a Bill of (first generation) Rights from preserving the unjust economic and social status quo.

Pierre de Vos identified a negative component of a right that '...places a duty on the state to respect the specific right by not interfering with its enjoyment...[which] is the non-transformative aspect of the right, as it attempts to preserve the existing situation in a society without reference to the larger social and economic context or the transformative goals of the Constitution'; and again 'there will, of course, often be a tension between the negative and positive aspects of the various rights because the negative aspect of the right is primarily aimed at freezing the status quo while the positive aspect is aimed at achieving a society that would look dramatically different from the one we live in now'. ${ }^{56}$

Hanri Mostert refers to the 'inherent contradictions' of 'assuming that the constitutional protection and regulation of private property in South Africa is a tool for both protecting individual freedom and security and initiating social change'. 57

In the fourth Bram Fischer memorial lecture Justice Moseneke was also emphatic in carving a role for the Constitutional Court as an agent of transformation: '.. the Constitution enjoins the judiciary to uphold and advance its transformative design' and '...transformative adjudica-

55 P de Vos 'Grootboom, the Right of Access to Housing and Substantive Equality as Contextual Fairness' (2001) 17 SAJHR 258 at 260; K Klare 'Legal Culture and Transformative Constitutionalism' (1998) 14 SAJHR 146 at 169 . Sunstein (note 5 above) at 4 distinguishes between broadly 'preservative' and broadly 'transformative' constitutions and classifies South Africa's Final Constitution as '... the world's leading example of a transformative constitution'. It is possible to read a tension between Sunstein's favourable analysis of the transformative character of the South African Constitution and his concerns a decade earlier in CA Sunstein 'On Property and Constitutionalism' (1991) Chicago Law and Economics Working Paper no 3 at 14, where he expressed serious reservations about the inclusion of 'aspirations' in a constitution. For a number of other perspectives on the concept of a transformative constitution and the associated role of rights see the volume edited by H Botha, AJ van der Walt \& J van der Walt (note 3 above).

56 De Vos (note 55 above) at 273-274.

57 H Mostert 'Liberty, Social Responsibility and Fairness in the Context of Constitutional Property Protection and Regulation' in H Botha, AJ van der Walt \& J van der Walt (eds) (note 3 above) 131 at 131. 
tion must be put to the task of achieving (in conjunction with the other organs of the state and diverse organs of civil society) social redistributive justice. The primary purpose of the Constitution is to intervene in unjust, uneven and impermissible power and resource distributions, in order to restore substantive equality, permissive or tolerable in a country, which has committed to foundational values such as are found in our Constitution'.58

Dennis Davis argued that if negative rights that protect a private sphere of control were privileged by the Constitution and the Constitutional Court then '...much of the apartheid legacy would continue to be immune from the imperative of changing the essentials of apartheid society...'? 59

On this issue the economic and legal literatures are evidently at odds. The description of rights as institutions above did not mention preserving the status quo. On the contrary, the discussion emphasised that first generation rights, inter alia, are an integral part of a theory of social change. The gap between the two approaches is especially wide with respect to a claim, such as that of de Vos, that there is an 'obvious' tension between negative and positive aspects of rights in their transformative impact. ${ }^{60}$

Klaaren gives a concrete character to this tension by referring to a spectrum along which one might place the different understandings of the transformative potential of a constitution, starting with a minimal interpretation of a classically liberal type at one end and ending with a 'radically democratic' interpretation at the other. ${ }^{61}$ The positive study of actual change in society (as described above) does not lend itself to such a one dimensional ranking. It might be true that the associated social change in what Klaaren characterises as a classically liberal understanding of the Constitution is decentralised, but that does not detract from (i) the dynamic character of decentralised societies, or (ii) the magnitude of the change that has occurred in these societies over the past two centuries, nor (iii) from the widespread distribution of benefits in developed societies. ${ }^{62}$

The dynamic contribution of, for example, property rights to social change is associated with the incentives it creates as an institution:63 firstly, it creates incentives for the efficient alloca-

58 Moseneke (note 4 above) at 314, 318.

59 D Davis 'Elegy to Transformative Constitutionalism' in H Botha, AJ van der Walt \& J van der Walt (eds) (note 3 above) 57 at 58 .

60 De Vos (note 55 above) at 274. M Pieterse 'Beyond the Welfare State: Globalisation of Neo-liberal Culture and the Constitutional Protection of Social and Economic Rights in South Africa' (2003) 14 Stellenbosch $L R 3$ at 18 chooses to articulate this tension in an analytical scheme whereby civil and political rights are associated with a 'neo-liberal' ideology of the state's role in a market economy. In his ideological discourse Pieterse argues that neo-liberalist conceptions of society are '...contrary to the goals of social transformation in that it requires that current distribution patterns are to be left intact...'.

$61 \mathrm{~J}$ Klaaren 'An Institutional Interpretation of Socio-Economic Rights and Judicial Remedies after TAC' in H Botha, AJ van der Walt \& J van der Walt (eds) (note 3 above) 105 at 107.

62 RJ Lucas 'Some Macroeconomics for the 21st Century' (2000) 14 Journal of Economic Perspectives 159 at 166.

63 This dynamic interpretation of, for example, property rights is not restricted to the economics literature. Legal scholars such as Cass Sunstein have acknowledged the same, for example: CR Sunstein 'On Property and Constitutionalism' (1991) Chicago Law and Economics Working Paper no 3 at 11. But Sunstein (note 63 above) at 11 goes further to argue that property rights are not just crucial to economic development and change, but added the political philosophy proposition that '...one of the best ways to destroy a democratic system is to ensure that the distribution of wealth and resources is unstable and constantly up for new evaluation by the political process... a constitutional system that respects private property should be regarded, not as an effort to oppose liberal rights to collective self-government, but instead as a way to fortify democratic processes'. While that argument is not pursued in this chapter, it is consistent with and reinforces the ideas stated here. Further, he added immediately that a system of property rights requires the support of a 
tion of productive resources by allowing the property owner to appropriate the gains of employing different factors of production. Secondly, property rights facilitate the complex co-ordination of decentralised decisions that characterise a market economy and that avoids the relatively clumsy coordination of a centralised system.

Thirdly, property rights offer one (often particularly efficient) solution to the problem of externalities. Mainstream economics predict many adverse consequences from the imprecise de jure and de facto allocation of property rights, including the tragedy of the commons and under-provision due to externalities. ${ }^{64}$ Finally, as explored in the previous section, property rights lower transaction costs and contribute to the stability and predictability of behaviour which is crucial for the dynamic efficiency brought by specialisation and trade in a decentralised system. Absent such rights, transactions are often prohibitively expensive due to the arbitrary behaviour of contracted parties and the unenforceability of agreements. In such a state of affairs the incentives for investing in physical and human capital as well as technology - three components crucial to economic development - are seriously compromised.

In contrast with many legal scholars, economists argue (using a theory consistent with the historical record and econometric investigation) that the private sector is often the most dynamic force in society, while the public sector has often prevented the transformation of society. 65 Or, as William Easterly expressed the same argument more forcefully: 'Because becoming rich - that is, growth - is so sensitive to the incentive to lower present consumption in return for higher future income, anything that mucks up that incentive will affect growth. The suspect for mucking up incentives is government'. ${ }^{66}$ Economic development, or the transformation to greater and shared prosperity, is not something that is done to a country (not by any branch of government); it is generally a decentralised and highly complex process which society effects on herself, given (at a minimum) a favourable institutional setting.

Hayek has long since argued that a desire for change does not, as such, prejudge the choice of social and political model. ${ }^{67} \mathrm{~A}$ desire for the change associated with economic development does not prejudge whether that change should be centralised or decentralised. The desire for transformation in South Africa does not, therefore, prejudge whether such change should be centralised or decentralised; whether the Constitution should provide the framework against which the transformation of this society is to unfold, or whether it should be a tool with which the Constitutional Court will transform society.

Such issues cannot be settled a priori, or on normative grounds, as Edmund Burke observed about the revolution in France: 'The science of constructing a commonwealth, or renovating it, or reforming it, is, like every other experimental science, not to be taught a priori...[since] very

system of social and economic rights to create not 'economic equality - a truly disastrous goal - but instead to bring about genuine equality of opportunity and, freedom, for all people in society, from desperate conditions': Sunstein (note 63 above) at 12.

$64 \mathrm{RH}$ Coase 'The Institutional Structure of Production' in RH Coase (ed) Essays on Economics and Economists (1994) 3 at 10.

65 North (note 23 above) passim. In contrast, Pieterse (note 60 above) at 15 claims that the 'evidence is overwhelming that [economic growth does]... not translate into better conditions for citizens'. The latter is admittedly an extreme version of the view that there is a tension between growth-supporting civil and political rights and socio-economic rights. It is also an empirical view that is unsupported by the data. See D Dollar \& A Kraay 'Growth is Good for the Poor' (2001) World Bank Policy Research Working Paper Series 2587; X Sala-i-Martin 'The World Distribution of Income' (2002) NBER Working Paper 8933.

66 Easterly (note 11 above) at 235.

67 FA Hayek The Constitution of Liberty (1960) at 399. 
plausible schemes, with very pleasing commencements, have often shameful and lamentable conclusions'.68

A positive theory of social change is required to judge which of these two models are more likely to support social transformation in South Africa. Absent such a theory, the Constitutional Court cannot judge how it might contribute to social transformation, except if the justices held the Utopian doctrine that amassing enough (political and economic) power is sufficient to see their project carried through. Moseneke escaped from this Utopianism danger by the mechanism of accountability. Constitutional Court Justices should, Moseneke argued, understand that they 'are responsible for the social and distributive consequences that result from these choices, and should be judged accordingly'. ${ }^{69}$ But in this way Moseneke moved a long way towards a positive theory where monitoring of actual outcomes and (possibly) decentralised evaluation occurs. This small step by Moseneke seems most promising for this project about theories of social justice.

Despite the discordance mentioned in this section, the success of the collaborative effort between economists and jurists in the field of law and economics, which has improved both our understanding of society and our understanding of the implications of the legal system, demonstrates that the positive theory of economics and legal theory might often be complementary. ${ }^{70}$ The 'social and distributive consequences' at stake in this consideration of social and economic rights are, in addition to all their normative connotations, fundamentally empirical. This suggests a field where economists and jurists might cooperate to sharpen the theoretical hypothesis and the relevant empirical tests. ${ }^{71}$

A positive theory of social change will also be required if the Constitutional Court is to adjudicate the many issues that follow from having included social and economic rights in the Constitution. Here is a short list of contemporary examples:

1. The long term affordability as well as the incentive effects of the proposed basic income grant. 72

2. The implications for monetary policy, wage negotiations, inflation expectations and so on, if social assistance was index-linked. ${ }^{73}$

3. The impact on the future supply and cost of medical services if the 'certificate of need' (Chapter 6 of the National Health Bill) for health care professionals impinges on the right of individuals to choose the location of their practise.

4. The impact of an expanded social assistance network on economic growth. Liebenberg refers to '....strong arguments... that social assistance programmes complement and support economic growth' but offers no evidence to support these arguments. ${ }^{74}$

68 E Burke 'Reflections on the Revolution in France' in E Burke (ed) On Taste; On the Sublime and Beautiful; Reflections on the French Revolution; A Letter to a Noble Lord (1937) 143 at 198-199.

69 Moseneke (note 4 above) at 317.

70 RH Coase 'Economics and Contiguous Disciplines' in RH Coase (ed) (note 64 above) 34 at 37.

71 Justice Posner cautioned that '...the taste for fact that I would like to see developed in judges and law professors will turn to gall if unaccompanied by a taste for theory - not normative theory, so not what passes for theory in constitutional law, but positive theory, economic or otherwise, that guides the search for significant facts'. See RA Posner Overcoming Law (1995) at 427.

72 S Liebenberg 'The Right to Social Assistence: The Implications of Grootboom for Policy Reform in South Africa' (2001)17 SAJHR 231 at 254.

73 Liebenberg (note 72 above) at 241.

74 Liebenberg (note 72 above) at 256. 
Economics can provide the positive theory needed to complement legal theory in these cases, as has occurred in the USA in recent decades. ${ }^{75}$ Gauri provides a recent example of how positive economic theory could be used explicitly in the service of justiciable social and economic rights. ${ }^{76}$ She disputes the sometimes sharp delineation between an 'economic approach' to social and economic rights that focuses on incentives and the role of markets and prices on the on hand and a 'rights based approach' focusing on Constitutional Law on the other. In specific examples - Gauri considers health care and education provision in Brazil - the two approaches often require complementary interventions. ${ }^{77}$

There is no disagreement between the positive and normative approaches on the importance of, for example, improved health care provision for all citizens, especially the poor. Whereas the normative theories might emphasise the role of basic health care in almost any conception of a decent and responsible life or appeal to the wide ranging 'equality clause' in the South African Constitution, positive theories emphasise the importance of such health care as an enabling step that allows a person to participate socially and productively. In practice the two approaches would often meet, as in the TAC case where both normative and positive evaluation of the existing government programme concurred. 78

Notwithstanding this scope for agreement, a constitutional court which hopes to encourage transformation through justiciable social and economic rights will have to incorporate positive theory when undertaking judicial review of positive programmes. The relevant positive theory in such a case goes beyond the cost-benefit analysis often associated with economics ${ }^{79}$ to consider the institutional nature of principal-agent problems ${ }^{80}$ associated with many policies. ${ }^{81}$ Indeed, Barberton contrasts two interpretations of 'progressive realisation of social and economic rights, from the perspective of economics, with the first focused on inputs and the second on outputs. ${ }^{82}$ This distinction becomes non-trivial when considering the principal-agent problem inherent to a focus on outcomes. From the principal-agent or 'outcomes' perspective

75 Posner (note 8 above) at 2 .

76 V Gauri 'Social Rights and Economics. Claims to Health Care and Education in Developing Countries' (2003) World Bank Policy Research Paper 3006 at 3.

77 Gauri (note 76 above) at 11.

78 Minister of Health and Others $v$ Treatment Action Campaign and Others (No 2) 2002 (5) SA 721 (CC) at 116, 122, 130, 131.

79 This perspective also moves beyond considering the social and economic context of the problem. While the context is often an important part of the analysis, the institutional concern is explicitly dynamic and with a dynamic analysis the present context can only ever be a starting point.

80 A principal-agent problem arises when one party (called the principal) is interested in certain 'good' behaviour by another party (called the agent) but the principal either has insufficient information or insufficient means to ensure the desired behaviour by the agent. These problems typically occur when the agent's goal is unclear, unobservable or otherwise hard or expensive to monitor, or where the principal and agent have different goals. In these circumstances, the incentive effect of the contract between the principal and agent can have a material effect on the behaviour of the agent and hence the efficiency of the outcome from the principal's perspective. See JE Stiglitz 'Principal and Agent' in J Eatwell, M Milgate \& P Newman (eds) The New Palgrave Dictionary of Economics (1987) 966 at 967.

81 Principal-agent problems are central to the attempts at progressively realising many social and economic rights. Education is a case in point in South Africa where a massive expansion in resources devoted to primary and secondary education has yet failed to deliver an improvement in the quality of education offered. See S van der Berg \& R Burger 'Social Delivery in South Africa' (2003) Stellenbosch Report prepared for the CDE. By implication, judicial review of programmes related to these rights have to grapple with the institutional features of the policy that shape the incentives for public and private behaviour.

82 C Barberton “"Progressive Realisation” of Socio-Economic Rights' (1999) 2 Economic and Social Rights Review 1 at 2 . 
the judicial review of programmes for the progressive realisation of social and economic rights has to consider issues such as transparency, accountability, monitoring and other features that affect the incentives of public and private behaviour under such programmes.

Solving a principal-agent problem requires explicit attention to the flow of information (and hence focus on transparency and participation) to monitoring (with a consequent focus on accountability and empowerment) and to the incentives created by any policy or judicial review of that policy. It is the analysis of incentive effects which often distinguishes the positive approach from the normative approach when the emphasis shifts to moral hazard and adverse selection considerations.

Principal-agent problems require a careful design of incentives to align the expected behaviour of the agent (the government in many social rights cases) with the goals of the principal (the presently disadvantaged in a typical rights case). In positive economic theory it is institutions which shape these incentives and it was argued above that rights can often be understood as a subset of these institutions. However, there is no unique combination of institutions which is invariably optimal for all societies or for the same society at different times. On the contrary, the optimality of institutions - and hence of optimal role of social and economic rights requires a positive analysis of the existing matrix of formal and informal institutions, to ensure that changes (motivated by an appeal to rights) do not create perverse incentives. Such an analysis of incentives, information flow, transparency and accountability, is an application of a positive theory of social change, and the arguments of such a theory are what I have called the 'new tools for the Constitutional Bench' in this chapter.

New tools from the positive social science should, on the argument in this chapter, be added to the tests of reasonableness which the Constitutional court has used in its judicial review of social-economic rights cases to date, notably the Soobramooney, ${ }^{83}$ Grootboom ${ }^{84}$ and TAC ${ }^{85}$ cases. The Constitutional Court spelled out this reasonableness test at some length in Grootboom, arguing that:

...A reasonable programme therefore must clearly allocate responsibilities and tasks to the different spheres of government and ensure that the appropriate financial and human resources are available...Mere legislation is not enough. The State is obliged to act to achieve the intended result, and the legislative measures will invariably have to be supported by appropriate, well directed policies and programmes by the executive. These policies must be reasonable both in their conception and their implementation...balanced and flexible and make provision for attention to housing crises and to short, medium and long term needs...those whose needs are the most urgent and whose ability to enjoy all rights therefore is most in peril, must not be ignored by the measures aimed at achieving realisation of the right... ${ }^{86}$

It is not possible for the Constitutional Court to carry out the judicial review envisaged by its own test of reasonableness without engaging in positive social science. ${ }^{87}$ Absent positive

83 Soobramoney v Minister of Health, Kwazulu-Natal 1998 (1) 765 (CC).

84 Government of the Republic of South Africa v Grootboom 2001 (1) SA 46 (CC).

85 Minister of Health and Others $v$ Treatment Action Campaign and Others (No 2) 2002 (5) SA 721 (CC).

86 Government of the Republic of South Africa v Grootboom 2001 (1) SA 46 (CC) at para 39-44.

87 D Brand 'The Proceduralisation of South African Socio-Economic Rights Jurisprudence, or 'What are SocioEconomic Rights For?' in H Botha, AJ van der Walt \& J van der Walt (eds) (note 3 above) fn 45 has sug- 
social science the Court will not be in a position to weigh intended and unintended consequences - and the issues here are not those of cost-benefit analysis alone, but especially principal-agent problems. Further the Court would not know whether a proposed programme falls within the set of reasonably conceived programmes without method and knowledge to judge the empirical literature that evaluates such policies. Nor is this an attempt to push the Court into a new field or endeavour. On the contrary, the Court is already practicing social science when it implements its own reasonableness test.

\section{Conclusion}

In this chapter I argued that accepting the inclusion of socio-economic rights in a Constitution such as South Africa's with a transformative vision does not prejudge whether such transformation should be centralised or decentralised; socio-economic rights are compatible with both. Understanding the actual transformation of societies, however, requires a positive theory of social change and it was suggested above that economics could offer a successful positive theory of decentralised change that can analyse the role of rights as institutions in social change. This theory - drawn from the New Institutional Economics - does not model the same tension between first and second generation rights in the process of social change as is often presumed a priori in the legal literature. For this reason alone the theory would be useful to consider. But there are two further reasons for including the New Institutional Economics in the new tools of the Constitutional Bench, that is: it offers a logically and empirically successful positive theory of social change and it informs the social science implicit in the Court's own test of reasonableness.

gested as much when he suggested that within a model of judicial review the standard of scrutiny in the 'means -ends' reasonableness model evidently adopted by the Constitutional Court operates on two levels: first, an indication of how the Court will decide whether a programme is appropriately related to the stated goal and second, the burden of proof or evidence or persuasion that the Court will require of the parties in such a matter. A positive theory of social science is well suited to addressing these questions. 


\title{
Social Justice and Theological Method
}

\author{
- Fanie DU ToIT \\ Programme Manager, \\ Institute for Justice and Reconciliation, \\ Cape Town; Associated Researcher, \\ Faculty of Theology, \\ Stellenbosch University
}

The Spirit of the Lord has been given to me.

For he has anointed me.

He has sent me to bring good news to the poor,

To proclaim liberty to the captives

And to the blind new sight,

To set the downtrodden free

To proclaim the Lord's year of favour. ${ }^{1}$

\section{Introduction}

A range of religions envision utopian societies as their ultimate goal. In the Torah, a time is predicted when a 'river of justice' will flood the land. Everyone will be given enough to eat. Each person will receive a home. The weakest and poorest will have their dignity restored. Fighting will cease, swords beaten into ploughshares and spears turned into pruning hooks. Even lambs and wolves will lie down in peace.

This vision is reintroduced in Christ's words quoted above some 1000 years later, where the liberation of the poor and marginalised is singled out as a key indicator of justice, and a first step towards peace associated with the 'Lord's year of favour'.

There are differing opinions about whether such theological idealism motivates quietism or activism. Perhaps it relates to both. On the one hand, the difference between reality and such a grand vision may seem too great, motivating a retreat into the fatalist acceptance of the powers to be - in the hope that God, one day, will intervene. Utopian visions can become the opium of the masses. Seeing no real hope, people find religious solace in beautiful dreams.

On the other hand, for 'court theologians' whose interests are represented by those in the pound seats, the temptation to become defenders of the status quo often results in compromised, muted social critique. Since the Constantinian era first saw Christianity become the official faith of the Roman Empire, every regime has had 'court theologians' who, in God's name, specialise in justifying the unjustifiable.

But there have always also been the extremists, who seek change that destroys more than it 
builds. The Crusaders left a trail of destruction in the name of social justice. Believing that theirs is the only truth, fundamentalist believers in this mould have, over the ages, resorted to unprecedented violence in the name of justice - and often achieved the opposite.

This essay explores some of the conditions under which theological discourse facilitate positive activism. We are interested in a particular type of change - towards a fairer, more inclusive society, in fairer, more inclusive ways. The process is vital. We see inclusivity, as it takes shape in the logic and discourses of reconciliation, as a precondition, an enabler, of justice. Justice is forged from consensus and through cooperation. It is by working together that adversaries create the conditions for growth and prosperity.

Without revisiting the protracted debate about the relation between theory and praxis, the assumption is that political praxis and academic theory do, in fact, exert influence on one another. We assume that theoretical reflection influences policies and practises, whether as source of, or as reflection on, praxis.

Provided it finds it own voice, therefore, theoretical theology (but not abstract theology!) has a distinctive contribution to make to the quest for multifarious dimensions of justice.

To concretise the discussion, I choose to focus specifically on Christian theology within the South African context. South African Christianity has produced liberating theologies, and, as we know only too well, deeply oppressive ones. This history emphasises the importance of asking about the 'ground rules' for theological contributions towards social justice - in order to ensure both positive impact on society, as well as truthful witness to its own nature.

It remains perplexing that progress towards social and economic justice is not more rapid. In the first section, I analyse this malaise by distinguishing between material and political impediments to justice. Political rights are, generally, better institutionalised than economic or social rights. Yet, it is often the lack of political will that impedes the progress of social and economic justice. At the heart of this failure to act, I claim, lies a moral impasse that is central to the theological task. ${ }^{2}$

2 This lack of will to create a better world is highlighted in a crucial report, Human Security Now, presented to the United Nations Secretary-General, Kofi Annan on 1 May 2003 by the Co-Chairs of the Commission on Human Security, Sadako Ogata and Amartya Sen. The Sunday Independent, at the time, called it 'probably the most important document yet drawn up by an influential group of global citizens concerning the future of humanity'. The findings of the Commission concerning Africa were based on wide-ranging interviews with citizens in 14 African countries, representing $26 \%$ of African nations. The commissioners sought to answer the question: 'What makes people secure or insecure and what interventions are needed to address people's concerns in this regard?' Top of the list, not surprisingly, came poverty and lack of basic services, followed by violent conflict, refugees, poor governance, political instability and human rights abuses. Interestingly however, participants identified leadership, spirituality and morality, dignity and inter-group relations as the key to an African understanding of human security. The extent to which this seminal report identified the way forward in terms of relational matters, rather than material challenges, is telling of the measure to which material and human challenges combine to form the agenda for human development in Africa today. This is an important insight, not only for political analysts, but also for religious scholars and leaders seeking to define the role of faith in the development of Africa. It seems to open an opportunity for faith-based communities in the public arena and removes doubt that subjective aspects of human development have a role to play in Africa's renewal process. The Commission on Human Security was established in January 2001 through the initiative of the Government of Japan and in response to the UN SecretaryGeneral's call at the 2000 Millennium Summit for a world 'free of want' and 'free of fear.' The Commission consisted of twelve prominent international figures. The full report is available at http://www.humansecurity-chs.org/finalreport/index.html. 


\section{South Africa and the Growing International Consensus on What Needs to be Done}

Part of the build-up towards a 'Scenario 2015' planning exercise of the United Nations in March 2005, was to identify 'signs of hope' for those concerned with the promotion of justice. One prominent such sign was the growing international consensus on developmental priorities for the next ten years. These priorities, known as the United Nations Millennium Development Goals (MDG), represent significant international consensus on global priorities on the road to a more just world.

Ratified by heads of State and Governments and adopted by the UN General Assembly in New York on September 8, 2000, the Millennium Declaration states that signatories are 'determined to establish a just and lasting peace all over the world'. 3 To achieve this, six fundamental values are identified, namely: freedom, equality, solidarity, tolerance, respect for nature and shared responsibility. The further formulation of eight specific Millennium Development Goals, along with an action plan, represents a significant achievement. Never before has there been such wide consensus about how to eradicate poverty. ${ }^{4}$

South Africa's development project has taken root in and continues to be shaped by this new international idealism. How do South Africa's achievements to date compare to the MDG?

The feat of uniting warring adversaries in a single body politic that enjoys the support of the majority of South Africans, and that is based on a progressive Constitution, the writing of which was itself an exercise in democratic participation, remains the envy of many. That the transition was further cloaked in the discourses of reconciliation, accountability (albeit limited with amnesty provisions) and justice - representing an impressive framework for post-conflict reconstruction - moved even the most cynical observers to admiration. Add to this the operationalisation of some of the world's most expanded service delivery programmes such as housing, primary health care and educational restructuring. On top of this, fiscal discipline and frugal government spending have created the conditions for economic growth now perched at somewhere upward of $4 \%$ in a climate inspiring growing investor confidence. Is the miracle continuing? Many would seem to think so, and there seems to be plenty of reasons why they may be right.

Yet, on the flipside, unlikely names such as Diepsloot and Phomolong have become symbols of growing discontent about the pace of service delivery that, ten years into democracy, is yet to touch the lives of many deeply poor communities. Perceptions, rightly or wrongly, that they

3 http://www.un.org/millennium/declaration/ares552e.htm.

4 To this end, the UN resolved, by 2015, to:

1 Halve the proportion of world's people whose income is less than one dollar a day, and the proportion of the people who suffer from hunger.

2 Ensure that, by the same date, children everywhere, boys and girls alike, will be able to complete a full course of primary schooling

3 Ensure that girls and boys will have equal access to all levels of education.

4 Have reduced, by the same date, maternal mortality by three quarters, of their current rates.

5 Have reduced, by the same date, under-five child mortality by two-thirds, of their current rates.

6 Have, by then, halted, and begun to reverse, the spread of HIV/Aids, the scourge of malaria and other major diseases that afflict humanity, to provide special assistance to children orphaned by HIV/Aids.

7 Have achieved, by 2020, a significant improvement in the lives of at least 100 million slum dwellers as proposed in the 'Cities Without Slums' initiative and by the same date, to halve the proportion of the people are unable to reach or to afford safe drinking water.

8 Develop an open trading and financial system that is rules-based, predictable and non-discriminatory. This includes a commitment to good governance and addressing the special needs of the least developed countries. For more information, see http://www.un.org/millenniumgoals/. 
represent the 'forgotten people' are reinforced by the apparent infrastructural muscles, power lines, telecommunication grids and roads, bulging around them, but failing to make any direct impact on their lives. The sudden and fabulous wealth of the black elite, coupled with the South African government's direct involvement in many parts of Africa, creates the impression of a jet-set elite that has relegated the original goals of the RDP, and even more treacherously, the liberation movement, to the back seat. Compounding this scenario of deepening poverty are the twin social scourges of HIV/AIDS and violent anti-social behaviour, including organised and domestic crime. The implosion of South Africa's neighbour and main regional trading partner, Zimbabwe, to levels of political anarchy and economic meltdown reminiscent of apartheid South Africa, has not helped either.

How does one make analytical sense of this complex situation? The Institute for Justice and Reconciliation, recognizing in its mission statement that reconciliation and justice are inter-related goals, produced a first-of-its-kind report in 2004 to investigate some of these issues. Entitled Taking Power in the Economy - Gains and Directions, this publication forms the first in an annual series of Economic Transformation Audits (TA) to hold up the mirror to the nation as a whole and ask: How are we doing in our quest towards a more socially and economically just society?

This study was born in an attempt to move beyond simplistic assessments, either uncritically positive, or one-sidedly negative. Four areas are assessed critically in terms of progress since 1994. These are unemployment, poverty, inequality and education. ${ }^{5}$

As may be expected, the findings present a mixed scorecard. In terms of unemployment, the TA shows that despite the fact that a million new jobs had been created since 1994, the number of jobseekers have also exploded, mainly as a result of rising rural deprivation and a steep incline in women work seekers. There is an increasing demand for skilled workers, but lowskills job have declined.

These conditions have contributed to more poor people in 2001 in South Africa than in 1996. With some spectacular advances amongst those who have benefited from empowerment and fresh business opportunities, this reality has resulted in increasing inequality since 1996. Despite Black Economic Empowerment, the average African income as a percentage of white income fell to $6.99 \%$. These negative findings need, however, to be balanced with massive increases in access to services to the poor.

The TA shows that economic growth has been slow but steady, while inflation steadied downward. The TA claims further that the current BEE (Black economic empowerment) strategy is not yet an anti-poverty strategy. It is (still) largely a redistributive strategy. The current policy is therefore appropriately shifting towards a more broad-based approach, with emphasis on skills-development, preferential procurement, employment equity and job-creation.

Dubbed the 'broken link' by the TA, education has delivered relatively disappointing results towards producing a better-educated workforce with more mathematically skilled members. Schooling is not giving the youths the skills they need to embrace developmental opportunities. With more than $20 \%$ of the annual budget allocated to education, better output was envisioned. The problems seem to have to do with quality of teaching, availability of textbooks and school management. ${ }^{6}$

5 S Brown and A Fölscher Taking Power in the Economy - Gains and Directions (2004) at xi.

6 A 2005 Nelson Mandela Foundation/HSRC Report, Emerging Voices: A Report on Education in South African Rural Communities, asked 4332 respondents, including many teachers about the most important problems that teachers face. In first place, with $71 \%$ support, is lack of teaching aids, and second, at $60 \%$, is lack of cooperation from parents. 
So, is South Africa a more just society than ten years ago? Probably yes. Is there a sufficient concentration of minds on the eradication of poverty to ascertain that South Africa does not slide back into slow decay and anarchy? Probably not. We are not yet displaying the levels of societal consensus and efficiency required to deal with poverty within the timeframe allowed for by the UN referred to above or appropriate to the available political capital. The haunting question remains: given the high stakes, why is there not a broader and deeper sense of urgency to fight inequality, poverty, bad education and unemployment? This lack of urgency is not unique to South Africa; in fact, South Africa is probably more engaged with the fight to end poverty than most, and yet, even here, it seems unlikely that we will have achieved our goals by 2015 .

Early global assessments on progress towards the Millennium goals have also met with disappointment. It is no surprise therefore that implementation strategies are coming under scrutiny. ${ }^{7}$

The debate is no longer about what needs to be done. It is now about when and through whom these goals are to be achieved- and how role players will be motivated to contribute. In South Africa, too, everyone seems to be in agreement that the poor should be helped. There is even agreement about who should do what and by when. The challenge remains to put into action these plans within an acceptable timeframe. The quest for justice, particularly equity, seems now more than ever, to be about political and moral stamina - and this where the debate becomes complex.

\section{Two Possible Causes of the Malaise: Traumatised Societies and Growing Inequality}

A fundamental premise to help identify root causes of this malaise is the distinction between socio-economic (material) and more subjective dimensions (political will, human capacity) of justice. I contend that focusing on the former to the exclusion of the latter is a recipe for nondelivery. Socio-economic justice is not simply about the achievement of material challenges, infrastructural backlogs and trading links, vital as these are. Amartya Sen reminds us that development is about more than material reconstruction and development. ${ }^{8}$ It is about the restoration of human dignity and freedom, about fostering the capacity to choose lives that we value. Development, properly understood, is about more than creating economic opportunity. It is about creating the opportunities to become economically active.

The multi-dimensional process of human development lies at the heart of the quest for justice. In biblical terms there can be no justice without genuine peace, and peace starts with change in the hearts and minds of people. Development harbours profound political, social and psychological challenges for developing as well as developed countries. Yet, these dimensions are often overlooked.

7 On January 17th 2005 the most comprehensive action-plan yet to achieve the Millennium Goals was published. A blue-ribbon team of 265 of the world's leading development experts drew up a package of scores of specific cost-effective measures that together could achieve the Millennium Goals. The prelude to this action plan states: 'We have the opportunity in the coming decade to cut world poverty by half. Billions more people could enjoy the fruits of the global economy. Tens of millions of lives can be saved. The practical solutions exist. The political framework is established. And for the first time, the cost is utterly affordable. Whatever one's motivation for attacking the crisis of extreme poverty-human rights, religious values, security, fiscal prudence, ideology-the solutions are the same. All that is needed is action. 'The experts who contributed to this huge undertaking has shown without a doubt that we can still meet the Goals - if we start putting this plan into action right now' said Prof JD Sachs, who leads the project.

8 A Sen Development as Freedom (1999). 
Thus, the failure to take into account the human factor in human development may be the cause for many retarded delivery processes. The importance of the human factor begs a number of questions of all parties involved; the disempowered, the freshly empowered as well as the empowering:

- Developing countries struggle to find ways to empower people to embrace opportunities. Justice seems to require integrated restoration and healing processes where people explore ways to overcome bad memories, internalised forms of dehumanised identity and stereotyped divisions associated with intense suffering, oppression or violation. But these strategies seem thin on the ground.

- Developed countries, on the other hand, need to find ways to generate moral, political and economic solidarity that supersedes citizenship. There is an urgent need for a fairer and more accountable international trading and governance system where richer nations take steps to ensure greater power sharing and a more equitable international order. What is needed is a deeper sense of solidarity between the rich and the poor. Too much involvement by the rich in the affairs of the poor still bears the hallmark of patronising charity born of a lack of indepth exposure, understanding and solidarity. Frightening and growing inequality may explain deepening incomprehension and solidarity, despite a veritable explosion in news coverage and other global forms of information flows.

These challenges exceed the normal ambit of political and economic activity. It requires 'the extra mile'. Their unusual, 'out-of-the-box' character causes these challenges often to be ignored, but, left unattended, they have the potential to undermine the quest for justice.

Justice includes the overcoming of the trauma associated with extreme poverty, oppression and violence at both personal and public levels. For anyone who doubts the intensity of personal trauma caused by poverty, consider the following anecdote, recorded in an interview of the Institute for Justice and Reconciliation:

My mother would come home to the six of us with one plate of food from the Madam. We would stand around her and hold out our hands. She would then divide the plate into six portions and place the pieces of food, bit by bit, into our open hands. Other nights, when there was nothing, she would keep up our spirits by boiling water with a brick or stone in the pot. Occasionally she would "test" the stone in the pot with a fork to inform us that the potatoes were not soft yet. At least we fell asleep with the hope that food would be on the table soon.

This trauma is often exacerbated by political oppression and violence, gross inequality and social isolation all phenomena commonly associated with the poorest of the poor communities in developing countries.

The subjective dimension to development goes beyond the psychological. Trauma works itself into the fibre of the social and political institutions of a society. Thus justice becomes a question of social transformation. It is not just about the healing of individuals. It is about social reconstruction and impacting the ethos of collectives. The systemic, structural dimensions of injustice remain embedded in the fibre of developing countries. To this end, turning decrepit and biased institutions into inclusive, transparent and democratic ones is one of the main challenges of development efforts the world over. Institutionalised power-relations originating from an unjust past naturally resist such moves towards equity. Integration of former enemies at all 
levels of society becomes a central task. The question becomes: how does one facilitate conditions where former enemies may develop into business partners or opposition politicians within a democratic framework?

A reconciliatory ethos envisions cycles of deepening engagement across divisions. A lack of this 'reconciliatory ethos' contributes, I contend, to unsustainable development. It explains the perplexing lack of enthusiasm, despite declarations to the opposite, of potential beneficiaries of development, as well as of potential drivers and donours. Justice requires solidarity and inclusive processes adhering to the logic of reconciliation, where the dignity of people is recognised and restored.

We have a goal - we even have a plan. Yet we seem to lack the will to travel this road. The flesh is strong, but the spirit, seemingly, remains weak. Can theology help to motivate people towards the extra-ordinary efforts it will take to conquer human deprivation?

\section{Theological Possibilities}

In his Theology of Reconstruction, Charles Villa-Vicencio reminds us that responsible theology has to be utopian. Priests are obliged to be turbulent and annoyingly visionary in even the most socially responsible societies. And yet the church must also be realistically committed to what is attainable here and now as part of a greater vision. ${ }^{9}$

Utopian ideals, whatever the source, continue to have a role to play in the fight for justice. For one, they are able to rule out complacency and fatalism, and continue to spur social change. At the same time, utopian zeal can be dangerous. Emil Brunner writes that: 'Christians cannot "sanctify" the world, that is, humanity, in such a manner as they sanctify themselves'. 10

In what follows I unpack four traits, describing basic features of a theology for human development that may serve to help overcome some of the psychological, political and moral obstacles that lie at the root of the malaise of realising integrated justice for all.

The four traits each have a thematic texture: each have a content that is derived from a particular understanding of what is central to Christian theology. Each trait also has contextual relevance with the potential, so I contend, to have real impact on the social, political and moral landscapes we inhabit.

The allocated space does not permit an extended application of these theological traits to the quest for justice. Moreover, the author is no development specialist. Yet, guidelines are presented and preliminary observations made about how a theology shaped by particular conceptions of grace, truth, hope and justice may serve the cause of socio-economic justice in the twenty-first century.

Remarkably, it is now possible to envision the implementation of the UN's MDG's. In South Africa's case at least, this task requires an enormous, concerted and unremitting effort. How can this be sustained? The temptation to rest on the laurels of South Africa's considerable achievements grows only stronger with time. Stamina - political, moral and social - is required if the fight against poverty is be overcome. When operating, in the precarious space between fatalism and idealism, theology can foster responsible and creative contributions to the promotion of justice.

9 C Villa-Vicencio A Theology of Reconstruction - Nationbuilding and Human Rights (1992) at 31.

10 E Brunner Dogmatics (1950) at 315. 


\section{(A) GRACE}

To be a voice for justice, theology needs to recognise itself as teleological. This is no convenient innovation. Theology is, in fact, teleological - always pulling towards a goal - always beyond itself. Theology is not content to refer to truth. It seeks to realise this truth. It does not rest until the goal is achieved. It longs and works for ideals it realises cannot be achieved immediately.

Importantly, this dynamism does not depend on observers or admirers of theological truth. Theologians cannot sustain this restlessness. It is the object of theological enquiry itself that pulls, pushes and cajoles. Encountering the object of theology is transformative.

But how is this restlessness to be understood? What is it that theology pushes towards? What/who is doing the pulling? Karl Barth, the Swiss theologian whose writings profoundly influenced $20^{\text {th }}$ century theology, and who wrote in the time of deep social change in Europe between the first and second World Wars, claims that theology's central focus is to be found in grace.

Writing in 1918, as the hazy religio-cultural chauvinism that dominated Europe up to then began to dissolve, Barth seeks a uniquely Christian truth - something to distinguish itself from the folly of European self-aggrandisation, and from forms of liberal theology absorbed into the culture of the time.

Barth's starting point is that humans have no capacity to enter into a relationship with God. ${ }^{11}$ Any link with the Divine has to be given to us from beyond ourselves. Once established, a relationship with the Divine cannot be 'owned'. Theological truth never belongs to theologians - it remains a free, unexpected gift whereever it occurs.

Although grace falls beyond human capacity, it does not override or diminish humanity. In fact, it draws humans beyond themselves into communion with God and fellow human beings. ${ }^{12}$ God's grace is the condition for human fulfilment, not the negation thereof. Human fulfilment, viewed theologically, lies beyond what is possible for human beings to attain or to become. Precisely because theology draws us towards this fulfilment, it remains restless. When theology relinquishes this restlessness, its distinctive contribution is lost.

This happens when grace is no longer the focus. Theology becomes a 'moralistic affair', 'indifferent to the question of man itself', the question of human suffering and misery. ${ }^{13}$ Fully institutionalised, it becomes the voice of the well endowed and powerful. Therefore grace - as embodied in Jesus Christ - favours the poor and marginalised almost to the point of prejudice. ${ }^{14}$ The essence of the restlessness of true theology is found in its passion for the excluded, poor and marginalised.

This also means that reconciliation - humanising engagement over divides - occupies a central place in Barth's thought. God crosses, in freedom, the divide with the human race and establishes a new humanity. God shows solidarity with human beings in their hopelessness, creating a new humanity through reconciliation. The restoration of justice coincides with the restoration of reconciled community, of restored fellowship.

'Why Jesus's existence was so unsettling on every side was that He set all programmes and principles in question', writes Barth. To this end, 'he enjoyed and displayed a remarkable freedom...He simply revealed the limit and frontier of all these things - the freedom of the Kingdom of God. He existed in freedom and summoned others to it.'15

11 K Barth Church Dogmatics (1960) at 238.

12 G Hunsinger How to Read Karl Barth - The Shape of His Theology (1991) at 31f.

13 See DJ Smit 'Paradigms of Radical Grace' in C Villa-Vicencio (eds) On Reading Karl Barth in South Africa (1988) at 33.

14 Smit 'Paradigms' (note 13 above) at 23.

15 Smit 'Paradigms' (note 13 above) at 24. These quotations are from Barth (note 11 above) at IV/2. 
Theology needs to be vigilant. When it is no longer determined by grace and becomes a selfreliant system of thought, it loses the dynamism that is the hallmark of divine grace. Public theology, aiming to promote socio-political justice, needs to orientate itself continuously towards this gift of grace. Above all, a theology steeped in grace realises its own needs and imperfections, opening the door to deeper solidarity with those whose needs are perhaps emphasized by socio-economic deprivation and injustice.

\section{(B) TRUTH}

Yet grace can be cheap. When all is forgiven and accepted, when accountability dies in the cheap embrace of amnesia, the violation of human dignity becomes permanent. A justice built on forgetting injustice is not only unlikely to survive, it is fundamentally flawed. The restoration of human dignity, after periods of gross injustice, requires a search for truth and for acknowledgement, however hesitantly, however relative, however perspectival. A theology of human development has to compliment its focus on grace with a focus on truth.

Truth represents more than a focus on neglected facts about degrees of poverty, suffering or violation. It is about creating the space for the oppressed to speak out for themselves, and for them to become conversation partners in the formation of the strategies to establish justice. The Truth and Reconciliation Commission understood its mandate to be the mediation of forgotten voices. To some extent (and with many shortcomings) it did succeed to bring these voices into the mainstream. Ten years later, there is again a need for South Africans to listen carefully.

In our current political climate the voices of the poor and marginalised need amplification. But this requires mediation. These truths are not easily heard or understood. Communication between the disempowered and the rich and the poor cannot be taken for granted, for it has to cross the chasm of inequality that runs through the heart of the South African society, rendering it one of the most unequal in the world.

Theology may provide such mediation precisely because its truth-claims are inherently accommodating and inclusive. Theology's 'modest truth' is a result of the nature of the way that God reveals Himself to the world, at once hiding as much as it reveals. God's truth may be present in our world, but it is a subtle, 'hidden' presence, as Barth explains:

The veil is thick. We do not possess the Word of God otherwise than in the mystery of its world-involvement. ...Its form is not a suitable but an unsuitable medium for God's presentation of Himself. It does not unveil, but rather veils it. ${ }^{16}$

The moment theological truth is captured, it dies. God's truth breaks into human discourse, in a miraculous way, that is, through none of our doing, despite the fact that language 'seen from our side' has no capacity to produce the kind of truth-claims that would encapsulate the Divine, says Barth. God's revelation remains God's mystery. ${ }^{17}$ Thomas F Torrance writes about this concept of truth:

Behind all this questioning on Barth's part lies a deep humility before the face of Truth: in his recognition that the Truth will not and cannot be mastered by our dis-

16 Barth (note 11 above) at 188.

17 SF du Toit Ideas of Truth and Revelation in the Light of the Challenge of Postmodernism (University of Oxford: DPhil Thesis, 1995) 157. 
tinctions and formulations, that we cannot give shape or form to the Truth, but that we can only follow after it, and in his recognition that all our expressions and expositions of the Truth are human attempts that fall far short of the Truth itself, so that far from resting content with what we have already done, we are driven on by respect for the Truth...18

Theological truth's inherent modesty enables it to venture into public space, often in secular guise, to facilitate the truths of those who are not often heard. Political discourse falls back into the relativisation of non-derogable human rights most easily, when voices from the margins of society are not appropriately accommodated within public dialogue. South Africa has a remarkable record of failure as well as achievement in this area. To dwell on the positive: we know that over two million submissions were received during the writing of the 1995 Constitution, making this one of the most inclusive such processes ever. The Truth and Reconciliation Commission saturated middle class living rooms for two years with tales of sorrow and loss from the very margins of society, in a manner unprecedented internationally and making it impossible for any South African to claim with any credibility that he or she does not know that terrible things happened to others in the past.

But how much do we really know about poverty today? How prevalent are the voices from the margins of society today? Everybody claims to speak on behalf of the poor, but who really does? How aware are we about the true extent of trauma associated with poverty; trauma that at times matches the trauma associated with gross human rights violations such as murder, rape, abduction and torture? Poverty, indeed, is daily torture. It is the murdering of dreams and personalities. It is the abduction from society, of millions of talented people. It is the rape of a nation. Can theology help to generate a national sense of urgency around poverty as did emerge around political change?

Theological discourse needs to reflect teleological restlessness and pastoral solidarity, outspoken urgency and self-effacing modesty. Is this not a contradiction? How are these seemingly conflicting traits to be reconciled? Can theology at once be forceful and self-effacing?

To this end, it may be helpful to examine the nature of Christian truth-claims more closely, in order to understand how a nuanced reading of scripture can in fact yield truth-claims that are forceful, yet modest.

Theology drinks from different fountains: scriptures, traditions of interpretation and praxis, contextual demands and dialogue with other faiths. Amongst these sources, theologians tend to prioritise scripture. Scripture is often held as the norm according to which other theological norms and sources are judged.

Scripture, however, presents anything but simple, hegemonic norms. Containing a library of sixty-six books, produced over a period of more than 2000 years in many different parts of world, and recorded in an array of languages, it covers a historical epoch stretching back into the very origins of human memory. A litany of characters, narratives, perspectives, positions and ethical frameworks confronts the systematic reader of the Biblical canon.

Yet, despite this indelible diversity, scriptures offer a number of longitudinal themes and perspectives that cut across books and epochs. The identification of these synthetic concentrations of ideas is central to the task of systematic theology.

Theology has, to this end, embraced the 'scopic nature' of scriptural hermeneutics. The sco- 
pus is a longitudinal theme or perspective singled out as the heart of the message and intention of all sixty-six books and serves to provide the singular hermeneutical frame within which the entire collection of scriptures needs to be interpreted and understood. A Christ-centric scopus, for example, focuses on the person and words of Jesus Christ as the prism through which all scriptures are understood.

This is not an arbitrary hermeneutical strategy, but is rooted, so theologians believe, in the world presupposed by scripture itself. The Judeo-Christian world, in which the Bible has its roots, operates with a fluctuating, dynamic view of history. It is into this ever-changing arenas that Hebrew sees divine truth seeping, little by little, and with sensitivity to the fragile conceptual frameworks that constitute human understanding. This hermeneutical strategy is shared by Christian theologies of many different persuasions, including some of the most dominant traditions in South Africa.

It differs from a fundamentalist approach where the very idea of a scopus is rejected. Seeing nuanced hermeneutical readings as undue human interference with the Divine Word, fundamentalist theology claims to take each word, each passage and each narrative of the Bible as the literal, unchanging and eternal word of God.

Yet there is an evident irony in the way this reading of scriptures plays itself out. Fundamentalists achieve exactly what they seek to avoid. Their effort to 'purify' theology of human perspective in fact serves to obscure and entrench the pivotal role of subjectivity in the reading of scripture. Because it equates divine truth with the immediate, subjective encounter of reading the Bible (of whatever truth emerges there and then) the context within which the reading takes place becomes all-important. And yet, from a fundamentalist perspective, this impact of context is not only ignored, but vehemently denied. As a result, the dominant voices in a particular context become the voice of God. The result: fundamentalist truth-claims render theology more relative, not less. The Truth With Which There Can Be No Argument, is a truth that emanates from intensely private, deeply parochial positions of leaders powerful within their own groups of followers, but usually situated on the fringe of society.

The ideological opposite to fundamentalism is radical relativism, ${ }^{19}$ where theology relinquishes any pretence to truth that is not in every respect cultural and contextual. Scripture as a whole loses priority and competes, on equal footing, with all other sources. In this approach there is a real danger that theology will lose its distinctive voice and become just another weak mirage - a second-hand version - of other disciplines such as sociology, anthropology or poetry.

Ironically the same danger of arbitrariness confronts the relativist theologian and his fundamentalist counterpart. To relativists, any hint of 'truth', any trace of the universal or transcendent, is denied. Yet, in the place of the Divine, human subjectivity assumes the central position.

When opinion, speculation and perspective are acknowledged as the only social currency, power once again takes the place of argumentation. Dialogue always presupposes moving towards some form of 'truth' - inter-subjective and provisional as it may be. But when this possibility falls away completely, dialogue collapses into rhetoric of the most cynical kind. Even Foucault reminds us never to give up our quest for truth. In the Nietzschean context of radical relativism, whoever possesses the largest megaphone (or gun) normally wins the argument.

The advantages of a more sophisticated, scopus-defined hermeneutics now become clearer:

19 See for example TJJ Altizer The Genesis of God - A Theological Genealogy (1993); MCE Taylor Erring: A Postmodern A/theology (1984); D Cupitt The Long-legged Fly (1987); D Griffen Primordial Truth and Postmodern Theology (1989). See also G Ward (ed) The Postmodern God: A Theological Reader (1998). 
Admitting to the perspectival nature of all theological truth, makes for more transparent and honest dialogue where presuppositions can be voiced and influenced.

Admitting to perspectival readings of theological sources opens the door for contesting interpretations, and limits the possibility for hegemony and tyranny in the name of God's truth.

Scopus-hermeneutics also helps to negotiate the vast historical and contextual differences and even paradoxes found between different scriptural passages. It allows for progression of truth and insight and can therefore identify certain prescriptions as time-bound and culture-relative whilst others can consistently be identified as culture-relativising.

Scopus-hermeneutics counters radical relativism and proclaims, in an era of rampant nihilist consumerism, the elusive presence of transcendent truth.

Scopus-hermeneutics thus creates the conditions for genuine inter-subjectivity - the proper breeding ground for theological truth. This is a position between the tyranny of absolute, objective truth with which there can be no argument, and the different tyranny of radical subjective relativism; a space where the possibility of argumentation falls away.

'Knowing-in-part' is the forte of good theology. The science that finds its orientation in the face of God can only see its truth as 'a poor reflection as in a mirror'. If theology knows anything, it is that truth finally lies beyond us. It is not a carrier of truth, but a pointer, self-effacing, to divine words that can never be repeated, to divine presence that remains hidden and to a divine community that remains scattered.

It is therefore, in its best moments, a troublemaker in the company of those 'who know': posing questions, unravelling arguments and exposing those voices of the marginalised and maligned not often heard. This is what it is called to do. When things go wrong, and theology tries, like a slightly awkward child, to 'fit in with the rest', to develop certain knowledge and pose proudly in the conceptual designer wear of its age, it invariably comes to grief. Like the awkward child, when it struggles to assert itself, it usually does so with too much force. Theology is a tricky business.

\section{(C) Hope}

Up to now human development and the quest for justice have been used virtually interchangeably, as if the one implies the other. Of course, this is not always the case. Not all development is just. Development is mostly inherently ambiguous and its impact on humanity has positive as well as negative effects. Social development is an unstoppable reality, that proceeds with or without moral input. Economic development is also a self-propelling phenomenon, operating with or without moral guidance.

Justice calls for a certain kind of development, associated to some extent with integrated visions of development presented by Amartya Sen and others mentioned above. This humanfocused development, aiming to restore human dignity, is in my view central to the Biblical call of justice.

There is considerable difference of opinion about how successful such development efforts can be expected to be in the long term. Some claim that South Africa will remain, certainly for the foreseeable future, fundamentally unequal. Others predict a speedy eradication of poverty, with social services up and running within the decade; coinciding with a proliferation of employment, improved education and growing industrial output.

Who should be believed - the pessimists or the optimists?

Theologies that believe the pessimists offer options for utopian withdrawal with strong dosages of what Karl Marx would call 'opium for the masses'; feel-good, emotionally soothing 
fellowship where people gather to anticipate reward in the after-life. In this life justice will always be but a dream.

Theologies that believe the optimists tend to align with activist groups in society who often are radically critical of mainstream society and post-apartheid policy decisions, but who are often short on engaged, constructive proposals for change.

What does theology base its hope on? A negative historical prognosis typically coincides with an emphasis on human depravation and sin. A positive prognosis typically emerges from an emphasis on the inherent goodness of people, on some concept of the image of God that all people carry. Importantly, what one expects from human development, what we dare hope, is largely based on these anthropological foundations.

Anthropology is therefore worthy of special focus. Formulating a Christian anthropology has been the aim of countless volumes of theology, but it remains a highly complex task - not least in the context of a transitional society emerging from oppression and violence. Social change of this magnitude and depth typically gives rise to deeply complex anthropological phenomena. ${ }^{20}$

Classic theological debates, ranging on the spectrum outlined above, traditionally paid a lot of attention to the epistemological foundations of anthropology. This has often resulted in the questioning of the relationship between divine revelation, theology and anthropology. Can God be known in and through the human spirit, or can the human spirit only be known in the light of Divine Self-revelation? The former position, a classic tenet of liberal theology, was described by Ludwig Feuerbach as nothing else than a projection of the human self against the screen of eternity:

Religion, at least the Christian, is the relation of man to himself, or more correctly to his own nature... The divine being is nothing else than the human being, or rather, the human nature purified, freed from the limits of the individual man made objective... All attributes of the divine nature are, therefore, attributes of the human nature. ${ }^{21}$

For Feuerbach, theology is anthropology. Such reductionism invited sharp reactions, not least from Karl Barth and his Neo-Orthodox colleagues early in the $20^{\text {th }}$ century. They insisted that theological anthropology could never exist as an independent subject. Humans could never know themselves without prior knowledge of the Divine. In fact, without the Divine, the human being is not even an object of knowledge. To them, anthropology is an extension of theological descriptions of divine revelation.

The resolution of this debate lies outside the scope of this essay. Whilst acknowledging the different positions, the key question for us is whether this and other theological debates provide us with substantive anthropological insights, however derived, that could help guide and stimulate responsible efforts towards social justice.

Perhaps it will suffice to say that following Barth in his epistemological agnosticism (we can

20 Victims of human rights violations frequently do not have the emotional strength to face deep change or ambitious development programmes. Formerly disadvantaged citizens often suffer from a lack of confidence and skills. Beneficiaries of past injustice often feel a sense of moral condemnation and mourn a loss of privilege or power. They either feel unable to contribute to the new order or take refuge in a secluded, privatised environment - not infrequently sponsored by theologies of a different nature. Some ex-combatants fail to be integrated into society long after the battles are over. They often become dependent on the welfare, or resort to violence and crime. Perpetrators of gross human rights atrocities may seek to subvert the new order, to avoid prosecution or consider ways to pursue violence through other means. They may also simply withdraw.

21 L Feuerbach The Essence of Christianity (1989, first published in 1841) at 14. 
never fully know Divine truth) does not necessarily imply that we follow him in his extreme anthropological assumptions, where the very possibility of a contact point in the human spirit with the Divine is vehemently denied.

It is possible, I contend, to hold onto Barth's epistemological modesty but at the same time develop some form of positive anthropology, perhaps shaped by the concept of the universal image of God. Created in God's image, people all carry the ability to and propensity for relationships. When God's word goes out into the universe, it finds a response in kind only at one point: the human spirit. Created to be able to respond to the words from God, and thus to enter into a relationship with the Divine, human beings carry an inherent, indestructible ability to relate. Even the most inhumane individuals never lose this capacity. They may deny it, abuse it, or even actively seek to subvert it, but they cannot destroy it. This positive assertion about human nature is a centre piece of many forms of Christian theology and remains the starting point of many prominent and sophisticated theories of human nature. I use the word 'sophisticated', precisely because it creates a nuanced view of human nature as neither totally depraved, nor innately good. The ability to relate forms the basis of firm hope for progress, but since this capacity can clearly be abused, it is no automatic guarantee of progress or justice.

However, because it is an indestructible reality it cannot be ignored either. It continues to prompt and nudge human society towards the building of relations across boundaries. This implies that all people, in the developed and the developing worlds alike, share a basic propensity for entering into relationships with others because they all share in the image of God. (At the same time, of course, the dark side, the self-isolating apartheid-side of human nature pulls and pushes in the opposite direction.)

The mere possibility of progress, structurally and universally given as a constituent part of human nature, is cause for hope, albeit nuanced hope. No progress is assured. No outcome is guaranteed, but the possibility to progress towards a more just world is a structural anthropological reality.

So, what may South Africans hope for? We may hope for more progress, deeper solidarity and more overt social justice. History is open with these and other possibilities. We may also, with good cause, fear failure. The rational response would be to put as much effort as possible into the creation of a more humane, more dignified society, knowing that this corresponds to ancient and modern conceptions of what humans are all about. The outcome is not yet determined, but there are grounds for hope and enough reason to commit ourselves fully to the project of justice for all.

\section{(D) Justice}

Human rights discourses are often suspected of Western bias, a kind of latter day colonialism based on European (or Enlightenment) chauvinism. It is becoming clearer that, human rights discourses, to have genuine universal appeal and legitimacy, need to demonstrate, not least in contexts of deep suffering, some understanding of concrete conditions and contextual realities. In more practical terms, the abstract individualism at the root of rights discourses needs to be complemented with insights derived from collective identities, shaped by historical, cultural and religious practises and beliefs.

The postulation of universal equality, certainly in the founding fathers of theories of natural rights, such as Locke and Hobbes, was built on the identification of similarities in people the world over. This led to the gradual devaluation of contextual differences, a reality that is now gaining prominence again. 
So-called 'thin universals', the idea that human rights can be formulated as general 'one-liners' encapsulating on a human right true of all place and all people, feed (necessarily so) off strongly reduced, abstracted meanings. Indispensable as these formulations have become, they fail to do justice to the social dynamics of different contexts the world over.

One example may be taken from the Hebrew Scriptures, where individual responsibility is conceived as fundamentally social in nature. In this context, social rights are not some nice afterthought, but indeed the precondition for the achievement of even the most basic individual rights.

'Thicker' versions of human rights have a better chance of achieving lasting appeal in different contexts, than simplistically abstracted and applied individual rights, but one has to be careful not to compromise the essential message of freedom, equality and security for all. Maurice Cranston contends that the expansion of the term 'human right' to incorporate social considerations all but renders the term meaningless. Cranston describes a human right as a 'form of moral right' attributable to 'all people at all times in all situations'. ${ }^{22}$ 'A right differs from an ideal, in that it represents something that can, and from a moral point of view must, be respected here and now', says Cranston. 'A rights claim is a powerful demand for action', adds Donnely. ${ }^{23} \mathrm{~A}$ right is only a right if it has as collorative a duty. That is, a right that does not imply a duty to respond to the claim cannot be called a right. In short, human rights are not a wish-list thought out in splendid isolation, but a limited, sharply focused set of universally enforcable claim-rights.

This position offers important insights not to be lost in our haste to accommodate contextual realities. Human rights would have lost its essence if watered down, or 'contextualised' to the point where they would condone repressive social hierarchies or regimes that demand absolute submission. At the same time rights discourses need to learn to speak to people in their particular settings, as whole, integrated individuals with more than legal, civic or political needs, but with equally pressing economic, social and environmental needs. Moreover, they operate in systems of thought and meaning that may substantially enrich human rights conceptions of equality and freedom.

One such system of thought, itself deeply diverse the world over, is Christian theology. Christianity holds the incarnation of truth not only dear, but as the sacred way that God revealed His Universal Truth to the human race - through incarnation into the concrete living conditions of Palestine 2000 years ago. At the same time the transcendent message was not lost, but in fact emphasised.

From here it is but a small conceptual step to recognise the fundamental importance that the Bible places on justice for the whole human being, in all her dimensions and in her concrete context. Theology is a potential source of the grammar and contents of thicker versions of justice that transcends the narrow (but important) categories of Enlightenment thought.

This makes theology and law ideal dialogue partners. Charles Villa-Vicencio argues that law provides a sense of order, integrity and purpose to society. Theology, on the other hand, provides an incentive to transform law, as John Witte says 'the telos, it needs to move forward.' Without religion law decays into empty formalism. Without law, religion decays into shallow spiritualism. Part of the crisis of our law today is that it has become formalistic, undirected, lacking vision. It lost its religious dimension. Part of the crises has of our religion is that it has

22 M Cranston, 'Human Rights, Real and Supposed' in DD Raphael (ed) Political Theory and the Rights of Man (1967) at 51-53.

23 J Donnely Universal Human Rights in Theory and Practice (1989) at $10 f$. 
become spiritualistic, disorganised, diluted, lacking in discipline. It has lost its legal dimension.' 24

To stimulate a sense of urgency and a collective understanding of what justice in its fullest sense would mean is the task of theology. Making sure we do it orderly and fairly is the task of law.

\section{$V$ Conclusion}

The essay aims to illustrate that truthful theology cannot ignore its public responsibility. Its restless reaching out to people, most notably the poor and marginalised, its modest truth-claims, its nuanced but firm hope, and its irrepressible quest for justice in all its dimensions propels theological discourse into the public sphere time and time again. Theology cannot avoid going public, but needs to do so responsibly.

The road to justice has never been clearer. At the same time much remains to be done. Theology can provide motivation, fuel and stamina for the journey to justice by providing vision, urgency and purpose to development initiatives.

For this to happen, theology would have to develop the analytical capacity to understand the current social and economic challenges and to move beyond mere sloganism and rhetoric towards concrete, constructive proposals that engage both the Christian message and the historical realities in South Africa.

This is at once a journey out of the laager of theological discourse but also, and I sought to emphasise this here, a journey back into the heart of what constitutes proper Christian theology. My view is that such a journey yields at least four insights that could act as guidelines on the way towards a more just, inclusive South Africa:

The quest for justice for those who are excluded constitutes the essence of the restlessness which characterises theology that remains true to its Source - the grace of God.

God's truth remains present in our world, but in a subtle, 'hidden' way, mediating the voices of the poor and marginalized.

The image of God in people forms the basis of social hope. This possibility of progress is cause for hope. Yet it remains a nuanced hope. No progress is assured.

Theology's concern with justice in all its dimensions prompts it to continue to engage other disciplines such as law, equally indispensable to the cause. It provides a constant reminder of the importance of incarnating universal human rights dicta into the concrete living conditions of the poor, the disenfranchised and the voiceless.

24 J Witte 'The Study of Law and Religion: An Apologia and Agenda' (1988) Fall Ministry and Mission at $14: 4$ 


\title{
A Not so Simple Justice: Frank Michelman on Social Rights, 1969 - Present*
}

\author{
William E FORBATH \\ Lloyd M Bentsen Chair in Law, \\ Professor of History, \\ University of Texas at Austin
}

\section{Introduction}

\section{(A) The Constitution in the Year 2020}

Periods of no power, Charles Black once wrote, are periods for 'reformation of thought,'1 for thinking anew and 'thinking large' about visions, goals, and strategies. In constitutional law, as elsewhere, liberals and progressives are out of power. We are on the defensive and are pressed to think small: criticizing countless decisions; defending doctrines and precepts under attack; advancing modest proposals, each apparently a tub on its own bottom, guided by no larger constitutional vision. We cannot afford to overlook the need to think large, about the constitutional bases on which we - or our students - will build anew, when the opportunity comes.

We must take a leaf from our adversaries. In the late 1970s and early 1980s, when their ideas were wildly out of tune with judicial doctrine and mainstream political and academic opinion, right-wing constitutional thinkers set about crafting an alternate account of our constitutional past, an alternate vision of our future, and a cogent set of ideas about the way constitutional law should unfold in every key area of their concerns. In the late 1980s, right-wing constitutional lawyers in the Reagan Justice Department produced a remarkable 185-page document entitled The Constitution in the Year $2000 ;{ }^{2}$ and the rest, as they say, is history. ${ }^{3}$

And while history does not repeat itself, it rhymes. So, we need to begin writing The Constitution in the Year 2020. One important chapter in that book will address the problems of poverty and economic inequality. Today's Supreme Court tells us that the Constitution affords no protection against desperate want, nor does it confer on Americans any other 'affir-

* Portions of this article draw substantially from WE Forbath “Constitutional Welfare Rights': A History, Critique and Reconstruction' (2001) 69 Fordham LR 1821. This article first appeared as William Forbath 'A not so Simple Justice: Frank Michelman on Social Rights, 1969 - Present' (2004) 39 Tulsa Law Review 597-638 and is reprinted here with the kind permission of W Forbath and Tulsa Law Review.

1 CL Black 'Further Reflections on the Constitutional Justice of Livelihood' (1986) 86 Col LR 1103 at 1115.

2 Official Legislative Policy Report to the Attorney General: The Constitution in the Year 2000: Choices Ahead in Constitutional Interpretation (US Dept of Justice 1988) (available at shttp://www.americanconstitutionsociety.org/pdf/year2000.pdf $>$ ).

3 See DE Johnsen 'Ronald Reagan and the Rehnquist Court on Congressional Power: Presidential Influences on Constitutional Change' (2003) 78 Ind LJ 363 (discussing the history and impact of the report). 
mative rights' to such basic goods as minimally adequate education or a realistic opportunity to make a livelihood. ${ }^{4}$ These 'social rights' are features of most of the world's constitutions; ${ }^{5}$ and many prominent constitutional courts have been elaborating and (some boldly, some gingerly) enforcing them, some with explicit textual bases, some without. ${ }^{6}$ Today's conservatives would have us think that social rights and the solicitude for them among the world's great courts are foreign to American constitutional experience. That is wrong. ${ }^{7}$ What is true, though, is that the current Court's hostility partly reflects the broader disillusionment with the New Deal and the welfare state, as these are understood in the US polity today. A key aspect of the liberal/progressive project today lies in reinvigorating the old convictions that all Americans are entitled to a modest share in the nation's wealth, to protection against desperate want, and to the opportunity to make a decent livelihood. There is substantial disagreement and uncertainty about what kinds of reforms or even what programmatic vision is best suited to carrying forward these commitments in the early twenty-first century; but they remain a defining feature of the nation we believe the Constitution promises to promote and redeem.

4 See DeShaney $v$ Winnebago County Dept of Soc Services 489 US 189196 (1989).

5 See G Casper 'Changing Concepts of Constitutionalism: 18th to 20th Century' (1989) S Ct Rev 311 at 31821; M Glendon 'Rights in Twentieth-Century Constitutions' (1992) 59 U Chi LR 519 at 523-24 (noting the anomalous nature of the United States Constitution for its lack of affirmative welfare obligations, as compared to the constitutions of other liberal democracies); A Ben-Bassat \& M Dahan 'Social Rights in the Constitution and in Practice' (Hebrew U of Jerusalem School of Public Policy Working Paper No 05-03 May 2003) (available at $\leq$ http://papers.ssrfncom/sol3/papers.cfm?abstract id $=407260>$ ) (examining the constitutional commitment to social rights in sixty-eight countries).

6 For recent comparative accounts of judicial enforcement of constitutional social rights, see M Tushnet 'Strong Rights, Weak Courts' (2004) 82 Tex LR 1895; M Tushnet 'State Action, Social Welfare Rights, and the Judicial Role: Some Comparative Observations' (2002) 3 Chi J Intl L 435; KL Scheppele 'A Realpolitik Theory of Social Rights' (2004) 82 Tex LR 1921. For the reflections of an architect of the South African Constitution's social rights provisions, now a justice of that nation's Constitutional Court, see Justice A Sachs 'Enforcement of Social and Economic Rights' (Speech at London School Econ Feb 27 2003) (available at $\leq$ http://www.lse.ac.uk/Depts/human-rights/Documents/Enforcement Social Economic Rights.doc $>$ ); see also the rich collection of research papers in Community Law Center, Realizing Socio-Economic Rights in South Africa: Progress and Challenges <http://www.communitylawcentre.org.za/ser/conferences.php $>$ (accessed Apr 24 2004).

7 In the 1960s and early 1970s, the Supreme Court came extremely close to recognizing such rights in a series of statutory and constitutional cases which produced remedial schemes comparable to several under construction abroad. The Supreme Court's personnel and the nation's political climate changed before a jurisprudence of social citizenship took root. See WE Forbath 'Lincoln, the Declaration, and the 'Grisly, Undying Corpse of States' Rights': History, Memory, and Imagination in the Constitution of a Southern Liberal' (2004) Geo LJ 709; WE Forbath "Constitutional Welfare Rights': A History, Critique and Reconstruction' (2001) 69 Fordham LR 1821 at 1823; infra text accompanying notes 28-61. On the long history of robust social rights discourse in the legislative and public political domains of constitutional argument and interpretation in America, see WE Forbath "Caste, Class, and Equal Citizenship" (1999) 98 Mich LR 1 [hereinafter Forbath 'Caste, Class, and Equal Citizenship'] and WE Forbath 'The New Deal Constitution' in Exile' (2001) 51 Duke LJ 165 [hereinafter Forbath 'The New Deal Constitution']. It was the rights discourse of New Deal and 1940s America that inspired the social rights provisions of many constitutions around the globe. See CR Sunstein 'The Second Bill of Rights: The Last Great Speech of Franklin Delano Roosevelt and America's Unfinished Pursuit of Freedom' (prelim draft 26 July 2003) (copy on file with Tulsa Law Review) (noting the influence on post-World War II constitution-making in Europe, Asia, and Africa, of Franklin Roosevelt's 'four freedoms' and 'second Bill of Rights,' and of the Universal Declaration of Human Rights, which Eleanor Roosevelt and others crafted to reflect FDR's 'four freedoms' and second 'Bill'). For a more sustained discussion, see M Glendon A World Made New: Eleanor Roosevelt and the Universal Declaration of Human Rights (2001). 
So, the authors of The Constitution in the Year 2020 will have to ponder anew whether, why, and how the Constitution and (a separate question) judicially enforced constitutional law should be interpreted to safeguard these commitments. When they do so, they will find no better interlocutor than Frank Michelman. No one has thought and written more deeply about the question of constitutional social rights. Spanning almost four decades, Michelman's work offers several of the most important approaches to the problems of poverty and economic inequality in the precincts of American constitutionalism.

In this brief essay, I will engage some of Michelman's most important contributions. Partly, I'll do so from the perspective of constitutional theory, partly, from the vantage point of an historian. Only by situating our past thinking in the context of the social movements and political moments that shaped that thinking can we appreciate its distinctive insights and blind spots. So, I will situate Michelman's classic essays on constitutional welfare rights in the context of the welfare rights movement and its distinctive possibilities and constraints. This contextual account will set the stage for a textual argument, a critical reading of Michelman's reading of Rawls's epoch-making 1971 book, A Theory of Justice. ${ }^{8}$ Michelman, I'll suggest, overlooks the extent to which Rawls is critical of welfare state liberalism in favor of a more ambitious constitutional political economy, which Rawls dubs 'property-owning democracy.' From Rawls, Michelman turned in the 1980s to republicanism, and a key aspect of Michelman's enormously influential contributions to the republican revival was his republican treatment of the distributive dimension of constitutional property claims. Michelman reads republicanism as he reads Rawls; both imply constitutional welfare rights. But the republican tradition is largely hostile to welfare rights; its distributive norms point to the distribution of material opportunities for self support and 'independence.' Welfare rights, I'll suggest, are better seen as a critique of this distributive dimension of republicanism than as an implication of it.

Happily, these historical and theoretical criticisms are part of a present conversation with Michelman about social rights. ${ }^{9}$ And as a round in that conversation, this essay is gratefully written, taking up not only Rawls and republicanism, but also more recent work by Michelman on social rights and constitutional democracy.

\section{(B) Dialogues with Frank Michelman: First Citizen of the REPUBLIC OF LETTERS}

I say gratefully written because, as Jefferson might have put it, Frank Michelman is a first citizen of the republic of letters, and there is no more generous, careful, and imaginative reader in the republic. He reads and engages with the works of fellow citizens everywhere, and every work is made deeper and clearer after Michelman's light has shined on it, exploring unmapped distinctions and uncharted implications and resonances, leaving the work richer and the author gladly indebted.

What's more, Michelman's style of engagement instantiates a dialogical ethics and helps make

8 J Rawls A Theory of Justice (1971).

9 See Forbath 'Constitutional Welfare Rights' (note 7 above) at 1825-27; FI Michelman 'The Constitution, Social Rights, and Liberal Political Justification' (2003) 1 Intl J Const L 13 at 25-34 (available at <http://www3.oup.co.uk/ijclaw/hdb/Volume_01/Issue_01/pdf/010013.pdf >) [hereinafter Michelman 'Constitution and Social Rights'] (discussing Forbath's conception of 'social citizenship' rights); FI Michelman "Democracy-Based Resistance' to a Constitutional Right of Social Citizenship: A Comment on Forbath' (2001) 69 Fordham LR 1893 [hereinafter Michelman Democracy Based-Resistance] (responding to Forbath 'Constitutional Welfare Rights' (note 7 above)). 
him an exemplar of some of the ideas his own writings explore. Compare, for just a moment, Michelman's manner of reading with that of one his most important interlocutors: Jürgen Habermas. Habermas reads, critiques, and appropriates, trimming off what doesn't fit and putting the useful parts to work in the ever-enlarging Habermasian machinery. Michelman's mode of appropriation is different, more respectful and also more provisional, more in the way of dialogue than system-building. Michelman is more inclined to put the insights of one school of thought to work in order to reveal the blindness of another. He seems most comfortable in-between.

Consider, for example, the controversies between pragmatists like Rorty and neo-Kantian liberals like Habermas. ${ }^{10}$ Inside law schools and elsewhere, it's common to find scholars who seem to think that Rorty or someone else has delivered the knock-out punch to Habermas and his kind, or vice versa. As finely and shrewdly as anyone, Michelman can turn a pragmatist critique of Habermas's categorical distinctions ethics versus morality; the good versus the right; the principles of justice versus their application, and so on. ${ }^{11}$ But in contrast to those who line up in one of the two camps, Michelman seems to feel the pull of the neo-Kantian enterprise as strongly as the counter-tug of pragmatism. And he brings them into revealing contact, into a sustained dialogue that Michelman's work enacts.

Another instance of this same dialogical in-betweenness in the work of Frank Michelman is in-between liberalism and critical legal studies (CLS), which was a rare enough position, I believe, in the heated politics of Harvard Law School in the 1970s and 1980s. I don't know how this translated in terms of faculty politics, but intellectually, Frank was distinctive: carrying on the liberal problematic justice, justifiability, justiciability, judicial review, and democracy while at the same time opening the doors of that discourse to fresh blasts of CLS and feminist insight. ${ }^{12}$ From the 1980s, however, we must hasten back to the 1960s, and follow this liberal man of the left back to his engagement with the War on Poverty.

\section{Why Welfare?: The War on Poverty and the Welfare Rights Movement}

Michelman's famous 1969 Harvard Foreword, 'On Protecting the Poor through the Fourteenth Amendment,'13 was a product of what Michelman called the 'great War' in a material as well

10 Among Rorty's most important works are R Rorty Philosophy and the Mirror of Nature (1980); R Rorty Contingency, Irony, and Solidarity (1989); and R Rorty Truth and Progress (1998). Habermas's important works include: J Habermas The Theory of Communicative Action (1987); J Habermas The Philosophical Discourse of Modernity: Twelve Lectures (1987); J Habermas, The Structural Transformation of the Public Sphere: An Inquiry into a Category of Bourgeois Society (1989); and J Habermas Between Facts and Norms: Contributions to a Discourse Theory of Law and Democracy (1996). For a law professor's reading of Rorty, see JW Singer 'The Player and the Cards: Nihilism and Legal Theory' (1984) 94 Yale LJ 1; and of Habermas, see WE Forbath 'Habermas's Constitution: A History, Guide, and Critique' (1998) 23 L \& Soc Inquiry 969.

11 See eg FI Michelman 'The Problem of Constitutional Interpretive Disagreement: Can "Discourse of Application" Help?' in M Aboulafai et al Habermas and Pragmatism (2002) 113-39; FI Michelman 'Family Quarrel' (1996) 17 Cardozo LR 1163 [hereinafter Michelman 'Family Quarrel'] (Symposium on Habermas on Law and Democracy).

12 See eg FI Michelman 'Justification (and Justifiability) of Law in a Contradictory World' in J R Pennock \& J W Chapman eds NOMOS XXVIII: Justification (1986) 71, 79-81; MJ Radin \& FI Michelman 'Pragmatist and Poststructuralist Critical Legal Practice' (1991) 139 U Pa LR 1019.

13 FI Michelman 'Foreword: On Protecting the Poor through the Fourteenth Amendment' (1969) 83 Harv LR 7. 
as a moral sense; we learn in its acknowledgments that the article 'was prepared ... with funds provided by The US Office of Economic Opportunity.' 14 The Office of Economic Opportunity was the command center of the Johnson administration's War on Poverty. It created Community Action Agencies, and alongside them, it created the Legal Services Organization (LSO). In addition to law offices in the inner cities, the LSO funded a handful of law school-based back-up centers, including Harvard's, with which Michelman was associated. ${ }^{15}$ A great portion of the work of these agencies and inner-city law offices involved 'getting poor people to apply for welfare and attacking the social and legal barriers to their receiving it. Centuries-old restrictions were broken down by a combination of civic unrest and federally funded organizing and litigation.' ${ }^{\prime 16}$

\section{(A) WhY 'WeLFARE'?}

Constitutional scholars see the origins of the constitutional welfare rights idea in the Warren Court's Fourteenth Amendment case law and the Court's new solicitude toward the nation's poor. But why was 'welfare' the terrain on which 1960s community activists, federal policymakers, and legal advocates and scholars like Michelman came to wage their 'War on Poverty'? The answer lies in the constraints and opportunities created by inherited statutory, institutional, and ideological frameworks- the results of the victories and defeats of earlier efforts to forge a more substantive and 'social' array of citizenship rights.

Put baldly, it was the defeat of key New Deal reforms in the 1930s and 1940s that deprived 1960s advocates of broader channels down which to try to nudge the Court's solicitude. FDR's famous 'second Bill of Rights' set forth not welfare but decent work and universal social insurance as the economic rights essential to free and equal citizenship in the twentieth century, but Roosevelt's vaunted right to decent work met defeat at the hands of Jim Crow and the Solid South.

Measures instituting rights to full employment, decent work, and social provision for all Americans enjoyed broad support; yet they expired in the New Deal Congress, doomed by the hammer lock that southern Democratic lawmakers enjoyed by dint of numbers, seniority, and key committee chairs. Hailing from an impoverished region with a populist tradition, most southern Democrats in Congress were staunch supporters of the New Deal until the late 1930s. In exchange for their support, however, they insisted on decentralized state administration and local standard setting of all labor measures, and they demanded that key bills exclude the main categories of southern labor. By allying with northern Republicans, or by threatening to do so, they stripped all the main pieces of New Deal legislation of any design or provision that threatened the separate southern labor market and its distinctive meld of class and caste relations, its racial segmentation, and its low wages. Keeping blacks dependent on local labor markets and poor relief was the principal reason for the segmented and caste-ridden system of social provision and labor rights bequeathed by the New Deal. ${ }^{17}$

A quarter-century later, this system underpinned a fairly robust private welfare state of job security, pensions, and health insurance for organized workers in core sectors of the industrial

14 Idem at 7.

15 See idem.

16 Forbath 'Constitutional Welfare Rights' (note 7 above) at 1842. For a more detailed account, see idem at 1838-66.

17 I develop this historical argument in Forbath 'Constitutional Welfare Rights' (note 7 above) at 1835-45. 
economy. But that meld of public and private rights excluded most African Americans, whose anger exploded in all the large cities of the North, where millions of southern blacks had moved over the preceding decades to escape Jim Crow and rural unemployment. For them, public assistance, primarily Aid to Families with Dependent Children (AFDC), stood as the sole federal protection against poverty.

\section{(в) Aid to Families with DePEndent ChILDREN}

Created by the Social Security Act of 1935,18 originally titled Aid to Dependent Children (ADC) and renamed AFDC in the 1950s, the federal ADC descended from the state-based Mothers' Pensions programs of the early twentieth century, themselves a modern variant of the age-old practice of giving poor relief to 'deserving widows.' 19 Like the other branches of the Social Security Act, ADC was drafted to propitiate the South. So the states could determine AFDC benefits levels, and local administrators enjoyed vast discretion in making eligibility determinations. ${ }^{20}$

Local administrators used that discretion to buttress low-wage labor markets and to exercise other kinds of disciplinary power. In the South, for example, AFDC officials deemed poor black women 'employable mothers,' and kept them off the rolls when their labor was needed in the cotton fields. ${ }^{21}$ More generally, AFDC payments in the South and indeed, in most states, were kept appreciably below official poverty levels. And throughout the nation, local administrators in the early 1960s still vigorously enforced man-in-the-house rules. Through home visits, unannounced nighttime searches, and the like, they removed from the rolls any woman found to be associating with a man, especially if he seemed to live in her house. In this fashion, welfare officers prevented public monies from supporting 'immoral women' and 'unsuitable mothers'; at the same time, they kept poor men from exploiting AFDC to escape any of the rigors of the low-wage labor market. ${ }^{22}$ Even for its target universe of impoverished single parent families, AFDC reached a tiny fraction of the whole. Most did not even apply; of those who did, poverty-stricken newcomers to a locale met almost certain rejection. Since colonial times, wayfaring paupers had been 'warned off' and forcibly excluded by the custodians of poor relief. Throughout the country, local custodians of AFDC carried on a modern version of this practice. In New York, for example, the very fact that you applied for welfare was presumptive proof of why you had come to the city. Rejected as ineligible, instead of welfare, you and your offspring got tickets on a Greyhound bus bound for home. ${ }^{23}$

It was this separate, decentralized, and deeply gendered benefits program, stamped with many of the centuries-old degradations of poor relief, that welfare rights organizers, advocates, and attorneys sought to transform into a dignifying right to a guaranteed income.

1849 Stat $620(1935)$.

19 W Bell Aid to Dependent Children (1965) 9 (internal quotation omitted); M Ladd-Taylor Mother-Work: Women, Child Welfare, and the State, 1890-1930 (1994) at 136-66; S Michel Children's Interests/Mothers' Rights: The Shaping of America's Child Care Policy (1999) 424-79; T Skocpol Protecting Soldiers and Mothers: The Political Origins of Social Policy in the United States (1992) 73-78.

20 Bell (note 9 above) at 33-34, 63-65, 76-79, 81-82, 108-09.

21 Idem at 34-35, 42, 55, 79, 83, 130, 138.

22 See idem at 4, 6, 80, 213 fn 7; R S Melnick Between the Lines: Interpreting Welfare Rights (1994) 57, 8590, 98, 121-22, 130.

23 See Melnick (note 22 above) at 77. 


\section{(C) The Welfare Rights Movement}

Fostered by the War on Poverty, the welfare rights movement of the 1960s was unique in the annals of American reform, and, as we'll see, Michelman's Foreword bears its stamp. Never before, or since, had poor African American women formed the rank and file of a nationally organized social movement. The movement departed from the vocabulary of reform bequeathed by earlier movements for social and economic justice. The welfare rights movement broke the links these older movements had forged between work and citizenship. Like them, the welfare rights movement claimed decent income as a right; unlike them, it did not tie this right to waged work. Generations of reformers had constructed their ideals of economic justice for the poor and working classes in a gendered fashion, around the workingman-citizen; decent income and social provision belonged, as of right, to (presumptively white male) waged workers, and to their economic dependents. Poor black women had always toiled outside their homes, ${ }^{24}$ but they had never been welcomed into the producers' republic of earlier reformers. By the 1960s poor black women had had enough experience in urban labor markets to know that decent jobs were hard to find, and enough experience with workfare programs to think them coercive and demeaning. Theirs was a consumers' republic. 25 "'Give Us Credit for Being Americans," read the [National Welfare Rights Organization's (NWRO)] placards demanding Sears credit cards for welfare recipients. ${ }^{26}$ For them a guaranteed adequate income was an unconditional citizenship right, essential to equal respect and an appropriate touchstone of equality in an affluent America.

This rupture with the past was both a strength and a limit of the NWRO. It highlighted the coercive and gendered aspects of older employment-based ideals of economic and distributive justice. Gaining welfare as a matter of right would relieve unwarranted suffering and indignity. But it would not do enough to help poor African Americans make their way into a shared social destiny of work and opportunity. Without other enabling rights to training, decent work, and childcare, welfare rights risked modernizing the badges and incidents of racial and economic subordination instead of abolishing them. Mimicking AFDC also led to the absence of poor men in a movement that claimed to represent the nation's poor and their needs. It led to a rights rhetoric that downplayed the disappearance of decently paid unskilled industrial jobs from the nation's old industrial regions and center cities. ${ }^{27}$ Welfare rights risked saddling poor African Americans with a new variant of the old racist imagery of blacks as idle and dependent.

But the NWRO played the hand that was dealt it. Perhaps only by mimicking AFDC and building on its provisions could a social movement of the poorest, most powerless Americans have been forged. By making AFDC-eligible women the movement's constituents, welfare rights organizers had something to offer the rank and file, and the rank and file developed a sense of efficacy and entitlement by gaining their demands from the nation's welfare departments. Likewise, AFDC provided a basis for substantial gains through litigation. And the litigation, of course, is what inspired Michelman's work, supporting and supported by the War on Poverty. The rupture between the older ideal of a right to decent work and the new ideal of a right to welfare also stamped Michelman's work in ways we are about to explore.

24 See J Jones, Labor of Love, Labor of Sorrow: Black Women, Work, and the Family from Slavery to the Present (1985).

25 See Forbath 'Constitutional Welfare Rights' (note 7 above) at 1850-55.

26 Idem at 1851.

27 This was the social fact that civil rights leaders like Martin Luther King and Bayard Rustin highlighted and called on Congress to remedy as a necessary condition for the "full emancipation and equality of Negroes and the poor': Forbath "Caste, Class, and Equal Citizenship" (note 7 above) at 87. 


\section{Frank Michelman's Constitutional 'War on Poverty'}

\section{(A) Welfare Rights in the Courts}

Constitutional scholars today remember Goldberg $v$ Kelly, ${ }^{28}$ Shapiro $v$ Thompson, ${ }^{29}$ and a handful of other constitutional decisions bearing on welfare rights, but we tend to forget the hundreds of statutory cases that dramatically broadened eligibility standards and went a remarkable distance toward transforming a grant-in-aid to the states to be administered as meanly as local officialdom saw fit, into a no-strings and no-stigmas national right to welfare. ${ }^{30}$ These cases saw the Supreme Court and the lower federal courts undertake dozens of remarkable doctrinal innovations and boldly revisionary readings of the statutory text and history. ${ }^{31}$ The whole push of these developments was reflected in the courts' repeated insistence that public assistance for all the nation's needy was, in the Supreme Court's words, a 'basic commitment,' not charity or largess, but a right.

The Court recognized a private right of action against the state welfare agencies that administered AFDC, 32 revising or ignoring jurisdictional rules that seemed to bar the way, ${ }^{33}$ and spurning the conventional remedy of federal funding cut-offs in favor of injunctive relief. ${ }^{34}$ Above all, the Court shoved aside the view, shared by judges, welfare administrators, and members of Congress alike for the first thirty years of AFDC's existence, that under AFDC states had authority to run their own programs, imposing such conditions and standards as they chose, subject only to a handful of limitations listed in the federal statute. ${ }^{35}$ State and local autonomy over the administration of federal relief had been the southern Democrats' sina qua non, and, as we know, the architects of the 1935 Social Security Act, of which AFDC was a part, had provided it. In place of the wide berth they had left for state discretion, the Court created a new presumption: 'a heavy burden lay on state lawmakers and administrators to justify any exclusion, test or condition that deviated from the principle of "actual need"'. ${ }^{36}$ LSO attorneys persuaded the federal courts to embrace this presumption and to wield it against hundreds of state rules excluding would-be AFDC recipients. ${ }^{37}$ Within the federal statutory categories, the federal courts in the 1960s and early 1970s proved extraordinarily willing to treat welfare under AFDC as a right of all needy individuals.

The leading statutory case was King $v$ Smith, 38 in which the Court struck down an Alabama

28397 US 254 (1970).

29394 US 618 (1969).

30 Forbath 'Constitutional Welfare Rights' (note 7 above) at 1862.

31 Idem at 1863.

32 See RB Stewart \& CR Sunstein 'Public Programs and Private Rights' (1982) 95 Harv LR 1195 at 1289-90.

33 See eg Hagans v Lavine 415 US 528 534-35 fn 5537 541-42 (1974); King $v$ Smith 392 US 309312 fn 3 (1968).

34 See Melnick (note 22 above) at 50.

35 See Bell (note 19 above) at 50; M Derthick The Influence of Federal Grants: Public Assistance in Massachusetts (1970); WJ Cohen 'The Social Security Act of 1935: Reflections Fifty Years Later' in The Report of the Committee on Economic Security of 1935 at 3 (50th anniversary ed Natl Conf on Soc Welfare 1985).

36 Forbath 'Constitutional Welfare Rights' (note 7 above) at 1859.

37 See SE Lawrence The Poor in Court: The Legal Services Program and Supreme Court Decision Making (1990) 123-48; generally MF Davis Brutal Need: Lawyers and The Welfare Rights Movement, 1960-1973 (1993).

38392 US 309 (1968). 
man-in-the-house eligibility rule issued by Governor George Wallace in 1964. Under Wallace's rule, Alabama had dropped 16,000 children ninety percent of them black from its welfare roll. The three-judge court below had invalidated the rule on equal protection grounds. ${ }^{39}$ At oral argument, however, plaintiff's LSO attorney sought a statutory ruling. ' $[\mathrm{I}] \mathrm{f}$ the decision goes off as the lower court's did, then very little will have been accomplished. Even if we win in Alabama, HEW will not stop similar practices in other states [where man-in-the-house rules had no such discriminatory purpose or effect]. ${ }^{40}$ A statutory holding, 'would give us all we wanted, 41 providing 'a way in which the narrowest of rulings would have the broadest of implications. ... "[G]ive us," 42 counsel asked the Court speaking for the NWRO rank-and-file, "a decision interpreting the Social Security Act as having rejected the concept of a worthy and an unworthy poor"'.43

And the Court did so, giving welfare rights attorneys a reading of the Act that would shape AFDC case law for the next two decades. ${ }^{44}$ In the face of legislative history that ran almost entirely to the contrary, a unanimous Supreme Court concluded that in 1935 Congress had intended that all 'needy, dependent children' would be entitled to AFDC benefits, and that states and localities could not enforce their own narrower definitions of eligible parents. Thus, Alabama, in dispersing AFDC, could not decide that Mrs. Smith's occasional visitor and lover (a Mr Williams with nine children of his own) was a 'substitute father' and breadwinner whose visits to Mrs Smith disqualified her and her children from the federal entitlement. ${ }^{45}$ Chief Justice Warren put aside a wealth of legislative history suggesting that Congress intended precisely to allow states to apply their own standards of 'moral character' and 'suitability' (acquiescing, as we saw, to the southern Democrats' insistence on local control over 'domestic affairs' of race, caste, and the social and economic authority of local white elites). This history might have been relevant at one time, Warren noted, because the 'social context' in 1935 was one in which the distinction between the 'worthy' poor and the 'undeserving' was generally accepted. ${ }^{46}$ Now both society and Congress took a different view, 'more sophisticated and enlightened than the "worthy-person" concept of earlier times." 47 The evidence that the Congresses that enacted the various post-1935 amendments to AFDC shared the Warren Court's enlightened perspective was scant at best. ${ }^{48}$ Nonetheless, the Chief Justice proceeded to read the preamble and statement of purpose of the 1935 Act itself to mean that AFDC 'was designed to meet a need unmet by programs providing employment for breadwinners. ${ }^{3} 9$

Thus, 'at the same time that it intended to provide programs for the economic security and protection of all children ... [Congress surely would not have allowed the states] arbitrarily to

39 Smith $v$ King 277 F Supp 3141 (MD Ala 1967).

40 M Garbus Ready for the Defense (1971) 194.

41 Idem.

42 Idem at 194-95.

43 Idem (internal quotations omitted).

44 See King 392 US 309.

45 Idem at 328-30.

46 Idem at $320,324-35$.

47 Idem at 324-25.

48 The year before, in 1967, Congress had enacted amendments to AFDC that penalized states if they failed to reduce the number of illegitimate children on AFDC. Senator Robert Kennedy complained that 'the manin-the-house rule emerges from the conference strengthened rather than weakened' and joined with other liberals in an unsuccessful attempt to kill the conference report. Melnick (note 22 above) at 87 (quoting 113 Cong Rec 36785 (Dec 14 1967)) (internal quotations omitted). 
leave one class of destitute children entirely without meaningful protection... Such an interpretation of congressional intent would be most unreasonable, and we decline to adopt it. ${ }^{50}$

Relying on King $v$ Smith, ${ }^{51}$ LSO attorneys went on to challenge a wide variety of state practices. Most northern states had their own, less draconian man-in-the-house rules, like New York's, which did not disqualify the family, but put some financial burden on the man involved. 52 The lower courts took a hard line against all such practices, and the Supreme Court upheld them, enshrining a principle of 'actual availability. ${ }^{53}$ Thus, the much-resented man-inthe-house rule fell by the wayside, its defeat a victory for the welfare rights movement's vision of woman's autonomy. Other forms of presumed income also were successfully challenged, and the upshot was that courts indirectly increased family's benefits. ${ }^{54}$

In the process of expanding their attack on man-in-the-house and other attributed income rules, the courts strengthened the general presumption against all types of state-imposed restrictions. Few facets of AFDC policy escaped scrutiny in the lower courts. State laws penalizing recipients for fraud; laws and regulations denying benefits to aliens; rules on verification procedure, foster care, and emergency assistance were all struck down. ${ }^{55}$ During the first thirty years of AFDC's existence, there had been but one reported federal case interpreting the statute. Then, between 1968 and 1975, the years Frank Michelman wrote his first seminal pieces on welfare rights, the Supreme Court decided eighteen AFDC cases, and the lower federal courts decided hundreds more..$^{56}$

Chiefly through statutory construction, the federal judiciary had gone a great distance toward transforming a grant-in-aid to the states into a no-strings, no-stigma, national right to welfare. But statutory construction could go only so far. It could not establish a decent social minimum as a floor on welfare benefits, or even prevent the states from diminishing payments as they expanded coverage under judicial nudging. ${ }^{57}$ And it could not challenge the exclusions inscribed in the statute's categorical system, forcing Congress to change the system into one embracing all of the nation's poor. If courts were to force these changes, it would be through constitutional adjudication.

At first, LSO relied heavily on constitutional challenges. Residency requirements, as we've noted, carried forward a centuries-old tradition of localities warning out wayfaring paupers. Nine out of eleven lower courts agreed with welfare rights groups and the LSO that these requirements trenched on the welfare recipient's right to travel; to be a member of the national community had always included the right freely to travel among the states. ${ }^{58}$ In Shapiro $v$ Thompson, the Supreme Court agreed that the states' residency requirements unconstitutionally burdened poor Americans' enjoyment of that right. ${ }^{59}$ More than that, Justice Brennan, writ-

50 Idem at 330.

51392 US 309 (1968).

52 Van Lare $v$ Hurley 421 US 338 339-42 (1975).

53 Melnick (note 22 above) at 88-89; Lewis v Martin 397 US 552 (1970).

54 Melnick (note 22 above) at 89.

55 See eg Holley $v$ Lavine 553 F2d 845851 (2d Cir 1977) (rules excluding aliens); Maryland $v$ Mathews 415 F Supp 1206 (DDC 1976) (verification procedures); Owens $v$ Roberts 377 F Supp 45 (MD Fla 1974); JA $v$ Riti 377 F Supp 1046 (DFNJ 1974) (rules penalizing fraud); Cooper $v$ Laupheimer 316 F Supp 264 (ED Pa 1970) (rules on emergency assistance).

56 See generally Lawrence (note 37 above).

57 Rosado $v$ Wyman 397 US 397 416-17 (1970).

58 Forbath 'Constitutional Welfare Rights' (note 7 above) at 1862.

59394 US 618 629-31 (1969). On the lower court litigation and rulings against residency requirements, see FS Bloch 'Cooperative Federalism and the Role of Litigation in the Development of Federal AFDC Eligibility Policy' (1979) Wis LR 1 at 8-12. 
ing for the Court, seemed to suggest (Justice Harlan, in dissent, called it a 'cryptic suggestion'60) that strict scrutiny, applying the compelling state interest test to the residency requirement, might be justified for another reason not the right to travel, but the fact that welfare affects 'the ability of the families to obtain the very means to subsist.' 61

\section{(B) Goldberg v Kelly, the ‘New Property'’ and the Hard Questions}

Eight lower courts heard LSO challenges to states' summary termination practices, and six held that the due process clause required pre-termination hearings. ${ }^{62}$ In 1970, with its decision in Goldberg $v$ Kelly, 63 the Supreme Court upheld the majority view. ${ }^{64}$

Declaring that welfare benefits were 'a matter of statutory entitlement ... [whose] termination involves state action that adjudicates important rights, ${ }^{6} 5$ Goldberg encapsulated the previous five years of federal litigation and decisional law. By recognizing private rights of action, stripping broad swathes of discretionary power from local officials, and eliminating non-need based eligibility criteria, this new body of law had made welfare benefits into just such rights. The Court seemed to go further, stating more fully and forcefully than ever before the premises behind the 'more sophisticated and enlightened' view of welfare it had evoked (and attributed to Congress) in King. ${ }^{66}$ In a footnote supporting its assertion that welfare benefits were 'a matter of statutory entitlement,' the Court observed, 'it may be realistic today to regard welfare entitlements as more like 'property' than a 'gratuity.' Much of the existing wealth in this country takes the form of rights that do not fall within traditional common-law concepts of property. It has been aptly noted that '[s]ociety today is built around entitlement... . Many of the most important of these entitlements now flow from government: subsidies to farmers and businessmen ... [and] social security pensions for individuals. Such sources of security, whether private or public, are no longer regarded as luxuries or gratuities; to the recipients they are essentials, fully deserved, and in no sense a form of charity. It is only the poor whose entitlements, although recognized by public policy, have not been effectively enforced.' 67

The long quotation was from Charles Reich, whose two enormously influential articles on the 'new property' were published in Yale Law Journal in 1964 and $1965 .{ }^{68}$ It is an argument about the status of welfare in an era in which 'government largess' takes myriad forms and constitutes so much of individual and corporate wealth. In Reich's account, the welfare recipient belonged to a whole social order of Americans 'liv[ing] on government largess.' 69 'Social insurance substitutes for savings[, and] a government contract replaces a businessman's customers and goodwill, 70 while in between the new pauper and pensioner and the new businessmen

60 Shapiro $v$ Thompson 394 US at 661 (Harlan J dissenting).

61 Idem at 627 (majority).

62 Forbath 'Constitutional Welfare Rights' (note 7 above) at 1863.

63397 US $254(1970)$.

64 See Bloch (note 59 above).

65397 US at 262.

66392 US at 324-25.

67 Goldberg 397 US at 262 fn 8 (quoting CA Reich 'Individual Rights and Social Welfare: The Emerging Legal Issues' (1965) 74 Yale LJ 1245 at 1255).

68 See CA Reich 'Individual Rights and Social Welfare: The Emerging Legal Issues' (1965) 74 Yale LJ 1245 [hereinafter Reich 'Individual Rights and Social Welfare']; CA Reich 'The "New Property"' (1964) 73 Yale LJ 733 [hereinafter Reich 'New Property'].

69 Reich 'New Property' (note 68 above) at 733.

70 Idem. 
stood petty entrepreneurs and tradesmen, the cab driver dependent on his medallion, the tavern keeper and the hunting guide whose livelihoods hinged on their licenses. ${ }^{71}$ In Reich's anxious and nostalgic liberal narrative of American life, political and cultural antagonists, the cab driver or tradesman and the welfare mother, the factory owner and the union worker, were united by their common vulnerability to the state. ${ }^{72}$ In fact, precious few of Reich's disparate forms of 'new property' were new. ${ }^{73}$ But the assimilation of pauper to tradesman and franchise-holder, the equation of welfare benefits with professional licenses and government contracts, was dramatically new, and this did the important discursive and doctrinal work. The 'new property' unlike the old was dispensed by the state in 'the form of rights or status rather than of tangible goods. ${ }^{74}$ How, then, Reich asked, can the new property fulfill the social function of the old property? How can it serve as an institution that secures the individual a measure of independence from state domination, when it is itself dispensed by the state? ${ }^{75}$ The question sounded in classical liberalism, and so did the answer. If government subsidies, contracts, pensions, and benefits were to serve as a basis for private autonomy and dignified existence, fulfilling the social function of property, then these various forms of largess must enjoy the same legal protections as traditional common law forms of property.

In particular, the new property, like the old, must be protected against arbitrary deprivations and invasions by the state. What the state gave, the state could not take away, at least not without due process. And, in fact, Reich observed, due process case law already had begun in the 1950s to establish that the state could not take away such government-granted goods as an occupational license without 'notice and a hearing. ${ }^{76}$ Where the 'freedom to earn a living' was implicated, courts recognized that procedural due process's protections of property applied. But welfare too involved livelihood; like traditional livelihoods, it had the potential to provide 'a secure minimum basis for individual well-being and dignity, ${ }^{, 77}$ but only if the legal order recognized it too as a form of property.

For all its resonance, Reich's argument left many questions dangling, and so did Goldberg. First was the question of distributive justice. Conceding that welfare benefits, if recognized as secure legal entitlements, could perform the 'social functions' Reich and the Court claimed for them, why were the poor entitled to them? On what distributive premise did they rest? On the face of it, welfare was not a moral equivalent to a professional license or a pension right in a union contract or even to government-based, but partly contributory, social insurance. Effort and exchange were the ordinary normative bases in liberal legal culture for such 'property' claims. What was the normative argument that made welfare a cognate right, when on the face of it, welfare differed from the others by distributing goods with neither effort nor exchange to underpin the result?

Second was the question of whether the legal/constitutional order's recognition of welfare as a right had only formal and procedural bite. If the social function of welfare as property was to provide 'a secure minimum basis for individual well-being and dignity,' then did the entitlement not entail a measure of substantive constitutional protection-say, against lawmakers' decision to repeal the entitlement or to diminish it below the minimum? ${ }^{78}$ Or was that kind of recognition of the property-like aspect of welfare strictly a matter of public policy for legislatures to determine?

71 See idem at 758-59.

72 Agency discretion wielded 'life and death' power over the livelihoods of one and all. See idem at 758.

73 See WJ Novak The People's Welfare: Law and Regulation in Nineteenth-Century America (1996).

74 See Reich 'New Property' (note 68 above) at 738.

75 See idem.

76 Idem at 741.

77 Idem at 786.

78 Idem. 
For Reich the right to welfare seemed to rest on the involuntary nature of individual poverty. 'Today,' he wrote in the full text of the passage from which the Goldberg Court quoted:

we see poverty as the consequence of large impersonal forces in a complex industrial society ... [Past eras saw poverty as flowing from individual 'idleness' and other moral failings.] It is closer to the truth to say that the poor are affirmative contributors to today's society, for we are so organized as virtually to compel this sacrifice by a segment of the population. Since the enactment of the Social Security Act, we have recognized that they have a right - not a mere privilege - to a minimal share in the commonwealth. ${ }^{79}$

As an assertion about the commitments inscribed in the nation's statutes, this is bunk. ${ }^{80}$ As moral reasoning, it also is somewhat odd. We may view compelled sacrifices as affirmative contributions to the commonwealth, but these tend to involve some measure of individual exertion say, the sacrifices endured as a conscript in a national army. What Reich describes here is more like a casualty loss from the accident of poverty or rather the accidental loss of a livelihood because American society is 'so organized as virtually to compel' one's exclusion from the labor market. This would point toward welfare as a kind of just compensation.

Of course, the compensation clause is not where the Court looked for constitutional footing. 'From its founding the Nation's basic commitment has been to foster the dignity and well-being of all persons within its borders. We have come to recognize that forces not within the control of the poor contribute to their poverty, ${ }^{81}$ the Court observed, citing and paraphrasing Reich.

Welfare, by meeting the basic demands of subsistence, can help bring within the reach of the poor the same opportunities that are available to others to participate meaningfully in the life of the community ... . Public assistance, then, is not mere charity, but a means to 'promote the general Welfare, and secure the Blessings of Liberty to ourselves and our Posterity." 82

So, the Court did not follow Reich in his blunt assertion that welfare was the poor person's just desert as a conscript in the reserve army of the unemployed. It did suggest that because supra-individual, social forces 'contribute' to a person's poverty, welfare should be dignifying and not degrading. Indeed, it implied that assuring that the material bases of 'well-being' were available in a dignifying manner stood as a fundamental or 'founding' national 'commitment.' Reich's bleak quid pro quo rubbed abrasively against the ideal of equal opportunity. That ideal signified bringing the nation's poor into a shared world of work and opportunity, not compensating them for permanent exclusion from it. So, the Court cast welfare not as compensation for the jobless poor's involuntary 'contribution' to the economy, but as a means of bringing within their reach 'opportunities ... to participate ... in the life of the community.' Presumably, this meant that without means of subsistence, the poor could not begin to attain education and decent work or to participate in civic life. Participating in these spheres not welfare as such is the social basis of equal citizenship, which is why welfare was more the fruit of the New Deal's

79 Reich 'Individual Rights and Social Welfare' (note 68 above) at 1255.

80 In point of fact, the Social Security Act recognized no such right; it provided time-limited unemployment insurance and old-age pensions to those who contributed, mothers' pensions (ADC), and public assistance for the blind and the elderly poor-those who could not presently or could no longer be expected to work, and nothing at all for the 'idle poor.' See Forbath 'Constitutional Welfare Rights' (note 7 above) at 68-81.

81 Goldberg 397 US at 264-65.

82 Idem at 265 (quoting US Constitution preamble). 
failure to enact social citizenship than its fulfillment. But here, in a case involving the children and grandchildren of the very Americans the New Deal had excluded, the Court was casting welfare provision, in the words of the Preamble, as a step toward including all Americans in a common framework of 'Liberty' and 'the general welfare.'

With these striking references to the Constitution, the Court seemed to be signaling a willingness to consider whether some constitutional provision might grant a right to welfare for those confronting what the Court called 'brutal need.' 83 As we've seen, this was the push of the Court's remarkable statutory construction cases that welfare was an individual entitlement and need the only legitimate touchstone of exclusion from it. The Court's reference to 'the Blessings of Liberty' suggested, in strong echoes of Roosevelt's 'second Bill of Rights,' that a measure of economic security was indispensable to freedom and citizenship. ${ }^{84}$ Even more clearly, the Court spurned the notion that welfare was simply a humanitarian measure; rather, it was a means of bringing 'within the reach of the poor ... opportunities ... to participate meaningfully in the life of the community. ${ }^{\prime} 5$ Welfare, then, was being cast as a necessary, though not a sufficient, basis of equal citizenship, a step toward including all Americans in a common framework of 'Liberty,' a matter of obvious constitutional significance.

Thus, the Court seemed to be verging on judicial recognition of something very much like rights to minimum welfare, education, and other forms of social provision, when the Republican victory in the 1968 presidential election deprived the Court's liberals of the votes they needed to carry the process forward. In 1969, President Nixon appointed Warren Burger; in 1970, Harry Blackmun, whose first years on the Court saw him aligned with the new Chief; in 1972, Nixon appointed Lewis Powell and William Rehnquist. Who can doubt that four Humphrey appointments, instead of four Nixon appointments, would have made the Dandridge $v$ Williams ${ }^{86}$ and San Antonio Independent School District $v$ Rodrigue ${ }^{87}$ dissents into majority opinions?

In Dandridge, the lower court had built on Goldberg and the other welfare rights precedents to strike down Maryland's dollar maximum (of $\$ 250$ per month) on welfare grants to poor families. Plaintiffs claimed that the maximum discriminated against poor children in large families, and the court agreed, applying heightened scrutiny to the measure because it affected the constitutionally important interest in welfare, and concluding that the law 'cut[] too broad a swath on an indiscriminate basis. 88 Under the new Chief Justice's leadership, the Supreme Court reversed, announcing that no longer would the Court attend to the details of welfare programs, even if they appeared discriminatory or made harsh distinctions among people equally in need. Acknowledging that 'administration of public welfare assistance ... involves the most basic economic needs of impoverished human beings,' 89 the Court declared that 'the dramatically real factual difference between [welfare regulation and regulation of business or industry provided] no basis for applying a different constitutional standard. 90

83 Idem at 261 (quoting Kelly $v$ Wyman 294 F Supp 893900 (SDFNY 1968) (quoting Student Author 'Withdrawal of Public Welfare: The Right to a Prior Hearing'(1967) 76 Yale LJ 1234 at 1234, 1244)) (internal quotations omitted).

84 Goldberg $v$ Kelly 397 US at 265

85 Idem.

86397 US 471 (1970).

87411 US 1 (1973).

88 Dandridge $v$ Williams 397 US at 484 (quoting Williams $v$ Dandridge 297 F Supp 450469 (D Md 1968)) (internal quotations omitted).

89 Idem at 485.

90 Idem. 
In dissent, Justice Marshall assailed 'the Court's emasculation of the Equal Protection Clause as a constitutional principle applicable to the area of social welfare administration.91 Marshall approvingly invoked the arguments of Michelman and others on behalf of a substantive right to welfare, as well as Article 25 of the Universal Declaration of Human Rights, ${ }^{92}$ which confers just such a right. Thus, he signaled the dissenters' inclination to read the Constitution as conferring something like a right to livelihood. On a Humphrey, rather than a Nixon, Court, the trajectory of constitutional doctrine after Dandridge most likely would have been in the direction of ever more exigent signals that Congress and the States must make up shortfalls between statutory offerings and the real world of 'brutal need' and include the statutorily excluded.

\section{(C) Michelman on the Hard Questions: 'Minimum Protection,' 'Just Wants,' AND 'BASIC NEEDS'}

Dandridge, however, lay in the future as Frank Michelman set to work on the unfinished normative underpinnings of constitutional welfare rights. The federal courts had labored mightily in statutory AFDC cases to make need the sole criterion for eligibility. Justice Brennan, in Shapiro, remember, even had intimated that need of families for the very means of subsistence might become a member of the new constitutional family of fundamental interests, and thereby subject classifications in and exclusions from welfare statutes to strict scrutiny. ${ }^{93}$ But need had never stood on the same plane as effort or exchange in the distributive norms of common law or constitutional doctrine. Need needed an argument that sounded in distributive justice. Charles Reich's articles did not provide one. ${ }^{94}$ Reich urged courts to attack official arbitrariness and discretion, and the insecurity and indignities they bred. He offered a sociological rationale for treating statutory welfare benefits as rights, but no moral or constitutional argument why courts were obliged to provide for the needy whom lawmakers had left out, or to remedy the shortfalls between statutory offerings and actual need. From the point of view of a legal scholar who sympathized with the welfare rights movement, the need-based right still needed arguments that extended beyond procedural to distributive justice and addressed the right's substantive reach and bounds.

Frank Michelman set out in search of such arguments. He reported on his progress in two pioneering articles, the 1969 Harvard Foreword, 'On Protecting the Poor through the Fourteenth Amendment,'95 and his 1973 'In Pursuit of Constitutional Welfare Rights: One View of Rawls' Theory of Justice.'96 'Protecting the Poor' was an effort to nudge doctrine and doctrinal scholarship toward a theory of judicially enforceable constitutional welfare rights. 'In Pursuit of Constitutional Welfare Rights' was a reading of John Rawls's epoch-making book, ${ }^{97}$ examining how Rawls's theory bore on the idea of justiciable welfare rights, and how such an examination, in turn, might illuminate Rawls's theory.

91 Idem at 508 (Marshall \& Brennan dissenting).

92 Idem at $521 \mathrm{fn} 14$.

93 See 394 US at 638.

94 The text oversimplifies. Reich, as we saw, did gesture toward a justificatory argument based on compensation: welfare was just compensation for society's more or less conscious choice of a political economy that offered too few decently paid jobs to go around.

95 Michelman (note 13 above).

96 FI Michelman 'In Pursuit of "Constitutional Welfare Rights": One View of Rawls' Theory of Justice' (1973) $121 \mathrm{U} \mathrm{Pa}$ LR 962.

97 See Rawls (note 8 above). 
What, asked Michelman, is 'the role of courts ... [in] the great War'98 on poverty? He answered with a reading of a handful of recent equal protection decisions Shapiro, which had been decided in the 1968 Term, Harper $v$ Virginia State Board of Elections, ${ }^{99}$ Douglas $v$ California, ${ }^{100}$ and a few of their kin. Michelman dubbed these cases the Court's 'contribution to the great War.'101 Shapiro, Harper, and Douglas all could be read as resting, partly, on a notion of wealth discrimination. ${ }^{102}$ Many lower courts 103 and liberal commentators wishfully read them as signs that the Court might bring the nation's poor into the 'inner circle' of judicially protected classes. 104

For his part, Michelman read the decisions differently. The Court, he agreed, was embarking on 'the elaboration of constitutional rights pertaining to the status of being poor,'105 and it had clothed the decisions presaging these rights in the 'verbiage of inequality and discrimination.'106 But the 'inchoate theories of social justice ... at the roots' 107 of these cases was ill expressed in the language of 'equality or evenhandedness.'108 Applying strict scrutiny to laws that fall unequally on the nation's poor would sweep too broadly; such government action is everywhere. Nor does equality offer a plausible benchmark for answering the question how much protection is 'enough.' '"As much as" seems to provide just the certainty of measure which "enough of" so sorely lacks.'109 But

98 See Michelman (note 13 above) at 8-9.

99383 US 663 (1966) (holding that state may not condition franchise on payment of tax or fee).

100372 US 353 (1963) (holding that state must provide counsel to criminal accused on first appeal as of right, irrespective of court's assessment of probable merits).

101 See Michelman (note 13 above) at 9.

102 Harper held that statutes discriminating on the basis of wealth were, like those discriminating based on race, 'traditionally disfavored' 383 US at 668. Douglas spoke of 'that equality demanded by the Fourteenth Amendment where the rich man ... enjoys the benefit of counsel's [assistance] ... while the indigent ... is forced to shift for himself': 372 US at 358 . The Court noted that 'the evil [in such a situation] is ... discrimination against the indigent,' idem at 355 , and that 'an unconstitutional line has been drawn between rich and poor.' Id at 357. In his Shapiro dissent, Justice Harlan lamented the majority's 'cryptic suggestion' that welfare constituted a fundamental interest giving rise to the strict scrutiny/compelling state interest test the Court's emergent equal protection doctrine had begun to extend from suspect racial classifications to other invidious discriminations and fundamental constitutional interests nowhere evident in the constitutional text: 394 US at 661 (Harlan J dissenting).

103 Thus, the same year as Michelman's 'Protecting the Poor,' a three-judge district court in New York enjoined a recent change in the state's welfare regulations, which reduced public assistance payments in counties surrounding New York City to levels below those paid to city residents, when they had previously been grouped together. Rothstein $v$ Wyman 303 F Supp 339 (SD FNY 1969). Applying strict scrutiny to the new classification scheme, the district court wrote, 'Receipt of welfare benefits may not at the present time constitute the exercise of a constitutional right'; nonetheless, the court deemed controlling the teaching of Harper and Shapiro, that classifications creating 'inequalities affecting the exercise of fundamental or critical personal rights' must be scrutinized under 'a more stringent standard': idem at 346. As in Harper and Shapiro, so here the court found a conjunction of a 'fundamental right' and a 'disadvantaged minority'only here the right was welfare and the minority the poor. While welfare was only an incipient constitutional right, an emergent fundamental interest, Shapiro still seemed to the Rothstein court to mark the Supreme Court's acknowledgment that '[a]ccess to [the] bare necessities of life' was as 'fundamental' as voting. See idem at 346-48. And Douglas marked a dawning recognition of the poor as a protected minority.

104 See JE Coons et al 'Educational Opportunity: A Workable Constitutional Test for State Financial Structures' (1969) 57 Cal LR 305 at 365; See generally AJ Goldberg 'Equality and Governmental Action' (1964) 39 FNY U LR 205; LG Sager 'Tight Little Islands: Exclusionary Zoning, Equal Protection, and the Indigent' (1969) 21 Stan LR 767.

105 See Michelman (note 13 above) at 16.

106 Idem.

107 Idem at 10.

108 Idem.

109 Idem at 18. 
would a court be comfortable explaining 'why $\mathrm{X}$ is entitled to, say, [as much legal assistance on his appeal as] $\mathrm{Y}$ in fact has rather than what justice requires?'110 If equal protection, as applied to the plight of poverty, swept too broadly, it also stopped short of the mark, because equal protection implies 'a "state action" qualification upon government's duties to relieve against hazards of poverty."111 Yet, it was "less easy to be reconciled to the "state action" notion when alleviation of certain, specially poignant hardships or crushing disadvantages is thought to be the object... . [Then,] the government's noninvolvement ... may come not as relief but as reproach. ${ }^{112}$

Thus, while inequality and discrimination were the doctrinal notions near at hand, they were misleading. The upsetting feature in the equal protection cases involving poverty was not some odious discrimination that might accompany a poor person's deprivation of a good he couldn't afford; what was disturbing was the deprivation itself. So, Michelman sought to use the cases as data points from which to infer the outlines of a constitutional universe of 'just wants' or 'basic needs.' Not equal protection, he insisted, but 'minimum protection' was the heart of the matter. ${ }^{113}$ Focusing on specific deprivations of basic needs was 'a much more manageable task'114 for courts. Michelman strapped himself to the mast of moderation, and vowed to keep 'resolutely deaf to [the Court's] superfluous [equality] rhetoric.' 115 His was a more modest picture of the courts' part in ending poverty: not 'railing against tides of economic inequality which they [can't stem], but ... busy with the critically important task of charting some islands of haven from economic disaster in the ocean of (what continues to be known as) free enterprise.'116

After Dandridge and Rodriguez, it became fairly clear that most of the Justices on the Burger Court would not compel states or Congress to make up any shortfall between statutory offerings and the real world of 'brutal need,' nor etch out a constitutional universe of just wants, nor subject state laws or practices that fell heavily or arbitrarily on the poor to any exacting constitutional standard. Not unless there were some other, more familiar constitutional value entwined in the case: the fairness of the criminal process, ending the South's disenfranchisement of blacks and poor whites, vindicating the citizen's right to travel among the states of the Union free from discrimination.

Indeed, the idea that 'lawyers in criminal courts are necessities, not luxuries' 117 harked back to the 1930s and Powell $v$ Alabama; ${ }^{118}$ it spoke to the Court's special solicitude for the integrity of the judicial process and its sensitivity toward the charge that 'the rich man can require the court to listen to argument of counsel before deciding on the merits, but a poor man cannot.'119 Harper, striking down Virginia's poll tax, seems likely to have been akin to Powell in most Justices' minds, completing the dismantling of Jim Crow, rather than identifying the first 'islands of [economic] haven' 120 on a constitutional map of basic needs and just wants.

What is important for us about 'Protecting the Poor,' however, is not its failed prophecy about doctrinal developments, which, after all, may merely have been the upshot of Nixon's

110 Michelman (note 13 above) at 18.

111 Idem at 11.

112 Idem.

113 Idem at $13-14$.

114 Idem at 8.

115 Michelman (note 13 above) at 33.

116 Idem.

117 Gideon v Wainwright 372 US 335344 (1963) (holding that indigent felony defendants entitled to statefunded trial counsel under the Sixth Amendment).

118287 US 45 (1932) (holding that indigent defendant in capital case entitled to state-financed counsel under the Sixth Amendment).

119 Douglas 372 US at 357.

120 Michelman (note 13 above) at 33. 
razor-thin victory in the 1968 election. What matters here is the Foreword's optimism about the open-ended quality of those developments and its identification of courts and author with the 'great War' on poverty. As we noted, 'Protecting the Poor' was written with 'funds provided by' the command center of that 'War' and while Michelman was associated with Harvard's LSO back-up center. ${ }^{121}$ The Harvard Center litigated special education and school desegregation cases; like other LSO offices, its occupants saw themselves battling against the intertwined evils of racism and poverty, training scores of LSO attorneys and working with community organizations. ${ }^{122}$ Unlike other back-up centers, like Columbia's, it lacked a strong 'movement' tilt, and had nothing quite like Columbia's close ties with the NWRO. ${ }^{123}$

Intellectually, however, Michelman joined the NWRO and the attorneys and policy mavens surrounding it in their sharp break with inherited rights discourse. In contrast with the NWRO, 'Protecting the Poor' and 'In Pursuit of Constitutional Welfare Rights' do not defend a guaranteed income but instead a bundle of 'insurance rights' (to food, shelter, health care, education). But in common with the NWRO, Michelman breaks the link with work. His constitutional welfare rights are unconditional. Thus, with the NWRO, Michelman rejects the centuries-old distinctions between 'worthy' and 'unworthy' candidates for public provision. There are no distinctions here between the disabled and able-bodied, the ill-fated and blameworthy, the widowed and promiscuous, the earnest job-seeker and the shiftless and idle. ${ }^{124}$ Instead, Michelman means to summon forth a theory of distributive justice that is insistently unsatisfied by a political economy affording everyone a 'fair opportunity' through 'full employment,' 'income transfers,' and the like ${ }^{125}$ to provide for everyone's basic needs or just wants. 'Protecting the Poor' requires 'more'; it requires basic needs or just wants 'will be met when and as felt, [regardless of] ... effort, thrift, or foresight.' 126

Michelman does not dispute that justice requires the kind of political economy that enables everyone to make a decent living through decent work. At one point, he even notes that a participant in a Rawlsian assembly might well seek in addition, and perhaps even prior to, insurance rights assurance of some of social citizenship's mainstays in the form of full employment, income supplements, and the like. ${ }^{127}$ But apart from this passing observation, work in all its forms waged and unwaged, dignifying and demeaning, decently rewarded and socially valued and not does not figure at all in Michelman's account of the constitutional dimensions of the 'great War' on poverty. ${ }^{128}$ In this, of course, Michelman departs from the social citizenship tra-

121 Idem at $7 \mathrm{fn}$ *

122 See generally MW Edelman Lanterns: A Memoir of Mentors (1999). Edelman was a director of the Harvard Center on Law and Education.

123 See Forbath 'Constitutional Welfare Rights' (note 7 above) at 1855-59.

124 Michelman welcomes the challenge to answer the 'compelling ... objection to welfare rights, that such rights signify redistribution from the prudent and industrious to those who have culpably failed to grasp opportunities to provide for their own security': Michelman (note 96 above) at 969.

125 See Michelman (note 13 above) at $14 \mathrm{fn} 18$.

$126 \mathrm{Idem}$ at 14.

127 Idem at $15 \mathrm{fn} 21$.

128 One might think that such social citizenship principles as a right to work are absent from Michelman's constitutional theorizing, because they lie beyond anything courts could hope to contribute to the anti-poverty campaign. But it seems fair to say that for the Michelman of these two essays, 'minimum protection' constitutes the full reach of the Constitution's-and not merely the constitutional courts' 'protection of the poor.' No Constitution seen from the vantage point of civil society or of Congress would contain any different rights or equality norms. As we'll see, infra text accompanying notes 172-78, Michelman does address constitutional advocacy in political fora, and he casts the social minimum for constituting equal citizenship in the same mold. 'Insurance rights' remain the constitutional ticket, whether in Congress or in the courts. 
dition I have reconstructed and chronicled elsewhere. ${ }^{129}$ It sought to find or include these norms in the Constitution-to serve, in much the same terms that Michelman applies to welfare rights, as touchstones for 'convincing advocacy' and 'foothold[s] for challenging legislative judgments'130 that fell short of assuring decent work opportunities and decent livelihoods for all.131

This lacuna results in an argument for welfare rights that assigns those rights social work they cannot do; they cannot secure the social bases of self-respect and mutual respect in American life. Or so I will suggest. But I will do so in the context of a critical reading of Michelman's reading of Rawls, to which we must turn.

\section{A Critical Reading of Michelman on Rawls and Welfare Rights}

\section{(a) The Difference Principle and Constitutional Political Economy}

What was afoot in the courts shaped the way Michelman approached Rawls's A Theory of Justice. When Michelman turned in earnest to Rawls, he did so with a mind to asking

[h]ow ... the book [bore] upon the work of legal investigators concerned or curious about recognition, through legal processes, of claimed affirmative rights (let us call them "welfare rights") to education, shelter, subsistence, health care and the like, or to the money these things cost. 132

The answer was a vexed one. Michelman rested welfare rights on a distributive principle of 'minimum protection' or 'just wants'; Rawls offered something different. The chief basis for welfare rights or for 'the money these things cost' in A Theory of Justice was Rawls's difference principle.

The difference principle, you'll recall, states that institutionalized inequalities must be justified by dint of being in the interests of the least advantaged. ${ }^{133}$ Inequalities that do not redound to the benefit of those at the bottom are illegitimate. For Rawls, this principle is not cashed out through income standards or transfer payments alone; it must imbue the general 'organization of the economy,' and the distribution of wealth, power, and authority as well as income. ${ }^{134}$ Because his focus rests on welfare, however, Michelman reads the difference principle with an eye to income. 'Even apart from the quest for justiciability,' 135 he writes (and we will return to that quest), 'the difference principle is unsatisfactory'; 136 for Rawls seems interested simply in maximizing the income

129 See Forbath 'Caste, Class, and Equal Citizenship' (note 7 above).

130 Michelman (note 96 above) at 1003.

131 Idem at 1002-03. Compare Michelman's language about welfare rights arguments in political fora to the statements of New Dealers, which I quote in some detail, in 'Caste, Class, and Equal Citizenship' (note 7 above) suggesting that constitutional social and economic rights should serve as standards for the polity to judge 'the acts of legislatures and executives.'

132 Michelman (note 96 above) at 962.

133 See Rawls (note 8 above) at 100-01; J Rawls Political Liberalism (1996) 283. Michelman explicates and criticizes the difference principle in 'In Pursuit of 'Constitutional Welfare Rights',' (note 96 above) at 976-88.

134 See Rawls (note 8 above) at 7-11, 54.

135 Michelman (note 96 above) at 982 .

136 Idem. 
of those at the bottom, irrespective of whether that income is adequate to meeting basic needs, ${ }^{137}$ or whether it substantially exceeds that level. ${ }^{138}$ Moreover, Michelman finds it difficult to feed the 'primary good of self-respect' 139 into the machinery of the difference principle, because the good of self-respect 'does not seem to fit the difference principle's "more is better" attitude.' 140 Yet, from the point of view of liberal constitutional theory, the centrality of self-respect and equal respect in Rawls's theory are an important part of his appeal.

Michelman does find some support for a just wants/insurance rights approach to welfare elsewhere in Rawls's theory. While the difference principle is uncongenial, it is possible that Rawls's equal liberty principle or his principle of fair equality of opportunity, or even 'justice as fairness' as a whole implies a bundle of 'insurance rights' such as Michelman is championing. ${ }^{141}$ Mainly, however, Michelman focuses on explicating and assessing the difference principle as a source of welfare rights.

Unlike the 'more is better' attitude of Rawls's difference principle, Michelman's 'just wants' theory provides a touchstone for determining the metes and bounds of welfare provision that seems directly tied to equal respect. ${ }^{142}$ Beyond the point at which welfare provides a decent minimum of social goods, it seems wiser to allow considerations of economic incentives and market efficiency to hold sway. As a rational actor behind Rawls's 'veil of ignorance,' one might well prefer assurance that one's 'just wants' be satisfied, and for the rest one might prefer to wager that one's individual capacities were at least middling as the market measures things and choose against the 'more is better' attitude of the difference principle.

Certainly, Michelman makes a valuable point about the vulnerability of the difference principle from the point of view of calibrating welfare rights or a minimum income. However, we risk being misled if we look at the difference principle only from this perspective. From it, we might surmise that what separates Rawls's views about social and economic rights from Michelman's is simply a quarrel over what form of income redistribution to enshrine in the Constitution minimum income pegged to the difference principle, or minimum welfare rights pegged to just wants. In fact, neither of these alternatives captures Rawls's view of how the principles of justice, including the difference principle, bear on constitutional political econo-

137 'A precept for the distribution of material social goods,' writes Michelman 'which ignores claims regarding basic needs as such, and is sensitive only to claims regarding money income, will for many of us Seem incomplete and thus not fully in harmony with our "considered judgments"'.

138 Michelman states: 'Income-transfer activity is simply to be intensified just up to the point where any further intensification lowers total output so much that the bottom's absolute income begins to fall even as its relative share of total consumer satisfaction continues to rise. Under the difference principle, that is all there is to it. There can be no implicit insurance-rights package because there is no concern for what the bottom spends (or is able to spend) its income own: Income is income a primary, an elemental, social good, of which the bottom simply wants and is entitled to as much as it can get': idem at 981.

139 Idem at 983.

140 Michelman (note 96 above) at 983.

141 After all, fair equality of opportunity implies a right to education, and that right entails 'subsistence or health or freedom from extreme environmental deprivation,' for without them, 'how could educational offerings effectuate fair equality of opportunity?' Idem at 989. So too, the '[e]njoyment of basic liberties' like freedom of speech has 'fairly straightforward and objective biological entailments,' which spell subsistence and the other insurance rights. Finally, the 'preeminent good of self-respect may imply welfare rights reaching beyond those biological entailments,' although Michelman does not explore how: idem at 990.

142 Michelman may have been the first sympathetic critic of Rawls to suggest that the difference principle and the income guarantee it entailed were not the only nor the most compelling principle that could be derived from Rawls's original position A just wants principle might fit the bill better. For a thoughtful later reading, canvassing the critics and making these points in greater detail, see J Waldron, Liberal Rights: Collected Papers 1981-1991 (1993) at 250-70. 
my. Rawls devotes great attention in A Theory of Justice to just this subject; what he writes makes plain, I think, that he would include constitutional baselines respecting work and participation in the economic order, as well as welfare.

Despite the tension he uncovers between the primary good of self-respect and the 'more is better' attitude of the difference principle applied to income, Michelman is right in suggesting that the difference principle is concerned with the social bases of self-respect and mutual respect. Indeed, it concerns them more than it does the rational actor's calculus of consent regarding income shares. When Rawls writes about consent, he is concerned about what it takes to make each person a consenting member a charter member of society. He is concerned not only, or even primarily, with rational choice, but with contract, undertaking, and commitment ${ }^{143}$ more precisely, with consent and commitment to the social enterprise, and, conversely, with the conditions which turn consent and commitment into submission and subjection. This is the problem Rawls dubs the 'strains of commitment.'144 Under an unjust political economy, such as ours, there are millions of citizens who cannot plausibly see themselves as members of a political community organized in their name to promote their interests and capacities. Instead of supporting their capacities for commitment we have strained them to a breaking point.

What, then, are the political-economic bases of consent and commitment? More important, writes Rawls, than 'a high material standard of life' 145 in securing 'a just and good society ... is meaningful work in free association with others, these associations regulating their relations to one another within a framework of just basic institutions. ${ }^{146}$ That is why, as you will recall, the difference principle reaches beyond income to the distribution of wealth and power; it concerns shared authority no less than a fair share of goods. This is the key difference between Rawls's constitutional political economy which he dubs a 'property-owning democracy'147 and the political economy of the welfare state. 'In a welfare state,' he writes in a 1987 preface to A Theory of Justice, 'the aim [of political institutions] is that none should fall below a decent standard of life ... . By contrast, in a property-owning democracy the aim is to carry out the idea of society as a fair system of cooperation over time between citizens as free and equal persons.' 148 The 'background institutions of property-owning democracy ... try to disperse the ownership of wealth and capital, and thus to prevent a small part of society from controlling the economy and indirectly political life itself.' 149 'The idea is not simply to assist those who lose out through accident or misfortune (although this must be done), but instead to put all citizens in a position to manage their own affairs and to take part in social cooperation on a footing of mutual respect ....'150

In a word, Rawls's precepts for political economy fall squarely within the social citizenship tradition. His political economy of citizenship bears a strong family resemblance to those of the Populists, Progressives, and New Dealers who fashioned the variants of social citizenship thought in America. Like them, he holds that one cannot be a consenting, charter member, a 'citizen,' of

143 Rawls (note 8 above) at 176: '[W]hen we enter an agreement we must be able to honor it even should the worst possibilities prove to be the case... . Thus the parties must weigh with care whether they will be able to stick by their commitment in all circumstances.'

144 Idem at 145, 176, 423. For a thoughtful discussion of this theme in Rawls, see Waldron (note 142 above) at 259-63.

145 Rawls (note 8 above) at 290.

146 Idem.

147 J Rawls 'Preface for the French Edition of A Theory of Justice' in Samuel Freeman (ed) Collected Papers (1999) 415 at 419.

148 Idem.

149 Idem.

150 Idem. 
the national community without decent work, a measure of economic independence, and at least a small share of authority over the governance of one's work and shared economic life.

Whether one rests one's normative claim for welfare rights on some variant of Rawlsian liberalism, as Michelman does in the work we have been considering, or one relies on the republican tradition, as he does in the essays we take up later, a key part of the argument for welfare rights is this: These rights are necessary to secure the social bases of self-respect (the main concern in Rawls) and of independence and mutual respect or equal standing (republicanism's primary emphasis). In sum, welfare rights are necessary to a liberal republican (or, if you prefer, a republican liberal) conception of equal citizenship. Yet, plainly the social bases of equal citizenship consist of more than a decent minimum of food, shelter, and other material needs. They also demand a right to earn a livelihood through decent work; they require an opportunity to contribute in some recognized fashion to the social enterprise as well as to civic and political life. This broader view of the material dimensions of constitutional equality has a better mooring in the empirical literature that treats the social and economic underpinnings of self-respect ${ }^{151}$ and mutual respect ${ }^{152}$ among women and men in today's America and a better mooring in our constitutional history.

\section{(B) JustiCIABILITY — A CONCERn FOR JUdiCIAL COMPETENCE AND LEGITIMACY}

The family resemblance we found between Rawls and earlier proponents of social citizenship is one that critics like Sandel studiously smudge over, in order to claim that Rawls has abandoned the 'formative' project of developing good citizens. ${ }^{153}$ Michelman is as careful and generous a reader as dwells in the republic of letters; he does not smudge over these aspects of Rawls's political economy, but openly puts them aside to carry on with 'minimum protection' and constitutional welfare rights. Probably Michelman would have invoked justiciability as reason enough to have put other social citizenship norms to one side, both in reading Rawls and in his own constitutional theorizing. 'Justiciability', indeed, was Michelman's reason for seeking insurance rights, even though he conceded that it was 'easier and more natural to find in Rawls [a right to a] guaranteed money income' 154 or, more generally, a 'right[] against excessive or unnecessary inequality of wealth or income.' 155 Justiciability has two dimensions here.

151 See eg WJ Wilson When Work Disappears: The World of the New Urban Poor (1996); AH Goldsmith et al 'The Psychological Impact of Unemployment and Joblessness' (1996) 25 J Socio-Eco 333; A Sen The Penalties of Unemployment (Banca D’Italia Working Paper No 307 1997).

152 Of course, complex patterns of respect, deference, and degradation form around class and occupational hierarchies, but all the empirical literature suggests that the most salient border between minimum respect and degradation in today's class structure falls along the line between those who are recognized by organized society as working and providing a decent living for themselves and their families, and those men and women at the bottom of the nation's class hierarchy who are not. See eg JF Handler \& Y Hasenfeld We the Poor People: Work, Poverty, and Welfare (1997); KS Newman, No Shame in My Game: The Working Poor in the Inner City (1999). On the experience of women in regard to the identities of housewife and '[waged] working woman' and the dilemmas of self-respect and social recognition as a full and equal member of American society, see V Schultz 'Life's Work' (2000) $100 \mathrm{Col} \mathrm{LR} 1881$ at 1883 (arguing that for women, no less than men, the right to participate in decent work is indispensable to equal citizenship; canvassing empirical literature showing that 'a robust conception of equality [for women] can be best achieved through paid work, rather than despite it.').

153 MJ Sandel Democracy's Discontent: America in Search of a Public Philosophy 6 (1996); see MJ Sandel Liberalism and the Limits of Justice (1982); Rawls (note 8 above) at 259 (noting that not only their capacity for self-respect but more broadly 'the sort of persons [citizens] want to be as well as the sort of persons they are' are shaped by the political economy they live under).

154 Michelman (note 96 above) at 966.

155 Idem. 
The first concerns institutional capacity, or 'judicial competence' in legal process-ese. The second concerns the degree to which a given norm is formally law-like, determinate, and objective in its application. This dimension of justiciability obtains whether the setting is the courtroom, the legislature, or the constitutional convention, when 'constitutional amendment is the chosen avenue of reform.' ${ }^{156}$ In any of these fora, one must be concerned that the norms one is crafting or deriving from more general constitutional texts are such norms about which one can say with some measure of certainty that this constitutional requirement has or has not been or is or is not in the process of being met.

Begin with judicial competence. Here, surely the starting point must be 'compared to what?' Is a right to decent work any more beyond judicial capacities or more insulting to separation of powers constraints than the rights to welfare, health care, and decent housing with which Michelman conjures? With the former as with the latter, a number of competency and separation of powers concerns arise, and a variety of judicial strategies are open.

The concerns and the strategies are familiar, and Michelman briefly surveys several. 157 '[P]erplexing questions of economic feasibility'158 may arise; a decree fulfilling a 'claimed housing [or employment] right [might] leav[e] the bottom worse off, on the whole, than it now is. ${ }^{159}$ But, says Michelman, such questions 'do not seem different in essence from other issues that courts have deemed judicially triable. ${ }^{.160}$ And in respect of housing and school finance, as well as other social citizenly matters, judicial experience has grown since 1973, particularly if one takes account of developments abroad and in America's state courts. ${ }^{161}$ Courts have found credible ways to assess claims of glaring failure on the part of national and subnational governments to address and meet guarantees of social rights. But it must be admitted that this body of constitutional (as distinct from statutory-interpretive) judicial experience has not addressed work and employment; and certainly, it is plausible that the many-sided determinants of the availability of decent work might counsel against a judicial role in interpreting and enforcing this as opposed to other social rights. I want to leave this possibility hanging, to be revisited when more of Michelman's and my own thoughts about judicial and non-judicial interpretation and enforcement of social rights are on the table.

'More plausible' than the argument for adjudicative incompetence, notes Michelman, 'is the notion of remedial incompetence.' 162 Courts have no way of enforcing social rights without the raising and appropriating of public funds and the creation of new administrative structures. Such actions are not only under the control of the other branches, but also 'involve[] a complex of subsidiary but vitally important choices which the judiciary lacks all basis for making.' ${ }^{, 63}$

156 Idem at 967.

157 See idem at $1004-10$.

158 Idem at 1006.

159 Michelman (note 96 above) at 1006.

160 Idem.

161 Fior a chastened but positive assessment of judicial contributions in the education financing arena, see $\mathrm{M}$ Minow 'Just Education: An Essay for Frank Michelman' (2004) 39 Tulsa LR 547. On the South African Constitutional Court's interventions in the domain of housing, see Michelman 'Constitution and Social Rights' (note 9 above) at 17-18, 26-27. Most strikingly, perhaps, has been the work of German constitutional courts, at both the national and subnational levels, in respect of constitutional rights to housing and to a decent livelihood. See PE Quint 'The Constitutional Guarantees of Social Welfare in the Process of German Unification' (1999) 47 Am J Comp L 303. For a general discussion of constitutional adjudicatory experience with social rights, see C Fabre Social Rights under the Constitution: Government and the Decent Life (2000) 152-81.

162 Michelman (note 96 above) at 1006 .

163 Idem. 
One response to this problem is 'a judicial mandate to legislative, executive, or administrative officers to prepare, submit, and carry out a corrective plan.'164

Separation of powers presents a different order of concern. Here, Rawlsian principles, on Michelman's account, may collide. Judicial vindication of substantive welfare rights may come at too high a cost 'in participatory inequality [as between the judiciary's and the citizenry's respective roles in identifying the social rights to which a society's shared principles of justice commit it] which damages [the citizen's] self-respect.'165 The trade-off between 'justice in participatory rights and justice in substantive rights, ${ }^{166}$ may demand judicial forbearance. Or at least, it may demand that courts 'not cut welfare rights out of the whole cloth of speculative moral theory.' 167 Likewise, I'd add, for the same reason, courts ought to forebear from cutting social citizenship rights out of the whole cloth of interpretative recollection of extra-judicial constitutional tradition.

But such judgments do not exhaust the question of whether judges should ever allow such a theory to inform their application of 'due process and equal protection guaranties in their formal and non-substantive aspects'168 to statutory materials. Here Michelman takes inspiration from the lower federal courts' pre-Dandridge readiness to find in equal protection a command to invalidate even seemingly plausible classifications among potential eligibles 169 and generally to put the statutory programs' limitations and qualifications under strain, in the name of making need alone the valid criterion. Too, he finds in cases like King $v$ Smith studies of how courts can find in AFDC and kindred legislation statutory rights that amounted to 'justice-inspired [legislative] supplementation of the constitutional catalogue.' 170 Certainly, this is a credible way to interpret the Court's reading of Congress's intent against the grain of legislative history and of Congress's knowing acquiescence in state practices the Court went on to condemn. Unprepared to declare the existence of such a constitutional right (and so openly and irrevocably to constrain Congress), the Court nonetheless was prepared to expand and deepen the limited and qualified commitments Congress had made.

Not only is this a plausible reconstruction of the interaction between Court and Congress, but it is suggestive of how a judiciary mindful of the constitutional dimensions of work and participation could read statutory material in the area of labor and employment. ${ }^{171}$ In the case of statutory work and employment rights, however, a court would not need to rely on 'enlightened,' emergent, contemporary notions of democracy and justice. Nudging state or federal agencies to construe their congressional mandates in ways that leaned toward inclusion or actual availability of work opportunities, courts could proceed in a somewhat more conservative interpretative style, relying on old, not emerging or 'enlightened' elite understandings of equal rights and constitutional equality.

164 Idem.

165 Idem at 1010.

166 Idem.

167 Michelman (note 96 above) at 1010.

168 Idem.

169 See idem at 1011-12.

170 Idem at 1011.

171 For a like-minded account of possible readings of the Wagner Act see M Barenberg 'Democracy and Domination in the Law of Workplace Cooperation: From Bureaucratic to Flexible Production' (1994) 94 Col LR 753. 


\section{(C) Justiciability AND PRoblems of INDETERMinacy AND of Constraints on Democracy in Public Political Fora}

'In Search of Constitutional Welfare Rights' holds that welfare rights are the best vocabulary for expressing a constitutional commitment to a social minimum, partly by dint of their supposedly greater crispness and formal, determinate applicability. Donning the hat of counselor to hypothetical constitution-framers, Michelman says this: If you want to lay a basis for 'convincing [constitutional] advocacy in political forums, ${ }^{172}$ then state your commitment to a social minimum in the form of 'insurance rights.' ${ }^{\text {'73 }}$ To rely on a more Rawlsian vocabulary 'would [fail to] give ... advocates any special foothold for challenging legislative judgments.' 174 Of course, here Michelman is comparing insurance rights to Rawls's difference principle. The comparison that interests us, however, is a different one.

Is the legal-rhetorical foothold supplied by a right to decent housing any more secure from contending interpretations than that provided by a right to decent work? We need not belabor the point. Michelman concedes it in a recent engagement with the arguments I am raising here.

'If we ... compare a social-citizenship conception with a welfare-right conception of a positive constitutional guarantee in the economic sphere, we can see that neither sort of conception trumps the other on the scale of justiciability.' ${ }^{175}$ Indeed, the examples Michelman chooses are those we've been employing. He points to the welfare right found in the present South African Constitution, 'to have access to adequate housing,' a welfare right whose 'progressive realization' the state must take 'reasonable' steps 'to achieve.' 176 And he asks whether such a right registers any higher on the scale of justiciability 'than would a declared duty of the state to do the best it can to maintain an economy and society in which everyone who wants it has access to respectable, fulfilling, adequately remunerated work.' ${ }^{177}$ The answer, he concedes, is no. ${ }^{178}$

If the welfare-right conception has an edge in respect of 'concerns about constitutional-legal form,' 179 it is on the scale of what Michelman now calls 'narrowness.' 180 This is a concern distinct from justiciability. It does not concern courts' remedial competence or democratic deficits, nor whether a given norm is too general and wide-open-to-competing-interpretations. Rather, it concerns how widely or narrowly a norm 'preempt[s] major public policy choices from the ordinary politics of democratic debate and decision.'181 More than a welfare right, 'a constitutional social-citizenship right ... reach[es] in a hundred directions ... into the deepest redoubts of the common law and the most basic choices of political economy a modern society can make.' 182

Certainly, if my historical scholarship is right about the way these rights have figured in public political discourse and debate about everything from currency to education to industrial

172 Michelman (note 96 above) at 1002 .

173 Idem.

174 Idem at 1003.

175 See Michelman 'Democracy-Based Resistance' (note 9 above) at 1896.

176 Idem.

177 Idem.

178 See idem.

179 Idem at 1895.

180 See Michelman 'Democracy-Based Resistance' (note 9 above) at 1895-96.

181 Idem at 1895.

182 Idem at 1897. 
organization, then Michelman is right. And note: Michelman's point pertains independently of the scope of judicial enforceability, as long as we presume our public officials to be conscientious.

Here, Michelman's thinking merges with the social citizenship tradition's conception of how its norms would bear on democratic lawmaking-not via judicial review, but instead by directly constraining participants and the standards they apply and the arguments they offer in debates and decisions about public policy-making. Over against the charge of non'narrowness' or democracy-stymieing, Michelman offers a defense on behalf of social citizenship norms. It is precisely the "blatant "non-justiciability" of a social-citizenship right its utter lack of mechanical applicability to any hard or contested question of public policy ... [that] saves it from charges of contrariety to democracy.' 183 Instead of thwarting democracy, social citizenship norms would mark a 'gain for democracy ... [by] impos[ing] a certain constraint on how citizens and their elected representatives would frame and approach sundry questions of public policy.' 184 That is, the norms would demand of all concerned an 'exercise[] of ... judgment ... [about] which choice will best conduce to the social citizenship of everyone.' 185

By invoking Michelman present to respond to Michelman past, we have strayed from Michelman on Rawls and welfare rights in 1973. The burden of this foray into the present has been to suggest that Michelman's insistence on the justiciability of social and economic rights in nonjudicial fora was a product of the politics and doctrine of the day. Today, doctrine and politics afford neither the same possibilities nor their concomitant constraints, and we do better to pursue the path of social citizenship down which Rawls and our home-grown ideals of social citizenship direct us. Or as Michelman observes in reference to a fuller version of the criticisms leveled here, if we count ourselves among those who 'maintain that constitutional law outside the courts can figure importantly in the conduct of public affairs [and] that contention outside the courts over constitutional-legal meanings and obligations very possibly can be ... a site for democracy in action,'186 then should we not put justiciability issues aside, and ask: 'Is there any reason why we who take this view should hesitate to embrace a social-citizenship conception of constitutional social rights, in preference to a welfare-right conception, assuming we find the former to be morally the more appealing conception?'187

There is more to say about the interaction of social-citizenship norms and democratic politics and lawmaking, and more of Michelman's insights and qualms to consider. We may yet conclude that a sparer set of social rights, a set of social minima, ought to enjoy constitutional pride of place, over against the broader, more historically rooted, and, perhaps, 'morally ... more appealing' social-citizenship conception that I have put forward. We may yet conclude that judicial safeguards should obtain for essential welfare rights but not for the social citizenship principle. And we may find ourselves, with Michelman, in the grip of genuine dilemmas. But further consideration should await a reading of Michelman's republican case for welfare rights. This brings us to his turn to history, and his thoughtful reading of Progressive constitutionalism.

183 Idem at 1898.

184 Idem.

185 Michelman 'Democracy-Based Resistance' (note 9 above) at 1898 (emphasis omitted).

186 Michelman 'Constitution and Social Rights' (note 9 above) at 28.

187 Idem at 28-29. 


\section{$V$ Michelman's Republican Case for Welfare Rights}

\section{(A) The Distributive Dimension of Constitutional Property Rights AND THE PROBlem OF LEgal Form}

By the late 1970s, the Court had begun to cut the solicitous strands of doctrine well short of substantive welfare rights, declaring ever more categorically that its Constitution confers 'no affirmative right to governmental aid, even where such aid may be necessary to secure life, liberty, or property .... .'188 Liberal constitutional scholarship grew more theoretical as the Court grew more conservative. Theorists acknowledged the limits of judicial competence and legitimacy in the area of affirmative rights. They began to reflect on the 'gap between the reach of constitutional case law and the reach of the Constitution.' 189 They built up more general, less court-centered accounts of constitutional democracy as a system of self-government.

For his part, Michelman made civic republicanism and contemporary pragmatism and critical theory his own, and brought them into an internal dialogue with liberal constitutional theory. Out of this emerged a profound series of reflections on the dilemmas of constitutional selfgovernment, the tensions between popular sovereignty and the rule of law, the nature of adjudication, and, most germane here, the 'possessive' and 'distributive' conceptions of constitutional property rights. ${ }^{190}$ Written in 1986, Michelman's exploration of the tensions between these two kinds of property norms sets out to reconstruct the republican logic and history of the distributive side of constitutional property claims, to suggest why this side has been the recessive one in constitutional law, and to join issue with those, like Michael Walzer, who object for staunchly democratic reasons to the constitutionalization of 'welfare claims as rights.' 191

Michelman seized hold of the founders' venerable republican conviction that 'security of property holdings was [not just a matter of] private self-interest'; 192 it was 'of general political concern.'193 Material independence was 'viewed as indispensable if one's independence and competence as a participant in public affairs was to be guaranteed.' 194 This maxim had obvious bearing on the antiredistributive, property-protecting provisions in the founders' Constitution; but it also implied a distributive imperative. This imperative, too, found support in much that the founders wrote and did. But it found no obvious expression in the provisions and architecture of their Constitution. The distributive norm was deferred, Michelman suggests. Given the prospect of westward expansion, the founding generation could envision 'a freehold beneath every household ... supporting the freeholder's independence.' 195 As long as this state of affairs continued, the Constitution's possessive regard for property was sufficient to answer the founders' distributive concerns.

188 DeShaney $v$ Winnebago City Dept of Social Services 489 US at 196.

189 See LG Sager 'Justice in Plain Clothes: Reflections on the Thinness of Constitutional Law' (1993) 88 Nw $U L R 410$ at 419.

190 See eg FI Michelman 'Conceptions of Democracy in American Constitutional Argument: Voting Rights' (1989) 41 Fla LR 443; FI Michelman 'Law's Republic' (1988) 97 Yale LJ 1493; FI Michelman "Possession vs. Distribution' in the Constitutional Idea of Property' (1987) 72 Iowa LR 1319 [hereinafter Michelman 'Possession vs. Distribution']; FI Michelman 'Foreword: Traces of Self-Government' (1986) 100 Harv LR 4; Radin \& Michelman (note 12 above).

191 Michelman 'Possession vs. Distribution' (note 190 above) at 1320-21. The essay by Michael Walzer which Michelman addresses is M Walzer 'Philosophy and Democracy' (1981) 9 Pol Theory 379.

192 Michelman 'Possession vs. Distribution' (note 190 above) at 1329.

193 Idem (emphasis omitted).

194 Idem at 1329.

195 Idem at 1332. 
By the end of the nineteenth century, however, a 'Progressive critique' of this constitutional arrangement had emerged. With the rise of industrial capitalism, a regime of anti-redistributive property rights - so the critique ran - might itself 'constitute undemocratic relationships of power and subjection.' 196 On this account, persons-wage earners, tenant farmers, and others 'subjected to the proprietary power of others lacked ... the material foundations of independent political competence.' 197 In short, with the rise of large-scale corporate enterprise and its impact on the legal-political-intellectual culture of the late nineteenth century, the distributive and anti-redistributive sides of our tradition's constitutional understanding of property claims were set on a collision course. Once it was firmly recognized that 'uncontrolled so-called private power'198 exposes individuals to subjection, it behooved government to act. 'Logically, however, the state cannot offer protection ... by the same formal law that would protect absolutely against redistributive political "interventions." 199 Accordingly, while the Progressive critique largely succeeded in undoing the regime of anti-redistributive property norms, it did not succeed, on Michelman's account, in supplanting those norms with distributive ones. Indeed, Michelman implies that the Progressive reformers never sought to embed such distributive norms into constitutional discourse. They hardly could have hoped to do so, it appears in his view, since distributive norms, whatever their claim to constitutional status, seem to place an unbearable burden on our commitment to formally realizable, objective, 'law'-like standards as the sole, legitimate lingua franca in the province and discourse of the Constitution. 200

As you might guess, I am on all fours with Michelman and he with me all the way to the last point. There, as an historical and interpretative matter, we seem to part ways in modest degree; for I read the Progressives, and their forebears and descendants, stretching from the 1880s to the 1940s generations of reformers which, following Michelman, for present purposes, I'll simply call Progressives somewhat differently. As I've encountered them in years of reading, these generations of Progressives found no insoluble tension inherent in the effort to 'cast substantively appealing and defensible distributive norms'201 as constitutional standards. They did not neglect 'the classical negative understanding of fundamental rights'202 (in the thick of Lochnerism, how could they?), nor the appeal that understanding made to a deep-seated image of constitutional norms as 'strongly objective' abstract, simple, formal and, thereby, law-like. But they treated the grip of these ideas on 'the American constitutional imagination'203 as contingent and contestable via tools Michelman knows well: pragmatism, context, a 'changing Constitution.' Thus, as I've shown elsewhere in needlepoint detail, their view was this: the need to make the constitutional tradition's distributive imperatives into direct claims against the state did not compel divorcing constitutional from political economic discourse; it did demand dethroning the courts and installing Congress and the 'active branches' as the nation's new 'constitutional political economists.'204

In tandem with this reallocation of interpretive authority, I've shown how Progressives set

196 Idem at 1335.

197 Michelman 'Possession vs. Distribution' (note 190 above) at 1335.

198 Idem.

199 Idem at 1336.

200 Idem at 1337.

$201 \mathrm{Idem}$ at 1321.

202 Michelman 'Possession vs. Distribution' (note 190 above) at 1321 (quoting DP Currie 'Positive and Negative Constitutional Rights' (1986) 53 U Chi LR 864 at 889) (internal quotations omitted).

204 See Forbath 'Caste, Class, and Equal Citizenship' (note 7 above) at 51-57. 
about the hermeneutic task of translating "the "old and sacred possessive [common-law based and anti-redistributive] rights" of property and labor'205 into new 'social and economic rights,' to enable "“a return to values lost in the course of ... economic development" and "a recovery" of the "old rights" once robust social meaning.' 206 The 'active branches' and the citizenry itself, so Progressives and, later, New Dealers contended, were better suited to the task of interpreting and applying the new 'social meaning' of constitutional property norms in part for the kinds of justiciability reasons Michelman highlights, but also because they sought to advance a more dialogic and democratic mode of constitutional interpretation and decisionmaking.

Interestingly, if I am right about this history, I do no more than provide an ancestry for the revisionist aspect of Michelman's argument about the forms of constitutional law and democratic politics. ${ }^{207}$ Michelman's urging is this: If we can but relax the hold of our inherited ideal of legality in favor of a revised and more pragmatic one, then we might open the space for a fuller consideration of 'distributive property claims ... [in] the province[] and discourse[] of constitutional law.'208

\section{(B) Republicanism vs Welfare Rights}

Perhaps because his attention rests so largely upon the seeming tension between distributive norms and 'legal' ones, and perhaps because his proof text is Walzer's critique of the idea of constitutional legalization of welfare rights, the latter remains Michelman's only specification of what a modern distributive constitutional property claim deserving of our more ample consideration might be. As a result, another, perhaps equally deep, tension goes unexplored. That is the tension between the modern welfare rights claim and the republican underpinning Michelman claims for it.

Republican maxims hold that a measure of material independence is a necessary basis for political competence and standing. That is Michelman's normative baseline. But in the republican outlook he invokes, such citizenly standing and competence have always been bound up with the status of one who fulfills some recognized, responsible role in the social enterprise - one who 'earns' her measure of material security and 'independence.' 209 We certainly may find, as far back as the seventeenth and eighteenth centuries, support in both 'liberal' and 'republican' texts for the view

205 Idem at 69 (quoting FD Roosevelt 'Message to Congress Reviewing the Broad Objectives and Accomplishments of the Administration (June 8 1934)' in The Public Papers and Addresses of Franklin D Roosevelt (1938) 291-92).

206 Idem (quoting same) (internal quotations omitted). Nor were these reform thinkers unmindful of the problem Michelman identifies of mediating between distributive and possessive property claims. See Michelman 'Possession vs. Distribution' (note 190 above) at 1321. Progressive reformers like Brandeis and Commons devoted vast attention to reconciling the various possessive property claims of employers with such social rights as minimum livelihoods and unemployment insurance and with the claims of employees, as of right, to a voice in the governance of the enterprise. It is true, though, that their efforts at reconciliation, while principled, did not take the form of 'strongly objective standards' but were rather more contextual and pragmatic. See eg JR Commons Legal Foundations of Capitalism (1924).

207 Ancestors who were, at least until World War I, largely blind to what we now know-and what post-war Progressives began to surmise-about the democratic resources in rights, 'higher law,' and judicial authority.

208 Michelman 'Possession vs. Distribution' (note 190 above) at 1324.

209 See WE Forbath 'The Ambiguities of Free Labor: Labor and the Law in the Gilded Age' (1985) Wis LR 767 (tracing this theme in republican discourse of political and legal elites and labor reformers in US from 1780s to 1880s); Forbath 'Caste, Class, and Equal Citizenship' (note 7 above) at 13-15, 18-19) 26-51 (same, adding inflections of theme in women's, African American, and agrarian movements, and carrying forward into 1890s-1930s). 
that the poor have a subsistence claim on society's resources. In truth, that claim was well-defended by Locke; it is there, too, in the writings of Adam Smith. ${ }^{210}$ But that is a far cry from making this longstanding claim a basis for citizenship in the sense of full membership in the political community. Neither Locke, nor Smith, nor Madison and Jefferson in the 'republican' texts Michelman relies on, ${ }^{211}$ nor later renderings of liberalism and republicanism, up to and including Professors Rawls and Sandel - none of these lend support to the idea of making public assistance simpliciter the material base of citizenship. That base, that dignifying social minimum, must rest on some socially recognized contribution on a person's part to the common enterprise.

\section{Welfare vs Social Citizenship Rights}

\section{(a) Thus Far: The Social-Citizenship Conception Is the Better One}

This broader, more participatory conception of social citizenship may not be necessary in every liberal democratic society today to assure a person's standing as an 'equal participant in public affairs.' But to use a phrase with which Michelman recently has conjured, this account seems firmly embedded in America's 'constitutional identity.' 212 The longstanding links between work, equal respect, and citizenship seem constitutive of 'who we think we are and aim to be as a politically constituted people, [of] where we think we have come from and where we think we are headed. ${ }^{213}$

The idea that welfare rights fit well with either a liberal or a republican understanding of the material bases of equal citizenship was first forged in the context of the welfare rights movement, as a scholar's contribution to that inspiring struggle. But the movement, like any social movement of subordinate people, was sharply constrained. It played the hand that history and the White House dealt it. Its programmatic vision, its strategy and goals, all were shaped by the social provision and institutional resources at hand to address black poverty AFDC, LSO, and the Community Action Agencies. But nothing about this conjuncture gave any assurance that welfare rights were the right solution to the problem of social and economic exclusion confronting poor black citizens. Black leaders like King and Rustin plainly thought otherwise; they called for a 'Negroes' New Deal' that emphasized decent work. As a normative matter, and as a constitutional one, I have suggested, they were right.

210 Regarding Locke, see eg, J Locke Two Treatises of Government 170 (1960) (poor man has a right to 'Title to so much out of another's Plenty as will keep him from extreme want'); TA Horne Property Rights and Poverty: Political Argument in Britain, 1605-1834 (1990) at 48-65; and R Ashcraft 'Liberalism and the Problem of Poverty' (1992) 6 Crit Rev 493 at 497 (demonstrating that Locke and classical liberalism emphasize natural right to subsistence; they see 'poor relief [as a] constitutive and necessary feature of any legitimate society'). Regarding Smith, see eg A Smith An Inquiry into the Nature and Causes of the Wealth of Nations (1950) 80 ('No society can surely be flourishing ... of which the far greater part of the members are poor and miserable.'); I Hont \& M Ignatieff, Needs and Justice in the Wealth of Nations: An Introductory Essay, in Wealth and Virtue: The Shaping of Political Economy in the Scottish Enlightenment (1983) 1 (identifying meeting needs of poor as Smith's theoretical axis for assessing political-economic arrangements).

211 For a Madison or Jefferson, poor relief left paupers still 'dependent' and, therefore, unqualified for citizenship. They favored ample material opportunities (they even occasionally championed rights to property in 'full and absolute dominion') for all white men willing and able to exploit them, and charity or coercion for the rest. See Forbath 'Caste, Class, and Equal Citizenship' (note 7 above) at 13-14 (discussing and quoting from the Madison and Jefferson texts relied on by Michelman and other 'Constitutional Welfare Rights' defenders like Sunstein).

212 See FI Michelman 'Morality, Identity and 'Constitutional Patriotism” (1999) 76 Denv U LR 1009 at 1025.

213 Idem. 
The vision of citizenship fashioned by the welfare rights movement also was shaped by the fact that the movement's constituents were women and mothers. King and Rustin had nothing to say about this fact, and precious little to say about gender equality in general. But everything we know about welfare and work suggests that generous and guaranteed welfare provision however morally imperative it may be - cannot do the main work of securing gender equality for poor women. That also demands reconstructing the low wage labor market, striving to assure decent jobs for women, no less than men, and providing enabling rights, as well, to training and child care and old-age pensions, as well as provision and incentives that enable and encourage equitable sharing of dependent-care.

A liberal society that prizes the dignity of the individual, if it is an affluent one that can afford a guaranteed income that protects all against desperate want, must do so. To refuse is, in Rawls's terms, to put an unbearable and unjust strain on individuals' commitments to the social compact. But that is not enough. Equal citizenship also requires social citizenship. Or, as Michelman most recently put the claim on our joint behalf:

[We cannot] call on everyone ... to submit their fates to a democratic-majoritarian lawmaking system, without also committing our society, from the start, to run itself in ways designed to constitute and sustain every person as a competent and respected contributor to political exchange and contestation and furthermore to social and economic life at large. ${ }^{214}$

Once one embraces the view that the Constitution must vouchsafe the minimum social conditions of democratic lawmaking, one cannot leave the question of social citizenship where Michelman first left it in his Rawlsian and republican arguments. One cannot leave the work- and economicindependence-and-participation-related aspects of social citizenship to the give and take of ordinary politics. Specification of what counts as decent work or recognized but non-waged contribution (such as child- or elder-care), and how, at a particular time, the nation ought to go about assuring such opportunities to all, of what counts as a decent livelihood at said time, of what counts as incapacity, and of what quantum of income should separate those, not incapacitated, who avail themselves of 'welfare' or a guaranteed income versus those who 'work' all these issues and more may and, practically, must be addressed through political and market processes. But if social citizenship guarantees are prerequisites to political equality, then, at the most general level, these commitments must precede ordinary politics; otherwise, a broad swathe of the citizenry would be denied as today they are denied a constitutionally fair opportunity to act as citizen-participants in the very debates and decisionmaking upon which their citizenly standing depends.

As I've noted, Michelman, in his most recent work on constitutional social rights, seems to sign on to the 'Forbath-style constitutional guarantee of social citizenship.'215 In that work, he rehearses the justiciability issues, which had preoccupied him in his first, 1973, engagement with Rawls. These problems of 'judicial role and competence' he says, should be the 'least of our concerns.'216 'Judges who know their business ... can find both properly adjudicative standards for testing claims of social-rights violations and worthwhile, properly judicial remedies for violations when found. ${ }^{217}$

214 Michelman 'Constitution and Social Rights' (note 9 above) at 25.

$215 \mathrm{Idem}$ at 27; see idem at $29 \mathrm{fn} 61$ (noting the 'persuasive case for the moral superiority of the social-citizenship conception').

216 Idem at 13.

217 Idem at 15 (footnote omitted). Courts, therefore, 'exercising constitutional review in entirely convention- 


\section{(B) A New Dilemma: Does the Social Citizenship Conception REQUIRE ABANDONING JUSTICIABILITY?}

More troubling than justiciability, Michelman argues, are two other sorts of objections. One is the problem of constraining democratic decision-making, which we've already glimpsed; the other objection goes to the 'non-transparency' or lack of 'ascertainability' of the social citizenship guarantee. For a constitutional order to be legitimate, all its core commitments must be such that citizens can see or ascertain that their 'fellow citizens and their government [are] really complying with [them]. 218 Without this quality of 'transparency' or 'ascertainability,' how could one expect a reasonable citizen reasonably to assent to the constitutional order? The dilemma with the social citizenship guarantee, then, is that it is (a) a prerequisite for a legitimate liberal democratic constitution, ${ }^{219}$ yet, at the same time, (b) deeply problematic in virtue of its 'raging indeterminacy' and the fact that, therefore, 'it will almost always be impossible for anyone to say decisively whether [that guarantee] is or is not being pursued in earnest.' 220 In other words, the social citizenship requirement seems to land its proponents in contradiction. The constitutional regime is not legitimate if it does not include the guarantee; but it also is not legitimate if any of its basic guarantees are 'such that citizens cannot judge whether those guarantees in fact are being kept, or at least at all times being pursued in good faith.'221

At the end of the day, however, Michelman puts both of these 'deeper objections' to the social citizenship guarantee to rest; and he does so through the same device. 'Rawlsian thought,' he suggests, 'offers a way out of this bind': 222 loosening the constitutional requirements of social citizenship from 'rights' to 'directive principles'223 (as that phrase is used in several of the world's constitutions to denote judicially non-cognizable but nevertheless basic and binding commitments ${ }^{224}$ ), or what Rawls would call 'a constraint on public reason.' 225 The upshot is

al, nonworrisome ways almost certainly can play a useful role in the promotion of the distributive aims of social rights guarantees.' Michelman 'Constitution and Social Rights' (note 9 above) at 15.

218 Idem at 31.

219 Idem at $26,30,32$.

220 Idem at 30. Thus, suppose that 'effective social citizenship on fair terms for all who seek it' is, indeed, among the principles to which the government must 'visibly be committed ... in order that the total governance system may be one that meets the ... standard' of constitutional legitimacy - see idem and suppose that lawmakers this year have replaced welfare with workfare, increased by one half the budget allocation for job training, reduced the minimum wage by one-third, extended the collective bargaining laws to cover employers of as few as ten workers, abolished rent control, budgeted an annual sum of 30 billion crowns for housing allowances and job training, increased income tax rates by five percent, reduced the prime lending rate by two percentage points, doubled the size of the employment discrimination mediation corps, and approved a new tariff schedule somewhat less protective than its predecessor, in exchange for reciprocal concessions from abroad. Michelman 'Constitution and Social Rights' (note 9 above) at 30-31. Is the government complying with the constitutional guarantee of social citizenship? 'Raging indeterminacy of this sort seems to disqualify a clause like [the social citizenship guarantee] from figuring as a required component in a complete and legitimating constitutional agreement': idem at 31.

221 Idem at 32.

222 Idem.

223 Idem.

224 Thus, for example, the Irish Constitution and the Indian Constitution (following the Irish model) both contain a list of social rights in a part headed 'Directive Principles of Social Policy.' Its opening paragraph states: 'The principles of social policy set forth in this Article are intended for the general guidance of the [Parliament]. The application of those principles ... shall not be cognisable by any Court under any of the provisions of this Constitution': Art 45, Constitution of Ireland, 1937.

225 Michelman 'Constitution and Social Rights' (note 9 above) at 32 fn 65 (quoting and citing Rawls (note 133 at 216-20, 223-27) (internal quotations omitted). 
a constitutional order in which 'the basic negative liberties freedoms of conscience and expression, for example'226 require 'fully firm, strict, and reliable substantive guarantees of compliance,'227 while 'the rest of social citizenship' 228 stands as a requirement that every lawmaker 'and indeed every voter stands ready ... to explain and defend all their votes, on matters affecting the structural conditions of social citizenship, as expressions of their honest best judgments about which choice is most conducive to assurance of social citizenship for all ... .229 The distinction Michelman draws between 'the basic negative liberties' and 'the rest of social citizenship' makes plain that by 'the rest of social citizenship' he here means not only the right to decent work or other rights we have labeled participatory, but rather all affirmative social rights including 'welfare' rights. ${ }^{230}$

This shift from rights to directive principles seems to put Michelman's answers to his three objections in conflict with one another. Michelman's answer to the judicial overreaching objection is to underscore that courts can play a modest but valuable role in securing social rights, while abiding by more or less determinate, law-like standards for testing rights claims and ordinary views about the boundaries of courts' institutional competence and authority. Michelman's answer to the democracy- and transparency-based objections is to propose making social rights into not-rights-but-directive-principles fit not for courts, but for citizens and lawmakers in view of their 'raging indeterminacy,' and in virtue of the modest but valuable role that constitutional directive principles can play as 'constraints on' or 'inflections of' public reason and deliberation.

In other words, Michelman seems to be ascribing a contradictory nature to the social citizenship guarantee. If the guarantee, conceived as 'a right or set of rights,' is 'such that citizens cannot judge whether [they] in fact are being kept,' then one is hard-pressed to imagine how such 'a right or set of rights' could yield judges 'properly adjudicative standards for testing claims of social-rights violations and worthwhile, properly judicial remedies for violations when found.'

\section{(C) 'RAging IndeTERMinacy'?: Normative and PRACTICAL Bases FOR Sorting Social Citizenship into Rights AND Directive Principles}

There are various possible ways out of this contradiction; the best route may be this. Perhaps, in the absence of statutory specification, some social citizenship norms are and others are not reasonably well-suited for courts to help enforce. This, we saw, was Michelman's view back in 1973, when he contrasted Rawls's difference principle, as an equality guarantee, to welfare rights to food, shelter, health care, and education. The latter lent themselves to a measure of judicial enforceability; the former did not. Of late, however, Michelman has embraced enlarging the circle of social rights to include, for example, decent work; and this may have contributed to inclining him to the view that judgments about the 'progressive realization' or 'good faith pursuit' of any and all social rights are imbued with so many controvertible policy choices and trade-offs that they ought properly be made by the polity and not the courts.

\section{Idem at 32.}

227 Idem.

228 Idem.

229 Idem.

230 See Michelman 'Constitution and Social Rights' (note 9 above) at 33 (contrasting 'formal, legal guarantees of ... the core, basic negative liberties' with 'confidence that public reason ... prevails in public decisionmaking over matters affecting ... social citizenship'). 
But transmuting social rights into judicially non-cognizable directive principles comes at an obvious price; for as Michelman recognizes, courts can play a useful role in promoting (at least some elements of) social citizenship. So, it is worth asking whether there is a case for sorting out social citizenship guarantees into sub-categories of rights and directive principles. With the mediating idea of directive principles in hand, we will not be drawn, as Michelman was in 1973, to conflate the justiciability of a particular element of social citizenship with an answer to the question whether that element carries important constitutional weight and significance.

So, let us return to the comparison and contrast between the 'welfare right' to housing or shelter and the 'social-citizenship right' to decent work. Along some important dimensions of justiciability, we have noted, neither of these rights trumps the other. We also have seen that the availability of decent work is a state of affairs which may have a uniquely large and disparate set of potential policy levers surrounding it, running to everything from childcare and job training to the prime lending rate, tax and tariff policies, public investments and employment, and beyond. This leads Michelman to query whether anyone, including presumably a court, could 'say decisively whether [the guarantee] is or is not being pursued in earnest.' But practical complexity is not all that may importantly distinguish the social citizenship guarantee from welfare rights, like the right to housing.

Practical complexity is linked to complexities of social meaning and of cultural contention and change. What it means to ensure that no member of the community is homeless or without adequate shelter is not self-evident; but the range of plausible meanings is vastly more definite and exigent than what it means to ensure 'decent work' for all, or to sustain every member as 'a competent and respected contributor to political[,] ... social, and economic life at large.'231

\section{(D) Imagining Welfare Rights and Social Citizenship in America IN 2020}

Imagine an America in the year 2020 constitutionally committed to welfare rights and likewise committed to guaranteeing social citizenship for all. In that America, if some are homeless, they should be entitled to say that the Constitution requires that government act in some fashion to ensure an increase in the supply of available, affordable housing and to ensure emergency shelter in the meantime. But if some are 'jobless,' say by dint of a rash of outsourcing of jobs overseas, ought they be entitled to say that the Constitution requires that government act to increase the supply of full-time jobs? Putting all practical difficulties and impediments aside, there would remain the question whether that response vindicating the asserted entitlement to a new 'fulltime' job would be the only or the best way to sustain those newly jobless Americans as 'competent and respected contributors' to social and economic life.

Many, I am sure, would think not. Posed with this question and a chance to deliberate about it, many Americans would probably observe that too many people are laboring their lives away, and that the overwork of some contributes to the unemployment and poverty of others. They might contend that a better response to the moral and material injuries of joblessness would include a broader distribution of decent work, combined with a compensating social wage in cash, or in health insurance or other goods, so that more Americans had decent work and more Americans also had more time for family, community, and other things besides earning wages. Thus, as polities, large or small, considered how to make good on the social citizenship guarantee, there surely would be good faith normative disagreement about striking the balance between (a) the freedom-enhancing virtues of ensuring decent, dignified livelihoods through 
income guarantees and publicly funded social insurance and (b) the 'participation' and 'individual responsibility' values served by requiring people to 'earn' those livelihoods via, say, a greater emphasis on public investment and job creation.

More narrowly, many Americans would hold that some part of the joblessness problemand the loss of social and self-respect joblessness produces might be better addressed by remunerating and dignifying the work of child or elder care than by creating new full-time jobs outside the home. Some might even suggest incentives to encourage men, in particular, to spend more time in those pursuits, and to see them as a fair avenue for fulfilling a part of their role as 'respected contributors.'232 Finally, many Americans, as always, would contend that access to education and the wherewithal to pursue it are an essential alternative response to joblessness, at least for those who aspire to some kind of work for which their present education level has not outfitted them. And this is just a brief sampling of the kind of normative debate, contestation and change that we have every reason to expect would attend the process of honoring a social citizenship guarantee in the year 2020.

So, a crucial difference between welfare rights and the broader right of social citizenship lies not simply along the dimension of practical complexity but also along the intersecting dimension of normative indeterminacy. The normative meaning of the social citizenship guarantee seems properly subject to a level of good faith disagreement, contestation and change that is quite different from welfare rights to food, clothing, shelter, or even education. In an America constituted by both kinds of guarantees, the response to homelessness, and the incapacitation and indignity it threatens, must be some kind of home; but the response to the marginality and exclusion threatened by joblessness may rightly be more open-ended. It properly entails ongoing revaluation of what we mean by 'full time' and 'work' and 'respected contribution.' And if that is so, then there is good reason to conceptualize welfare rights as rights, and the social citizenship guarantee as a directive principle.

Welfare rights are suited, in ways we've already canvassed, to some non-trivial measure of judicial oversight, even though enforcing them to the hilt is well beyond the courts' domain. Since they are essential to constituting every American as a free and equal member of the polity, it seems folly to forsake the judiciary's contribution. The social citizenship guarantee is no less essential, but because of the wide-open practical and normative choices encircling it, that guarantee presents distinct and intractable justiciability problems. It makes sense, therefore, to deem it a directive principle. So, Michelman's recent reliance on 'Rawlsian thought' for the idea of transmuting social rights into directive principles or 'constraints on public reason' seems to me half right. ${ }^{233}$ If instead we

232 For acknowledgement by the present Court of the constitutional stakes in ensuring that men bear an equal share of the work of family care, see Nevada Department of Human Resources v Hibbs 123 S Ct 1972 (2003) (holding that because the unequal distribution of family care between women and men contributes to women's social and economic inequality, public employment practices that perpetuate this inequality amount to constitutional injuries, which Congress is empowered to redress under the Fourteenth Amendment).

233 I note that Rawls himself, in Political Liberalism, did not draw the category of 'constitutional essentials' as narrowly as Michelman seems to suggest. In addition to the basic negative liberties like freedom of conscience, Rawls also holds that 'a social minimum providing for the basic needs of all citizens' also belongs in the category of 'constitutional essentials' requiring fully firm, strict, and reliable substantive guarantees of compliance. See Rawls (note 133 above) at 228-29 \& fn 23 (noting that Rawls finds himself 'accepting Frank Michelman's view as stated in "Welfare Rights and Constitutional Democracy"'). Thus, what Rawls leaves out of his category of 'constitutional essentials' (and puts into the category of principles that instead must serve as 'constraints on public reason') seems closer to what I am suggesting: the difference principle and fair equality of opportunity. See idem at 226-29. 
divvy up the constitutional universe of social rights into rights and directive principles, perhaps, we better serve the competing concerns which prompted Michelman.

Such a division might help insure against an obvious danger posed by the full-scale morphing of rights into directive principles: while the polity deliberates, and public reason unfolds, people starve. Good faith disagreement shades imperceptibly into dawdling and indifference. And the voices of those at the margins weaken. Judicially cognizable welfare rights might provide a hook and a prod, to use Michelman's own metaphors, for securing the livelihoods of those at the margins, boosting slightly their ability to participate in the polity's conversations about its directive principles, about what it means to sustain everyone as a participant and contributor. What is more, the simpler we make the cognizable essentials of social citizenship, the more vigorously our constitutional courts might provide stays against political failures.

Today, social provision, social rights, even the social safety net are in tatters and disrepute. The working poor constitute a growing part of the nation's labor force, and the scandal of overwork, demeaning conditions, and impoverishing wages for millions of Americans goes largely unaddressed. During this dry season, no scholar has done more than Michelman to keep intellectually alive and vivid the view that high constitutional values and commitments are at stake in how America responds to poverty and material inequality. As we ponder the shape and the practice of social rights and social citizenship in a progressive Constitution for the year 2020, we are lucky to have Frank Michelman to begin the conversation. 


\title{
The Just Community: Emile Durkheim on Liberalism and Society
}

\author{
DERIK GELDERBLOM \\ Department of Sociology, \\ UNISA
}

\section{Introduction}

My aim in this chapter is to provide an overview, and evaluation, of an early communitarian critic of liberalism: Emile Durkheim (1858-1917). Durkheim was one of the founders of academic sociology. His work later inspired the functionalist school in anthropology and sociology. He was also an important forerunner of the structuralist movement of the 1960s and 1970s in France and elsewhere.

Durkheim's contribution towards the debates on liberalism and human rights arose in the context of his lifelong concern to investigate the relationship between individual and society. $\mathrm{He}$ tried to reconcile an emphasis on individual freedom with the demands of social integration and justice. This is especially relevant in our current context where the failures of both a collectivist Marxism and an individualist capitalism are all too apparent.

In terms of the current debates between liberals and communitarians, he can best be classified as a communitarian. He was especially critical of free-market liberals and their belief that the invisible hand of the market had the capacity to create spontaneous order out of the selfish exchanges of individuals. Although he found much he could agree with in Kant's epistemology and ethics, he objected to a core point of departure of Kant's philosophy. He felt that Kant's emphasis on a transhistorical, autonomous subject of knowledge neglected the social factors in the rise of this subject, and could not give an account of the individual's dependency on society. These points all address themes common to the communitarian critique of liberalism. At the same time, however, Durkheim believed that individual freedom and justice were core values that any modern society had to defend. He also did not regard traditional sources of community such as religion, ethnicity and the family as viable options for a modern society, and believed that new sources of community had to be found. Durkheim's defence of communitarianism was very sophisticated, and deserves better scrutiny in this debate.

\section{The Nature of Rights}

Durkheim's critique of free-market liberals relates to their exclusive emphasis on so-called negative rights. An ongoing dispute in human rights discourse (and within the liberal tradition) concerns the

nature of the rights that have to be extended to individuals in order to guarantee their liberty. ${ }^{1}$ One

1 J Christman Social and Political Philosophy. A Contemporary Introduction (2002) at 47, 216 endnote 1. 
side, nowadays called the libertarians, argue that these are limited to protection against interference from others. In practice this means that the state must protect the life and property of individuals from depredations by others, and otherwise guarantee their freedom to live their life as best as possible. Their opponents, of which John Rawls is within the liberal tradition the most prominent exponent, believes that additional rights are necessary to guarantee the minimum level of living necessary to meaningfully exercise those rights (so-called positive rights). This means that the state must act to reduce gross poverty that impedes the self-realisation of some individuals. As is well-known, the South African constitution is relatively unique in the sense that it contains provisions supporting positive rights. It is also common knowledge that, in the Grootboom case, the Constitutional Court has committed itself to an, at least limited, degree of judicial oversight regarding the government's duty to give effect to those provisions.

In Durkheim's time, the negative rights argument was articulated most prominently by Herbert Spencer, and it was against him that Durkheim's criticisms were directed. As we shall see below, Durkheim was an advocate of justice in economic exchanges, and believed that redistribution was necessary to ensure justice. He was therefore critical of the free-market argument's rejection of positive rights. However, this is not what is at issue in the next few paragraphs. Here we will attend to what can be called a sub-argument within the bigger argument about rights. Durkheim was in particular critical of Spencer's argument that social order can be attained purely on the basis of self-interested exchanges in the marketplace. This argument was first advanced by the Scottish political economist and Enlightenment philosopher, Adam Smith, in his famous book The Wealth of Nations (1776). Philosophers differ in other respects with regard to their justification of the primacy of negative rights (some departing from a utilitarian framework, and others such as Nozick basing their arguments on Locke's social contract theory, as well as Kant), but Smith's argument about the possibility of social integration purely on the basis of market exchanges is central to all of them. Any theory that defends a notion of a limited state and an exclusive emphasis on negative rights needs to prove that a setup in which rights are limited in that way is viable and will not create conflict.

\section{Social Order Based Purely on Self-Interested Market Exchanges}

Smith's argument was advanced in a context where philosophers had been wondering for some time how social order could be maintained in the new society that was then forming in Europe. Religious wars following upon the Protestant Reformation, the decline of feudal society and later the beginning of the Industrial Revolution all contributed to disruptive social change. Hobbes formulated this question in terms of what later came to be known as the 'problem of order': Given that all people are inherently selfish, how will it be possible for us to avoid a state of constant conflict? As is well-known, his answer was that individuals will agree to subordinate themselves to a strong sovereign, who will be charged to keep order among them. A more extreme answer was provided some time later by the reactionary Frenchman, Joseph De Maistre. Social order, he said, is guaranteed in the last instance by one man only: the executioner. $^{2}$ Both of these believed that it is necessary for individuals to offer up their freedom to ensure social order. This was not Smith's viewpoint. His argument was that neither the

2 I Berlin 'The Counter-Enlightenment' in Against the Current: Essays in the History of Ideas (1980) at 23. 
sovereign not the executioner is necessary. Social order can arise spontaneously, if the right institutional setting is provided, from the free actions of individuals in the marketplace.

Smith (and Spencer) believed that the 'invisible hand' of the market has the remarkable capacity to ensure that the greater good will be served if people pursue their own selfish ends. The argument is as follows: The basis for progress in a society is the increasing division of labour. If a large enough market exists in which individuals can freely exchange their products, the division of labour in a society will grow more complex. People will specialise in making one product only, and will cease to be self-sufficient. This specialisation will both make people more dependent on others and lead to increased productivity and economic growth.

Division of labour is also the key to social integration. Market exchanges take place because people need the products produced by others. In a competitive environment, it will be in the enlightened self-interest of sellers not to exploit their customers, because customers can always patronise the competition if they are not satisfied. Market pressures therefore make it possible to regulate the relationships between exchange partners so that conflict does not result from their interaction. In a free market, social order arises, purely unintentionally, from the selfish desires of individuals. It is obvious why this argument is attractive to libertarians. Central direction from the state, or any other form of extraneous regulation, is not necessary to create social order. In fact, they believe it would distort the working of the market and should therefore be avoided. ${ }^{3}$ Thus the responsibilites of the state to its citizens should be limited to guaranteeing the negative freedoms of individuals. Redistributive actions to ensure positive rights are consequently forbidden.

\section{Durkheim's Critique}

The first part of this argument was less contentious for Durkheim. He certainly recognised the capacity of the division of labour to increase productivity. He did, however, have major problems with the next part of this position, which was that the free market, by itself, was able to integrate society and that it should therefore be left unregulated. Durkheim insisted on the opposite: if implemented consistently, free-market policies would lead to conflict and social disorganisation and destabilise society. It would encourage a radical individualism that elevated the interests of the individual above that of society. This radical individualism, he said, placed no limits on the individual's desires. As a result, these desires become uncontrollable, which leads to conflict between people as their massive egos clash in search of self-gratification. ${ }^{4}$ But this does not mean that all kinds of individualism are bad. A more responsible individualism that takes into account social needs was indeed a good thing.

Durkheim, like Smith and Spencer, supported individual freedom against the depredations of the sovereign and the executioner. This put him in the liberal camp in terms of the debates of the day. He made it clear that the old basis of social order, which centred around unquestioning obedience to church, king and country was no longer viable. People had become emancipated from these structures, and this was a good thing; not something to be deplored. What

3 Smith's book has been somewhat unfairly typecast as an unqualified defence of freemarket capitalism. His book also contains cogent arguments about the need for state interventions in some cases.

4 E Durkheim The Division of Labour in Society (1984) at xxxii; E Durkheim The Elementary Forms of Religious Life (1995) at 427. 
was needed now, he argued, was new institutions and values with the capacity to gain the respect and support of modern, emancipated, individuals. These institutions will aim to defend individual freedom, even as they guard against the abuse of this freedom.

We now move to the specifics of Durkheim's argument against Spencer. Durkheim claimed that Spencer was wrong in believing that self-interest and the negative rights necessary to pursue it could act as the basis for social peace. ${ }^{5}$ He made the following points:

Self-interest is not stable enough to act as the basis for social peace. According to Durkheim, it may be in my interests to cooperate with you today, but then again it may be against my interests to do so tomorrow. ${ }^{6}$ Durkheim unfortunately did not elaborate on this point, so it is not clear why he thought self-interest should be so inconstant in its effects. It is not difficult to find reasons to support his argument, though. The free market analysed by Smith represents an idealised situation that does not appear very often in reality. It assumes a multitude of sellers and buyers, with no single one of them big enough to force his/her terms on the others. In the real world, of course, monopolies and oligopolies are common, entry costs to new competitors high, and arm-twisting (and leg-breaking) rife, so market discipline is absent to a significant extent. In these cases, self-interest leads to exploitation by the powerful. Even the idealised free-market situation can only account for relationships between buyers and sellers. It does not provide any antidote to conflict, and hard-ball tactics, between sellers, for example. A good example of this was the state of war that existed in the unregulated minibus-taxi industry of South Africa until recently.

The free-market argument is particularly problematic in the case of the labour/capital relationship. According to Durkheim, free-market ideologues like to say that, if employers offer salaries that are too low, they will not find workers to fill these positions, because no rational person will work in an occupation if the salary does not match the work involved. ${ }^{7}$ They therefore believe that the market forces of supply and demand will, by themselves, ensure that workers are compensated at a level equivalent to their productivity, because a shortage of workers will force employers to increase wages. What they forget is that a whole section of the population cannot abandon their function in this way, since no other is available to them. A worker may very well find him- or herself in such a powerless position. Such a person may be desperate to find a job simply to ward off starvation, in which case s/he will take any job on offer regardless of the employment conditions. The weak bargaining position of workers may therefore render the discipline of market forces on employers inoperative, because they will not experience a shortage in their labour supply that can force them to improve conditions of work. This can lead to great injustices.

The negative rights that people are exercising in their contractual relations 'detach them from one another, and mark out clearly the barriers separating them'. ${ }^{8}$ This can indeed limit the encroachment of one person upon another, according to Durkheim. But this is not enough to bring about social peace; instead 'it presumes it': 'In fact, for a man to acknowledge that others have rights... he must have agreed to limit his own. Consequently this mutual limitation was only realisable in a spirit of understanding and mutual harmony'. 9 The name Durkheim gave

5 E Durkheim Professional Ethics and Civic Morals (1957) at 52-53, 71-72; Durkheim The Division of Labour (note 4 above) at 149.

6 Durkheim The Division of Labour (note 4 above) at 152.

7 Durkheim The Division of Labour (note 4 above) at 310.

8 Durkheim The Division of Labour (note 4 above) at 75.

9 Durkheim The Division of Labour (note 4 above) at 76. 
for the social cohesion that causes people not to interfere with others, and thus enables their negative rights, was solidarity. Durkheim's argument here assumes that the argument above about the inconstancy of self-interest is proven. It is not immediately clear that solidarity is the only reason why people would agree to limit their own rights. Enlightened self-interest, for example, can also be a reason, and unless this is excluded as a motivation, his argument is incomplete. But as we have seen, self-interest does indeed not guarantee social order, so this objection does not apply.

\section{Durkheimian and Marxist Critiques of the Free Market}

Durkheim was one of the first social theorists to question the ability of free markets to integrate society. As is well-known, Marx and Engels before him were very critical of the impact of the division of labour on the working classes, as well as the conflict produced by capitalist relations of production. ${ }^{10}$ It should be clear that Durkheim's analysis of the forced division of labour shows some similarities to Marx's critique. Durkheim was also sympathetic to some socialist policies, as we shall see later on. Nevertheless, he differed from the Marxists in one important respect. ${ }^{11}$ Durkheim claimed that the socialisation of the means of production was not, by itself, the solution to such problems. If the selfishness of individuals is not subjected to moral constraint, even socialism would not put an end to conflict. Individual desires will only remain within the capacity of a socialist society to satisfy them if they are controlled by the common morality. ${ }^{12}$

\section{Durkheim and Neo-Institutionalism}

The belief in the self-regulating market later came to occupy a central position in the successor to the political economy tradition of Adam Smith: neo-classical economics. Recently however, economists in the neo-institutionalist school have become critical of the ability of the market to serve by itself as a guarantor of social peace, and thus of neo-classical economics. ${ }^{13}$ According to them, markets and contracts can serve to discipline discrete (that is, non-repetitive) transactions where there is a choice of alternative suppliers and buyers and the goods exchanged are standardised. However, such transactions form only a small part of the total sum of transactions in the economy. For the rest, more elaborate governance structures are necessary. This can either take the form of the vertically-integrated firm (that is the firm buys out the supplier, or starts one up by itself) or the form of relational contracting.

Williamson explains the rise of the latter two governance structures with reference to the need to minimise transaction costs. ${ }^{14}$ Transaction costs arise from two characteristics of exchange. Williamson firstly relaxes the unrealistic neo-classical assumption that the exchange parties both possess perfect information and replaces it with one of bounded rationality. In bounded rationality information is costly to obtain, and actors find it difficult to process even

10 K Marx \& F Engels The Communist Manifesto (1848).

11 Durkheim Professional Ethics (note 5 above) at 10-11, 31.

12 Durkheim Professional Ethics (note 5 above) at 10-11.

13 I Macneil 'Economic Analysis of Contractual Relations' in P Burrows \& CG Veljanovski (eds) The Economic Approach to Law (1981) 61; OE Williamson 'Contract Analysis: The Transaction Cost Approach' in P Burrows \& CG Veljanovski (eds) The Economic Approach to Law (1981) 39.

Williamson 'Contract Analysis' (note 13 above) at 45-46. 
the little information that they have. This creates a need to economise on the time and effort involved in decision-making. In addition, he assumes that opportunism is a reality in exchanges. This implies that actors are often tempted to hide their real intentions to others, and therefore profit by deceit. The costs resulting from the gathering and processing of information, as well as the safeguards against opportunism, are known as transaction costs.

In relational contracting, the buyers and sellers build up a long-term relationship. Here, informal norms that regulate their exchanges develop over time between buyer and seller. In addition, a feeling of solidarity develops between the partners. This builds up trust between them. These characteristics of relational contracting allow actors to reduce their transaction costs. Long-term relationships simplify decision-making, and trust reduces the need to guard against opportunism. As a result, the partners are prepared to limit their immediate self-interest for the sake of the relationship. Their attitude tends to become more one of enlightened selfinterest, taking the longer view. They realise that their relationship allows them to benefit more as a group than would otherwise have been possible if they had acted as individuals only.

Although I am not aware of any direct line of influence from Durkheim to the new institutionalists, it should be clear that there are important similarities between Durkheim's work and theirs. However, there are also important differences. Despite their deviations from neo-classical economics, Williamson and others in this tradition still depart from a micro-perspective, taking the individual as their point of departure. They also share an economising perspective with neo-classical economics. Both of these points of departure are foreign to Durkheim. Moral behaviour is not just a means to an end for Durkheim, as it is for the neo-institutionalists, it is an important end in itself: 'It is not merely a matter of increasing the exchanges of goods and services, but of seeing that they are done by rules that are more just; it is not simply that everyone should have access to rich supplies of food and drink. ${ }^{15}$ Rather, it is that each one should be treated as he deserves, each be freed from an unjust and humiliating tutelage, and that, in holding to his fellows and his group, a man should not sacrifice his individuality.' Durkheim finally was resolutely a macro-theorist. For him society was a reality in its own right that had a major impact on the individual, as we shall see below.

\section{Durkheim's Ideal Typical Picture of Social Development}

In the light of the foregoing, it is not surprising that Durkheim thought that contemporary European societies exhibited numerous symptoms of social disintegration. Industrialisation caused the disintegration of the feudal societies of earlier times. In their place, a new society was coming into being, with industrial capitalism as its mode of production and individual freedom as its dominant ideology. Opinions varied about the viability, and desirability, of this new world, which later came to be known as 'modernity'. For Durkheim this new world was not viable in its then current form. The market was subject to few controls. Old forms of community were eroded by capitalism and new forms were not instituted. The disorganisation he observed was precisely what would follow from the absence of regulation of economic exchanges, and the failure to install solidarity and new forms of sociability between people. This leads to the social problems of what he called egoism and anomie.

In order to understand why these problems come to the fore, we need to briefly consider 
Durkheim's exposition of the role of increasing division of labour and decreasing collective consciousness in the rise of modern societies. In his book Division of Labour in Society Durkheim worked out an ideal typical scheme of social development. He defined the problem he was going to study as follows: 'How does it come about that the individual, whilst becoming more autonomous, depends ever more closely upon society?'. ${ }^{16}$ This then was Durkheim's vision of social development: There is an historical trend towards increasing individualism. Under ideal circumstances this trend does not produce a lack of social cohesion, and it was the intention of his book to show why this was possible. Because this ideal line of development was not followed, the extremes of egoism and anomie mentioned above, resulted. Armed with the concepts developed here, we will return later on to the discussion of what in his view went wrong.

Durkheim believed that the division of labour is very simple in primitive societies. In a hunter and gatherer type of society, men are the hunters and women the childminders and gatherers. Here the division of labour is largely based on gender, with some distinctions made on the basis of age. As societies develop the division of labour becomes more complex. In the stage of settled agriculture there are occupations such as craftsmen, priests, soldiers, herdsmen and farmers. Industrialisation, of course, has an enormous impact on the division of labour. Initially, hundreds but later thousands of new occupations are created as a result of industrialisation.

The simple division of labour of primitive societies, where people have similar occupations, is associated with similarities in the feelings, values and beliefs of people. They thus share a strong, collective consciousness. The French term used by Durkheim is conscience collective, which suggests similarities in both cognitive and moral beliefs. ${ }^{17}$ Durkheim (and his English translators) had a number of names for the collective conscience, which gives an idea of what he meant by it. Besides 'collective consciousness', it is alternatively called civic morals, public opinion, common morality or collective representations. The common morality is the basis of what Durkheim calls mechanical solidarity. People feel connected to their neighbours because they are all alike.

Durkheim believed that the higher ranges of every person's consciousness can be divided into two parts: an individual (or unique) part, not shared with other people, and a collective part that consists of the ideas and beliefs similar to other people. ${ }^{18}$ Mechanical solidarity can only be strong if the second part, that is, the ideas and beliefs common to people, occupy a larger part in each of our minds than the unique part. ${ }^{19}$ It follows from this that the individual personality, understood as a reasoning and moral being, cannot exist if the collective consciousness occupies our minds completely. In other words, the decline of the collective consciousness is a precondition for the rise of the individual personality. ${ }^{20}$

This is what happens when the division of labour becomes more complex. More variety creeps into people's ideas, and this leads to the erosion of the collective consciousness. Like the division of labour, the collective consciousness becomes more fragmented. ${ }^{21}$ Because people now have such diverse experiences in the world of work due to the division of labour, ideas and

16 Durkheim The Division of Labour (note 4 above) at xxx.

17 Durkheim The Elementary Forms (note 4 above) at 214; A Giddens Studies in Social and Political Theory (1977).

18 Durkheim The Division of Labour (note 4 above) at 61.

19 Durkheim The Division of Labour (note 4 above) at 84 .

20 Durkheim The Division of Labour (note 4 above) at 142; D Gelderblom Morality, Individual and Society: Emile Durkheim (2004).

21 Durkheim The Division of Labour (note 4 above) at 172. 
beliefs are no longer shared. In other words, the collective consciousness divides up into parts, each part regulating a particular occupation.

The impact of the division of labour on the collective consciousness indicates the link that Durkheim posited between social organisation and belief systems. A small-scale intimate society produces intensely-held common beliefs, and a large-scale differentiated society produces more variety in and less commitment to common values.

The rising division of labour and the declining collective consciousness can, if conditions are right, produce a new kind of solidarity, called organic solidarity. The conditions Durkheim had in mind was the following: division of labour, morality and legal regulation. It should be apparent that Durkheim thought that these conditions were not yet in place. Durkheim believed that Spencer and Smith were right to give the division of labour a role in the integration of society, but were wrong about the mechanism by which it would do so. ${ }^{22}$ The division of labour leads to social harmony, not because it co-ordinates interests, but because it creates solidarity. Because we each specialise in producing only one product (or part thereof) or service, households are no longer self-sufficient. The division of labour therefore makes us dependent on other people to survive. When we become aware of this mutual dependence, we develop a liking for others, as well as a willingness to submit our interests to social regulation. Peaceful and orderly exchanges between individuals depend on these feelings.

Durkheim made it very clear that the interdependence created by the division of labour was not enough to serve as the basis of solidarity, however. ${ }^{23}$ The new occupations created by the division of labour needed to be regulated to make sure that conflict does not arise.

The first form of social regulation was moral. As Durkheim put it: 'A state of order or peace among men cannot follow of itself from any entirely material causes, from any blind mechanism, however scientific it may be. It is a moral task'. ${ }^{24}$ The 'blind mechanism' that Durkheim was referring to here was obviously the invisible hand of the market. Moral regulation is necessary to prevent 'the law of the strongest from being applied too brutally in industrial and commercial relationships'. ${ }^{25}$ It imposes control over the selfish impulses of individuals. It also leads to just outcomes in the marketplace, which makes the less privileged more inclined to accept the outcomes of economic exchanges.

Durkheim believed that for every occupation a professional morality was necessary, along the lines of the ethical standards that apply to advocates. The fact that this was absent in the case of most other occupations was a matter of concern to Durkheim. ${ }^{26}$ Professional ethics would not arise in a social vacuum, however, and consequently Durkheim argued that it was necessary to organise all the occupations into occupational groups. ${ }^{27}$ These groups would provide the facilitating context that could induce such moralities, as we shall see later.

Professional moralities were guided by a broader social morality, the collective conscience. In modern societies this common morality revolved around what he called the "cult of the individual'. ${ }^{28}$ This cult comes to prominence in the modern world because this kind of society

22 Durkheim The Division of Labour (note 4 above) at 333.

23 Durkheim The Division of Labour (note 4 above) at 172-173, 301.

24 Durkheim Professional Ethics (note 5 above) at 12.

25 Durkheim The Division of Labour (note 4 above) at xxxix.

26 Durkheim Professional Ethics (note 5 above) at 30; Durkheim The Division of Labour (note 4 above) at 174.

27 Durkheim Professional Ethics (note 5 above) at 7-12.

28 Durkheim Professional Ethics (note 5 above) at 56, 69-70; Durkheim The Division of Labour (note 4 above) at 122 . 
accords the individual a sacred status: "We carry on the worship of the dignity of the human person...it is indeed a common faith'. ${ }^{29}$ As traditional religion loses its credibility the cult of the individual grows to take its place.

Durkheim's recourse to the common morality seems somewhat paradoxical on the surface, because his analysis has also demonstrated that it weakens as a result of division of labour. It also makes mechanical and organic solidarity less distinct. At least part of the solution to this paradox is that it now serves only as a backup to the professional morality: it only regulates broader conflicts in society across occupational lines. Perhaps Durkheim also sensed a problem here. Later in his life he investigated how religious (and secular) rituals could strengthen the common beliefs of communities. It thus seems as if Durkheim later on tried to look for mechanisms by which common beliefs could be reinvigorated. Another problem is the vagueness about which of the two factors are independent and which dependent variables: social organisation or beliefs? Division of labour (social organisation) affects beliefs, but beliefs are necessary to forestall social disorganisation in the form of conflict, and so on. There is in principle no objection if both affect each other, but more clarity about the logic involved here would have been welcome. This is so especially in the light of his inclination, noted by Lukes, toward circular argumentation. 30

Moral ideas find expression in the legal system, which is the second form of regulation. It is necessary for contracts to be embedded in a legal framework that can clarify the many grey areas that can arise when two individuals enter into a contract. A contract therefore implies duties that go beyond those that individuals have agreed upon. ${ }^{31}$

\section{The Reality of Social Disintegration}

We have now finished with the ideal picture; the way development should have happened according to Durkheim. We now need to find out what went wrong to produce the egoism and anomie that he perceived around him at the time.

Egoism occurs when people are too self-centred. ${ }^{32}$ Durkheim linked this excessive individualism to a decline in the levels of social integration. If social bonds weaken, people do not build up strong associations with groups; that is, they no longer feel part of a group. As a result, the group ceases to be an important anchor for individuals, and they become isolated and feel they lack meaning in life.

Pre-industrial societies showed higher levels of social integration than modern societies, according to Durkheim. The ways in which they manufactured those high levels of integration are no longer viable, however, and alternatives have to be found. ${ }^{33}$ They created high levels of integration by restricting individual initiative in unacceptable ways, or through institutions that no longer exist in their original form. For example, religious belief systems were protected against doubt by restrictions on free thinking, and this ensured the continued viability of religious groups as sources of social contact for individuals. ${ }^{34}$ However, the restrictions placed by

29 Durkheim The Division of Labour (note 4 above) at 122.

30 S Lukes Émile Durkheim. His Life and Work: A Historical and Critical Study (1975) at 31.

31 Durkheim The Division of Labour (note 4 above) at 159.

32 E Durkheim Suicide. A Study in Sociology (1952) at 209.

33 Durkheim Suicide (note 32 above) at 375.

34 Durkheim Suicide (note 32 above) at 374. 
religion on free thinking offends modern value systems. Unlike in the past, people no longer unquestioningly accept the authority of religion, and will not allow religious bodies to prescribe to them how they must think. Another source of integration was the pre-industrial family. According to Durkheim, this family type was large and close-knit and provided many opportunities for social contact. Modern families are much smaller and isolated from communal contact however, and can no longer play the integrating role they used to. ${ }^{35}$

Anomie is the result of the frustration, and consequent suffering, of people when their appetites outrun their ability to satisfy them. Anomie is related to egoism, as Durkheim remarks, because it also results from 'society's insufficient presence in individuals'. ${ }^{36}$ Despite this similarity, egoism and anomie differ with regard to the part of society in which this lack is experienced. Egoism derives from the world of morality and the intellect, and produces a lack of meaning and purpose in life. Anomie, by contrast, is located in the world of the economy.

Anomie is endemic in modern society. According to Durkheim, this is because human needs have grown out of all proportion. ${ }^{37}$ Apart from some physical needs such as food, where physiological processes create a feeling of satiation once they have been met, human needs such as the need for luxury or money are, in principle, insatiable. Needs that can never be satisfied cause the individual to chase after infinity. It means being placed on a treadmill, running ever faster after a goal that can never be met. Needs have grown so much in modern societies because they are no longer limited, as before, by forces such as religion which taught people to be satisfied with their station in life. The market has also grown to such an extent that it has reached global proportions. Like Marx, Durkheim anticipated the globalizing tendency of the capitalist market. ${ }^{38}$ The development of the global market was associated with the rise of another phenomenon, which Durkheim did not foresee: the advertising industry. This industry is dedicated to the manufacturing of new needs and increases the extent to which people's desires outrun their ability to satisfy them.

\section{Durkheim's Solutions}

This is the set of circumstances that has made anomie endemic in modern societies. To solve this problem, people need to accept their desires being limited for the greater good. Morality is the only force with the capacity to ensure this agreement, according to Durkheim. ${ }^{39}$ It would do so as follows: In a just society there would be a broad consensus on the level of remuneration that each occupation in society deserves. For every occupation, there will be a generally accepted maximum beyond which it is regarded as unrealistic, and immoral, to strive. This social determination of acceptable living standards for each occupation was not very exact. ${ }^{40}$ It gives a range within which each individual can set his or her expectations for life, with the result that people have some scope for improving their circumstances within these limits. The important thing, though, is that it sets a maximum, and thus ensures that individuals do not become frustrated as a result of their inability to fulfil their unlimited desires.

35 Durkheim Suicide (note 32 above) at 377.

36 Durkheim Suicide (note 32 above) at 258.

37 Durkheim Suicide (note 32 above) at 247.

38 Durkheim Suicide (note 32 above) at 255-256.

39 Durkheim Suicide (note 32 above) at 248-249.

40 Durkheim Suicide (note 32 above) at 250. 
Durkheim's belief that people will allow their desires to be limited in this way is open to criticism. People do indeed accept their station in life to a remarkable degree. They tend to limit their expectations of life to within the horizons of what they perceive to be the possible. But there is also a constant conflict over the distribution of resources in modern societies, which suggests that this self-imposed limitation only goes so far. In Durkheim's defence one can say that he did not believe that the modern societies he analysed actually exhibited such consensus: only in a just society will such a consensus exist. In fact, this is the whole point of his analysis of anomie: regulatory structures have not yet developed, thus predisposing modern societies to anomie. People will not accept that others deserve to be remunerated better than they if the latter started out with unfair advantages in life. Until such time, conflict over the distribution of resources will indeed be rife. A just distribution of resources is therefore a precondition for solving anomie.

This raises the question of what Durkheim meant by 'just'. What social arrangements need to be in place for just outcomes to be produced in the marketplace? In short, Durkheim believed that only distributional outcomes that resulted from a situation where everybody had an equal chance to perform, were just. Only those social arrangements that allow people to rise to positions based purely on their merits, and where the accident of birth played no role whatsoever in their career path, thus qualified. ${ }^{41}$ This means that any mechanism by which the privileged could transmit their privileged position to their children had to be eliminated. Durkheim therefore made a plea for inherited wealth to be abolished. ${ }^{42}$ Inherited wealth gave those lucky enough to have acquired it an unfair advantage in life's race. The same applies to factors such as unequal access to education. If there are obstacles placed in the way of individuals' realising their talents, such as inherited poverty, or a lack of education, the division of labour is forced and equality of opportunity cannot be realised. ${ }^{43}$ Durkheim's plea was thus for a system of meritocracy.

But this still leaves an important objection. What is so compelling about meritocracy that people will generally accept it as the guiding distribution principle? It is only one out of a number of theories of justice. There are also different versions of the meritocratic principle. ${ }^{44}$ Some theorists believe that the only social arrangements necessary for equality of opportunity to be realised is the absence of legal obstacles (such as job discrimination) to individual advancement. Others are more demanding with regard to the criteria that need to be in place for it to be realised. This more radical version of meritocracy also prescribes that people need to be given the same resources to perform. It should be clear that Durkheim falls in the latter category. Even if we grant Durkheim that the notion of meritocracy has powerful resonance in modern society, why should people necessarily accept his version of the principle rather than others?

Durkheim did have an answer to this objection, but it is not very convincing. As we said above, he postulated a close correlation between the type of social organisation and the kind of belief systems that will be found in a society. Given that the individual occupies such an important place in modern society, only philosophies that elevated the individual to a high status and that wanted to give each an equal chance would be viable, he believed. Although there certainly is some truth to this belief, the picture is much more complex than this, as the variety in political philosophies competing for acceptance in modern societies demonstrates.

41 Durkheim Suicide (note 32 above) at 251.

42 Durkheim Suicide (note 32 above) at 251; Durkheim The Division of Labour (note 4 above) at 313-314.

43 Durkheim The Division of Labour (note 4 above) at 314.

44 Christman Social and Political Philosophy (note 1 above) at 62-63. 
A further objection to Durkheim's theory is that he does not provide a criterium to distinguish a forced consensus from a genuine one. What is called 'public opinion' often reflects the views of powerful, and wealthy, people in society rather than the views of ordinary people. It is the powerful and the wealthy who own and control newspapers and television stations, not the latter.

Nevertheless, Durkheim's belief that individual desires need to be constrained has some resonance if we look at the ecological imperatives faced by late modern societies. It is doubtful that the planet has the capacity to absorb the damage that will be caused to its ecosystems if everybody consumed at the level of the average American.

Besides the notion of justice, Durkheim also foresaw a role for two social structures in his solution to egoism and anomie. These are the professional group and the state. They will respectively nurture the professional ethics and the common morality necessary to regulate economic life. The professional group will also form the vehicle by which the close community bonds of yore will be recreated.

With the advent of the division of labour, morality starts to differentiate between the different occupations, as we have seen above. But morality remains very weakly developed and feebly enforced if there isn't a group that is dedicated to promoting it. The stronger the group cohesion, the more numerous and binding the moral rules will be. Occupational groups are, according to Durkheim, particularly suited to fulfill this task. Durkheim's idea was that each trade or occupation should constitute itself into a professional group with regulatory powers. All the people that work in the construction industry, for example, employers and employees alike, should come together on a national basis in a professional group that is dedicated to that industry. ${ }^{45}$ In this group, decisions will be made about the appropriate regulations governing the relationships between employer and employee, between competitors, and between contractors and their clients. ${ }^{46}$

Durkheim hoped that such a group would, over time, start taking on an almost familial character. ${ }^{47}$ People will find their most important social bonds in this group. Durkheim hoped that these groups would cause 'the present cold moral temperature' of the world of work to become warmer. ${ }^{48}$ This group would also look after the welfare of individuals, providing services such as unemployment insurance and pensions. ${ }^{49}$ If a breadwinner falls ill for example, this group will support his or her dependents.

However, professional groups could not regulate the economy on their own. Some agency is necessary to guide the relationships between the different spheres of work. Each profession would naturally attempt to promote the interests of their own members, sometimes at the expense of the interests of others. This is where the state comes in, according to Durkheim. ${ }^{50}$ It was the only agency with a broad enough view to look after the interests of society as a whole, and thus to guard against abuses committed by sectional interests. It has to formulate and administer the general laws that regulate economic life. Professional groups, for their part, had to keep the state in check. ${ }^{51}$ In their absence, the state may become totalitarian, and completely stifle individual freedom.

45 Durkheim Professional Ethics (note 5 above) at 37.

46 Durkheim Professional Ethics (note 5 above) at 9.

47 Durkheim Professional Ethics (note 5 above) at 21.

48 Durkheim Suicide (note 32 above) at 381.

49 Durkheim Suicide (note 32 above) at 380.

50 Durkheim Suicide (note 32 above) at 374; Durkheim Professional Ethics (note 5 above) at 62; Durkheim The Division of Labour (note 4 above) at li, liv.

51 Durkheim Suicide (note 32 above) at 380; Durkheim Professional Ethics (note 5 above) at 63; Durkheim The Division of Labour (note 4 above) at liv. 
This balance of opposing forces was essential for individual freedom to be realised, according to Durkheim. The state is necessary to free individuals from the 'collective particularisms' of secondary groups. ${ }^{52}$ These can take the form of professional groups, local communities, religious groups or clans. Although they provide communal bonds and opportunities for sociability to the individual, these groups can also, because of their cohesiveness, repress individuality if they are not held in check. Due to the important role of the state in this regard, it is thus not true to claim that a small state is necessary for individual freedom, as free-market liberals claim, according to Durkheim. ${ }^{53}$ In fact, the opposite is the case, provided that a strong civic life exists to keep the state in check.

\section{$X$ Why the Invisible Hand of the Market is not Good Enough: A Summary}

It is perhaps now time to draw the different strands of Durkheim's complex argument against free market liberalism together. The free market does not have the capacity to create spontaneous social order out of the economic exchanges of selfish individual egos. It will, instead, produce conflict and social disorganisation. It assumes, for its functioning, social cohesion, but destroys such cohesion wherever it exists. This because it destroys previous forms of community, and does not replace them with anything new. It is also because it produces market outcomes that are clearly unjust, and that cannot receive popular legitimacy. Its end result is enormous individual egos with no conception of the common good.

To solve this problem, new forms of community are necessary that are more viable in the light of the division of labour. To make sure that these forms of community do not repeat the mistake of the old and repress individuality completely, the state is necessary to protect, and nurture individual freedoms. The communal groups are likewise needed to keep the state in check. These forms of social organisation should also produce the professional and common moralities needed to provide social cohesion in modernity.

Durkheim's critique of 'atomistic' liberalism and his emphasis on the need for communal bonds to maintain social cohesion have clear similarities with the current proponents of communitarianism such as Alasdair MacIntyre. He differs from them however with regard to his choice of community to provide these communal bonds: the professional group. His choice of this group, and his discourse on the need for the state to watch over communal groups to ensure that they do not repress individuality, demonstrates his sophistication. He thus anticipated the criticism of liberals like Kymlicka who pointed to the repressive tendencies of these groups. Durkheim can also be criticised however for his somewhat optimistic belief in the capacity of a common morality to contain the conflict of interests between the employer and employee constituents of the professional groups.

\section{The Social Construction of the Moral Subject}

We can now move on to another part of Durkheim's communitarian critique of liberalism: its conception of the subject. The notion of a free human subject of knowledge forms the basis for

52 Durkheim Professional Ethics (note 5 above) at 61-62.

53 Durkheim Professional Ethics (note 5 above) at 57. 
the defence of human rights in many currents of human rights discourse. ${ }^{54}$ It is derived essentially from the work of the $18^{\text {th }}$ century German philosopher, Immanuel Kant. For Kant knowledge is only possible on condition that a subject of such knowledge exists. Knowledge of the world cannot only be built upon the manifold impressions received from the senses. The sense impressions have to be constituted into meaningful perceptions, otherwise they will remain essentially chaotic. This is done by what Kant called the intuitions of space and time, and the categories of understanding such as cause, number, modality, and so on. The intuitions and categories are the basis of the knowing subject. Because they are a precondition for observation they cannot themselves be observed. This is why Kant called them a priori. The subject of knowledge therefore stands observation; it is the ground of observation but never itself the object of observation. The subject, as Kant defined it, is universal. All individual subjects with the capacity for knowledge have these attributes.

This subject is also the precondition for our ability to act morally. Because it is not constituted by observations of external (the world outside us) or internal (our own feelings and desires) objects, it completely escapes determination by them. It is therefore essentially free of outside conditioning. For Kant our actions can only be truly moral if they are based on a free exercise of our will, and not the result of conditioning by other forces. The existence of free will is the starting point of Kant's ethics. Society should be ordered in such a way that maximum scope is offered to individuals to freely exercise their will. In addition, my interaction with others must always take into account that they also possess a free will, just like me. I must therefore treat other people as ends in themselves and not as means to my own ends. Ethical rules should furthermore be universal: I can only act in a particular way if I also accept that the consequences will be acceptable if everybody else acts in that way.

Durkheim agreed with Kant's ethics, as well has his views on the need for a priori categories of understanding to make sense of observation. However, he differed from him in one important respect: the moral subject is a social construction, and not innate. From this it follows that the subject can never be as autonomous as Kant thought s/he should be. Individual autonomy must always be balanced by individual dependency on society. In the next few paragraphs we will pursue Durkheim's differences with Kant. In tune with his notion that the collective consciousness contains both a cognitive and a moral dimension, he gives attention to both aspects in Kant's thought.

To begin with the subject of knowledge: According to Durkheim, proponents of the view that the categories are innate, such as Kant, have the problem of explaining where they come from. ${ }^{55}$ But the alternative view, that the categories must have come from experience, was not acceptable either. This view implies that every individual subconsciously learns to make sense of his/her experience by slowly developing these categories over time. This empiricist approach, Durkheim argued, is no solution to the problem. The categories are prior to experience and they cannot be derived from experience. If this is done, they lose their universality and necessity.

To overcome this dilemma, Durkheim offered a new solution. In his view, the categories are social in origin. ${ }^{56}$ They are collective representations that have developed over many generations and that therefore contain the accumulated wisdom of innumerable numbers of individuals. Because they have been tested in experience over such a long time, they have acquired a

54 MJ Sandel Liberalism and the Limits of Justice (1998).

55 Durkheim The Elementary Forms (note 4 above) at 13-14.

56 Durkheim The Elementary Forms (note 4 above) at 15. 
degree of impersonality and objectivity and can therefore serve as a ground for our experience. ${ }^{57}$

Because of the social derivation of knowledge, it changes as social organisation changes. Initially it is very much culture-bound. Since the beginning of the modern world, a new kind of society has arisen, however, which Durkheim called international life, or international society. 58 This is Durkheim's version of globalization theory. Because society now becomes more universal, knowledge has to become more universal as well. As a result it jettisons its particularistic attachments, and this allows us to comes much closer to universal truths. In this case, then, the categories will indeed be universal, like Kant said, but that universality is not due to an innate characteristic of the human subject. It is rather the product of social development.

Durkheim makes much the same argument with regard to the moral subject: 'What lies at the basis of individual right is not the notion of the individual as he is, but the way society puts the right into practice, looks upon it and appraises it...The reason why he has more or fewer rights, certain rights and not others, is not that he is constituted in a particular way; it is because society attributes this or that importance to him'. ${ }^{59}$ An indication of this is the fact that the rights of individuals are 'in a state of evolution'. ${ }^{60}$ Durkheim is further convinced that the autonomy that Kant ascribes to humans cannot ever be absolute. ${ }^{61}$ Human autonomy always has to be counterbalanced by the real dependency of ourselves upon society.

Durkheim's emphasis on individual autonomy as well as dependency has to be seen in the light of his project to, on the one hand, combat a radical individualism, that is an individualism that elevated the interests of the individual above that of society, and to find space for individual freedom on the other. His argument for our dependency on society was as follows: We are dependent upon society, firstly, for our own survival. ${ }^{62}$ With the rise of the division of labour, other people become the source of the food we eat and all the products we consume. Society is secondly also a source of social recognition and of companionship. We furthermore owe our culture to society: 'We speak a language we did not create; we use instruments we did not invent; we claim rights we did not establish; each generation inherits a treasury of knowledge that it did not itself amass, and so on. We owe these varied benefits of civilization to society, and although in general we do not see where they come from, we know at least that they are not of our own making.' 63 Society can finally uplift and strengthen us. In communal gatherings, crowd psychology can lead to great outpourings of emotion which can leave people feeling transformed and renewed. 64

To make sense of Durkheim's position, we have to return to his vision of social development outlined above. He viewed human personalities as having a double nature: it consists of a collective and an individual part. The individual person only comes into existence when the collective conscience erodes enough so that it no longer rests so heavily on individual personalities. This is the result of the development of the division of labour.

Predictably, Durkheim was heavily criticized for this notion of a collective consciousness and

57 Durkheim The Elementary Forms (note 4 above) at 437.

58 Durkheim The Elementary Forms (note 4 above) at 446.

59 Durkheim Professional Ethics (note 5 above) at 67; Durkheim The Division of Labour (note 4 above) at 335.

60 Durkheim Professional Ethics (note 5 above) at 68.

61 Durkheim Professional Ethics (note 5 above) at 68.

62 Durkheim The Elementary Forms (note 4 above) at 208.

63 Durkheim The Elementary Forms (note 4 above) at 214.

64 Durkheim The Elementary Forms (note 4 above) at 211-212. 
his attendant belief in the reality of society as a force above individuals. Durkheim believed that society was a reality in its own right, separate from the individuals constituting it, even though it consisted of nothing but them in their combination. Because it questions dearly-held assumptions about the autonomy of individuals, this idea has encountered a lot of resistance. Especially the liberal tradition with its emphasis on the rights of individuals has had great difficulty accommodating it. Even the great John Rawls objected to notions that 'society is an organic whole with a life of its own distinct from and superior to that of all its members in their relations with one another'. ${ }^{65}$ A common reaction seems to be that the belief in a separate social reality contains illegitimate metaphysical assumptions, but it is really nothing of the sort. Durkheim's notion of social reality is based on the very straightforward principle of emergent systemic properties.

The argument is as follows: society is a complex system. It comes into being when individuals are combined in an organised way. ${ }^{66}$ The combination produces something new, something that is different from the parts. ${ }^{67}$ Society is therefore an emergent property of the complex organisation of individuals, to put it in the language of systems theory. The way society arises from the organisation of its parts is no different from the way life arises from the properties of organic molecules in their combination, or the way consciousness arises from the complex organisation of the brain for that matter. ${ }^{68}$ The materialist objection that consciousness must be an illusion because there is nothing in the brain but physical matter, is as silly as the idea that society must be an illusion because there is nothing in society but individual people. Both are emergent properties of complex systems. Understood in this way, it is difficult to see that the notion that society is a separate reality makes ontological assumptions any different from those implied by Kant's moral subject, or the freely choosing individuals so dear to neo-classical economics.

What evidence do we have that society is a reality in its own right? Well, Durkheim says, we become aware of the independent existence of society through the effects it has upon us. ${ }^{69}$ One of these is the constraint imposed by social norms. ${ }^{70}$ According to Durkheim, we are not, in the normal conduct of our lives, aware that our actions are constrained. ${ }^{71}$ As he puts it somewhere, we are no more aware of the weight of society than we are aware of the weight of the atmosphere pressing upon us. It is only when we transgress social expectations that we become aware of these constraints. The obvious case of this is the penalties that await us if we break the law. But there exist other, less obvious ways, of controlling our behaviour in the form of our fear of being rejected by our peers.

We also see the effects of society in the way social intercourse can transform individuals. During rituals, people lose their individuality to some extent, and become part of a bigger whole. They emerge from these experiences transformed and reinvigorated. This experience is especially common during times of collective ferment, such as political uprisings. Describing the situation during the French Revolution, Durkheim says: 'We see the most mediocre or harmless bourgeois transformed by the general exaltation into a hero or an executioner'. ${ }^{72}$ But this trans-

65 Sandel Liberalism (note 54 above) at 53.

66 E Durkheim The Rules of Sociological Method and Selected Texts on Sociology and its Method (1982) at 129.

67 Durkheim The Rules of Sociological Method (note 66 above) at 39, 45.

68 Durkheim The Rules of Sociological Method (note 66 above) at 43.

69 Durkheim The Rules of Sociological Method (note 66 above) at 43-51.

70 Durkheim The Rules of Sociological Method (note 66 above) at 51.

71 Durkheim The Rules of Sociological Method (note 66 above) at 51.

72 Durkheim The Elementary Forms (note 4 above) at 212. 
formative effect is not only restricted to exceptional circumstances. Religious rituals, or civic celebrations, can have such an effect on a regular basis.

Society is mostly made up of representations, and it therefore 'ideal' in that sense. These representations have a logic of their own, separate from individual representations. Durkheim's vision of collective representations is similar to the notion of 'culture', as it has been developed by anthropologists. Language, and belief systems, and 'discourses', are all collective representations in Durkheim's sense. They all have a certain autonomy from individual conceptions of them, and they all have their own logic, or 'conditions of existence'.

Durkheim's emphasis on the reality of the social, and its impact on individuals, finds a lot of resonance in the recent communitarian critiques of liberalism. Sandel's analysis of three different views of community provides a very useful space to parachute Durkheim into this debate. ${ }^{73}$ John Rawls's distinction between two different kinds of community forms the first two of his three categories. Because he puts it so well, I will quote him at length: ${ }^{74}$

... Of the two accounts of community Rawls presents, both are individualistic, although the way they are individualistic differs in each case. The instrumental account is individualistic in that the subjects of co-operation are assumed to be governed by self-interested motivations alone, and the good of the community consists solely in the advantages individuals derive from co-operating in pursuit of their egoistic ends. Rawls's account is individualistic in the sense of assuming the antecedent individuation of the subjects of co-operation, whose actual motivations may include benevolent aims as well as selfish ones...

The first sense of community is the one that results from the free actions of individuals in the marketplace, and is the one Durkheim criticised at length. Rawls's sense of community denies the subject any supra-individual or intersubjective aspects, and is bound to his rejection of the notion of an independent social reality. This is why it assumes the antecedent individuation of subjects. It does, however, recognise that subjects may be motivated by more than self-interest. In this respect, Rawls signals his rejection of a long tradition in social analysis (neo-classical economics, rational choice theory in sociology) which uses individuals' quest for maximum selfgratification as their main, if not only, explanatory variable. It also signals his rejection of the atomistic, libertarian politics that follows from it. In Rawls's view, subjects do not only have egoistic motivations, but can also be more altruistic in their intentions.

Sandel argues that even Rawls's 'sentimental' view of community is deficient in its conceptualization of the relationship between the individual and the social:

...On this strong view, to say the members of a society are bound by a sense of community is not simply to say that a great many of them profess communitarian sentiments and pursue communitarian aims, but that they conceive of their identity - the subject and not just the object of their feelings and aspirations - as defined to some extent by the community of which they are a part... . ${ }^{75}$

Sandel believes that Rawls's conceptions of distributive justice can only be defended on the basis

73 Sandel Liberalism (note 54 above) at 147-154.

74 Sandel Liberalism (note 54 above) at 148-149.

75 Sandel Liberalism (note 54 above) at 150. 
of such a 'constitutive' view of community, even though Rawls denies the viability of such a view. Because it rests on 'antecedently individuated' individuals, Rawls's view of community is also impoverished. I once again quote at length:

...Where "collective" assets imply endowments once separately held, now ceded to society as a whole, "common" assets do not necessarily; they need not logically presuppose a prior individuation. And while "reciprocity" implies a principle of exchange and hence a plurality of agents, the notion of "sharing" may suggest a solidarity such that no exchange need be involved, as in sharing a joke, or an aspiration, or an understanding. And while "association" and "co-operation" typically presuppose the antecedent plurality of those who join together to associate or cooperate, "community" and "participation" may describe a form of life in which the members find themselves commonly situated "to begin with", their commonality consisting less in relationships they have entered than in attachments they have found... . ${ }^{76}$

Sandel believes that the constitutive view of community, which he supports, would choose the latter term in this series of oppositions. Sandel's subject has an individual and a social part, and in this respect it is similar to Durkheim's view of the subject. His criticisms of Rawls are also similar to the criticisms that one can imagine Durkheim would make. But there is an important difference, and this suggests a limitation to Durkheim's theory (and in fact to all social constructionist accounts of the subject that Durkheim has, directly and indirectly, inspired many years later). Sandel's subject also has an, albeit limited, capacity for self-reflexivity, both individually and communally. ${ }^{77}$ It can, alone and in conversation with friends, gain some selfknowledge by distancing itself from its preferences and beliefs. However, the self that I discover in this way is always ready made, and the distancing only relative. It is never something that I, as a free agent, using the will, can create anew. This self-knowledge is therefore necessarily situated, and thus limited, but important nevertheless. Through it, the subject has some capacity to subject the values of the surrounding community to critical reflection. ${ }^{78}$ Notions of justice and the good are therefore never simply the product of 'ethnocentrism', as in Rorty's 'we do not do that around here', but also demands the capacity to criticize community values. ${ }^{79}$ This is why Sandel feels somewhat uncomfortable with the communitarian label he has acquired ${ }^{80}$ It is of course also the case that he isn't completely in Kymlicka's camp either, since the latter completely overestimates the subject's insight into itself.

Durkheim believes that subjects attain some level of distance from communal values as a result of the destruction of pre-industrial communities. They are therefore not completely taken up by the social any more. But this process of individuation seems to rest completely upon social forces, and entails little, if any, activity of self-reflection by the individual. This ties in with another problem with Durkheim's view of the subject: the lack of agency he ascribes to it.

This problem has received extensive attention in the so-called agency-structure debate in sociology, among others by the realist philosopher Roy Bhaskar. Bhaskar agrees with

76 Sandel Liberalism (note 54 above) at 150.

77 Sandel Liberalism (note 54 above) at 179-181.

78 Sandel Liberalism (note 54 above) at xi.

79 W Kymlicka Liberalism, Community and Culture (1989) at 66.

80 Sandel Liberalism (note 54 above) at xi. 
Durkheim's proof for the existence of society as a real entity (against methodological individualism) on the basis of its effects on individuals, and uses it as part of his own argument for the reality of society. ${ }^{81} \mathrm{He}$ criticizes Durkheim however because he had a reified conception of the social as existing separate from the intentional activity of people. Bhaskar summarises his own model of the social as follows:

Men do not create society. For it always pre-exists them. Rather it is an ensemble of structures, practices and conventions that individuals reproduce or transform, but which would not exist unless they did so. Society does not exist independently of conscious human activity (the error of reification). But it is not the product of the latter (the error of voluntarism). 82

Bhaskar's conception of society therefore accommodates both the idea of the reality of the social and the importance of human agency. His conception of society is similar to Sandel's vision of the subject. We always find society ready made, just as the subject always finds itself ready made. It is something we can reproduce or transform, but not something we can create anew. This places limits on our capacity to reconstruct it according to our preferences, just as there are limits on our ability to reconstruct ourselves according to our preferences. It also places limits on our ability to gain knowledge of it, just as there are limits on our ability to get to know ourselves. Neither society nor ourselves as subjects is ever completely transparent to ourselves.

Realist philosophers are concerned to reclaim the world as a reality external to our cognitions of it, in the face of both empiricism and idealism (and latterly postmodernism). All of these schools ended up viewing the external world as either unknowable, or illusory. It employs a stratified ontology, allocating causal powers and emergent properties to the different levels of the world. This provides a very appealing way to conceive of both the subject and society as mutually-constitutive realities. According to Margaret Archer both the subject and society are the result of emergent properties. ${ }^{83}$ Both can be viewed as complex systems, as I mentioned above, with a reality of their own. Against postmodernism and social constructionism (and Durkheim) she argues that the subject consists of 'personal emergent properties' that are needed to make sense of sociability. Role performance by subjects would be impossible in the absence of a subject with a sense of its own continuity and thus self-identity. This subject, in concert with other subjects, has the capacity to transform society, yet it is also partly the result of social conditioning. This, realist notion of society and the subject is in my view superior to both that of Durkheim (and social constructionism) and the atomistic subject of liberal theory.

However, Durkheim's vision of the subject is problematic for another reason, related to the difference between Sandel's first (instrumental) and second (sentimental) conceptions of community. It is never clear if the subject is inherently selfish, and thus needful of restraint by the common morality, or inherently both egoistic and altruistic. Most of the time, he opts for the first position, but sometimes he seems to mean the second. Part of the confusion is generated by the different

81 Sandel Liberalism (note 54 above) at xi; R Bhaskar 'On the Possibility of Social Scientific Knowledge and the Limits of Naturalism' in J Mepham \& DH Rubin (eds) Issues in Marxist philosophy Vol 3: Epistemology, Science, Ideology (1979) at 125.

82 Bhaskar 'On the Possibility' (note 81 above) at 120.

83 M Archer 'The Private Life of The Social Agent: What Difference Does It Make?' in J Cruickshank (ed) Critical Realism. The Difference it Makes (2003) 91. 
parts he identified in the personality. ${ }^{84}$ Lying below the individual and social parts of the personality is what Durkheim called 'physical man'. ${ }^{85}$ This is the consciousness that we have of our own bodies and feelings. It is the field of psychological (rather than social) facts, dealing with perceptions such as hunger, sadness, anger, love and so on. Superimposed on this is 'social man', which is the higher parts of the human personality, consisting of individual and social aspects.

'Physical man', concerned as it is with its own perceptions, is selfish, and thus needs to be restrained. On the other hand, Durkheim also suggested that people have an inherent need for social harmony and interaction with others, and that they come to value this harmony very much once they have experienced it. ${ }^{86}$ This seems to ascribe altruistic inclinations to 'physical man', which leads to a confusing picture. The basic problem, as Lukes points out, is that Durkheim tried to avoid using psychological notions in his concern to make the case for sociology as a discipline. ${ }^{87}$ However, in the process he inevitably smuggled in many psychological ideas, but did not theorise them properly, thus causing confusion.

Unlike the vagueness surrounding Durkheim's views of the inclinations of 'physical man', he was very clear in his views on the collective consciousness. The collective consciousness, he said, is altruistic. The collective consciousness represents the voice of society within us; it is, consequently, our collective conscience at the same time as it is our collective consciousness. As far as the individual part of our consciousness is concerned, Durkheim suggested that it is altruistic in an egoistic way. ${ }^{88} \mathrm{He}$ seems to have understood this as meaning that each of us is sociable (altruistic) in an individualistic (egoistic) way. But this causes even more confusion, because it implies that individualism is necessarily selfish, something he has just denied.

\section{Conclusion}

Durkheim presented a very meticulous critique of free-market capitalism, and a sophisticated and thoughtful defence of communitarianism. In his concern to establish the reality of the social and the essential role it has to play in a cohesive and just society, he did lean too much to the social side, and he did not give enough attention to the subject's capacity for self-reflection and agency. This mistake is repeated in the social constructionist accounts of the subject that is so prominent today. Durkheim spent much time considering the forms of communality that would be appropriate to a modern society. His alternative of the occupational groups have their shortcomings in a context where many people are unemployed on a long-term basis. Because they will form part of the public sphere and do not address the private sphere of the family, they also have shortcomings from a gender perspective, something that Durkheim, like his contemporaries, did not seriously consider. Durkheim also underestimated the staying power of traditional forms of community, such as religion and ethnicity. Nevertheless, it is fair to say that his alternative of the occupational group was never really tried, and deserves greater scrutiny. The same can be said for his possible contribution to the liberal-communitarian debate.

84 Gelderblom (note 20 above).

85 Durkheim Suicide (note 32 above) at 213.

86 Durkheim The Division of Labour (note 4 above) at xliii.

87 Lukes Émile Durkheim (note 30 above).

88 Durkheim The Division of Labour (note 4 above) at 146. 


\title{
Theology and the Fulfillment of Social and Economic Rights: Some Theoretical Considerations
}

\author{
- Nico N KoOpMAN \\ Beyers Naudé Centre For Public Theology, \\ Stellenbosch University
}

\section{Introduction}

It is an important presupposition of this article and in fact of the research project of which this book is a product that theory-formation is indispensable for addressing social and economic challenges. In fact the Greek root of the word 'theory' suggests that theory literally has to do with the way we see and think about the world. These ways of thinking and seeing influence our practices. ${ }^{1}$ The claim is legitimately made that there is no practice without theory. ${ }^{2}$ It is then indeed a challenge of the research project to impact on the theories, the ways of seeing and thinking regarding social and economic justice. Impacting the way appropriate role players see and think about social and economic rights paves the way for an impact on the various practices regarding social and economic justice. Prevailing practices might be revisited and transformed. Where constructive practices are not existing the way may be paved for the development of such practices.

In this article it is argued that theology may contribute to this process of theory-formation. Theology, as critical reflection upon the faith and practices of religion, ${ }^{3}$ through the ages indeed impacted on the theories that informed and guided the practices of faith and other communities regarding political, social and economic justice. Unfortunately this role has not always been constructive. Historically religion and theology fulfilled an ambiguous role. ${ }^{4}$ It made negative as well as constructive contributions to the wellbeing of society, also with regard to social and economic justice. The history of the world is full of examples of the negative effects of religion,

1 The Greek word (theõreõ) literally means to look or gaze at, to see, to perceive, to think, to discern and even to participate in and experience what you see. See in this regard G Abbott-Smith A Manual Greek Lexicon of the New Testament (1977) at 206-207.

2 For an extensive outline of the idea that all practices are theory-laden practices, see $\mathrm{D}$ Browning $A$ Fundamental Practical Theology. Descriptive and Strategic Proposals (1996).

3 This paper focuses mainly on Christian churches and theology. However, various points of convergence with other religions do exist.

4 For a good analysis of the potential destructive role of religions, see S Huntington The Clash of Civilizations and the Remaking of Worldorder (1997). For very helpful outlines of the ambiguous roles of religion with regard to social and economic justice, see two collections of essays in P Berger (ed) The Desecularization of the World. Resurgent Religion and World Politics (1999) and also W Green and J Neusner (eds) The Religion Factor. An Introduction to how Religion Matters (1996). The work of Roman Catholic theologian Hans Küng regarding the potential destructive and constructive roles of religion is also of importance. See amongst others H Küng (ed) Yes to a Global Ethic (1996) and also H Küng and KJ Kuschel (eds) A Global Ethic. The Declaration of the Parliament of World Religions (1993). 
eg crusades, inquisitions, killing of those who differ on doctrinal issues, killing of millions in the name of holy wars, and the legitimation of evils like Nazism and apartheid.

There is, however, also ample evidence of the constructive contributions of religion. The protest of the Confessing Church in Germany during the Nazi regime and the public involvement and witness of so-called struggle churches during the quest for inclusive democracy and during the first decade of democracy in South Africa bear witness to the redemptive role of religion and theology. ${ }^{5}$

This ambiguous role of churches also prevailed specifically with regard to the development of human rights. Churches did not only in its long history contribute to the violation of human rights, as practices like the subjugation of women and the justification of evils like racism and slavery demonstrate, but churches also offered theological arguments, ${ }^{6}$ albeit meagre ones, against the notion of human rights. On the other hand, there are ample evidence that the Christian tradition offered theological arguments in favour of, advocated for and helped to lay the foundation for the establishment of human rights. ${ }^{7}$

Villa-Vicencio makes a strong case to prove that the theological endeavours of mainly southern churches, in cooperation with churches in northern countries as well as partners in civil society and government, helped to ensure that so-called second and third generation rights be taken up into bills of rights more explicitly. In this regard Villa-Vicencio refers with appreciation to the positions of the Lutheran World Federation, the World Alliance of Reformed Churches and the Roman Catholic Church. ${ }^{8}$ The emphasis in these ecumenical positions on second and third generation rights was encouraged to a high extent by Christians in southern countries.

During the struggle years South African theologians developed, in dialogue and cooperation with struggle organizations in the political sphere and in civil society and also with other religious and secular traditions, a vision of social and economic justice. They articulated this vision publicly and eloquently during the years of the anti-apartheid struggle. This communication of the vision was done in the media and in theological studies, declarations and even an official confession of faith. ${ }^{9}$ It would perhaps not be pretentious to say that theology did not only impact on the public opinion during those years, but that it also helped to prepare the way for the eventual articulation of this vision of social and economic justice in the South African Bill of Rights.

5 For an outline of the constructive role of theology during and after apartheid see amongst others P Walshe 'Christianity and the Anti-apartheid Struggle: The Prophetic Voice within Divided Churches' in R Elphick and R Davenport (eds) Christianity in South Africa. A Political, Social and Cultural History (1997) at 383 - 399, and J de Gruchy 'African Theology: South Africa' in D Ford (ed) The Modern Theologians. An Introduction to Christian Theology in the Twentieth Century (1997) at $445-454$ and N Koopman 'Some Comments About Public Theology Today' (2003) Journal of Theology for Southern Africa 1 - 19 .

6 Typical arguments are: humans are sinners who can only talk about grace and privileges and not claims and rights; salvation is spiritual and private, and not political and economical. Therefore religious matters on the one hand, and political and economic matters on the other hand should be separated.

7 For an outline of the constructive role of theology in the development of the notion of human rights, see C Villa-Vicencio A Theology of Reconstruction: Nationbuilding and Human Rights (1992) and J de Gruchy Christianity and Democracy. A Theology for a Just World Order (1995), and Walshe (note 5 above) at $383-399$.

8 See Villa-Vicencio (note 7 above) at $131-153$.

9 The famous 1985 Kairos Document is one of the best examples of a theological declaration that opposed injustices. The document opposes so-called state and church theologies and opted for prophetic theology that spells out visions of an alternative society that cherishes justice. See The Kairos Document: Challenge to the Church: A Theological Comment on the Political Crisis in South Africa (1985). The former Dutch Reformed Mission Church even adopted a confession in which social and economic justice is described as not only a social and economic matter, but a moral matter, moreover, a matter of faith. See The Confession of Belhar (1986). 
Theology indeed made a crucial contribution to acknowledging social and economic justice issues as human rights issues. It contributed to the development of so-called second and third generation rights. The challenge for theology now is to explore ways of contributing to the fulfillment, implementation and actual practicing of these rights; to develop theories, ways of seeing and thinking, ways of public thinking, that foster the practical and concrete enforcement, implementation and fulfillment of these rights. Keeping the vision of social and economic justice alive is important, ensuring the articulation of this vision in bills of rights is important. But exploring ways of ensuring that this vision be embodied now calls for our attention.

This paper consequently considers the role of theology in developing theories that might enhance the fulfillment ${ }^{10}$ of social and economic rights ${ }^{11}$ and the eventual dawning of a more just society. The potential contribution of theology to the process of theory building that serves the fulfillment of social and economic rights is investigated with reference to the dialogue and cooperation of theology with three environments, namely broader society, the academy and religious organizations, specifically churches. ${ }^{12}$ This threefold distinction is very helpful, though room should be left for the fact that the three realms are not neatly separated from each other. They do impact on each other, and some themes are addressed in all three though with different emphases and modes.

The emphasis of dialogue and cooperation does not only build on the style in which theology was done by so-called struggle theologians in the apartheid era. It spells out the mode in which theology is to be done that seeks serious attention in a pluralistic society. The outline of these various dialogues and cooperations will hopefully verify this point.

10 Human rights scholar, A Gewirth 'Are there any Absolute Rights?' in J Waldron Theories of Rights (1984) at 92, offers a useful distinction on the different applications of human rights: 'A right is fulfilled when the correlative duty is carried out, ie when the required action is performed or the prohibited action is not performed. A right is infringed when the correlative duty is not carried out, ie when the required action is not performed or the prohibited action is performed. Thus someone's right to life is infringed when the prohibited action of killing him is performed, someone's right to medical care is infringed when the required action of providing him with medical care is not performed. A right is violated when it is unjustifiably infringed, when the required action is unjustifiably not performed or the prohibited action is unjustifiably performed. And a right is overridden when it is justifiably infringed, so that there is sufficient justification for not carrying out the correlative duty, and the required action is justifiably not performed or the prohibited action is justifiably performed.'

11 Economic and social rights are distinguished from so-called political and civil rights. In the first centuries of the development of human rights the emphasis was on the latter rights. During the second part of the twentieth century economic and social rights were increasingly emphasized, especially at initiative of socalled poorer southern countries. For the distinction between three generations of rights, namely first generation (blue) rights, second generation (red) rights and third generation (green) rights, see J van der Westhuizen 'The Human Rights Debate in South Africa' in K Nürnberger (ed) A Democratic Vision for South Africa. Political Realism and Christian Response (1991) at 471 - 487. The idea of generations of rights should not give the impression that the social, economic and environmental rights did not feature in the earlier phases of the development of human rights. However, they did not receive the same level of attention as the so-called first generation rights.

12 This threefold distinction is borrowed from North American Catholic theologian David Tracy who identifies the church, the academy and the broader society as the three publics, reference groups or social locations that theology engages with. See his The Analogical Imagination. Christian Theology and the Culture of Pluralism (1981) at 3, 5. Tracy (at 21) is of opinion that all theology is in some meaningful sense church theology, ie ecclesial theology. Theology develops in a sense from within the church as both a pneumatological and sociological body. When he refers to the church as one of the publics of theology, he especially has this sociological nature of the church in mind. 


\section{Theology in Dialogue and Cooperation with Broader Society}

In investigating the role of theology in developing thinking that will enhance the fulfillment of social and economic rights, dialogue and cooperation with broader society is required. Dirkie Smit ${ }^{13}$ offers a very helpful description of modern democratic societies. He is of opinion that modern societies consist of four spheres, namely the political and economic spheres, as well as the spheres of civil society and public opinion formation. ${ }^{14}$

The political sphere focuses on the state, government, political power and the control and regulating of public life. The economic sphere entails aspects like the so-called autonomous market-economy, globalisation, ecology, science and technology. Civil society focuses on themes relating to the relationship between theology and, amongst others, the institutions, organizations, associations and movements of civil society which, independently from the state and economy, strive to enhance the quality of life, satisfy the needs and foster the interests of people, change the nature of society and build the common good, that is a life of quality for all. Schools, legal bodies, cultural and sports clubs and the neighbourhood are all institutions of civil society. Sociologically speaking churches are part of civil society, albeit institutions with both a sociological and pneumatological character. The area of public opinion formation focuses on themes like the nature of society, the common foundational values for society, common challenges and common priorities for society. The ensuing public opinion paves the way for jointly striving towards the common good. 15

The dialogue and cooperation of theology with these spheres take place in appropriate modes. In this regard the typology of North American theologian James Gustafson ${ }^{16}$ is very helpful. He identifies four varieties of moral discourse which suggest four ways in which theology can engage with these spheres.

The prophetic discourse takes on the form of indictment and a more utopian form. Indict-

13 See D Smit 'Oor die Unieke Openbare Rol van die Kerk' (1996) Tydskrif vir Geesteswetenskappe 190-198.

14 Tracy (note 12 above) at $6-14$ divides the public of society into three spheres, namely the realm of the technoeconomic structure that deals with the organization and allocation of goods and services; the realm of the polity where the aim is to embody social justice in the traditions and institutions of society through the legitimate use of power and force, and the regulation of conflict within the rule of law. The realm of culture which includes art and religion explores and expresses the meaning and values of individual, group and communal existence.

15 Smit's distinctions coincide with the distinctions of Jürgen Habermas. For him the democratic public consists of four spheres. At its centre are government, the civil service, judiciary, parliament, political parties, elections and party competition. Outside this core system, but still belonging to the state is an inner periphery of institutions such as regulatory agencies with powers delegated by the state. The second public sphere, which is part of the outer periphery, is organizations that Habermas calls customers, ie business associations, labour unions and private organizations. The third public sphere, which is also part of the outer periphery consists of organizations that he calls the suppliers, ie voluntary associations, churches, new social movements and public interest groups. Fourthly he makes room for the public opinion that is formed by the dialogue of public interest groups and professionals who, as the sensors of society, identify, draw attention to and interpret social problems and who, with the aid of the media, propose solutions and apply pressure that can bring forth change that will better the situation of especially the disadvantaged. See J Habermas Between Facts and Norms (1996).

16 See J Gustafson 'An Analysis of Church and Society Social Ethical Writings' (1988) 40 Ecumenical Review at 267 -278; 'Varieties of Moral Discourse: Prophetic, Narrative, Ethical and Policy' (1988) The Stob Lectures of Calvin College and Seminary; 'Moral Discourse About Medicine: A Variety of Forms' (1990) Journal of Medicine and Philosophy $125-142$. 
ment points to the roots of moral or social problems. Utopian discourse evokes a hopeful vision. It proclaims an ideal state of affairs in the future and allures and motivates people towards its realization. In the narrative discourse stories and parables are told of significant events and of moral heroes in the community and tradition. These stories sustain common memory in a community. They shape the consciences, moral identities and characters of members of the community. More than a rigorous casuistic argument stories provide illumination and help in the process of moral decisionmaking. The ethical or technical discourse uses philosophical and rigorous modes of moral argumentation. Logic, precise distinctions, precision in use of concepts like justice and rights and the identification of the rational grounds of autonomous ethics, which might be backed by Christian convictions which can be shared with non-believers, are typical features of this discourse. The policy discourse is the discourse of the policy and decision makers in society. They deal with questions like: what is desirable within the constraints of what is possible; do we have power to affect change, what are the time frames for the achievement of ends; do we have all the necessary information and knowledge? The policy discourse entails that we have to distinguish between matters of ethical principle and the inferences we draw for policy. We can be more certain about the first than the second.

In the dialogue and cooperation of theology with the various spheres of society on the achievement of social and economic justice attention is to be given to all these discourses. The vision of an alternative society that energises and opens innovative possibilities should be spelled out. ${ }^{17}$ Clear critique should be voiced where injustices exist. The grass roots stories of poverty and suffering are to be heard, but also the stories of even smaller achievements and successes. The technical discourse is of immense importance. It suggests that it is not enough to spell out broad principles and visions of justice. The hard work of critical, scientific, interdisciplinary and intersectoral analysis and deliberation which can lead to even preliminary solutions that are jointly reached is of crucial importance. Engagement with these various discourses paves the way for appropriate interventions in the policymaking processes on different levels of governance and authority in different spheres of society. ${ }^{18}$

In engaging these spheres it is important that theology resist the temptation to fulfill the role of being the only watchdog of society that just engages in the prophetic discourse of critique

17 Envisioning opens up creative, innovative and surprising possibilities that technical reflection alone cannot. Old Testament theologian Walter Brueggemann The Prophetic Imagination (1978) at 13 argues that envisioning, imagining, enables us to see new possibilities that are in contrast to the dominant gloomy beforehand possibilities. Vision creates hope in situation of despair and energy where people feel powerless. Vision, on the other hand, helps us to be clearly aware of the shortcomings of our endeavours and policies. Vision opens the door for courageous and constructive criticism. Various forms of the church help to develop this vision of an alternative society. North American theologian Stanley Hauerwas argues that ethicists function like artists. What they see determine not only their choices and actions but also who they are. We are and we do what we see. Vision determines ethics. See S Hauerwas Vision and Virtue: Essays in Christian Ethical Reflection (1974); Truthfulness and Tragedy: Further Investigations in Christian Ethics (1977); A Community of Character: Toward a Constructive Christian Social Ethic (1981); The Peaceable Kingdom: A Primer in Christian Ethics (1983) and various other works.

18 Theology's dialogue and interaction with broader spheres of society occur mainly through the denominational and ecumenical church. There are instances where theologians make direct input in their personal and professional capacities, eg in ethical committees of hospitals, ethical committees in the business and public media sectors as well as parliamentary portfolio committees. The bulk of inputs are however made through church bodies. The remarks made here are therefore also relevant to the section on the institutional church below. 
and indictment. In the same vein it is not responsible theology to merely spell out the vision of a good society. ${ }^{19}$ The road of partnership that institutions like the South African Council of Churches currently opt for is perhaps the most fruitful path to follow. In this cooperation it is important that theology not be co-opted by the agenda of the state. ${ }^{20}$ A guiding principle for this cooperation is to continually ask what the impact of dialogue, cooperation, compromises and policies are on poor and vulnerable people. One of the most cherished notions in Christian theology that Liberation Theology reminded us about during the 1960s to 1980s is the conviction that God is in special way the God of the poor, the destitute and the wronged. The acid test for our social and economic discourses, policies and priorities is the question on how they impact on the most vulnerable in society.

Where the engagement of theology with political institutions, business and trade unions, sport and cultural bodies, schools and other organs of civil society, different forms of the modern communication media, takes place within the parameters, modes and style outlined above, these encounters might prove to be fruitful for the quest of developing new ways of thinking about and new practices for the fulfillment of social and economic rights.

\section{Theology in Dialogue and Cooperation with the Academy}

Tracy ${ }^{21}$ describes the academy as that public or social location of theology where serious, critical scientific enquiry takes place with other academic disciplines. In its engagement with the academy theology is challenged to provide arguments that all reasonable people from diverse religious and secular traditions can recognize as reasonable. In this discourse appeals are made to universal faculties such as experience, intelligence, rationality and responsibility. Claims are stated with appropriate warrants, backings and rebuttal procedures. He also pleads that although theologians confess allegiance to a specific religious tradition or to a praxis movement bearing religious significance, they should abstract themselves from these faith commitments for the sake of critical analysis of religious and theological claims by outsiders and by those who belong to the tradition. There are of course many theologians who would oppose Tracy on this point. They would argue that you need not abstract and distance yourself from your faith commitments in order to do critical and honest introspection into the cognitive claims of your tradition. Such a withdrawal for the sake of honest scientific enquiry is viewed as being dishonest.

With an appeal to Thomas Kuhn's paradigm theory Dutch systematic theologian Gijsbert van den Brink, 22 supports the later developments in the philosophy of science discourse which make room for adherence to particularistic commitments in the scientific endeavour. Although

19 For an analysis of the prophetic task of churches in the context of poverty in a democratic society see $\mathrm{N}$ Koopman 'Freedom of Religion and the Prophetic Role of the Church' (2002) 43 NGTT 237 - 247 and also my 'Let the Plight of the Poor be Heard. Prophetic Speaking about Poverty Today' (2004) 45 NGTT $440-451$.

20 For a description of the danger of Constantinianism see $\mathrm{N}$ Koopman 'Tussen die Duiwel van Konstantinisme en die Diep Blou See van Sektarisme - Kerk en Staat Verhoudinge in Post-apartheid SuidAfrika' (2001) 43 NGTT 135 - 146. The concept 'Constantinianism' derives from the era since Caesar Constantine when the once persecuted Christian religion became state religion after the conversion of Constantine to Christianity in the fourth century. The concept refers to any co-option of the church by the agenda of the state.

21 See Tracy (note 12 above) at 56-59.

22 See G van den Brink Een Publieke Zaak. Theologie tussen Geloof en Wetenskap (2004). 
he reckons that there is something to be learned from older important philosophies of science, ${ }^{23}$ it remains his conviction that these approaches do not take the significant and determinative particularistic influences like faith commitments of scientists seriously enough.

In the encounter with the academic public theology makes the choice for scientific reflection, for making faith convictions as far as possible rationally accessible to all reasonable people, for constructing arguments that pass the test of coherence, consistency and logical reasoning. However, theology does not have to distance itself from its faith commitments, but takes care that such commitments do not exclude scientific scrutiny. The age-old Christian notion of fides quaerens intellectum (faith seeking understanding) that Anselm of Canterbury framed in the $11 / 12^{\text {th }}$ century needs fresh application in this dialogue of theology with the academic public.

Against this background sketched in the previous paragraphs some suggestions can be made about the contribution of theology in the dialogue and cooperation with the academy.

A first contribution of theology might be to help dialogue partners to view the challenge of the implementation of human rights not only as a political, social, economic, legal, philosophical and sociological challenge but as a moral challenge. Morality has to do with the wellbeing, happiness and wholeness of human beings and other creatures. Something is morally good when it serves this wellbeing and it is morally bad if it does not. ${ }^{24}$ If theology embarks on this endeavour it strengthens those in other disciplines who already view the challenge of social and economic justice as a moral challenge.

Some theologians are of the opinion that the contribution of theology to social-ethical and economic-ethical challenges is merely to help portraying these as ethical challenges and to provide a meaning-giving framework that is based in religious or secular belief systems, and that serves to motivate people to participate in the quest to address these challenges. Other theologians, however, are of opinion that theology indeed can make a unique contribution to the contents of the debate. ${ }^{25}$

I am of the opinion that theology might enrich the contents of the discourse on the implementation of human rights. Theology might be able, for instance, to assist the discourse in reaching thicker descriptions of justice. Elsewhere ${ }^{26}$ I described various forms of justice and

23 Van den Brink reasons that despite their weaknesses older philosophies of science still pose some important challenges. Logical positivism challenges us to ensure that cognitive meaningful statements be verifiable as far as possible; confirmationism teaches us that it is much more difficult to confirm so-called non-existence statements then existence statements; the falsification theory of Karl Popper challenges us to open ourselves to criticism, to continuous disturbance and critical opposition by researchers who do not just take our positions for granted. See Van den Brink (note 22 above) at 219-221.

24 For a definition of morality in terms of this notion of security and wellbeing, see B Birch and L Rasmussen Bible and Ethics in the Christian Life (1989) at 38-39.

25 For an extensive discussion of these two opposing views regarding the contribution of religion and theology to ethical challenges see $\mathrm{N}$ Koopman 'The Role of Tradition in Moral Decisionmaking and Moral Consensus' (2004) 45 NGTT 838 - 848. In this article I discuss the so-called liberal position of Dutch scholar Harry Kuitert who reckons that religion and theology do not contribute to the contents of morality, but that it merely serves as protector, feeder and sustainer of morality, and as motivator for morally good living. I bring this position in dialogue with the so-called postliberal position of Stanley Hauerwas who reckons that religion and theology fulfill a crucial role with regard to the contents of morality since morality is in essence agent, narrative and community-dependent.

26 For a brief outline of utilitarian, libertarian, communitarian and egalitarian theories of justice and the theory proposed by theologian Karin Lebacqz, see N Koopman 'Justice and Land Reform' (2004) paper read at the international conference on land reform in Utrecht, Netherlands, and accepted for publication in Studies in Reformed Theology. Karin Lebacqz expresses appreciation for Rawls' emphasis of the least advantaged, Nozick's valuing of freedom, the emphasis of the priority of the poor in the 1986 pastoral letter on eco- 
then opted for an understanding of justice as compassionate justice. Hereby I mean that justice has two dimensions that can be derived from two different words for justice in Hebrew. Tsedaqah refers to the sacrifice that is required to transform people into just people and into people who are also willing to make sacrifices for the sake of the other. Mispat refers to forensic justice that is enforced by legal measures. These measures would include contemporary notions like human rights. Compassionate justice therefore would argue that legal justice and the ethos of compassion and sacrifice cooperate to bring forth a life of justice and dignity for all humans and the environment. Making the notion of sacrifice part of the discourse about social and economic justice might enhance our progress towards fruitful solutions. The implication of the notion of sacrifice for current and potentially new political, economic and legal measures of reparation for the sake of higher levels of equilibrium, might be an important part of the discourse on social and economic justice.

\section{Theology in Dialogue and Cooperation with Churches}

The dialogue and cooperation of theology with churches is very important. The mutual impact of theology and this realm is also prevalent as with the two other publics. For various reasons churches do have the potential to make a significant contribution to the realizing of social and economic rights. The potential of churches is amongst others reflected in the high percentage of people belonging to religions in South African society. The dawning of modernisation in its institutionalized forms of democratic state, market-driven economy, civil society and sophisticated and influential public media, as well as its Zeitgeist of individualism and rationalism have not lead to secularization in South Africa. On the contrary, most recent statistics indicate that more than $90 \%$ of South Africans belong to one or the other form of religion. The percentage of Christians rose during the last few years to almost $80 \% .27$

It should, however, be noted that although modernization has not been accompanied by secularization, it has affected religion in terms of modernity's central feature of the fragmentation of society into various autonomous life spheres. This development has created a high potential for the privatization of religion. So although people might still be religious, religion is removed from the various public spheres of society. The potential of such a privatized religion to impact positively on society is very low. On the contrary, private religion does not only imply withdrawal from society, it often also entails destructive forms of religion and morality, eg fundamentalism, intolerance, moral absolutism and judgementalism. When we embark on the investigation of the role of churches in the advancement of social and economic rights these facts should be taken into consideration. Whilst doing this we should also always be

nomic justice of the North American Catholic Bishops, and the recognition of the epistemological privilege of the poor, ie God is only known in the doing of justice by liberation theologian Jose Miranda. Based on these positions she constructs her own position that calls for more attention to the narratives of the marginalized in the discourse about social and economic justice.

27 See in this regard H Hendriks The Future of the Church, the Church of the Future (2004) Unpublished Inaugural lecture, University of Stellenbosch. This trend of growth in religiosity is not limited to South Africa. Peter Berger has replaced his secularization thesis with a de-secularisation thesis. After arguing since the sixties of the previous century that secularization will spread all over the world and that religion will be increasingly marginalized he now observes growth of religiosity in all parts of the world, especially in South America, Africa and Asia. Although Western Europe is highly secularized he is of opinion that religion survives in non-institutional form in some of the Western European regions. See Berger (note 4 above) at 1-18. 
aware of the ambiguous history of religion in social matters as described earlier in this article. The challenge to theology is to assist and guide churches in discovering and actualizing their constructive potential with regard to the challenge of the realization of social and economic rights.

In investigating the role of churches in the fulfillment of social and economic rights, Dirkie Smit's identification of six forms of the church might be helpful. ${ }^{28}$ The first four forms constitute the church as institution. They are worship services, local congregations with their various practices, denominations and ecumenical bodies. The other two forms constitute the church as organism, namely individual Christians in their normal daily roles in family, work, neighbourhood etcetera, and individual Christians in voluntary organizations.

(a) Worship services have the potential to transform people into just people who can enhance the social and economic transformation of society. The impact of worship on ethics, also economic ethics is increasingly treasured by a growing number of authors. In a recent publication American theologians Stanley Hauerwas and Samuel Wells pleaded for an end to the separation of worship and ethics that developed under the influence of Immanuel Kant. From different perspectives various authors demonstrate how worship impacts on our ethical choices, policies and moral living in various walks of life, specifically in the area of social and economic justice. ${ }^{29}$ The transformative, subversive and revolutionary potential of worship services are investigated by an increasing number of theologians. Those participating in worship see alternative realities that are in conflict to the prior realities of a world where injustice reigns supreme and they are transformed to participate in the building of these alternative realities. Those who pray for daily bread, see a world where there is bread for everyone and they participate in creating such a world.

(b) Various practices of congregations also enhance the fulfillment of social and economic rights. The definition of practices according to American theologians Craig Dykstra and Dorothy Bass ${ }^{30}$ is very helpful. They define practices as follows: 'By "Christian practices" we mean things Christian people do together over time to address fundamental human needs in response to and in the light of God's active presence for the life of the world.'31 Practices refer to cooperative and meaningful human endeavours in which certain beliefs, virtues and skills are entwined with certain behaviours, relationships and symbols. ${ }^{32}$

For the purpose of this article I briefly refer only to two important Christian practices that impact constructively on the quest for economic justice. Stanley Hauerwas writes clearly about the role of baptism and eucharist as Christian practices that impact on public life, specifically on the quest for social and economic justice. He states that baptism and eucharist are not only motives or causes for our social work, they are our effective social work. In them we see most clearly the marks of God's kingdom in the world. ${ }^{33}$ Elsewhere he describes how the celebration of the eucharist in the United Methodist congregation of

28 See D Smit 'Oor die Kerk as Unieke Samelewingsverband' (1996) Tydskrif vir Geesteswetenskappe at 119 $-129$.

29 See S Hauerwas and S Wells (eds) The Blackwell Companion to Christian Ethics (2004).

30 See C Dykstra and D Bass 'A Theological Understanding of Christian Practices' in M Volf and D Bass Practicing Theology. Beliefs and Practices in Christian Life (2002) at 13-32.

31 See Dykstra and Bass (note 30 above) at 18.

32 See Dykstra and Bass (note 30 above) at 19-21.

33 See S Hauerwas The Peaceable Kingdom. A Primer in Christian Ethics (1983) at 108. 
South Band, Indiana, has lead to meal sharing with poor members of the neighbourhood that made it clear 'that we were not simply another social agency that does a little good, but a people called out to witness to God's presence in the world. That presence which comes in the meal we share sustained that church's ability to be present in that neighbourhood as a symbol that all was not lost'. ${ }^{34}$

(c) Denominations and ecumenical bodies can embark on the so-called priestly task of showing solidarity with the marginalized and the wronged. This care, compassion and solidarity are expressed in the various diaconal services of churches, amongst others homes for the aged, disabled, orphans (especially the growing number of aids related orphans), day care centres, crèches, after school care centres for children whose parents are working long hours, church schools, soup kitchens and other feeding schemes, shelters for refugees and victims of disasters like burnt down informal settlements, employment creation initiatives and entrepreneurial courses and initiatives. Many of these initiatives are undertaken in cooperation with role players in other spheres of society, amongst others governmental institutions, businesses, trade unions and even the media. These priestly practices of solidarity and care are not small endeavours to fulfill social and economic rights in humble and preliminary ways. This direct involvement in the plight of those who do not experience humane living conditions also constructively inform, influence and inspire thinking on the fulfillment of social and economic rights and justice.

Denominations and ecumenical bodies also fulfill the prophetic task of clearly spelling out the vision of a good society where people enjoy a life of dignity and justice. This prophetic task also involves a critique of society where the conditions of this good society are not met. Through declarations of faith and even confessions of faith churches spell out this vision and offer this constructive critique. A very recent example of the involvement of ecumenical church bodies on this level is the adoption of a processus confessionis, that means engaging in a process of confessing faith, on economic justice by the World Alliance of Reformed Churches, the Lutheran World Federation and the World Council of Churches. This processus confessionis is the initiative of the Southern African Alliance of Reformed Churches (SAARC) in which Stellenbosch theologian Russel Botman, who was then president of SAARC, played a pivotal role. 35 The thinking on matters of social and economic justice in many Reformed Christians in Southern Africa, as well as in other parts of the world are increasingly influenced by the Confession of Belhar. In October 2004 Christians from Reformed churches in South Africa, other African countries, Belgium, Germany, The Netherlands, Sweden and the USA met in Stellenbosch at the Beyers Naudé Centre for Public Theology for an international conference on the theme Confessing and Embodying Belhar and Barmen Today. The theme of this conference suggests that Christians view social and economic justice as a faith issue. This means to confess faith in God is to work for social and economic justice. ${ }^{36}$

Churches on denominational and ecumenical level also have the responsibility to intervene

34 See S Hauerwas Christian Existence Today. Essays on Church, World and Living in Between (1995) at 124.

35 For a discussion of this processus confessionis, see N Koopman “ "... in a special way the God of the poor, the destitute and the wronged...". A Basic and Neglected Conviction of (Reformed) Theology?' in P Coertzen (ed) 350 Years Reformed 1652-2002 (2002) 252 -260.

36 The Confession of Belhar (note 9 above). The Barmen Declaration is a confessional document that was adopted in 1934 by the Confessing Church in the city of Barmen, Germany. The Christians in this Confessing Church opposed the growth of Nazism in Germany. 
in public policy processes. ${ }^{37}$ It is crucial to help ensure that laws are formulated that enhance the vision and ideals of justice and dignity spelled out in the Bill of Rights. For this purpose various denominations and ecumenical bodies have already established public policy liaison offices at national parliament in Cape Town, amongst others the South African Council of Churches, the South African Catholic Bishops Conference, the Dutch Reformed Church as well as the Baptist Church. These bodies do not only influence the public policy processes through presentations to the portfolio committees of parliament. They also conscientise and inform local congregations and individual Christians on public policy matters, amongst others specific issues of social and economic justice. One of the remarkable achievements of these offices is the annual Peoples Budget initiative with trade unions and other institutions of civil society. These partners undertake a critical evaluation of the national budget in terms of its impact on poor people. They also suggest constructive alternatives. Denominational and ecumenical bodies are also challenged to even inform local worship services regarding issues of social and economic justice through appropriate information and guidelines for liturgies. ${ }^{38}$

(d) Individual Christians in their normal daily roles and in voluntary organizations are equipped by the institutional church to participate in appropriate ways in various sectors of society in the fulfillment of social and economic rights and the achievement of social and economic justice. They are equipped with regard to moral decisionmaking ${ }^{39}$ on economic matters as well as the embodiment of central economic-ethical values. Without pretending to become economists it is important to have some orientation regarding economic matters in order to be able to impact in an informed and responsible way on the direction these matters are taking at home, school, neighbourhood, local government, business, trade unions, churches and all walks of life. Proper utilization of the media, amongst others newspapers, magazines, radio, television, internet, art and music can enhance this process of influencing the thinking and practices of people regarding social and economic justice matters. Individual Christians in their various affiliations also participate in advocacy and protest

37 North American theologian, JP Wogaman Christian Perspectives on Politics (2000) at 264 - 273 summarises the public responsibility of churches as follows: Influencing the public ethos, educating the church's own membership about particular public issues, participating in advocacy and lobbying initiatives, supporting specific political parties and candidates with positive records on civil rights and other social justice issues, encourage lay Christians to establish a Christian political party if circumstances warrant this move, engage in truly extreme situations of oppression in civil disobedience and participation in even violent revolutions. The contentious nature of some of these proposals are obvious.

38 In 2004 the Beyers Naudé Centre for Public Theology was requested by the South African Council of Churches to do research on the response of South African churches to the arms deals of the South African government during the first decade of democracy. These findings were tabled at an international conference on the international arms trade in Sweden. One of various suggestions was that ecumenical bodies like the South African Council of Churches provide local congregations with guidelines for liturgies on human security which entails the building of social and economic justice and peace. During the Anti-apartheid struggle these liturgies played a crucial role in influencing and transforming the thinking of people regarding matters of social and economic justice. See in this regard N Koopman 'Defence in a Democracy. A Church Perspective on the Postapartheid Defence Review Process' in K Haglind (ed) Arms Trade. Final Report from the 2nd Ecumenical Conference in Gothenburg (2004).

39 Decision making occurs at the hand of three classical approaches to moral decisionmaking, namely the deontological and teleological as well as virtue approaches to ethics. For very helpful orientations to various approaches to moral decisionmaking see amongst others M Baron, P Pettit and M Slote Three Methods of Ethics: A Debate (1999); P Singer (ed) A Companion to Ethics (2002); R Lovin Christian Ethics. An Essential Guide (2000). 
activities for the sake of the materialisation of social and economic justice. These actions which are mainly the initiative of civil society organizations can occur on local, provincial and national levels. Due to the astronomic developments in the area of information technology such actions can take on international dimensions. The protest of civil society in 2003 against the war in Iraq is a very good example of a joint international campaign of civil societies from various parts of the world. Such international actions are crucial in the light of the ambiguous effects of economic globalisation.

Individual Christians contribute to ways of thinking and practices that enhance the fulfillment of social and economic rights by embodying the values that they are campaigning for. The institutional church, through its worship services, congregational practices, denominational and ecumenical policies, declarations, confessional statements and public actions and witnesses, contributes to the transformation of individual Christians into people who live with specific virtues. According to North American theologian J Philip Wogaman a virtue is the tendency and predisposition to be and to act in accordance with goodness. ${ }^{40}$ Virtues are incarnated, embodied, practiced values. ${ }^{41}$ Where these virtues, with their personal and public dimensions, are cherished and developed, ${ }^{42}$ significant impact is made on the development of theories and practices that enhance the fulfillment of social and economic rights.

\section{$V$ Conclusion}

The quest for theories that seek the fulfillment of social and economic rights and the restoration of a life of dignity for all is an act of responsibility. The ethics of responsibility gained momentum in the midst of the immense suffering due to amongst others the two destructive world wars of the twentieth century. Political scientists, lawyers, economists, philosophers and theologians joined the search for just, peaceful and sustainable societies where the life of current and future generations could flourish. North American theologian Helmut Richard Niebuhr ${ }^{43}$ joined this quest. For him responsibility starts with the question: what is going on

40 See J Wogaman Christian Moral Judgment (1988) especially chapter 2.

41 The Christian tradition formulated seven virtues. Four of them are borrowed from Greek philosophical thinking, specifically from Aristotle, and are called the cardinal virtues. Justice entails that people embody fairness, commitment to a life of equality, dignity and and joy for all. Just people are even willing to sacrifice for the sake of the other. The other three cardinal virtues are temperance, discernment or wisdom, and fortitude or courage. The three theological virtues that complete the list of seven Christian virtues are faith, hope and love. All these virtues impact on a life of social and economic justice and dignity for all. For very helpful accounts of the virtues see besides the works mentioned above about approaches to moral decisionmaking also S Hauerwas and C Pinches Christians among the Virtues. Theological Conversations with Ancient and Modern Ethics (1997) and N Richardson 'Ethics of character and community' in C VillaVicencio and J de Gruchy (eds) Doing Ethics in Context. South African Perspectives (1994) 89 - 101.

42 Recently much work is done in the field of moral and virtue formation. Both the theological and anthropological dimensions of these processes are investigated. For a general orientation to the work of moral formation see N Koopman and R Vosloo Die Ligtheid van die Lig. Morele Oriëntasie in ' $n$ Postmoderne Tyd (2002). For a very helpful description of the various modes of moral formation, see the important and famous work of Roman Catholic Dutch theologian J van der Ven Formation of the Moral Self (1998). He identifies seven modes of moral formation, namely discipline, socialization, value transmission, value clarification, moral development, emotional development and character formation.

43 See H Niebuhr The Responsible Self. An Essay in Christian Moral Philosophy (1978) especially 12 - 19. 
around us? What is happening around us? According to him Christians would add the question: what is God busy doing in our world? Decades later social scientists in the USA like Robert Bellah and his co-authors would reason in the same vein and argue that democracy cannot succeed if there are not people who pay attention, people who are aware and conscious of what is going on around them. ${ }^{44}$ Still later the South African anti-apartheid struggle gained momentum when people like Steve Bantu Biko, who is hailed as the father of the Black Consciousness Movement, embarked on an intentional process of conscientisation, of making people aware of not only the oppressive dimensions of their reality, but also of the liberative potential in that reality. 45

Three decades later scholars from different disciplines participate in the research project on the enforcement of social and economic rights of which this book is a product. Thereby they embark on this first step of responsible living. They pay attention and see that whilst the socalled first generation rights of the treasured South African Bill of Rights enjoy much attention in public discourse and even in court cases, the so-called second and third generation social and economic rights are limited to the margins of the public discourse. They see that lastmentioned rights are not enforced to the same extent as the former rights. In dialogue with each other they seek ways of addressing this challenge. They strive to build theories that will hopefully assist South African policy makers in different public spheres as well as individual South Africans in all walks of life to see what is going on around them, to pay attention and to address the immense challenges with creativity and innovation. Theology is privileged to participate in this quest.

44 See R Bellah et al Habits of the Heart. Individualism and Commitment in American Life (1985) and also R Bellah et al The Good Society (1991).

45 For his writings on the insights of the Black Consciousness Movement, see S Biko I Write What I Like (2004). 


\title{
The Value of Human Dignity in Interpreting Socio-Economic Rights*
}

\author{
- SANDRA LIEBENBERG \\ H Oppenheimer Chair for Human Rights, \\ Stellenbosch University
}

...Without the ability to secure the immediate needs of the present, the future is little more than a far-off possibility, remote both in perception and in reality..."*

\section{Introduction}

The inclusion of socio-economic rights as justiciable rights in the Bill of Rights of South Africa's Constitution affirms the critical importance of material conditions to human survival and development. ${ }^{1}$ In their seminal article, arguing for the constitutional protection of socio-economic rights in South Africa, Craig Scott and Patrick Maklem argued as follows:

...Perhaps the strongest reason for including a certain number of economic and social rights is that by constitutionalising half of the human rights equation, South Africans would be constitutionalising only part of what it is to be a full person. A constitution containing only civil and political rights projects an image of truncated humanity. Symbolically, but still brutally it excludes those segments of society for whom autonomy means little without the necessities of life... ${ }^{2}$

Socio-economic rights are not valued as commodities, but because of what they enable human

* Earlier versions of this paper were read at the conference of the SA Journal on Human Rights, 'Twenty Years of Human Rights Scholarship and Ten-Years of Democracy' (5 - 7 July 2004), and at the Stellenbosch Institute for Advanced Study (STIAS) seminar on 'Theories of Social and Economic Justice' (30 - 31 July 2004). This article first appeared in (2005) 21 SAJHR $1-31$ and is re-published with kind permission of S Liebenberg, I Currie (editor of SAJHR) and Juta \& Co. Participants at both the aforesaid events provided valuable comments and suggestions for which I am indebted. I am also grateful for the comments and insights of my colleagues, André van der Walt and Lourens du Plessis, as well as the suggestions received from the SAJHR editors. Finally, I would like to thank Beth Goldblatt for challenging me to think critically about the limits of human dignity in advancing a transformative constitutional jurisprudence.

* Per Arbour J in Gosselin v Quebec (Attorney General), 2002 SCC 84 at para 392.

1 The preamble of the Constitution of the Republic of South Africa Act 108 of 1996 [hereafter 'the Constitution'] proclaims that it was adopted with the purpose (amongst others) to '[i]mprove the quality of life of all citizens and free the potential of each person'.

2 'Constitutional Ropes of Sand or Justiciable Guarantees? Social Rights in a New South African Constitution’ (1992) 141 Univ of Pennsylvania LR 1, 29. 
beings to do and to be. ${ }^{3}$ If basic subsistence needs are not met, humans face severe threats to life and health. But, in addition, such deprivation impedes the development of a whole range of human capabilities, including the ability to fulfill life plans and participate effectively in political, economic and social life. ${ }^{4}$ It also deprives society of the contributions of all its members. ${ }^{5}$ Thus both the individual and society are impoverished by our collective failure to ensure living conditions worthy of the dignity of people as both individual and social beings. ${ }^{6}$

As justiciable rights, socio-economic rights must be interpreted in the context of concrete cases. The courts must determine how much must be provided, to whom, at what pace and in what order of priority. In order to do so, they must explicate the underlying values that guide its interpretation. In so doing, the Court also affirms the values constituting our post-apartheid society. ${ }^{7}$

3 Martha Nussbaum has provided an influential philosophical justification for constitutional principles aimed at ensuring the conditions for the development and exercise of human capabilities: See particularly M C Nussbaum Women and Human Development - The Capabilities Approach (2000) [hereafter 'Women and Human Development']. Her approach focuses 'on human capabilities, that is, what people are actually able to do and to be - in a way informed by an intuitive idea of a life that is worthy of the dignity of the human being': Nussbaum (2000) 5. On the relationship between capabilities and human rights, see Nussbaum (2000) 96 - 101; and Nussbaum 'Capabilities, Human Rights and the Universal Declaration' in B H Weston \& S P Marks (eds) The Future of International Human Rights (1999) 25 - 64. In development economics, the capabilities approach to quality of life assessments was pioneered by Amartya Sen through a range of works, including his collaboration of the Human Development Reports of the United Nations Development Programme (UNDP). See, eg, 'Equality of What' in A Sen Choice, Welfare and Measurement (1982) 353 369, and his recent work Development as Freedom (2001). For Sen, the goal of development should be to expand the capabilities of persons 'to lead the kind of lives they value - and have reason to value': Development as Freedom (2001) 18. Nussbaum discusses the differences between her and Sen's 'capabilities' theory at $11-15$ of Women and Human Development. However, both view the 'capabilities' approach as more appropriate to quality of life assessments in human development than many of the traditional alternatives. Nussbaum discusses the defects of standard approaches such as GNP per capita, utilitarian approaches (which ask about the total or average utility of the population, as measured by expressions of satisfaction), and approaches focusing on basic resource distribution in Women and Human Development (at 59-70).

4 For an account of the impact and experience of poverty in South Africa, see J May Poverty and Inequality in South Africa: Report prepared for the Office of the Executive Deputy President and the Inter-Ministerial Committee for Poverty and Inequality (PIR Report) (1998). See particularly the experiences of poverty documented by The South African Participatory Poverty Assessment: 'The Experience and Perceptions of Poverty', Data Research Africa Report (SA-PPA) cited on pp 3 - 5 of the PIR Report. These include: alienation from the community, emotional stress and anxiety, food insecurity, the impact of time-consuming domestic tasks particularly for poor women, overcrowded living conditions with the associated loss of privacy, and an increased exposure to violence. The impact of a lack of access to basic services and productive resources such as land on people's life chances is also vividly illustrated in the Report of the National 'Speak Out on Poverty' Hearings convened by the Commission for Gender Equality, the South African Human Rights Commission and the South African NGO Coalition from March - June 1998: D Budlender The People's Voices (1998).

5 Sen expresses this reciprocal relationship as follows: 'These capabilities can be enhanced by public policy, but also, on the other side, the direction of public policy can be influenced by the effective use of participatory capabilities by the public': Development as Freedom (note 3 above) 18.

6 Jennifer Nedelsky describes human beings 'as both essentially individual and essentially social creatures': 'Reconceiving Rights as Relationship' (1993) 1 Review of Constitutional Studies 1, 8. In National Coalition for Gay \& Lesbian Equality $v$ Minister of Justice and Others 1999 (1) SA 6 (CC), Sachs J refers to the constitutional recognition of the associational dimensions of human life as follows: 'While recognising the unique worth of each person, the Constitution does not presuppose that a holder of rights is an isolated, lonely and abstract figure possessing a disembodied and socially disconnected self. It acknowledges that people live in their bodies, their communities, their cultures, their places and their times' (at para 117). See also Bernstein v Bester 1996 (2) SA 751 (CC) at para 67.

7 In Dawood v Minister of Home Affairs; Shalabiv Minister of Home Affairs; Thomas $v$ Minister of Home Affairs 2000 (3) SA 936 (CC), O'Regan J describes the role of the constitutional value of human dignity in 
Human dignity as a right and value has played a central role in the Court's human rights jurisprudence. ${ }^{8}$ The Court has also invoked dignity as the central value informing its approach to the interpretation of socio-economic rights, particularly the reasonableness standard of review for the positive duties imposed by these rights. ${ }^{9}$ Thus Yacoob J stated in Grootboom:

...It is fundamental to an evaluation of the reasonableness of State action that account be taken of the inherent dignity of human beings. The Constitution will be worth infinitely less than its paper if the reasonableness of State action concerned with housing is determined without regard to the fundamental constitutional value of human dignity. Section 26, read in the context of the Bill of Rights as a whole, must mean that the respondents have a right to reasonable action by the State in all circumstances and with particular regard to human dignity. In short, I emphasise that human beings are required to be treated as human beings... ${ }^{10}$

This article explores the value of human dignity in interpreting socio-economic rights. ${ }^{11} \mathrm{My}$ focus is primarily on the positive duties imposed on these rights to facilitate and provide access to social benefits. ${ }^{12}$ It examines the critiques that have been made of human dignity as a guiding value in the context of South Africa's equality jurisprudence. In response to these critiques the article seeks to explore traditions in the interpretation of human dignity that can make a positive contribution to our evolving jurisprudence on socio-economic rights.

By focusing on human dignity, I am not claiming that dignity is the only value that explicates

constituting post-apartheid society: 'The Constitution asserts dignity to contradict our past in which human dignity for black South Africans was routinely and cruelly denied. It asserts it too to inform the future, to invest in our democracy respect for the intrinsic worth of all human beings' (at para 35).

8 In Dawood v Minister of Home Affairs; Shalabiv Minister of Home Affairs; Thomas $v$ Minister of Home Affairs 2000 (3) SA 936 (CC) the Court held that the value of human dignity 'is a value that informs the interpretation of many, possibly all, other rights' (at para 35). See, for example, $S v$ Makwanyane \& Another 1995 (3) SA 391 (CC) at para 144 (per Chaskalson P) and at para 328 (per O'Regan J) (death penalty); August and Another v Electoral Commission and Others 1999 (3) SA 1 (CC) para 16 (per Sachs J) (right to vote); and the range of equality cases in which dignity is a central factor in identifying 'unfair' discrimination: eg Harksen v Lane NO and Others 1998 (1) SA 300 (CC) at paras 50 - 51; National Coalition for Gay o Lesbian Equality v Minister of Justice and Others 1999 (1) SA 6 (CC) at paras 15 28 (per Ackermann J), and paras 120 - 129 (per Sachs J).

9 Government of the Republic of South Africa v Grootboom 2001 (1) SA 46 (CC) paras 38, 41.

10 Note 9 above, para 83. On the relationship between human dignity as an independent right, the other rights specifically entrenched in the Bill of Rights, and the value of human dignity, see Dawood $v$ Minister of Home Affairs; Shalabi v Minister of Home Affairs; Thomas v Minister of Home Affairs 2000 (3) SA 936 (CC) para 35.

11 On the relationship between human dignity as an independent right, the other rights specifically entrenched in the Bill of Rights, and the value of human dignity, see Dawood v Minister of Home Affairs; Shalabi $v$ Minister of Home Affairs; Thomas v Minister of Home Affairs 2000 (3) SA 936 (CC) para 35; Jaftha v Schoeman and Others; Van Rooyen $v$ Stoltz and Others 2005 (1) BCLR 78 (CC) para 21.

12 Section 7(2) of the Constitution places an overarching duty on the State 'to respect, protect, promote and fulfil' the rights in the Bill of Rights. This signals that the rights in the Bill of Rights impose a combination of negative and positive duties. For a discussion of these duties in the context of socio-economic rights, see $S$ Liebenberg 'The Interpretation of Socio-Economic Rights' in M Chaskalson et al Constitutional Law of South Africa (2nd edition 2004) ch 33, 6 - 7; see also The Social and Economic Rights Action Centre and the Centre for Economic and Social Rights v Nigeria Communication No 155/96 October 2001, African Commission on Human and Peoples' Rights, paras $44-47$. 
our commitment to socio-economic rights. ${ }^{13}$ There is an important body of literature that explores the significance of a number of other values in relation to socio-economic rights. ${ }^{14}$ The core foundational values of human dignity, freedom and equality are in any event highly interrelated. ${ }^{15}$ I focus on human dignity because of the important role it has played in the Court's human rights jurisprudence in general, and because its role in the interpretation of socio-economic rights has been relatively unexplored. I also seek to develop a concept of human dignity that can help us identify deficiencies in the Court's current socio-economic rights jurisprudence and illuminate how the jurisprudence should be developed to constitute a stronger response to socio-economic deprivation.

\section{Critiques of Dignity as a Value in Constitutional Adjudication}

A number of critiques have been made of human dignity as a guiding value in constitutional adjudication, particularly in relation to equality jurisprudence and the test for unfair discrimination. ${ }^{16}$ However, these critiques are also relevant to human dignity as a guiding value in socio-economic rights jurisprudence and for this reason they require careful consideration here.

Three major critiques of dignity as a value in human rights adjudication have been articulated. The first relates to the alleged indeterminacy of human dignity as a normative concept. Thus it has been argued that dignity is too vague and multifaceted a concept to serve us well as a guiding

13 The Court has affirmed that all three foundational constitutional values are implicated in a denial of socioeconomic rights: 'All the rights in our Bill of Rights are inter-related and mutually supporting. There can be no doubt that human dignity, freedom and equality, the foundational values of our society, are denied those who have no food, clothing or shelter. Affording socio-economic rights to all people therefore enables them to enjoy the other rights enshrined in Chapter 2. The realisation of these rights is also key to the advancement of race and gender equality and the evolution of a society in which men and women are equally able to achieve their full potential': Government of the Republic of South Africa v Grootboom 2001 (1) SA 46 (CC) para 23. See also Soobramoney v Minister of Health, KwaZulu-Natal 1998 (1) SA 765 (CC) para 8.

14 See, for example, N Haysom 'Constitutionalism, Majoritarian Democracy and Socio-Economic Rights' (1992) 2 SAJHR 451 (a basic floor of socio-economic rights is required to guarantee a minimum degree of civic and political participation). For a similar argument in the US context, see: FI Michelman 'Welfare Rights in a Constitutional Democracy' (1979) 3 Wash Univ LQ 659 (socio-economic are necessary prerequisites of effective participation in representative democracy); P de Vos 'Grootboom, The Right of Access to Housing and Substantive Equality as Contextual Fairness’ (2001) 17 SAJHR 258 (the right to equality and socio-economic rights are 'two sides of the same coin' in that they seek to achieve '.... specific contextual form of equality as the realisation of particular social and economic rights' at 263,265 ). For a discussion of the shortcomings and theoretical limitations of an equality-based theoretical justification of socio-economic rights: see A van der Walt 'A South African Reading of Frank Michelman's Theory of Social Justice' in H Botha, A van der Walt, and J van der Walt (eds) Rights and Democracy in a Transformative Constitution (2004) 163 at $174-179$. Nonetheless, as this paper illustrates, there are important insights in equality jurisprudence regarding the application of human dignity to adjudicate the constitutionality of people's exclusion from social benefits.

15 Kriegler J refers to human dignity, equality and freedom as 'conjoined, reciprocal and covalent values' which are 'foundational' to South Africa: S v Mamabolo (E TV and Others Intervening) 2001 (3) SA 409 (CC) at para 41.

16 The Court's approach to section 9 of the Constitution is set out in Harksen v Lane NO and Others 1998 (1) SA 300 (CC) at paras 50-53. Dignity plays an important role both in the identification of unlisted prohibited grounds of discrimination and in the factors for determining whether the discrimination is unfair: see Harksen paras 49 and 51. 
value in equality jurisprudence. ${ }^{17}$ The second critique asserts that human dignity as a value is irrevocably linked with protection of freedom and autonomy. As such, it serves to discourage the positive, redistributive measures needed to remedy conditions of material inequality and disadvantage. ${ }^{18}$ Cathi Albertyn and Beth Goldblatt have most forcefully articulated the final critique (which is closely related to the second) in the context of equality jurisprudence. They argue that the reliance on the value of dignity in the test for unfair discrimination promotes a narrow focus on individual personality issues as opposed to 'a group-based understanding of material advantage and disadvantage'. ${ }^{19}$ It could result in 'an individualised and abstract conception of equality divorced from actual social and economic disadvantage. 20 Thus the need to redress systemic patterns of inequality and disadvantage are obscured by focusing on individual personality issues related to subjective feelings of self-respect and self-worth.

If dignity as a value is inextricably aligned with negative liberty and individual personality issues, it will be inimical to the development of a transformative socio-economic rights jurisprudence. In the next section I develop an argument that there are positive traditions associated with the interpretation of human dignity that can add value to our socio-economic rights jurisprudence. In so doing, I am not seeking to deny the dangers of a regressive deployment of human dignity in the interpretation of rights such as equality, and indeed, socio-economic rights. Certainly, I believe that there is a case to be made that the Court has not engaged sufficiently with the value of equality in its section 9 jurisprudence. ${ }^{21} \mathrm{My}$ concern is to examine how the value of human dignity can enrich, rather than impoverish, our evolving jurisprudence on socio-economic rights.

\section{Human Dignity as a Value}

Dignity has deep roots in Kantian moral philosophy that affirms the inherent worth of human beings. According to the Kantian imperative human beings should be treated 'never simply as a

17 For example, Davis alludes to the 'multifaceted meanings' of dignity, and argues that the Court 'has given dignity both a content and scope that make for a piece of jurisprudential Legoland - to be used in whatever form and shape is required by the demands of the judicial designer': D Davis 'Equality: The Majesty of Legoland Jurisprudence' (1999) 116 SALJ 398 at 413. See also in this regard D Davis Democracy and Deliberation (1999) at $69-95$.

18 This critique is discussed by Susie Cowen in her article defending the use of the value of human dignity in South African's equality jurisprudence: 'Can "Dignity" Guide South Africa's Equality Jurisprudence?' (2001) 17 SAJHR 34 at $51-58$.

19 C Albertyn \& B Goldblatt 'Facing the Challenge of Transformation: Difficulties in the Development of an Indigenous Jurisprudence of Equality' (1998) 14 SAJHR 248 at $257-258,272$. Similar arguments in support of the development of a more substantive approach to equality were made by the Centre for Applied Legal Studies in their amicus intervention in National Coalition for Gay \& Lesbian Equality $v$ Minister of Justice and Others 1999 (1) SA 6 (CC): see paras 58 - 64 (per Ackermann J), and paras 120 - 129 (per Sachs J).

20 C Albertyn 'Equality' in M H Cheadle, D M Davis and N R L Haysom (eds) South African Constitutional Law: The Bill of Rights (2002) 51 at 60.

21 Albertyn attributes this reluctance, at least partially, to the Court's discomfort with the notion that 'the value of equality encompasses an idea of material equality and economic redistribution': She argues that this 'redistributive function sits uncomfortably with the institutional role of courts and with the distinction the courts seek to draw between issues of social policy and issues of law': Albertyn (note 20 above) at 63 65; See also D Davis 'Legoland Jurisprudence' (note 17 above) at 413 - 414. For a recent consideration by the Court of the value of equality in the context of section 9 and the positive duties it imposes on the state, see Minister of Finance \& Another $v$ Van Heerden 2004 (11) BCLR 1125 (CC) at paras $22-27$. 
means, but always at the same time as an end. 22 In other words, we should relate to each other as having intrinsic worth as human beings. O'Regan J affirms the notion of human dignity as follows:

\begin{abstract}
...The importance of dignity as a founding value of our new Constitution cannot be over-emphasised. Recognising a right to dignity is an acknowledgment of the intrinsic worth of human beings: human beings are entitled to be treated as worthy of respect and concern...23
\end{abstract}

Human dignity is closely related to the notion that human beings are agents capable of making moral choices, of shaping our identity, resisting injustice and participating in the shaping of society. ${ }^{24}$ Martha Nussbaum expresses this notion thus:

The core idea is that of the human being as a dignified free being who shapes his or her own life in cooperation and reciprocity with others, rather than being passively shaped or pushed around by the world in the manner of a "flock" or "herd" animal. A life that is really human is one that is shaped throughout by these human powers of practical reason and sociability. 25

Thus to value the inherent dignity of human beings as a society is to ensure that people enjoy

22 I Kant The Moral Law: Kant's Groundwork of the Metaphysic of Morals (1963) (trans H J Patron) 96 cited and discussed in D Meyerson Rights Limited (1997) at 12 - 13. See also the discussion of the Kantian imperative and concept of human dignity by L Ackermann 'Equality and the South African Constitution: The Role of Dignity' (2000) 60 The Heidelberg Journal for International Law 537 at $540-542$.

$23 S v$ Makwanyane \& Another 1995 (3) SA 391 (CC) para 328 (emphasis added). See also the comments of Ackermann J in National Coalition for Gay \& Lesbian Equality v Minister of Justice and Others 1999 (1) SA 6 (CC): 'Dignity is a difficult concept to capture in precise terms. At its least, it is clear that the constitutional protection of dignity requires us to acknowledge the value and worth of all individuals as members of society' (at para 29).

24 In the context of evictions, the Constitutional Court has recently highlighted the importance of mediation and serious consideration of the need of occupiers for suitable alternative land in considering whether an eviction is 'just and equitable' in terms of The Prevention of Illegal Eviction from and Unlawful Occupation of Land Act 19 of 1998 (PIE). Sachs J refers to the importance of mutual respect for people's agency in the following terms: 'Thus those seeking eviction should not be encouraged to rely on concepts of faceless and anonymous squatters automatically to be expelled as obnoxious social nuisances. Such a stereotypical approach has no place in the society envisaged by the Constitution; justice and equity require that everyone is to be treated as an individual bearer of rights entitled to respect for his or her dignity. At the same time those who find themselves compelled by poverty and landlessness to live in shacks on the land of others, should be discouraged from regarding themselves as helpless victims, lacking the possibility of personal moral agency': Port Elizabeth Municipality $v$ Various Occupiers 2005 (1) SA 217 (CC) para 41.

25 M Nussbaum Women and Human Development (note 3 above) 72 (footnotes omitted). Nussbaum's notion of 'a life that is really human' has been the subject of criticism on the basis that that an attempt to elaborate the conditions of a fully human life implies that those who are denied these conditions have lost their dignity and are no longer 'dignified': see D Cornell 'A Call for a Nuanced Constitutional Jurisprudence: Ubuntu, Dignity, and Reconciliation' paper presented at a New Social Forms Seminar organised by the Department of Sociology and Social Anthropology, Stellenbosch University, 23 July 2004 (paper on line at www.sun.ac.za/sociology/activities_nsf.htm). My own reading of Nussbaum is that she is not claiming that poverty deprives people of their dignity, but rather that society fails to respect the dignity of people by neglecting to create the conditions under which people's capabilities can develop and be effectively exercised. As she puts it: 'We begin, then, with a sense of the worth and dignity of basic human powers, thinking of them as claims to a chance for functioning, claims that give rise to correlated social and political duties': Women and Human Development (note 3 above) 84. See further the discussion at $84-86$. 
civil and political liberties and also have effective access to the social and economic means indispensable to the development of their physical, emotional, creative and associational capabilities. Nussbaum develops a provisional list of 'central human capabilities' that should be secured as a basic social minimum to all in political and constitutional principles. Through this list she seeks to isolate 'those human capabilities that can be convincingly argued to be of central importance in any human life, whatever else the person pursues or chooses. 26 She argues that that they have 'special claim to be supported for political purposes in a pluralistic society' because of their importance in making any choice of a way of life possible. ${ }^{27}$ Nussbaum's project of developing a list of 'central human capabilities' has been criticised for being reductive and insufficiently sensitive to human difference, complexity and freedom. ${ }^{28}$ A valuable feature of the list is its holistic portrayal of human life. It illustrates that access to socio-economic rights is not simply a matter of bare survival, but also includes the development and exercise of the people's associational, intellectual and emotional capabilities. In any event, I do not believe that it is necessary to subscribe to her list (or even her project of compiling a list) to support the central idea that we show respect for human potential and agency by creating an environment of basic liberties and material support which enables their flourishing. ${ }^{29}$

In his analysis of human dignity as a normative concept, Oscar Schachter distinguishes between 'the subjective aspect of human dignity (how one feels or thinks about another) and the objective aspect (how one treats another)'. ${ }^{30}$ In its objective, social dimension, he argues that human dignity 'requires recognition of a minimal concept of distributive justice that would require satisfaction of the essential needs of everyone.'31 Thus he includes in his list of conduct and ideas that offend or denigrate the worth and dignity of individuals, '[d]egrading living conditions and deprivation of basic needs. ${ }^{32}$ International human rights law derives civil and political rights as well as social, economic and cultural rights from the value of human

26 Nussbaum Women and Human Development (note 3 above) 74. Her list of central human functional capabilities relates to the following dimensions of human existence: life; health; bodily integrity; the senses, imagination and thought; emotions, practical reason, affiliation; other species; play; political and material control over one's environment (at $77-80)$.

27 Nussbaum Women and Human Development (note 3 above) 75.

28 See K Van Marle “"The Capabilities Approach", "The Imaginary Domain", and "Asymmetrical Reciprocity": Feminist Perspectives on Equality and Justice' (2003) 11 Feminist Legal Studies 255 - 278 , particularly the discussion at $272-273$. Sen's reservations regarding the search for a list of central human capabilities relates to the difficulty 'in seeing how the exact lists and weights would be chosen without appropriate specification of the context of their use (which could vary), but also from a disinclination to accept any substantive diminution of the domain of public reasoning': For Sen the framework of human capabilities is important for clarifying and illuminating 'the subject matter of public reasoning...It does not - and cannot - displace the need for public reasoning': A Sen 'Elements of a Theory of Human Rights' (2004) 32 Philosophy and Public Affairs 315 - 356 at 333.

29 Nussbaum herself emphasises that the list 'remains open-ended and humble; it can always be contested and remade'. It aims at 'multiple realisability', leaving room for more concrete specification according to local beliefs and circumstances: Women and Human Development (note 3 above) 77.

30 O Schachter 'Human Dignity as a Normative Concept' (1983) 77 Am J of Int Law 848, 849.

31 Schachter (note 30 above) 851. David Feldman makes the following observations in relation to the subjective and objective dimensions of human dignity: 'In relation to the subjective aspect of dignity, the law of human rights will typically be concerned to prevent treatment which damages a person's self-respect and physical or moral integrity. With regard to the objective aspect, the law will usually have to go further, imposing positive duties on people to act in ways which optimise the conditions for social respect and dignity': 'Human Dignity as a Value - Part I' (1999) 14 Public Law 682 at 686 - 687.

Schachter (note 30 above) 852. 
dignity. ${ }^{33}$ The Constitutional Court has also on a number of occasions referred to the disjuncture between our founding constitutional values and conditions of material deprivation. ${ }^{34}$

The above approaches to human dignity illustrate that its ambit is by no means confined to subjective personality issues. To the contrary, respect for human dignity requires that we pay close attention to conditions of material disadvantage and its impact on different groups in our society.

This brings us to the concern that human dignity is irrevocably connected with negative liberty. Accordingly, dignity as a value would support constraints on State interference with individual liberties, and would discourage intervention to redistribute social resources. Human dignity undeniably requires respect for personal autonomy and choices. ${ }^{35}$ But at the same time our commitment to respect for each person's substantive freedom and life choices requires the creation of the social conditions on which people's capacity for personal fulfilment and agency depends. This leads David Feldman to describe dignity as a 'two-edged sword', which can operate both to uphold and restrict personal liberties:

...[W]e must not assume that the idea of dignity is inextricably linked to a liberalindividualistic view of human beings whose life-choices deserve respect. If the state takes a particular view of what is required for people to live dignified lives, it may introduce regulations to restrict the freedom which people have to make choices which, in the state's view interfere with the dignity of the individual, a social group or the human race as a whole. ...The quest for human dignity may subvert rather than enhance choice and in some circumstances may limit rather than extend the scope of traditional 'first generation' human rights and fundamental freedoms... ${ }^{36}$

33 The preambles of both the International Covenant on Economic, Social, and Cultural Rights (1966) and the International Covenant on Civil and Political Rights (1966) recognise that the rights contained in the respective Covenants 'derive from the inherent dignity of the human person': In The Social and Economic Rights Action Center and the Center for Economic and Social Rights v Nigeria (note 12 above), the African Commission on Human and Peoples' Rights derived the right to food from a number of other provisions in the African Charter on Human and Peoples' Rights. In particular, it held that the right to food 'is inseparably linked to the dignity of human beings and is therefore essential for the enjoyment and fulfilment of other rights as health, education, work and political participation' (at para 65).

34 In Soobramoney v Minister of Health, KwaZulu-Natal 1998 (1) SA 765 (CC), the Court affirmed that the Constitution commits us to transform the intolerable conditions in which people live in order to vindicate the values of human dignity, equality and freedom: paras 8 -10. In Government of the Republic of South Africa $v$ Grootboom 2001 (1) SA 46 (CC) the Court stated that the issues in the case remind us of the intolerable conditions under which many of our people are still living and brings home 'the harsh reality that the Constitution's promise of dignity and equality for all remains a distant dream': (para 2). See also A Chaskalson (The Third Bram Fischer Lecture) 'Human Dignity as a Foundational Value of our Constitutional Order' (2000) 16 SAJHR 193 at $204-205$.

35 The links between dignity and freedom are described in the following terms by Ackermann J in Ferreira $v$ Levin NO 1996 (1) SA 984 (CC): 'Human dignity cannot be fully valued or respected unless individuals are able to develop their humanity, their "humanness" to the full extent of its potential. Each human being is uniquely talented. Part of the dignity of every human being is the fact and awareness of this uniqueness. An individual's human dignity cannot be fully respected or valued unless the individual is permitted to develop his or her talents optimally. Human dignity has little value without freedom; for without freedom personal development and fulfilment are not possible. Without freedom, human dignity is little more than an abstraction. Freedom and dignity are inseparably linked. To deny people their freedom is to deny them their dignity': (at para 49). See also Prince $v$ President of the Law Society of the Cape of Good Hope \& Others 2002 (2) SA 794 (CC): 'Our society is diverse...The protection of diversity is the hallmark of a free and open society. It is the recognition of the inherent dignity of all human beings. Freedom is an indispensable ingredient of human dignity': (per Ngcobo J at para 49). 
This may suggest that dignity is an indeterminate value - it cannot guide us as to when constraints should be placed on State interference with liberties and when it should require positive intervention. The capabilities approach to human dignity developed by Nussbaum provides us with at least one set of criteria for requiring positive state intervention. In Nussbaum's account, the State has a strong duty to guarantee the social basis of each person's basic human capabilities based on a principle of each person as an end. ${ }^{37}$ This fundamental commitment necessarily implies that the State is entitled to restrict the liberties of some members of society (provided it does not impinge on their basic human capabilities) in order to guarantee to everyone the social basis of basic human capabilities. ${ }^{38}$ In this sense a focus on capabilities as social goals is also closely related to human equality. As Nussbaum explains:

...[M]aking capabilities the goal entails promoting for all citizens a greater measure of material equality than exists in most societies, since we are unlikely to get all citizens above a minimum threshold of capability for truly human functioning without some redistributive policies... ${ }^{39}$

Nussbaum's approach is compatible with a range of different theories as to the degree of material equality that should be guaranteed in a just society, including complete egalitarianism, a Rawlsian difference principle, and a focus on an ample social minimum for all. ${ }^{40}$ However, in most societies in the world, including South Africa, we are very far from providing even the basic minimum required for promoting human capabilities. ${ }^{41}$

It is also helpful in this context to conceive of human dignity as a relational value. According to this notion we are interconnected beings. Our sense of self-worth, personal development and well-being is inextricably bound up with the extent to which we are valued by others and the society at large. O'Regan J expresses this when she writes in Makwanyane:

...the right to life was included in the Constitution not simply to enshrine the right to existence. It is not life as mere organic matter that the Constitution cherishes, but the right to human life: the right to live as a human being, to be part of a broader community, to share in the experience of humanity...The right to life is more than existence, it is a right to be treated as a human being with dignity... . ${ }^{42}$

37 M Nussbaum Women and Human Development (note 3 above) at $5-6,89$. In certain core areas of human functioning, 'a necessary condition of justice for a public political arrangement is that it delivers to citizens a certain basic level of capability': (at 71). She draws a distinction between capability and functioning, defending the former as the appropriate political goal given the value we attach to respecting people's choices. It is not the role of government to push people into 'functioning of the requisite sort': (at 87). She argues that 'for political purposes it is appropriate that we shoot for capabilities and those alone. Citizens must be left free to determine their own course after that. The person with plenty of food may always choose to fast, but there is a great difference between fasting and starving, and it is this difference that I wish to capture': (at 87).

38 In discussing socio-economic rights such as the right to shelter in terms of her capabilities approach, Nussbaum identifies the central focus to be 'how people are actually enabled to live': 'Analyzing economic and material rights in terms of capabilities thus enables us to set forth clearly a rationale we have for spending unequal amounts of money on the disadvantaged, or creating special programs to assist their transition to full capability': Women and Human Development (note 3 above) 99.

39 Nussbaum Women and Human Development (note 3 above) 86.

40 Ibid.

41 See further in this regard Women and Human Development (note 3 above) 12, 86.

$42 S v$ Makwanyane \& Another 1995 (3) SA 391 (CC) paras 326 -7. In Soobramoney v Minister of Health, KwaZulu-Natal 1998 (1) SA 765 (CC) the Court affirmed that having access to social goods and services 
To value human dignity is not to create zero-sum trade-offs between negative liberty and welfare, but to constitute positive social relationships that both respect autonomy and foster the conditions in which it can flourish. ${ }^{43}$ Dignity as a relational value can help us to perceive the limits of individual claims on social resources with reference to the needs and equal worth of others and the available resources of the society. ${ }^{44}$ But the corollary is a collective acknowledgement we are diminished as a society to the extent that any of our members are deprived of the opportunities to develop their basic capabilities to function as individual and social beings. ${ }^{45}$ Mokgoro J expresses this idea in the following passage in the case of Khosa v Minister of Social Development:

...Sharing responsibility for the problems and consequences of poverty equally as a community represents the extent to which wealthier members of the community view the minimal well-being of the poor as connected with their personal well-being and

were aspects of the right to '...human life: the right to live as a human being, to be part of a broader community to share in the experience of humanity': (at para 31). The associational dimensions of human dignity were also recently affirmed by the Supreme Court of Appeal in the decision of Minister of Home Affairs and Others $v$ Watchenuka and Another 2004 (2) BCLR 120 (SCA). The Court held that conditions imposed on refugees and asylum-seekers prohibiting them from undertaking employment and from studying constituted an infringement of their rights to human dignity and education. The Court (per Nugent JA) stated: 'The freedom to engage in productive work - even where that is not required in order to survive - is indeed an important component of human dignity...for mankind is pre-eminently a social species with an instinct for meaningful association. Self-esteem and the sense of self-worth - the fulfilment of what it is to be human - is most often bound up with being accepted as socially useful': (para 27). It is important, however, not to associate the right to work only with productive, waged work. One of the major contributing factors to gender inequality is society's persistent undervaluing of reproductive work of which women bear the disproportionate burden. See in this regard, President of the Republic of South African and Another v Hugo 1997 (4) SA 1 (CC) at para 38 (per Goldstone J).

43 The relational conception of autonomy is described in the following terms by Jennifer Nedelsky: 'Interdependence becomes the central fact of political life, not an issue to be shunted to the periphery in the basic question of how to ensure individual autonomy in the inevitable face of collective power. The human interactions to be governed are not seen primarily in terms of the clashing of rights and interests, but in terms of the way patterns of relationship can develop and sustain both an enriching collective life and the scope for genuine individual autonomy...The constitutional protection of autonomy is then no longer an effort to carve out a space into which the collective cannot intrude, but a means of structuring the relations between individuals and the sources of collective power so that autonomy is fostered rather than undermined': (note 6 above) 8. In the South African context, the interdependence between individual and community is captured by the spirit of ubuntu. Mokgoro J explains that while 'ubuntu envelops the key values of group solidarity, compassion, respect, human dignity, conformity to basic norms and collective unity, in its fundamental sense it denotes humanity and morality. Its spirit emphasises a respect for human dignity, marking a shift from confrontation to conciliation': $S v$ Makwanyane $\&$ Another 1995 (3) SA 391 (CC) para 308 (per Mokgoro J). In Port Elizabeth Municipality v Various Occupiers 2005 (1) SA 217 (CC) the Court (per Sachs J) further noted: 'The spirit of ubuntu, part of the deep cultural heritage of the majority of the population, suffuses the whole constitutional order. It combines individual rights with a communitarian philosophy. It is a unifying motif of the Bill of Rights, which is nothing if not a structured, institutionalised and operational declaration in our evolving new society of the need for human interdependence, respect and concern': (para 37, footnotes omitted).

44 In Soobramoney $v$ Minister of Health, KwaZulu-Natal 1998 (1) SA 765 (CC) the Court justified the limitation of the appellant's right to tertiary-level health care services by referring to the State's duty to manage its resources so as to meet the basic needs of others: paras 28, 31 (per Chaskalson P), and para 54 (per Sachs J). See, however, the critique of Soobramoney in Karin van Marle "No Last Word" - Reflections on the Imaginary Domain, Dignity and Intrinsic Worth' (2002) Stell LR 299, particularly at $305-307$.

45 In an article on the application of the value of human dignity in criminal law, Shannon Hoctor argues that 'dignity has a communitarian aspect: by requiring respect for others' claims to dignity, vindication of the human dignity of all is better assured, and a community of mutual co-operation and solidarity is fostered': 'Dignity, Criminal Law and the Bill of Rights' (2004) 121 SALJ 265 at 315 (footnotes omitted). 
the well-being of the community as a whole. In other words, decisions about the allocation of public benefits represent the extent to which poor people are treated as equal members of society... 46

It is implicit in a relational concept of dignity that claims on social resources are strongly justified when people lack the basic material necessities of life to enable them to survive and develop as members of the community. If we are to constitute ourselves as a society that respects human dignity (as we have through the founding values of our Constitution), we are committed to redressing the social and economic conditions of those whose capacity for development and agency is stunted by poverty. By failing to do so, we undermine the very foundations of our new constitutional democracy. ${ }^{4}$

The decision in Minister of Health $v$ Treatment Action Campaign 48 (hereafter 'TAC') illustrates the underlying relational concept of human dignity at work. The government was being asked to provide a relatively cheap anti-retroviral drug (Nevirapine) ${ }^{49}$ with a significant potential of reducing the risk of mother-to-child transmission of HIV. ${ }^{50}$ While there were additional costs associated with prescribing the drug, particularly the costs of HIV-testing and counselling facilities, the Court found that government had the resources to extend these facilities to hospitals and clinics throughout the public health sector beyond the limited number of test sites. ${ }^{51}$ For the babies of poor women who give birth in the public health sector, this drug has significant life-saving potential. For society to deny poor women and their newborns access to 'a simple, cheap and potentially lifesaving medical intervention' 52 would clearly indicate a lack of respect for their dignity as human beings entitled to be treated as worthy of respect and concern.

I have sought to illustrate that human dignity derives from the value we ascribe to human beings. Because we value them, we wish to ensure that conditions are created that enable them to develop their capabilities and to flourish as individual and social beings. This encompasses respect for people's diverse identities, their associational freedoms, as well as concern for the material conditions that shape their life choices. Dignity as a value requires respect for people's freedoms, but also helps us to understand why these liberties must sometimes be constrained to protect and nurture the capabilities of others. Finally, I have argued that a relational concept of human dignity best captures the interdependence between individual and social welfare, and

46 Khosa \& Others $v$ Minister of Social Development and Others; Mablaule and Another v Minister of Social Development and Others 2004 (6) BCLR 569 (CC) para 74 (footnotes omitted).

47 In the context of unfair discrimination, the Court has held that 'the interests of the community lie in the recognition of the inherent dignity of every human being and the elimination of all forms of discrimination': Hoffman $v$ SAA 2000 (11) BCLR 1211 (CC) at para 43. In the context of evictions of poor people from their homes, the Court has stated: 'It is not only the dignity of the poor that is assailed when homeless people are driven from pillar to post in a desperate quest for a place where they and their families can rest their heads. Our society as a whole is demeaned when state action intensifies rather than mitigates their marginalisation. The integrity of the rights-based vision of the Constitution is punctured when governmental action augments rather than reduces denial of the claims of the desperately poor to the basic elements of a decent existence. Hence the need for special judicial control of a process that is both socially stressful and potentially conflictual': Port Elizabeth Municipality v Various Occupiers 2005 (1) SA 217 (CC) para 18. 2002 (5) SA 721 (CC).

49 The manufacturers of Nevirapine had offered to make it available to the South African government free of charge for a period of five years, for the purpose of reducing the risk of mother-to-child transmission of HIV. Minister of Health $v$ Treatment Action Campaign (2) 2002 (5) SA 721 (CC) para 19 read with paras 71 and 80.

50 Para 57.

51 Paras $118-120$.

52 Para 73. 
also illuminates the circumstances in which people have justified claims to social resources.

In the next section I examine how the value of human dignity can be applied to enrich South Africa's socio-economic rights jurisprudence. I also examine, through my discussion of the Canadian case of Gosselin, ${ }^{53}$ applications of human dignity that can operate to exclude the poor from access to benefits, rather than facilitate their inclusion.

\section{Human Dignity and its Value in Socio-Economic Rights Jurisprudence}

I have argued for a relational concept of human dignity in which society's neglect to redress conditions of socio-economic disadvantage represents a collective failure to value human dignity. This concept helps to challenge stigmatizing notions of the poor as 'dependants' of society and undeserving of social support. ${ }^{54}$ Conditions of poverty are not a reflection of the moral blameworthiness of groups experiencing poverty; 55 they reflect how we as a society have failed to value human dignity.

There is another dimension of human dignity that can make an important contribution to the development of our socio-economic rights jurisprudence. This is the concept of the equal worth of people that lies at the heart of human dignity. As the Court has affirmed in the context of its equality jurisprudence, the acknowledgment of equal moral worth requires treatment as an equal as opposed to equal treatment. ${ }^{56}$ Treatment as an equal requires full acknowledgement of the racial, gender, social, economic, cultural and other differences between groups in society. Thus the quest for equal worth or dignity is not a quest for uniformity, but a quest to eliminate the disadvantages and inferior status that attach to membership of particular groups. ${ }^{57}$ This substantive approach to equality inevitably requires a contextual analysis which is able to identify the real situations and disadvantages experienced by various groups in the light of our history as well as current social, economic, political and gender relations. 58

Treatment as an equal demands that we also respond appropriately to the actual needs of dif-

53 Gosselinv Quebec (Attorney General), 2002 SCC 84, 221 DLR (4th) 257.

54 The Court has affirmed the close relationship between human dignity and social assistance in the cases of Khosa \& Others $v$ Minister of Social Development and Others; Mablaule and Another v Minister of Social Development and Others 2004 (6) BCLR 569 (CC) paras 41 and 52 and Mashavha $v$ President of the RSA \& Others 2004 (12) BCLR 1243 (CC) para 51.

55 On approaches to adjudication in the US premised on notions of the moral blameworthiness of the poor, and the attitude of 'helplessness' in response to their claims, see T Ross 'The Rhetoric of Poverty: Their Immorality, Our Helplessness' (1991) 79 Georgetown Law Journal 1499 - 1547.

56 See R Dworkin Taking Rights Seriously (1977) at 227 cited in Prinsloo v Van der Linde 1997 (3) SA 1012 (CC) at para 32.

57 As Sachs J states in National Coalition for Gay \& Lesbian Equality v Minister of Justice and Others 1999 (1) SA 6 (CC): 'At the heart of the equality jurisprudence is the rescuing of people from a caste-like status and putting an end to their being treated as lesser human beings because they belong to a particular group. The indignity and subordinate status may flow from institutionally imposed exclusion from the mainstream of society or else from powerlessness within the mainstream...' (para 129). He goes on to affirm that '[e]quality means equal concern and respect across difference' as opposed to uniformity which 'can be the enemy of equality': (para 132).

58 In Brink $v$ Kitshoff NO 1996 (4) SA 197 (CC) O’Regan J refers to the 'deep patterns of disadvantage' which have resulted from gender discrimination in our society, particularly in the case of black women. A 'key message of the Constitution' is that 'all such discrimination needs to be eradicated from our society': (para 44). In its socio-economic rights jurisprudence, the Court has also indicated the reasonableness of the State's measures to realise socio-economic rights must be evaluated in the light of their 'social, economic and historical context': Government of the Republic of South Africa v Grootboom 2001 (1) SA 46 (CC) para 43. 
ferently situated groups. In Harksen $v$ Lane NO, O'Regan J (in her dissenting judgment) affirms that respect for human dignity in equality jurisprudence requires an approach that is responsive to individual needs and circumstances in order to create a buffer against the construction of further patterns of discrimination:

...Such patterns of discrimination can occur where people are treated without the respect that individual human beings deserve and particularly where treatment is determined not by the needs or circumstances of particular individuals, but by their attributes and characteristics, whether biologically or socially determined... 59

Building on this concept of human dignity in equality jurisprudence, dignity as a value in socioeconomic rights jurisprudence requires that we take account of the relative urgency of the needs of different individuals and groups and respond correspondingly. ${ }^{60}$ This implies a contextual analysis with regard to the position of particular groups in society and the different orders and types of need experienced by these groups. Thus, for example, one would be required to consider the multifarious ways in which gender relations contribute to women's unequal access to socio-economic resources. ${ }^{61}$ One would also have to consider the nature of the deprivation and the seriousness of its impact upon the affected individuals.

In Watchenuka's case, the Supreme Court of Appeal held that a consideration of the severe impact of an administrative decision on the socio-economic circumstances of the applicants was a highly relevant factor. ${ }^{62}$ Thus, while the State could justifiably limit the rights of non-nationals (such as asylum-seekers) to undertake employment and education, different considerations applied when the applicants were destitute. When employment 'is the only reasonable means for the person's support' what is then in issue 'is not merely a restriction upon the person's

59 Harksen $v$ Lane NO and Others 1998 (1) SA 300 (CC) para 92 [emphasis added]. In Canadian equality jurisprudence, human dignity is also central to the determination of discrimination in terms of sec 15 of the Canadian Charter of Rights and Freedoms. In Law v Canada (Minister of Employment and Immigration) (1999) 170 DLR (4th) 1, [1999] 1 SCR 497 the Court developed the following understanding of what respect for human dignity in equality jurisprudence requires: 'Human dignity means that an individual or group feels self-respect and self-worth. It is concerned with physical and psychological integrity and empowerment. Human dignity is harmed by unfair treatment premised upon personal traits or circumstances which do not relate to individual needs, capacities or merits. It is enhanced by laws which are sensitive to the needs, capacities, and merits of different individuals, taking into account the context underlying their differences. Human dignity is harmed when individuals and groups are marginalized, ignored, or devalued, and is enhanced when laws recognise the full place of all individuals and groups within Canadian society." (at para 53) [emphasis added]. In her dissenting judgment in Gosselin v Quebec (Attorney General) 2002 SCC 84, 221 DLR (4th) L'Heureux-Dubé J states: 'Prejudicial effects giving rise to a s 15 claim may result when a legislature simply fails to turn its mind to the particular needs and abilities of individuals or groups so as to provide equal benefit under the law to all members of society': (at para 120).

60 See the discussion by Bilchitz of the concept of urgency in protecting people's basic interest in survival and non-impaired functioning: D Bilchitz 'Giving Socio-Economic Rights Teeth: The Minimum Core and its Importance' (2002) 118 SALJ 484 at $490-491$.

61 Martha Nussbaum argues for the importance of 'an approach that is respectful of each person's struggle for flourishing, that treats each person as an end and as a source of agency and worth in her own right': (note 3 above) 69. She critiques utilitarian and resource-based approaches to human development as 'insensitive to contextual variation, to the way circumstances shape preferences and the ability of individuals to convert resources into meaningful human activity': (note 3 above) 69 - 70. Particularly in the developing world we need to be 'highly alert' to individual variations of need and the extent to which differently-situated individuals can 'convert resources into valuable functionings': (note 3 above) 68. 
capacity for self-fulfilment, but a restriction upon his or her ability to live without positive humiliation of degradation. ${ }^{63}$ To prohibit work and study in these circumstances would normally be unlawful. This requires the Refugee Reception Offices and the Standing Committee on Refugee Affairs to carefully consider the impact of a restrictive condition regarding work or study on the individual applicant and his or her family.

In its socio-economic rights jurisprudence the Court has affirmed that a reasonable government policy must cater for different groups and orders of need in society. 64 The Court has also taken the critical step of affirming that a government programme that neglects to attend to urgent needs cannot be reasonable. In Grootboom the government's otherwise comprehensive and rational housing programme 65 was faulted for failing to cater for groups in urgent need:

...To be reasonable, measures cannot leave out of account the degree and extent of the denial of the right they endeavour to realise. Those whose needs are most urgent and whose ability to enjoy all rights therefore is most in peril, must not be ignored by the measures aimed at achieving the realisation of the right. It may not be sufficient to meet the test of reasonableness to show that the measures are capable of achieving a statistical advance in the realisation of the right. Furthermore, the Constitution requires that everyone must be treated with care and concern. If the measures, though statistically successful, fail to respond to the needs of those most desperate, they may not pass the test...66

The Court has further acknowledged that 'the poor are particularly vulnerable and their needs

63 Minister of Home Affairs and Others $v$ Watchenuka and Another 2004 (2) BCLR 120 (SCA) para 32 (per Nugent JA). In relation to freedom of education Nugent JA held that when 'a child is lawfully in this country to seek asylum (there might be other circumstances as well) I can see no justification for limiting that right so as to deprive him or her of the opportunity for human fulfilment at a critical period...A general prohibition that does not allow for study to be permitted in appropriate circumstances is in my view unlawful': (at para 36) [footnotes omitted, emphasis added].

64 Thus in Government of the Republic of South Africa v Grootboom 2001 (1) SA 46 (CC) the Court held that a reasonable programme 'must be balanced and flexible and make appropriate provision for attention to housing crises and to short, medium and long-term needs. A programme that excludes a significant segment of society cannot be said to be reasonable': (para 43).

65 Government of the Republic of South Africa v Grootboom 2001 (1) SA 46 (CC) paras 53 - 54.

66 Government of the Republic of South Africa v Grootboom 2001 (1) SA 46 (CC) para 44 [emphasis added]. See also para 52: '[T] here is no express provision [in the Housing Act, 107 of 1997] to facilitate access to temporary relief for people who have no access to land, no roof over their heads, for people who are living in intolerable conditions and for people who are in crisis because of natural disasters such as floods and fire, or because their home homes are under threat of demolition. These are people in desperate need': See also Minister of Health v Treatment Action Campaign 2002 (5) SA 721 (CC): 'The provision of a single dose of Nevirapine to mother and child for the purpose of protecting the child against the transmission of HIV is, as far as the children are concerned, essential. Their needs are "most urgent" and their inability to have access to Nevirapine profoundly affects their ability to enjoy all rights to which they are entitled. Their rights are "most in peril" as a result of the policy that has been adopted and most affected by a rigid and inflexible policy that excludes them from having access to Nevirapine': (para 78). In Port Elizabeth Municipality $v$ Various Occupiers 2005 (1) SA 217 (CC), the Court emphasised the importance of taking account of 'the actual situation' of the persons concerned in eviction proceedings: 'In a society founded on human dignity, equality and freedom it cannot be presupposed that the greatest good for the many can be achieved at the cost of intolerable hardship for the few, particularly if by a reasonable application of judicial and administrative statecraft such human distress could be avoided': (para 29). 
require special attention.' 67 Respect for human dignity requires society to marshal its resources and respond strongly to situations in which certain groups are unable to gain access to basic socio-economic needs. The consequences of the deprivation will be severe (either in terms of threats to life or health), and erode the foundations for the further development of people's capabilities. To value human beings as a society demands an appropriate response. The overall resources and capacity of the society concerned will naturally determine this response. But dignity demands that society do its utmost to ensure that those groups who are unable to gain access to basic socio-economic needs are assisted. 68

This duty is recognised by the United Nations Committee on Economic, Social and Cultural Rights in interpreting States parties' obligations under the International Covenant on Economic, Social and Cultural Rights (1966). According to the Committee, '.... State party in which any significant number of individuals is deprived of essential foodstuffs, of essential primary health care, of basic shelter and housing, or of the most basic forms of education is, prima facie, failing to discharge its obligations under the Covenant.' 69 This places a burden on the State, should it seek to attribute its failure to meet its core obligation to a lack of available resources, to 'demonstrate that every effort has been made to use all resources that are at its disposal in an effort to satisfy, as a matter of priority, those minimum obligations.' 70

In Grootboom and TAC, the Court rejected the invitation of the amici to base their decision on the concept of a minimum core obligation. In doing so the Court articulated a range of concerns relating to the concept. These included the assumed inflexibility of the minimum core, difficulties in setting minimum standards in the context of varying needs and opportunities for accessing the rights, the lack of institutional competence for determining minimum standards, and the impossibility of giving everyone access to even a 'core' service immediately. ${ }^{71}$ However, the minimum core obligation, properly conceived, is neither an absolute duty nor a rigid standard. Rather, it establishes a high threshold of justification when a deprivation of 'essential' levels of socio-economic goods and services is at issue. The State is required to show that it has exhausted all available methods, and that its resources are 'demonstrably inadequate' 72 to meeting those needs. This raises the central importance of justification in ensuring the strong protection of socio-economic rights. This issue will be revisited in Part V below.

67 Government of the Republic of South Africa v Grootboom 2001 (1) SA 46 (CC) para 36; Minister of Health v Treatment Action Campaign 2002 (5) SA 721 (CC) para 70.

68 In Khosa \& Others $v$ Minister of Social Development and Others; Mablaule and Another $v$ Minister of Social Development and Others 2004 (6) BCLR 569 (CC), the Court (per Mokgoro J) stated: 'The right of access to social security, including social assistance, for those unable to support themselves and their dependants is entrenched because as a society we value human beings and want to ensure that people are afforded their basic needs. A society must seek to ensure that the basic necessities of life are accessible to all if it is to be a society in which human dignity, freedom and equality are foundational': (at para 52) [emphasis added, footnotes omitted]. Nussbaum argues: 'Programs aimed at raising general or average well-being do not improve the situation of the least well-off, unless they go to work directly to improve the quality of those people's lives. If we combine this observation with the thought... that each person is valuable and worthy of respect as an end, we must conclude that we should look not just to the total or the average, but to the functioning of each and every person. We may call this the principle of each person as end': Women and Human Development (note 3 above) at 56.

69 General Comment No. 3 (Fifth session, 1990) The Nature of States Parties Obligations (art 2(1) of the Covenant), UN doc E/1991/23 at para 10.

70 Ibid.

71 Government of the Republic of South Africa v Grootboom 2001 (1) SA 46 (CC) paras 29 - 33; Minister of Health $v$ Treatment Action Campaign 2002 (5) SA 721 (CC) paras 26 - 39.

72 General Comment No 3 (note 69 above) para 11. 
Thus far I have argued that the value of human dignity can enrich our socio-economic rights jurisprudence, first, by justifying claims against social resources when groups lack the material conditions necessary for the development of their capabilities as human beings. Second, respect and concern for the dignity of each person requires an approach that considers the impact of the deprivation upon the actual needs and circumstances of the individuals and groups concerned. Finally, it requires an appropriate response to these conditions. Urgent needs and severe deprivations demand a strong, immediate response. We give expression to the value of human dignity in our constitutional jurisprudence by placing the State under a stringent burden of justification in claims involving a deprivation of basic needs.

However, the use of human dignity in socio-economic rights jurisprudence is not without its pitfalls. As critics have cautioned in relation to South Africa's equality jurisprudence, ${ }^{73}$ there is a danger that human dignity in our socio-economic jurisprudence will result in a focus on subjective personality issues such as the claimants' feelings of self worth and self-respect. This focus can divert attention away from the real issue of the impact of the deprivation on claimants.

The Canadian Supreme Court decision in Gosselin illustrates how differing conceptions of human dignity can influence the outcome of a social benefits claim. ${ }^{74}$ A class action was brought challenging social security regulations in Quebec which set the base amount of welfare benefits for adults between the ages of eighteen and thirty years at about one-third the base amount payable to those thirty years and over. This amounted to a difference between $\$ 170$ per month compared to $\$ 466$ per month (for the over 30 years and over age group). The latter was deemed by the legislature to constitute 'the bare minimum for the sustainment of life. ${ }^{.75}$ The only way that those under 30 years could raise their benefits was to participate in various educational and employability programmes. However, for the majority of young welfare recipients like the appellant participation in these programmes was fraught with difficulties, including their restrictive eligibility requirements and the limited number of places available. ${ }^{76}$ The Supreme Court of Canada had to consider whether the challenged regulation violated section 15 (equality right) of the Charter on the grounds that it discriminated on the basis of age. In addition, violations of section 7 of the Charter ${ }^{77}$ and section 45 of the Quebec Charter of Rights and Freedoms 78 were also alleged.

The majority of the Court found no violations of the Canadian Charter of Rights and Freedoms or the Quebec Charter. In regard to section 15, the majority held that a reasonable person in the claimant's circumstances would have perceived the government's positive motives in creating an incentive-based welfare scheme for young people. According to the

73 See Part II above and the works cited there.

74 Gosselinv Quebec (Attorney General) 2002 SCC 84221 DLR (4th).

75 Gosselinv Quebec (Attorney General) 2002 SCC 84221 DLR (4th) at paras 251, 285 (per Bastarche J), and at para 334 (per Arbour J).

76 Thus the government of Quebec had only made 30000 programme places available even though 85000 single people under 30 years of age were on social assistance. See Gosselin v Quebec (Attorney General) 2002 SCC 84221 DLR (4th) para 283. Four of the dissenting judgments on $\mathrm{s} 15$ raised serious issues regarding the accessibility of these programmes and questioned whether the regulation was really designed to enhance the long-term situation of those under 30 years as opposed to simply saving money. See, for example, the discussion by Bastarche J at paras $276-283$, and Arbour J at para 393.

77 Section 7 of the Charter provides that: 'Everyone has the right to life, liberty and security of the person and the right not to be deprived thereof except in accordance with the principles of fundamental justice'.

78 Section 45 of the Quebec Charter provides that every person in need has a right to 'measures of financial assistance and to social measures provided for by law, susceptible of ensuring such person an acceptable standard of living'. 
government this scheme was designed to promote the long-term employability of young people. Thus making welfare payments conditional in this manner did not violate the dignity or human worth of persons under 30 years of age. ${ }^{79}$ This can be contrasted with the more impacts-based approach to human dignity in the dissenting judgment of L'Heureux-Dubé J. After dealing with the practical effects of the regulation on the claimant's ability to meet basic subsistence needs, ${ }^{80}$ she considered whether the claimant would perceive that her dignity had been threatened:

...The reasonable claimant...would have been told that the long-term goal of the legislative scheme was to affirm her dignity. The reasonable claimant would also likely have been a member of the 88.8 percent who were eligible for the programs and whose income did not rise to the levels available to all adults 30 years of age and over.... The reasonable claimant would have made daily life choices in the face of an imminent and severe threat of poverty. The reasonable claimant would likely have suffered malnourishment. She might have turned to prostitution and crime to make ends meet. The reasonable claimant would have perceived that as a result of her deep poverty she had been excluded from full participation in Canadian society. She would have perceived that her right to dignity was infringed as a sole consequence of being under 30 years of age, a factor over which, at any given moment, she had no control... 81

In L'Heureux-Dubé J's judgment, the legislature's good motives did not outweigh the severe impact of the regulation on the claimant's physical and psychological integrity and her human dignity as a member of Canadian society. Her approach to the question whether there was a correspondence between the ground of distinction and the actual needs and circumstances of the affected group is also significant. In this regard, she held that 'there should be a strong presumption that a legislative scheme which causes individuals to suffer severe threats to their physical and psychological integrity as a result of their possessing a characteristic which cannot be changed does not adequately take into account the needs, capacity or circumstances of the individual or group in question.' 82

The approach of the majority in Gosselin to the assessment of whether human dignity had been infringed by the relevant regulation illustrates the dangers of a narrow, 'personality interests'-type approach to human dignity in assessing the constitutionality of a group's exclusion from social benefits. This is further complicated by the introduction of an objective element, focusing not on the actual experiences of the applicant, but on conjecture regarding what a reasonable person in the applicant's position would feel. As Sandy Fredman argues, '[t] he reasonable person turns out to be no more than the government's own perception of its policy aims,

79 Gosselin v Quebec (Attorney General) 2002 SCC 84221 DLR (4th) paras 52 - 53, 65 (per McLachlin CJC). In Law (note 59 above), the Supreme Court of Canada had held that the key issue in determining whether a distinction conflicts with sec 15(1) is whether 'a reasonable person in circumstances similar to those of the claimant would find that the legislation which imposes differential treatment has the effect of demeaning his or her dignity' having regard to the individual's or group's traits, history, and circumstances': (para 60; cited in Gosselin v Quebec (Attorney General) 2002 SCC 84221 DLR (4th) at para 25).

80 She found that the regulation in question exposed Ms Gosselin to the risk of severe poverty and in so doing breached her psychological and physical integrity. For example, she pointed out that in 1987, the monthly cost of proper nourishment was $\$ 152$ whereas the guaranteed monthly welfare payment to young adults was \$170: Gosselinv Quebec (Attorney General) 2002 SCC 84221 DLR (4th) para 130.

81 Gosselinv Quebec (Attorney General) 2002 SCC 84221 DLR (4th) paras 131 - 132.

82 Gosselin v Quebec (Attorney General) 2002 SCC 84221 DLR (4th) para 135 [emphasis added]. 
thus underscoring the deference of the standard of review. ${ }^{93}$ The majority in Gosselin is too deferential to legislative choices that result in a vulnerable group suffering severe deprivation ostensibly to promote the longer-term objectives of greater self-sufficiency and employability among youth on welfare. The minority judgments, in contrast, emphasise the impact on young welfare beneficiaries of the exclusion from a minimally adequate standard of benefits. The infringement of human dignity arises from the fact that the exclusion seriously undermines the physical and psychological integrity of young welfare beneficiaries. This places a burden on the State to justify the exclusion based on compelling evidence and arguments. The minority concludes that the consequences were of such a severe nature that they could not be justified by the state's long-term objectives. ${ }^{84}$

The minority's approach to human dignity in Gosselin holds the most potential for positively influencing our socio-economic rights jurisprudence. The final section examines how the value of human dignity can influence our socio-economic rights jurisprudence to make it more responsive to claims for the provision of basic human needs.

\section{$V$ Strengthening our Constitutional Response to Basic Needs Claims}

In many respects the evolving jurisprudence on socio-economic rights gives effect to the value of human dignity developed thus far. The Court endorses positive state measures to achieve access to socio-economic rights, a context-sensitive evaluation of reasonableness, and the requirement that a reasonable government programme includes short-term relief for those in urgent need and living in intolerable conditions. This applies even if the overall programme is statistically successful in the long-term in advancing people's access to socio-economic rights. ${ }^{85}$

The Court's model of review for positive socio-economic rights claims ${ }^{86}$ centres on the rea-

83 S Fredman 'Providing Equality: Substantive Equality and the Positive Duty to Provide' unpublished paper delivered at SAJHR Conference, 5 - 7 July 2004 (on file with author), at 11. See also G Brodsky 'Gosselin v Quebec (Attorney General): Autonomy with a Vengeance' (2003) 15 Canadian Journal of Women and the Law 194.

84 Thus, for example, Arbour J held as follows in considering the sec 1 limitation inquiry (having found that the regulation breaches the s 7 rights to life and security of the person): '...it is difficult to accept that denial of the basic means of subsistence is rationally connected to values of promoting the long-term liberty and inherent dignity of young adults. Indeed, the long-term importance of continuing education and integration into the workforce is undermined where those at whom such "help" is directed cannot meet their basic short-term subsistence requirements. Without the ability to secure the immediate needs of the present, the future is little more than a faroff possibility, remote both in perception and in reality': Gosselin v Quebec (Attorney General) 2002 SCC 84221 DLR (4th) para 392. This also has resonance with the rationale in Government of the Republic of South Africa $v$ Grootboom 2001 (1) SA 46 (CC). Here the government's rational housing programme that was geared to the long-term goal of providing housing for all was nonetheless constitutionally defective for its failure to attend to short-term, urgent housing needs (see notes 64 - 66 above and accompanying text).

85 Government of the Republic of South Africa v Grootboom 2001 (1) SA 46 (CC) paras 44, 68 and see the Court's order at para 99.

86 These claims involve two main situations. The first is the exclusion of a particular group from an existing social programme, the second entails the absence of a suitable programme providing access to particular benefits. In the first type of situation, as Khosa \& Others $v$ Minister of Social Development and Others; Mahlaule and Another $v$ Minister of Social Development and Others 2004 (6) BCLR 569 (CC) illustrates, socio-economic rights and equality claims may often overlap. In the second situation, litigants may rely on the socio-economic rights provisions in the Bill of Rights to argue that the State is under a duty to adopt an appropriate programme 'capable of facilitating the realisation of the right' in question. See Government of the Republic of South Africa v Grootboom 2001 (1) SA 46 (CC) para 41. The absence of a programme catering for the provision of basic needs may also engage the right to equality interpreted substantively. 
sonableness inquiry. The fundamental question to be answered by the Court in such cases is whether the measures adopted by the State (or the failure to adopt appropriate measures) are reasonable in the circumstances. The reasonableness inquiry is further conditioned by the qualifying phrases in the second subsections of sections 26 and 27, namely the availability of resources and the latitude of 'progressive realisation' afforded the State. ${ }^{87}$ The Court is clearly reluctant to dictate particular policy choices to government. Instead it contemplates in Grootboom that 'a wide range of possible measures' would meet the requirements of reasonableness and thus comply with sections 26 and $27 .{ }^{88}$ It is certainly appropriate that the Court respects the primary role of the democratically elected legislature in relation to socioeconomic policy. The executive also has particular institutional competency to design and implement appropriate policies and programmes. Reasonableness review provides the courts with a flexible, context-sensitive tool for adjudicating positive socio-economic rights claims. ${ }^{89}$

However, its application in relation to claims involving a deprivation of the basic necessities of life is inadequate. The stakes are high for the individuals and groups who approach the Court for relief, entailing severe threats to life, health and the ability to function in society. I have sought to develop the argument that a failure by society to respond in proportion to the seriousness of the deprivations faced by its members represents a failure to value their fundamental dignity as human beings. In this section I will argue why I believe that the judicial protection of these claims is insufficient, and how it could be improved. Stronger judicial potential of these claims will also signal to the State the constitutional importance of a robust response to situations of severe material deprivation.

One of the shortcomings of the current structure of reasonableness review is that individual litigants bear an onerous burden of proof and persuasion to demonstrate the unreasonableness of government programmes. The Court has made it clear that sections 26 and 27 confer no direct entitlement to claim immediate delivery of goods and services from the State only a right to require government to adopt a reasonable programme. ${ }^{90}$ Thus it is not enough for a group of litigants to approach the Court alleging that they are poor and seriously malnourished, thereby establishing a prima facie violation of the right to food in section 27 of the Constitution. Instead litigants will have to show that the State's actions or omissions are unreasonable in terms of the second subsection of section 27. To do so, they will have to review a wide range of government social programmes, and assess their reasonableness in the context of the State's

87 Government of the Republic of South Africa v Grootboom 2001 (1) SA 46 (CC) paras 38, 41, 45-6. Although 'progressive realisation' affords the State the latitude of not requiring immediate realisation of the right, the Court also affirms that it imposes specific obligations on the State to make demonstrable progress in facilitating access to the rights, and in avoiding retrogressive measures: see Grootboom para 45.

88 Grootboom para 41.

89 The following key features of a reasonable government programme to realise socio-economic rights were developed by the Court in the Government of the Republic of South Africa v Grootboom 2001 (1) SA 46 (CC) and the Minister of Health $v$ Treatment Action Campaign 2002 (5) SA 721 (CC) cases: the programme must be comprehensive, coherent, coordinated; it must be balanced and flexible, making appropriate provision for short, medium and long-term needs, and not exclude a significant segment of society; it must include reasonable provision for those in urgent need; it must be reasonably conceived and implemented; it must be transparent, and its contents must be made known effectively to the public. See Grootboom paras 39 - 43; Treatment Action Campaign para 123.

90 Government of the Republic of South Africa v Grootboom 2001 (1) SA 46 (CC) paras 41, 95; Minister of Health v Treatment Action Campaign 2002 (5) SA 721 (CC) 32 - 39, and 125. 
capacity and available resources. ${ }^{91}$ Establishing the unreasonableness of a disparate set of government programmes in the light of the State's available resources will be a matter of great factual and legal complexity which will often be beyond the capacity of indigent and vulnerable groups. ${ }^{92}$ It thus does not facilitate the practical justiciability of this class of claims. ${ }^{93}$

In cases (such as the one discussed above) where people will face irreparable harm through not having their basic needs met, a more appropriate response would be to give the applicants the benefit of a presumption of unreasonableness. The effect would be that prima facie unreasonableness is established when a disadvantaged group shows that they lack access to the social goods and services that are required to sustain life, health and a basic level of functioning. The burden would shift to the State to rebut this presumption with compelling reasons. This presumption would not be dissimilar to that operating in the context of the equality clause where discrimination on a listed ground is presumptively unfair. ${ }^{94}$ A clear presumption in favour of this category of socio-economic rights claimants recognises that a social failure to value human dignity is at stake when individuals and groups experience severe socio-economic deprivations. These groups are denied the opportunity to survive and to develop their capabilities. Respect and concern for the value and intrinsic worth of the individuals so afflicted should trigger a presumption of unreasonableness and place a burden of justification on the State.

It should be evident that this approach does not require the setting of inflexible minimum standards of delivery for each socio-economic right. As the Court observed in Grootboom, such an approach would be insensitive to the varying needs and circumstances of differently situated groups in society. ${ }^{95}$ It also does not impose an absolute standard of performance on the State regardless of the social and economic context. It does require placing a strong burden of justification on the State regarding the absence of basic levels of provisioning for groups living in poverty. 96

91 The Court indicated that it would take into account the 'interconnectedness' of rights' in assessing whether the state has fulfilled its obligations: Grootboom para 24. Among the measures that the Court indicated would be relevant in relation to access to housing were steps to make the rural areas of the country more viable so as to limit the migration of people from rural to urban areas in search of jobs (para 34). It also indicated that social assistance programmes put in place under sec 27 'would be relevant to the state's obligations in respect of other socio-economic rights': (para 36).

92 See in this regard the submissions of the amici in Treatment Action Campaign (Community Law Centre and IDASA) (24 April 2002, on-line at: www.communitylawcentre.org.za/ser/docs 2002/TAC MTCT Case Heads of Arguments.doc) at para 31.1.

93 The impact of the Court's rejection of the concept of a minimum core obligation on the practical justiciability of socio-economic rights was developed by Adv Wim Trengove in representing the amici curiae in the Treatment Action Campaign case. They argued that practical justiciability is of particular importance in the enforcement of socio-economic rights because the purpose of these rights is to protect the interests of the poor who lack access to basic amenities of life: 'For most of them, the right of access to court is already a paper right and not a practical reality. The very socio-economic rights designed for their protection and advancement must accordingly not be interpreted in a way that makes enforcement practically impossible': (para 30.2).

94 Section 9(5).

95 See note 71 above and accompanying text. As Nussbaum argues, 'individuals vary greatly in their needs for resources and in their abilities to convert resources into valuable functionings': Women and Human Development (note 3 above) at 68. She gives the examples of a pregnant or lactating woman who needs more nutrients than a nonpregnant woman, a child needs more protein than an adult and a person with paralysed limbs needs many more resources to achieve the same level of mobility as a person without this disability. See further the discussion at $68-70$.

96 See the similar presumption suggested by L’Heureux-Dubé J in Gosselin v Quebec (Attorney General) 2002 SCC 84221 DLR (4th): see note 82 above and accompanying text. 
However, given the nature of the deprivations at stake and the seriousness of the consequences for the affected groups, this should not be an easy burden to discharge. A rigorous standard of scrutiny is required. In terms of the relational concept of human dignity I have sought to develop, dignity fails to be protected when the standard of justification demanded of government in respect of a failure to fulfil basic needs is low. A response that is not proportionate to the nature of the deprivation and its impact communicates a message that the affected group is not worthy of equal respect and concern. ${ }^{97}$ I suggest two elements of a stricter review standard for this category of claims.

A stricter standard of scrutiny would require a compelling government purpose for failure to ensure that vulnerable groups have access to basic needs. Competing state priorities and resources-based justifications often give the Courts the most difficulty as they raise issues of separation of powers and institutional competence. ${ }^{98}$ However, respect for the dignity of human beings requires a serious engagement with these justifications. It is not sufficient as the Court did in TAC to simply assert that '[i]t is impossible to give everyone access even to a "core" service immediately." 99 The State should at least be required to establish the factual underpinnings of its justifications based on resources. 100 There are different formulations of the threshold to be met concerning resource-based justifications for limiting access to constitutional rights. For example, the UN Committee on Economic, Social and Cultural Rights requires States to show that their resources are 'demonstrably inadequate' for meeting basic needs in the context of other equally important government purposes. ${ }^{101}$ In Eldridge $v$ British Columbia

97 In Khosa \& Others $v$ Minister of Social Development and Others; Mablaule and Another $v$ Minister of Social Development and Others 2004 (6) BCLR 569 (CC), the Court held that 'when the rights to life, dignity and equality are implicated in cases involving socio-economic rights, they have to be taken into account along with the availability of human and financial resources in determining whether the state has complied with the constitutional standard of reasonableness': (at para 44). Although not explicitly stated, this suggests a tightening of the review standard in a socio-economic rights case when life, dignity and equality are at stake. In Jaftha $v$ Schoeman and others; Van Rooyen $v$ Stoltz and Others 2005 (1) BCLR 78 (CC), the Court held that the relevant provisions of the Magistrates' Court Act 32 of 1944 (permitting sales of execution against people's homes for debt without judicial oversight) rendered people vulnerable to homelessness as they would no longer qualify for housing subsidies. Without such assistance 'they may be rendered homeless and never able to restore the conditions for human dignity': (para 39). The Court accordingly held, in the limitations analysis (s 36), that this constituted 'a severe limitation of an important right': (para 39). The European Court of Human Rights recently held in Connors $v$ The United Kingdom 2005 (40) EHRR 189 (judgment of 27 May 2004) that the eviction of a gypsy family from a council-owned cite constituted a serious interference with their right to respect for their 'private and family life' and their home in terms of article 8 of the European Convention of Human Rights (1950). The Court observed that article 8 'concerns rights of central importance to the individual's identity, selfdetermination, physical and moral integrity, maintenance of relationships with others and a settled and secure place in the community': (para 82). The consequence of the eviction was homelessness for the family 'with the adverse consequences on security and well-being which that entails': (para 85). These serious consequences warranted, in the Court's opinion, 'particularly weighty reasons of public interest by way of justification': In these circumstances, 'the margin of appreciation to be afforded to the national authorities must be regarded as correspondingly narrowed': (para 86).

98 See, for example, Minister of Health v Treatment Action Campaign 2002 (5) SA 721 (CC): 'It should be borne in mind that in dealing with such matters the courts are not institutionally equipped to make the wide-ranging factual and political enquiries necessary for determining what the minimum-core standards...should be, nor for deciding how public revenues should most effectively be spent': (para 37).

99 Minister of Health $v$ Treatment Action Campaign 2002 (5) SA 721 (CC) para 35.

100 In the context of the positive duties imposed by civil and political rights such as the right to vote, the courts have required that the factual basis for justifications based on logistics and costs be established by the State in the context of a limitations enquiry: Minister of Home Affairs $v$ National Institute for Crime Prevention (NICRO) \& Others 2004 (5) BCLR 445 (CC) at paras $47-51$.

101 See notes 69 and 70 above and accompanying text. 
(Attorney General), 102 the Canadian Supreme Court held that section 15(1) (equality) imposed positive duties on the government to ensure 'reasonable accommodation' of disadvantaged groups in government programmes to the point of 'undue hardship.' 103

Whatever formulation is adopted, the Court should scrutinise the State's evidence and arguments closely with a view to assessing whether it constitutes a compelling justification in the context of current South African society for failing to provide basic needs. The State is not necessarily required to show the diversion of all resources to the provision of basic needs. Ideally basic needs claims should be addressed in the context of integrated social programmes as opposed to ad hoc, crisis interventions. ${ }^{104}$ Sometimes, however, temporary solutions may be essential to respond to individual needs until the groups can be catered for within mainstream programmes. What should be required is evidence that the State is taking concrete and well-targeted budgetary and other measures to effectively address the situation of those who are experiencing severe deprivations of basic needs. Despite the above statement in the TAC case, the Court in fact proceeded to carefully analyse the State's resource-based justifications for the failure to extend the provision of Nevirapine throughout the public health sector, and concluded that they were unconvincing. 105 The Court's decision in Khosa also illustrates that the Court is both willing and able to engage vigorously with the State's resource-based justifications for failing to fulfil socio-economic rights. 106

The second element of a strengthened review standard concerns the inclusion of a more rigorous proportionality analysis. 107 The Court comes close to a proportionality test by establishing, as an important factor in the reasonableness enquiry, whether the State has made provision for those in immediate need. As Danie Brand argues, the Court 'leans significantly closer [to a proportionality test] by incorporating such an element into its standard of scrutiny, narrowing the range of policy options that it would be legitimate for government to choose from and thinking about the relative efficiency of different policy options. ${ }^{108}$ In TAC, the Court required government to adopt a

102 (1997) 151 DLR (4th) 577 (SC). The Court was faced with a challenge to the failure of the Medical Services Commission of British Columbia to provide sign language interpretation for deaf patients in the health system. It held that this omission constituted a prima facie violation of their right to equal benefit of the law without discrimination under s 15(1) of the Charter.

103 Eldridge v British Columbia (Attorney General) (1997) 151 DLR (4th) 577 (SC) paras 77 - 80. In response to the government's argument in the sec 1 (limitations) analysis that the appellants' claim would have 'a ripple effect throughout the health care field, forcing governments to spend precious health care dollars accommodating the needs of a myriad of disadvantaged persons' (at para 91), the Court held as follows: 'The respondents have presented no evidence that this type of accommodation, if extended to other government services, will unduly strain the fiscal resources of the state. To deny the appellants' claim on such conjectural grounds, in my view, would denude s 15(1) of its egalitarian promise and render the disabled's goal of a barrier-free society distressingly remote': (at para 92).

104 As the Court observed in Government of the Republic of South Africa v Grootboom 2001 (1) SA 46 (CC) a reasonable programme 'must be balanced and flexible and make appropriate provision for attention to housing crises and to short, medium and long term needs': (at para 43).

105 See notes 48 - 52 above and accompanying text.

106 Khosa \& Others $v$ Minister of Social Development and Others; Mablaule and Another $v$ Minister of Social Development and Others 2004 (6) BCLR 569 (CC) at paras $60-62$ (the inclusion of permanent residents in the social grants system 'will be only a small proportion of the total cost').

107 Theunis Roux observes that, although the reasonableness test 'undoubtedly requires the court to substitute its view of what the constitution requires - the inclusion of the excluded group - for that of the political branches', it 'stops short... of a full blown proportionality test': T Roux 'Legitimating Transformation: Political Resource Allocation in the South African Constitutional Court' (2003) 10 Democratization 92 at 97.

108 D Brand 'The Proceduralisation of South African Socio-Economic Rights Jurisprudence, or "What are Socio-Economic Rights For?" ' in H Botha, A van der Walt and J van der Walt (eds) Rights and Democracy in a Transformative Constitution (2004) 33 at 41. 
particular policy, namely the provision of Nevirapine (or any other equally appropriate or better method) throughout the public health sector for the prevention of mother-to-child transmission of HIV. This was unavoidable given the fact that there was in fact very little scope for a range of policy choices. Without the provision of Nevirapine (or a similar anti-retroviral drug), large numbers of infants would continue to be infected with HIV and die prematurely as a result of mother-tochild transmission. Where the State does have a legitimate range of policy choices to respond to basic needs claims it would be appropriate for the Court to give the legislature and executive the first opportunity to design an appropriate programme. However, this could be achieved at the remedial stage and should not preclude a finding that government has failed to fulfil its positive duties. ${ }^{109}$

The inclusion of a more explicit proportionality analysis should include a requirement that government show that there are not less restrictive means to achieve its purposes than a total denial of access to basic socio-economic goods and services. ${ }^{110}$ This should also entail showing that it has taken steps to mitigate the harms suffered as a result of the deprivation. Mitigating measures are particularly important when the provision of even a basic level of services to all who need them is unattainable in the short term. The situation of these groups must remain a matter of high priority and programmes aimed at alleviating the worst impact of the deprivations experienced must be put in place. ${ }^{111}$ In addition, the State must show that it is monitoring the deprivation of basic needs, and devising programmes and strategies for remedying the situation with the shortest possible period of time. 112

In many respects, this inquiry resembles the limitations inquiry under section 36 . This is an inevitable consequence of the model of reasonableness review adopted by the Court for measuring compliance with the State's positive obligations under sections 26 and 27. In the Khosa case, the Court alluded to the 'difficulty in applying section 36 of the Constitution to the socioeconomic rights entrenched in sections 26 and 27 of the Constitution.' 113 The Court held that

109 This could be facilitated through the use of the remedy of supervisory jurisdiction, which is discussed further below.

110 J De Waal, I Currie and MG Erasmus describe this element of the proportionality analysis as follows: 'The limitation will not be proportionate if other means could be employed to achieve the same ends that will either not restrict rights at all, or will not restrict them to the same extent. The Bill of Rights Handbook (4th ed) (2001) 161 - 162. In Eldridge v British Columbia (Attorney General) (1997) 151 DLR (4th) 577 (SC), the Canadian Supreme Court held, in its sec 1 (limitations) enquiry, that the government had 'manifestly failed to demonstrate that it has a reasonable basis for concluding that a total denial of medical interpretation services for the deaf constituted a minimum impairment of their rights': (para 87). The Ministry of Health had decided not to fund the interpretation programme even in part. In this regard, the Court held: 'Other options such as the partial or interim funding of the program offered by the Western Institute for the Deaf and Hard of Hearing, or the institution of a scheme requiring users to pay either a portion of the cost of interpreters or the full amount if they could afford to do so, were either not considered or were considered and rejected': (at para 93).

111 In General Comment No 3 (note 69 above), the UN Committee on Economic, Social and Cultural Rights emphasised that 'even where the available resources are demonstrably inadequate, the obligation remains for a State party to strive to ensure the widest possible enjoyment of the relevant rights under the prevailing circumstances': (at para 11). It goes on to highlight the continuing obligation to protect the poor even during periods of resource scarcity: 'Similarly, the Committee underlines the fact that even in times of severe resource constraints whether caused by a process of adjustment, of economic recession, or by other factors the vulnerable members of society can and indeed must be protected by the adoption of relatively low-cost targeted programmes': (para 12).

112 The UN Committee on Economic, Social and Cultural Rights has adopted the view that the State's duties 'to monitor the extent of realization, or more especially of the non-realization, of economic, social and cultural rights and to devise strategies and programmes for their promotion, are not in any way eliminated as a result of resource constraints': General Comment No 3 (note 69 above), para 11.

113 Khosa \& Others $v$ Minister of Social Development and Others; Mablaule and Another $v$ Minister of Social Development and Others 2004 (6) BCLR 569 (CC) para 83. See also the academic commentaries cited by the Court at note 88 of the judgment. 
it was not necessary to decide the issue of whether 'a different threshold of reasonableness' is called for in sections 26 and 27 than is the case in section 36. ${ }^{114}$ An advantage of conducting the inquiry into the justifiability of the State's acts or omission in terms of the general limitations clause (section 36) is the requirement of a law of general application. This has the important benefit that limitations on people's access to basic needs would have to be publicly debated and adopted by the elected representatives of the people. ${ }^{115}$ However, if the internal limitations in sections 26(2) and 27(2) are going to do the major work in assessing the State's compliance with its positive duties, it should encompass a high standard of justification, including a more rigorous proportionality analysis, at least in respect of basic needs claims.

The standard of scrutiny may vary in intensity, depending on the nature of the interests at stake. A strict level of judicial scrutiny is appropriate when a case concerns the claimants' inability to gain access to a minimally adequate level of resources to survive and function effectively. 116 This strict form of scrutiny should not be triggered only in emergency or crisis situations. The Court in Grootboom also referred in its order to those 'living in intolerable conditions'. ${ }^{117}$ This clearly contemplates a broader set of circumstances than emergencies. In insisting on the strong judicial protection of basic survival needs, we should not lose sight of the fact that we are concerned not only with physical survival, but the essential material conditions that each person needs to develop their capabilities and to function effectively as members of society. This includes the physical, psychological and social dimensions of their personhood. ${ }^{118}$ The standard of review can be progressively relaxed when claims are made to levels of social provisioning that are less closely related to people's ability to survive and function effectively in society. This graduated standard of review is accommodated by the concept of 'progressive realisation' in sections 26(2) and 27(2). 119 Thus while a stronger standard of review is justified for basic needs claims, it seems appropriate to allow the State a greater latitude (in terms of both time and resource allocation priorities) when the claim involves more tertiary levels of provisioning. In the case of children, material deprivation can have a profound impact on the future development of their basic capabilities, calling for heightened scrutiny of the impact of such deprivations. ${ }^{120}$

114 Khosa \& Others $v$ Minister of Social Development and Others; Mablaule and Another $v$ Minister of Social Development and Others 2004 (6) BCLR 569 (CC) para 84. For a recent view on the relationship between the internal limitations in sections 26 and 26 and the general limitations clause in s 36, see K Iles 'Limiting Socio-Economic Rights: Beyond the Internal Limitations Clauses' (2004) 20 SAJHR 448.

115 It is noteworthy that in respect of the negative violation of the duty not to deprive people of existing access to socio-economic rights, the Court has now held in Jaftha $v$ Schoeman and Others; Van Rooyen $v$ Stoltz and Others 2005 (1) BCLR 78 (CC) that justification is appropriately considered in terms of the general limitations clause. See paras 31 to 34 .

116 David Bilchitz refers to people's basic or 'urgent' interest 'in being free from threats to one's survival, being free from severe physical suffering, and not being exposed to serious health risks that impair one's ability to act': 'Giving Socio-Economic Rights Teeth: The Minimum Core and its Importance' (2002) 118 SALJ 484 at 490 . He argues that the urgency of the interests at stake justifies strong judicial protection (at 491).

117 Government of the Republic of South Africa v Grootboom 2001 (1) SA 46 (CC) para 99.

118 See the discussion of Nussbaum's list of 'central human capabilities' at notes 26 to 29 and accompanying text. Bilchitz also refers to people's more extensive interest 'in living in an environment that is conducive to their flourishing and development on physical, emotional and mental levels': (note 116 above) 490.

119 See the discussion of the Court's interpretation of 'progressive realisation' in Liebenberg (note 12 above) ch $33,41-42$.

120 The drafting of section $28(1)(\mathrm{c})$ of the Constitution suggests a stronger standard of scrutiny for children's socio-economic rights. Prima facie children are guaranteed a basic level of socio-economic rights, with limitations to this entitlement falling to be determined in terms of the general limitations clause (sec 36). For a critical evaluation of the Court's approach to the interpretation of children's socio-economic rights, see Liebenberg (note 12 above) ch 33, $48-52$. 
The final area where the Court could strengthen its constitutional response to socio-economic rights claims is in the area of remedial jurisprudence. A detailed discussion of this aspect is beyond the scope of the present paper. However, it is evident that the nature of the urgent interests at stake in the socio-economic rights claims that are the focus of this paper demands an appropriate and effective remedy. The orders handed down in cases such as TAC will ultimately result in the extension of critical benefits to significant numbers of people. ${ }^{121}$ However, the Court has indicated that a finding that a government programme is unreasonable will not necessarily imply that all in desperate need should receive relief immediately. ${ }^{122}$ Nonetheless, as the Court indicated in TAC, '[e]very effort must, however, be made to do so as soon as reasonably possible. ${ }^{\prime 23}$ There will be situations where it would be impossible to immediately remedy a situation that has been found to be in violation of sections 26 and 27, or where the granting of relief to only the litigants before the court would be inequitable to other similarly-situated groups. The Court's broad power to make 'any order that is just and equitable'124 provides the remedial flexibility to make appropriate orders in these situations. However, sight should never be lost of the fact that there are serious interests of human survival and dignity at stake. The language of the orders handed down by the Court should reflect this fact, and signal the requirement that the State remedy the defect 'diligently and without delay.' 125 This is exemplified in the mandatory nature of the order handed down in TAC combined with the duty to take the steps specified in the order 'without delay.' 126 When it is not manifestly inappropriate or unjust, the Court should lean in favour of granting individual remedies to the successful litigants. ${ }^{127}$ This reflects the value we should place on the dignity of each person.

The TAC order has been criticised for its failure to grant the supervisory order sought by the applicants. ${ }^{128}$ While the Court accepted that such orders could be given in appropriate circumstances, it indicated that that they should generally not be made in those terms 'unless this is necessary' to secure compliance with a court order. ${ }^{129}$ The Court went on to express its faith that the government would respect and execute its orders. However, an equally important con-

121 This of course assumes that the State diligently executes the Court's orders and that there is effective monitoring and advocacy in respect of the implementation of the orders by institutions such as the SA Human Rights Commission, the press and NGOs. On the efforts of the Treatment Action Campaign in seeking to ensure the implementation of the Treatment Action Campaign order, see M Heywood 'Contempt or Compliance: The TAC Case after the Constitutional Court Judgment' (2003) 4 ESR Review 7.

122 Government of the Republic of South Africa v Grootboom 2001 (1) SA 46 (CC) para 69; Minister of Health $v$ Treatment Action Campaign 2002 (5) SA 721 (CC) para 125.

123 Treatment Action Campaign para 125.

$124 \mathrm{Sec} 172(1)(\mathrm{b})$ of the Constitution.

125 See sec 237 of the Constitution.

126 Treatment Action Campaign para 135. The Grootboom order has been criticised for its purely declaratory nature and the impact this had on the slow implementation of the order: see K Pillay 'Implementation of Grootboom: Implications for the Enforcement of Socio-economic Rights' (2002) 6 Law, Democracy \& Development 255.

127 As the Court pointed out in August v Electoral Commission 1999 (3) SA 1 (CC): 'We cannot deny strong actual claims timeously asserted by determinate people because of the possible existence of hypothetical claims that might conceivably have been brought by indeterminate groups': (at para 30).

128 See D Bilchitz 'Towards a Reasonable Approach to the Minimum Core: Laying the Foundations for Future Socio-economic Rights Jurisprudence' (2003) 19 SAJHR 1 at 23 - 26. The High Courts in both the Grootboom and TAC cases handed down supervisory orders: Grootboom v Oostenberg Municipality \& Others 2000 (3) BCLR 277 (C) at 293 H - 294 C; Treatment Action Campaign \& Others v Minister of Health \& Others 2002 (4) BCLR $356(\mathrm{~T})$ at $386 \mathrm{I}-384 \mathrm{H}$.

129 Minister of Health $v$ Treatment Action Campaign 2002 (5) SA 721 (CC) para 129. 
sideration, as Geoff Budlender has suggested, 'is the risk of severe consequences (such as the loss of life)' in the event of a failure by the government to comply with its obligations. ${ }^{130}$ In cases where severe economic deprivation threatens people's lives and capacity for future development, this fact should weigh heavily with the Court in considering a supervisory order. This is particularly the case where the breach cannot be remedied by a single action, ${ }^{131}$ but requires a series of structural reforms and administrative actions taken over a period of time. ${ }^{132}$ Finally, if there are a range of policy options for responding to basic needs claims (as in the Grootboom situation), the remedy of supervisory jurisdiction can be formulated to allow the State to select the appropriate policy while retaining judicial supervision in respect of constitutionality of the policy choice and its implementation. In this way, a supervisory remedy may be crafted that respects the roles and competencies of the legislature and executive without abdicating judicial responsibility for the enforcement of socio-economic rights.

\section{Conclusion}

At the core of the value of human dignity lies the injunction to respect the intrinsic worth of all human beings. Drawing on Nussbaum's work, I have argued that we value human beings by viewing them in the context of the reality of their lives and inquiring what they are actually able to be and do. Through this inquiry we are confronted with the importance of social power relations and material conditions for people's ability to survive and develop their capabilities as individual and social beings.

To constitute ourselves as a society that values human dignity, we must develop appropriate responses to conditions of disadvantage and material deprivation in social policy and constitutional adjudication. In constitutional adjudication this requires a focus on the actual impact of the State's actions or omissions on the life chances of disadvantaged groups. It also demands a proportionately urgent response to conditions that undermine people's ability to survive and develop their capabilities. This is promoted by placing a strong burden of justification on the State in claims where a deprivation of access to basic human needs is at stake.

This approach does not advocate a two-tier standard of review based on a rigid distinction between 'core' and 'non-core' needs. If minimum core obligations are conceived as universal, abstract and a-contextual standards of state provision, they will certainly be unjust to a range of groups who do not fit the background norms and conditions that inform the setting of these standards. Instead what is envisaged is a continuum of judicial scrutiny informed by a contextual, evolving assessment of the position of the claimant in society, the nature of the resource or service to which access is sought, and the impact of the denial of such access on the affected group.

In many respects the Constitutional Court's evolving jurisprudence on socio-economic rights

130 G Budlender 'Access to Courts' (2004) 121 SALJ 339 at 358.

131 For example, the 'reading in' remedy granted in Khosa \& Others $v$ Minister of Social Development and Others; Mahlaule and Another v Minister of Social Development and Others 2004 (6) BCLR 569 (CC) to cure the omission of permanent residents from the Social Assistance Act 59 of 1992 (at para 98).

132 See: W Trengove 'Judicial Remedies for Violations of Socio-Economic Rights' (1999) 1 ESR Rev 88 at 9 10. 
promotes the contextual, relational conception of human dignity developed in this paper. However, our constitutional response to claims of material deprivation could be strengthened, and I have suggested how this could be accomplished within the Court's model of reasonableness review and remedial jurisprudence.

A society characterised by stark inequalities and deep poverty is most in peril of failing to value the human dignity of the poor. The role of the Constitutional Court is to hold us accountable to the vision we articulated when we adopted our Constitution 'so as to -...[i]mprove the quality of life of all citizens and free the potential of each person.'133 


\title{
The Fiscal Implications of Social and Economic Justice: An Overview of the Changing Theoretical Framework
}

\author{
— Elsabé LoOTS \\ Professor, Department of Economics, \\ University of the Free State, \\ Bloemfontein
}

\section{Introduction}

The addition of economic and social rights, or second-generation rights as they are sometimes classified, has vastly expanded the claimed domain of human rights. Economic, social and cultural rights ${ }^{1}$ are no longer neglected as they once were, relative to civil and political rights. Despite this improved awareness, we still live in a world where social and economic justice is frequently ignored and repeatedly violated and threatened. In many quarters threats are caused and entrenched by the process of globalisation, global environmental destruction and political instability between and within countries. In contrast with these external threats, a large number of developing countries that are sensitive to calls for social and economic justice simply do not have the fiscal means to address all of these needs or injustices.

The development of awareness of social and economic rights issues within the international community took quite some time. While the General Assembly of the United Nations adopted the Universal Declaration of Human Rights on 10 December 1948 it was not immediately followed by, in Smith's ${ }^{2}$ words, 'a binding enforceable tabulation of rights'. It took 18 years before consensus was reached on the text of the International Covenant on Economic, Social and Cultural Rights (1966) and a further ten years before the instrument attracted sufficient ratification to enter into force in 1976. The importance of social and economic rights was further strengthened by the influential 1986 Principles on the Implementation of Economic, Social and Cultural Rights as well by the 1997 Maastricht Guidelines on Violations of Economic, Social and Cultural Rights. ${ }^{3}$ Despite the fact that these declarations and guidelines have achieved wide recognition internationally and status within the United Nations, the framework on the core elements of these rights, the setting of standards and the identification of minimum state obligations are still in the development stage and incomplete.

1 Economic, social and cultural rights are grouped together in the International Covenant of Economic, Social and Cultural Rights. For the purpose of this research only the social and economic dimensions will be included.

2 RKM Smith Textbook in International Human Rights (2003).

3 For more details on the development of these declarations and guidelines, see Smith (note 2 above), and D Brand \& S Russell (eds) Exploring the Core Content of Socio-economic Rights: South African and International Perspectives (2002). 
The state obligations and the related fiscal implications within the social and economic justice context are controversial. Two related issues are of importance when it comes to what the state's obligations are in this regard. The first issue refers to the debate on equity and efficiency. The second issue refers to the particular rights included in the country's constitution. Within the social and economic justice debate issues such as equity and efficiency are firmly embedded. A reasonably efficient economy where perfect competition exists and markets are clearing on a continuous basis should in theory also ensure sustainable social justice. An equitable social dispensation could in theory also support an efficient economy. This implies that equity and efficiency should in theory be mutually reinforcing. In practice, countries and communities that experience social and economic injustices are struggling to sustain equity and efficiency, and mostly regard them as trade-offs.

The second issue, namely which social and economic rights are included in a particular country's constitution, also impact on the state's responsibility. Apart from the fact that the International Covenant on Economic, Social and Cultural Rights includes rights such as equal pay for equal work, trade union rights, child labour laws, a number of educational rights and academic, scientific and artistic freedom, the South African Constitution has gone further and has included the aforementioned rights as well as several rights not explicitly stated in the Covenant. These include rights such as access to water and to a clean and healthy environment. ${ }^{4}$ The South African Constitution ${ }^{5}$ therefore entrenched the following social and economic rights: labour rights; the right to have access to land, housing, health care services, sufficient food and social security; children's rights to basic nutrition, shelter, basic health care and social services; the right to basic education and in some cases further education; and a number of detained person's rights. These expanded and detailed lists of rights have serious implications for the state's obligations in this regard.

The dilemma of states having limited resources led to the development of the concept of minimum state obligation. Two important questions arise from this minimum state obligation concept. The first question is how human rights in general and social and economic rights in particular could be addressed if states do not have the available resources even to meet the minimum state obligation. The second question relates to the identification of a minimum state obligation if all the components of the stated rights are important and the ultimate goal is full implementation. The aim of this chapter is to discuss the latest approaches that have developed in theory and literature on social and economic justice on how to deal with these dilemmas.

The analysis on this topic will commence with some historical background by discussing the way approaches and theories on social and economic justice were aligned with the political ideologies of the day. Each of these approaches will be linked to the role of the state, the mainstream theoretical economic thinking of the time and the implied fiscal implications. This will be followed by a discussion of the latest theoretical approaches to addressing social and economic justice, with particular reference to the changing structural and responsibility frameworks, respectively. In this regard the discussion will predominantly focus on the theoretical contribution of Amartya Sen and his role in the paradigm shift on development and human rights as reflected in the various Human Development Reports of the United Nations Development Programme.

The analysis reveals that social and economic rights have increased in importance since the

4 Brand \& Russell (note 3 above) at 13, 14.

5 Act 108 of 1996. 
early 1990s. This trend, as well as the inclusion of third-generation rights, has blurred the previous artificial division between first-, second- and third-generation rights to form a broader concern with all rights. The broader and extended redefinition of the concepts of development led to a convergence of the human rights agenda and the human development agenda, in both concept and action, including the notion that they are mutually reinforcing. This convergence has extended the leftist state-centred model of accountability to a more centre-leftist approach where the state's responsibility changed to include non-state actors. Another important trend is the increased importance of the state's obligation beyond national borders.

\section{The Changing Framework of Human Rights: An Overview}

The starting point of this discussion is the notion that the appropriate distribution of income and wealth has been determined by the political system or ideology of the day. The economic system is normally aligned with this ideology in order to achieve maximum efficiency in the production and distribution of commodities. These particular ideologies formed the basis of the human rights debate over the past fifty years. From this basic starting point, the discussion will centre on the ideologies on the extreme right and left of the spectrum, as well as the more recent centre leftist approach, as illustrated in Figure 1. The framework in Figure 1 also refers to the role of the state within the particular ideology, the most prominent economic and/or social theorists of the time and the implied state obligation.

\section{Figure 1}

FRAMEWORK FOR THE FISCAL IMPLICATIONS OF SOCIAL AND ECONOMIC RIGHTS

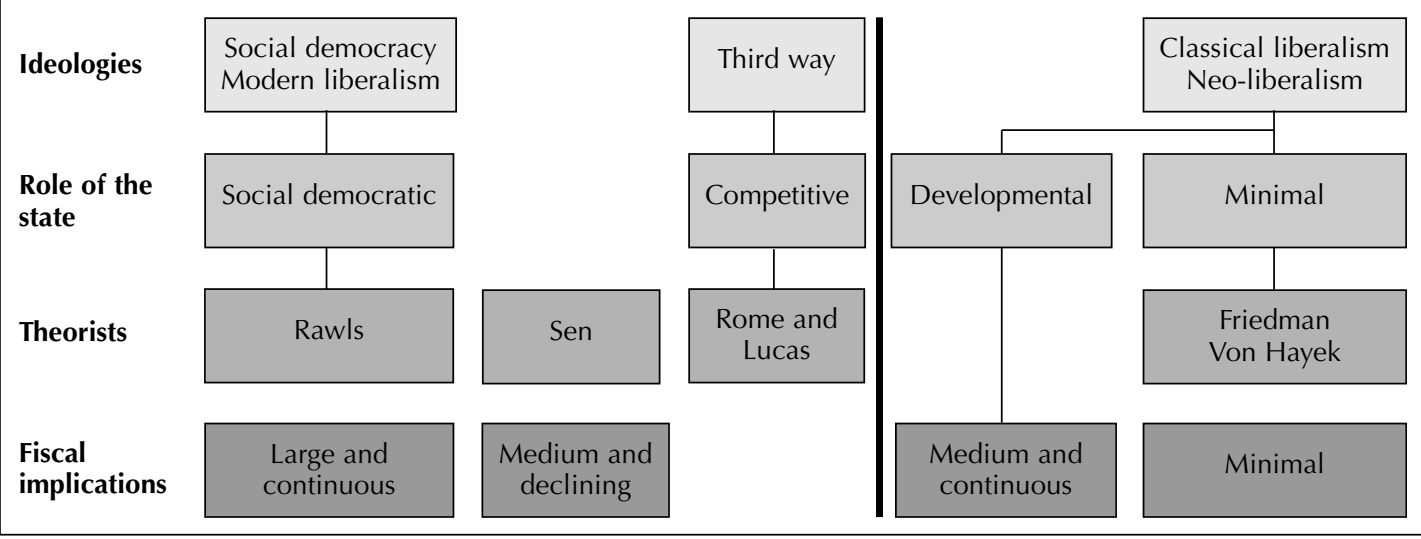

The extreme right of the spectrum is the free market ideologies such as the classic liberals and the neo-liberals. Classical liberalism entails economic liberalism (laissez-faire capitalism) and the belief that the market is a self-regulating mechanism that will deliver general prosperity and opportunities for all - in other words, will ensure social justice. The central pillars of neo-liberalism are the market and the individual. The neo-liberal goal is to 'roll back the frontiers of 
the state'. ${ }^{6}$ Unregulated markets will deliver efficiency, growth and prosperity. These free market ideologies emphasised that the dead hand of the state has a damaging effect upon human affairs. These extreme right ideologies prefer a minimal state or in some case a developmental state where individuals enjoy the widest possible degree of freedom. State intervention in the economy is limited to the provision of a police force and military of some kind, as well as a judicial system. Economic, social, cultural, moral and other rights and responsibilities belong to the individual and are seen as the responsibility of civil society. ${ }^{7}$ Civil rights therefore predominate over human rights. The leading economists within this paradigm are free-market economists such as Milton Friedman and Friedrich von Hayek, who viewed state intervention as something that reduces competition, efficiency and production. Due to the minimalist state and the lack of attention to human rights, state obligation is minimal and limited.

Stronger emphasis on the need for social and economic justice originated predominantly within the social democracy and modern liberal paradigms, fitting into the extreme left of the spectrum. The ideology of social democracy represents a balance between the market and the state, between the individual and community. It is also in favour of a compromise between the capitalistic generation of wealth and a desire to distribute wealth in accordance with moral principles. ${ }^{8}$ The main characteristic of modern social democratic thought is a concern for the underdog in society - the weak and the vulnerable. ${ }^{9}$ Principles such as welfarism, redistribution and social justice are important. Social democracy overlaps with modern liberalism, which is more in favour of a large or interventionist government, implying economic management and social regulation.

The most influential modern attempt to reconcile the principles of modern liberalism and social democracy with the politics of welfare and redistribution was undertaken by John Rawls in his Theory of Justice (1970). Rawls proposed a theory of justice as fairness that is based on the belief that social inequality can be justified only if it is of benefit to the least advantaged. It should provide them with an incentive to work. For most people the fear of being poor will outweigh the desire to be rich; therefore redistribution and welfare can be defended on the grounds of fairness. The presumptions of his earlier work were modified in Political Liberalism (1993).

Social-democratic states represent a shift from the negative minimalist view of the state to a positive view of the state. Social-democratic states intervene to bring about broader social restructuring, usually in accordance with principles of fairness, equality and social justice. They focus on creating an enabling state, dedicated to the principle of individual empowerment. From a fiscal viewpoint, this paradigm could contribute to a free for all principle or cradle to grave welfare, and the subsequent emergence of the so-called welfare state. The continued growth in public spending, with eroding economic incentives and personal freedom, constitutes a serious fiscal threat to economies since it is leading to government overload. ${ }^{10}$ Analysis in developed economies by Lindbeck, as well as by Tanzi and Schuknecht, ${ }^{11}$ argued that the welfare state has developed into a transfer state, where redistributions of income occur among peo-

6 A Heywood Politics (2002) at 96.

7 Heywood (note 6 above) at 95 .

8 The European Social Charter of 1961, where jurisdiction was limited to Europe, gave rise to the leftist approach to the realisation of economic and social justice and the subsequent welfare-doctrine.

9 Heywood (note 6 above) at 57.

10 E Calitz \& K Siebritz: 'Macroeconomic Stability and Developmental Expectations: Fiscal Consolidation in Post-apartheid South Africa' (2003) Paper Presented at the Biennial Conference of the Economic Society of South Africa, Somerset West: September 2003.

11 See reference in Calitz and Siebritz (note 10 above). 
ple of comparable living standards, rather than from the rich to the poor. When expanding social expenditure coincides with recession and declining tax revenues, it could have serious fiscal implications. This extreme leftist approach implies a large and continuous state obligation, with serious consequences for states with limited fiscal means.

The analysis of the framework on social and economic justice shows that both the extreme right and leftist approaches failed in setting acceptable standards and responsibilities in ensuring social and economic justice for all. The extreme right approach envisaged minimum state intervention and required the individual through civil society to be responsible if social and economic rights are claimed. In contrast, the extreme leftist approach placed the responsibility for the provision of a broad spectrum of social and economics rights solely in the hands of the state. The state's fiscal responsibility within these two approaches also varies between extremes of large and continuous and minimal and limited responsabilities. These two extreme approaches do not provide acceptable solutions to the problem of developing a framework for social and economic rights or to how these rights could be addressed in countries with limited fiscal means.

The more recent trend in facilitating economic and social justice is a shift to the right from social-democratic states (or in some cases being seen as centre-left) and is known as the third way (see Figure 1). Third-way politics draws on various ideological traditions such as modern liberalism, one-nation conservatism and modernised social democracy. ${ }^{12}$ It serves as an alternative to old-style social democracy and neo-liberalism. Within this framework the importance of the phenomenon of globalisation and its contribution of the knowledge economy is accepted, as are individual skills and both business and labour flexibility. Government still has a vital economic and social role, but this role is more focused and concentrates on enhancing international competitiveness through education and skills development and strengthening civil society to contain the pressures generated by market capitalism. Third-way proponents call for a balance between rights and entrepreneurialism, on the one hand, and social duty and moral responsibility, on the other. In contrast with cradle to grave welfare, third-way politics is in favour of the essential modern liberal belief of helping people to help themselves. This supports a workfare state (in contrast with a welfare state) in which government support in terms of benefits or education is conditional upon individuals seeking work and becoming self-reliant. The key third-way values are opportunity, responsibility and community involvement.

Two of the most influential schools of thought within the so-called third way are those that emphasise endogenous growth, which tend to be more centrist in nature, and those of Amartya Sen, which are more centre-left in nature. Although the focus of this analysis will be predominantly on the centre-left approach in general and specifically those of Sen, it is worth noting the views of the endogenous growth theories. The endogenous growth models ${ }^{13}$ propose an active role for public policy in the promotion of economic development through direct and indirect investment in human capital formation. They also support the encouragement of foreign private investment in knowledge-intensive industries. Although these models fit into the general third-way political stream, they offer no suggestions on how human rights will be addressed. In contrast, Sen's contribution, which will be discussed subsequently, falls within the broader third-way stream. This latest trend in the facilitation and promotion of human rights in general and eco-

12 See Heywood (note 6 above) at 58, 59 for a detailed discussion.

13 See PM Romer 'The Origins of Endogenous Growth' (1994) Journal of Economic Perspectives at 8 for a detailed discussion on endogenous growth. 
nomic and social justice in particular recognises that civil society can play a crucial role in enhancing the traditional function fulfilled by government. The recognition of the role of non-state actors constitutes a revolutionary advancement in the discourse on human rights. Apart from the fact that it reduces fiscal pressures on the state, evidence shows that it contributes in general towards greater self-reliance and the creation of capabilities. The general well-being of society entails a particular role for the state vis-à-vis an efficient and equitable market, and a healthy environment in a just economic and social context. ${ }^{14}$ The various theories on and approaches to the changing structure as well as the shared responsibility between the state and civil society on matters pertaining to social and economic justice are discussed below.

\section{Modern Social and Economic Justice Theories and Approaches: Changes in Structure and Responsibilities}

The movement from the extreme left thinking on social and economic justice to a more centreleftist approach, where the responsibility for human rights is shared, is a paradigm shift from the traditional viewpoint held on the general framework of these rights. This shift is evident in the structure of these rights as well as in the conventional notion that these rights are the sole responsibility of the state. The structure and therefore the concept of rights directly influences the state's duty or programme of action and they are therefore mutually reinforcing.

\section{(a) Changing Structural Framework}

The structural human rights framework has changed significantly in recent times. The shift in paradigm can be ascribed to the broader and more inclusive concern with all rights, the influence of the human development approach on the thinking on human rights, and, lastly, the narrowing of the divide and convergence between the human rights agenda and the human development agenda.

The first and perhaps least prominent influence on the changing human rights framework is evident in the shift from a narrow and dominant focus on civil and political rights to a broader concern with all rights, including second-generation rights such as social, economic and cultural rights, as well as third-generation rights such as the right to development and the right to a safe environment. Although second-generation rights have been part of the original human rights framework, they have increased in prominence over the past decade or more. Their prominence was further strengthened by action from within the international legal human rights movement itself, where so-called third-generation rights such as the explicit right to development and gender rights were included in the human rights framework of the United Nations (see the 1986 UN Declaration on the Rights to Development and the Vienna World Conference on Human Rights of 1993). The fact that an ever-increasing number of ratifying countries have to report to various United Nations committees on their respective performances also serves to enhance awareness in this regard.

The second shift involves the increased awareness since the early 1990s of the importance of human development in the development process of countries. ${ }^{15}$ Where the earlier views on

14 N Malan 'Civil Society and the Right to have Access to Social Security in South Africa' (2004) Unpublished Research Paper, RAU: Johannesburg.

15 See the various Human Development Reports of the United Nations Development Program (UNDP) from 1991 to 2004 for details on the developments in the human development debate. 
development were purely focused on a narrow top-down approach, where an increase in per capita income was seen as the only prerequisite for development, the human development approach is broader and bottom-up in nature. Under the auspices of human development the notion is held that development only takes place through the process of enlarging people's choices by expanding human functionings and capabilities. According to the United Nations Development Program ${ }^{16}$ the essential capabilities are for people to lead a long and healthy life, to be knowledgeable and to have access to the resources needed for a decent standard of living. These capabilities reflect the freedom to achieve functionings (valuable things a person can do or be), implying that human development is freedom. Human development is 'development of the people, for the people and by the people.' 17

However, the most pronounced change in the structural framework is evident in the link between human rights and human development. These two concepts followed parallel paths in the past, as can be seen in the fact that human development was dominated by economists, social scientists and policy-makers, while political activists, lawyers and philosophers dominated the human rights debate. Over the past decade the two hitherto parallel paths have converged in both concept and action, implying that the divide between the human rights agenda and the human development agenda is narrowing. The 2000 Human Development Report ${ }^{18}$ links the mutually reinforcing nature of the two concepts as follows: 'Human development thus contributes to building a long-run strategy for the realisation of rights'.

Amartya Sen, who won the Nobel Prize in $1998,{ }^{19}$ has offered the most significant theoretical contribution to the conceptualisation of the human development and human rights debates, respectively. Through his theoretical contribution, he also firmly entrenched the link between the two concepts. Sen was critical of welfarism and utilitarianism, on the one hand, and of the Rawlsian approach, on the other. As Sen put it: 'Economic growth cannot be sensibly treated as an end in itself. Development has to be more concerned with enhancing the lives we lead and the freedoms we enjoy'. ${ }^{20} \mathrm{He}$ sees human rights as an important element of human development in general and social and economic freedoms in particular. Freedoms, or capabilities as he calls them, require that a distinction be made between substantive opportunities and freedom of processes. ${ }^{21}$ His capability approach, which was subsequently incorporated in the human development paradigm, focuses on what he calls the capability to function. This capability to function is what really matters for the status of a poor or non-poor person. Capability, which is the opportunity aspect of freedom, is the opportunity to achieve valuable combinations of human functionings. He distinguishes between realised functionings (what a person is actually able to do) or on the set of alternatives she has, or real opportunities. Functioning is what a person does with the commodities of given characteristics he or she then comes to possess or control. He defines capabilities as 'the freedom that a person has in terms of the choice of functioning, given his personal features and his command over commodities'. Functioning reflects the various things a person may value doing or being. This may vary from elementary ones such as being adequately nourished and being free from disease to taking part in the life of the community and having self-respect.

16 UNDP (note 15 above) at 17.

17 UNDP (note 15 above) at 17.

18 UNDP (note 15 above) at 2.

19 Development as Freedom (1999); Commodities and Capabilities (1985); On Economic Inequality (1997).

20 A Sen Development as Freedom (1999).

21 A Sen 'Elements of a Theory of Human Rights' (2004) 32 Philosophy \& Public Affairs at 332. 
Sen's capability approach acknowledges that two persons can have different substantial opportunities, even in circumstances where they have the same set of means or incomes. This approach therefore distinguishes between means or income, on the one hand, and actual opportunities on the other. Freedom is therefore the opportunity to achieve combinations of functionings. Sen 22 remarks that the general idea of freedom with its many distinct components seems particularly relevant to the theory of justice. His contributions to this debate led to wider recognition of the idea that 'human rights links directly to the safeguarding and advance of human freedoms'.23

With his capability approach Sen established the foundation on which the human development approach was based, and his theoretical contributions on freedom contributed to the convergence between the human development and human rights concepts. The redefining of the concept of human rights to include a broader and more inclusive viewpoint on the importance of all rights as well as the importance of choices for all people within the human development framework not only established a permanent link between the two, but also shifted the state's obligations in almost all respects.

\section{(B) Changing ResponsibiLity FrameWork}

Since the early 1990s the extreme leftist approach and its related state-centred model of accountability to social and economic justice has been criticised from various quarters. The criticism came from state actors themselves in response to fiscal constraints as well as from non-state actors who are of the opinion that within the human development framework the range of choices of people could only be enlarged if they form part of the decision-making process on choices that affect their daily lives. Suggestions are coming to the fore on extension of the accountability from states to non-state actors as well as the state's obligation beyond national borders. Two important and interrelated issues arise from this new notion on the state's obligation: first the minimum state obligation, which is linked to the realisation of rights; and second how the state can strengthen and support social and economic rights within this new framework.

On the realisation of rights, Sen provides answers firstly through his so-called threshold conditions, and secondly, through his so-called institutionalisation critique and feasibility critique. ${ }^{24}$ In his reference to threshold conditions, he asks the question whether a specific human right is important enough to cross the threshold to social significance. His analysis of thresholds relates to both the seriousness and the social influenceability of particular freedoms or capabilities. On the institutional critique of economic and social rights, the importance of institutions in the realisation of these rights is acknowledged, but when this does not exist, the ethical significance of these rights provides good grounds for seeking realisation through institutional expansion and reform. The feasibility critique argues that even with the best of efforts it may not be feasible to arrange the realisation of many of the alleged economic and social rights for all. Sen also asks why complete feasibility should be a condition of cogency of human rights when the objective is to work towards enhancing their actual realisation, if necessary through expanding their feasibility. An understanding must prevail that a change in the prevailing circumstances must be striven for in order to make the unrealised rights realisable. Sen ${ }^{25}$ con-

22 Sen (note 21 above) at 335.

23 UNDP (note 15 above) at 15.

24 Sen (note 21 above) at 330, 346-348.

25 Sen (note 21 above) at 356 . 
cludes by referring to the fact that human rights are only sustainable by a continuous process of open public reasoning, which may or may not be reflected in the legal framework of a country. In cases where it is not reflected in the legal framework, other ways of implementing these rights are through public recognition, agitation and monitoring. This again strengthens the role and responsibility of non-state actors in the human rights debate.

Russell ${ }^{26}$ addresses the issue of the state's obligation by referring to the fact that the International Covenant on Economic, Social and Cultural Rights does not necessarily anticipate that all resources will come from the state. The implication was rather that the resources available from the broader society - in other words, public and private sectors - should be mobilised by the state. He also stresses the responsibilities of richer countries to supply funding to poorer countries, suggesting the international obligation of states. Secondly, many resource needs are centred on the misallocation of resources, eg expensive weapons instead of food security. The misallocation problem could be solved by a reordering of the state's priorities. Thirdly, countries facing severe resource constraints can focus on progressive realisation by developing plans that states its obligations over time. Fourthly, the state has an obligation to ensure that rights are not violated. Although these solutions sound feasible, all these suggestions predominantly still focus on the central role of the state decision-making process and do not allow for participatory development on a broader scale.

In addressing the issue of the state's responsibility within the broader framework of human development and the links with human rights, the United Nations through its Human Development Report ${ }^{27}$ suggests that, although a shift is evident from state to non-state actors, the state still has the responsibility to strengthen its policies and social arrangements, respectively, in securing human freedoms. On the policy front, the state has an obligation to implement policies that help realise social and economic rights, especially for the most deprived. This must, however, be based on a participatory process and be transparent. The state's social arrangements should be effected through norms, institutions, legal frameworks and an enabling economic environment. In addressing the norms issue, the state has the responsibility to promote awareness of human rights by building and promoting these through press freedom, human rights education in schools, etc. The state has the obligation to ensure that appropriate institutions are in place to support certain human rights (eg children's rights) that cannot be guaranteed without strong and effective institutions. States also have the first obligation to participate in the international rights regime and to establish legal frameworks. Finally, the state is obligated to create an economic environment that supports human rights. It should ensure that economic growth is pro-poor, pro-rights and sustainable.

A number of related approaches have developed to support the notion that the state's accountability should be expanded to include non-state actors. Heller ${ }^{28}$ presented the International Monetary Fund's perspective when he concludes that social justice is far better achieved when those directly involved reveal their own values and put them together. This perspective is more inclusive and allows for participatory development. Smith, ${ }^{29}$ on the future of the international dimension of human rights, remarked that the responsibility of the realisation of human rights has to be extended outside the nation-state domain. Non-governmental organ-

26 Brand \& Russell (note 3 above) at 17.

27 UNDP (2000) 7, 8.

28 PS Heller 'Wealth Creation and Social Justice: an IMF perspective' (2003) Paper Presented at the World Council of Churches/World Bank/IMF Meeting, February 2003.

29 Smith (note 2 above) at 340. 
isations (NGOs), civil society and non-state agents all have a responsibility. These various role players in the funding chain of human rights are also emphasised by Hegarty and Leonard, 30 who include the role and responsibility of the global economy, foreign aid agencies, the link between trade and human rights, corporate codes of conduct and the role of NGOs.

The involvement of non-state actors in supporting the state's accountability in the human rights debate is, within the context of the human development framework, mutually reinforcing. In the 2000 Human Development Report ${ }^{31}$ various examples of the mutual participation of state and non-state actors are given. If the state ensures civil and political rights in general, poor people will be empowered to claim their social and economic rights. Ensuring freedom for NGOs and media and worker organisations can enhance the participation of poor people in decision-making processes and policy-making that affect their lives. In the same vein, the right to housing or education does not imply a right to free services or to a state handout. These are claims to social arrangements and policies that promote access to these rights through both the market (housing) and the state (free primary education). Worldwide public spending on social and economic rights is inadequate and unevenly distributed. Faster economic growth is needed to generate more resources to support social and economic justice. But, within the context of the human development framework, economic growth on its own is not enough. It has to be accompanied by transparent and participatory policy reforms that are aimed at channelling funds into poverty eradication and human development.

On the international front the state's responsibility to support and ensure human rights and human development is expanding. Apart from strengthening regional initiatives for human rights, individual states should also embark collectively on continuous efforts for peacemaking and peacekeeping. Individual states, in their responsibility through development cooperation in the form of aid flows, debt relief, access to trade and financial flows, and ensuring stability in the global economy, can all support the full realisation of rights in the poorest and least developed countries of the world. Again, non-state actors such as multinational corporations are also accountable and have an obligation to raise the standard of human rights.

\section{Conclusion}

The fiscal implications of social and economic rights are firmly embedded in political ideologies and the subsequent role of the state. This has clearly being shown in the changing rights framework, where the first shift occurred from the right side of the spectrum, which proposed no formal entrenchment of social and economic rights, to the extreme left side of the human rights spectrum, where the state has the sole responsibility to ensure social and economic justice. However, over the past decade the second shift, which has been classified as the rights revolution, took place in the shift from the extreme left of the spectrum to a more centre-left approach with implications for the structure of the human rights framework as well as the state.

The analysis reveals that social and economic rights have increased in importance since the early 1990s. This trend, as well as the inclusion of third-generation rights, blurred the previous artificial division between first-, second- and third-generation rights to form a broader concern with all rights. Coupled with the broader and extended redefinition of the concepts of devel-

30 A Hegarty \& S Leonard Human Rights. An Agenda for the 21st Century (1999).

31 UNDP (note 27 above) at 8,9 . 
opment, this led to convergence of the human rights agenda and the human development agen$\mathrm{da}$, in both concept and action, including the notion that they are mutually reinforcing. This convergence has extended the leftist state-centred model of accountability to a more centre-left approach where the state's responsibility changed to include non-state actors. Another important trend is the increased importance of the state's obligation beyond national borders.

The changing framework of human rights discussed in this chapter is based upon the latest approaches as seen in the literature and theory of social and economic justice. However, it is important to note that, despite these continuous attempts to address these dilemmas, they have not so far been completely resolved. Of course, a theory of human rights can and should leave room for continuous discussion, disputations and arguments. 


\title{
The Historical Development of the Modern South African Health-Care System: From Privilege to Egalitarianism*
}

\author{
- Charles NGWENA \\ Professor, Department of Constitutional \\ Law and Legal Philosophy, University of \\ the Free State
}

\section{Introduction}

This article seeks to explore the extent to which equity as a notion of fairness in access to health care has been integrated into the South African health-care system in recent history. The article discusses the main legislative and policy instruments that have shaped the South African healthcare system. It begins with an analysis of the main pillars of the Public Health Act of 19191 and includes discussion on more recent developments, including the National Health Act. ${ }^{2}$ The article also comments on court cases that impact on equity in access to health care, including Minister of Health $v$ Treatment Action Campaign. ${ }^{3}$

The point of departure is the ideal of creating a health-care system that strives for egalitarianism in respect of access to health-care services. It will be submitted that the Public Health Act of 1919 bequeathed to the country a system that was fragmented, dysfunctional, and above all, lacking in egalitarian values. Attempts to radically reform the Public Health Act through instruments such as the National Health Act of $1977^{4}$ failed to change a system that was biased towards urban, curative and hospital-based care. Moreover, the intensification of racial segregation during apartheid and the privatisation of health-care services served to accentuate inequality in access to health care. It was not until the democratisation of South Africa that the health-care system began in earnest to transform towards universal access. At a policy level, the White Paper on Transformation of the Health System in South Africa (1997) 5 stands as a beacon of change, with its emphasis on primary health care for all. At the level of fundamental law, the Constitution ${ }^{6}$ acknowledges access to health care. The National Health Act seeks to put on statutory footing the institutional framework for universal access to health care.

* This article is based on a paper delivered at the Conference of the Southern African Society of Legal Historians at Stellenbosch University from 15-17 January 2003. The article first appeared in (2004) 37 De Jure 290-312 and is reprinted here (with minor changes) with the kind permission of C Ngwena and De Jure, the editor of De Jure and Lexis-Nexis Butterworths.

136 of 1919.

2 Act 61 of 2003.

32002 (5) SA 721 (CC).

463 of 1977.

5 GG 17910 of $1997-04-16$.

6 Constitution of the Republic of South Africa Act 108 of 1996 (the Constitution) supplanting the Constitution of the Republic of South Africa Act 200 of 1993 (the interim Constitution). 


\section{Equity in Access to Health Care}

Margolis is correct to say that merely appealing to notions of justice or fairness has inherent limitations in that any theory of justice or fairness is, ultimately, a human construct. ${ }^{7}$ A theory of justice cannot, by itself, establish a conclusive case for a desired outcome, and so it is with the notion of equity. Equity is a notion of justice. Much like other notions of justice, such as equality, it does not admit a single meaning. Its ultimate complexion depends on the ideological leanings of the interpreter. Thus, any notion of justice is necessarily a value judgement. In the context of access to health care, equity means different things to different interpreters. The notion of a right of access to health care is a contested right, not least at the level of philosophical theory and political ideology.

In South Africa and elsewhere, though a number of diverse contractarian theories have been invoked when addressing the issue of access to health care, two main standpoints are discernible, namely libertarianism and egalitarianism. In one sense, there is unity between these two positions in that they both converge on the desirability of achieving justice, and each purports to offer a coherent view of life. At the same time, the two positions are characterised by pivotal points of contrast and opposition, not only in respect of conceptions of justice, but also in the delineation of the parameters of state vis-à-vis private-sector provision of health care.

To classical libertarians, equitable access to health care might mean no more than treating people equally by desisting from unfair discrimination on the conventional prohibited grounds such as race, gender or sexual orientation. ${ }^{8}$ It usually means minimal state interference in the delivery of health care and the removal of state impediments such as the deregulation of the state health-care system in order to allow access to private health care. ${ }^{9}$ In this classic libertarian sense, equity is not synonymous with granting access to health care on the basis of need, or imposing an obligation on the state to take primary responsibility for the provision of health-care services to everyone.

As Rhodes points out, the assumptions in classical liberal theory are that individuals are normally responsible for their health and that they ought to be able to make their own health transactions in a free market. ${ }^{10}$ Those that are more affluent are able to purchase greater privileges because they deserve them, so it is argued. However, even the most ardent advocates of free markets do not dispute that the state has not only a role, but also a duty to discharge in respect of provision of health care. It is conceded, for example, that the state has an obligation to prevent and combat epidemics. ${ }^{11}$ The modern industrial state has, itself, contributed to many conditions that impact adversely on health such as environmental degradation and soaring crime. It has never been seriously argued by libertarians that the state should divest itself of all responsibility in these areas. What classical libertarians object to however, is a collectivist approach to equality where all groups are entitled to expect, as of right, a minimum standard of socio-economic goods, including health care. 12

To egalitarians, however, equity is a more exacting concept. ${ }^{13}$ Much of the egalitarian con-

7 J Margolis 'The Rights of Man' (1978) 4 Social Theory and Practice 423.

8 D Feldman Civil Liberties and Human Rights in England and Wales (1993) at 901-902; HT Engelhardt 'Rights to Health Care: A Critical Appraisal' (1979) 4 Journal of Medicine and Philosophy 113.

9 Feldman (note 8 above); Engelhardt (note 8 above).

10 RP Rhodes Health Care Politics, Policy and Distributive Justice (1992) 19.

11 Rhodes (note 10 above) at 20.

12 Engelhardt (note 8 above).

13 RM Green 'Health Care and Justice in Contract Perspective' in RM Veatch \& R Branson (eds) Ethics and Health Policy (1976) at 111-126. 
ception of access to health care was drawn substantially from Rawls's theory of justice. ${ }^{14}$ According to Rawls, an individual in the original position' makes his or her decisions behind a 'veil of ignorance'. Acting out of rationality rather than altruism, the individual will try to maximise his or her life chances by choosing universal political liberties so as not to risk the possibility of ills such as oppression, grinding poverty and so on. Such an individual will try to protect equality of opportunity and, thus, secure for himself or herself minimum primary goods.

While Rawls did not specifically list the provision and organisation of health care among the primary goods that an individual in the original position would require in order to enjoy equality of opportunity, proponents of his theory of justice have done so. Perhaps the most persuasive exponent in this connection has been Daniels. ${ }^{15}$ Daniels's contribution to an egalitarian conception of access to health care has been to extend Rawls's theory of justice to health care. ${ }^{16}$ Daniels has adapted Rawls's principle of equality of opportunity into a principle of 'normal opportunity range'. Daniels's central premise is that if an acceptable theory of justice includes a principle for fair opportunity, then health care institutions and, perforce, health care policy and practice, should be among the goods governed by such a principle. ${ }^{17}$

According to Daniels, for any given society, there is a 'normal opportunity range' which comprises of the 'array of life plans reasonable to pursue within given conditions obtaining in society'. ${ }^{18}$ The resources of a society must be organised in such a way as to allow everyone to attain a normal opportunity range. Disease, most certainly, impairs in a fundamental manner the opportunity of an individual relative to the the normal opportunity range in a society governed by the principle of fair equality of opportunity. ${ }^{19}$ Access to health care, thus, becomes an essential prerequisite, or a primary good in terms of indispensability to the attainment of the normal opportunity range for a given society. In practical terms, the right to exercise a normal opportunity range translates into a right to a minimum, decent level of health care. There should be no obstacles - financial, racial, sexual, geographical, and so on - to access to care as long as health needs are present.

Of course, Daniels has not been without critics. Buchanan, for example, says that one of the more significant difficulties with Daniels's 'normal opportunity range' and array of life-plans reasonable to pursue' is that they are open to different interpretations. ${ }^{20}$ Buchanan contends that it is not clear for whom a life plan must be reasonable. If subjective view is taken, given different abilities and skills in any given society, some individuals might end up with claims that are so strong as to be unsustainable to the extent that resources are finite. Equally, Buchanan says that if an objective view is taken, what is reasonable for everyone might be too modest as to be insufficient to provide a basic for a substantive universal right to health care. In response to his critics, Daniels concedes that whilst the notion of normal opportunity range is not unassailable, it is, nonetheless, workable. ${ }^{21}$ According to Daniels, each society can construct for

14 J Rawls A Theory of Justice (1972).

15 N Daniels 'Health Care Needs and Distributive Justice' (1981) 10 Philosophy and Public Affairs 146-179.

16 Daniels (note 15 above) at 163-168.

17 Daniels (note 15 above) 160-161.

18 Daniels (note 15 above) 158.

19 Daniels (note 15 above) 159.

20 A Buchanan 'The Right to a Decent Minimum of Health Care' (1984) 13(1) Philosophy and Public Affairs 55-78. See also L Stern 'Opportunity and Health Care: Criticims and Suggestions' (1983) 8(4) Journal of Medicine and Philosophy 339-361; J Moskop 'Rawslian Justice and a Human Rights to Health Care' (1983) 8(4) Journal of Medicine and Philosophy 329-338.

21 N Daniels 'A Reply to Stern Critics and a Remark on Health Care Rights' (1983) 8 Journal of Medicine and Philosophy 363-371. 
itself its objective normal opportunity range. The range will be influenced by the key features of that society such as its stage of socio-economic development, material wealth, technological development and important cultural facts. ${ }^{22}$

Notwithstanding the criticisms of Daniels' normal opportunity range and any of its inherent shortcomings, it is, nonetheless, a theoretical approach that has resonance with the egalitarian underpinnings of rights concerning health under international human rights law. As will become apparent in the ensuing discussion, the consequent duty upon the state to provide a decent minimum level of health care under human rights law is society-relative rather than abstract. It is not conceived in a vacuum. Rather, it allows for the decent minimum to be pegged flexibly so that as the particular society becomes more affluent, the minimum floor is commensurately adjusted upwards. Individuals will be free to purchase health care. The state is not put under a duty to provide everyone with the best available health care. Instead, the duty upon the state is limited to what is affordable for that society.

An egalitarian conception of access to health care goes beyond the Aristotelian minimal principle of justice in that it means much more than merely desisting from unfair discrimination or allowing for choice in health care. It means, at the very least, developing a health-care system that is responsive to need rather than the ability to pay. ${ }^{23}$ It also means maximal rather than minimal state interference in the provision of health care, with the state assuming primary responsibility for the provision of health care. ${ }^{24}$ Access to health care is conceived as a communal or social good that should be determined by need rather than life's arbitrary lottery of birth, natural endowment, socioeconomic status or historical circumstances. Health care should be distributed not merely on the basis of what is wanted or desired, but according to the basic needs for a worthwhile human life. ${ }^{25}$ It is to this egalitarian notion of equity that this article subscribes.

It must be emphasised at the outset that equity does not imply the elimination of all differences in health or the guaranteeing of equal health outcomes. Indeed, this would be an impossible goal to achieve since health-care services are but one of several health determinants. Genetic factors, income, housing, nutrition, water, sanitation, education and the general environment arguably impact to a greater extent on health outcomes than the mere provision of health-care services. ${ }^{26}$ Rather, the aim behind equity is to ensure that everyone has a fair opportunity to access one of the determinants of health as part of the enjoyment of equality, freedom and human dignity in a democratic and caring society. Without access to health care one cannot effectively make autonomous choices, including realising one's potential in a free society. ${ }^{27}$

For the greater part of the $20^{\text {th }}$ century, it has been primarily moral philosophers, sociologists, and health care providers and professionals that have imprinted egalitarian notions of equity into the provision of health care. ${ }^{28}$ Lately, however, human rights experts and activists have begun to champion egalitarian notions of health care. ${ }^{29}$ A human rights approach to health care has developed, not least on account of the emergence of socio-economic rights as tangible rights that are different in kind but have the same status as conventional civil or polit-

22 Daniels (note 15 above) 158.

23 HCJ Van Rensburg Health Care in South Africa: Structure and Dynamics (1992) at 364-370.

24 Van Rensburg (note 23 above).

25 W Landman 'Appropriate Health Care as a Human Right' in A Van Niekerk (ed) Health Care as Human Right (1993) at 36-71.

26 P Townsend et al The Black Report and the Health Divide (1990) at 104-106 and 286-305.

27 Landman (note 25 above) at 37-40.

28 Van Rensburg (note 23 above) at 352-403.

29 BCA Toebes The Right to Health as a Human Right in International Law (1999) at 3-36. 
ical rights. The right to health now enjoys the status of an international human right. The most important international instrument in terms of acknowledging, as well as expounding, the right to health is article 12 of the International Covenant on Economic, Social and Cultural Rights (ICESCR). ${ }^{30}$ Article 12 doubtlessly subscribes to equity in an egalitarian sense. ${ }^{31}$

Under article 12, state parties acknowledge the right of everyone to enjoy the highest attainable standard of physical and mental health. In General Comment 14 the Committee on Economic, Social and Cultural Rights (Committee on ESCR), the organ responsible for monitoring state compliance with socio-economic rights, has put a gloss on the meaning and content of article $12 .{ }^{32}$ The Committee on ESCR concedes that there are limitations insofar as realising the right to health is concerned. The right to health cannot be equated with a right to be healthy. ${ }^{33}$ Indeed, the state cannot guarantee health. The right to health does not imply guaranteeing all the services that are available. The notion of the highest attainable standard of health must necessarily take into account the individual's biological and socio-economic preconditions and the resources of the state. ${ }^{34}$ Notwithstanding these limitations, the provision of health-care facilities, goods and services are an important determinant of health. Health care must, thus, be dispensed on an equitable basis. In this regard, the Committee on ESCR posits four requirements that must be met. ${ }^{35}$

Firstly, health care must be available. ${ }^{36}$ Public health and health-care facilities, goods and services must be available to all in sufficient quantity, including the underlying determinants of health such as safe and potable drinking water and adequate sanitation facilities. Secondly, the facilities, goods and services must be accessible. ${ }^{37} \mathrm{It}$ is this dimension, more than any other, that underscores the notion of equity in the provision of health care. According to General Comment 14 , accessibility has four overlapping dimensions, namely non-discrimination, physical accessibility, economic accessibility and information accessibility. ${ }^{38}$

Non-discrimination means providing health care without discrimination on any of the prohibited grounds. Physical accessibility means that the facilities, goods and services must be within safe physical reach of everyone, especially vulnerable groups. Economic accessibility means health care should be affordable for all. The General Comment explicitly says that payment for health-care services must be based on the principle of equity to ensure that health-care services are affordable for all, including socially disadvantaged groups. ${ }^{39}$ Furthermore, equity demands that poorer households should not be disproportionately burdened with health-care expenses as compared to richer households. ${ }^{40}$ Information accessibility means recognising and protect-

30 Adopted and opened for signature, ratification and accession by General Assembly Resolution 2200A (XXI) of 1966-12-16. The right to health is also found in other international instruments. Examples in this regard are: article 12 of the Convention on the Elimination of All Forms of Discrimination Against Women (1979); article 24 of the Convention of the Rights of the Child (2002); and article 16 of the African Charter of Human and People's Rights (1981).

31 A Chapman 'Core Obligations Related to the Right to Health and their Relevance for South Africa' (2002) in D Brand \& S Russell (eds) Exploring the Core Content of Socio-Economic Rights: South African and International Perspectives (2002) at 35-60; Toebes (note 29 above) at 243-289.

32 Committee on Economic, Social and Cultural Rights General Comment 14 UN ESCOR (2000) Doc no E/C $12 / 2000 / 4$.

33 Par 8.

34 Par 9.

35 Par 12.

36 Par 12(a).

37 Par 12(b).

38 Ibid.

39 Ibid.

40 Ibid. 
ing the right to seek, receive and impart information concerning health issues.

A third requirement of an equitable health-care system under General Comment 14 is acceptability. ${ }^{41}$ Provided health care should be ethically and culturally appropriate. It must be respectful of the culture of individuals, minorities, peoples and communities. The fourth requirement is quality. ${ }^{42}$ Health care must be scientifically and medically appropriate and of good quality.

General Comment 14 is not only instructive because of its convergence with philosophical and sociological notions of egalitarianism in health-care provision, ${ }^{43}$ but also because of its aptness in terms of the notion of substantive equality under the South African Constitution. The Constitutional Court has ascribed to section 9 - the equality clause - an expansive and substantive concept of equality that goes beyond the mere achievement of formal equality. ${ }^{44}$ In the context of access to health care, substantive equality means providing access to health care taking social and historical circumstances into account. The lasting nature of structural inequality that apartheid, especially, created among different population groups in terms of differential and inequitable access to the determinants of health such as education, housing, employment and health care has also to be dealt with and redressed through restitution and other compensatory means. ${ }^{45}$ As will be elaborated upon in a subsequent section, the commitment to substantive equality in the sphere of health-care provision is based beyond a doubt on section 27 of the Constitution. It provides:

(1) Everyone has the right to have access to -

(a) health care services including reproductive health care;

(b) sufficient food and water; and

(c) social security, including, if unable to support themselves and their dependents, appropriate social assistance.

(2) The state must take reasonable legislative and other measures, within its available resources, to achieve a progressive realization of each of these rights.

(3) No one may be refused emergency medical treatment. ${ }^{46}$

How has the modern South African health-care system fared in terms of guaranteeing equitable access? To borrow from the language of the Committee on ESCR's interpretation of article 12 of the ICESCR, has South African health care been available, accessible, acceptable and of good quality?

41 Par 12(c).

$42 \operatorname{Par} 12(\mathrm{~d})$.

43 According to Van Rensburg (note 23 above) at 364-365, writing from a sociological perspective, a socially accountable heath-care system should meet the following demands: availability (geographically, strategically and logistically); appropriateness and relevance; acceptability (personally and socio-culturally); adaptability and flexibility; accessibility (meaning the annulment of geographical, financial, racial, political and other barriers) and affordability.

44 See eg City Council of Pretoria $v$ Walker 1998 (2) SA 363 (CC) par 62; National Coalition for Gay \& Lesbian Equality v Minister of Justice 2000 (2) SA 1 (CC) par 62; J De Waal, I Currie \& G Erasmus The Bill of Rights Handbook (2002) at 200-201; C Albertyn \& B Goldblatt 'Facing the Challenge of Transformation: The Difficulties in the Development of an Indigenous Jurisprudence of Equality' (1998) 14 SAJHR 248.

45 C Ngwena 'Substantive Equality in South African Health Care: The Limits of the Law' (2000) 4 Medical Law International 111 at 111 and 115.

46 Emphasis added. 


\section{The Genesis of the Modern Health-Care System: The Public Health Act of 1919}

The Public Health Act of 1919 marked the beginning of a modern health-care system in South Africa. ${ }^{47}$ It was the first comprehensive legislative measure on health services for the Union of South Africa. The Act was intended to supplant colonial legislation. The main objective was to create a central or national authority for the provision and regulation of health-care services. The South Africa Act of 1909, which created the Union of South Africa and unified the four colonies as a single political entity, did not unify colonial health legislation and policy. ${ }^{48}$ Instead, it merely effected a transfer of colonial powers and duties to provincial authorities. As a result, the provision of health care remained fragmented, with no central authority to formulate or co-ordinate policy. Until 1919, the department of internal affairs had the responsibility of controlling the district surgeon system and institutions for the mentally ill and those afflicted with leprosy, and was therefore the only body with pretentions of being a central health authority. 49

It is significant to note that prior to the Act, the health of the population and the availability of health care were not major social concerns or, for that matter, a primary responsibility of government. Individuals, with the assistance of their families, had to provide for their own health-care services. ${ }^{50}$ The public health facilities essentially catered only for serious illnesses or infectious diseases of an epidemic nature. ${ }^{51}$ There was no real organisational structure for rendering health care. The Act was the first legislation to define national responsibilities for public health. The impetus for change came with the influenza epidemic of 1918 . The epidemic had high morbidity and mortality rates, killing an estimated 142000 people. ${ }^{52}$ The epidemic unmasked the deficiencies of the prevailing health-care systems and underscored the need for the state to assume primary responsibility for health care and to reorganise health-care services. The Public Health Act of 1919 was the response.

In essence, the 1919 Act created a tripartite system. The first tier was a national department of public health responsible for the control of the following: contagious diseases and advancement of environmental health; district surgeon services; and institutions for the mentally ill and those afflicted with leprosy and tuberculosis. The second tier comprised provincial administrations. Provincial administrations were charged with establishing, maintaining and managing hospitals and other curative services. Local authorities were the third tier. They were conceived as agents of the department of public health and were responsible for controlling contagious diseases and environmental health.

The 1919 Act had minimal success. ${ }^{53}$ According to Van Rensburg et al, the 1919 Act drew the lasting contours of a highly fragmented system of health provision that became not only the main characteristic, but also the fundamental problem, in the organisation and dispensation of South African health care. ${ }^{54}$ The 1919 Act chiefly failed because of the fragmented nature of

47 Note 1 above.

48 Van Rensburg (note 23 above) at 59; see also C De Beer 'A Forward View of the Health Services in South Africa' (1976) 50 South African Medical Journal at 431.

49 Ibid.

50 JJN Cloete Administration of Health Services (1981) at 2-3; BE Leech 'The Right of the HIV-Positive Patient to Medical Care: An Analysis of Costs of Providing Medical Treatment' (1993) 9 SAJHR 39 at 43.

51 Ibid.

52 Van Rensburg (note 23 above) at 59.

53 Van Rensburg (note 23 above) at 60.

54 Ibid. 
the tripartite system. There was little co-ordination between the department of public health and local authorities. Each tier tended to function at the exclusion of the other, at the expense of providing a broader spectrum of co-ordinated services. There was polarisation between curative and preventative services. Provincial authorities unduly preoccupied themselves with the provision of curative hospital-based care. Community health or primary health was virtually neglected. In part, the 1919 Act failed because it had not been conceived to render universal comprehensive care. It could not stand up to the demands of the South African society in the 1930s and 1940s especially. The Great Depression, the poverty among Blacks as well as Whites, large scale industrialisation, rapid urbanisation, expansion of the black labour class, desperate housing conditions, unhygienic living conditions and widespread malnutrition expressed themselves partly in escalating conditions of poor health. ${ }^{55}$ Tubercular epidemics, nutritional deficiency diseases, venereal disease, high levels of morbidity and high infant and maternal mortality among all sectors of the population indicated the Act's deficiencies. Indeed, it was these shortcomings that spurred government into appointing commissions of inquiry to investigate and ameliorate harsh social conditions. In the health sphere, the most significant commission of inquiry was the National Health Services Commission, the Gluckman Commission, that was appointed in 1942.56

\section{Reforms: The Gluckman Commission}

The Gluckman Commission was set up to inquire into both the provision of an organised national service, and the necessary administrative, legislative and financial measures for such a service. The Commission was admirably loyal to its brief. In 1944 it reported its findings and recommended the reorganisation of the health service in the light of deteriorating health indicators and social conditions. The Commission sought to reorganise health services and 'bring these services within reach of all sections of the population, according to need, and without regard to race, colour, means or station in life'. ${ }^{57}$ Though the Gluckman Commission eschewed the language of entitlement and rights, its egalitarian thrust is unmistakable. This is all the more remarkable given the Commission was operating in a society that was highly stratified, not least in terms of race, and that the language of health as a human right had yet to take root even in Western liberal democracies, let alone in South Africa. At an international level, it was not until

55 Van Rensburg (note 23 above) at 60; R Packard White Plague, Black Labor: Tuberculosis and the Political Economy of Health and Disease in South Africa (1989) at 126-193; A Jeeves 'Public Health and Epidemiology in the Era of South Africa's VD Pandemic of the 1930s and 1940s' paper read at AIDS in Context International Conference held at the University of the Witwatersrand from 4-7 April 2001 (copy on file with author).

56 D Gluckman Report of the National Health Services Commission (1944). Prior to the Gluckman Commission the government had from time to time appointed a committee to inquire into various matters pertaining to the provision of health-care services. The Committee of Inquiry regarding Public Hospitals and Kindred Institutions of 1925 looked into the deterioration in the health of the black population in rural and urban areas. The Committee of Inquiry on Medical Training for Natives of 1928 looked into the state subsidy for and training of black medical personnel and the establishment of health units in rural areas as a response to the deteriorating health of the black population. The Committee of National Health Insurance of 1936 inquired into the feasibility of introducing a national health insurance scheme. However, the findings and recommendations of these committees were never acted on by government: Van Rensburg (note 23 above) at 61 .

57 Gluckman Commission (note 56 above) at 8 . 
1946 that the notion of access to health as a universal right was first articulated, when the World Health Organisation in the preamble to its constitution proclaimed that the 'enjoyment of the highest attainable standard of health is one of the fundamental rights of which every human being, without distinction of race, religion, political belief, economic or social conditions', is entitled. 58

The Commission found a health system that was fragmented and uncoordinated. The system unduly emphasised institutional care and ignored preventive and community-based care. It suffered from deprivation, especially for Blacks, with the deprivation more acute in rural reserves. The private sector was a distorting element. Not only was private health care unaffordable for the majority of people, it was also geographically inaccessible as private practitioners predominantly positioned themselves in cities and major towns.

The recommendations of the Commission were, in essence, a blueprint for an egalitarian health-care system. In the main, the Commission recommended the establishment of a unified single health authority, with the state assuming primary responsibility for the provision of health care. Significantly, services would be free and financed out of general taxation. Services were to be decentralised. Community health services would be established to bring health-care services close to people and to reduce dependence on curative care. Even more radically, the Commission recommended the phasing out altogether of private practice on account of its distorting effect. The Commission was not oblivious to the fact that health is not an outcome of the mere provision of health-care services alone and that other socio-economic factors had an even greater impact on health. As part of augmenting the provision of health-care services, the Commission called for vast improvements in nutrition, housing and health education. According to the Commission, health-care services alone could not make up for the deficiencies of the socio-economic system. ${ }^{59}$ In short, the Commission called for fundamental reform.

Regrettably, however, the substance of the Commission's recommendations was never implemented by the incumbent government, except for a limited programme of establishing community health centres. ${ }^{60} \mathrm{~A}$ number of factors conspired to ensure the demise of the Commission's recommendations. Initially the recommendations fell victim to apathy and procrastination on the part of the Smuts government. 61 The Smuts government was unwilling to encroach upon provincial powers as part of the reorganisation of services. Provinces in turn resisted change and were unwilling to relinquish their jurisdiction over curative institutions. ${ }^{62}$ The medical profession also resisted change as it feared losing professional autonomy and the profits of private practice. ${ }^{63}$ However, the factor that dealt a mortal blow to the recommendations was the coming to power of the National Party in 1948. The recommendations were resolutely cast aside in the intensification of racial segregation under apartheid. De Beer aptly summed up the fate of the Gluckman Commission when he said:

58 The Constitution of the World Health Organisation was opened for signature on 1946-07-22 and entered into force on 1948-04-07; Toebes (note 29 above) 31.

59 Gluckman Commission (note 56 above) at 27.

60 An attempt was made to implement the recommendations of the Gluckman Commission through the National Health Act of 1946. The most tangible outcome of this Act was the establishment of 50 community health centres: Van Rensburg (note 23 above) at 63 .

61 Ibid.

62 Ibid.

63 Ibid. 
The tragedy is not that the proposals of the Gluckman Commission were not implemented. The tragedy is that they could not possibly have been implemented. There is simply no way that a society built on division, oppression, and exploitation could accommodate a health service premised on unity, equality, and the elevation of the needs of all above the needs of the privileged elite. ${ }^{64}$

Thus, nothing short of a fundamental radical transformation of the prevailing political economy was needed if the recommendations of the Gluckman Commission were to be adopted and implemented by the government of the day.

\section{$V$ Apartheid and South African Health Care}

The Medical Research Council described the South African health-care system during apartheid as a 'bureaucratic entanglement of racially and ethnically fragmented services; wasteful and neglectful of the health of more than two thirds of the population'. ${ }^{65}$ During apartheid, income, geographical location and, most importantly, race became the arch determinants of the quantity and quality of health care received by the populace. ${ }^{66}$ State-ordained racially-based inequality in access to health care became the defining characteristic of the South African health-care system.

It bears mentioning, however, that racial segregation in the organisation of health services has a long history and did not commence in 1948 with official apartheid. Since the colonisation of South Africa, health services evolved along the lines of racial segregation with a systematic bias towards Whites. ${ }^{67}$ What was done during apartheid, however, was to take the segregation in the form of separate and unequal access to services to extreme levels. According to Van Rensburg and Benatar, apartheid has been the most important historical force in the moulding of both the South African health-care system and the health of the people of South Africa in modern times. ${ }^{68}$

During apartheid, the provision of health facilities, the allocation of public funds, and the deployment of health-care personnel were stratified according to race. As in other socio-economic spheres that were commanded by the state, the health-care system became a tool for shoring up white supremacy. ${ }^{69}$ Whites were the privileged class and Blacks the worst provided for in terms of access to health-care facilities. Coloureds and Indians occupied an intermediate position. Per capita expenditure on health during apartheid shows that Whites received four times as much as Africans from the public health sector budget. ${ }^{70}$

64 C de Beer 'Explaining the Present: Why Health Services do not meet the Health Needs of the Population' in A Zwi \& WB Saunders (eds) Towards Health Care for All (1985) at 59.

65 Medical Research Council Changing Health in South Africa: Towards New Perspectives in Research (1991) at 7.

66 Van Rensburg (note 23 above) at 56-58.

67 HCJ van Rensburg \& SR Benatar 'The Legacy of Apartheid in Health and Health Care' (1993) 24 SA Journal of Sociology 99 at 99.

68 Ibid at 99.

69 M Price 'Health Care as an Instrument of Apartheid Policy in South Africa' (1986) 1 Health Policy and Planning 158 at 158.

70 DE McIntyre \& RE Dorrington 'Trends in the Distribution of South African Health Care Expenditure' (1990) 78 SAMJ 125 at 125; HCJ van Rensburg 'South African Health Care in Change' (1991) 22 SA Journal of Sociology 1 at 5. 
Apart from prescribing inequitable access to health-care services, the effects of apartheid were also manifest in racial discrepancies in health status. The burden of morbidity and mortality was disproportionately carried by Blacks and Coloureds. ${ }^{71}$ However, it is important not to ascribe differential health status to segregated health-care services alone. As alluded to earlier, health status is not merely an outcome of health care, but an outcome of a multiplicity of socio-economic factors. Racial discrepancies in health status are attributable to differential access not only to health-care services, but also to other goods reliant on socio-economic station such as nutrition, employment, housing and sanitation, which were similarly shaped by apartheid.

The racial fragmentation of services was accentuated by the homelands policy, which created bantustans, and by the tricameral Constitution of 1983, which established ethnically based departments of health. ${ }^{72}$ The homelands policy established ten separate health authorities for the bantustans. The tricameral Constitution added three "own affairs" health authorities for Coloureds, Indians and Whites. The racial segregation of services also accentuated the urbanrural chasm in the provision of services. Health-care services were prioritised for Whites who were concentrated in the urban areas. For Africans in the rural areas, access to health-care services was virtually unattainable. ${ }^{73}$

Attempts to reform the health-care system were submerged by the overarching apartheid superstructure, which consciously ensured that the primary beneficiaries of any reform would be first and foremost Whites, with Indians and Coloureds occupying somewhat intermediate positions. The most significant attempt to reform the system bequeathed by the 1919 Act was the passing of the Health Act 63 of 1977. The Act was intended to repeal the 1919 Act and provide for the rendition of health services to the inhabitants of South Africa. The Act created new structures, in particular the National Health Policy Council, which had the responsibility of formulating national policy on health and co-ordinating services. The Act's professed intention was to provide, through the department of health and welfare, 'comprehensive health services for the population of the Republic of South Africa' ${ }^{74}$ However, it failed dismally in this regard, not least because it preoccupied itself with the provision of health-care services to White South Africa only.

It was not only race which compromised the 1977 Act, but also deregulation of the health sector in the 1970s. ${ }^{75}$ Privatisation gave the private health sector a lasting and dominant position in the provision of health care in South Africa. Private-sector health care, with its exorbitant fees, served only twenty percent of the population and thus accentuated inequalities in access to health care. ${ }^{76}$

71 From 1980 to 1985 infant mortality was $13 \%$ for Whites, $18.9 \%$ for Indians, $56 \%$ for Coloureds and $82 \%$ for Africans. Life expectancy was 66.8 for Whites, 63.1 for Indians, 55.4 for Coloureds and 55.1 for Africans: Van Rensburg \& Benatar (note 67 above) at 106.

72 M Price Health Policy and Planning (1986) at 148.

73 Van Rensburg \& Benatar (note 67 above) at 104.

74 Sec 14(a) of the Act.

75 Van Rensburg (note 23 above) at 79-83; HCJ an Rensburg \& A Fourie 'Privatisation of South African Health Care: In Whose Interest?' (1988) 11 Curationis 1 at 1.

Ibid. 


\section{Reforms in the Democratic Era}

\section{(A) Policy and LegisLation}

Since the advent of the new constitutional dispensation, health-care reforms have been truly anchored in equity, not least because the achievement of substantive equality is a constitutional imperative. Moreover, the Constitution recognises the right of every person to have access to health care. ${ }^{77}$ The state has an obligation to deploy resources at its disposal in order to achieve on a progressive basis the realisation of the right to have access to health care. ${ }^{78}$ To use the language of the Committee on ESCR, once again, the goal now is to achieve a health-care system that is available, accessible, acceptable and of a good quality.

As stated in the introduction, the White Paper for Transformation of the Health System in South Africa (White Paper) has provided the arch policy blueprint for egalitarian health care at a policy level. ${ }^{79}$ It was explicitly aimed at 'promoting equity by developing a single, unified health system'. ${ }^{80}$ It espoused the goal of making primary health care available as the health-care system's point of entry for all people, irrespective of race, means and geographical locality. ${ }^{81}$ It sought to bridge the urban-rural divide and the disparities in economic means by, inter alia, 'focusing on the rural, peri-urban and urban poor and the aged, with an emphasis on vulnerable groups'. ${ }^{82}$

The philosophy underpinning the White Paper is not only a product of constitutional imperatives, but also a reflection of acceptance of international consensus on the equitable provision of health-care services. The concept of primary health care, which is all pervasive in the White Paper, is largely a progeny of the international authority on health, the World Health Organisation (WHO). ${ }^{83}$ The WHO developed the concept in the 1970s with the aim of ensuring that everyone gains access to health care necessary for leading a 'socially and economically productive life'. ${ }^{84}$ The concept was given a boost in 1978 by the international conference of primary health care that was held in Alma Ata. ${ }^{85}$ In the Declaration of Alma Ata, which was adopted at this conference, primary health care is defined in the following terms:

Primary health care is essential care based on practical, scientifically sound and socially acceptable methods and technology made universally accessible to individuals and families in the community though their full participation and at a cost that the community can afford to maintain at every stage of their development in the spirit of self-reliance and self-determination. It forms an integral part of both the country's health system of which it is the central function and main focus, and of the overall social economic development of the community. It is the first level of contact of

\footnotetext{
77 Sec 27 of the Constitution.

78 Sec 27(2) of the Constitution.

79 Par I above.

80 White Paper at 10.

81 White Paper at 10.

82 White Paper at 14.

83 World Health Organisation Global Strategy for Health for All by the Year 2000 (1981). Note, however, that according to Toebes (note 29 above) 34 the idea of primary health care was not entirely borne out of WHO. As far back as in 1931 and in 1937, the Health Organisation of the League of Nations had, at two health conferences on rural health, promoted the idea of primary health services for all.
}

84 Ibid.

85 Toebes (note 29 above) at 35 . 
individuals, the family and the community with the health system bringing health as close as possible to where people live and work, and constitutes the first element of a continuing health care process. 86

Thus, the cardinal idea behind the principle of primary health care is that there are health-care services that are essential or basic to the socio-economic survival and development of individuals and communities. Consequently, such health care ought to be within the reach of everyone and means and distance should not be obstacles. It is for government to ensure the accessibility of health care. Moreover, there must be democratic involvement of the community in the planning and implementation of health care so as to ensure acceptability of the services that are rendered.

As part of the promotion of equity, and implementation of the primary health-care system, a redistribution of public health resources is underway. ${ }^{87}$ The historical bias towards urban-based curative institutions is being reversed in favour of equitable geographical allocations of health resources and facilities. The move is geared towards providing health facilities in areas that have been historically deprived. In this regard, a massive clinic-building system is underway throughout the country to implement primary health care. ${ }^{88} \mathrm{~A}$ complementary development has been the implementation of the District Health System (DHS) as a way of not only decentralising, but also democratising health-care services. ${ }^{89}$ The DHS is challenging the legacy of the Public Health Act of 1919, which bequeathed a fragmented and dysfunctional health-care system.

There have also been numerous legislative interventions with a view to facilitating the realisation of equitable access to health care. ${ }^{90}$ The egalitarian organisation of the South African health system has, at long last, been placed on a statutory footing with the passing in 2004 of the National Health Act. ${ }^{91}$ The Act is built on an edifice of the achievement of substantive equality in the provision of health care. In its preamble, the Act recognises the socio-economic injustices and the inequities of health services in the past. It seeks to comply with the state's constitutional obligation to take reasonable, legislative and other measures within its means to achieve the progressive realisation of the right of everyone to have access to health-care services under section 27 of the Constitution. The Act subscribes to co-operative governance and decentralised management of health services in which national government, provinces, municipalities and health districts collectively address questions of health policy and delivery of health care services. ${ }^{92}$ As part of the democratisation of health services, the Act provides for the involvement of the community in the governance of health care services. ${ }^{93}$

86 At VI of the Declaration of Alma Ata.

87 HCJ Van Rensburg 'Health and Health Care in South Africa in Transition: A Macro Perspective' (1999) 31 Acta Academica 1 at 1; SR Benatar 'Health Care Reform in the New South Africa' (1997) 336 The New England Journal of Medicine 881 at 891.

88 Ibid.

89 Ibid.

90 Eg: In 1994 a presidential decree accorded pregnant mothers and children under 6 years entitlement to free health services; The Choice on Termination of Pregnancy Act 92 of 1996 radically reformed abortion law to, inter alia, provide abortion on request in the first 12 weeks of pregnancy; the Medical Schemes Act 131 of 1998 outlawing unfair discrimination in the provision of health cover under medical schemes. Some pieces of legislation have engendered strong criticism or opposition. An example is the attempt by government to permit compulsory licencing and parallel importation of drugs through the Medicines and Related Substances Act 90 of 1997, that was met with vociferous opposition not only from the South African pharmaceutical industry but also by foreign conglomerates and many industrialised countries.

91 Note 2 above.

92 Preamble to the Act.

93 Section 31 of the National Health Act. 


\section{(B) JUDiCIAL DECISIONS}

In the democratic era, courts have, by virtue of constitutional imperatives, begun to accord judicial confirmation to the egalitarian ethos that underpins access to health care in the new South Africa. A particularly welcome development in this regard is the relatively recent decision of the Constitutional Court in Minister of Health $v$ Treatment Action Campaign, where government was ordered to provide antiretroviral therapy at public health facilities on a universal basis for the prevention of mother-to-child transmission of HIV. ${ }^{94}$ In this case, government policy of restricting the provision of Nevirapine (administered for the purpose of preventing the mother-to-child transmission of HIV) to eighteen pilot sites in the country was challenged on the ground, inter alia, that it was contrary to section 27 of the Constitution. 95 Government had sought to justify its decision on the grounds that it had to monitor the possible side effects of Nevirapine so as to ensure the safety of the drug and that it was necessary to study the socio-economic and public health implications of providing the drug before developing a universal comprehensive package of care. The government's arguments failed before the Constitutional Court.

In Treatment Action Campaign, the court drew from principles for the adjudication of socioeconomic rights that had been developed earlier in Government of the Republic of South Africa $v$ Grootboom. ${ }^{96}$ In Grootboom, the court was concerned with whether a state housing policy and programme, inter alia, complied with the duties imposed upon the state by section 26 of the Constitution. Section 26 is analogous to section 27 in that both provisions guarantee access to a socio-economic good and require the state to take reasonable legislative and other measures to achieve the progressive realisation of the right in question. Grootboom represents a holistic approach to the interpretation of socio-economic rights. ${ }^{97}$ Recourse to the jurisprudence of the Committee on ESCR was crucial in dispelling the myth that socio-economic rights are intangible, unascertainable and unrealisable. Throughout the judgment, the court drew sustenance from the foundational values of the Constitution. Achieving substantive equality and protecting human dignity in the aftermath of a legacy of state-spawned gross inequality in access to housing were given due emphasis, as was the imperative to protect the most vulnerable and weakest in our society as part of the transformation of post-colonial and post-apartheid South Africa. In Grootboom, the court was of the view that although the respondent's housing

92 Preamble to the Act.

93 Section 31 of the National Health Act.

942002 (5) SA 721 (CC).

95 Note that apart from sec 27 of the Constitution, there was also reliance on other provisions, especially at first instance, sec $7(2)$ which enjoins the state to respect, protect, promote and fulfil the rights in the Constitution; sec 10 which guarantees human dignity; sec 12(2)(a) which guarantees the right to bodily and psychological integrity including the right to make decisions about reproduction; sec 28(1)(c) which, inter alia, guarantees a child a right to basic health-care services; sec 195 which, inter alia, enjoins that public administration must be governed by the democratic values that are enshrined in the Constitution and that a high standard of professional ethics must be promoted and maintained, and sec 237 which provides that all constitutional obligations must be performed diligently without delay.

962001 (1) SA 46 (CC).

$97 \mathrm{P}$ de Vos 'Grootboom, the Right of Access to Housing and Substantive Equality as Contextual Fairness' (2001) 13 SAJHR 258 at 258; S Liebenberg 'The Right to Social Assistance: The Implications of Grootboom for Policy Reform in South Africa' (2001) 13 SAJHR 232 at 232; J SlothNielsen 'The Right to Social Services, the Right to Social Security, and the Primary Prevention of Child Abuse in the Aftermath of Grootboom' (2001) 13 SAJHR 210 at 224. 
programme was commendable in many respects, it did not pass constitutional muster because it did not accommodate the immediate needs of the poorest and, perforce, most vulnerable in our society. ${ }^{98}$ Thus Grootboom constitutes a triumph for the realisation of an egalitarian ethos.

In Treatment Action Campaign, the court, taking its cue from Grootboom, demonstrated a bold willingness to impugn executive policy to the extent that the policy impacted on the respect, protection, promotion and fulfilment of fundamental rights in the Constitution. While the court conceded that the executive had constitutional pre-eminence in policy decision-making, the court did not at the same time interpret the doctrine of separation of powers as implying judicial abdication on policy matters that impact on fundamental rights. ${ }^{99}$ Government had a positive duty to take reasonable legislative and other measures, with consideration of its available resources, to achieve the progressive realisation of the right of access to health-care services. ${ }^{100}$ The court was of the unanimous view that government policy was inconsistent with the faithful discharge of this duty. Government policy was inflexible. ${ }^{101}$ It denied 90 percent of mothers and their babies who relied on public health facilities the opportunity to access safe, life-saving therapy that was manifestly affordable to the state. ${ }^{102}$ The court was clearly aware that these mothers and consequently their children were indigent and unable to access private health-care facilities, where Nevirapine was available for a fee. ${ }^{103}$ In reaching this conclusion, the court also took cognisance of section 28 of the Constitution which guarantees children a package of rights, including a right to 'basic health services'. ${ }^{104}$ According to the court, Nevirapine was 'essential' to the child. ${ }^{105}$ Without Nevirapine the life of the rights would be 'most in peril'. 106

Although Treatment Action Campaign was concerned only with the issue of access to antiretroviral therapy for the prevention of mother-to-child transmission of HIV, it appears to have heralded positive changes in government policy towards the provision of antiretroviral therapy generally. For many years government policy has been to provide symptomatic treatment only for HIV/AIDS. Government had maintained that it could not afford the cost of antiretrovirals. However, in 2003, government announced that it was committed to the universal provision of antiretroviral therapy for people living with AIDS and set up a committee to plan and oversee the implementation of its commitment. ${ }^{107}$ South Africa has the highest number of people living with HIV/AIDS in a single country. It is estimated that 5.3 million people (approximately twelve and a half percent of the population) are living with AIDS. ${ }^{108}$ HIV/AIDS-related deaths account for 25 percent of all adult deaths. ${ }^{109}$ On account of costs, antiretroviral therapy has thus far been inaccessible to the majority of people living with HIV/AIDS, with a consequent toll on morbidity and mortality. There is little doubt that if the commitment to provide univer-

\footnotetext{
98 Grootboom 2001 (1) SA 46 (CC) paras 44, 52, 56, 63, and 69.

99 Treatment Action Campaign 2002 (5) SA 721 (CC) paras 98-99.

$100 \mathrm{Sec} 27(2)$ of the Constitution.

101 Treatment Action Campaign 2002 (5) SA 721 (CC) par 80.

102 Par 98.

$103 \operatorname{Par} 79$.

$104 \mathrm{Sec} 28(1)(\mathrm{c})$ of the Constitution.

105 Treatment Action Campaign 2002 (5) SA 721 (CC) par 78.

106 Par 78.

107 Department of Health Operational Plan for Comprehensive HIV and AIDS Care, Management and Treatment for South Africa (2003).

108 Department of Health National HIV and Syphilis Sero-Prevalence Survey of Women Attending Ante-Natal Clinics in South Africa in 2001 (2003).

109 RE Dorrington et al The Impact of HIVIAIDS on Adult Mortality in South Africa (2001) at 6.
} 
sal access to antiretroviral therapy is implemented, it will go a long way towards redressing the lottery of income in determining access to life-saving therapy.

It is not, however, suggested that the change in policy on antiretroviral therapy should be ascribed to Treatment Action Campaign. A number of factors came into play, including a government-commissioned report, indicating that it was feasible to provide antiretroviral therapy in the public sector; ${ }^{110}$ political pressure brought to bear on government by civil society; ${ }^{111}$ significant lowering of the price of antiretroviral therapy by pharmaceutical multinational firms; ${ }^{112}$ and international commitments to permit developing countries facing dire HIV/AIDS pandemics to avail themselves of strategies such as parallel importation and compulsory licensing under the Agreement on Trade Related Aspects of Intellectual Property Rights without fear of economic reprisals from Western countries. ${ }^{113}$ What Treatment Action Campaign managed to do, however, was to facilitate the sustenance and intensification of the public debate on equitable access to antiretroviral therapy in the media and other fora.

It is important to appreciate that Treatment Action Campaign is not the only case in which the courts have dealt with a fundamental right impacting on access to health-care services. There are two earlier cases, $B v$ Minister of Correctional Services 114 and Soobramoney $v$ Minister of Health, KwaZulu-Natal,115 where courts adjudicated on access to health care. Neither case can be regarded as particularly instructive on the development of principles that relate to equitable access to health-care services.

In $B$ four prisoners who were HIV-positive had been refused access to antiretroviral therapy by the department of correctional services on the ground of cost. Antiretroviral therapy had been prescribed for two of the prisoners. They sought an order before the High Court to require provision of antiretroviral therapy. They based their case on section 35(2)(e) of the Constitution, which guarantees a person in state incarceration a right to 'adequate medical treatment'. The court held that the department had a duty to provide the therapy to only the two prisoners to whom it had been prescribed.

A number of criticisms can be levelled at the $B$ case. Much of the case dealt with determining whether anti-retroviral therapy was within the ambit of adequate medical treatment, given its costliness. However, the court did not turn to international human rights jurisprudence for interpretive guidance on this point, except to observe that the term 'adequate' was relative and that its meaning could only be determined according to a given context, taking into account available resources. Notwithstanding the relative exorbitant price of antiretroviral therapy at the time and its inaccessibility to the majority of South Africans living with HIV/AIDS, the court was satisfied that the treatment the prisoners were seeking was no more than adequate. ${ }^{116}$ The case seemed to turn on the narrow point that the department of correctional services had pleaded lack of resources, but had failed to submit convincing supporting evidence.

110 J Kindra 'AIDS: Ministers Revolt' Mail \& Guardian 2003-08-15 to 2003-08-21 at 2.

111 C Keeton 'Turning Point for AIDS Treatment' Sunday Times 2003-08-10 at 17.

112 Globally, the annual cost of antiretroviral therapy has fallen from about $\$ 12000$ to $\$ 300 \mathrm{pp}$.

113 On 2003-08-30, the WTO agreed to permit developing countries badly affected by HIV/AIDS, tuberculosis, and malaria to import cheap generic drugs: C Kapp 'World Trade Organisation Reaches Agreement on Generic Medicines' (2003) 362 Lancet 807 at 807; N Courage 'WTO Agreement Improves Access to LifeSaving Drugs' The Lawyers Weekly 2003-09-26 at http://www.bereskinparr.ca/publications/art html/biotechwto-html.

1141997 (6) BCLR 789 (C).

1151998 (1) SA 765 (CC).

116 B v Minister of Correctional Services 1997 (6) BCLR 789 (C) par 60. 
Even if it is accepted that the court was correct in regarding antiretroviral therapy as adequate medical treatment within the meaning of section 35(2)(e), the order to provide antiretroviral therapy to only two of the applicants is problematic. As the judge observed, the overcrowding in prisons exacerbates the vulnerability of prisoners living with HIV to opportunistic infections, including tuberculosis and pneumonia. ${ }^{117}$ Overcrowding contributes significantly to neglect of hygiene, care and supervision. Over and above the overcrowding, there is stress, violence and malnutrition to contend with. ${ }^{118}$ South African prisons are characteristically violent places. Rape is rampant. ${ }^{119}$ It has been suggested that incarceration reduces the life expectancy of a person living with HIV by 50 percent by accelerating the infectious stage of the disease to fullblown AIDS. ${ }^{120}$ In 1999 a study conducted by a judicial inspectorate found that 90 percent of deaths of people who are incarcerated are AIDS-related. ${ }^{121}$ Voluntary as well as coerced sex in prisons adds significantly to HIV prevalence among male prisoners. It is estimated that 65 percent of male prisoners engage in homosexual activity. 122

Even though prisoners have a higher morbidity and mortality rate from HIV/AIDS than their counterparts in the community, the court in $B$ did not consider whether antiretroviral therapy would also constitute adequate treatment for other prisoners for whom it had not been prescribed, but were nonetheless seeking it on the ground that it had a prophylactic effect in people living with HIV/AIDS. Brand J rejected the claim of the prisoners for whom the therapy had not been prescribed on the ground that granting the order would amount to instructing medical doctors to prescribe the therapy. ${ }^{123}$ The judge erroneously equated granting an order of constitutional entitlement to antiretroviral therapy with obliging doctors to prescribe those entitlements. As shown by Treatment Action Campaign, it would have been possible for the court to grant a wider order to the effect that where antiretroviral therapy is medically indicated for prisoners living with HIV/AIDS, there is a constitutional duty to provide it on the part of the state, but subject to available resources. That way, the decision of the court would have assisted other prisoners falling in the same class as the successful applicants. It would have provided clearer guidance to those doctors who are consulted by prisoners living with HIV/AIDS.

The Soobramoney case concerns a man who was seeking to compel the respondent to provide him with renal dialysis. He suffered from chronic renal failure. He had been receiving dialysis through private care, but his funds had run out. He sought to have dialysis provided to him, at state expense, by a renal unit of a state hospital. Otherwise he would have died. His request was declined. The renal unit could only meet 30 percent of the demand for renal dialysis. It could only provide renal dialysis to patients who were candidates for renal transplantation. Thus, it could only provide dialysis to those patients who needed it in the short term and not as life-long therapy. The applicant was not a candidate for transplantation. He suffered from ischaemic heart disease and was a diabetic with peripheral vascular disease. In the previous year, he had suffered a stroke.

Though the applicant canvassed several grounds in support of his application, in the main,

117 Par 54.

118 KC Goyer 'HIV/AIDS in South African Prisons' http://www.iss.co.za/Pubs/Monographs/ No79/Chap1.html accessed on 2004-01-18.

119 Ibid.

120 Ibid.

121 Ibid.

122 Ibid.

123 B v Minister of Correctional Services 1997 (6) BCLR 789 (C) par 37. 
he contended that the respondent's decision had infringed his right to life in terms of section 11 of the Constitution and his right not to be refused emergency medical treatment in terms of section 27(3). The court was of the opinion that the right to life argument was inappropriate as the Constitution provided explicitly for rights concerning access to health-care services. In respect of section 27(3), the court held that although the section was capable of being more broadly interpreted to include ongoing treatment for chronic conditions, it had a narrower meaning. It was not intended for a condition such as chronic renal failure. Instead it was intended for a sudden catastrophe or unexpected trauma. In any event, the court was also of the view that even if chronic renal failure constituted an emergency, the state was not violating its obligations when it declined to provide renal dialysis, as its resources were limited.

Although the applicant had not raised the issue, the court also took the opportunity to consider the application of section 27(1) and (2) to the facts of the case. The court suggested that these sections were more appropriate to the facts of the case than sections 11 or 27(3) of the Constitution. It was held, unanimously, that on account of scarcity of resources, it could not be said that the state had failed to discharge its section 27(2) obligations. 124

For a number of reasons Soobramoney did not contribute much to the understanding of socio-economic rights. ${ }^{125}$ The outcome of the case itself was correct, given the prevailing scarcity of resources to provide life-long renal dialysis at a time when the state health sector could meet only 30 percent of the demand for renal dialysis. ${ }^{126}$ Under the guidelines that had been worked out by the state renal unit, priority was given to patients who were candidates for renal transplant and, thus, did not require life-long dialysis.

Despite reaching the correct decision, the court was unduly restrictive in its interpretation of section 27(3). It had been argued by the appellant that section 11 of the Constitution was relevant to the interpretation of section 27(3) to the extent that refusal to provide renal dialysis meant that the right to life would be nullified. In retort, the court took the view that the right to life argument was inappropriate as the Constitution had express provisions governing issues of access to health-care services. In adopting this approach, the court unduly minimised the relevance of section 11. Even conceding that chronic renal failure of the type that the appellant was afflicted with did not constitute a medical emergency as contemplated by section 27(3), the effect of the court's interpretation was to cast the provisions of the Bill of Rights as individual elements that are not linked. The court thus adopted a legalistic interpretation of section 27(3) in contrast with its own professed generous, purposive approach. 127

It was also a mistake for the court to interpret section $27(3)$ as a negative rather than a positive right. ${ }^{128}$ The court held that section $27(3)$ created a negative right only: the right not to be turned away arbitrarily by an institution or facility that is able to provide emergency treatment. ${ }^{129}$ To the extent that the court's approach can be construed as imposing no obligation upon the state to develop and make emergency services available, the import of the positive duties of health-care providers was undermined. ${ }^{130}$ Socio-economic rights draw sustenance

124 Chaskalson P delivered the leading judgment.

125 C Scott \& P Alston 'Adjudicating Constitutional Priorities in a Transnational Context: A Comment on Soobramoney's Legacy and Grootboom's Promise' (2000) 16 SAJHR 207 at 206; De Vos (note 97 above) at $258-259$.

126 Soobramoney 1998 (1) SA 765 (CC) par 26.

127 S v Makwanyane 1995 (3) SA 391 (CC) par 9; De Waal, Currie \& Erasmus (note 44 above) at 130-135.

128 Soobramoney 1998 (1) SA 765 (CC) par 20.

129 Ibid.

130 Scott \& Alston (note 125 above) at 235-237. 
from the imposition of positive obligations. Scott and Alston have described the court's approach as constituting 'negative textual inferentialism'.131

Soobramoney also seems to paint a picture of undue judicial deference in decisions on the allocation of health-care resources and the protection of socio-economic rights in general. ${ }^{132}$ The court seemed to take as its starting point that once it has been asserted by a provincial or national health-care provider that resources are unavailable, then that per se limits the realisation of a right of access to the service. The court did not inquire into whether the state and the province were in fact according due priority to the realisation of the right sought by making available resources that ought to be available and utilising such resources effectively. It seemed enough for the health-care provider to 'toll the bell of tight resources'.133

Soobramoney, unlike Treatment Action Campaign, is of little use for understanding the constitutional right to equitable access to health-care services. The court did not consider how the right to health or the right of access to health care has been interpreted under international human rights instruments. In particular, the court failed to make use of jurisprudence that had been developed by the Committee on ESCR. Failure to consider international law was a serious shortcoming on the part of the court, not least because the Constitution enjoins the courts to consider any relevant international law. ${ }^{134}$

\section{Conclusion}

When viewed from an egalitarian perspective, the South African health-care system had for the greater part of the twentieth century conformed to the paradigm of a lottery where race, income and geographical location have been the main determinants of access. Postapartheid reforms are, however, challenging this lottery, not least through major health-care reforms and the constitutional imperatives to achieve substantive equality, and perforce equitable access to health-care services. Section 27 of the Constitution is the clearest indication of a commitment towards equity in access to health care. However, political reforms rarely come without contradictions and the same stands true for the reform of the South African health-care system.

While the trajectory towards a health-care system that embraces egalitarian equity is clear, there are attendant problems and detracting factors. Providing universal care is costly to a middle-income country that does not have a national health insurance system and has a high unemployment rate. ${ }^{135}$ South Africa still has poor indicators for health when compared with other middle-income countries. ${ }^{136}$ The health-care sector is competing with

131 Scott \& Alston (note 125 above) at 237.

132 D Mollendorf 'Reasoning about Resources: Soobramoney and the Future of Economic Rights Claims' (1998) 14 SAJHR 327 at 327.

$133 R v$ Cambridge Health Authority, ex Pb (a minor) (QBD) 25 BMLR 517 per Laws J; Soobramoney 1998 (1) SA 765 (CC) par 52 per Sachs J (where drawing from Cambridge Health Authority he said that '[i]n a case as the present which engages our compassion to the full, I feel it necessary to underline the fact that Chaskalson P's judgment, as I understand it, does not "merely toll the bell of lack of resources"').

$134 \mathrm{Sec} 39$ of the Constitution.

135 M Bachmann 'Would Social Health Insurance Improve South African Health Care? What other Middle Income Countries Can Teach Us' (1994) 24 Transformation 26 at 26.

136 Bachmann (note 135 above) at 27. 
other sectors for scarce resources. Skilled health workers are emigrating in significant numbers. 137 The burden on the health-care system is increasing on account of rising levels of poverty and unemployment. Perhaps more than any other factor, the gigantic scale of the country's HIV/AIDS epidemic has been a constraining factor in the realisation of universal access to health care. The divide between a first rate but expensive private health-care sector and a second-class public health sector remains and will persist for the foreseeable future. ${ }^{138}$ Furthermore, the pace of transformation itself is not above criticism. Changes have at times been introduced well ahead of creating capacity in terms of human resources and other infrastructure. ${ }^{139}$ Despite these impediments, it is, nonetheless, incontestable that the building blocks for an equitable health-care system are being laid. At least in the medium to long term, there is no reason why South Africa cannot realise for all of its people the provision of a decent basic minimum package of care commensurate with resources.

While this article has focused on equity in access to health from the angle of policy and practice, it is important to bear in mind that in the case of developing countries the factors that impact on equity are governed not only by internal factors, but also external ones. ${ }^{140}$ The costs of life-saving or life-prolonging drugs that are manufactured by conglomerates that are based in developed countries are a major constraining factor. The global inequity in access to AIDS drugs is a clear illustration. ${ }^{141}$ Regardless of the extent of commitment to the provision of antiretroviral drugs, if the price of drugs is exorbitant and patent protection rules are unduly restrictive and indifferent to public health catastrophes, equity cannot be obtained for the poor in developing countries.

137 'Young Doctors Plan to Bolt en Masse' Sunday Times 2002-12-08. A survey carried out on new medical graduates has revealed that $43 \%$ intend to leave the country and that only $38 \%$ are committed to working in the public health sector.

138 Van Rensburg (note 87 above) at 1.

139 Ibid.

140 HCJ Van Rensburg \& C Ngwena 'Health and Health Care in South Africa against an African Background' in WC Cockerham (ed) The Blackwell Companion to Medical Sociology (2001) at 365-391.

141 CA Reich 'The Global Drug Gap' (2000) 287 Science 1979 at 1979; D Resnik 'Developing Drugs for the Developing World: An Economic, Legal, Moral and Political Dilemma' (2001) 1 Developing World Bioethics 11 at 11 . 


\title{
Pro-Poor Court, Anti-Poor Outcomes: Explaining The Performance of the South African Land Claims Court
}

\author{
- Theunis RouX* \\ Director, South African Institute for \\ Advanced Constitutional, Public, \\ Human Rights and International Law; \\ Honorary Reader in Law, \\ University of the Witwatersrand
}

\section{Introduction}

Why has a specialist court that was purposely established to adjudicate claims made under propoor legislation come to play a very minor role in the adjudication of those claims? How did it happen that a decision of that court rejecting a claim by an indigenous community should be overturned by an appellate court staffed by non-specialist judges? And why did the specialist court, in several decisions across different areas of law, interpret social rights so narrowly that they were rendered virtually meaningless?

These are some of the questions that have driven the writing of this article. The court in question, the Land Claims Court of South Africa ('the LCC'), was established in 1996 under a statute that was among the first wave of legislation enacted by the post-apartheid legislature. Indeed, the statute concerned, the Restitution of Land Rights Act, ${ }^{1}$ was so important to the new democratic government that special authorisation for it was built into the transitional constitution. ${ }^{2}$ Anyone reading the Restitution Act at the time of its promulgation would have had no doubt that the LCC had been established to oversee the reversal of eighty years of state-orchestrated land dispossession. And anyone observing the process of its establishment would have noted that the judges chosen to staff the Court all had strong human rights credentials. None of them had served as a judge under apartheid, ${ }^{3}$ and all had in their previous work as practising lawyers demonstrated their commitment to improving the lives of the poor and the landless. And yet, ten years later, the LCC plays no

* I would like to thank the anonymous referees of this article for their helpful comments, and also the participants in the two conferences at which draft versions of this article were presented: the Centre for Applied Legal Studies conference on Human Rights, Democracy and Social Transformation: When do Rights Work? (November 2003), and the University of the Witwatersrand Law School conference celebrating Twenty Years of Human Rights Scholarship and Ten Years of Democracy (July 2004). This article first appeared in (2004) 20 SAJHR 511-543 and is reprinted here with the kind permission of T Roux, I Currie (editor of SAJHR) and Juta \& Co.

1 Act 22 of 1994 ('the Restitution Act').

2 See sections 121-123 of the Constitution of the Republic of South Africa, Act 200 of 1993.

3 As noted below, the President of the court, Fikile Bam, had acted as an additional member of the Industrial Courts in the former Ciskei and Transkei 'homelands', after being deported from South Africa in 1980. 
meaningful role in overseeing the land restitution process, and has concurrent jurisdiction over another statute that, at least in part because of the way the Court has interpreted it, is regarded as 'facilitating' a new wave of land dispossession. ${ }^{4}$

In seeking to explain this anomaly, this article draws on the work of a group of scholars who are studying the role of courts in new democracies. The group is particularly interested in two issues: the accountability function of courts (which concerns the capacity of courts to check the power of the political branches), and the role of courts in social transformation. The first phase of this study has been completed. ${ }^{5}$ The second phase, to which this article belongs, tests a theoretical model of the role of courts in social transformation that is described in detail elsewhere. ${ }^{6}$ In brief, the model assumes that the capacity of courts to be used as agents for social transformation is influenced by a number of 'indicators', including: institutional indicators (such as the structure of the legal system and the social composition of the judiciary), indicators of poor groups' voice (the frequency and nature of cases brought), and resource indicators and indicators of access to justice barriers (such as access to legal aid and other funding for litigation, and motivational, psychological and practical barriers to access). ${ }^{7}$

What makes the study of the LCC interesting for purposes of this model is that it provides an opportunity to eliminate some of the variables that typically condition the social transformation performance of courts, such as the social composition of the judiciary and the underlying legal framework. Neither of these factors can explain the performance of the LCC in the areas of law just described. The judges on the court, one may safely assume, have not changed their political opinions since their appointment, and the legislation that the LCC is required to enforce remains stridently pro-poor. If the theoretical model tested in this article is sound, this means that the performance of the LCC in these areas must be explicable in terms of one or more of the remaining indicators: either a resource indicator (such as the absence of legal aid or lawyers capable of pursuing effective, pro-poor legal strategies), an access to justice barrier (such as the physical location of the court, the inaccessibility of the legal language used to articulate the claims of the poor, and various other motivational and psychological barriers to access), or an institutional indicator (such as the influence of legal culture, the doctrinal force of the common law, or professional concerns amongst the judges about how their decisions are perceived).

Before examining the possible role of these indicators it is necessary first to describe in more detail the nature and functions of the LCC, including the social background of the judges who staff it, the history of its establishment, and the character of the legislation it administers. In addition to reinforcing the points made already in relation to the history of the Court, this sec-

4 The term 'facilitating' was used by several speakers at the ESTA Review Workshop held in November 1999 to describe the impact of the Extension of Security of Tenure Act 62 of 1997 ('the ESTA') on farm workers. See Department of Land Affairs: Land Rights Directorate ESTA Review Workshop Report (December 1999). At this workshop, which was attended by a wide cross-section of government officials, NGO workers and representatives of the farming community, the ESTA and various judgments of the LCC were severely criticised for failing to stem the tide of farm worker evictions in South Africa. There is at present no empirical evidence to support this claim.

5 See sec Gloppen, R Gargarella \& E Skaar (eds) Democratization and the Judiciary: The Accountability Function of Courts in New Democracies (2004) (first published as a special issue of the journal Democratization in 2003).

6 See sec Gloppen 'Analyzing the Role of Courts in Social Transformation: Social Rights Litigation, Court Responsiveness and Capability' paper presented at the Centre for Applied Legal Studies Workshop on Human Rights, Democracy and Social Transformation: When do Rights Work? (November 2003).

Ibid. 
tion is intended to make the analysis presented here more accessible to non-South African scholars interested in the lessons to be learned from the performance of the LCC.

It will also be necessary as a preliminary matter to make out a stronger case for the poor, pro-poor performance of the Court in the areas of law chosen for analysis. Assessments of courts' performance are inevitably contested, with judges themselves necessarily taking the view, at least when justifying their decisions, that their judgments are doctrinally sound. In addition, other legal academics may take a different view from the one presented here on the doctrinal correctness of the decisions discussed. Since the assessment of the correctness of a legal decision is itself an act of legal interpretation, the argument presented in this article is vulnerable to the criticism that it is based on a flawed understanding of the record of the Court, particularly since only a fraction of the total number of decisions handed down by the Court will be discussed. The further difficulty is that there is a (very respectable) view in the literature that, given the expense of litigation, every case that goes to court must in theory be capable of decision in favour of either party, and therefore that every act of adjudication is really a decision between plausible legal outcomes. ${ }^{8}$ Indeed, if the LCC never handed down a decision unfavourable to a poor litigant, this in itself would be anomalous, and of course the landowners who litigate the other side of these cases would soon seek another forum in which to defend their interests.

This methodological problem is addressed in the following way. After describing the nature and functions of the LCC, the third section of this article discusses a series of cases in four areas of law that produced anti-poor outcomes. By 'anti-poor outcomes' is meant cases in which the losing party was poor. ${ }^{9}$ In relation to cases heard in the LCC the identification of a poor litigant is not difficult: the vast majority of the cases decided by the Court involve poor, mostly black claimants asserting or defending their statutory land rights against relatively affluent, mostly white landowners. ${ }^{10}$ Having classified the cases in this way, the article proceeds to

8 See F Schauer Playing by the Rules: A Philosophical Examination of Rule-Based Decision-making in Law and in Life (1991) 193 (citing G Priest \& W Klein 'The Selection of Disputes for Litigation' (1984) 13 J of Legal Studies 1-23) and F Schauer 'Judging in a Corner of the Law' (1988) 61 Southern California LR 171733).

9 I draw here on some of the methodology developed in scalogram analysis. In its application by judicial behaviouralists, this form of analysis amounts to distinguishing various judicial attitudes, expressed as antinomies (eg pro-labour/pro-business, pro-regulation/anti-regulation) and then assessing the performance of judges in relation to these antinomies across a number of decisions. See M Shapiro \& A Stone Sweet On Law, Politics, and Judicialization (2002) 44-46. Scalogram analysis is generally used to study ordinary courts applying the common law, and in respect of non-unanimous decisions involving issues of public policy decided on the merits. See DE Fouts 'Policy-Making in the Supreme Court of Canada, 1950-1960' in G Schubert \& DJ Danelski (eds) Comparative Judicial Behavior: Cross-Cultural Studies of Political DecisionMaking in the East and West (1969) 257-91, 265. The non-unanimity requirement comes from an assumption that the handing down of a dissenting judgment means that there were at least two legally plausible outcomes to the case, and that judicial discretion (in the form of an underlying attitude) therefore came into play. It is this part of the methodology that I draw on here. The full application of scalogram analysis is inappropriate because there has not been a single dissenting judgment in the entire history of the LCC, and the LCC is of course not an ordinary court applying the common law.

10 By using the label 'anti-poor' to describe the outcomes in these cases I do not mean to suggest that the Court was motivated by anti-poor sentiments. As will become clearer below, the explanation I posit for these antipoor outcomes is independent of the judges' private political views - as indeed it must be, since those views, as far as can be ascertained, are not anti-poor. Rather, I choose the term 'anti-poor' because it is the binary opposite of the term 'pro-poor', and the anomaly I wish to explore is the anomaly of a pro-poor court, interpreting pro-poor legislation, handing down decisions that adversely affected not just the poor litigants involved, but also other similarly situated poor people. 
analyse the written reasons given for the decision in each case. The point of this exercise is not to argue that the cases were wrongly decided, in the sense that the Court made clear mistakes of law. Rather, it is to show that plausible, pro-poor legal arguments were presented to the Court, and then either rejected or ignored.

Of course, there is room for doubt at this stage over whether the contention that the rejected or ignored arguments were plausible is itself doctrinally sound. In two instances, however, the argument that the cases might have been decided differently is supported by decisions of other courts - one of them the appellate decision mentioned earlier, and the other a minority judgment of a judge of a court of equivalent status to the LCC. By referring to these instances, this article shifts the burden of persuasion onto those who would disagree with its interpretation of the cases to show why these other judgments were so clearly wrong that they were not even plausible.

The second way in which this article shores up its arguments relating to plausibility is by referring to independent evidence of the way in which the Court's decisions were perceived. This evidence comes in the form of responses by the legislature to the LCC's decisions. In two instances one can draw a direct line of causation between a decision discussed here and an amending statute aimed at counteracting that decision. This does not demonstrate, of course, that the two LCC decisions concerned were not doctrinally sound, or that the pro-poor arguments they ignored or rejected were plausible, but it does indicate that the legislature was dissatisfied with the LCC's performance. Since the LCC is a creature of statute, this result is significant enough to warrant investigating. From the perspective of the theoretical model tested in this article, a legislative amendment to social transformation legislation is evidence of poor judicial performance in the weak political sense.

The next part of the article considers some possible explanations for the poor, pro-poor performance of the LCC in the four areas of law discussed, drawing on, and at the same time testing, the theoretical model introduced above. In addition to the two sets of indicators already eliminated, two further explanations will not be pursued in detail here: the absence of legal aid, and the legal strategies pursued by the poor to assert their rights. The absence of legal aid cannot explain anti-poor outcomes in a series of cases across several areas of law where plausible, pro-poor legal arguments were presented to the court. ${ }^{11}$ The same logic applies to the legal strategies pursued by the poor: to the extent that the LCC was presented with plausible propoor legal arguments in the cases discussed here, the anti-poor outcomes cannot be attributed to the legal strategies pursued.

This leaves three other possible explanations, all of which have to do with institutional indicators, viz the influence of South African legal culture, the doctrinal force of the common law, and the LCC's desire for approval from its professional peers. The final part of the article revisits the cases in an attempt to find an explanation for the anti-poor outcomes in these factors.

11 It could, of course, explain a general tendency of interpreting the rights framework in a way contrary to the poor, but this is a different issue. 


\section{Background}

\section{(A) The LCC's Jurisdiction AND COMPETEnCE}

The LCC was established in 1996 and handed down its first decision on 16 April 1996. Since then it has handed down over 300 decisions. ${ }^{12}$ The LCC's powers and functions are set out in Chapter III of the Restitution Act. As noted above, the Restitution Act was one of the first statutes to be passed by the post-apartheid legislature, from which one may deduce that the issue of land restitution was given high priority by the incoming government. With hindsight, the Restitution Act was perhaps a little too hastily enacted, as there have been numerous amendments to it, one each year from 1995-2000, and again in 2002. The 1999 amendments were very extensive indeed, and virtually legislated the LCC out of the restitution process. This circumstances giving rise to these amendments are discussed in III (A) below.

The LCC's foundational jurisdiction is derived from section 22 of the Restitution Act. In addition, section 13 of the Land Reform (Labour Tenants) Act ('the LTA') 13 and section 20 of the Extension of Security of Tenure Act ('the ESTA') ${ }^{14}$ define the LCC's particular jurisdiction in relation to these statutes. The LCC's jurisdiction over the Restitution Act and the LTA is exclusive of other courts, whereas it shares jurisdiction over the ESTA with the magistrates' courts and the High Court. In practice, the LCC hands down very few decisions under the Restitution Act (about seven a year), 15 and the overwhelming majority of restitution claims are settled in terms of the powers conferred on the Minister of Land Affairs under section 42D of the Restitution Act (as amended in 1999). ${ }^{16}$ The LCC also decides very few labour tenants cases (about five a year), ${ }^{17}$ notwithstanding the provision in section 13 of the LTA that all labour tenants matters in other courts be referred to the LCC, except where oral evidence has already been led.

The vast majority of the LCC's work, as a proportion of judgments delivered, involves its automatic review jurisdiction under section 19(3) of the ESTA. Over 50 per cent of the LCC's total output since 1998 has consisted of decisions of this type. ${ }^{18}$ The LCC's automatic review jurisdiction has been described as a hybrid jurisdiction, combining elements of appeal and review. ${ }^{19}$ In essence, on every occasion in which a magistrate hands down an order for eviction against a person who qualifies as a protected occupier under the ESTA, the decision must be sent on review to the LCC. In an important line of cases, the LCC has extended its jurisdiction in this context to all magistrates' court orders for eviction falling into the 'sphere of law' defined by the ESTA. ${ }^{20}$ Thus, even where the eviction order is not technically speaking handed down

12 As at the end of June 2004.

13 Act 3 of 1996.

14 Act 62 of 1997.

15 My list contains 53 decisions between 1996 and July 2003, including decisions in applications for leave to appeal.

16 The latest figure available from the Commission on Restitution of Land Rights is that 36908 restitution claims had been settled by 28 February 2003.

17 My list contains 38 decisions between 1996 and July 2003, including decisions in applications for leave to appeal.

18 The respective percentages for each year of operation of the ESTA are: $1998(28.8 \%), 1999(51.5 \%), 2000$ (72\%), $2001(68.5 \%), 2002(59.4 \%), 2003(40.7 \%), 2004$ to date $(61.5 \%)$.

19 Lategan $v$ Koopman en Andere 1998 (3) SA 457 (LCC) at 464C, Atkinson v Van Wyk and Another 1999 (1) SA 1080 (LCC) at 1085-86.

20 See Skhosana and Others $v$ Roos t/a Roos se Oord and Others 2000 (4) SA 561 (LCC), Pitout v Mbolane [2000] 2 All SA 377 (LCC), Mahlangu and another $v$ Van Eeden and another [2000] 3 All SA 321 (LCC), Bergboerdery v Makgoro 2000 (4) SA 575 (LCC), Kbuzwayo v Dludla [2000] 4 All SA 329 (LCC), and Van Zyl NO v Maarman [2000] 4 All SA 212 (LCC). 
in terms of the ESTA, the LCC will assume jurisdiction to review it if the ESTA was raised in argument, or should have been applied as a matter of law.

In a further important decision handed down in 2001, however, the LCC held that its automatic review decisions, being decisions of a single judge sitting in chambers, were not formal decisions as such. ${ }^{21}$ Accordingly, in the event of an appeal being raised against such a decision, the appeal should lie first to a two-judge bench of the LCC, and then to the Supreme Court of Appeal. This means that just more than half of the LCC's decisions are not really decisions at all.

The remainder of the LCC's workload consists of cases under the ESTA that are initiated in the LCC itself. These cases mainly take the form of urgent applications for eviction and applications to enforce occupiers' or owners' use rights. The magistrates' court rules in South Africa are not designed to deal with urgent applications, and hence these cases go directly to the LCC.

\section{(B) The Social Composition of the Court}

There are now four LCC judges: two African men, one Indian woman, and one white man. A fifth judge, a white man, resigned from the Court in 2000 to pursue a career as an advocate at the Johannesburg Bar.

The four sitting judges all have backgrounds in human rights law.22 The Judge President, Fikile Bam, was a former Director of the Legal Resources Centre in Port Elizabeth, and sat on the Goldstone Commission of Inquiry. Judge Antonie Gildenhuys, although a former member of the secret Afrikaner club, the Broederbond, went through a self-described personal political transformation in the early 1990s as chair of the National Peace Secretariat. Judge Gildenhuys is also a former President of the Transvaal Law Society, and the author of a leading academic textbook on the law of expropriation.

Judge Yasmin Meer's human rights background includes a brief stint, in 1995, as National Director of South Africa's leading public interest litigation firm, the Legal Resources Centre. Before that, she practised as an attorney at the Legal Resources Centre for 12 years. Judge Justice Moloto ('Justice' is his first name), although never a human rights lawyer, was executive director of the Black Lawyers' Legal Education Centre for five years, and has been committed throughout his professional career to the development of young black lawyers.

\section{(c) Legal Education and Training OF Judges}

All of the LCC judges have had a formal university legal education. During the period when the judges were in training, university education in South Africa was, with a few exceptions, segregated on racial lines, and black lawyers were thus trained either at an historically black university (like the University of Durban-Westville, where Judge Meer obtained her BA degree) or at a distance learning university, like the University of South Africa (Judges Bam and Moloto). Judge Meer later attended the University of Cape Town for her LLB degree, and the University of Warwick (LLM). Very unusually for his time, President Bam's first law degree, a BA (Law), was from the University of Cape Town. Judge Gildenhuys graduated BA LLB from the University of Pretoria. He also has a LLD from the University of South Africa.

Three of the four judges practised as attorneys before being appointed to the LCC, Judge

21 See Magodi and others $v$ Van Rensburg [2001] 4 All SA 485 (LCC).

22 The information in this section and the next one is taken from the LCC's website $\leq$ www.wits.law.ac.za/lcc>. 
Meer at the LRC, Judge Gildenhuys in a commercial law firm in Johannesburg, and Judge Moloto as an attorney in Durban. The only former advocate amongst the judges is Judge President Bam, who was a member of the Johannesburg Bar and then the Transkei Bar, after being deported from South Africa in 1980. Judge President Bam is also the only one of the four to have had previous judicial experience, as an additional member of the Industrial Courts in the former Ciskei and Transkei 'homelands'.

\section{(D) Judges’ Perception of Their Role}

In its early judgments the LCC expressly stated that it saw itself as interpreting and applying 'social legislation', by which it meant legislation whose primary objective was to transform social power structures in favour of the landless groups identified in that legislation. This approach came out most strongly in its judgments on costs orders, where it developed the principle that costs should generally not be awarded against a poor litigant who litigates in good faith on a novel point of law. Thus the LCC has held that punitive, attorney-client costs will only be awarded where one party litigates 'maliciously or in wilful disregard of the [other party's] rights', ${ }^{23}$ that '[i]t is not always appropriate to grant [ordinary] costs orders in respect of litigation under [the ESTA]', ${ }^{24}$ and that parties should not be discouraged from enforcing their rights under social legislation by the fear of an adverse costs order. ${ }^{25}$ The principle that costs should generally not be awarded against a litigant who has litigated in good faith is directly opposed to the common-law principle that 'costs follow the result', ie that the losing party should pay the other side's costs, whatever their personal economic circumstances might be.

The mere fact that the judges of the LCC perceive themselves to be interpreting social legislation does not, of course, mean that their judgments have the effect of promoting the objectives of that legislation. As argued below, it may be that in practice other factors, such as the legal culture in which they are operating, their greater familiarity with the common law, and their desire for professional respect, exert a restraining influence on their choice of legal rules. Only a close reading of the cases will reveal the extent of the rule choices open to them, and the possible influences on the exercise of their discretion in areas of legal uncertainty - to which task this article now turns.

\section{The Cases}

The four areas of law chosen for analysis in this article are: (a) the confirmation of out-of-court settlement agreements made in terms of the Restitution Act; (b) the validity of a claim made by an indigenous community under the Restitution Act to return of its ancestral land; (c) the enforcement of rural farm dwellers' right under the Extension of Security of Tenure Act 62 of 1997 ('the ESTA') to bury their relatives on the land on which they are residing; and (d) dependants and spouses' rights under the ESTA not to be arbitrarily evicted. As explained above, these areas were all chosen because they illustrate instances in which the LCC decided cases against poor litigants,

23 Karabo and Others $v$ Kok and Others 1998 (1) SA 1014 (LCC) at 1024I.

24 Serole and Another $v$ Pienaar 2000 (1) SA 328 (LCC) at 336E.

25 Skhosana $v$ Roos [1999] 2 All SA 652 (LCC) at 666c-e. See also the LCC's decisions on costs orders under the LTA: Hlatshwayo $v$ Hein 1999 (2) SA 834 (LCC) at 844-50 and Mahlangu $v$ De Jager 1996 (3) SA 325 (LCC) at $246 \mathrm{~F}-247 \mathrm{D}$. 
despite the existence of plausible legal arguments justifying an alternative outcome. The cases discussed represent only a fraction of the total number of cases decided by the LCC, most of which have had pro-poor outcomes. The discussion that follows therefore does not purport to be an assessment of the overall performance of the LCC, which would require a book-length study. Rather, my intention is to focus on a set of apparently anomalous outcomes in the hope that the explantory power of the model tested in this article can be demonstrated.

\section{(A) SupERVision of Restitution SETTLEMENTS}

In its very first decision under the Restitution Act, In re Macleantown Residents Association: Re Certain Erven and Commonage in Macleantown ('the Macleantown case'), ${ }^{26}$ the LCC was required to endorse a settlement agreement that had been reached between an urban landclaiming community, a local ratepayers' association, and a municipality. The agreement had been signed after painstaking negotiations, and was described by the LCC in its judgment as demonstrating 'a common-sense approach to the restitution claim'. ${ }^{27}$ Nevertheless, the LCC refused to endorse it. The main reasons given for this decision were: 'the papers submitted to the Court [did] not contain a list of [individual] claimants' ${ }^{28}$ no resolutions were filed authorising the representatives of the land-claiming community and the ratepayers' association to sign the settlement agreement on behalf of their constituents, ${ }^{29}$ there was no proof that the local government authority had the legal power to transfer the land in question to the land-claiming community, ${ }^{30}$ the 'involvement' of each individual member of the land-claiming community in the original land dispossession had not been made out on the papers, ${ }^{31}$ and the proper Deeds Office description of the land claimed had not been submitted to court. ${ }^{32}$

Although all of these requirements were technically speaking necessary for the Court to make an effective order, the Restitution Act did not expressly confer on the Court the power to refuse to endorse a settlement agreement for non-compliance with these requirements. Rather, the Court arrives at this rule through interpreting section 14(3) of the Act. ${ }^{33}$ Section 14(3), as it was then formulated, ${ }^{34}$ simply set out the procedure that the Commission on Restitution of Land Rights had to follow in referring settlement agreements to the Court. Section 14(6), to which the Court refers in a footnote, 35 then went on to provide that the Court should not make an order 'unless the Commission has, in respect of the claim in question, acted in accordance with the provisions of this section'. 36 This provision plainly referred to compliance by the Commission with the procedural steps required by section 14, rather than the substantive requirements for a valid restitution claim. And yet, it is the latter interpretation that the Court prefers, glossing section 14(6) as meaning that, before making a settlement agreement an order

261996 (4) SA 1272 (LCC).

27 Ibid $1275 \mathrm{C}$.

28 Ibid 1278B.

29 Ibid 1279D.

30 Ibid $1279 \mathrm{~F}$.

31 Ibid 1280E.

32 Ibid 1281E.

33 Ibid 1276G-I.

34 This subsection has since been substituted by sec $6(\mathrm{~b})$ of the Land Restitution and Reform Laws Amendment Act 18 of 1999.

35 Macleantown (note 26 above) 1276J.

36 This subsection has also since been amended, by sec 10(1)(b) of the Land Restitution and Reform Laws Amendment Act and sec 6(e) of the Land Restitution and Reform Laws Amendment Act 18 of 1999. 
of court, it must 'determine whether all requirements imposed by such legislation [ie the Restitution Act] have been met'. 37

Not surprisingly, the Macleantown decision was very badly received by the Commission, which seems to have understood it as a criticism of its technical competence. At the time, the Commission was struggling under the massive weight of the unexpectedly large number of restitution claims lodged, which were then reckoned at 64000.38 Of these, the Commission had settled only one by the end of the fiscal year in which the Macleantown case was decided. ${ }^{39}$ By insisting on detailed technical compliance with the Act in an uncontested case where all the parties were in favour of the solution reached, the LCC missed a crucial opportunity to set itself up as a partner to the Commission in pursuit of the overall policy objectives of the Act.

That the decision in the Macleantown case was not dictated by the Restitution Act is illustrated by a decision of the LCC handed down some three months later, In re Elandskloof Vereniging. ${ }^{40}$ In this case, the LCC held that its role in relation to the supervision of settlement agreements was not, after all, to assess the underlying validity of the restitution claim, provided the settlement agreement was fairly reached. ${ }^{41}$ This holding directly contradicted the dictum in Macleantown that ' $[\mathrm{t}]$ he Court can only make a settlement agreement an order of Court if it is a competent order of the Court in terms of the Act'. ${ }^{42}$ Although the meaning of this dictum is not entirely clear in the abstract, the Court in the very next paragraph of the Macleantown judgment proceeded to inquire whether the claimants had been 'dispossessed after 1913 under racially discriminatory legislation', ${ }^{43}$ confirming that it thought that it was under a duty to ensure that the claim was a valid one under the Restitution Act. This aspect of the holding in Macleantown is quietly abandoned in the Elandskloof case, which does not refer to the Macleantown decision, despite the fact that it was directly in point.

Within a year and a half of the Macleantown decision, a new section 42D had been inserted in the Restitution Act giving the Minister of Land Affairs the power to endorse settlement agreements in consultation with the Commission on Restitution of Land Rights, to the exclusion of the Court. ${ }^{44}$ It is impossible to determine the role played by the Macleantown decision in this amendment. But the consequence of the amendment is clear: today, only a minute fraction of the total number of restitution claims are decided by the LCC, the vast majority being settled through the administrative procedure laid down in section 42D. The LCC, which was originally conceived as the main institution through which restitution claims would be adjudicated, has been virtually legislated out of the restitution process.

37 Macleantown (note 26 above) $1276 \mathrm{H}$.

38 The total number of restitution claims lodged changes as the investigation of the claims by the Commission proceeds, mainly because some claims are split on investigation into two or more claims. As at the end of December 1998, the total number of claims stood at 63 455, but this has since escalated to 72975 . See R Hall 'Rural Land Restitution in South Africa' paper prepared for Programme for Land and Agrarian Studies (July 2003) at 25.

39 Ibid 26.

401999 (1) SA 176 (LCC).

41 Ibid 179E.

42 Macleantown (note 26 above) at 1276I-J.

43 Ibid 1277A-F.

44 Inserted by sec 30 of the Land Restitution and Reform Laws Amendment Act 63 of 1997, which came into effect on 21 November 1997. (The Macleantown decision was ahnded down on 4 July 1996.) Section 42D was later substituted by sec 12 of the Land Restitution and Reform Laws Amendment Act 18 of 1999. The substituted provision, which was enacted after a comprehensive ministerial review of the restitution process, including interviews with the LCC and the Commission, goes even further in empowering the Minister to enter into settlement agreements with parties interested in a claim. 
(B) Claims Based on the Doctrine of Aboriginal Title UNDER THE RESTITUTION ACT

The question whether the doctrine of aboriginal title, which has been used by indigenous groups in Australia and Canada to claim back their ancestral land, might be applicable in South Africa has loomed large over the restitution process for some time. ${ }^{45}$ Given the scale of land dispossession, and the proportion of the population that would be able to show a continuing connection to an indigenous group, the adoption of this doctrine would have a significant impact on the stability of land titles across the country. In recognition of this, the African National Congress, during the constitutional negotiations leading up to the adoption of the 1993 South African Constitution, agreed to set 19 June 1913 as the cut-off date for the statutory land restitution process. ${ }^{46}$ The effect of this agreement was to prohibit claims for restitution from people or communities who had been dispossessed of a right in land before this date. The cut-off date did not, however, exclude such claims from being brought under the common law, or indeed claims under the Restitution Act in which the claimants alleged that they had been dispossessed of their aboriginal rights after 19 June 1913.

The first, and thus far only, claim of this kind brought in South Africa involved a community of Khoi San people whose ancestral land is situated in the northwestern corner of South Africa, just south of the Namibian border, stretching all the way to the Atlantic Ocean. The coastal portion of the land is the site of rich alluvial diamond deposits, which have for a long time been mined by a state-owned mining company, Alexkor Ltd. The claimant group, known collectively as the Richtersveld Community, launched two separate cases claiming return of this land. The first case, in the Cape High Court, was based squarely on the doctrine of aboriginal title, which the Richtersveld Community alleged was part of South African common law. The second case, under the Restitution Act, was launched in the LCC.

In its first decision in this case, the LCC dismissed a special plea of lis pendens by Alexkor Ltd, holding that the Richterveld Community's cause of action in the High Court case was sufficiently different from the case launched in the LCC to warrant continuing with the latter. ${ }^{47} \mathrm{In}$ its decision on the main issue, ${ }^{48}$ however, the LCC ruled against the claimant community. According to the first principle of intertemporal law, the Court held, the consequences of the colonial acquisition of a territory must be examined on the basis of the conditions and rules in existence at the time of colonisation. ${ }^{49}$ It was clear from the surrounding documents that, upon annexation in 1847, the British colonial government assumed full ownership of the Richtersveld, to the exclusion of the Richtersveld Community. The community accordingly had no ownership rights in the subject land after 1913.50 To the extent that their claim was based not on ownership but on aboriginal title, the LCC did not have jurisdiction to decide it because the recognition of aboriginal title depended on the development of the common law. ${ }^{51}$ Whilst

45 See T Bennett \& C Powell 'Aboriginal Title in South Africa Revisted' (1999) 15 SAJHR at 449.

46 See Constitution of the Republic of South Africa, Act 200 of 1993. This date is repeated in sec 25(7) of the 1996 Constitution, and in sec 2 of the Restitution Act. Its significance derives from the fact that it was the day on which the Natives Land Act 28 of 1913 commenced.

47 Richtersveld Community v Alexkor Ltd and another 2000 (1) SA 337 (LCC).

48 Richtersveld Community and others $v$ Alexkor Ltd and another 2001 (3) SA 1293 (LCC).

49 Ibid para 42.

50 Ibid para 43.

51 Ibid para 47. 
it was possible that an aboriginal title right could be recognised as a 'customary law interest' for purposes of the Restitution Act, the Court held, such a step again depended on the development of the common law, and thus fell outside the LCC's jurisdiction. ${ }^{52}$ The only basis, therefore, on which the Richtersveld Community could be said to have enjoyed rights in land over the Richtersveld was as beneficial occupiers. ${ }^{53}$ To succeed in their claim, the Richtersveld Community had to prove that they had been dispossessed of such rights after 1913 as a result of 'past racially discriminatory laws or practices'. According to the LCC's previous decisions on this point, this meant that they had to prove dispossession in terms of 'a law or practice designed to bring about spatial apartheid'. ${ }^{54}$ None of the laws that had been used to dispossess the Richtersveld Community were of this type, the Court held, being mostly mining laws that were only indirectly discriminatory. ${ }^{55}$ Nor were any of the practices followed in dispossessing the Richtersveld Community of their land deliberately racist. Rather, they were race-neutral practices aimed at securing the land for mining purposes. ${ }^{56}$ The LCC accordingly dismissed the claim with a recommendation that the Minister of Land Affairs should consider granting the plaintiffs alternative relief in terms of section $38 \mathrm{E}(\mathrm{d})$ of the Restitution Act. ${ }^{57}$

The LCC was soon asked to revisit its decision in the form of an application for leave to appeal to the Constitutional Court, alternatively the Supreme Court of Appeal. In accordance with the somewhat curious practice that prevails in South Africa, this required the LCC to decide whether there was a reasonable prospect that the Constitutional Court or the Supreme Court of Appeal would come to a different conclusion, which was a bit like asking it to decide whether there was any possibility that it might have been wrong. In the event, the LCC refused leave to appeal for much the same reasons given in its main judgment. 58 The Richtersveld Community's direct application to the Supreme Court of Appeal was, however, subsequently granted.

The confidence demonstrated by the LCC in refusing leave to appeal was not borne out by the Supreme Court of Appeal's judgment, which emphatically rejected the two main bases for the LCC's decision. ${ }^{59}$ The first point of difference concerned the effect of the annexation of the Richtersveld by the Cape Colony in 1847. On this point, the LCC had held that, since the colonial authorities had not expressly recognised the existing rights of the Richtersveld people, the effect of the annexation was to extinguish them. On the contrary, the Supreme Court of Appeal held, 'a mere change in sovereignty does not extinguish the private property rights of the inhabitants of a conquered territory which continue in force unless confiscated by an act of state'. 60 In any event, on the facts, it was not clear whether the colonial authorities had not recognised the rights of the Richtersveld people. ${ }^{61}$

In relation to the issue of whether the Richtersveld Community had been dispossessed of their rights 'as a result of past racially discriminatory laws or practices', the Supreme Court of

52 Ibid para 53.

53 Ibid para 65. A beneficial occupier under the Restitution Act is someone who has been in occupation of the land for 'not less than 10 years prior to the dispossession in question' (see definition of 'right in land' in sec 1).

54 Ibid para 93, citing Minister of Land Affairs and Another v Slamdien and others [1999] 1 All SA 608 (LCC); 1999 (4) BCLR 413 (LCC).

55 Ibid para 98.

56 Ibid para 113.

57 Ibid para 118.

58 Richtersveld and others $v$ Alexkor Ltd and another [2001] 4 All SA 563 (LCC) paras 13-26.

59 Richtersveld Community and others $v$ Alexkor Ltd and another [2003] 2 All SA 27 (SCA).

60 Ibid para 55.

61 Ibid para 62. 
Appeal again emphatically rejected the LCC's reasoning. In particular, the Supreme Court of Appeal held that the LCC's interpretation of this phrase as meaning that the law or practice concerned had to relate to the furtherance of 'spatial apartheid' was too 'restrictive'. ${ }^{62}$ 'The real ratio of the judgment in Slamdien was ... not the absence of "spatial apartheid" measures but that the [Restitution] Act limited restitution remedies to people who had been discriminated against in the exercise of their land rights'. ${ }^{63}$ It was clear from the evidence that, although there may have been no intention on the part of the state to discriminate against the Richtersveld Community, the effect of the laws and practices applied to them had been discriminatory. ${ }^{64}$ In accordance with the Constitutional Court's equality jurisprudence, this was all that the claimant community had to show. 65

The significance of the Supreme Court of Appeal's reversal of the LCC's decision in the Richtersveld case is that it is based on two principles of law that a specialised court might have been expected to have got right. The LCC's 'doctrine of recognition' approach to the effect of the annexation of the Richtersveld has been widely discredited in foreign law and was not in any event borne out by the evidence. Similarly, the LCC's failure to emphasise the obviously discriminatory impact of the laws and practices at issue in this case is very puzzling. The passages on this point in the LCC judgment read like a wilful denial of the obvious. At the very least, the Supreme Court of Appeal's decision confirms that there were plausible legal arguments justifying a pro-poor outcome to the case, and that these were ignored. Why should this have happened? The answer clearly does not lie in the absence of legal aid or in the legal strategy pursued by the Richtersveld Community, since the Legal Resources Centre supported the Community throughout, with the assistance of one of South Africa's leading advocates. ${ }^{66}$ The answer must lie somewhere else, in one or more of the institutional indicators impacting on the LCC's performance. The next section explores this question further. Before doing so, two additional areas of law in which the LCC has ignored or rejected plausible pro-poor arguments are discussed, this time involving the interpretation of the Extension of Security of Tenure Act, a tenancy protection statute over which the LCC was given jurisdiction in 1997.

\section{(c) Rights of Spouses and Dependants against Arbitrary Eviction}

According to the semi-feudal arrangements that still prevail on many South African farms, the primary employment relationship is that between the farmer and the male 'head' of the farm worker household, with the household head's spouse and other dependants deriving their right to reside on the farm through him. Often, this belies an actual situation where the spouse is also employed on the farm, with her own separate contractual relationship with the landowner. Under the common law, and according to conventional pleading practice, the de facto existence of two separate contractual relationships is ignored, and a plaintiff may institute an action for ejectment against the male head of household, citing the spouse and dependants as 'all those who derive their right to occupy the property through him'.

In the draft version of the Extension of Security of Tenure Act ('ESTA') that was published for public comment in February 1997, an express distinction was made between 'primary' and

62 Ibid para 97.

63 Ibid para 99.

64 Ibid para 104.

65 Ibid para 105. The Supreme Court of Appeal's decision was confirmed on appeal to the Constitutional Court. See Alexkor Ltd and Another v Richtersveld Community and Others 2004 (5) SA 460 (CC).

Wim Trengove SC. 
'secondary' occupiers, the latter category consisting mainly of women and children living on commercial farms. The clear intention behind this distinction was to amend the common law by providing special protection against arbitrary eviction to the latter group. After an intervention by the National Land Committee, ${ }^{67}$ however, the drafters were persuaded that the distinction between primary and secondary occupiers would only perpetuate the discriminatory treatment of female farm workers. The distinction was accordingly dropped. Secondary occupiers, the drafters assured everyone, would be protected as occupiers in their own right.

In its decision in Conradie $v$ Hanekom and Another, ${ }^{68}$ the LCC appeared to vindicate this bold step when ruling that a woman, whose husband had been dismissed for assaulting a fellow farm worker, could not be evicted merely for that reason. Since she was herself an employee on the farm, and therefore an occupier in her own right, the LCC held, separate grounds for evicting her had to be alleged and proven. ${ }^{69}$ Not only that, but her husband, although lawfully dismissed and therefore liable to eviction under the Act, could not be denied access to the farm, because his wife's right to family life entitled her to have him stay with her. ${ }^{70}$ In effect, this meant that he could not be evicted either.

The Conradie judgment was immediately hailed as a triumph for court-driven social transformation in South Africa, overturning as it did the centuries-old vulnerability of female farm workers to the consequences of their husbands' actions. Unfortunately, the victory was short-lived: some two and a half years later, in Die Landbou Navorsingsraaad $v$ Klaasen, ${ }^{71}$ a different judge of the LCC glossed and restricted the Conradie judgment. The Klaasen gloss effectively re-instates the discarded distinction between primary and secondary occupiers, but without restoring the special protection originally provided for the latter group. According to the LCC in this case, the 'general rule' in eviction proceedings in South Africa is that 'the sheriff may remove from the farm any person claiming [a right of occupation] through or under [an] occupier'. ${ }^{72}$ The ESTA did not expressly change this rule. On the contrary, it appeared to support it in a number of provisions that implied that 'an eviction order against an "occupier" (as defined) is also operative against family members living with that occupier. ${ }^{73}$ In addition, the term occupier in the ESTA was used inconsistently, resulting in several 'incongruities', including the situation at issue in the Conradie case, where a lawfully dismissed farm worker was allowed to remain on the farm on the basis of his wife's right to family life. ${ }^{74}$ It followed that the word 'occupier' had to be understood in a wide and a narrow sense. Occupiers in the wide sense fell 'outside the statutory definition of "occupier"' and accordingly did not enjoy protection in their own right. ${ }^{75}$ This interpretation, the Court added, would not 'disempower' such occupiers because their needs were given special attention in the Act, and they would in the end enjoy the same protection against eviction as the occupier from whom they derived their right to reside on the land. ${ }^{76}$

67 One of the main non-governmental organisations active in the land sector in South Africa.

681999 (4) SA 491 (LCC).

69 Ibid para 20.

70 Ibid para 21(vii), citing sec 6(2)(d) of ESTA.

71 LCC Case 83R/01 (unreported judgment of Gildenhuys AJ handed down on 29 October 2001) para 24.

72 Ibid para 26, citing Ntai and others $v$ Vereniging Town Council and Another 1953 (4) SA 579 (A) at 584 and 590 .

73 Ibid para 26 (citing two examples in paras 27 and 28).

74 Ibid para 32.

75 Ibid para 33.

76 Ibid para 34. 
Whereas the effect of the Conradie judgment had been to force landowners, when drafting pleadings in an action for ejectment under the ESTA, to cite each member of the male farm worker's family by name, and allege separate substantive grounds for their eviction (which might have included an express allegation that their permission to reside on the property was entirely derived through the male farm worker), the practical effect of the Klaasen judgment has been to restore the common-law position in so far as the method of citation of a farm worker's spouse and dependants is concerned. In the result, female farm workers and their children are once again being routinely evicted along with their husbands, unless they can prove (the burden being on them) that their tenure rights are not derivative on the tenure rights of the male head of household (because, for example, their employment contract states or implies that they have a right to reside on the farm notwithstanding the dismissal of their husband) .

\section{(D) Farm Dwellers' Burial Rights Under the ESTA}

The LCC's somewhat reluctant embrace of the transformative potential of the ESTA is further discernible in its approach to occupiers' right to bury relatives on land belonging to someone else. In South African law, the right to bury a relative is a sui generis right, but comes closest to a personal servitude in favour of the deceased's relatives, in perpetuity. ${ }^{77}$ At common law, personal servitudes are typically created by agreement between the owner of the servient tenement and the servitude holder. The servitude binds successors in title of the servient tenement if registered, provided it satisfies the so-called 'subtraction from dominium' test. ${ }^{78}$

As originally enacted, section 6 of the ESTA conferred certain use and service rights on stautorily protected occupiers, but did not specifically confer on them the right to bury their relatives on the land on which they were staying. Rather, section 6(4) conferred on everyone (whether or not they qualified as an occupier) the right to visit and maintain family graves, subject to reasonable conditions imposed by the owner or person in charge of the land. The ESTA also conferred on occupiers the right to 'freedom of religion, belief and opinion and of expression', ${ }^{79}$ and the right 'to family life in accordance with the culture of that family'. ${ }^{80}$ For many rural African families in South Africa, the right to culture protects a sphere of personal life that is indistinguishable from that protected by the freedom of religion, and includes the important cultural practice of communicating with their ancestors through the establishment, ritual visiting, and maintenance of family burial sites.

In Serole and Another $v$ Pienaar, ${ }^{81}$ the LCC was asked to enforce an alleged right to bury the applicant's family member, either as a use right under the ESTA, or in terms of the applicant's rights, as a protected occupier, to culture. Comparing the granting of permission to establish a grave to the granting of a servitude, and therefore 'a significant inroad into the owner's common-law property rights'82 the LCC dismissed the application. Before enforcing a right to bury a relative on land belonging to someone else, the LCC held, the Court would need to be convinced by suitable evidence

77 It is not a personal servitude in the strict sense, because a personal servitude is typically granted in favour of a single person for their lifetime. In the case of burial rights, the servitude is effectively granted in favour of a family, including descendants yet to be born.

78 Laid down in Ex parte Geldenhuys 1926 OPD 155.

79 Sec 5(e).

80 Sec 6(2)(d).

812000 (1) SA 328 (LCC).

82 Ibid para 16. 
that occupiers had an express or tacit contractual right to this effect. ${ }^{83}$ Mere evidence of the existence of a graveyard that had been used in the past would not suffice. ${ }^{84}$

The Serole decision was cited with approval in Bubrmann $v$ Nkosi and another, ${ }^{85}$ a Full Bench decision of the Transvaal Provincial Division, which was was later confirmed on appeal. ${ }^{86}$ Although the reasons for decision given in the two main Bubrmann judgments differ somewhat from the reasons given in the LCC judgment, the three courts adopt essentially the same view, viz that in a direct conflict between the right to property and the right to culture and religion, the former must trump the latter. The only dissenting voice in Bubrmann was that of Ngoepe JP, who wrote a minority judgment in the Full Bench decision in which he argued that a landowner's property right in a small piece of earth could not be said to trump a sincerely held religious belief. ${ }^{87}$ It is perhaps not insignificant that Ngoepe JP was the only African judge involved in deciding the Bubrmann case. Certainly, his judgment, in quoting a lengthy passage from the occupier's affidavit, ${ }^{88}$ reveals an understanding of the importance of the practice of ancestor worship that is absent from the other judgments. Not only is his judgment more understanding of this practice, but it also presents a plausible legal argument that might have justified an alternative outcome, not only in the Bubrmann case, but also in Serole. In essence, Ngoepe JP argues, the dispute over occupiers' burial rights under the ESTA represents an irresoluble conflict between the interests of owners and occupiers, each of whom can claim protection for their interests in both statutory and constitutional rights. In such a situation, the judge has no choice but to vindicate one right at the expense of the other. In so doing, he or she must be guided by the relative importance attached to the competing rights, both in the statute under consideration and in the Constitution. ${ }^{89}$ Further guidance can be found in considering the practical consequences of the decision, one way or the other. ${ }^{90}$

The plausibility of Ngoepe JP's argument is enhanced by the fact that the main judgments in the Serole and Bubrmann cases are all premised on the closest thing to a clear mistake of law one is ever likely to encounter, viz the view that it was never the intention of the legislature when enacting the ESTA to confer servitudinal rights on occupiers. On the contrary, section 24(1) of the ESTA provides that ' $[t]$ he rights of an occupier shall ... be binding on a successor in title of an owner or person in charge of the land concerned'. According to the subtraction from the dominium test mentioned earlier, this means that occupiers' rights are statutory real rights with the same legal effect as registered personal servitudes.

Whether motivated by the frustration of its original intention, or because of a supervening intention to alter the outcome of the Serole and Bubrmann cases, the legislature quickly responded to the Supreme Court of Appeal's decision in Bubrmann by amending the ESTA so as to make it clear that occupiers enjoyed the right in certain circumstances to bury their relatives on land belonging to someone else. In particular, section 6(2) of the ESTA was

83 Ibid para 17.

84 Ibid.

85 [1999] 4 All SA 337 (T).

86 Nkosi and another $v$ Bubrmann 2002 (1) SA 372 (SCA).

87 Bubrmann (note 86 above) at $352 \mathrm{c}$ and $354 \mathrm{c}$.

88 Ibid 351a-e.

89 In this regard, Ngoepe JP argues that secs 5 and 6 of the ESTA, together with other sections, 'are specifically aimed at making some inroad into [owners' rights]', and therefore that the right of ownership must in this instance give way to the right of freedom of religion in sec 5(d) of the ESTA (ibid at 353j).

90 Ibid 354c (dismissing fears that 'an avalanche of burials might follow' the granting of the application in the Bubrmann case). 
amended by the insertion of a new paragraph, para (dA), which provides that:

...[An occupier shall have the right] to bury a deceased member of his or her family who, at the time of that person's death, was residing on the land on which the occupier is residing, in accordance with their religion or cultural belief, if an established practice in respect of that land exists... ${ }^{91}$

At the same time, 'established practice' was defined in s 1(1) as meaning:

a practice in terms of which the owner or person in charge or his or her predecessor in title routinely gave permission to people residing on the land to bury deceased members of their family on that land in accordance with their religion or cultural belief. ${ }^{92}$

The effect of this amendment was to give occupiers who are able to prove that they were routinely granted permission to bury their family members in the past, the right to do so, without the permission of the landowner. ${ }^{93}$ As argued earlier, although this amendment does not show that the LCC, the Full Bench of the TPD and the Supreme Court of Appeal, in deciding the Serole and Bubrmann cases, made clear mistakes of law, or that Ngoepe JP's argument in support of an alternative outcome was plausible, it does indicate that the LCC failed to fulfil the social transformation function allocated to it by the legislature. The possible explanations for this result are themselves worth investigating for what they reveal about the role of courts in new democracies, particularly since, in the case of the LCC, some of the factors that might typically have influenced it were absent.

\section{The Possible Explanations}

In all four areas of law discussed in the previous section the LCC handed down decisions that were unfavourable to poor litigants, despite the existence of plausible legal arguments to the contrary. This is most clearly apparent in the Richtersveld case, where a higher court overturned the LCC decision in terms quite dismissive of its reasoning. In the case of spouses and dependants' rights under the ESTA, the LCC restricted the impact of a rule laid down in one of its prior decisions that had been more favourable to the poor, thereby exposing female farm workers and their children to the possibility of being evicted through no fault of their own. In the burial rights cases, Ngoepe JP's dissenting judgment in Bubrmann is indicative of the way that the issue might have been decided in Serole had the LCC not proceeded from an erroneous legal premise. That the LCC's decision did not accord with the legislature's social transformation objectives is evidenced by the amendment rapidly effected to the ESTA after the appellate deci-

91 As inserted by sec 7(a) of the Land Affairs General Amendment Act 51 of 2001.

92 Definition of 'established practice' inserted by the Land Affairs General Amendment Act 51 of 2001.

93 In an interesting sequel to this story, the constitutionality of this amendment was challenged soon after its enactment under the constitutional property clause. See Nhlabativ Fick [2003] 2 All SA 323 (LCC); 2003 (7) BCLR 806 (LCC). Finding that the amendment provided for the uncompensated expropriation of property contrary to sec 25(2) and (3) of the Constitution, the LCC upheld it under the general limitations clause as being a limitation on the right to property that was reasonable and justifiable in an open and democratic society. 
sion in Bubrmann. The Macleantown decision, too, met with a fairly swift legislative response that virtually eliminated the LCC from the restitution process. The fact that the LCC had by this time tacitly overruled its own decision suggests that a plausible pro-poor legal argument had all along been available to it, but was for some reason ignored.

The absence of effective legal aid for the rural poor has certainly contributed to the failure of the legislation over which the LCC has jurisdiction to achieve its objectives, but this factor on its own cannot explain anti-poor outcomes in cases where the poor were effectively represented. The absence of an effective legal strategy on the part of poor litigants also does not explain these outcomes, since two of the cases discussed (Richtersveld and Serole) were taken on by experienced human rights lawyers, and the others involved areas of law in which the legal strategy pursued was initially successful (Conradie) or in which there was no need for a legal strategy because the LCC was simply required to confirm a settlement agreement (Macleantown).

Enough at least has been said to suggest that the performance of the LCC must be attributable to other factors. If the theoretical model tested in this article is sound, it must be possible to explain the outcomes in these cases by reference to one or more of the three institutional indicators identified, these being: the legal culture in which the LCC is operating, the residual influence of common-law rules and forms of legal reasoning, or a desire on the part of the judges for professional respect. The possible role of these indicators in explaining the performance of the LCC is now discussed in turn.

\section{(A) The Influence of Legal Culture}

\section{(i) Defining South African Legal Culture}

By far the most comprehensive study of South African legal culture is that by Martin Chanock in The Making of South African Legal Culture 1902-1936: Fear, Favour and Prejudice. ${ }^{94}$ As its title suggests, this work is mainly a historical study, although it does contain a speculative final chapter in which Chanock considers how the transition to democracy in 1994 might have affected the received legal culture he describes in the rest of his book. For Chanock, 'a legal culture is made up of an interrelated set of discourses about law: some professional, some administrative, some political, some popular'. ${ }^{95}$ This is a very broad definition, to which he is driven because of his concern to shift the debate about South African legal culture away from what 'courts and judges' do towards the study of bureaucratic behaviour. Chanock thus makes a distinction between professional legal discourse, which he assumes was dominated by legal formalism, ${ }^{96}$ and bureaucratic legal discourse, which he argues was legal realist in character. ${ }^{97} \mathrm{He}$ then goes on to discuss in detail the nature of bureaucratic legal culture, reducing the discussion of professional legal discourse to a single chapter. ${ }^{98}$ In the result, Chanock's study, despite its length and theoretical ambition, has little to contribute to the debate about the nature of professional legal discourse in South Africa.

Unsurprisingly, the most intense period of debate about South African legal culture in the

94 Published by Cambridge University Press in 2001.

95 Ibid 23.

96 Ibid.

97 Ibid.

98 Ibid chapter 10. 
narrow sense occurred during the last decade and a half of apartheid, when liberal legal academics produced a series of studies on the role of lawyers and judges in that system. The best known of these studies are those by Hugh Corder, ${ }^{99}$ Christopher Forsyth, ${ }^{100}$ John Dugard, ${ }^{101}$ Stephen Ellmann, ${ }^{102}$ David Dyzenhaus, ${ }^{103}$ and Richard Abel. ${ }^{104}$ In general, this literature depicts professional legal culture as 'executive-minded', 105 by which is meant a tendency to defer to the intuited wishes of the executive, whether by formalistic application of clearly articulated rules, or by filling doctrinal gaps with rules that the legal professional perceived to be in line with the executive's preferred policy choice. ${ }^{106}$

In relation to judges, the point of this debate was of course to expose or defend the degree of discretion enjoyed by the judiciary when deciding politically controversial cases, and thereby to explore the extent of the opportunities available to judges to soften the impact of apartheid laws. Interestingly, the liberal camp split into two on this issue, with some academics positing the existence of some discretion as the moral justification judges had for staying in office and others the absence of any real discretion as the reason why judges had a moral duty to resign. ${ }^{107}$ For conservative defenders of the judiciary, of course, the absence of discretion was the very reason why judges could not be charged with complicity in the apartheid system. ${ }^{108}$ In this way, one section of the liberal camp and the conservative camp may have had a common strategic interest in typifying professional legal discourse as being more committed to legal formalism than it actually was. Certainly, the extreme view that judges are never required to fill doctrinal gaps by resort to policy-reasoning would have been dismissed by professionals of all political stripes. ${ }^{109}$ Nevertheless, there does seem to be an overwhelming consensus in the literature that professional legal discourse under apartheid, particularly in relation to the interpretation of statutes, ${ }^{110}$ was predominantly

99 Judges at Work: The Role and Attitudes of the South African Appellate Judiciary, 1910-50 (1984).

100 In Danger for their Talents: A Study of the Appellate Division of the Supreme Court of South Africa from 1950-80 (1985).

101 'The Judicial Process, Positivism and Civil Liberty' (1971) 88 SALJ 181 at 182. See also J Dugard Human Rights and the South African Legal Order (1978).

102 In a Time of Trouble: Law and Liberty in South Africa's State of Emergency (1992).

103 Hard Cases in Wicked Legal Systems: South African Law in the Perspective of Legal Philosophy (1991) (hereafter Dyzenhaus Hard Cases). See too D Dyzenhaus Truth, Reconciliation and the Apartheid Legal Order (1998) (hereafter Dyzenhaus Truth, Reconciliation and the Apartheid Legal Order).

104 Politics by Other Means: Law in the Struggle against Apartheid, 1980-1994 (1995).

105 The origin of this term appears to be a passage in Lord Atkin's dissent in Liversidge $v$ Anderson [1952] AC 206. See Dyzenhaus Hard Cases (note 103 above) 93-97. The Liversidge decision later played a central role in the South African Appellate Division's approach to national security cases, and Lord Atkin's phrase consequently came to be used by liberal legal academics as a convenient label for this approach. See, for example, Cameron 'Legal Chauvinism, Executive-Mindedness and Justice: LC Steyn's Impact on South African Law' (1982) 99 SALJ 38, and Forsyth (note 100 above) 226-34.

106 Note David Dyzenhaus's interesting alternative thesis that the South African judiciary under apartheid was not so much 'executive-minded' as committed to a doctrine of judicial responsibility that required them to align themselves with the views of the executive (Dyzenhaus Hard Cases (note 103 above) 105).

107 See R Wacks 'Judges and Injustice' (1984) 101 SALJ 266; J Dugard 'Should Judges Resign? A Reply to Professor Wacks' (1984) 101 SALJ at 286.

108 See A Van Blerk 'The Irony of Labels' (1982) 99 SALJ 365 and A Van Blerk Judge and Be Judged (1988). See also LC Steyn 'Regsbank en Regsfakulteit' (1967) 30 THRHR at 101.

109 See Forsyth (note 100 above) at 230 (arguing that judicial formalism in South Africa under aparthied was not so much the expression of a firmly held legal theory as a device to 'conceal the reality of [judicial] choice ... from the reader of the judgment').

110 See Forsyth (note 100 above) at 207 commenting on the use of 'principle and policy' in the development of the common law under apartheid. 
formalistic. ${ }^{111}$ Even liberal defenders of the judiciary had to concede that the opportunities for softening the impact of apartheid laws by exploiting doctrinal gaps were few and far between. ${ }^{112}$ This was partly the result of the apartheid legislature's use of increasingly detailed rules. But it was also partly the result of the fact that legal professional discourse censured any overt instances of judicial law making, however well intentioned.

The question whether South African legal culture in the narrow sense has begun to change under the influence of the new democratic order has not been extensively studied, but there is some research that touches on this issue indirectly. After the Constitutional Court's first year of operation, Alfred Cockrell published a much-cited article in which he argued that the Constitutional Court had yet to develop the coherent 'substantive vision of law' required by the new Constitution. ${ }^{113} \mathrm{He}$ attributed this failure in large measure to the lag-effect of the judges' background and training in a rule-bound, 'formal vision of law'.114 Two years' later, Karl Klare published an equally celebrated article in which he examined the new modes of legal reasoning required by the South African Constitution, and pondered on the likelihood of these new modes being adopted by the legal profession and judges. ${ }^{115}$ In a section devoted specifically to legal culture, Klare remarked that '[a] visiting U.S. lawyer cannot help but be struck by the conservatism of South African legal culture'. ${ }^{116}$ He went on to explain that what he meant by this was not 'conservatism' in the form of political ideology, but 'cautious traditions of analysis common to South African lawyers of all political outlooks'. 117

More recently, Cora Hoexter has defined legal formalism in its South African guise as 'a judicial tendency to attach undue importance to the pigeonholing of a legal problem and to its superficial or outward characteristics; and a concomitant judicial tendency to rely on technicality rather than substantive principle or policy, and on conceptualism instead of common sense'. ${ }^{118}$ As Hoexter notes, this approach to legal interpretation is not necessarily conservative, since a formalistic interpretative strategy can be, and was under apartheid, used to achieve progressive results. ${ }^{119}$ For the same reason, a formalistic approach to progressive, social legis-

111 For example, David Dyzenhaus's account of the South African judiciary's approach to the interpretation of apartheid legislation dealing with racial segregation and national security distinguishes between two main approaches: a 'plain fact' approach and a 'common law' approach. He describes the former approach as open to the 'charge of formalism and mechanism' (Dyzenhaus Hard Cases (note 103 above) at 58) because of its tendency to fill interpretative gaps 'by deciding the case in accordance with what would jump to the minds of most white South Africans'. Later he states that 'a blinkered focus on the provisions of the statute' is a 'hallmark of the plain fact approach', one that goes 'with a doctrine of judicial responsibility which seeks to keep a judge's moral and political convictions out of interpretation' (ibid 90). See also D Dyzenhaus Truth, Reconcilation and the Apartheid Legal Order (note 103 above) at 77 (describing the plain fact approach as 'part of a judicial response pattern ... identified' by Robert Cover as a 'retreat to a mechanistic formalism' (quoting R Cover Justice Accused: Antislavery and the Judicial Process (1975) at 232). The common law approach identified by Dyzenhaus is, in my view, equally a retreat to 'a mechanistic formalism' in as much as the common law, rather than principled or policy-based reasoning, is used to fill the interpretative gap.

112 See Dugard (note 107 above) at 291 (remarking that there was 'some room for judicial advancement of human rights in the interstices of the apartheid legal order').

113 A Cockrell 'Rainbow Jurisprudence' (1996) 12 SAJHR at 1.

114 Ibid 35.

115 Karl E Klare 'Legal Culture and Transformative Constitutionalism’ (1998) 14 SAJHR at 146.

116 Ibid 168.

117 Ibid.

118 'Contracts in Administrative Law: Life after Formalism?' (2004) 121 SALJ 595-618.

119 See Abel (note 104 above) at 490 (referring to legal formalism as a 'two-edged sword', which 'could be invoked by the state as well as against it', and to the fact that 'parties and courts opportunistically used and ignored legal formalism'). 
lation is not necessarily an indication of conservative judicial politics, inasmuch as the formal application of a clearly stated pro-poor rule should in theory produce a pro-poor outcome. Where the legislation is unclear, however, or where it requires judges to engage in substantive reasoning as part of the formulated rule, a culture of legal formalism may work against the achievement of the objectives of a social transformation law. The next section explores this question in greater detail.

\section{(ii) Legal Formalism and the Interpretation of Social Transformation Statutes}

The literature on legal formalism distinguishes between legal formalism as a legal theory and legal formalism as a mode of legal reasoning. ${ }^{120}$ The two senses of the term are said to share a common 'attitude to verbally formulated rules which both seeks to disguise and to minimize the need for [decision-maker] choice, once the general rule has been laid down'.121 The charge of legal formalism is almost always pejorative, ${ }^{122}$ and consequently no serious scholar is said to espouse this theory, at least in its pure form. ${ }^{123}$ Rather, legal formalism is said to consist either in the mistaken belief 'that a particular abstract legal norm can generate a particular subrule', or in a 'general tendency to overestimate the capacity of norms ... to generate subrules by deduction'. ${ }^{124}$ A tendency of this sort was the tendency against which the legal realist movement in the United States is said to have reacted in the early part of the last century. ${ }^{125}$ In jurisdictions where legal realism is the dominant professional legal culture, such as the United States after the attack on formalism, legal formalism survives in individual instances of legal interpretation. 126

In the context of adjudication, legal formalism in the narrow sense may manifest itself in one of two main ways: either as a genuine mistake regarding the ambit of the rule being applied, such that the judge sincerely believes that the outcome of the case is determined by deduction from the rule being applied; or as a discursive strategy used to mask an outcome that is motivated by a policy choice that the judge for some or other reason does not wish to articulate expressly. Where adjudication occurs against the background of a professional legal culture that censures overt judicial law making, such as that prevailing in South Africa, the reason for not disclosing a policy choice need not be the sinister reason that the judge wishes to legislate by stealth. It may simply be that the judge has been so immersed in a culture of justifying decisions by deduction from general rules that he or she is incapable, for professional reasons, of justifying decisions in any other way.

It follows that, when interpreting a legislative rule, any ambiguity in the formulation of the rule, or any under-inclusiveness of the rule when applied to the facts, will create a kind of pro-

120 See D Kennedy A Critique of Adjudication (fin de siècle) (1997) at 105-07; HLA Hart The Concept of Law (1961) 121-150; NE Simmonds Central Issues in Jurisprudence: Justice, Law and Rights (1986) at 87 (discussing Hart's distinction between formalism and rule-scepticism).

121 Hart (note 120 above) at 126.

122 Ibid (referring to the 'vice known to legal theory as formalism or conceptualism'). See also F Schauer Playing by the Rules: A Philosophical Examination of Rule-Based Decision-Making in Law and in Life (1991) 214 (referring to the 'argument for what is often pejoratively referred to as "formalism"').

123 See, however, BA Garner (ed) Black's Law Dictionary (7ed 1999) at 904, which lists Christopher Columbus Langdell and Lon Fuller as legal formalists.

124 Kennedy (note 120 above) at 106 .

125 Brian Bix Jurisprudence: Theory and Context (1996) at 152-53.

126 Kennedy (note 120 above) at 106-7. 
fessional tension in the mind of a judge committed to legal formalism, all the more so where the rule occurs in a social transformation statute. By definition, the issue to be decided in a case involving the interpretation of this sort of statute will be the extent to which the legislature intended to transform the social order, either directly or by amendment of the existing legal rules. Faced by a situation of legal indeterminacy, the instinctive reaction of a judge committed to legal formalism is to try to close the doctrinal gap by falling back on the maxim of statutory interpretation that the statute amends the existing legal rules only to the extent that it does so expressly. In many cases, this means that, rather than filling the doctrinal gap with a principle-based or policy-derived rule, the judge will come to the conclusion that the pre-existing legal rules (of common law or statute) have not been amended. Of course, this does not mean that the doctrinal gap left by the social transformation statute remains unfilled. It simply means that it is filled by the pre-existing legal rules.

Karl Klare's observation about the role of 'cautious traditions of analysis common to South African lawyers of all political outlooks' 127 makes much the same point: it is not that judges committed to legal formalism are necessarily conservative, it is that their professional training and, in particular, their aversion to policy-reasoning, often drives them to fill doctrinal gaps in social transformation statutes with pre-existing legal rules. The distinction Klare draws between judicial ideology and the dominant professional legal culture in South Africa is, I think, an important one for the assessment of the performance of the LCC. As noted earlier, the LCC judges all had prior careers as human rights lawyers or lawyers engaged in what might loosely be termed 'progressive' causes, such as the education of black lawyers or the national peace process. Although there is probably a range of political thought represented on the Court, none of the judges can be described as a political conservative. Nevertheless, they were all trained in the apartheid era, and can therefore be expected to have absorbed the then dominant professional legal culture, a culture in which respect for the techniques of deductive reasoning tended to outweigh resort to principles or policy arguments. If this is correct, what we should expect to find in the LCC's judgments is a tendency to shun principles and policy arguments in favour of strained deductions from general rules.

\section{(iii) Revisiting the Cases}

The Macleantown decision, as we have seen, is characterised by the high value placed by the Court on formal compliance with the Restitution Act and an almost wilful disregard of the consequences of its decision for the restitution process. The LCC must have been aware, as it wrote its judgment, of the painfully slow progress the Commission on Restitution of Land Rights had been making in settling claims. And yet it chose to hand down a highly technical judgment in which the fact that the parties were all in agreement as to how the claim should be settled was given less weight than the question whether the enforcement of the settlement agreement would be a competent order for the Court to make. Had the deficiencies in the settlement agreement been substantial, or the likely impact on the parties and other affected persons of the endorsement of a technically deficient agreement severe, this might have been a reasonable approach for the Court to have taken. But neither of these factors was present. Nor did the Court attempt, in the fashioning of its order, to balance its concern for technical correctness with the need to assist the Commission in the performance of its duties. Rather, the relationship that the 
Court sought to construct with the Commission was that of hierophant and acolyte, with the Court initiating the Commission into the sacred mysteries of the law. This approach is very typical of a professional legal culture in which judges' legitimacy is built on an assumed absence of discretion in the face of determinate rules.

The problem confronting the LCC in the Macleantown case, however, was that the Restitution Act was unclear on what its role in enforcing settlement agreements should be. As we have seen, section 14(3) of the Act (as originally formulated) simply set out the procedure that the Commission had to follow in referring settlement agreements to the Court, and section 14(6) provided that the Court should refuse to endorse a settlement agreement if the proper procedure had not been followed. But by what criteria the Court should decide whether or not to enforce a settlement agreement the Restitution Act did not say. Faced with this doctrinal gap, the judges' professional training led them to supply a rule as if by logical deduction from the statute. Since the enforcement of a settlement agreement amounts to the making of a court order, the Court reasons, 'the Court can only make a settlement agreement an order of the Court if it is a competent order of the Court in terms of the Act'. ${ }^{128}$ This is a neat syllogism, but the rule the Court thereby derives is hardly dictated by the Restitution Act in the manner the Court would have us believe.

The closest the Court in Macleantown gets to policy reasoning is in its statement that the consequence of the enforcement of the settlement agreement would be 'the transfer of land rights either to dispossessed black families or to a community'. ${ }^{129}$ This consequence of course justifies taking its duty to enforce settlement agreements seriously. But the degree of time and resources invested in ensuring that settlement agreements under the Restitution Act are technically correct obviously has to be weighed against the total number of claims lodged, the average time and resources available for the settlement of each claim, and the political context in which the restitution process is taking place. These are all factors that a court more disposed towards filling doctrinal gaps by resort to policy reasoning might have seen fit to mention. That the LCC does not mention these factors is a function of the relative weight accorded by South African professional legal culture to deductive reasoning vis-à-vis policy reasoning.

The influence of South African legal culture is also evident in the LCC's decision in the Richtersveld case, although here it is apparent that a formalistic mode of reasoning was used to justify an outcome that appears to have been motivated by policy considerations. As noted earlier, the issue of the recognition of the doctrine of aboriginal title in South Africa is a highly controversial one, since the recognition of this doctrine would call into question the validity of a great many title deeds. Rather than confronting this policy question head on, the LCC in the Richtersveld case deploys a highly formalistic argument around the question of the recognition of aboriginal title to decide the case against the claimant community. In this instance, the culture of legal formalism is less a straightjacket from which the Court is unable to escape, than a convenient disguise for the policy choice the Court feels unable openly to articulate.

The situation confronting the Court in the Conradie and Klaasen cases was somewhat different. It will be recalled that the legislative history leading up to the enactment of the ESTA was one in which a late change had been made to a fundamental principle underlying the statute, namely whether to treat women and children living on commercial farms as protected occupiers in their own right, or as secondary occupiers with special protection. In the nature of 
last-minute amendments, the conversion of the statute to one based on the former principle was not perfectly realised by the legislative drafter, leaving a number of textual traces of the latter principle at the level of rule formulation. It is these textual traces to which the Court referred in the Klaasen judgment, after having initially upheld the occupiers-in-their-own-right principle in Conradie. Of particular interest here is the Court's about-face on the question whether a female farm worker, who is herself employed by the farmer, is an occupier in her own right. In Conradie these were the precise facts that presented themselves for decision, and the Court seemingly had little trouble in deciding that the principle underpinning the ESTA was that each person should be treated as an occupier in his or her own right, and accordingly that a woman could not be evicted merely in consequence of her husband's actions. This of course produced an anomaly in that the husband, although in principle liable to eviction, could not in fact be evicted because his wife's right to family life provided an alternative legal basis on which he could remain on the farm.

In Klaasen, the Court, whilst acknowledging the Conradie situation as an exception to the general rule, ${ }^{130}$ later refers to exactly this situation as an example of one of the 'incongruities' that follows from reading the ESTA as being based on the principle that family members of an occupier are occupiers in their own right. ${ }^{131}$ In particular, the incongruity is said to consist in the fact that, if family members are recognised as occupiers in their own right, they 'will be allowed to remain on the farm, and as part of their right to family life, they will be allowed to bring the evicted farm labourer back to live with them'. ${ }^{132}$ Instead of confronting this incongruity head on by weighing the competing interests involved, the LCC resorts to the legal formalist mantra that ' $[t]$ his could never have been the intention of the legislature.'133 But of course it was, at least to the extent that the legislature could be said to have applied it mind in advance to this particular situation.

In Conradie, by contrast, when confronted by the 'incongruous' result produced by the occupiers-in-their-own right principle, the Court simply states that the landowner will have to seek 'other remedies in respect of [the husband's] misbehaviour'.134 What is going on here? Is the difference in outcome simply a function of the fact that the Conradie and Klaasen judgments were handed down by different judges, one of whom may be more ideologically predisposed to the kind of social transformation envisaged by the ESTA than the other? Or was it because the facts in Conradie (where the husband was clearly prone to violence) drove the Court to articulate a broad equitable principle that it later regretted? It seems to me that the two judgments are best explained by the fact that the last-minute amendments to the ESTA effected an imperfect conversion of that statute at the level of detailed rules from a statute based on the principle of primary and secondary occupiers to one based on the occupiers-in-their-own-right principle. When confronted by the resultant contradiction at the level of detailed rules, what the Court in Klaasen did was to fall back on the organising principle that most closely resembled the principle that had always been applied at common law, namely that the spouse and dependants of a male occupier should be treated as secondary occupiers. The fact that this choice of principle exposed women and children living on commercial farms to eviction through no fault of their own was a consequence that lay outside the Court's field of reference. Why? Because

130 Klaasen (note 71 above) para 24.

131 Ibid para 32.

132 Ibid.

133 Ibid.

134 Conradie (note 67 above) para 21(vii). 
consequentialist, policy-based reasoning was a form of reasoning with which the Court was not particularly comfortable. To have adopted the occupiers-in-their-own-right principle would have required the Court to expose itself to the possibility of having to legislate afresh each time a case came before it in which the contradiction produced an anomaly. Far better for the Court to adopt the secondary-occupiers principle since that principle came ready-to-use with a set of accepted common-law rules. Once again, it would seem, the prevailing professional legal culture in South Africa provides an adequate explanation for the poor, pro-poor performance of the Court.

The three areas of law discussed thus far represent three different types of legal indeterminacy that the LCC resolved in ways that obviated the need to engage in policy reasoning. In Macleantown, the Restitution Act was silent as to the role of the Court in supervising settlement agreements, and the Court filled the gap with a rule that it purported to deduce from the language of the statute, but which was in actual fact a rule of its own making. In the Richtersveld case, faced with the awkward uncertainty in the Restitution Act as to what to do about aboriginal title claims, the Court made a policy choice and then disguised this choice by resort to formalistic reasoning. And in Klaasen, as we have just seen, the Court decided between two competing principles by choosing the one that most closely resembled the principle applicable at common law.

The Serole case produced a fourth type of legal indeterminacy that the LCC dealt with in much the same way. In this case, it will be recalled, the Court was asked to vindicate one of two competing rights: the landowner's property right in a patch of ground, and the occupiers' right to freedom of religion and culture. As Ngoepe JP's minority judgment in the Bubrmann case shows, there was really no way of deciding this issue other than to declare the contradiction, and to seek a principled and policy-based justification for choosing one right in preference to the other. Instead what the LCC (together with the Full Bench of the TPD and the Supreme Court of Appeal) did was to eschew a potentially radical in effect, but textually supported, interpretation of the ESTA (as conferring real rights on occupiers), so as to bolster the landowner's property right at the expense of the occupiers' right to freedom of religion and culture. Once again, the mantra of the cautious judge - that the legislature could not have intended to alter the common law to the extent suggested 135 - is used to close the doctrinal gap and justify the rule-choice without resort to policy reasoning. And once again, what looks at first blush like an outcome motivated purely by conservative judicial politics, is really an outcome influenced by the prevailing professional legal culture.

\section{(B) OTHER INSTITUTIONAL INDICATORS}

The theoretical model tested in this article posits two other institutional indicators that may condition the social transformation performance of courts: the influence of the common law, and judges' desire for professional respect. Both of these indicators have, however, already been subsumed under the influence of professional legal culture as defined. In a culture dominated by legal formalism, the influence of the common law is registered as a source of ready-made legal rules on which the cautious judge may rely in order to fill doctrinal gaps, without engaging in policy reasoning. Confronted by a situation of legal indeterminacy when interpreting a

135 Serole (note 81 above) para 16 (holding that the right to establish a grave is 'not the kind of right which the legislature intended to grant to occupiers'). 
social transformation statute, the cautious judge, rather than justifying his or her decision on policy grounds, does one of two things: either he or she alludes to the ambiguity and fills it with a pre-existing legal rule drawn from the common law, or the judge makes the ambiguity disappear by straining the language of the statute to produce a gap-filling rule. The common law, in other words, exerts an influence on the social transformation performance of courts in a legal formalist culture by providing a fallback source of legal rules in cases of legal indeterminacy. Since the statute being applied is by definition a statute that attempts to transform the existing social order by transforming the rules that regulate it, the result is almost always a 'conservative' result, in the sense that the existing social and legal order remains unchanged. But this does not necessarily mean that the judges who are responsible for such results are themselves conservative, or that the results are attributable in some mechanistic way to the influence of conservative judicial politics.

The influence of the judges' natural desire for professional respect has also already been accommodated in the concept of professional legal culture used here. It is precisely because the judges of the LCC want to be recognised as professionally competent that they are susceptible to the influence of professional legal culture. The fact that the judges of the LCC were not drawn from the ranks of practising advocates or sitting judges only exacerbates this situation, since the absence of prior approval from their peers provides all the more reason for the judges to want to establish their professional credentials. This influence emerges clearly in the highly technical decision in Macleantown, which probably had a lot to do with the LCC's desire to establish its credibility in its first decision. The same desire for professional respect might explain the Court's reluctance to depart from established forms of civil procedure in relation to the citation of spouses and dependants in actions for ejectment under the ESTA. In the other cases, the desire for professional respect is less obviously present, but exerts an indirect influence in the manner just described, ie as a necessary condition for the influence exerted by the prevailing professional legal culture.

\section{Conclusion}

This article has sought to test a theoretical model of the role of courts in social transformation through examining the performance of the South African Land Claims Court in four areas of law. The LCC was chosen for analysis because it provided an opportunity to eliminate some of the variables that typically condition the performance of courts in this context. If the model is sound, the elimination of non-relevant variables should not affect the capacity of the model to explain the observed phenomenon. In this case, however, the further problem is that the observed phenomenon - the record of the LCC in the four areas chosen for analysis - is in the nature of a sub-atomic particle that cannot be measured without distorting the result. In order to guard against this danger, the methodology pursued in this article has been to lower the standard of persuasion that is ordinarily required in acts of legal interpretation. Rather than arguing that the cases studied here were wrongly decided, this article has argued that they ignored or rejected pro-poor legal arguments that could have been used to justify an alternative outcome. In some cases, independent evidence of the existence of pro-poor legal arguments is found in the form of minority or appellate judgments. In others, the legislature's response to decisions of the LCC is used to crosscheck its performance in the weak political sense.

Having made out the case for the poor, pro-poor performance of the LCC in this way, this article set out to explain that performance in terms of the indicators suggested by the model. 
For various reasons, all but the so-called 'institutional indicators' were capable of elimination, and the main institutional indicator - the influence of professional legal culture - was defined in such a way as to incorporate the other two (the influence of the common law and the judges' desire for professional respect). Although there is some difference in emphasis, the literature on South African legal culture in the narrow sense portrays that culture as predominantly legal formalist in character. Legal formalism was defined as a tendency at a discursive level to assume or pretend that legal rules are capable of producing determinate outcomes in every case, without resort to policy reasoning. This being so, the theoretical model suggested that the judgments studied here should be explicable as instances in which the LCC's allegiance to the discursive methods and professional standards of legal formalism outweighed any ideological predisposition it might have had to decide the cases differently. Conversely, in the event that the judges' private political views are adduced as possible explanations of the outcomes in these cases, adherence to legal formalism should be capable of providing an adequate alternative explanation.

Tested in this way, the theoretical model survived contradiction. In all four areas of law examined here the anti-poor outcomes were adequately explained in terms of the LCC's resort to quasi-deductive reasoning when faced by doctrinal gaps in the rules relevant to the decision. In the Macleantown case the gap consisted in the legislature's failure to regulate the precise function of the Court in enforcing settlement agreements under the Restitution Act. In the Richtersveld case, the gap took the form of a crucial ambiguity surrounding the application of the Restitution Act to claims based on the doctrine of aboriginal title. In the remaining two areas, the doctrinal gap was produced by competing principles (Conradie and Klaasen) and contradictory rights (Serole). In every case, rather than filling the gap by reasoning on the basis of principle or policy, the LCC attempted to fill it by quasi-deductive methods typical of the culture of legal formalism in which it is operating.

This result confirms the soundness of the theoretical model to this extent. At the same time it provides an insight into the way in which South African professional legal culture continues to exert a restraining influence on the capacity of courts to be used as agents of social transformation. If there is a single, ironic lesson to be learned from this study, it is that the same methods that were used under apartheid to turn the courts into agents of that malevolent policy - the use of detailed prescriptive rules - might have to be used to ensure that the courts play an effective role in democratic social transformation. Of course, this recommendation itself places too much legal formalist faith in the capacity of rules to produce determinate results. Until such time as South African professional legal culture has changed from one dominated by a 'formal vision' of law to one dominated by a 'substantive vision', 136 however, there appears to be little alternative. 


\title{
On Social and Economic Justice in South Africa Today: A Theological Perspective on Theoretical Paradigms
}

\author{
DJ SMIT \\ Department of Systematic Theology and \\ Ecclesiology, Stellenbosch University
}

\section{Introduction}

The present research project is developed around two hypotheses about social and economic transformation in South Africa. The first is that theory matters, that theoretical frameworks and paradigms have an influence upon the developments taking place within and around them, more specifically, that prevailing and dominant theoretical paradigms concerning social and economic justice in South Africa today have an influence on the implementation of policy, legislation and general transformation. The second is that theoretical drag may be partly responsible for slower delivery on social and economic justice than the Constitution promises, more specifically, that the theoretical framework in which present transformations have to take place fails in many ways to support the necessary implementation, thereby frustrating rather than facilitating social and economic justice.

Christian theology - probably similar to law and economy - does not speak with one voice. Historically, the dominant theological traditions - including the Orthodox, Catholic, and Protestant traditions - have developed different views concerning ethical approaches. This also applies to theories of justice. Even within these traditions themselves - for example Protestantism, or even more specifically the Reformed faith - different approaches complement and often contradict one another. There is no single authoritative theological position regarding theories and practices of social, economic or legal justice. All claims are therefore modest and contextual, and reflect specific traditions, experiences and perspectives. The following comments are accordingly also made from a specific perspective, namely that of Protestant and ecumenical developments during the last century, particularly associated with the confessional tradition of Barmen and experiences of resistance against injustices in Germany, Latin America and apartheid-South Africa. ${ }^{1}$

1 For the confessional tradition of Barmen, including theological understandings of the notion of justice from the so-called Confessional Church Struggle in Germany, see K Barth Texte zur Barmer Theologischen Erklärung (1984), A Burgsmüller and R Weth (eds) Die Barmer Theologische Erklärung: Einführung und Dokumentation (1983), and E Busch Die Barmer Thesen 1934 - 2004 (2004). For a helpful discussion of the reception of the notion of 'the preferential option for the poor' from Latin American church struggles for social and economic justice in ecumenical documents, see $\mathrm{H}$ Bedford-Strohm Vorrang für die Armen: auf dem Weg zu einer theologischen Theorie der Gerechtigkeit (1993). For the church struggle against the theology of apartheid and specifically the historical context and thrust of the Confession of Belhar, see GD Cloete and DJ Smit A Moment of Truth: The Confession of the Dutch Reformed Mission Church (1984). 
From this specific theological perspective, the two hypotheses seem very plausible, and some of their implications are of direct importance to theology and the church. To put it in theologicalethical and ecclesiological language, it seems possible to argue, firstly, that the way the public opinion thinks and speaks about justice will have a definite impact on any possible structural implementation of social and economic justice ('theory matters'), and secondly, that many of the processes needed to implement more social and economic justice in South Africa today may be hindered by the way the public opinion thinks and speaks about justice ('theoretical drag'). Therefore, changing the way the South African public opinion thinks and speaks about justice the prevailing and dominant theoretical framework - may contribute toward overcoming the present theoretical drag and the slow pace of implementing social and economic justice. Given the nature and the calling of the Christian church, as seen from this specific theological perspective, together with the social position and role of the church in the South African society today, it may be argued that the church should and could make a meaningful contribution in this regard. The following paragraphs will develop these general claims somewhat more fully.

\section{II 'Theory Matters'}

From this specific theological perspective, it is of crucial importance to affirm an intimate relationship between justice (that is, legal justice, but also political, economic and social justice) and ethics (and therefore morality, and theology). Where total separation between law and ethics has historically developed (particularly in Western modernity's separation of legality and morality, especially since Kant), this development is regarded as one-sided and suspect, from this theological viewpoint. Such varieties of separation would include diverse forms of legal positivism, but also different theoretical claims to exclude moral and ethical discourses from economic and political rationalities. ${ }^{2}$

Some of the important reasons for affirming such a relationship between law and ethics are given both with the nature and content of the Christian faith, as well as with historical experiences of large-scale injustices. Such historical experiences include the failure of twentieth-century legal systems and political and economic rationalities to deal adequately with the social injustices they faced.

From this specific theological perspective, however, this relationship between law and ethics is not and should not be construed as one of identity, for example by subsuming the one in the other. Instead, it is regarded as of crucial importance to distinguish between legal, moral, ethical and therefore theological discourses. ${ }^{3}$ All forms of identification between law and ethics that have historically developed, including all (theological, philosophical and legal) theories of nat-

2 For an extensive theological critique of these forms of separation, see W Huber Gerechtigkeit und Recht: Grundlinien Christlicher Rechtsethik (1996). For a related but philosophical treatment, see many of the later works of Jürgen Habermas, including for example his article 'Vom pragmatischen, ethischen und moralischen Gebrauch der praktischen Vernunft' in J Habermas Erläuterungen zur Diskursethik (1991) at 100-118; J Habermas Faktizität und Geltung: Beiträge zur Diskurstheorie des Rechts und des demokratischen Rechtsstaats (1992).

3 For different ways of maintaining such distinctions, see eg J Habermas Erläuterungen zur Diskursethik (1991); N Luhmann Ausdifferenzierung des Rechts: Beiträge zur Rechtssoziologie und Rechtstheorie (1981); W Huber Gerechtigkeit und Recht (1996); as well as the influential work of the systematic theologian also working within this Reformed tradition, M Welker 'Moral, Recht und Ethos in evangelisch-theologischer Sicht' in W Härle and R Preul (eds) Ethik und Recht (2002) at 67-82. 
ural law, are seen as deeply problematic and even dangerous, since they can easily lead to ideological misuse. Any form of moralising of the law, politics or the economy is rejected.

This theological perspective, therefore, will show affinity with theoretical paradigms and theories of justice that seek ways between positivism on the one hand and natural law on the other hand, respectively making absolute claims for what is on the one hand and for what should be on the other hand.

What could the contribution be of such a 'critical theology of law'?4 Broadly speaking, it will seek to contribute both loyalty to, as well as criticism and reform of the existing legal, political and economic systems. It will both strongly support the existing justice and, wherever and whenever it is regarded as necessary, plead and work for better and more justice. Both these approaches - loyalty and criticism - are deeply embedded in the Biblical and Christian traditions, for example with its well-known command to obey all authority, yet if necessary to obey God more than any form of human authority.

This obviously raises many questions, including questions concerning the theory of justice involved. When should loyalty become criticism and reform? What would be the theological norm? Which criteria of justice are used to discern between moments of loyalty and moments of criticism, between conditions calling for support and conditions calling for renewal and even resistance? ${ }^{5}$ Is there - to put it differently - a specifically theological theory of justice? ${ }^{6}$

4 This is for example the way that Huber characterises his own approach, see Huber (note 2 above) at 17, 26-27, 97-106. He explains: 'Die erste christlicher Rechtsethik war deshalb nicht nur eine Ethik der Rechtsloyalität, ... sondern sie war zugleich eine Ethik des zivilen Ungehorsams: 'Man muss Gott mehr gehorchen als den Menschen'. Damit ist dem christlichen Nachdenken über das Recht eine kritischer Impuls mitgegeben, der freilich in der Geschichte des Christentums allzu häufig verdrängt wurde. Eine theologische Beschäftigung mit dem Recht die jene Anfänge nicht verdrängt, kann nur die Gestalt einer kritischen Theologie des Rechts annehmen. Gerade so kann sie zu einer kritischen Theorie des Rechts beitragen....

Damit ist auch die bestimmende Frage dieses Buches genannt. Es lässt sich von folgender Überzeugung leiten: Eine Rekonstruktion der Sphäre des Rechts muss bei der Situation derer beginnen, die unter den spezifisch modernen Formen der Rechtlosigkeit leiden. Nicht das Stöhnen der Wohlhabenden unter der Verrechtlichung der Industriegesellschaft, sondern das Leiden der Unterdrückten und Entrechteten unter Ungerechtigkeit steht am Anfang. Eine kritische Theologie des Rechts beginnt mit den Ausgeschlossenen und Eingesperrten, die politischer Willkür ausgeliefert sind. Sie beginnt mit denen, die sich in ihrem eigenen Land nicht mehr zu Hause wissen und in der Fremde Asyl suchen. Sie beginnt mit den Diskriminierten, die unter einer rassistischen Gewaltherrschaft leben müssen. Sie beginnt mit den Opfern schneller wirtschaftlicher Entwicklung, die sich häufig mit einer autoritären Staatsordnung verbindet. Sie beginnt mit dem Blick auf Menschen, denen in ideologisch beherrschten Ländern das Recht der Meinungsfreiheit geraubt wird. Sie beginnt mit der Perspektive von Frauen, denen in männlich bestimmten Gesellschaften Selbstverwirklichung und Gleichheit vorenthalten werden. Sie beginnt mit denen, die in reichen Industriestaaten dem Modernisierungsprozess weichen müssen und in die Arbeitslosigkeit gedrängt werden. Für sie alle hat das Recht nur Bedeutung, wenn es in den Dienst der Gerechtigkeit tritt, auf die sie hoffen.

Wenn dies die bestimmende Perspective auf das Recht ist, wird es freilich unmöglich, Recht und Ethik - die Frage nach dem, was gilt, und die Frage nach dem, was gut ist - voneinander zu trennen. Eben diese Trennung aber bildete einen entscheidenden Schritt in der Ausbildung des neuzeitlichen Rechtsverständnisses. Müssen wir dieses Rechtsverständnis hinter uns lassen? Stehen wir vor einem Epochenwechsel?' - This then becomes the leading question of his extensive historical and systematic reflections.

5 In a recent key collection of essays edited by P Dabrock et al Kriterien der Gerechtigkeit: Festschrift für Christofer Frey zum 65. Geburtstag (2003), published in honour of the German ethicist Christofer Frey, three theological approaches to justice are for example discussed. A first section on the foundations of justice (Begründungen) offers firstly Old and New Testament perspectives on justice, followed by discussions on justice in the writings of Martin Luther and in evangelical ethics, amongst others. An important contribution by the ethicist Johannes Fischer ('Jenseits reiner Normativität: Skizze einer theologisch-ethischen Annäherung and die Gerechtigkeitsthematik' in P Dabrock et al (eds) Kriterien der Gerechtigkeit (2003)) provides a synopsis of current theological-ethical theory on justice. A second (and the largest) section investigates how these various 
For this specific perspective, theology does not claim to have its own (alternative) theory of justice. ${ }^{7}$ Rather, it seeks to engage with existing theoretical frameworks by drawing on its own sources and resources. Drawing on these sources and resources, this theology hopes to contribute to some broad theoretical orientation concerning justice that could be helpful in formulating law, in evaluating law, and in evaluating the implementation of law. This theology would further support political and economic attempts to implement, practice and embody such forms of justice and join forces with those criticising and resisting failures to embody such forms of justice.

In this respect theology can certainly play a role in the present research project. Firstly, both Old and New Testament records can offer valuable orientation and perspective; secondly, the Christian tradition of interpretation can provide instructive developments and case studies; and thirdly, recent and contemporary ecumenical discussions may help to discern critical issues and insights. Research into all three these fields of inquiry (biblical, historical, systematic) could play an important role in developing theology's own voice and particular contribution. ${ }^{8}$ Some well-known examples from these, often conflicting histories of interpretation could suffice: understanding the nature and role of justice according to the complex and manifold New Testament traditions; ${ }^{9}$ understanding justice against the background of the Sermon on the Mount; ${ }^{10}$ understanding the relationship between justice and love, historically often falsely con-

insights are to be applied in a number of social disciplines (Anwendungen), that is in ecological theory, in biogenetics, in medicine, in just war theory, in matters of asylum seeking, in economy, labour and business, and in family studies. The third and final section (Vermittlungen) deals specifically with how these applications are to be communicated to the public, particularly through visual and audio media, through religious education and through the diaconate of the church - themes of special importance for this research project, which also involves questions of communication and the formation of public opinion.

6 The question whether there is something like a theological theory of justice is often acknowledged and discussed as a very complex and controversial matter. This is demonstrated, for instance, in two successive studies by the respected North American ethicist Karen Lebacqz. In Six Theories of Justice: Perspectives from Philosophical and Theological Ethics (1986), she discusses various theological and philosophical views on justice. She compares influential positions such as John Stuart Mill's utilitarianism, John Rawls' contract theory and Robert Nozick's 'entitlement' view with responses from Catholic, Protestant and Liberation perspectives. She emphasises that different people mean different things by justice and that it is, therefore, an illusive concept - without one single theological solution or approach. In a subsequent collection, K Lebacqz Justice in an Unjust World: Foundations for a Christian Approach to Justice (1987), she attempts to formulate an own theory of justice by relating the righteousness of God to injustice in the world and she draws on Scripture to interpret such injustice. Again, she does not offer a comprehensive theological response to the question of justice. She subsequently uses concrete examples to demonstrate how 'justice' can be brought about 'in an unjust world'.

7 For popular discussion of this theme from the perspective of Reformed ethics and proclamation, see DJ Smit 'Reformed Ethics and Economic Justice' (1996) 37 Nederduitse Gereformeerde Teologiese Tydskrif 438455; DJ Smit 'Oor die Prediking van Regverdiging en Reg' in BA Müller et al (eds) Riglyne vir Prediking oor Regverdiging en Reg. Woord teen die Lig III/3 (1993) 1-14; DJ Smit 'Die Droom van Bybelse Geregtigheid' (1985) 15 Scriptura 51-70.

8 Many theologians have done this and developed their own discussions of justice from a theological perspective. See for example the classical study by E Brunner Gerechtigkeit: eine Lehre von den Grundgesetzen der Gesellschaftsordnung (1943), as well as the popular W Lienemann Gerechtigkeit (1995), an ethicist from Bern, Switzerland, writing an overview for ecumenical use.

9 See for example H Balz 'Die Gerechtigkeit der Gerechtfertigten: eine neutestamentliche Skizze' in P Dabrock et al (eds) Kriterien der Gerechtigkeit (2003) 45-61.

10 In many Christian theological circles, especially since the Enlightenment, the Sermon on the Mount has been a very popular extract or summary of the Biblical teaching and was often used as the only source for 
strued as exclusive of one another; ${ }^{11}$ understanding justice against the background of the legal traditions of the Old Testament, an area of research that recently led to major new and valuable insights; ${ }^{12}$ understanding the complex historical developments in which classical and Biblical theories of justice contradicted, but also complemented one another; ${ }^{13}$ understanding philosophical and legal developments in modernity, in which deliberately secular theories of justice were often developed in direct opposition to ecclesial, theological and often ethical perspectives; understanding conflicting theological theories of justice that build respectively on notions of creation, providence, sin, anthropology and eschatology; ${ }^{14}$ and finally understanding recent ecumenical debates and struggles concerning justice, freedom, liberation, human rights and the dignity of creation. ${ }^{15}$ It is immediately obvious that such theological research will necessarily have to be inter-disciplinary, involving scholars from different theological disciplines.

What form could such theological contributions to some broad theoretical orientation concerning justice take? At the outset, at least six possible forms could perhaps be foreseen.

Firstly, this specific theological perspective brings an eschatological (in philosophical terms:

Christian ethics. The interpretation of the Sermon on the Mount is, however, complicated and controversial, and so also its use in ethical questions. For a discussion see DJ Smit 'Die Bergrede in die Geskiedenis' in CW Burger et al (eds) Riglyne vir Prediking oor die Bergrede (1990) at 11-25; DJ Smit 'Die bergrede en Christelike etiek' in CW Burger et al (eds) Riglyne vir Prediking oor die Bergrede (1990) at 34-38.

11 A well-known example has been the influential work of the North-American Reformed theologian Reinhold Niebuhr. See for example the four very authoritative studies of his work by LB Gilkey On Niebuhr: A Theological Study (2001); CW Kegley Reinhold Niebubr, His Religious, Social, and Political Thought (1984); HB Clark Serenity, Courage, and Wisdom: The Enduring Legacy of Reinhold Niebubr (1994); RH Stone Reinhold Niebuhr: Prophet to Politicians (1981). See also the unpublished doctoral thesis of SM de Gruchy Not Liberation but Justice: An Analysis of Reinhold Niebubr's Understanding of Human Destiny in the Light of the Doctrine of the Atonement (1992) DTh thesis, University of the Western Cape, Bellville.

12 The German systematic theologian Michael Welker has written extensively on justice in the legal traditions of the Old Testament, often together with the widely known Old Testament scholars Jan Assmann and Bernhard Janowski. See the collection of essays in J Assmann et al Gerechtigkeit: Richten und Retten in der abendländischen Tradition und ibren altorientalischen Ursprüngen (1998); also M Welker 'Dynamiken der Rechtsentwicklung in den biblischen Überlieferungen' in A Aarnio (ed) Rechtsnorm und Rechtswirklichkeit: Festschrift f. Werner Krawietz zum 60. Geburtstag (1993) at 779-795. Another very influential theologian in this field is the Old Testament scholar Frank Crüsemann. See for example the seminal essay F Crüsemann 'Jahwes Gerechtigkeit im Alten Testament' (1976) 36 Evangelische Theologie 427-450, as well as the recent collection of essays in his Festschrift, published as C Hardmeier et al (eds) Freiheit und Recht: Festschrift für Frank Crüsemann zum 65. Geburtstag (2003).

13 A well-known example is the influence of Aristotle and the principle of suum quique, via Thomas Aquinas and scholasticism, in Christian theology. See for T Aquinas 'Treatment of Justice' in J Porter 'The Virtue of Justice' in SJ Pope (ed) The Ethics of Aquinas (2002); as well as the influential A MacIntyre Whose Justice? Which Rationality? (1988), who makes use of conflicting traditions of interpretation of this legacy in constructing his own argument and position.

14 Both in more general theological discussions of justice, and in the ecumenical debates on the so-called theological basis for human rights, the traditional confessional preferences for some of these theological loci often played a determinative role, for example the central vision of the covenant in the World Alliance of Reformed Churches, the doctrine of justification in the Lutheran World Federation and traditions of moral anthropology for the Roman Catholic Bishops.

15 For a helpful overview of the development of ecumenical social thought during the twentieth century, see M Robra Ökumenische Sozialethik (1994); and for the state of the present discussion in the Ecumenical Movement on some of these themes, see U Duchrow 'Justice' in N Lossky et al (eds) Dictionary of the Ecumenical Movement (2002) at 627-630; E Weingärtner 'Human Rights' in N Lossky et al (eds) Dictionary of the Ecumenical Movement (2002) at 548-551; DJ Smit 'Liberty/Freedom' in N Lossky et al (eds) Dictionary of the Ecumenical Movement (2002) 685-688. 
teleological) orientation to the discourse. It speaks a language of hope. It reminds everyone of justice not yet real and fulfilled. It thereby moves and inspires agents for justice, and it empowers those who suffer under present injustices not to surrender hope and not to accept their lot without struggle and resistance. It calls the church and all believers to keep praying, to long for this justice and to dream of this reign, and therefore to take all possible steps, small as they may be, in witnessing to this coming reality. ${ }^{16}$

Secondly, because of this eschatological orientation, it strengthens critical and self-critical thought. This theology encourages those involved in working for justice, particularly those in legal, political and economic spheres. It supports all those actors, including legal theorists, practitioners and activists, who seek to strengthen theoretical paradigms that will lead to legal, economic and social transformations and to practical policy implementations that will contribute to serve justice. From the perspective of the Christian faith, it reminds everyone to remain selfcritical, to acknowledge that full justice will never be realized historically, and therefore to emphasise that even - and precisely - the best constitutions, laws and catalogues remain open to (self-) critical evaluation and improvement.

Thirdly, based on the content of the Biblical traditions, particularly as they have come to be understood in certain twentieth-century contexts of historical injustice, this theological perspective advocates a view of justice that takes the perspective of those who suffer under such injustices very seriously. Perhaps this is the most characteristic material contribution of the Biblical traditions concerning justice to any contemporary theory of justice. In South Africa, this perspective has, for example, been expressed in the third article of the Belhar Confession, where it is claimed that the Biblical God has been revealed as 'in a special way the God of the destitute, the poor and the wronged, ${ }^{17}$ and that this God calls the church to follow in this way. 18

16 For an extended argument on the importance of seeing as first step in the process of ethical decision-making, also regarding issues of poverty, suffering and social justice, see DJ Smit 'On Learning to See? A Reformed Perspective on the Church and the Poor' in P Couture and BJ Miller-McLemore (eds) Suffering, Poverty, and HIV-AIDS (2003) at 55-70. The famous German systematic theologian Jürgen Moltmann has made a major impact on the discussion on justice and eschatology. Throughout his life he has been actively involved in human rights debates within ecumenical circles and he wrote extensively on this through the years. Already in his collection J Moltmann The Experiment Hope (1975), he published three articles on racism, human rights and human dignity. A decade later he wrote specifically on human dignity, as the title suggests: J Moltmann On Human Dignity: Political Theology and Ethics (1984). This volume was wholly dedicated to human rights, where he examined, amongst others, the ecumenical debate on human rights, the relationship between Christian faith and human rights, and the right to 'meaningful work'. In his recent (and somewhat more popular) book J Moltmann God for a Secular Society: The Public Relevance of Theology (1999), he continues these reflections in a section on human rights (117-134), which includes topics such as 'individual and social rights', 'economic rights and ecological obligations' and 'the world religions in the forum of human rights.'

17 The third article on justice reads as follows: 'We believe that God has revealed himself as the One who wishes to bring about justice and true peace among people; that in a world full of injustice and enmity He is in a special way the God of the destitute, the poor and the wronged and that He calls his Church to follow Him in this; that He brings justice to the oppressed and gives bread to the hungry; that He frees the prisoner and restores sight to the blind; that He supports the downtrodden, protects the stranger, helps orphans and widows and blocks the path of the ungodly; that for Him pure and undefiled religion is to visit the orphans and the widows in their suffering; that He wishes to teach His people to do what is good and to seek the right;

'That the Church must therefore stand by people in any form of suffering and need, which implies, among other things, that the Church must witness against and strive against any form of injustice, so that justice may roll down like waters, and righteousness like an ever-flowing stream; 
Fourthly, it is therefore to be expected that this theological perspective will show a special sensitivity for all those - individuals, groups and categories of people - who suffer forms of injustice, oppression, rejection, exclusion, violation or abuse. For this reason, the church sometimes, under specific historical circumstances, feels itself called to be a voice for the voiceless, a public conscience, an advocate for the oppressed, or a critical, prophetic challenge to authorities and powers. ${ }^{19}$ Such claims do not imply that the church - in whichever form - has an alternative theory of justice, but only that its own message and the very reason for its existence, its faith, involves a calling to care for those who suffer injustices and to plea and act on their behalf. The involvement of the ecumenical church and theology today in issues of economic globalisation provides an instructive example. ${ }^{20}$ The church does not resist contemporary global transformations in any of their complex forms (whether cultural, political or economic), but is concerned with some of the disastrous effects of economic globalisation in its present form, especially the exclusion, marginalisation and triage of many, including many living in Africa today. In asking whether this form of economic life should not concern the faith of Christians - which is the way the major ecumenical bodies, like the World Alliance of Reformed Churches recently in Accra, ${ }^{21}$ are framing the question - they do not claim to have any alternative theory of economic justice. They do, however, remind everyone of the suffering of many, and of the injustice thereof, and appeal to everyone in positions of (legal, social, economic and political) responsibility and influence to take this suffering seriously.

Fifthly, this theological perspective understandably shows a strong affinity for those theories

'That the Church as the possession of God must stand where He stands, namely against injustice and with the wronged; that in following Christ the Church must witness against all the powerful and privileged who selfishly seek their own interests and thus control and harm others.

'Therefore, we reject any ideology which would legitimate forms of injustice and any doctrine which is unwilling to resist such an ideology in the name of the gospel' (in GD Cloete and DJ Smit A Moment of Truth: The Confession of the Dutch Reformed Mission Church (1984) at 1-6).

18 For historical accounts, interpretations and theological reflections on the God-images at stake, see J Botha and P Naude Op Pad met Belhar: Goeie Nuus vir Gister, Vandag en Môre (1998); and the essays DJ Smit 'Paradigms of Radical Grace' in C Villa-Vicencio (ed) On reading Karl Barth in South Africa (1988); and DJ Smit '.. in a special way the God of the destitute, the poor and the wronged...' in GD Cloete and DJ Smit (eds) (note 17 above) 127-150.

19 Recent history demonstrates various instances where the church understands itself to be a voice for the voiceless. Three such examples are, for instance, the publication of the Dutch Reformed Church in Africa 'Transition and Poverty' (1990) 2/90 (Supplement) DRCA Action 1-25; the more recent document by the Southern African Catholic Church, Economic Justice in South Africa: A Pastoral Statement (1999), but also the very influential German document published jointly by the Evangelical and Catholic Churches, For a Future Founded on Solidarity and Justice: A Statement of the Evangelical Church in Germany and the German Bishops' Conference on the Economic and Social Situation in Germany (1997).

20 The literature from the ecumenical church is already vast. For three recent contributions from people involved in the Beyers Naudé Centre, see HR Botman 'Human Dignity and Economic Globalization' in HR Botman and K Sporre (eds) Building a Human Rights Culture: South African and Swedish Perspectives (2003) at 20-34; M Haspel Protestantische Ethik vor der Herausforderung der Globalisierung (2004); DJ Smit 'Theologische Ansätze für kirchliches Engagement in Fragen der Globalisierung - Reformierte Perspektiven aus dem Südlichen Afrika' 2004 Ökumenische Rundschau 160-175.

21 See Covenanting for Justice in the Economy and the Earth, agreed by the General Council, World Alliance of Reformed Churches, 24th General Council, Accra, Ghana, July 30 - August 13, 2004, http://www.warc.org. 
of justice in which the dignity of the human person is regarded as central.22 The inalienable worth and dignity of the human person is the boundary that may not be transgressed, the norm that may not be ignored, the ultimate criterion to apply to social, political and economic life together. Again, this is argued on inner-theological grounds, based on the content and thrust of the Biblical message - although it too has been very controversial within theological circles. ${ }^{23}$ Despite all these historical and even recent theological debates, however, it is fair to claim that

22 The impact of the German ethicist and bishop Wolfgang Huber on the theological debates on human dignity, human rights and justice cannot be overstated. He has become the leading theological figure in the field. He made several contributions regarding theological theories of justice, for example W Huber 'Beten und Tun des Gerechten' in W Huber and I Tödt (eds) Ethik im Ernstfall: Dietrich Bonhoeffers Stellung zu den Juden und ihre Aktualitat (1982) at 11-22; W Huber 'Recht im Horizont der Liebe' in Brandt et al (eds) Ein Richter, ein Bürger, ein Christ: Festschrift für Helmut Simon (1987) at 1045-1058; W Huber 'Justice, Peace and the Integrity of Creation: A Challenge for Ecumenical Theology' (1988) 24 Scriptura 1-16; W Huber 'Menschenrechte - Christenrechte' in Recht nach Gottes Wort: Menschenrechte und Grundrechte in Gesellschaft und Kirche (1989) at 82-100; W Huber Konflikt und Konsens: Studien zur Ethik der Verantwortung (1990); W Huber 'Menschenrechte und biblisches Rechtsdenken: ein Versuch' (1993) 2 Neukirchener Theologische Zeitschrift: Kirche und Israel 144-160; W Huber 'Die Prediking oor Regverdigheid en Geregtigheid' in CW Burger (note 10 above) at 15-24; W Huber 'Gottesrecht und Menschenrechte in gesellschaftspolitischen Entwürfen' (1995) 32 epd-Dokumentation 55-60; W Huber Rechtfertigung und Recht: über die christlichen Wurzeln der europäischen Rechtskultur (2001).

In the process he often reflected on legal theory, law and German constitutional law; see for example W Huber 'Das Grundgesetz und die Menschenrechte' (1989) 33 Zeitschrift für Evangelische Ethik 82-85; W Huber 'Die Menschenrechte und das Grundgesetz: theologische Überlegungen' in M Pfeiffer (ed) Auftrag Grundgesetz: Wirklichkeit und Perspektiven (1989) at 190-213; W Huber 'Recht als Beruf: Verantwortung für das Recht im Horizont der Gerechtigkeit' in U Neumann and L Schulz (eds) Verantwortung in Recht und Moral: Referate der Tagung der Deutschen Sektion der Internationalen Vereinigung für Rechts- und Sozialphilosophie (2000) at 39-55 (also published as W Huber 'Recht als Beruf: Verantwortung für das Recht im Horizont der Gerechtigkeit' in Limbach et al (eds) Ist der Rechtsstaat auch ein Gerechtigkeitsstaat? Interdisziplinäre Referatsreihe an der Universität Basel (2000) at 31-59). He dealt extensively with the notion of human dignity; see W Huber 'Die Würde des Menschen ist antastbar: Anfragen aus der Sicht der christlichen Ethik' (1990) 45 Universitas 852-861; W Huber 'Menschenrechte/Menschenwürde' in Theologische Realencyklopädie XXII (1992) at 577-602; W Huber Die tägliche Gewalt: Gegen die Ausverkauf der Menschenwürde (1993) (translated as W Huber Violence: The Unrelenting Assault on Human Dignity (1996)); W Huber 'Menschenwürde? Gewalt und Intimität als Unterhaltung' in W Wunden (ed) Öffentlichkeit und Kommunikationskultur (1994) at 181-199; W Huber 'Lebenswert und Lebensrecht' (1995) 31 epd-Dokumentation 51-56; W Huber 'Die Würde des Menschen ist antastbar: Anfragen aus der Sicht der christlichen Ethik' in S Abarbanell et al (eds) Fernsebzeit (1996) at 185-195; and he regularly published on human rights; see W Huber 'Human Rights: A Concept and its History' (1979) 124 Concilium 1-10; W Huber 'Menschenrechte' in Staatslexikon Bd. 3 (1987) at 1103-1118; W Huber 'Menschenrechte' in L Engel et al (eds) Hoffnung in der Krise: Dokumente einer christlichen Existenz in Südafrika zum 65. Geburtstag von Wolfram Kistner (1988) at 298-311. Together with HE Tödt he published an authoritative study called W Huber and HE Tödt Menschenrechte: Perspektiven einer menschlichen Welt (1977). He also contributed on specific themes, such as the right to protest, for example W Huber Protestantismus und Protest: zum Verhältnis von Ethik und Politik (1987) and the rights of nature, W Huber 'Rights of Nature or Dignity of Nature?' (1992) The Annual of the Society of Christian Ethics 43-61. These contributions culminated in his magnum opus, W Huber Gerechtigkeit und Recht (1996).

23 The very influential German theologian Karl Barth, for instance, placed human dignity central in his whole theology. See for example his well-known essay K Barth The Humanity of God (1967) in which he explained this autobiographically. For a fuller discussion of Barth's views on justice within his approach to ethics, see DJ Smit '... The Doing of the Little Righteousness' - On Justice in Barth's view of the Christian life' in M Welker and C Jarvis (eds) Serving God with Our Minds: Festschrift for Wallace Alston (2004) at 120-145. For human dignity within theology, see also the collection of key essays in I Balderman et al (eds) Menschenwürde: JBTh 15 (2001). Another important collection is a special edition of the ecumenical journal Una Sancta devoted wholly to human dignity: G Voss et al 'Menschenwürde neu buchstabieren' (2000) 55 Una Sancta - Zeitschrift für ökumenische Begegnung 97-176. 
contemporary ecumenical theology is in very strong agreement that the message of the gospel, the good news of the loving and gracious Triune God, affirms in all its aspects the importance, value and dignity of human beings. ${ }^{24}$

What is human dignity? Can it be defined or described? Is it possible to give material content to the notion of human dignity? Recent and contemporary discussions - for example the debate in the European Convention on the inclusion or exclusion of human dignity in the European Constitution, and its possible material content, should it be included - have shown that this is not really fully possible, even in those circles where people are deeply committed to the notion and dedicated to serve and protect human dignity, to determine its content in any definite way. Still, it is possible to agree on certain characteristics, often defined negatively, for example in the Universal Declaration of Human Rights, suggesting that human beings deserve to be protected from fear and from want. Of course, these are very broad and general guidelines, and their implementation will always remain open, dependent on concrete interpretations and realities, yet, they are not for that reason without importance and usefulness.

From this theological perspective, it is indeed a very helpful guideline, to link human dignity to freedom from fear and freedom from want, and to search for means of common life, including economic life, that could contribute to protect human beings - very specific, concrete individuals and groups of human beings, under very specific and concrete conditions - from causes of fear and causes of want that could indeed be prevented.

Sixthly, for that reason, contemporary ecumenical theology (after earlier hesitation) also strongly supports theoretical paradigms in which human rights, as the concrete embodiment of the inalienable human dignity, are central. ${ }^{25}$ This is not a strong claim. It does not claim, for example, that human rights can be based on or deduced from Scripture, or that human rights

24 For a popular statement of this conviction, see DJ Smit 'Oor die God wat Ons Roep' in Handelinge van die NGK in SA (Wes- en Suid-Kaapland) (2003) at H99-H103. See also various publications from the ecumenical church, for instance AO Miller (ed) A Christian Declaration on Human Rights: Theological Studies of the World Alliance of Reformed Churches (1977); as well as the special edition of the journal Reformed World on 'Theology and Human Rights' with contributions by AD Falconer 'Pressing the Claims: Reflections in the Theological Basis of Human Rights' (1998) 48 Reformed World 50-62, J Schaeffer 'WARC's Historic Commitments to Justice and Human Rights' (1998) 48 Reformed World 63-78, and C John 'Human Rights and the Churches: The New Challenges' (1998) 48 Reformed World 79-96; see also the earlier, but popular statement by the Reformed Ecumenical Council RES Testimony on Human Rights (1983).

25 See for instance the study by the influential ethicist M Honecker Das Recht des Menschen: Einführung in die evangelische Sozialethik (1978). An important collection (with contributions by Claus Westermann, Ulrich Luck, Martin Brecht and Jörg Baur) is J Baur (ed) Zum Thema Menschenrechte: theologische Versuche und Entwürfe (1977). For a recent collection of essays on the theological reflection on human rights, see for instance L Gearon Human Rights \& Religion: A Reader (2002). This reader includes a valuable introduction by Gearon and offers various positions on the relationship between religion (including different religions) and international human rights, with case studies from various regions throughout the world. The point of the reader is to show not only how human rights discourses contribute to individuals' and groups' rights to religious freedom, but also to demonstrate how different religions view the importance of human rights as such. Included is also a contribution by the South African theologian C Villa-Vicencio 'Theology and Human Rights' in L Gearon (ed) Human Rights \& Religion (2002) at 98-119, where he specifically attempts to bridge the historical divide between individual and socio-economic rights via theology and the central theological affirmation of the worth and dignity of being human. In the closing essay (C Wellman 'The Proliferation of Rights: Moral Progress or Empty Rhetoric?' in L Gearon (ed) Human Rights \& Religion (2002) at 368-388) the complex and, perhaps, troubled relationship between first, second and third generation rights is discussed. Apart from Villa-Vicencio's work, another South African ethicist who contributed to human rights debates over many years is Danie du Toit; see D du Toit (ed) Menseregte: Opstelle (1984); D du Toit Die Mens en sy Regte: Geloof en Praktyk in Suid-Afrika (1988). 
developed historically as a direct product of the Christian tradition, or that human rights represent a universal value system that other traditions and cultures must merely accept in its present form. It is simply the modest claim that in their complex and controversial inter-relationships and in their openness for continuous improvement and criticism, contemporary human rights provide 'perspectives of a human world' ${ }^{26}$ with very strong analogies to central convictions of the Christian faith. This is also true of South Africa, and part of the reasons why churches and the local ecumenical church enthusiastically claim the Constitution and the Bill of Rights, and often eagerly monitor real or potential human rights violations. This is in fact the reason why churches could be expected to show a particular interest in implementing the socalled social and economic rights, whether as already formulated in the Constitution, or perhaps in even stronger form as well.

It would therefore - at least from this theological perspective - be totally consistent with the faith, confession and theology of the Christian church if the South African ecumenical church, denominations and congregations, including church leaders and individual believers, would show very strong commitment to support the increased implementation of these social and economic rights, and would be very concerned with slow social transformation and delivery. To the extent that the South African church - understood in this comprehensive way - is not eagerly involved in supporting such implementation and does not contribute to the formation of public opinion and thereby practical policies in this direction, this would indeed be inconsistent with the faith, confession and theology of the church, and would raise the question of 'theoretical drag'.

\section{III 'Theoretical Drag'}

Theoretical drag may be partly responsible for slow implementation of social and economic justice in different ways and for different reasons. Popularly speaking, at least two major ways may be distinguished. On the one hand, the embodiment of social and economic justice in the form of laws and policies may be slow to follow public expectation and opinion. This happens for very understandable reasons. One of the strengths of modern legal systems is their reliability. The law is slow to change because it is intended to serve security of expectations, Rechtssicherheit.27 What is legal today should not be illegal tomorrow. The law can therefore not be changed arbitrarily, but tends to be conservative. Accordingly, laws carry the imprints of their origins and history, and they are often slow to respond to new challenges and problems, creating a certain 'time-lag'.

...Das durch die moralischen Vorstellungen, Herrschaftsformen und Machtverhältnisse seiner Entstehungszeit geformte Recht gilt aber oft für lange Zeit; seine Beständigkeit soll ja gerade Verläßlichkeit und Rechtssicherheit verbürgen. Gegenüber neuen Problemlagen ist das Recht deshalb oft ungleichzeitig; wenn neue

26 See for example the very helpful systematic reflections of W Huber and HE Tödt Menschenrechte: Perspektiven einer menschlichen Welt (note 22 above) written by two Lutheran ethicists, but without doubt still one of the most valuable theological contributions in the field.

27 See N Luhmann Ausdifferenzierung des Rechts (note 3 above); M Welker 'Security of expectations' (1986) 66 Journal of Religion 237-260. Michael Welker, a Reformed systematic theological from Heidelberg and one of the most respected voices in postmodern theology, made extensive use of Luhmann's complex theories on modern societies in his earlier work and combined that in very insightful ways with Old and New Testament perspectives on justice, law and morality. 
Lebensverhältnisse entstehen, wenn neue moralische Vorstellungen sich durchsetzen, wenn tradierte Herrschaftsformen und Machtverhältnisse in Frage gestellt werden, zeigt sich oft ein 'time-lag' des Rechts. Seine konservativer Charakter mindert seine Steuerungs- und Orientierungsleistung. Es wirkt lähmend, ja vielleicht sogar lebensfeindlich... . ${ }^{28}$

On the other hand, the embodiment of social and economic justice in the form of laws and policies may be slow because public expectation and opinion is not yet ready for it. Again, this may happen for very understandable reasons. Another strength of modern legal systems is precisely its independence from any specific moral or ethical viewpoint. That is indeed the important element of truth in positivist theories of justice. The legal system in a pluralist society, like South Africa, should not be moralised or ideologically misused by any particular tradition or community, but should rather enable diverse moral and religious traditions and communities to coexist peacefully and fairly. These two seemingly opposing processes may therefore take place simultaneously in a specific society. The implementation of social and economic rights may be slow since it does not (yet) reflect the expectations of specific (also moral and religious) communities and traditions in society, and it may be slow since it (still) reflects the opinion of perhaps the majority of (also moral and religious) communities and traditions in the same society.

Empirical research by others will have to ascertain and document whether these processes are indeed at work in South Africa today. To the extent that these time-lags are indeed present in the implementation of social and economic justice in South Africa, this kind of ecumenical (and Reformed) theology will certainly be deeply concerned.

This theological perspective supports those theoretical positions that argue that human rights are not only implemented by legal means and therefore also argue against all those restrictive views which claim that only individual rights should be regarded as proper rights, since only they are presumably justifiable and enforceable. Rather, this theological viewpoint would claim that human rights are promoted, implemented and realised, firstly, by political means, secondly by legal means and thirdly by resistance. ${ }^{29}$ Accordingly, the political and social preconditions must also be created without which human rights could not be enjoyed, including many of the rights formulated in sections of the South African Constitution's Bill of Rights under environment (24), property (25, for example on land reform), housing (26), health care, food, water and social security (27) children (28), education (29), language, culture, religion and life in community (30 and $31)$. From this theological perspective, the state indeed has the responsibility to respect and protect, but also 'to promote and fulfil' these rights (Chapter 2, section 7(2), Constitution). Necessary social and economic measures must be implemented and initiatives in the formation of public opinion that prepare, claim and welcome such measures should be supported and strengthened.

Under specific circumstances, theology may be concerned with all three ways of implementing human rights, including social and economic rights. Theology can, therefore, support victims of violations seeking legal remedies, especially when other social institutions fail to act (the second means). Theology can, also, join others in forms of public resistance whenever human dignity is systematically violated (the third means). The recent South African history bears witness to both these forms of theological involvement. The ecumeni-

28 W Huber Gerechtigkeit und Recht (note 22 above) at 59.

29 For an authoritative discussion of the integral role of protest and resistance within the Protestant theology and tradition, see W Huber Protestantismus und Protest (note 22 above); see also W Huber Gerechtigkeit und Recht (note 22 above) at 400-419. 
cal church has been deeply involved, both in helping victims of human rights violations, also by seeking legal support, as well as in civil disobedience (regarding specific laws seen as unjust) and public resistance of the apartheid system as such. ${ }^{30}$ Under normal circumstances, however, theology is particularly concerned with the first means of implementation, namely the political - creating the political conditions, strengthening the political will, finding concrete political policies and decisions and supporting practical political measures and actions that will help to implement human rights. Through the formation of public opinion, political action that will provide the conditions necessary for freedom and for living lives of human dignity is made possible. ${ }^{31}$

Theology does this - contributing to the formation of public opinion - primarily by serving the church. ${ }^{32}$ The ideal of theology and theologians directly impacting on society and public opinion is an illusion, at least in contemporary South Africa. ${ }^{33}$ The church, however, is a complex institution, with many forms and activities, and with the ability to influence South African

30 During the time of apartheid, for instance, the ecumenical church in South Africa through the South African Council of Churches and the Southern African Catholic Bishops' Conference made various studies and took part in many actions to address, challenge and overcome the human rights abuses in the country. See for example B Johanson (ed) Human Rights in South Africa (1974); as well as Human Rights and Repression in Southern Africa: The Apartheid Machine Grinds On (1989).

31 The Scottish ecumenical theologian Duncan Forrester has worked extensively on the subject of justice and public theology. For his views on the insights that Christian theology can provide for contemporary theories of justice, see D Forrester Christian Justice and Public Policy (1997). Another very insightful essay on the origin and meaning of the term 'public theology' may be found in EH Breitenberg 'To Tell the Truth: Will the Real Public Theology Please Stand Up?' (2003) 23 Journal of the Society of Christian Ethics 5596. Breitenberg distinguishes public theology from civil religion (out of which it partially developed), political theology, public church, public philosophy and public (or social) ethics. Another important and challenging study on the role of the church in public life is by the renowned social ethicist LL Rasmussen Moral Fragments and Moral Community: A Proposal for Church in Society (1993). Also in the context of South Africa, this debate may be followed with the valuable book by K Clements Learning to Speak: The Church's Voice in Public Affairs (1995), as well as contributions by NN Koopman 'Some Comments on Public Theology Today' (2003) 117 Journal of Theology for Southern Africa 3-19, and KT August The Quest for Being Public Church (2003) DTh thesis, University of Stellenbosch, Stellenbosch.

32 In this regard the relationship between church and ethics becomes important, as has been acknowledged in much recent debate in the ecumenical movement. An important study by the World Council of Churches on ecclesiology and ethics 'sought to explore the link between what the church is and what the church does. It explored the ethical dimension not as a separate "department" of the church's life, but as integrally related to its worship, its confession of faith, its witness and service in the world' (TF Best and M Robra 'Introduction' in TF Best and M Robra (eds) Ecclesiology and Ethics: Ecumenical Engagement, Moral Formation and The Nature of the Church (1997) at vii). On the many publications that have appeared on this important debate, see especially the work of the systematic theologian LS Mudge The Church as Moral Community: Ecclesiology and Ethics in Ecumenical Debate (1998), and the ethicist R Hütter Evangelische Ethik als kirchliches Zeugnis: Interpretationen zu Schlüsselfragen theologischer Ethik in der Gegenwart (1993). For a survey of the vast amount of work that the World Council of Churches has done on the church's responsibility to be a moral community (that not only reflects on its ethical dimension but also partakes in the search for justice in the world), see the influential study TF Best and M Robra (eds) Ecclesiology and Ethics: Ecumenical Engagement, Moral Formation and The Nature of the Church (1997). This work deals with the three groundbreaking documents, 'Costly Unity' (1993), 'Costly Commitment' (1994) and 'Costly Obedience' (1996) which paved the way towards a new approach to the relationship between ecclesiology and ethics, as well as further contributions by Duncan Forrester and Larry Rasmussen, already referred to in the previous note.

33 In South African scholarly circles the impact of theology on society and public opinion has often been discussed; see for example BC Lategan 'Taking the Third Public Seriously' in JW de Gruchy and S Martin (eds) Religion and the Reconstruction of Civil Society (1995) at 217-230; DJ Smit 'Oor die Kerk as ' $\mathrm{n}$ Unieke Samelewingsverband' (1996) 36 Tydskrif vir Geesteswetenskappe 119-129; DJ Smit 'Oor die Unieke 
society in important ways. ${ }^{34}$ It may, therefore, indeed and in several practical ways contribute towards changing the dominant theoretical paradigm - which, in the form of present public opinion, is probably contributing to resist the implementation of social and economic justice, according to the hypotheses of this project.

So-called public theology and the public church participate in the formation of public opinion - with all its practical consequences also for the implementation of social and economic justice. It does this in the full awareness of being only voices amongst many other voices, and without any special claims. Public theology includes social ethics, as well as the specialised so-called ethics of social institutions or different spheres of life in modern societies. ${ }^{35}$ Public theology through the public church has different modes of discourse as well as a wide range of activities at its disposal. These modes of discourse include the wisdom discourses of research, study, dialogue, consultation and education. It includes the priestly discourses of service and engagement, for example breaking down hostility and helping to build trust and reconciliation. ${ }^{36}$ It also includes - according to many, but not all - prophetic discourses such as critical witness and advocacy, when judged necessary. ${ }^{37}$ The activities

Openbare Rol van die Kerk' (1996) 36 Tydskrif vir Geesteswetenskappe 190-204; DJ Smit 'Openbare Getuienis en Publieke Teologie Vandag?' (2003) 82 Scriptura 39-48.

34 For more detailed analyses of the church's impact on South African society, see for example DJ Smit 'The Impact of the Church in South Africa after the Collapse of the Apartheid Regime' in K Bediako et al (eds) A New Day Dawning: African Christians Living the Gospel (2004) at 128-149; DJ Smit 'Oor die Kerk en Maatskaplike Uitdagings in Ons Land' (2004) 45 Nederduitse Gereformeerde Teologiese Tydskrif 350-362. In the last article for example it is argued that the church takes on at least six different social forms, namely: the worshiping assembly; the local congregation as human community; denominational structures and institutions; diverse local, regional and national ecumenical forms; individual believers in the fullness of their life and activity; participation of believers in different organisations, initiatives and forms of civil society. It is argued that each of these forms potentially impacts on society.

35 For essays dealing from different perspectives with the complex ways of building a human rights culture, see the volume of conference papers Botman and Sporre (eds) Building a Human Rights Culture (note 20 above).

36 A very instructive recent study on practices of social reconciliation, including consideration of the potential contribution of religious communities, is available in SF du Toit Learning to Live Together: Practices of Social Reconciliation (2003).

37 The respected social ethicist James Gustafson, formerly from the University of Chicago, gave a lecture series in 1987-88 on four such modes of moral discourse, which was subsequently published as J Gustafson Varieties of Moral Discourse: Prophetic, Narrative, Ethical, and Policy (1988). The first form of moral discourse, namely prophetic discourse, seeks to identify a moral evil in society and to raise awareness of the particular issue. It uses passionate language to criticise and confront existing power structures and offers ideal alternatives to the state of affairs. Narrative discourse tells paradigmatic stories that may reveal overt or hidden morals. Narrative tries, in a more subtle way than prophetic discourse, to persuade and inspire people and communities. On their own these two forms are, however, not sufficient. Moral discourse requires policy discourse, which rather asks what actions and transformation would in fact be possible (rather than simply desirable) within the given circumstances. Finally it also requires technical, ethical discourse in the strict sense, which tries to analyse and clarify matters through conceptual distinctions. Gustafson's typology initially remained limited to the ecumenical sphere (where it in fact originated after he made a thorough study of the ethical documentation of the World Council of Churches), but recently it has been taken up in the wider field of Christian ethics, such as the recent book by BV Brady The Moral Bond of Community: Justice and Discourse in Christian Morality (1998). This has also been introduced in South African Christian ethical circles - see for example DJ Smit and De Villiers 'Hoe Christene in Suid-Afrika by Mekaar Verby Praat ... Oor Vier Morele Spreekwyses in die Suid-Afrikaanse Kerklike Konteks' (1994) 15 Skrif en Kerk 228-247. 
of the public church range from the worship of local congregations ${ }^{38}$ through the institutional work of denominations and ecumenical bodies to the initiatives of believers and voluntary initiatives. The Beyers Naudé Center for Public Theology is dedicated to serve these purposes through such research, education and involvement, thereby hopefully contributing to more social and economic justice in South Africa today. 39

38 For a discussion of the both constructive and destructive ways that Christian worship can contribute to social justice, see DJ Smit 'On Learning to See' in; DJ Smit 'Seeing Things Differently' - On Prayer and Politics' in L Holness and RK Wüstenberg (eds) Theology in Dialogue: The Impact of the Arts, Humanities, and Science on Contemporary Religious Thought: Essays in Honor of John W de Gruchy (2002) at 271284.

39 The Beyers Naude Centre for Public Theology is one of a growing number of public theology institutes in the ecumenical church (www.sun.ac.za/theology/bnc). Others may be found in Scotland (The Centre for Theology and Public Issues at the University of Edinburgh, http:/www.div.ed.ac.uk/theologypubl.html), the United States (The Abraham Kuyper Center for Public Theology at Princeton Theological Seminary, http://www.ptsem.edu/grow/kuyper/; The Center for Business, Religion and Public Life at Pittsburgh Theological Seminary, http://www.pts.edu/busrel.html) and elsewhere. 


\title{
Beyond Labour Law's Parochialism: A Re-envisioning of the Discourse of Redistribution*
}

\author{
- LUCY A Williams \\ Professor of Law, Northeastern University \\ School of Law, Boston
}

\section{Introduction}

Left labour and welfare law constitute two primary fields of discourse about redistribution. However, each has traditionally seen itself as isolated, not only from one another but also from the critically related fields of immigration, family, and international law. The failure of each to engage with the other results in theoretical and political gaps that have contributed to both fields' inability to envision redistribution strategies sufficient to measure up to the power and pervasiveness of the conservative/neo-liberal agenda.

This essay seeks to draw threads between fields of inquiry and practice that progressives, especially labour and welfare lawyers, must understand as intimately linked. I argue that any progressive transformation of labour law requires intense engagement with welfare law. With notable exceptions, labour law still largely situates questions of power and income distribution within the framework of labour markets. Its perspective on work remains limited to wage labour. And it still privileges collective bargaining by unions within a nation-state as the primary site of progressive initiatives for economic and social redistribution. These internalized ways of thinking guarantee that labour law will become increasingly stultified and marginalized as the new century progresses, and that labour lawyers will have steadily less to contribute to economic redistribution and social change.

Likewise, progressive welfare lawyers have traditionally focused almost exclusively on central government transfers as the redistributive hub, failing to engage with and expose the state's role in constructing labour markets. More recently, since the 1996 US 'welfare reform', discussed below, progressive welfare lawyers have often focused on developing social services to help poor families 'overcome barriers to employment,' instead of challenging the structure of low-wage labour markets. Activists in both welfare and labour law, viewing their constituencies within nation-state boundaries, have not infrequently voiced protectionist rhetoric.

Privileging nation-state waged work as the site for redistributional politics ignores and devalues the needs and concerns of millions of productive, low- and non-waged workers in the globalized economy. Likewise privileging government transfers as the primary site of redistribution,

* This paper was originally published in J Conaghan, RM Fischl \& K Klare (eds) Labour Law in an Era of Globalization: Transformative Practices and Possibilities (2002) at 93-114 and is reprinted here with kind permission of L Williams, J Conaghan, RM Fischl and K Klare and Oxford University Press. 
counterintuitive as this might sound, contributes to the dominant discourse of a 'free market' by failing to expose the politically chosen, legally constructed labour market structures that reinforce income disparity. Left lawyers certainly do not intend their theoretical formulations and political stances to render disempowered populations invisible. But often, through lack of interdisciplinary and cross-border dialogue, we fail effectively to criticize our own positions and re-imagine broad-based redistributive political agendas.

This chapter attempts to expose ways in which many left labour and welfare lawyers have unwittingly played into a discourse that reinforces the economic status quo by validating the economic structures creating poverty. The left's default can be seen particularly in a failure fully to appreciate and expose the reinforcing links between three seemingly disparate legal-theoretic discourses that feed into the dominant political consensus on social policy. Together these discourses privilege and naturalize waged labour within a free market as the arena for productive participation in society, thereby justifying the assault on the welfare state.

The first is the discourse of the public and private distinction. Mainstream legal thought, both conservative and liberal, conceives private law as arising more or less naturally, rather than being a contingent product of state policy. Within this understanding, private law, and the institutions it structures such as market and family, arise 'prior to' and independent of state power. This conceptual framework naturalizes the existing distribution of wealth and power in these social arenas, which then appear to have nothing to do with, and indeed, to require protection from state intervention. In addition, it necessarily marginalizes welfare law and policy by portraying it as government 'intervention' into natural market outcomes and family arrangements. When welfare lawyers focus on government transfers, and when labour lawyers marginalize welfare law as state intervention, both are contributing to the legitimization of the 'free market.'

Similarly central within the dominant legal and policy framework, is the conception of a 'worker' as someone engaged in wage labour. Social protection laws connected to waged work frequently further narrow the meaning of 'worker' to those in full-time, high-wage, long-term jobs. This definition identifies as 'non-workers' and therefore excludes many individuals who are, in fact, active in waged work as well as the many who work but do not receive a wage. These definitions reinforce the socially constructed identities upon which mainstream discourse and political rhetoric are founded. By pursuing a traditional social welfare agenda ${ }^{1}$ primarily connected to an anachronistic image of the waged worker, and by distancing other members of society as 'non-productive,' labour contributes to the stigmatization of millions of low-waged and non-waged workers, including welfare recipients and immigrants.

Finally, there is the notion of social citizenship, to which some progressive welfare and labour policy-makers have subscribed, often as a repository of democratic and egalitarian aspirations, without critically assessing the gender, racial, and economic biases of traditional citizenship discourse. In addition, they typically view their fields within the boundaries of nation-state citizenship, without engaging with the current social reality of global economic integration or the

1 In the US, 'welfare' is commonly used to refer to Aid to Families with Dependent Children (AFDC), replaced in 1996 by Temporary Assistance to Needy Families (TANF). Throughout this chapter, I use the term 'welfare' to refer to social assistance programmes, the eligibility for which is means-tested, not conditioned on a requisite tie to waged work. I use the term 'social welfare' in a broader sense, to include both social assistance and social insurance programmes, in which eligibility is defined by a sufficient attachment to waged work. 
class, racial, and alienage implications of a citizenship paradigm that fails to incorporate a cross-border perspective.

By failing critically to analyse our roles in perpetuating these discourses, left labour and welfare theoreticians have, albeit inadvertently, ceded discursive and political ground to the conservative/neo-liberal consensus, contributing by default to the hegemonic discourses that portray the social status quo as natural. Through interdisciplinary and cross-national dialogue by and among progressives working in the fields of labour, welfare, immigration, and international economic organization, we can strengthen our critiques, and better position ourselves to disrupt the 'naturalness' and self-fulfilling quality of dominant discourse.

My particular focus is on the perceived lack of connection between labour and welfare law, primarily in a US and UK context. I then draw threads from labour and welfare to the areas of family, immigration, and international economic law. My hope is that by elucidating theoretical and political gaps in and among these fields, we can develop a more sophisticated redistributive agenda - one that is multicultural and gender-sensitive, allowing, indeed encouraging, transformation of social roles, and one that incorporates a re-imagined, globalized conception of citizenship, attentive to racial and gender differences. Finally, it should be one that reclaims and re-legitimates redistribution, moving beyond the mere redistribution of income to facilitate the redistribution of power, resulting in self-actualization and active citizenship within the market, family, and political community. One (although only one) step toward developing the theoretical tools needed to revitalize transformative politics is for labour lawyers and others thoroughly to engage with the insights and innovations of modern welfare law.

\section{The Legal Creation of Poverty}

Welfare law is premised upon and uniquely illuminates fundamental teachings of critical legal thought first developed, in the US, by the Legal Realists. The core insight is that all legal rules are contingent products of human choice that have distributive consequences. That is, legal rules affect the distribution of wealth and power, whether vertically among classes, horizontally among races and genders, or internationally among regions, communities, and nation-states. For a century, traditional legal thinkers have engaged in intense ideological work to suppress or marginalize these insights. Left-legal theorists and practitioners have resisted this hegemonic view. But they have never fully appreciated the theoretical contributions of welfare law or its potential as a forum to expose the legal means by which poverty is perpetuated. By uncritically accepting the mainstream view that welfare law takes market outcomes as its starting point, left-legal theory has implicitly validated the mainstream view that the background rules structuring market behaviour are not really acts of government.

The dominant political discourse in Western nations, reinforced by our legal culture, teaches that poverty arises naturally and that the legal system bears no responsibility for causing it. Private law concepts of family, tort, property, and freedom of contract are made to appear as the necessary and neutral framework of social and economic power relations, arising independently of law. The dominant political culture denies that these background rules privilege any group or have anything to do with allocating wealth or income. The role of law in distributing property, valuing waged labour, and consequently devaluing family work, is almost always invisible.

In fact, the stubborn persistence of poverty, in both developed and developing countries, largely results from political and legal decisions and institutions that generate and sustain a 
sharply unequal distribution of wealth and resources. Far from being natural or neutral, legal rules, norms, and practices play a central part in maintaining poverty by according privilege to and legitimating certain values, interests, and concerns over others. Legal precepts shape social roles by assigning power and responsibility in social relationships, whether within the family or in the workplace.

For example, the everyday common sense of modern, democratic, political and legal cultures that the family is a private haven from the public realms of market and government - ignores the intimate, indispensable, and legally constructed connections between these social spheres. As discussed below, the production of goods and services for the market by paid workers depends on the subsidy of unpaid care-givers' - predominantly women's - labour. Similarly, family wealth and income could not exist without the full range of property rules entrenched by government. The rules that comprise freedom of contract, referring to rich and poor, male and female, and employer and employee as 'equals' because they formally share the power to contract, ratify steeply unequal access by individuals and families to the economic means of life-enjoyment. The state is not independent from other social structures. The state entrenches those structures.

Nor is the existing array of background legal rules inevitable. Human actors, making implicit or explicit moral and political decisions about who is and is not deserving of reward, create legal entitlements that reflect and enact distinct political values. All of the ways in which society sustains income inequality and poverty - whether through government programmes funded by general taxation, market structures, familial responsibility, or private charity - reflect politically chosen regulatory policies.

Welfare law, whose raison d'être is to question the existing distribution of wealth and income, provides a forum for exploding the neutrality of these background rules of entitlement. It is, therefore, at least potentially, a permanent threat within mainstream jurisprudence because it reveals the false pretense or illusion that the bedrock common law of property, market, and family is distributionally neutral and exists prior to and independent of governmental action. From a critical perspective, welfare discourse sees every legal artifact as crafted by officials in a given historical and institutional framework. Thus, welfare law persistently threatens to reveal the contingency and political character of all law.

Mainstream politicians, at least subliminally alert to the Trojan-horse nature of welfare law and its potential to explode the most basic assumptions of the legal culture, periodically go to considerable lengths to suppress its critical aspect and to recast welfare law in a manner consistent with status quo assumptions. Just as labour law's potentially radical implications for wealth and power distribution, even within the limited waged work sphere, were blunted by a functional reinterpretation of the discourse, ${ }^{2}$ so, too, have progressive ideas in welfare law needed to be domesticated or marginalized. Thus, mainstream policymakers and jurists face the intellectual challenge of creating a conception of welfare law that, while moderately re-distributive, does not disrupt or delegitimate core institutions.

To accomplish this goal, a modicum of procedural due process, and thus a perception of fundamental fairness, was incorporated into welfare law. ${ }^{3}$ But this concession, important as it was, has been ultimately overwhelmed in significance by increasingly vitriolic debate about the welfare system's very purpose. The normative foundations of welfare state theory are ideas about

2 K E Klare 'Workplace Democracy and Market Reconstruction: An Agenda for Legal Reform'(1988) 38 Catholic University L Rev at 1, 'Judicial Deradicalization of the Wagner Act and the Origins of Modern Legal Consciousness' (1978) 62 Minnesota LR at 1049.

3 See, eg, Goldberg v Kelly 397 US 254 (1970) and its progeny. 
equality and minimum material circumstances for a meaningful life-experience. Over the last twenty years, the 'new' welfare theory, legitimated and promoted by a policy consensus of conservatives (for example, Thatcher and Reagan) and liberal/neo-liberals (for example, Blair and Clinton), has promoted different assumptions and commitments.

One normative baseline of this strange alliance is a modernized version of the old ideal of liberty, meaning freedom from governmental interference. Advancing under the banner of the so-called 'Washington Consensus' and espousing the virtues of deregulation, limited government spending, and free trade, politicians in many Western nations ${ }^{4}$ have attacked and dismantled previously well-established welfare programmes. Most varieties of the neo-liberal tradition take the position that social provision is a sometime necessary evil to correct market failures and imperfections, just as sometimes the state must 'intervene' in domestic matters because of family-breakdown. ${ }^{5}$ Many New Right theorists and politicians acknowledge the possibility of market failure in theory but doubt its existence in practice. Accordingly, social provision for them is simply an interference with the free market and has no legitimate purpose. But the various wings coalesce around so-called free markets and the two-parent heterosexual family as the appropriate institutions for distributing wealth and power.

In sum, the intellectual achievement (if one can call it that) of the conservative/neo-liberal 'welfare reform' consensus is to formulate social policy as an adjunct to private law. Questions of income, wealth, and power inequality - let alone redistribution - fade from the picture.

Moreover, the consensus is also built on historical ambivalence over how much the poor are responsible for their own plight, resurfacing the causation issue with intensely pejorative rhetoric. Welfare benefits, the consensus holds, generate pernicious social consequences, as well as inefficiencies, and must be eliminated because they foster a culture among the poor that does not reflect majoritarian values. ${ }^{6}$ This discourse attributes poverty to individual fault, characterized as a lack of the work ethic in the first world and a lack of acquaintance with or mastery of entrepreneurial values and skills in developing countries. The common assumption is that individual agency can always overcome cultural, societal, and economic obstacles. The argument continues that these individual character flaws are largely created and sustained by the institution of welfare. Thus it is argued, without a trace of irony, that because the welfare state creates dependency, welfare actually causes poverty rather than ameliorating it. Without state intervention, the free market would create the incentives for mainstream attitudes and behaviour, by which is meant those consistent with waged work and the patriarchal family. The rhetoric of individual responsibility and institutional dependency legitimates the inevitability of

4 Of course, many European countries continue to maintain more expansive welfare states, including additional family supports, albeit still retaining elements of gender bias as well as racist connotations in terms of immigration law and immigrant access to benefits. The role of social protection and labour in many Latin American, African, and Asian countries is, in many ways, even more complex. This chapter does not attempt to highlight and problematize the labour and social welfare debate throughout the world, but focuses rather on US/UK discourse, which currently forms the basis of discussion in many other countries, in part because of World Bank and International Monetary Fund structural austerity measures.

5 FE Olsen 'The Myth of State Intervention in the Family' (1985) 18 University of Michigan J of Law Reform 835 at 835 .

6 For discussions of the history of welfare theory from various sub-movements of the right, see L Williams 'Welfare Law and Legal Entitlements: The Social Roots of Poverty' in D Kairys (ed) The Politics of Law: A Progressive Critique (1998) 569; L Williams Decades of Distortion: The Right's 30-Year Assault on Welfare (1997); L Williams 'The Ideology of Division: Behavior Modification Welfare Reform Proposals' (1992) 102 Yale L J 719. 
growing disparity in the distribution of wealth both within and between nation-states and underwrites the policy imperative of dismantling the welfare state. The hegemonic success of this rhetoric has led to a significant retrenchment in availability of and entitlement to social protection benefits.

Despite differences, mainstream political rhetoric about welfare, from moderate-liberal to the far right, have come to share a common thread in recent decades by subsuming welfare policy into private law. At best, welfare smooths out rough edges of the free market (what are technically called 'market imperfections' or 'externalities'). This theoretical ploy cried out for a progressive response aimed to show that the background rules and assumptions by which law regulates the free market themselves constitute a site of distributive conflict. Instead, most left-legal criticism has pursued one of two alternative avenues.

Progressive welfare theorists have largely seen their task as that of defending the legitimacy of state 'intervention' to achieve egalitarian redistribution. Of course, they make strong arguments against welfare retrenchment, for example, skillfully rebutting the argument that welfare is an addictive drug, and exposing the racism and sexism inherent in the welfare reform consensus. But their ultimate solution to poverty and inequality is still framed as a system of central government transfer payments, criticized by some politicians as a 'tax and spend mentality.' The Achilles heel of this approach is that it concedes the mainstream's central premises, that free markets and governmental regulation are diametrically opposed modes of social ordering, and that family and markets are autonomous from state power. Progressive welfare advocates' method of redistribution assumes a conceptual framework in which a 'regulatory' state intervenes in a 'free market.' That focus contributes to the belief that the legal background rules governing the market and the family have no part in the distribution of income and power and operate in a totally separate realm from welfare law. In other words, welfare law is about state intervention in a normally 'free' realm, while background legal rules arise more or less spontaneously in private spheres. Thus welfare law's traditional, bounded assumption that central government transfer policy is the primary arena of redistribution has frustrated its efforts to counter the centre/right consensus and challenge the overall legal structure of inequality.

While labour lawyers take for granted that labour markets are sites of distributive conflict, they customarily fixate on increasing waged workers' bargaining power. Unable to think very far beyond labour market conflict as the engine of redistribution, left labour academics and activists have unwittingly reinforced the naturalization of family, contract, property, and tort law. Rarely do they deploy their critical arsenal against the background rules of private law that give existing labour markets their highly inegalitarian shape. Like most practitioners and legal academics, they fail to appreciate the importance and theoretical richness of welfare law or to develop its connections with and implications for labour law. By marginalizing welfare law as separate from labour law, they have contributed to a discourse that frames welfare law as comprising isolated acts of 'state regulation,' thereby naturalizing the free market.

This limited view of welfare law as anomalous state intervention, and the artificial conceptual divisions between family, state, and market, ${ }^{7}$ regrettably mirrors the ideas behind the current welfare reform consensus. The hegemonic rhetoric, in both the US and UK, deflects attention from the political underpinnings of income inequality and instead focuses on an alleged

7 See generally AS Orloff 'Gender and the Social Rights of Citizenship: The Comparative Analysis of Gender Relations and Welfare States' (1993) 58 American Sociological Rev 303. 
breakdown of the natural family and the failure of poor people, particularly lone mothers, to participate in the 'free' market. The prevailing political consensus relies on this unchallenged belief in the neutrality of private law to support the dismantling of welfare programmes, articulated as public interventions in the natural order but which are really ameliorative adjuncts to alienated waged work. Critical welfare and labour law must expose the state's presence in structuring and distributing power in families and markets, and it must reclaim welfare law as a site of redistributional politics. It must engage with and undermine the central premise of the contemporary welfare reform consensus (and its historical antecedents) that poverty can be alleviated simply by strengthening families and pushing people into wage labour. And it must expose and challenge the class, gender, and racial biases of the legal rules structuring family life and market processes.

\section{Social Welfare Laws Construct Identities and Exclusions}

Having artificially distinguished public and private realms, placing welfare in the former, the next challenge for mainstream political discourse was to explain why some central government income transfers are legitimate without exposing the contingency of all socio-economic structures. Why choose some income transfers and not others, just as easy to imagine (for example, a guaranteed minimum income funded by steeply progressive taxation)? One solution has been to define 'legitimate' income transfers so as to reinforce the core institutions and understandings of the social status quo, made 'natural' by common law background rules. Thus, social welfare laws and policies were crafted in the shadow of an assumed model of alienated wage labour, comprised of breadwinners who were subsidized by unpaid work in the home based on a gendered division of labour. In the process, social welfare law built upon and added its own nuances to law's naturalizing and legitimation projects.

An area of doctrine that illuminates this process concerns the legal designation of eligible claimants for various social welfare programmes. In legal fiction, drafters of social welfare statutes develop policy based on a population consisting of people with fixed identities independent of law (for example, a person who is, in medical terms, permanently disabled from waged work). But drafting and administering welfare laws are political practices with discursive as well as instrumental consequences. In short, legal work creates meanings. Social welfarerelated legal practices partially construct the identities of deserving and undeserving claimants.

By way of illustration, one of the most fundamental distinctions in social welfare law is between programmes for 'workers' who suffer income interruption (due, for example, to unemployment, accident, or retirement) and programmes for 'non-workers.' Social insurance programmes for 'workers' or ex-workers are typically financed by employer-employee contribution schemes. Social assistance programmes for 'non-workers' are commonly financed from general revenues, and are less generous and highly stigmatized. An elaborate body of statutory rules and doctrines determines who is a 'worker' and who is not.

The worker versus non-worker distinction is highly ideological. It draws upon and develops the messages of the legal culture generally - the public/private distinction, the disjuncture of family and market, and the privileging of market activity. The highly negative popular image of welfare beneficiaries is largely a self-fulfilling prophecy of general social welfare law and policy, built upon long-standing prejudice against the poor, whether in waged or non-waged work.

To begin with, the fundamental, and fundamentally gendered, assumption of mainstream theory is that 'work' means paid work, and 'worker' means someone who works almost exclu- 
sively in wage labour. Traditional theories of 'productivity' largely exclude the value of unpaid labour as an integral factor, a cost of production. Workplace productivity assessments are based on factors that isolate one's role in paid work and ignore other parts of life that influence, contribute to, or detract from productivity. While economists and lawyers speculate about increased 'efficiency' or 'productivity' as if these were fixed or 'natural' concepts, they ignore production costs currently absorbed by the household, such as the provision of health care and childcare. The production of value outside and apart from paid work for employers does not 'count' (it is valuated at zero), so policy makers take this form of subsidy largely for granted. ${ }^{8}$

In addition, since everyone (including, by the twentieth century, women) owns his or her labour power and has freedom of contract, everyone potentially can work (that is, earn wages). So if a woman does not earn wages, and also fails to marry and make a home for a wage-earning spouse, her poverty is attributable to her social deviancy. Such a person becomes 'dependent' on 'the state.' The main point of this rhetoric is, of course, to stigmatize the victim, but there are several powerful subtexts. First, since waged work is the opposite of non-waged work, and since non-waged work is 'dependent,' waged work must be 'independent.' Therefore mainstream theory complacently ignores or actively suppresses the alienated, subordinate, often authoritarian character of waged work, and most waged workers' utter dependence on how well their employers manage and cope with technological and market shifts.

Secondly, since 'non-worker' recipients of social assistance are dependent on the state, everyone else must be independent of the state. Therefore, mainstream theory ignores the role of government in creating and protecting the 'entitlement programmes' of the well-to-do, namely, the background laws of property, contract, family, and tort, not to mention tax and other subsidies to business and to middle and upper-class households.

The mainstream framing of social welfare policy in terms of the worker/non-worker distinction produces many unfortunate consequences for both general public debate and the left's ability to imagine transformative alternatives. Among the most damaging is that this perspective renders invisible the population who are both 'workers' (that is, waged workers) and 'non-workers' (welfare recipients, most of whom do massive amounts of unpaid family work).

Large numbers of people cycle between low-waged work and welfare programmes. Studies within the US, immediately preceding the 1996 US 'welfare reform', document welfare and waged work as inextricably intertwined, thereby challenging the widely held assumption that welfare recipients are a category separate and distinct from paid workers. A majority of women receiving welfare move in and out of low-waged work on a regular basis. ${ }^{9}$ One study found that of the sixty-four per cent of women on welfare for the first time who left the rolls within two years, almost half left for work. But of those who left, three-quarters eventually returned; forty-

8 On the economic interdependence of paid and unpaid work and its invisibility in dominant discourse, see further K Rittich 'Feminization and Contingency: Regulating the Stakes of work for Woman' in J Conaghan, RM Fischl \& K Klare (eds) Labour Law in an Era of Globalization: Transformative Practices and Possibilities (2002) 117-137.

9 If one used 'point in time' data, ie, counting the percentage of those on a given day both receiving welfare and participating in wage work, there appears to be very little overlap, figures showing only about $7 \%$ of welfare recipients are also in paid labour. Staff of House Committee on Ways and Means Background Material and Data on Programs. Within the Jurisdiction of the Committee on Ways and Means (1996) 104th Cong $2 d$ Sess at 474. But this type of data collection does not take into account the 'cyclical welfare/work population.' 
five per cent returned within a year. ${ }^{10}$ Another study found that seventy per cent of welfare recipients participated in some way in the wage labour force over a two-year period: twenty per cent combined paid work and welfare, twenty-three per cent worked intermittently, receiving welfare between jobs, seven per cent worked limited hours and looked for more paid work, and twenty three per cent searched for, but could not obtain, paid work. The women in this study held an average of 1.7 paid jobs over the two-year period and spent an average of sixteen weeks looking for paid work. ${ }^{11}$

As in most Western nations, the US legal rules concerning eligibility for benefits under the Unemployment Insurance (UI) system reflect the false dichotomy between waged workers and welfare recipients. Although low-waged workers contribute to the UI benefit-pool in the sense that employers pass payroll taxes onto them in the form of lower wages, UI rules exclude many lowwaged workers, particularly women ${ }^{12}$ and people of colour, from the definition of 'employee.'13 Minimum past earning requirements in many states ${ }^{14}$ render ineligible many part-time, low-wage workers. ${ }^{15}$ Thus most of the single mothers who moved from welfare to wage labour and then lost their jobs found they were ineligible for the UI Program. In one study of women-maintained families in which the mother was employed for at least three months, almost three times as many families turned to welfare as to UI. In another study of 1,200 single mothers who received welfare for at least two months in a twenty-four month period, forty-three per cent also worked, averaging just about half-time. However, only eleven per cent of those who worked later qualified for UI. By denying many low-wage earning mothers transitional support when they become unemployed, forcing them to resort or return to welfare, UI law constructs them as persons who are 'not attached to the labour force,' that is, as social deviants who cause their own poverty by refusing to work and who are, therefore, unworthy of assistance from society.

10 LD Pavetti The Dynamics of Welfare and Work: Exploring the Process by Which Young Women Work Their Way Off Welfare, unpublished PhD dissertation, JFK School of Government, Harvard University (1993).

11 R Spalter-Roth Making Work Pay: The Real Employment Opportunities of Single Mothers Participating in the AFDC Program (Washington DC: Institute for Women's Policy Research, 1994).

$1220 \%$ of women were excluded based on minimum weeks of prior employment as opposed to eight percent of men. $10 \%$ of women were disqualified based on the required amount of earnings in the highest earning quarter compared to $4 \%$ of men. Minimum earnings requirements disqualified $4 \%$ of women as opposed to $2 \%$ of men. Taken together, prior earnings requirements excluded $34 \%$ of women as opposed to $15 \%$ of men. YH Yoon, R Spalter-Roth \& M Baldwin Unemployment Insurance: Barriers to Access for Women and Part-Time Workers (Washington DC: National Commission for Employment Policy, 1995) 24.

13 For example, UI coverage requires not just a connection to waged work, but a sufficient connection, disadvantaging low-waged and contingent workers. To meet monetary eligibility minimums, low-waged workers must work more hours than higher paid workers: Advisory Council on Unemployment Compensation, Report and Recommendations (Washington, DC: US Government Printing Office, 1995) 17. In nine states, a half-time, full-year (1040 hours of work) worker who earns minimum wage is completely ineligible for benefits, while the worker who earns $\$ 8.00$ an hour for the same hours of work is eligible (ibid). Likewise, a two-day a week, full-year worker earning minimum wage would be ineligible in 29 states, but the same worker earning $\$ 8.00$ an hour would be eligible in all but two states (ibid).

1433 states require that a minimum amount of earnings be received in an individual's high-waged quarter. Thus, workers who concentrate their work hours in a shorter period are more likely to meet the eligibility requirements (Advisory Council on Unemployment Compensation (note 13 above) at 94, 98). For example, nine states would disqualify a half-time, full-year minimum wage worker (who worked 1040 hours), but only one state would disqualify the same worker if she worked the same number of hours full-time for 26 weeks and did not work at all for the rest of the base period (ibid 98).

15 One study found that $10 \%$ of all unemployed part-time workers received unemployment insurance as opposed to $36 \%$ of full-time workers: Yoon et al (note 12 above) at 34 . 
Far from welfare recipients demonstrating an unwillingness to work, these studies suggest that most welfare recipients prefer and endeavor to earn wages even under the most trying personal circumstances. Their efforts are frequently frustrated by barriers for which legal rules and public policies are responsible. Often, they cannot find employment for which they are qualified. Even in times of low unemployment, low-waged work conditions are so precarious as to guarantee that many low-waged earners will periodically cycle through periods of unemployment. Low-waged jobs in the US, UK, and many other developed nations pay below-subsistence wages (thereby ensuring that workers cannot provide for their families), provide little or no training or advancement opportunities, and typically have inflexible work schedules allowing no adjustment for the family care needs of low-income families who do not have nannies or other family members available to care for their children and elders. Low-wage employers often induce employee turnover as a wage-depression strategy. Far from providing a forum for selfactualization, independence, autonomy, and empowerment, these jobs generate self-alienation, depression, poverty within wage work, and disempowerment.

The perceived bifurcation of waged work and welfare receipt allows the idea of dependency to be severed from any connection with the sale of labour power in the market, discursively erasing the alienation and subordination within low-waged work. The legal system defines who is a worker and who is independent, thereby stigmatizing adults who do not meet the legal definition of worker as trapped in dependency. The legally constructed identity of welfare recipients as shiftless non-workers, rather than as 'autonomous' wage earners, reinforces the negative images of welfare recipients that resonate so deeply with much of the US and UK public. This 'reality' drives the debate about welfare reform, as, for example, during the US debates leading to the passage of the 1996 Personal Responsibility and Work Opportunity Reconciliation Act (PRWORA). The PRWORA limits a family's ability to get welfare to a maximum of five years in a lifetime, and mandates stringent work requirements even during the eligibility period. In other words, the Orwellian power of legal discourse to portray workers as non-workers creates a disconnection between people's experience as workers and their recognition as workers. Like the background rules that divide the family and the market into independent 'private' spheres, both separated from 'state-imposed' welfare, social welfare laws create and reinforce identities and images that deeply influence labour and welfare policy debates.

Unfortunately, progressive labour lawyers have often played into this discourse, again privileging labour markets as the site for redistributive politics and wage labour as the arena of productivity. The dominant consensus treating 'dependency' as a condition located outside waged work helps sustain a cultural and psychological framework that encourages the labour movement and waged workers to deny or overlook their dependency and subordination. Labour movements can and do view government transfer programmes serving paid workers as legitimate entitlements for those who contribute to society, not for those dependent on society.

For example, UI laws in the US often reflect hard fought victories for the labour movement. But traditionally, as US unions lobby for improvements in and expansion of UI laws, they have consciously distanced themselves from welfare recipients. Indeed, in urging UI reform, unions have often explicitly invoked the rhetoric of the 'worthiness' of UI as an earned entitlement, specifically juxtaposed against a view of welfare as an unearned 'dole' for non-workers. Perhaps they have done so under an assumption that union members or prospective members will never need to rely on welfare or be out of waged work for substantial periods of time because of family responsibilities, or that incremental victories for waged workers within the bargaining unit can only be achieved by valorizing a certain 'self-reliant' image of earner. However justified, this 
approach has deflected labour's attention away from government social policy as an arena of redistributive politics separate from ameliorating market imperfections.

Thus organized labour plays into the fundamentally conservative vision that even favoured social programmes like UI (as we have seen for welfare programmes as well) are simply an adjunct to market outcomes, rather than potentially redistributive programmes. And, however unwittingly, labour reinforces the social exclusion of non-waged workers.

\section{Who is a Citizen?}

Recently, activists and theorists on both the left and right have embraced a refurbished discourse of citizenship as a paradigm for developing welfare policy. Despite some rhetorical appeal, this turn to citizenship discourse has not avoided, and, in some ways, has deepened, the problems arising from more traditional framings of social policy questions: privileging the market as a site for self-actualization and independence, while often ignoring, misunderstanding, and, on occasion, rendering invisible invidious class, gender, racial, and alienage biases, thereby devaluing subordinated social groups.

Advocates of the New Right have advanced claims about the obligations of citizens to support arguments for reducing or eliminating social protection programmes. They pose 'active citizenship,' by which they mean participation in waged work, as an alternative to social protection. This rhetoric has been generously incorporated into current policy thinking in the US and UK and lends support to the welfare reform consensus. Ironically, many left activists and theorists in the US and UK are also embracing a discourse of citizenship, in part as a medium for developing arguments to defend social protection in the face of the welfare reform consensus. At times, they rely on an aspect of the idea of social citizenship, ${ }^{16}$ that communal provision of basic needs is critical to human flourishing and self-actualization. The democratic and republican overtones are appealing, and revitalizing the concept of social citizenship may be seen as a helpful way to move beyond the liberal conception of formal equality based on acquisition of property, the franchise, and the right to associate. On the other hand, the concept of citizenship carries considerable ideological baggage. The willingness of progressive activists and theorists to work within an unreconstituted, unchallenged discourse of citizenship can be dangerously misleading in two important ways:

First, within most political and theoretical discourse to date, the idea of citizenship is premised on one or another version of the public/private distinction, with the obligations of citizenship, albeit couched in neutral terms, incorporating racial and gendered models of white male productivity in the public sphere. Secondly, classical concepts of citizenship rest on a model of political community that most theorists, including most left theorists, have been unwilling or unable to detach from the notion of the 'nation-state.' The modern nation-state is the product of historical forces, including conquest, imperialism, exclusion, and genocide. Nationalism is sometimes an emancipatory discourse of self-determination, but is often a platform for racism and domination. Thus the left should interrogate not valorize the nation-state or build a political theory on it.

16 See generally TH Marshall 'On Citizenship and Social Class' in Class, Citizenship and Social Development (1964) at 28 where citizenship is defined as 'a status bestowed on those who are full members of a community' and developing three stages of citizenship: civil, connoting liberty and property rights, political, connoting the franchise and right to organize, and social, connoting economic welfare and security. 
Citizenship discourse encompasses both rights and obligations within the 'public' sphere. In its traditional, more limited, version, 'public' means 'governmental,' and 'private' includes the realms of market, waged work, and family. Public/private corresponds to state/civil society. Under this model, citizenship entails entitlements and duties to participate actively in the political affairs of the day (for example, by voting and the exercise of expressional rights). People of colour, women, children, and individuals without real property - groups who have historically suffered political disenfranchisement - have been to a significant extent excluded from this traditional conception of citizenship.

Progressives fought a long, uphill battle to bring the concept of citizenship into the paid workplace in the form of collective bargaining rights, minimum labour standards, and equal employment opportunities. Even so, the expansion of citizenship rights into paid work, as progressives traditionally fought for it, has incorporated a racialized, gendered breadwinner model. In other words, traditional progressivism effectively promotes a second version of the public/ private distinction, in which 'public' means government and economic activity, whereas 'private' denotes the family. Although the boundary between the public and private has shifted, citizenship obligations continue to incorporate racial and gender hierarchies and bias by excluding those who are economically disenfranchised, that is, insufficiently attached to waged work. Little conceptual progress has been made to imagine viable alternative forms of citizenship participation in other arenas. Specifically, citizenship obligations until heretofore have not included care-giving, and correspondingly, the image of the citizen does not include care-givers, whether wives, servants, or slaves.

As previously disenfranchised groups have acquired formal, political status as citizens, with rights to vote, contract, own property, and associate, the dominant political culture has embraced the assumption that 'equality' has been achieved - that all individuals, regardless of race, class, and gender, stand on an equal playing field and can negotiate in markets and family structures as equals in the pursuit of economic welfare and security. Thus, the traditional discourse of citizenship reinforces formal conceptions of equality, individualism, and self-reliance, and the view that individual responsibility (merit and effort) is the primary method for correcting economic and power imbalances. An imagery of citizenship focused on independent and autonomous individuals possessing rights and obligations within the public sphere legitimizes the correlative imagery of 'dependants' - people who are not full citizens because they are not in waged work. Paid work becomes the forum within which social citizenship can be recognized. In other words, the 'private' pre-legal rules of the market become the 'public' cultural sphere through which citizenship obligations can be fulfilled.

It is very difficult to erect a broad, multi-layered programme for economic redistribution on such a platform. Indeed, from this, it is a short step to rhetoric emphasizing the need for welfare recipients to be active and productive participants of society within the public sphere of waged work. This concept of citizenship - the white male breadwinner version - excludes welfare recipients cycling in and out of low-waged employment, juggling the demands of paid work and family responsibility, as well as care-givers who are not in the paid labour market. Like the statutory definitions of 'worker' that exclude low-waged workers and home-makers, building 'social citizenship' on the foundation of an unproblematized, liberal conception of who is a citizen risks excluding welfare recipients and others considered outside mainstream society. ${ }^{17}$

17 Note the current rhetorical deployment by the UK government of notions of 'exclusion' and 'inclusion,' often designating lone mothers as 'excluded' from society, reminiscent of the poverty discourse in Elizabethan times that viewed the pauper as outside the community, ie, in the poor house. On current UK welfare policy, see further Conaghan 'Woman, Work and Family: A British Revolution' in J Conaghan, RM 
Because the dominant discourse embraces formal, ahistorical conceptions of the individual, the citizen, and equality, concepts of social citizenship uncritically derived therefrom will not be sufficiently sensitive to the structural limitations of civic rights and entitlements in societies permeated by illegitimate racial, gender, and class domination.

Yet often left labour and welfare theorists have not attended to the highly gendered and racialized nature of citizenship as we know it, nor have they done much to re-envision the concept to include the life experiences and needs of the millions of people who cannot meet the conventionally defined obligations of citizenship. ${ }^{18}$ The forum for fulfilment of citizenship, even among progressive labour and welfare advocates, remains the public realm. Labour's conception of social citizenship refers largely to collective action and minimum guarantees in the labour market. Jurists interpreting welfare laws valorize waged work as the privileged site of human self-realization. ${ }^{19}$ Not surprisingly, since the PRWORA, many progressive welfare lawyers have focused on assisting poor families to overcome barriers to participation in paid work. They have done so, however, without seriously challenging the mainstream tenet that government 'interventions'- like welfare programmes - are presumptively inefficient and should be carefully limited to the role of ameliorating the contradictions, and correcting the imperfections, of the market. A left political agenda that merely grafts some socio-economic rights onto the model of citizenship, albeit within discourses of workplace democracy and egalitarian family relations, fails to problematize its foundational concepts.

Even if we were to develop a richer conception of participation, for example, by including care-giving activities currently denigrated because of the privileged place of politics and wage labour, it remains the case that citizenship discourse rest historically on notions of membership and participation in a particular polity or nation-state. ${ }^{20}$ Although this may not be logically entailed, membership is taken to imply exclusion, whether by social or geographic boundaries. But the nation-state as we know it owes more to conquest, racial exclusion, imperialism, and genocide than to the liberal-democratic revolutions and the progressive appeal of self-determination. ${ }^{21}$ When labour and welfare academics and activists take the national context for granted, we fail to grapple with the intricate connections linking social protection, labour, mobility of capital, and immigration, often, in ostrich-like fashion, hiding our heads in the sand in a time of increasing global economic integration.

Fischl \& K Klare (eds) Labour Law in an Era of Globalization: Transformative Practices and Possibilities (2002) 53-74.

18 Notable exceptions include JS O'Connor 'Gender, Class and Citizenship in the Comparative Analysis of Welfare State Regimes: Theoretical and Methodological Issues' (1993) 44 British J of Sociology 501; YuvalDavis 'Women, Citizenship and Difference' (1997) 57 Feminist Rev 4; Orloff (note 8 above); R Lister 'Citizenship: Towards a Feminist Synthesis' (1997) 57 Feminist Rev 28.

19 See, eg, New York State Department of Social Services v Dublino, 413 US 405 (1973), and Brief of the Appellants, New York State Departments of Social Services and Labor and their Commissioners at 36: '...But work is not an obligation that makes less of a man[sic], but rather it makes more of a man. Tub work is more than doing a job, putting in time and collecting pay. Work is a source of interest, of friendship, and of activity that gives meaning and fulfillment to life...'

20 For additional discussion of the idea of citizenship within the discursive framework of the nation-state, see further, Bosniak 'Critical Reflection on "Citizenship" as a Progressive Aspiration' in J Conaghan, RM Fischl \& K Klare (eds) Labour Law in an Era of Globalization: Transformative Practices and Possibilities (2002) 339-352.

21 Recent US critical approaches to international law have begun to articulate more complex, multi-layered notions of borders. See, eg R Buchanan 'Border Crossings: NAFTA, Regulatory Restructuring, and the Politics of Place' (1995) 2 Indiana J of Global Legal Studies 371. 
Of course, in light of the crisis of declining union power and the intensity of assaults on the welfare state, US labour and welfare advocates and theorists have understandably focused attention on their domestic scene. However, in so doing, our rhetoric often reflects a nostalgia for isolationism. Labour's nation-state focus is most evident in its fixation on collective bargaining as the privileged site of redistributional possibility. While this model has yielded many important victories, it rests on several increasingly problematical assumptions, including, for example, the assumption that nation-states can control the impact of capital flight and currency fluctuations; that immigration can be regulated through border enforcement of legal prohibitions established by nation-states; and that union density, even within a nation-state, will reach worker-majority levels and incorporate waged workers not currently included within any collective bargaining framework, so that vertical redistribution (from management to labour) through collective bargaining poses only limited risks of exacerbating horizontal inequalities (between higher paid unionized and non-unionized, low-wage workers).

While perhaps some of these assumptions were plausible in the postwar years, for reasons discussed below, social reality is rapidly pushing in a different direction. Labour and welfare law cannot be viewed as 'domestic issues' within any nation-state. In light of currently unfolding trends toward global economic integration, a concept of citizenship anchored solely in the nation-state is anachronistic. The expansion and liberalization of trade, increased volume and mobility of capital and financing, breakdown of the Bretton Woods mechanisms for currency control, portability of many production techniques and equipment, and the emergence of third world manufacturing all sharply call into question the assumption that employment and social policy can be made within a nation-state framework. All of this is in addition to the moral and political imperative for people in the developed world to accept responsibility for addressing the gross maldistribution of wealth and resources on a world scale.

Mainstream US politicians and, regrettably, many progressive critics, discuss 'transitioning' welfare recipients to work under the PRWORA within a framework based not only on a dichotomized image of welfare recipient versus waged worker, but also on a domestic labour market, as if the US had no links to the rest of the world. But economic life in the US involves massive cross-border capital and labour flows and integrated, cross-border production chains. Changes in labour or welfare laws in other countries often have important ramifications in the US (and vice-versa), whether in the form of human migration, capital migration, or rising naturalizations of legal immigrants. More restrictive immigration policy, rather than reducing migration, may produce more undocumented immigrants, creating a quite different impact on US low-wage labour markets than that produced by legal immigration. Progressive lawyers attempting to develop new institutional mechanisms for redistribution must grapple carefully with the tension between capital mobility and restrictions on the free movement of persons.

The relationship between the US and Mexico highlights the implications of cross-border labour, welfare, immigration, and trade interactions, particularly the impact of anti-NAFTA and anti-immigrant rhetoric on US welfare policy and naturalizations, and the artificiality of borders vis-à-vis citizenship. US labour union opposition to the NAFTA in 1994 was often voiced as a fear of 'losing US jobs to Mexico.' Two years later, the PRWORA terminated the eligibility of legal immigrants, whether or not in waged work, for virtually all welfare programmes. Mexicans formed the largest group of US legal immigrants by far, who had chosen not to naturalize as US citizens. Labour and welfare academics and activists condemned PRWORA, but there was virtually no self-critique as to whether labour's anti-NAFTA position might have, however unintentionally, fed into racist, anti-Mexican, and anti-immigration attitudes that culminated in the disqualification of thousands of legal immigrants. 
In ratifying the NAFTA, one bone that Congress threw to labour was the NAFTA-Trade Adjustment Act providing additional weeks of UI benefits for retraining workers (excluding workers not covered by UI laws) who lose their jobs due to increased imports or capital flight generated by the NAFTA. As a result, US taxpayers are funding the extended UI and retraining of workers dislocated by US trade policy, at the same time as they are defunding many welfare benefits to low-waged welfare recipients and legal, often Mexican, immigrants.

PRWORA's targeting of immigrants and similar political developments (such as California's Proposition 187 barring undocumented immigrants from receiving almost all education, social services, and health benefits) prompted the emergence of a new consciousness among legal Mexican immigrants in the US to become naturalized US citizens so that they could vote and participate fully politically. Until 1994, the number of naturalizations by Mexicans legally residing in the United States was fairly stable at about 20,000 per year. This development in turn has brought about profound changes in the political landscape. In 1994, the year that Californians adopted Proposition 187, naturalizations surged to 46,186, and in 1995, to 79,614. Most dramatically, in 1996 (the year the PRWORA was being debated and enacted), Mexico was the leading country-of-birth of persons naturalizing, with 254,988 or 24.4 per cent of total naturalizations. ${ }^{22}$ As naturalized citizens, these individuals enjoy greatly expanded legal rights to bring family members into the US. Thus the ironic result of anti-immigrant politics in the 1990s may be that even greater numbers of Mexican immigrants will settle in the US, naturalize and vote. This, in turn, raises questions about the effect of this additional supply of waged workers on both union density and decisions of companies to relocate cross-border.

Juxtapose these developments to recent dramatic changes in Mexican laws relating to dual citizenship and the ability of non-residents to vote in Mexican elections. Recent legal changes allow Mexican non-residents to maintain dual citizenship. In particular, Mexican immigrants who are naturalized US citizens are now permitted to reclaim their Mexican citizenship. ${ }^{23}$ Mexico's Congress enacted legislation, not yet implemented at the time of the 2000 election (in which the Institutional Revolutionary Party (PRI) was defeated for the first time since 1920 by the National Action Party (PAN)), which would allow non-resident Mexican citizens to vote in Mexican elections without returning to Mexico. ${ }^{24}$ Almost 10 million Mexicans more or less permanently residing in the US could be eligible to vote in Mexican elections and are expected to support either the PAN or the Party of the Democratic Revolution (PRD), Mexican political parties advocating the democratization of labour unions in Mexico. ${ }^{25}$ Thus the huge increase in US naturalizations by Mexicans (in turn opening the door for further immigration by family members) and the emergence of dual citizenship and dual voting privileges in Mexico could have broad implications for social protection and low-wage labour in both the US and Mexico,

22 US Dept of Justice, Immigration and Naturalization Service, 1996 Statistical Yearbook of the Immigration and Naturalization Service (1997) 152. Of course, there were other legal changes which factored into this increase, most specifically the numbers of undocumented immigrants allowed to naturalize pursuant to the Immigration Reform and Control Act of 1986, Pub L No 99-603, 100 Stat 3359 (1986).

23 Constitucion Politica de los Estados Unidos Mexicanos, art 30 (amended 1996).

24 Although the Chamber of Deputies had approved a package implementing this election reform, the Senate (controlled by the PRI) allowed the measure to die in July 1999. JF Smith 'Vote Denied to Mexicans Living Abroad' (1999) 2 July Los Angeles Times at A1.

25 PJ McDonnell 'US Votes Could Sway Mexico's Next Election' (1999) 15 February Los Angeles Times at A1. On labour politics in a Mexican context, see further C de Buen Unna 'Mexican Trade Unionism in a Time of Transition' in J Conaghan, RM Fischl \& K Klare (eds) Labour Law in an Era of Globalization: Transformative Practices and Possibilities (2002) 401-416. 
exemplifying why citizenship attached to the nation-state is an increasingly antiquated concept.

Most lawyers working to revivify the concept of social citizenship and enlist it in the service of progressive causes reflexively and unconsciously adopt the nation-state perspective or, at best, leave that aspect of citizenship discourse unexamined. But 'social citizenship' will never become the emblem of redistributive politics and transformative aspirations until it is re-imagined from a thoroughly globalized perspective.

\section{$V$ Conclusion}

The three legal discourses discussed in this essay individually and cumulatively privilege labour markets and waged work, marginalize broad redistributive agendas as exceptions, and obscure the understanding that all legal questions have distributive implications. Family and market are constructed as private, pre-legal, and autonomous from the state. The role of background legal rules in entrenching power imbalances within those societal spheres is ignored. Labour lawyers and welfare lawyers have both contributed to the discursive construction of income distribution as somehow independent of state action: labour lawyers by valorizing labour markets and collective bargaining as the privileged site of income distribution, while at the same time viewing welfare law as a 'special case' of state intervention, and welfare lawyers by fixating on government transfer policy and largely ignoring private law. Thus welfare law becomes a market corrective technique, an adjunct to private law, rather than a redistributive hub. Likewise social insurance and social assistance statutes, often fought for and defended by the left, separate 'workers' and 'non-workers' through artificial definitions that support the creation of partial identities. When labour lawyers argue for enhanced UI benefits on the ground that society should protect and reward primary-sector wage-earners, they are 'othering' many potential allies within waged work and denigrating non-waged work, thereby perpetuating a hierarchy of market work over family care-giving performed primarily by women. The discourse of citizenship perpetuates a male model of participation in the 'public' spheres of liberal democratic institutions and waged work as the means of fulfilling citizenship obligations and therefore acquiring full social status. And traditional citizenship discourse legitimates first-world protectionist policies and attitudes that perpetuate gross global inequalities, while ignoring the implications of increasing global interdependence. The discourses of these quite disparate fields reinforce one another. However unwittingly, progressive legal advocacy often reaffirms the prevailing political 'consensus' - that policies privileging the nation-state, market, and traditional family are natural and those dismantling the welfare state are inevitable.

In other words, the rhetoric of many progressive labour and welfare theoreticians and activists assumes that the identities constructed by statutory social welfare programmes accurately reflect a pre-legal order providing the appropriate framework for self-fulfilment and citizenship activity. The reaffirmation of the free market and the traditional family as the 'correct' framework for dealing with domestic and global income disparities - without challenging and transforming the background rules that structure markets and families - perpetuates class, racial and gender inequality and disempowerment.

I do not suggest that we must devise a single, integrated, cross-border low-wage labour and poverty policy. But we must challenge ourselves to look beyond our limited or narrowly defined constituencies, to frame new questions about labour and welfare strategy within an increasingly globalized economy. My hope is that, by increasing the amount and sophistication of dia- 
logue among social welfare, low-wage labour, immigration, family and economic globalization discourses, scholars and activists in these linked fields can begin to disrupt and undermine the ways legal culture legitimates and reinforces the social and economic status quo. This essay challenges both labour and welfare lawyers to enter more rigorously into interdisciplinary selfcritique as a basis for intellectual renewal and the creation of a transformative vision of the politics of redistribution. 


\title{
Opening the Door to More Equality
}

\author{
- ROSS ZUCKER \\ Professor of Political Science, Lander \\ College for Men, Kew Gardens Hills
}

The (Greek) colonists tended to divide the land they settled into equal shares, reflecting the egalitarian tendency inherent in the ethical system of the yeoman farmers in the mother cities. ${ }^{1}$

\section{Income Inequality and Contemporary Political Theory}

The idea of egalitarian rules of income distribution runs against the grain of much, if not most, of contemporary political theory. ${ }^{2}$ This is curious considering the fact that contemporary political theory is full of theories claiming to be egalitarian. Ronald Dworkin announces that 'egalitarian liberalism is the dominant substantive theory of justice - indeed it is hardly even much challenged. ${ }^{3}$ It may in fact be the dominant theory of justice, but it is, nevertheless, not well disposed toward rules that distribute market-generated inequalities of income more equally and is not egalitarian, at least in that way. (It only supports rules that redistribute inequalities stemming from social and natural background that are not generated by the market.) Similarly, communitarian opponents of liberal egalitarianism have not been formulating such rules, ${ }^{4}$ not to mention the position of liberalism's conservative challengers. ${ }^{5}$

The Anglo-American moral and political theories developed since World War II are more concerned about inequalities of so-called basic liberty, opportunity, social background, natural talents, and capabilities than they are about inequality of income. Many, perhaps most, of them accept the legitimacy of market outcomes, including income inequalities, as long as they arise under (variously stipulated) conditions of equal opportunity. As Rawls writes, '[O]nce a suitable minimum is provided by transfers, it may be perfectly fair that the rest of total income be settled by the price system.' 6 The newest school of political theory, real libertarianism, seeks to justify a basic income guarantee, but this measure is not coupled with a rule that limits relative inequality above the basic income.

Few on the left concern themselves with the concentration of income and wealth in the US, though it is warranted by the fact that 'the United States ha[s] just experienced the most colos-

1 D Kagan, S Ozment \& FM Turner The Western Heritage to 1715 (2001) at 48-49.

2 I would like to express my appreciation to Elizabeth Wagner for her comments on a draft of this paper.

3 R Dworkin 'Why We Are All Liberals' paper presented at the Program for the Study of Law, Philosophy \& Social Theory NYU School of Law 19 October 1995 at 1.

4 MJ Sandel Liberalism and the Limits of Justice (1982). Sandel's discussion implies that unequal income is justifiable if it is necessary in order to further a communal purpose.

5 See R Nozick Anarchy, State, and Utopia (1974).

6 J Rawls A Theory of Justice (1971) at 277. 
sal [upward] redistribution of wealth in world history. ${ }^{7}$ Some left liberals are concerned, not about very unequal income and wealth, but about egalitarian democratic theories that conceive of democracy in a way that entails strong economic equality. Believing that real progress toward economic equality is unlikely, these left liberals conclude that full democracy, requiring strong economic equality, is unrealistic. '[T]here are good reasons,' writes Stephen Elkin, 'to think this [real progress toward economic equality] cannot be the case. Economic theory suggests that strong economic equality is not available to us, not least because it will run afoul of the need for economic incentives required if there is to be a high level of economic prosperity.' 8 But the pendulum of income and wealth distribution has swung widely in the past hundred years. In 1944, the 94 percent top marginal tax rate on the highest incomes significantly reduced inequality in the US. ${ }^{9}$ Now the US has just experienced a huge upward distribution of income and wealth. With these swings here and those in Europe due to the adoption and rejection of the mixed economy, why is it unthinkable that a future change in public opinion could produce a large downward redistribution?

The old economic orthodoxy on incentives continues to have remarkable traction within contemporary political theory. Economic theory's mere suggestion about the need for incentives is enough to wash away the possibility of a more egalitarian society. Old ideas can be so authoritative that many contemporary political theorists do not even ask if society could achieve adequate productivity with substantially reduced income differentials.

Senior executives received as much as 200 or even 2000 times the annual incomes of their lowest paid workers in the US in recent years. ${ }^{10}$ But a productive economy can evidently be achieved using much lower multiples. About 35 times the annual income of the lowest paid worker adequately drove the American and Japanese economies in decades of strong growth during the twentieth century. ${ }^{11}$ And it is possible that lower multiples might have sufficed. Moreover, much of a person's salary does not have to do with incentives anyway. Salaries of senior executives in major corporations have as much to do with power as they do with incentives, as law professors Lucien Bebchuk, Jesse Fried and David Walker demonstrated in their analysis of executive compensation. ${ }^{12}$ Senior executives and corporate compensation committees are in a position to reward senior executives handsomely and they take advantage of the situation.

Liberals and left liberals who say 'economic theory' considers high income inequality necessary for incentives give a one-sided account of its position. Mainline economic theorists are not all of one mind on this. John Maynard Keynes differed from the economic orthodoxy of his day, which is not much different from current economic orthodoxy in this regard, when he said 'There are valuable human activities which require the motive of money-making and the environment of private wealth ownership for their full fruition. ... But it is not necessary for the stimulation of these activities ... that the game should be played for such high stakes. ... Much lower stakes will serve the purpose equally well, as soon as the players are accustomed to them.' ${ }^{13}$

7 Sam Pizzigati 'The Left and the Rich' Paper presented at the Global Left Forum, New York City (2005) at 1.

8 SL Elkin 'Notes on the Old Political Science for the Present Age' (2004) 1 The Good Society at 4.

9 S Pizzigati 'The Left and the Rich' (note 7 above) at 5.

10 P Bennis 'Talking Points: Iraq, The UN, \& US Corporations' (2003) Web publication by United for Peace and Justice: http://unitedforpeace.org/article.php?id=2031 3 at 1 . The 2000 figure refers to the multiple of Lockheed CEO Martin Vance Coffman's 2004 pay package over that of the entry level soldier.

11 'CEO Pay in '98: Insanity Marches On' (1999) 5 Too Much 1 at 3.

12 See L Bebchuk, J Fried \& D Walker 'Managerial Power and Rent Extraction in the Design of Executive Compensation' (2002) 69 University of Chicago LR 751.

13 The General Theory of Employment, Interest, and Money (1964) at 374. 
The government of the United States grapples more with the problem of unequal opportunity than with unequal income and wealth (not to say the amount of its attention to the former inequalities is adequate). One might expect that policies to reduce unequal opportunity and capability would indirectly reduce inequalities of income and wealth. But inequalities of income and wealth proved intractable in late twentieth and early twenty-first century America and some other countries. Indeed they grew considerably during the last three decades. A comprehensive analysis of contemporary inequalities of income and wealth, recently conducted by Sam Pizzigati, shows that they play a very large part in the story of contemporary America. ${ }^{14}$

Contemporary political theorists, for the most part, have not responded to evidence of the intractability of inequalities of income and wealth by developing justifications for rules of more equal distribution of income. That they have not done so serves to support a highly unequal system. Prevailing high levels of income inequality make it crucial to reconsider the direction that contemporary political theorists have chosen. Can contemporary political theory be reformulated to provide a justification for more direct and effective remedies to income inequality? The question turns, I think, on whether philosophical foundations for rules of egalitarian distribution of income and wealth can be formulated.

The income-inegalitarianism of contemporary theorists derives to a significant extent from its patrimony in the work of the distinguished philosopher John Rawls. ${ }^{15}$ They work within his paradigm in A Theory of Justice (1971) or within his related paradigm in Political Liberalism (1993). Rawls's highly influential 1971 book supports almost all of the forms of equality then known except equality of income and wealth. Theory treats income and wealth very differently from the basic liberties, lexically ordering the latter before the former. While basic liberties are subject to strictly equal distribution, income and wealth are relegated to treatment under the 'difference' principle. As a result, equality of liberty and of opportunity is required and unlimited inequalities of incomes and wealth are authorized as long as they work to the advantage of the worst off. Inequalities of income and wealth are deemed just, because and insofar as they generate incentives that augment the GNP and yield a larger portion for the worst off than they otherwise get.

Since A Theory of Justice was published thirty four years ago, theorists have diverged from Rawls on many points, but they tend to share his position on income inequalities, which may be characterized as follows:

1. Income inequality is not a primary concern.

2. Income inequality is justifiable.

3. The condition of the worst off is the major concern of distributive justice.

4. Market outcomes, and market inequalities, are legitimate for the rest of the population, so long they arise under equal opportunity.

5. The height of the income hierarchy cannot be limited by rules of egalitarian redistribution.

Many contemporary theories of economic justice stand or fall on the veracity of these propositions.

Rawls attempts to justify a principle authorizing extreme inequalities of income and wealth

14 S Pizzigati Greed and Good (2005).

15 M Nussbaum calls him 'the most distinguished moral and political philosopher of our age': 'The Enduring Significance of John Rawls' (2001) The Chronicle of Higher Education B7 at B7. 
by appealing to the judgment of all. Everyone in the 'original position' (a hypothetical condition designed to yield a just choice) would consent to that position, he claims. But the reasoning of the participants seems flawed to me. They err, firstly, in supposing that inequalities of income and wealth are mere matters of the 'good' rather than of the 'right'. As anyone can test out by trying to act upon one's choice of consumption bundle without any income or wealth, income and wealth are means of freedom. For this reason, inequalities of income and wealth are inequalities of freedom and they are, therefore, subject to control by the principle of right. Mistaking inequalities of income and wealth as matters of the good, the participants downgrade the importance of inequalities of income and wealth relative to the so-called basic liberties. This decision then leads them to authorize unlimited inequality of income and wealth for incentive purposes, as long as these steps benefit the worst off. ${ }^{16}$ The last two steps are not warranted, however, because income and wealth are means of freedom. The choices afforded by income and wealth are as basic as those Rawls deems 'basic liberties.' Far greater caution then needs to be exercised before allowing unlimited unequal distribution of them.

The reasoning of the participants seems flawed, secondly, because their concerns are parochial in comparison with the broad scope of justice. What they consent to, the difference principle, is very limited in its concerns. The difference principle holds that inequalities of income and wealth are just if they are to the advantage of the worst off members of society. The participants give their consent to this principle out of a grave concern that they may wind up among the worst off members of society. ${ }^{17}$ But they do not reflect much about inequalities over the rest of the income spectrum, though the worst off may be only a fraction of the total in a society with a mushrooming middle class. The upshot is a philosophical justification for a welfare state. The participants in the original position are blithely unconcerned that it might be accompanied by widening inequalities between the middle class and the upper class and between different strata within the middle class. Yet this is exactly what has come to pass in the United States. ${ }^{18}$ Indeed it is a dominant feature of contemporary life in America and increasingly in other countries as well.

The condition of the worst off members of society is, undoubtedly, an urgent matter from the standpoint of justice. But the difference principle is not a principle of justice, in my view, because the concerns of justice are general; they do not privilege one group, even the least advantaged, to such an extent that they withhold full consideration from everyone else. Incomes of people at the top of the income hierarchy supply them with tremendously more freedom than the incomes at the bottom supply the worst off with (if they receive any income). However, there are significant differences between the incomes of other individuals all along the income gradient. The inequality of freedom between someone who has 20 billion dollars worth of means of freedom and someone who has little or no financial means of freedom is more terrible than the inequality of freedom between someone with a 625,000 dollar per year income and another with a 40,000 dollar income, but justice cannot ignore the latter inequality. Because many of the income differences along the entire income hierarchy involve substantial differences between the means of freedom available to individuals, justice is concerned with achieving real progress toward equal means of freedom all along the income hierarchy, not just with the especially objectionable inequalities in the means of freedom between the worst off and the best off. This is not to say, however, that the general rule of economic justice would level income. Some inequalities of income may be necessary for equal

16 As to their being unlimited in Rawls's theory, see Rawls (note 6 above) at 151 .

17 Rawls (note 6 above) at 153.

18 See R Zucker 'On the Future of the Justice Debates' (2004) 13 The Good Society 67 at 76-77. 
freedom, due to differences between individuals' consumption and production ambitions. But many of them do not result from differences between individuals' consumption and production ambitions. ${ }^{19}$ To this extent they are inimical to equal freedom.

Rawls's focus on unequal opportunity for education and training suggests an implicit emphasis on supply side determinants of income inequality. Market rewards to productive agents depend, however, not only on training and education, but also on the demand for what is being produced. Since extreme inequalities of income naturally arise from within the market, even under conditions of fair equality of opportunity, equal opportunity rules exercise less control over income inequality than some might suppose. As William Julius Wilson demonstrated in The Truly Disadvantaged (1987), income inequality rose among blacks during the 1980s despite greater equality of opportunity afforded by the civil rights laws and legislation passed during 1960s and '70s. These facts suggest that egalitarian liberalism has shortchanged equality by emphasizing equality of opportunity at the expense of real progress toward equality of incomes. Any theorist concerned with limiting the range of income inequality might recognize a need to try to formulate principles of relative distribution of income, not just rules regarding capabilities or opportunities.

As economic inequality grew in the 1970s and 1980s, liberal theorists brought out a seemingly new approach, known as 'liberal egalitarianism.' In 'Equality of Resources - Part Two' Ronald Dworkin argued that inequalities of income and wealth that result from social background, natural talents, and brute luck are not outcomes of free choice. These inequalities are therefore inconsistent with equal freedom or real equality of resources and they should be nullified by optional insurance plans. ${ }^{20}$ Apart from concern with these sorts of inequalities, liberal egalitarians accept the legitimacy of market outcomes, including extreme inequalities of wealth and income.

Inequalities of income and wealth could have been significantly reduced if countries implemented liberal egalitarian principles for dealing with the ramifications of social background, natural talents, and unequal opportunity. But extreme inequalities of income and wealth would not be eliminated by such measures. Capital-based market systems have internal processes that would generate extreme inequalities despite measures to offset the income-effects of social background and natural talent. For example, liberal egalitarianism does not reduce demandside causes of inequalities of income. People with equal talents and social backgrounds can make extremely different incomes depending on consumer preferences for their products.

During the 1980s and 1990s contemporary political and moral theory supplemented its focus on the worst off, equal opportunity, social background, and natural talents by adding an emphasis on capabilities. This change roughly tracked the shift in the American economy from a capital-goods producing economy to a service economy and a high technology economy. The new economy is one where possession/ non-possession of marketable capabilities rivals ownership/non-ownership of capital as a determinant of income. ${ }^{21}$ Amartya Sen provided a philosophical justification for increased governmental and societal emphasis on the development of capabilities. ${ }^{22}$ In doing so, he broadened the moral scope of liberal theory considerably. But his formulation emphasizes capabilities over incomes and the principles that he proposes do not directly regulate the inequality of income. Sen

19 For more on this, see R Zucker 'Democracy and Economic Justice,' Paper presented at the annual meeting of the American Political Science Association 23 August 2003.

20 R Dworkin 'What Is Equality: Part 2: Equality of Resources' (1981)10 Philosophy and Public Affairs 283.

$21 \mathrm{C}$ Graham and S Pettinato Happiness and Hardship: Opportunity and Insecurity in New Market Economies (2002) at 41.

22 A Sen Choice, Welfare and Measurement (1982) at 367; A Sen Inequality Reexamined (1992) at 19-22. For an interesting, recent treatment of capabilities, see DP Levine 'Poverty, Capabilities, and Freedom' (2003) 15 Review of Political Economy 101. 
contended that every basal equality entails a secondary inequality. ${ }^{23}$ In a system of thought which accords priority to capabilities, this means that capability equality can require income inequality or, in other words, that income inequality is justified for the sake of capability equality.

The principles proposed by the foregoing liberal theories could have some beneficial effect upon economic inequality if they were implemented, but they would not adequately or directly reduce income inequality. Each one of them authorizes a wide scope for market-generated inequalities of income and wealth. These inequalities cannot be dealt with satisfactorily by liberal egalitarianism's roundabout methods. To rectify them direct limits need to be placed on the scope of market generated inequalities. Capping incomes is not necessary, however. A rule of redistribution that strictly equalizes part of a person's income and leaves another part of it unregulated would substantially reduce inequality without a cap. The central question for this article is whether such a rule is morally defensible.

Against the background of roundabout liberalism, 'real libertarianism' presents a welcome change. Finally there is a contemporary political theory that focuses directly on income and offers rules of income distribution. Van Parijs claims that this economic philosophy would provide real liberty if adopted. ${ }^{24}$ I suspect that it would not promote liberty as much as he maintains. The basic income guarantee provides basic means of freedom, but above this floor people can have extremely unequal means of freedom. No limit is defined for the height of the income hierarchy above the floor. Real libertarianism is a more direct form of liberalism in its treatment of income, but it is not a form of real liberty.

Direct libertarianism, if you will, does not answer to the challenge of $21^{\text {st }}$ century income inequality. Its central concept, a basic income, represents a throw back to Rawls's emphasis on the worst off or a way of realizing his emphasis on this group. The provision of a basic income adjusts the height of the floor, but - like previous welfare entitlements - allows extreme income inequality between the upper, middle, and lower strata. Van Parijs explicitly formulates the basic income theory as a leximining approach, which places tremendous weight on the condition of the worst off rather than on general inequality, just as the difference principle does. ${ }^{25}$ Sounding like Nozick, Van Parijs characterizes egalitarian rules of income distribution as violations of freedom and of basic security rights. ${ }^{26}$

Real libertarianism leaves in its wake the same question that the rest of contemporary political theory does: Is real progress toward equality of income justifiable?

\section{A Social Theory of Reward for Economic Contributions}

\section{(A) INTRODUCTION}

A theory of distributive justice sets forth principles stating that resources should be distributed in a certain way. Principles of just distribution are arrived at by reasoning guided in line with ideals of justice. One of these ideals is that people should be rewarded in proportion to their economic contributions. This ideal, the reasoning, and the principles comprise a branch of justice known as the 'ethics of reward for economic contributions' or as 'ethics of dueness for economic contributions.' Another branch of distributive justice, the 'ethics of community,' has a distinct ideal of justice: that

23 A Sen Inequality (note 22 above) at 19-22.

24 P van Parijs Real Freedom for All (1995).

25 Van Parijs Real Freedom (note 24 above) at 25, 33.

26 Van Parijs Real Freedom (note 24 above) at 25. 
the members of a community, united for the pursuit of some common end or ends, are entitled to share in the end(s) of association, to the extent that it is a community. Still another branch of justice, the 'ethics of freedom,' holds that resources should be so distributed that they contribute, as much as possible, to the realization of freedom. I will sketch a derivation of principles of just distribution within the first two branches of distributive justice.

Ethicists of reward for contributions usually take the position that unequal rewards are justified because some individuals make bigger contributions to the creation of value than others do. In fact, they usually think extremely unequal rewards are morally supportable as long as they are proportionate to contributions. Reward proportionate to contributions sounds like the standard distributive ethics in economics, but actually it is not. JR Hicks showed that the marginal product of labour or capital does not determine the wage or rent; it only equals the wage or rent. ${ }^{27}$ Thereafter most neoclassical economists ceased to view the ethics of reward as a scientific ethics of distribution.

The neoclassical theory nevertheless continues to provide a major underpinning for the ethics of unequal reward. However, ethicists rather than neoclassical theorists are for the most part the ones that treat this ethics as a scientifically well-founded approach. In neoclassical theory, the system is one where individuals receive unequal incomes partly because of differences between their labour-leisure choices and partly because the selling prices of the final products (which indirectly affect factor prices) are affected by consumer preferences that are different to the point of non-comparability. Since differences between individuals are vital to its account of the determination of major system variables, neoclassical theory has an elective affinity for the ethics of unequal reward. In view of this, it is not surprising that some normative economists (Hayek, Zamagni) and ethicists outside of the profession continue to uphold principles of unequal remuneration based on different contributions. Ostensibly value-free microeconomic theory perpetuates the ethics of reward for unequal contributions in the contemporary era.

The modern economic ethic of unequal reward can be assessed by reexamining the theory of the determination of economic value on which it is based. The theory of economic value is a theory of the determination of the value of commodities, that is, goods and services bought and sold on the market. As neoclassical theorists contend, individual contributions differ. But in what ways and to what extent? I will argue that individual contributions are also similar in some ways that ethicists have not taken into account when calculating appropriate rewards for contributions. If forms of equal contributions can be demonstrated, then these equalities must be taken into account when calculating just remuneration. The implications of their incorporation into an ethics of dueness are clear: people have been remunerated more unequally than they should have been and income should be distributed more equally than it is.

The theory of value presupposed by most theorists of reward is itself premised on a certain assumption about the kind of economic agents that make economic contributions. Producers are assumed to be the only kind of economic agents that can make economic contributors, since they are the only ones that can create economic value. The labour theory of value or the production theory of value was put forth by classical liberal theorists (eg Locke), classical political economist (eg Smith) and by Marx. Theorists of reward from the classical liberalism to the present day have tended to base their ethics upon an essentially classical theory of value and of contributions. In their assumption of a classical theory of value, contemporary theorists of reward for contributions have not found themselves much challenged. When they are challenged it is usually on other grounds. Encountering little challenge to their underlying theory of value, con- 
temporary theorists of reward have not provided any defense of this approach. Their assumption that only producers create value clearly is at odds with the established position of modern, or 'neoclassical' economic theory, which holds that consumers, not only producers, help to determine the value of commodities. Rewards theorists do not consider the implications of this for the ethics of reward because they do not take it much into account. Neoclassical theorists also do not bring out the full ethical implications of their value theory. In particular, they have not explored the possibility that consumers' part in the creation of value can be considered to be a contribution which can accrue entitlements for the value they create.

\section{(в) Do CONSUmers Qualify as CONTRIBUtors?}

The foregoing analysis raises a serious problem for the ethics of reward for contributions. Do consumers meet the criteria for remuneration under a theory of reward for economic contributions? The theory of reward is one that divides up rewards in proportion to contributions. As such, it must register any human source of economic creation. On this theory, inanimate objects and animals do not accrue entitlements for contributions, any more than they are entitled to any other sorts of rights. They can be protected, though, by fiduciary arrangements made on their behalf. An activity can qualify as an economically creative action if it contributes to the creation of the value of commodities. Consumer activities qualify as economically creative activities because they contribute to the determination of value and, therefore, satisfy the foregoing criterion of economically creative action. For this reason, consumer activities inexorably accrue moral titles for their contributions, on a principle of dueness.

Consumer activities, such as the pursuit of want satisfaction or need satisfaction, display the same qualities that entitle producers to reward for their contributions. Producer contributions qualify because and insofar as they help to create value in the sense of exchange value, not merely use-value for the person himself or herself. But consumer contributions can meet this test as well. Neoclassical models of the economy in a condition of general economic equilibrium show that consumer preferences help to determine relative prices or exchange values. Producer contributions qualify for remuneration because and insofar as they make socially valued contributions. Consumer contributions meet this test too. The effect of consumer preferences upon relative prices shows that they are socially valued. Since consumers meet all of the requirements for remuneration for contributions that producers meet, they qualify for remuneration proportionate to their contributions, just as producers do. To accord remuneration only to producers and to deny it to consumers would be, in a word, unjust.

One might object that producer and consumer contributions differ in other ways which preclude the latter from entitlement to rewards. Productive activities, one might argue, involve effort and they are disutilities, whereas preference satisfaction is pleasurable, effortless, and has utility. But productive activities do not compare to consumptive activities as labour or effort does to satisfaction. Robert Lane points out that '[i]t is in work, not in consumption and, as research reports show, not even in leisure, where most people engage in activities that they find most satisfying, where they learn to cope with their human and natural environments, and where they learn about themselves. The economists' ideas that work is the sacrifice or disutility that earns for workers the benefits or utilities of consumption is ... quite false. 28 If productive activities can be due rewards for contributions notwithstanding the fact that they can be satisfying, then consumer activities and wants cannot be disqualified for rewards simply because they are satisfying. And, if consumer activities 
are disqualified for rewards because they are satisfying, then work must be disqualified for remuneration as well - since it is satisfying for most people too.

In some of the leading contemporary theories of reward for contributions, contribution to the value of commodities, rather than the subjective experience of toil and trouble, is the major basis of reward for contributions. It would be inconsistent with this standpoint to preclude consumer activities, like the pursuit of want satisfaction, from receiving rewards for their contributions to value. Friedrich von Hayek argued that producers should be remunerated in proportion, not to the subjective experience of toil and trouble expended in production, but to the value of the product as determined by the market. ${ }^{29}$ Someone who enjoys tinkering, effortlessly invents a new widget, and sells it for a million dollars, is entitled to the market value of the widget in Hayekian ethics. Likewise a virtuoso pianist who practices constantly, but whom no one is willing to pay to hear, does not deserve any remuneration. Contemporary ethicists have not however drawn the implications of this argument for rewarding consumers for their value contributions. If producer activities should be rewarded for contributions to value, not for the 'toil and trouble' they involve, then consumer activities can be due rewards for their contributions to value.

\section{(C) Do Consumers Really Make Contributions?}

Thomas Spragens, a professor of political theory at Duke University, argues that the social theory of rewards that I have presented is unpersuasive. ${ }^{30}$ The egalitarian rewards for consumer contributions are not warranted because consumer preferences, wants, and needs do not help to create economic value. He also objects to my claim that consumers play a role in the determination of value in neoclassical economics. This last objection surprises me because the supply and demand graphs in almost every microeconomics textbook show consumers helping to determine relative prices and, in this sense, to create value. Moreover, mathematical models of general economic equilibrium are even clearer that postulated consumer preferences and the state of technological knowledge help to determine prices. ${ }^{31}$

Spragens' objection needs to be considered, however, because the egalitarian theory of reward cannot be valid if the underlying theory of value, involving a role for consumers, is wrong. 'Needs become contributions to the creation of economic value,' he writes, 'only when they are backed by the resources to make them 'effective,' and that results only when those with the needs have produced something others want in order to generate the wherewithal to make their demand effective'. ${ }^{32}$ Since consumer wants, preferences, and needs do not make a contribution to the value of commodities, he thinks that the consumer theory of reward cannot be right.

Spragens is correct to the extent that consumer preferences cannot help to determine relative prices if the consumer has no purchasing power. But from this point he moves to dismiss the possibility that consumer needs or preferences contribute to the value of commodities. My account of neoclassical economic theory does not deny the fact that consumer preferences cannot help to determine relative prices unless consumers have purchasing power. Moreover, the theory of value that I employ, which is not quite the same as neoclassical theory's approach, does not deny it and is not refuted by it.

The fact that consumer preferences have to be combined with purchasing power to have an effect

29 FA von Hayek The Constitution of Liberty (1960) at 94-97.

30 T Spragens 'Review Essay: Justice, Consensus, and Boundaries: Assessing Political Liberalism' (2003) 31 Political Theory 589 at 592.

31 G Debreu Theory of Value: An Axiomatic Analysis of Economic Equilibrium (1959).

32 Spragens 'Review Essay' (note 30 above) at 592. 
on prices does not mean that they cannot help to create value. It just means that they cannot help to create value without purchasing power. When Spragens denies that consumer preferences help to create value (because they can only do so when combined with purchasing power), he assumes that the influence of preferences is absolutely indistinguishable from the contribution which purchasing power makes. But they are distinguishable, though not wholly separable. Labour cannot engage in commodity production unless it is combined with capital in a production process, but that does not prevent labour from contributing to the creation of value. Everything in an interdependent neoclassical system effects prices through its relation to other variables, but that does not prevent them from making distinguishable contributions of their own.

As I have already noted, when Spragens reduces the influence of consumers upon prices to the value of the resources that they (in their capacity as producers) obtain from producing things, he then denies that consumer wants form part of the value-creation process. He is attempting to reduce the role of the consumer in price determination to production, so that production appears to be the underlying source of value. But neoclassical economic theory is not really reductive in the specific way Spragens suggests that it is. Such theory accords consumer preferences relative autonomy in the process of creating value. Their role can be seen by considering a neoclassical model of general economic equilibrium. If we alter the consumer preferences in the model, without changing the endowments (in this case of labour or wheat), relative prices change, suggesting, contrary to Spragens, that they make a distinguishable contribution to value.

To illustrate, let us consider a standard neoclassical $2 \times 2 \times 2$ general equilibrium model of the economy with decreasing returns to scale production functions.

\section{Specifications of the Model}

$w_{1}$..price of input 1

$w_{2} .$. price of input 2

$p_{1}$..price of good 1

$p_{2}$..price of good 2

$s_{1}^{1}$. share of profits in industry 1 owned by person $1 \quad 100 \%$ of $\pi_{1}$

$s_{1}^{2}$. share of profits in industry 1 owned by person $20 \%$ of $\pi_{1}$

$s_{2}^{1}$. share of the profits of industry 2 owned by person $1 \quad 0 \%$ of $\pi_{2}$

$s_{2}^{2}$.. share of profits of industry 2 owned by person $2 \quad 100 \%$ of $\pi_{2}$

$q_{1} .$. quantity of produced commodity 1

$q_{2} .$. quantity of produced commodity 2

$v_{1}$. .labour, $v_{2}$.. land

$\bar{v}_{1}^{1}$.. consumer 1's endowment of input 1 (labour)

$\bar{v}_{2}^{1}$.. consumer 1's endowment of input 2 (land)

$\bar{v}_{1}^{2}$. consumer 2's endowment of input 1

$\bar{v}_{2}^{2}$. consumer 2's endowment of input 2

$\bar{v}_{1}$.the total endowment of labour Let us suppose that the total endowment of labour is 20 .

$\bar{v}_{2} .$. the total endowment of land. Let us suppose that the total endowment of land is 16 .

$x_{1}$..wheat

$x_{2}$. wool

$x_{1}^{1}$.. amount of produced good 1 consumed by person 1

$x_{2}^{1}$.. amount of produced good 2 consumed by person 1

$x_{1}^{2}$.. amount of produced good 1 consumed by person 2

$x_{2}^{2}$. amount of produced good 2 consumed by person 2 
Utility functions:

Consumer 1

$U^{1}=\left(x_{1}^{1}\right)^{3 / 4}\left(x_{2}^{1}\right)^{1 / 4}$

Consumer 2

$U^{2}=\left(x_{1}^{1}\right)^{1 / 4}\left(x_{2}^{1}\right)^{3 / 4}$

Production functions:

Wheat production (Good 1; Labour intensive)

$q_{1}=\left(v_{1}^{1}\right)^{5 / 8}\left(v_{2}^{1}\right)^{2 / 8}$

Wool production (Good 2; Land intensive)

$q_{2}=\left(v_{1}^{2}\right)^{2 / 8}\left(v_{2}^{2}\right)^{5 / 8}$

Let us choose as the numeraire good. Solving the system of equations for this model, I obtained the following results: 33

$x_{1}^{1}=5.8$

$x_{2}^{1}=1.8$

$x_{1}^{2}=1.9$

$x_{2}^{2}=5.3$

$v_{2}^{1}=4.6$

$v_{1}^{1}=14.3$

$v_{1}^{2}=5.7$

$v_{2}^{2}=11.4$

$q_{1}=7.7$

$q_{2}=7$

$w_{1}=4$

$p_{1}=11.9$

$p_{2}=12.9$

$\pi_{1}=11.4$

$\pi_{2}=11.4$

Now let us suppose that one consumer's tastes are different from what we initially supposed. Initially consumer 1 was presumed to prefer wheat. Now let us presume that consumer 1 does not prefer wheat and that his or her tastes, as between wheat and wool, are about the same. The other consumer's tastes remain the same as we thought they were initially. But consumer 1 's utility function is now assumed to be

$U=\left(x_{1}^{1}\right)^{3 / 4}\left(x_{2}^{1}\right)^{1 / 4}$

There are no other changes to the parameters of the model. Endowments remain the same, as do the production functions. $w_{2}$ continues to be the numeraire and it is still set at 5 .

33 For the sake of brevity I have omitted the system of equations needed to perform the calculations. 
$w_{1}=3.2$

$x_{1}^{1}=4.2$

$x_{2}^{1}=3.4$

$x_{1}^{2}=2$

$x_{2}^{2}=4.9$

$p_{1}=9.9$

$p_{2}=12.4$

When consumer 1 was originally thought to have a preference for good 1 , he consumed 5.8 units of it. But when we realized that he does not prefer good 1 to good 2, his consumption of good 1 was only 4.2 units and the price of good 1 was lower as well (9.9 rather than 11.9). Prices changed in this model even though there was no change in the endowments of labour and wheat, demonstrating that the value of goods can change in response to a change in preferences even if there is no change in endowments.

Since consumers help to determine relative prices and, in this sense, help to create value, this analysis indicates that there can be a consumer theory of rewards dealing with contributions made by consumer wants. The analysis has not, however, determined yet whether the theory will be egalitarian or inegalitarian, which we will take up in a moment.

In constructing the consumer theory of rewards, one proceeds either by considering consumer wants and consumer activities in abstraction from their purchasing power or by considering them in conjunction with their purchasing power. The former approach would not deny that consumer wants work in conjunction with purchasing power, but would just factor out their role. Consumer wants and purchasing power can be distinguished for analytical purposes, on the basis of the view that purchasing power does not fully explain the consumer's contribution to relative prices, because consumer wants make a relatively autonomous contribution. I will consider both lines of development in this article. No attempt will be made, however, to determine which one of these ways is better than the other. It seems to me that that would be a worthwhile project for anyone who wanted to further pursue the consumer theory of rewards in the future.

\section{(D) An Initial Postulate}

Suppose for the moment that we consider consumer preferences in conjunction with purchasing power. If we do so, then it can be argued that the consumer theory of reward cannot be an egalitarian theory, because unequal purchasing power leads to unequal consumer contribution to value, which makes consumers unequally deserving of rewards. As Gary Mongiovi writes, 'agents with greater incomes demand, and therefore induce, greater levels of production than those with lower incomes, and so would be entitled to a larger reward.' 34 The unseemly logic of the theory would then be that "to him that has more, more should be given." 35 But this slogan is only implied if the analysis takes as its starting point an unequal initial distribution of income and wealth. If the starting point of the reasoning for the theory is a postulate that everyone had equal initial amounts of income and wealth, then the theory would be egalitarian in that it would posit equal shares of a portion of national income. 
Gary Mongiovi cautions, however, against making this postulate. 'If the purpose of the exercise [formulating an equalitarian theory of reward] is to provide a guide to policy, we need to know how to proceed from where we now find ourselves: that is, from a position in which distribution is unequal.' 36 For various reasons, I think it may be necessary to construct the theory from a postulate of initial unequal income and wealth. The postulate 'all men are equal,' which seventeenth and eighteenth century liberals laid down, represented an even greater disjunction from their societies, which were even more extremely and rigidly unequal than our own, yet it still motivated historical change.

To see how to proceed from where we are now, what we need to know is, not how our society would proceed, but how a just society functions. Its principles, not ours, should guide us. The critical question that needs to be addressed is this: do extreme inequalities of income naturally develop when economic dynamics are regulated by principles of justice? One way of finding the answer to this question is to inquire into whether highly unequal consumer contributions arise from an initial equality of income and wealth. Such an assumption does not bias the analysis in either an egalitarian or inegalitarian direction. Suppose that consumer preferences really do make unequal contributions to value. One person with the same endowments, but greater production and consumption ambitions than another person, makes a larger contribution to value that merits larger rewards. So, if consumer contributions really are unequal, they will still show up even after equal initial income and wealth is postulated. The postulate does not bias the analysis toward egalitarianism, so there should be no objection to it. But if we assume initial unequal purchasing power, it would bias the theory's conclusions. Unequal contributions and rewards would follow almost automatically, so that we would not get a test of the nature of contributions. There is therefore nothing lost and much to gain from constructing the theory beginning with a postulate of initial equal income and wealth.

The characteristics of a just economy, not of our own economy, are what we need to know if we want to know how to proceed from where we are now to a more just system. Hobbes, Locke, and Rousseau abstracted from their own societies and formulated a state of nature so that they could formulate a just society. Their own societies, fraught with a severe class system, made people appear to be very unequal. Under these circumstances, philosophers thought that they could only determine if people are truly equal by abstracting from the class system that made them unequal. Once the abstraction disclosed their equality, classical liberals had a basis for condemning master-servant relations and asserting equal entitlement to rights of property. The 'unrealistic' abstraction from empirical class systems was precisely what they needed in order to provide guidelines for policy.

Postulating an initial equal distribution of income and wealth is an analogous move with respect to the issue of equal contributions. By abstracting from prevailing sharp inequalities of purchasing power, it becomes possible to examine the logic of consumer contributions, free of the bias of unequal purchasing power, and thus to see whether consumer activities have an equal or unequal influence on the formation of value, and to act accordingly when devising distributive policy.

Since the egalitarianism of the consumer theory of reward depends on a postulate of initial equal distribution of economic resources, Chris Armstrong and Peter Dietsch argue that the application of the theory in practice 'depends on huge prior changes to the distribution of economic resources.' ${ }^{37}$ Dependence on this condition, which Dietsch believes is not likely to be achieved in the real world,

36 Mongiovi 'Distributive Justice' (note 34 above) at 46.

37 C Armstrong 'Equality, Community, and the Production of Value' (2004) European Journal of Political Theory 339 at 342; see also P Dietsch 'Review of Ross Zucker Democratic Distributive Justice' (2002) 14 The Review of Political Economy 397 at 398-399. 
renders the theory inapplicable to most real world countries. And if the theory was applied in an actual context, without equalizing the preexisting distribution of economic resources, the theory would not deliver egalitarian rewards. Because huge prior changes in the distribution of economic resources are unlikely in most places, he maintains that the theory will be strongly egalitarian only in restricted circumstances. Armstrong concludes that the social theory of rewards is not superior, as an egalitarian theory, to Rawls's theory, which also can be egalitarian only in specific circumstances.

There may be some misunderstanding over the requirements of the consumer theory of rewards. To construct the theory, which is to find out what a just economy morally entails, one has to postulate an initial equal allocation of economic resources. But to say that the theory must postulate an initial equal allocation does not mean that there must be an actual equal distribution before its principles can be applied to an actual economy. The theory can be operationalized without actually instituting a strictly equal distribution of income and wealth. Suppose that an egalitarian democratic regime is established by the adoption of a new set of amendments or the ratification of a new constitution altogether. Following the conclusion of the first economic period after its inauguration, just remuneration can be assessed by making a massive abstraction from contributions to economic value that come from higher or lower initial endowments of income and wealth, rather than by making an actual, initial, massive, redistribution of economic resources. By making this abstraction from unequal initial purchasing power, the calculations of reward will necessarily be more egalitarian than they would be if the abstraction was not made. Calculating rewards this way conforms to egalitarian principles of remuneration; it does not reproduce morally questionable preexisting inequalities. ${ }^{38}$

In short, the construction of the theory requires a massive abstraction from initial high inequalities; the application of it, however, may not require an actual initial equal distribution of income and wealth. For this reason, I think that the abstraction is not unrealistic or inegalitarian in its consequences.

When Dietsch objects to the unrealism of postulating an initial equal distribution of income and wealth, his concern is not just that it is uncharacteristic of real world economies, but that its adoption in the future is unrealistic. Many analysts share the view that major states are not likely to implement extensive egalitarian redistribution in the future. The rise of American conservatism and the collapse of communism in the former Soviet Union and Eastern Bloc lead many analysts to predict that major egalitarian changes will not occur in the future of advanced capital-based economic systems. But widespread repudiation of capitalism and acceptance of the mixed economy by populations in England and France just a few decades ago suggests that egalitarian democracy is not beyond the realm of possibility. ${ }^{39}$ Moreover, if the social welfare regime in the Netherlands and the corporatist welfare regime in Germany reduced income inequality by 30 to 40 percent in recent years, as Goodin and colleagues estimate, ${ }^{40}$ then egalitarian norms could undergo further evolution in public opinion, leading to the eventual establishment of a more egalitarian democracy in the future.

38 One question for further research is whether one could do this in successive periods. After the second period, the consumer's purchasing power would be a combination of past unjust inequalities of income and wealth plus a reward for equal contributions that was adjusted so that initial inequalities in purchasing power were adjusted. Calculation of egalitarian rewards in the next period would depend on whether one could continue to factor out the ongoing contribution of the initial unequal endowments. If one could not, then Mongiovi is right that the theory could not be operationalized without an actual initial equal distribution of income and wealth devoted to consumption.

39 D Yergin \& J Stanislaw The Commanding Heights (1998) at 22-25, 27.

40 R E Goodin, B Headey, R Muffels \& HJ Dirven The Real Worlds of Welfare Capitalism (1999) at 185. 


\section{(E) Social Theory, Forms of Equal Contributions, AND EGALITARIAN ENTITLEMENTS}

Social theory, liberal theory, and neoclassical theory (really just an economic form of liberal theory) all conceive of individuals as self-determined persons, but social theory diverges from the other two theories with respect to the nature of self-determination. Liberal and neoclassical theories are more individualistic than social theory in that they accord social influences less weight in the formation of the self, its ends and actions. Though liberal and neoclassical theories are not entirely individualistic, they may be designated 'individualistic' in view of the greater weight that they place on subjective attributes, desires, and ends. ${ }^{41}$

Individualistic theories underestimate the role of social influences in the formation of the self and, therefore, also in the determination of individual actions and ends. Neoclassical theory of consumer behavior is weakened by deemphasizing social influences in the formulation of consumer behavior. To be sure, neoclassical economists responded to criticism of the overly subjectivist theory of utility maximization by developing a theory of 'endogenous formation of preferences' or, in other words, of social formation of preferences. But this theory does not overcome the deficiencies in the neoclassical understanding of social influence. It recognizes only arbitrary and capricious social influences (like peer pressure and bandwagon effects), neglecting more important influences flowing from system requisites which shape individuals in accord with the requirements of the system of commodity exchangers and producers.

If the neoclassical theory of consumer preferences was selected for use in the theory of consumer rewards, the latter theory would not be egalitarian in its outcomes. The individualistic view of preferences stresses differences between consumer preferences that extend to the point of non-comparability. Individuals, understood in this way, will generate different amounts of value in the course of maximizing their utility. And those differences entitle them to very unequal amounts of rewards, on a theory of 'dueness' for economic contributions. But the social theory of consumer rewards which I propose is not inegalitarian, because it does not rely on the subjective theory of the consumer.

The social theory of the consumer that I formulate has very different implications for consumer rewards. In contrast to the neoclassical theory of subjective preferences or the neoclassical theory of endogenous formation of preferences I will argue that individuals have socially self-determined wants. By this I mean that individuals shape their wants, and their wants are shaped by and in accord with, the system of commodity exchangers and producers. Social analysis reveals that economic agents are subject to some of the same influences and conditions. As a result, they develop some of the same characteristics and undertake some of the same actions in creating economic value. By looking at the influences that are necessary to the existence of the system and identifying the profound and systematic social influences that help to form individuals, social theory can find general equalities in individuals' contributions to the creation of value, because the requirements of the system produce broad and deep influences affecting all alike. Using a social theory of consumer wants and desires (as well as of other attributes of the consumer), the theory of consumer rewards constitutes an egalitarian theory.

Socially self-determined wants have several defining features. Although they cannot all be treated within this article, I would like to discuss some of them. To attain satisfaction from

41 By social theory I mean Hegelian social theories: GWF Hegel The Philosophy of Right (1952); DP Levine Economic Theory (1978) vol 1; and RD Winfield The Just Economy (1990). Some other kinds of social theories, of course, do not accept the view that individuals are self-determined. 
commodities produced by others, a person must want them. To want them, a person must constitute herself and her needs in such a manner that she can be satisfied by what other persons can provide. This kind of wants is relevant to the theory of consumer rewards because it makes a contribution to economic value. Needs that are shaped by the individual and by the system, so that they accord with what the market offers, constitute a necessary condition for the existence of value. Commodities cannot have economic value, or price, unless they attract consumers and they cannot do the latter unless consumers are willing to shape their wants so that they can be satisfied by what the market provides. If consumers insist upon satisfying wholly subjective or psychological wants, commodity products will remain unsold and they will be valueless. Socially self-determined wants, therefore, make a contribution to value. It is, I suggest, a contribution people equally make. Everyone in a capital-based market system has wants of this sort and makes this sort of contribution. In this respect, consumers make an equal contribution to value. And this equal contribution makes them equally deserving of the value those help to create.

Another feature of socially self-determined wants is that they are quantitatively and qualitatively multiplied rather than fixed in kind and number. (Qualitative multiplication is a multiplication of kinds.) Every consumer's wants are approximately equal in that their wants are subject to a quantitative and qualitative multiplication. Almost no member of a capital-based economic system is content with the biological minimum.

Wants multiplied in kind and number is critical to the creation of value. In a capital-based market system, economic value is the value, not of a fixed and limited set of goods, but of a vast accumulation of commodities. The same can be said of value in a sustainable economy. The establishment of a no-(physical) growth economy, starting from the current enormous productive capacity, still generates a vast amount of value, but does so without physical expansion of inputs or outputs. The vast amount of value characteristic of either a capital-based market system or a sustainable economy is impossible without consumer wants that have been quantitatively and qualitatively multiplied. Value in a capital-based market system is capable of ongoing expansion through increases either in the physical or non-physical amounts of inputs and outputs. Expansion of value may also be possible in a sustainable economy, but it takes the form of growth without increases in physical magnitudes of inputs and outputs. Expansion of value either in a capitalist economy or a sustainable economy would be impossible if the wants of consumers were fixed in kind and number. Multiplied wants provide the motivational spur for the multiplication of commodities and the expansion of value. Multiplication of wants is, therefore, essential to the existence of value as self-expanding value.

Since every consumer's wants are subject to a quantitative and qualitative multiplication, each person is in this sense equally responsible for the existence of economic value. Corresponding to this form of equal responsibility for value, all consumers are equally responsible for the value that is generated by this kind of equality. Though they are not entitled to equal amounts of the total national income, because there are, in addition to their equal contributions, different contributions to value, such as in the amount and kind of their productive activities.

The quantitative and qualitative multiplication of wants is not something that varies with consumers' incomes, so its contribution to value does not differ depending with different consumers' incomes. The quantitative and qualitative multiplication of wants is excited by exposure to the manifold products of the division of labour, rather than being a function of individuals' incomes. It forms a motivational bedrock for the multiplication of commodities and for the expansion of value that is relatively independent of differences between consumers' 
incomes. While a person's purchasing power may limit his or her effective demand, that purchasing power will not be translated into an actual purchase unless the person's wants have been subject to quantitative and qualitative multiplication. The equality among persons' wants with respect to the quantitative and qualitative multiplication of wants makes them equally entitled to the part of value that is due to this form of wants.

\section{(F) INDIRECT CONTRIBUTIONS AND INDIRECT ENTITLEMENTS}

Another form of contribution that consumers make toward the creation of economic value is more indirect than the two described above and it deals with a different aspect of socially selfdetermined wants. A consumer can indirectly contribute to the creation of economic value by influencing the preferences of other consumers. As already noted, consumer preferences can affect prices. By the same token, an individual who influences other consumers' preferences plays an indirect role in their contribution to the creation of value. This influence can qualify as a contribution itself, despite being an indirect factor. If consumer preferences can contribute to the creation of value, then individual influences that help to form their preferences can also be contributions to the creation of value, though more indirectly. The reason for this is that almost any human contribution to the creation of value, direct or indirect, warrants remuneration on a principle of dueness for economic contributions.

If we grant that social influences upon consumer preferences can contribute to the creation of value, then the question arises whether it has egalitarian implications when incorporated into the theory of consumer rewards. This depends upon whether individuals contribute equally or unequally to the formation of consumer preferences. To answer this question, we have to explore the relevant social influences. For this purpose we may focus on the social formation of the following feature of consumer wants: the fact that they are quantitatively and qualitatively multiplied rather than fixed and limited.

At first it seems unlikely that individuals have equal influence upon consumer preferences in this respect. A large advertising agency, such as J Walter Thompson, presumably has greater impact upon the multiplication of consumer wants than the average individual does. Yet I will argue that the average individual exerts a profound, though less obvious, influence upon the multiplication of kinds and numbers of consumer preferences, And I will argue, further, that, in this process, she or he has equal formative influence upon other consumers' multiplicity of wants.

The multiplication of wants that is significantly responsible for the multiplication and expansion of value arises within the social process of formation of wants. By way of illustration consider the formation of the desire for a Mercedes Benz. Influences which help to create this sort of want are systemic. Although advertisers affect the market for Mercedes, they may not be the sole or primary influence on the desire for these cars. The interest of the wealthy in Mercedes presumes the existence of a society with a keen interest in automobiles. Mercedes provide their owners a status symbol, which impresses rich, poor, and middle class alike. But the status symbol that it provides is so ubiquitous because the great bulk of consumers value cars. The great car culture of the United States accounts more for the interest in Mercedes cars than an advertiser could. This car culture is not just an epiphenomenon of automobile advertisements, but a way of life embraced by the great bulk of consumers in the US. Interest in cars is excited by exposure to them in the neighborhood, by neighborhood talk about cars, and by cultural practices regarding cars. Ultimately it is due to the system of consumers because neighborhood talk and practices are influenced by interactions between people of different neighborhoods. Interactions between members of the system of commodity exchang- 
ers spread the virtues of cars far and wide. This case suggests that the multiplication of wants occurs through the interactions of a system of individuals. Because the system of commodity exchangers is profoundly responsible for multiplying the kinds and numbers of preferences, credit for this is spread equally among individuals. They are equally system-members and it is as system-members that they have their most profound influence. On a principle of remuneration for economic contributions, the account of the indirect formation of the multiplication of the kinds and number of wants supports an equal distribution of the value generated by the action of these socially self-determined preferences upon prices.

The argument that individuals have an equally strong mutual influence on each others' preferences - and that this justifies a certain distributive equality — is 'highly speculative' and 'less interesting,' according to Peter Dietsch, because it 'depends on equal income and wealth to start with,' which is an 'unrealistic premise.' 42 I have argued above that it is not unrealistic or unwarranted to postulate initial equal income and wealth. If that argument is correct, it follows that it is not unrealistic or uninteresting to argue that individuals have an equally strong mutual influence on others' preferences. Deutsch does not doubt that there would be relatively equal formative influence on preferences if there were an initial equal allocation of income and wealth. If this premise is realistic - relative to the nature of a just economy - then the rest of the characteristics that I have ascribed to this order are not highly speculative. Equally strong mutual influence on individual preferences would follow and equal indirect entitlements for value created thereby would also follow.

\section{(G) Another Form of Equal Contribution}

Consumers have another equal feature that contributes to the value of commodities. One of the most important causes of the subsistence of value is the process of ongoing circulation of commodities and money. I argue that consumers equally accept the system goal of ongoing circulation of commodities and money and that, by doing so, they make equal contributions to the subsistence of value through the circuit, which entitles them equally to shares of part of the value sustained and expanded by this process.

According to neoclassical economics, consumers are preference maximizers. That is their only goal. Contrary to this view, Adam Smith asserted that all individuals have a goal of having money at hand. ${ }^{43}$ The goal of having money at hand has no meaning or purpose in itself, but derives significance from the fact that it is necessary for the circulation to continue. Therefore, the goal of having money at hand is, inferably, a tacit acceptance of the system goal of ongoing circulation of commodities and money. General acceptance of this goal reflects centuries of accumulated experience with the circulation of commodities and money, and societal acceptance of the goal represents a tacit recognition that payment for produced goods is a necessary condition for the ongoing circulation of commodities and the reproduction and expansion of capital. Moreover, the exchange cannot be written off as reflecting ideological hegemony or domination, because the circulation of capital is necessary even in a socialist market system.

Unlike the neoclassical theory of consumer behavior in which preference maximization appears as subjective choice, self-seeking in accord with the goal of ongoing circulation of capital is a form of social self-determination. The individual has this goal through a social self-determination. Because individuals subsist within a system of commodity circulation, no one will give the indi- 
vidual anything economically valuable without receiving valuable consideration in exchange. The individual assimilates a goal of ongoing circulation because he or she must do so in order to subsist within a social process dependent upon ongoing circulation of commodities.

Self-seeking in accord with the goal of ongoing circulation is one of the individual's most important contributions to the subsistence of value through the circuit, and in this sense to the creation of value. Patterns of accountability for this kind of self-seeking therefore relate directly to the problem of determining individuals' dueness for value contributions, that is, for determining the amount of value that should be distributed to them because its creation is due to them.

The fact that the individual has a goal of ongoing circulation of commodities is partly due to every other member of the process. As determinants of her having this goal, they are also a fundamental source of her contribution to the value of commodities, for her actions in accord with this goal contribute to the subsistence of value and, therefore, to the creation of value. These other persons, therefore, have an indirect entitlement to a share of the value that accrues to her in the course of her socially self-determined self-seeking. This makes property a right to some significant equalization of value.

In what way do they all contribute to the fact that she has and pursues a goal of ongoing circulation? When the individual approaches the world of commodity exchange with the intent of acquiring a desired good, no one will give it to her without receiving another good or money in return, because each knows that he can't survive and flourish in a process of ongoing circulation unless he makes this stipulation. And this is an exceptionally strong inducement to the consumer to have a goal of having money at hand - the prime condition for the ongoing circulation of commodities and money.

In order for this indirect contribution to be an equal contribution (deserving of equal rewards), the influence of each other person upon the consumer would have to be equal. Is the contribution that others make to her having the goal of having money at hand an equal contribution? The fact that a wealthier person declines to turn over goods without consideration is no more or less responsible for her assimilation of said goal than the fact that a poorer person makes a similar stipulation for entering into exchange with her. It is clear, then, that everyone else has a relatively equal responsibility for the fact that the individual has a goal of ongoing circulation of commodities and money. The people exercising this indirect influence have an indirect entitlement to equal shares of part of the value that accrues to the subject in the course of her market activities, specifically, the part of the value due to their indirect influence. This has implications for Spragens' contention that purchasing power is the major consideration in considering a consumer's contributions to value. The indirect influence of the consumer on other consumers just discussed does not depend on differential purchasing power.

\section{(H) Distributive EFFECTS}

The social theory of rewards for contributions yields a right to an equal portion of part of the income that accrues to every other person in the course of her or his market activities. At this point in the development of the theory, I have not yet fixed the redistributable portion, except to say that it is clearly a substantial amount, in view of the enormous contribution that consumers make to the creation of value. We can get a sense of the theory's potential distributive effects by considering how inequality is affected by its adoption in two sorts of economies, one with a less unequal economy, another with a more unequal economy. Assume that the size of the redistributable portion is 10 percent of each person's income. This means that every citizen shall pay 10 percent of her or his income and that 10 percent of the income of every person will be distributed 
in equal amounts to every person. As the first half of Table 1 illustrates, this kind of redistribution can be effective in promoting equality in the less unequal economy. As a result of this redistribution, the income of the poorest 5 percent rises by 115 percent, the income of the next 15 percent of the population rises by 35.5 percent, the income of the second quintile rises by 12.2 percent, the income of the third quintile rises by 3.2 percent, while the fourth quintile experiences minimal reduction in income (only -1.4 percent), the next 15 percent of the people experience a moderate reduction in income of -4.5 percent, and the income of the richest 5 percent declines by -7.7 percent. Under this plan, a substantial increase in income equality is achieved at small cost to the middle class and without severe reduction in the position of the top 5 percent of the population. Only 20 percent of the population incurs noticeable loss of income and it is not a large loss compared to the very considerable gains they get from social cooperation.

\section{TABLE 1 \\ DISTRIBUTIVE CONSEQUENCES OF THE SOCIAL THEORY OF CONSUMER REWARDS, ASSUMING A $10 \%$ TAX $^{*}$}

\begin{tabular}{|c|c|c|c|c|c|c|c|c|}
\hline \multicolumn{9}{|c|}{ Distributive effects in a less unequal economy } \\
\hline & Bottom & Next & Next & Next & Next & Next & \multicolumn{2}{|l|}{ Top } \\
\hline Percentile & $\underline{5 \%}$ & $15 \%$ & $\underline{20 \%}$ & $\underline{20 \%}$ & $\underline{20 \%}$ & $\underline{15 \%}$ & \multicolumn{2}{|l|}{$\underline{5 \%}$} \\
\hline Share of Total Income & $0.4 \%$ & $3.3 \%$ & $9.0 \%$ & $15.1 \%$ & $23.3 \%$ & $27.3 \%$ & $21.6 \%$ & $100.0 \%$ \\
\hline Number of Persons & 1 & 3 & 4 & 4 & 4 & 3 & 1 & 20 \\
\hline Total Income & 4 & 33 & 90 & 151 & 233 & 273 & 216 & $\$ 1,000$ \\
\hline $10 \% \operatorname{Tax}$ & 0.4 & 3.3 & 9 & 15.1 & 23.3 & 27.3 & 21.6 & $\$ 100$ \\
\hline \multicolumn{9}{|l|}{ Redistributed on Per } \\
\hline Capital Basis & 5 & 15 & 20 & 20 & 20 & 15 & 5 & \multirow{4}{*}{$\begin{array}{c}\$ 100 \\
\$ 1,000\end{array}$} \\
\hline Income after Tax and Transfer & 8.6 & 44.7 & 101 & 155.9 & 229.7 & 260.7 & 199.4 & \\
\hline $\begin{array}{l}\text { Percentage Increase in } \\
\text { Income }\end{array}$ & & & & & & & & \\
\hline Income & $115.0 \%$ & $35.5 \%$ & $12.2 \%$ & $3.2 \%$ & $-1.4 \%$ & $-4.5 \%$ & $-7.7 \%$ & \\
\hline $\begin{array}{l}\text { Top 5\%/Bottom 5\% (pre-tax) } \\
\text { Top 5\%/Bottom 5\% (post-tax a }\end{array}$ & רsfer) & $\begin{aligned} & 54 \\
= & 23\end{aligned}$ & & & & & & \\
\hline
\end{tabular}

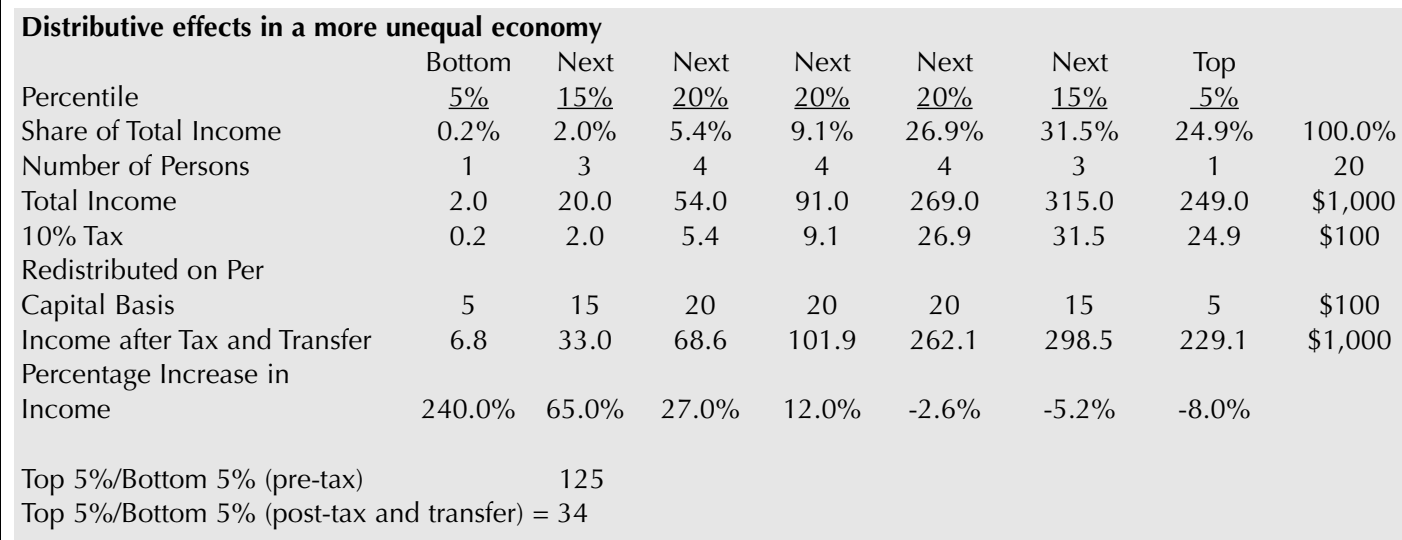

* I am grateful to KS Sastry for providing the first half of this table: Distributive Effects of the Social Theory of Rewards in a Less Unequal Economic Society. 
In the more unequal economy, the implementation of the egalitarian right achieves even more dramatic improvement in income equality. The lower three quintiles all make substantial increases of income, with the bottom 5 percent receiving a whopping 240 percent increase in their income, while only the highest quintile suffers substantially decreased incomes $(-8$ percent for top 5 percent and -5.2 percent for the next 15 percent), which does not seem large next to the benefits that they derive from social cooperation.

\section{Social Ethics of Economic Community}

\section{(A) INTRODUCTION}

The ethics of economic community can also help us to open the door to more equality. The central idea of this ethics is as follows: when a number of individuals are united for the pursuit of some end that they hold in common, they should be able to share in the attainment of that end. Although the ethics of economic community is controversial, this main theme is not particularly problematic. It has strong intuitive appeal, garnering support from people of diverse ideologies. Various theorists, ranging from classical liberals (Locke and Kant, whom some libertarians venerate $)^{44}$ to social theorists (Hegel and Charles Taylor) give their analytical support to it.

The ethics of economic community faces other difficulties. These problems relate to the appropriateness or relevance of communal ethics to capital-based market systems. It is quite clear that an association would have to be a community before it could qualify for regulation by the ethics of community. This is because community is the moral basis that invokes the distributive rule of the ethics of community. The contention that everyone should share equally in the ends of association is without foundation if the association is not a community. The communal requirement for applying the ethics of community seems to be an insuperable barrier to applying it to capital-based market systems, for these systems are not communities in the view of most analysts. Some theorists point out sub-communities within the modern economy. Others point to the surrounding community in the form of a political system with common ends. Still others say the economy is contained within a communal 'social capsule.' 45 But not even the most ardent communitarians like Amitai Etzioni claim that capital-based market systems are communities.

Scholars understand the capital-based market system as a competitive, rather than communal, system. Some tend to see it as atomistic. Others prefer to say it is individualistic. Still others qualify its individualism, saying the market and the division of labour are conditions of interdependence rather than of pure self-reliance. But even when qualified by interdependence, scholars do not generally regard the capital-based market economy as a community.

Recognition of interdependence does not lead them to pronounce it a community. Most scholars who position themselves on the matter maintain that market interdependence is not communal because it lacks the common action for common ends essential to community. ${ }^{46}$ Understanding the economy as a condition of individualistic interdependence rather than of

44 R Nozick Anarchy, State, and Utopia (1974) at 32, $337 \mathrm{fn} 4$.

45 A Etzioni The Moral Dimension (1988) at 212, 199-216.

46 C Armstrong 'Equality' (note 37 above) at 343; V Chibber 'Individualism, Community, and Distributive Justice' (2004) 13 The Good Society 62 at 63-65. 
communal interdependence leaves scholars indisposed toward egalitarian rules of distribution of income, because they can't see the communal basis for invoking such rules.

While capital-based market systems are evidently not fully communal, no one has proved that they do not contain a dimension of community on a systemwide scale. The existence of this dimension remains an open question. This possibility deserves further study, because it fulfills the prerequisites for applying communal ethics of distribution to these systems.

Community is more often contrasted with markets than identified with them, because it usually involves some sort of central direction or authority through which people implement their common purposes, whereas the market is composed of decentralized exchange relations though which people pursue alternate goals. ${ }^{47}$ Hierarchical medieval community, twentieth century communism, and liberal political community exemplify communities with central authority. Community can, however, take a decentralized form, such as general agreement or common character. So the market's decentralized character does not preclude its having a dimension of community. From this we can learn something more about the kind of object that the search for economic community is looking for. It seeks a dimension of community within a decentralized system. For that to exist, it would have to be possible for a system of individuals to engage in common action for common ends through decentralized interactions.

There is an intuitive basis for the notion of a dimension of community within capital-based market systems. As individuals compete in the modern market economy, they simultaneously stitch together something of a community by engaging in common actions for certain common ends. Each one of them is involved in doing things for other people that they would otherwise have to do for themselves, and that meets the definition of common action. Arguably, all economic agents have a common goal of preserving and expanding capital, because all of the goods and services that they desire hinge on the ongoing circuit of money and commodities, that is, the circuit of capital.

The common actions sustaining the circuit of capital are generated by socially influenced but individually willed actions. An element of cooperation arises between firms because they have to adjust their production processes to what other firms provide and need. Though opposed in a number of ways, capital and labour also unite to produce and gain portions of social wealth. Mutual adjustment is required for joint production. Labourers and managers of capital acquire skills and pattern their work for the efficient production of goods and capital. Moreover, since profits depend on sales, production and consumption are interrelated as well. While producers orient output toward the satisfaction of consumer wants, they also shape those wants by advertising their products and by other means.

This intuition suggests that capital-based market systems have a communal dimension. If so, this kind of system has the qualification for being regulated by the ethics of community, to some significant extent. Because this ethics morally warrants equal distribution of relevant resources among community members, capital-based market systems should be subject to this rule to the extent that they are communities.

From the intuitive account just given, it is apparent that individual actions and ends in the economy have an inter-subjective inner structure. By that I mean the inner composition of the person changed in response to the requirements for self-seeking under conditions of mutual dependence. For example, labour acquires skills and patterns her work for the efficient production of goods and capital, because she cannot gain a share of wealth unless she unites with 
capital in a process of commodity production. The inter-subjective inner structure of the person is noteworthy because it constitutes a nexus between individual action and ends and the actions and ends of others. Instead of being substantive, that is, independent and self-existent, individual action and ends, therefore, are dependent parts of common action and ends. By way of illustration, the nature of the skills acquired, the labour performed, and the education undertaken - are all characteristic of the inter-subjective inner structure of the worker, whose labour forms common action with other workers and with the owners and managers of capital. And only insofar as it constitutes common action does it constitute productive action.

Neoclassical economic theory does not grasp the dimension of community in the economy, partially because it passes over the internal changes which individuals make in response to the requirements for self-seeking within the circuit of capital. As mentioned above, neoclassical theory subscribes to conception of the self as having a subjective, rather than inter-subjective, structure of the self. On this basis it is not able to grasp the nexus between individual action and ends and common action and ends, which also renders it incapable of recognizing the existence of economic community. Instead it renders a stylized portrait of the economy as a highly individualized process, with market outcomes resulting from the choices of largely self-determined decision makers (producers, consumers and resource holders). 48

\section{(B) COmmunity among Consumers and Producers}

The next stage of argument is to elabourate upon the preceding sketch. To demonstrate a dimension of community in the economy, one has to show that - despite the existence of different categories of economic agents - the members of the economy share some attributes, actions, and ends. I will argue that consumers, producers, owners of capital, and managers of it share some fundamental attributes in common and they engage in common action toward a common end, even though they belong to different categories of economic agents. To begin with, let us consider the relationship between consumers and producers.

According to neoclassical economic theory, consumers and producers hold alternative behavioral goals: preference maximization and profit maximization. The engagement of consumers and producers in separate actions in pursuit of alternative goals would appear to refute the contention that they engage in common action toward a common end. But does it really? While consumers and producers pursue alternative goals through separate actions, could they not also be engaged at the same time in other actions toward other ends with communal features? The neoclassical portrayal elides these correlative communal actions and ends, but they can be restored to view.

Preference maximization and profit maximization each has a correlative action that reveals common action among consumers and producers. A producer does not just engage in profit maximization. She also produces useful and desirable items for the benefit of consumers. A consumer, meanwhile, does not just engage in preference maximization. He also pays money for the useful or desirable objects acquired from producers. Because profit maximization includes the production of use-values, it is designed to give consumers what they want. Likewise, because preference maximization includes the payment of money, it is designed to give producers what they want. Seen in relation to their correlative actions, preference maximization and profit maximization meet the qualification for common action in markets.

Common action in markets is defined by the conjunction of two sorts of actions: (a) an

48 Debreu Theory of Value (note 31 above). 
action by one person for another person that the second person would have to do for himself if the first person did not do for him and (b) an action by the second person for the first person that the first person would have to do for himself if the second person did not do it for him. Payment of money by the consumer to the producer and production of goods by the producer for the consumer unite preference maximization and profit maximization in common action. These two categories of maximizing behaviors, therefore, cannot be understood simply as alternative behaviors that separate consumer behavior from producer behavior.

Granting that consumers and producers engage in common actions, what about common ends? In neoclassical economics, the market system is defined as a mechanism for the allocation of scare resources between alternative ends. By definitional fiat, common ends are precluded. A better place to look for ends, I suggest, is in the process of circulation of capital.

The owner of capital seeks to exchange money for commodities. She then combines them as productive capital for the production of commodities for sale. The various actions of the capital owner have a common underlying goal: to acquire more economic value. Taken together these actions constitute an expansion of value, but the acquisition of value is not a final goal, it is just a means of renewing the circuit. It returns the capital owner to her starting point, which leads to multiple repetitions of the circuit. Production, then, is not simply production, but part of a larger circulatory process.

Consumer purchases help owners and managers to complete the circuit of the firm's capital. Because consumer payment is a necessary link that completes the producer's circuit, the two constitute common action. Consumer behavior is not ordinarily conceived of in this way. Consumers are said to make independent decisions about the kinds and quantities of goods they buy. These decisions may in turn injure the rejected producers rather than complete the circuit of their capital. For this reason, consumer behavior is generally not understood as action taken in common with producers. But consumers would have to perform the behavior of profit maximization if producers did not do it. It is for this reason that they induce producers to become profit maximizers by making profit maximizers better off than profit minimizers. Producers freely accept these action directives from consumers because they can become better off that way. Since producer activities are made to serve consumer goals through inducements offered by consumers, profit maximization forms a common activity with preference maximization, not simply an alternative to it.

Up to this point, we have considered bilateral relationships between the consumer and the circuit of individual capital. But in order to demonstrate a dimension of community on a systemwide scale, we have to identify a broader pattern of common action and ends than just bilateral ones. Every consumer does not relate only to the firms from which she makes her purchases. The capital of each firm, from which she purchases, is directly or indirectly related to that of other firms. The interdependence of producers is systematic. Exchange links them with every other owner of capital. As a result, every consumer interrelates with those other firms and, therefore, with the system of circulation. The systemic interdependence of individual circuits implies a correspondingly systemic scope of common action within the economy.

Consumers and producers have alternative ends, as neoclassical theory maintains, in the sense that consumer 1 may not want good $\mathrm{X}$ produced by producer 2 and seeks instead good $\mathrm{Y}$ produced by producer 3 . This condition of alternative ends precludes the existence of comprehensive community within the economy. But it does not preclude the existence of a community overarching the pursuit of these alternative particular ends. Relatively independent actions and ends are subsumed under more general common actions and ends: the ongoing process of circulation of capital. Although consumer 1 purchases producer 3's product, rather than produc- 
er 2's product, he nonetheless shares an overarching common end: the preservation of producers' capital. This goal glimmers through the consumer's actions when he pays money for goods received, because such payment is a general need of all producers, not just of producer 3 .

\section{(c) Community and Equal Shares of Part of National Income}

According to classical liberal theory, people unite for the sake of attaining a certain common goal: the goal of living under conditions where each person can define and pursue his or her own ends. These conditions are the conditions of right or ethically valid freedom. In other words, people unite in civil society because it is their common will to live under conditions of right. In the classical liberal theory, the presence of community with respect to living under conditions of right is the moral basis for the equal entitlement to rights. It entitles every member of civil society to the right of property. Property is a matter of right, not just a matter of the good, because it is the freedom of the person to define and pursue her own ends in relation to and over external things.

Classical liberal theory does not, however, maintain that people are entitled to equal amounts of property. While defending a communal basis for the equal right to property it denies a communal basis for the right to equal amounts of property. There is a union with respect to the general conditions needed for the free choice of ends, but not a union with respect to the amounts of goods a person should have. The sphere in which goods are pursued, which we call an economy, is characterized as a disunified multitude. 'Men have different views of the ... ends of happiness,' Kant states, 'so that as far as happiness is concerned, their will cannot be brought under any common principle. ${ }^{49}$ The disunified multitude with respect to the pursuit of the good cannot supply the necessary communal basis for a right to equal amounts of property. Owing to the absence of economic community, 'the utmost inequality of the mass in the degree of its possessions' is admissible, Kant maintains. ${ }^{50}$

The classical liberal principle of the distribution of property is mistaken, in my view, because it is based on a one-sided account of the economy. When Kant ascribes unqualified disunity to the economy, he neglects the presence of a dimension of community, which can supply communal basis for equal distribution of part of national income. He believes community is limited to what may be called a procedural community, where citizens are agreed that everyone should be able to choose his or her own ends. But citizens also agree on a substantive end, the goal of creating and acquiring wealth. Their common will to create and acquire wealth establishes a substantive community in the economy which morally grounds a right to equal shares of part of national income.

Contrary to the view that everyone in civil society seeks wealth, it is sometimes argued that some people just seek subsistence and other people just seek comfort. But most members of capital-based market systems exhibit larger numbers and kinds of needs than this view suggests. Most people in these systems do not seek mere biological subsistence. There are few who seek to subsist on a biological cocktail of the minimally necessary nutrients for survival. Even with respect to typical subsistence goods like food, the lower strata have preferences, for example between different sorts of bread. And their wants are not usually limited to classical subsistence goods. They manifest preferences for various kinds of processed foods and other goods. Most

49 I Kant 'On the Common Saying: "This May be True in Theory, But it Does not Apply in Practice"' in Hans Riess (ed) Kant's Political Writings (1970) 61 at 73-74.

50 Kant 'On the Common Saying' (note 49 above) at 75. 
people in a capital-based market system clearly have a wide range of needs: needs for televisions, radios, a telephone, McDonald's hamburgers, CDs, tapes, expensive sneakers and other fashionable garb, among other things.

Each person has a range of wants for things beyond fixed needs for subsistence, but he or she may differ from other persons in some of his or her specific preferences. The fact that some of the wants that people have differ from those of other persons does not however confirm Kant's view that people differ in the ends of happiness or that there cannot be any economic community. The range of wants just mentioned is not encompassed by needs for the naturally occurring surplus of nature or by the products of limited commodity production. It entails wants that are wants for social wealth, for a vast accumulation of commodities produced by a system of wealth. Reflective of the need for wealth, most people in the United States do not engage in production of use-values for self-consumption, which would supply a much more restricted range of goods. Rather, they seek a money wage that gives them command over part of the world of commodities, that is, over social wealth. Since the members of a capital-based market system all seek wealth in this sense, there is a community of ends among them, including the lower strata.

Against the claimed existence of economic community, one might argue that people pursue a great variety of different ends, not just the end of wealth. You use your wealth to buy a house because you like suburban living; I rent an apartment because I prefer urban living. But the goal of seeking wealth permeates every other goal of economic agents, whatever else they seek. Both an apartment and a house are forms of social wealth, bought and built with particles of social wealth; so they are not merely forms of natural shelter. The common goal of wealth, permeating different particular ends, substantiates a claim that a dimension of community pervades the economy.

To be sure, many people are content with a comfortable living and they may recoil from the garishness and materialism of those they view as seekers of wealth. But what many people call a desire for comfort is really a desire for wealth, properly understood. The desire for wealth is not best understood as a desire for a limousine or a penthouse. It should be grasped as the sort of desire that has been multiplied in kind and number and that cannot be satisfied without a social production process capable of producing an immense accumulation of commodities.

Let us take a look at the seemingly modest requirement for 'comfort.' In the United States today, the desire for comfort encompasses desires for things like automobiles, refrigerators, toaster ovens, televisions, stereo equipment, processed foods of manifold varieties, microwave ovens, clothes of considerable variety, furniture of various sorts, travel vacations, restaurants, computers, books, leisure for study or recreation, college and graduate education, movies, internet connections, highly advanced medical treatment. But these are in no sense modest wants, wants that can adequately be deemed 'comfort.'

Satisfying wants like these requires products that result from a prodigious system of wealth generation, whose products are parcels of social wealth. The fact that an immense accumulation of commodities is needed to satisfy quantitatively and qualitatively multiplied wants shows how little the term 'comfort' conveys about the average person's objectives in economic society. Wealth is, quite clearly, the only appropriate term to designate the amount and diversity of stuff under consideration. The desire for this, which is pervasive in capital-based market systems, is the desire for wealth. So the desire for wealth is a common desire.

Since everyone in a capital-based market system seeks wealth in the sense just described, a community of economic ends exists within the economic system. The dimension of economic community indicated by commonalities in economic ends supplies a communal basis for demanding equal distribution of part of national income. But it does not require equalization 
of all national income, because the economy is not entirely community, for although everyone seeks wealth they also seek different particular use-values. If, as Kant argued, community with regard to conditions for choosing one's own ends equally entitles members to the right of property, then union for the pursuit and acquisition of wealth must entitle them to equal distribution of part of national income, proportionate to the extent of community.

The members of a capital-based market system are united with respect to more than just employment or a minimally decent income. They are united with respect to a larger share of the economic resources of society. They are united for the sake of the preservation and expansion of the capital of the firm and of the system in its entirety. Given the interdependence of individual pursuits of wealth, there is a unity among them with respect to all of the capital wealth of the nation that is used for consumption. Labour has an interest, not only in a wage, but in all of the capital wealth of the firm and of the nation. Consumers seek not only to satisfy preferences but also to satisfy a multiplication of kinds and numbers of preferences, so they have a common desire for wealth. Analysis of their wants revealed that they have not only a common denominator in wanting at least a minimally decent level of consumption, but also a common denominator with respect to the rest of consumption. This common denominator consists in the quantitative and qualitative multiplication of all consumers' wants, which implies that they have a common desire for wealth. The community of ends is, therefore, much broader than theorists of the welfare state recognize. The consumers' goal of seeking wealth cannot be achieved without their participation in a system of commodity exchange and production based on capital, which has a dimension of common action, since individual circuits of capital are interconnected. Individual action in pursuit of wealth therefore exhibits a dimension of common action. The multiplication of wants unites consumers with producers in the circulation process, because this process continues and expands the circulation of capital.

Since economic agents are united with respect to many more economic resources than modern liberal theory realizes, they must, correspondingly, have an equal entitlement to a larger part of economic resources than such theory posits. The unity of capital owners, labourers, and consumers for the sake of the creation and acquisition of capital gives every member an equal entitlement to an equal share of part of the national income devoted to purposes of consumption. They are not just entitled to employment or subsistence, since their unity is not limited to the common pursuit of employment or subsistence. Given the interdependence between individual pursuits of wealth, there is a unity between them with respect to all of the capital wealth of the nation used for consumption. Claims based on membership in this sort of union extend to all of the capital wealth of the nation that is directed toward consumption and that is created by community. This membership does not, however, justify a strict equalization of income, because the overarching unity of economic actors includes a lot of relatively independent action for somewhat separate ends.

\section{(D) Do People Buy Chocolate Because They LiKe It?}

The notion of a common goal of acquiring and consuming wealth is 'very generalized' and 'insubstantial,' according to Chris Armstrong. ${ }^{51}$ The alleged dimension of community is therefore also insubstantial and it cannot supply the moral warrant for egalitarian regulation of income distribution in capital-based market systems, he argues. Furthermore, the desire for

51 Armstrong 'Equality' (note 37 above) at 343. 
wealth is unreal. 'Personally, I usually buy chocolate because I like it,' he says, not because I seek wealth. ${ }^{52}$

Intuitive appeal is, admittedly, all on the side of Armstrong's point. And it would seem to form a basis for a powerful critique of the ethics of economic community. If Armstrong is right in suggesting that people buy chocolate simply because they like it, then there is no common desire for wealth, in which case a major foundation for the theory of economic community is lost, along with the redistributive ethics of community that is built on top of it. Because the argument for the existence of community hinges on the existence of a common desire for wealth Armstrong's critique needs to be considered. For this reason we find ourselves is the rather awkward position of having to undertake a rather extended excursus on chocolate.

Although Armstrong has intuition on his side, the proper study of needs in capital-based markets requires abstraction. The issue calls to mind Adam Smith's statement that one can only appreciate the divided nature of manufacturing through theoretical analysis, because 'we can seldom see more, at any one time, than those employed in a single branch. ${ }^{53}$ In contrast, consumer goals, as Armstrong conceives of them, are entirely concrete and particular, devoid of any abstract or general feature substantial enough to constitute a community. Armstrong's point that people buy chocolate because they like it is seemingly self-evident, but it actually reduces a complex social phenomenon to a simple datum and underestimates the importance of the abstract and general features of desire, which form a real component of its nature, just as the division of labour is an essential aspect of labour.

The desire for chocolate or the want for chocolate is an instance of the desire for wealth rather than the natural need for subsistence. The need for subsistence is a need for food, clothing, and shelter in their most basic forms, as required for survival. In contrast, the desire for wealth may be defined as a desire that has been multiplied in two ways: it is multiplied, qualitatively, in terms of the kinds of things that individuals want to consume and, quantitatively, in regard to the amounts of things they want. There is no assignable limit upon the kinds and numbers of things that people who desire wealth can want, whereas people who seek subsistance seek a fixed and limited set of substances. Like the desire for other objects of wealth, the desire for chocolate has been multiplied in kind and number and it continues to increase without apparent limit.

Total US consumption of chocolate stood at 3.3 billion pounds in 1999 and per capita consumption rose above 11.9 pounds. ${ }^{54}$ At these levels, the desire for chocolate has clearly been multiplied in amount and it is widespread too: $84 \%$ of households consume it, $72 \%$ more than once a week. ${ }^{55}$ By the 1980s Hershey's found enough desire there to sell 25 million kisses a day. ${ }^{56}$ The kinds of desires for chocolate have also been subject to multiplication. The desire for chocolate candy has been diversified into desires for solid chocolate, solid chocolate with inclusions, enrobed or molded chocolate with bakery-product centre (eg, chocolate covered wafers), enrobed or molded with candy, fruit, nut, or granola centre (eg chocolate covered cherries), panned (eg chocolate-covered raisins), and assortments of the above types or others.

Between World War I and World War II, more than 30,000 varieties of chocolate bars were

52 Armstrong 'Equality' (note 37 above) at 343.

53 Smith (note 43 above) at 4.

54 R Lopez Chocolate: The Nature of Indulgence (2002) at 109.

55 RM Rees 'Bite-Sized Marketing: Candy Bars' in A Szogyi (ed) Chocolate: Food of the Gods (1997) 125 at 128; The Chocolate Market (2001) at 31 Web publication by MarketResearch.com Academic: www.academic.marketresearch.com/product/print/default.asp?. 
introduced. ${ }^{57}$ Desire for chocolate candy was subsequently differentiated into desires for chocolates distinguished by size and packaging, as well as by seasonal and non-seasonal characteristics. It has been multiplied by differentiating it into desires for four categories of chocolate products: chocolate candy, chocolate chips/baking chocolate, powdered cocoa mixes, and chocolate syrup/dessert toppings. It has also been differentiated and multiplied into desires for many other product types that contain chocolate but whose primary definition is not chocolate, such as cake mixes, frostings, and cake decorations; ice cream, puddings, and other deserts, and cocoa-flavored cereals. In fact, the desire for chocolate has been distinguished into so many types that it would take more than five pages to list the top brands and products of selected marketers in the US chocolate market alone. A single commercial supplier lists 2,000 types of chocolate. ${ }^{58}$ With the multiplication of kinds and numbers of desires for chocolate, the desire for chocolate has the character of a desire for wealth. The number and kinds of chocolate products are wealth in the sense that they clearly form part of a vast accumulation of commodities, which is what wealth is. And the desire for them is a desire for particles of social wealth. The kinds and numbers of these desires are too great to be classified as either subsistence wants or comfort.

Another feature of a desire for wealth that the desire for chocolate exhibits is that it expands and increases. 'Per capita consumption of chocolate candy has risen steadily over the past few years, growing $13 \%$ between 1994 and 1998, from 10.8 pounds to 12.2 pounds'. ${ }^{59}$ New desires keep arising in relation to new products that have been innovated. In 1999-2000, Hershey's alone introduced nine new products: Kit Kat Big Kat, line extensions to Hershey's bites - York Peppermint, etc - Novelty Dr Seuss's How the Grinch Stole Christmas packages, Whoppers, Cinnamon Chips, syrup in Hershel the Cow-shaped bottles, and Health Sundae Syrup, and Fudge Cookie Crunch Shell topping. Twenty percent of 'Hershey's recent sales come from new products'. 60

It is in the nature of wealth that it expands and increases. It is self-expanding value, rather than just value that gets reproduced at an arbitrarily assigned level. As an expanding desire, the desire for chocolate has the quality of the desire for particles of wealth.

We can also see that the desire for chocolate is a desire for wealth when we look at the process by which this desire is formed. Ideas play a role in the expansion of a person's desires, but these ideas may not all originate within the self. As Hegel explained, the multiplication of desires is caused by the division of labour, because the division of labour produces a multitude of products that excite a multiplicity of desires. The members of the system of commodity producers need to produce wealth, a vast accumulation of commodities, if they are to expand value and to attain wealth themselves. Desires stimulated by producers of wealth are desires for particles of wealth. The chocolate industry exposes prospective consumers to a multiplicity of chocolate products which excite interest in these products. It does so by displaying the product in widely distributed retail sites, and by extensive advertising in magazines, newspapers, television, radio, movies, and on the Internet. The industry assures its own growth by establishing 'almost infinite points of sale' where desires are excited. ${ }^{61}$ With an estimated ' 2 million places where confectionary can be purchased in the United States,' the opportunities for exciting inter-

57 Rees (note 55 above) at 127.

58 The Chocolate Market (2001) at 31 Web publication by MarketResearch.com Academic: www.academic.marketresearch.com/product/print/default.asp?.

59 The Chocolate Market (note 58 above) at 31.

60 Rees 'Bite-Sized Marketing' (note 55 above) at 128.

61 The Chocolate Market (note 58 above) at 68. 
est are truly vast. 62 Sites for exposing consumers to chocolate products have expanded out from candy stores to supermarkets, gourmet and specialty stores, convenience stores, mass merchandisers, vending machines, drugstores, warehouse clubs, hardware stores, office supply stores, video stores, craft and hobby stores, health and natural foods stores, the internet, ${ }^{63}$ and car washes. The upscale Toblerone brand is now available at the best truck stops.

Marketing through cross promotions and tie-ins also stimulates a lot of interest in chocolate. After ET reached for a Reece's peanut butter cup, the brand's sales tripled. ${ }^{64}$ The tie-in to Lindberg's solo flight across the Atlantic launched the Lindy Bar. ${ }^{65}$ Advertising also excites interest in chocolate. National consumer advertising expenditures in 1999 reached an estimated $\$ 369$ million. ${ }^{66}$ Hershey spends 10 percent of its enormous yearly sales on advertising ${ }^{67}$ giving it considerable capacity to stimulate desires for its chocolate.

If Chris Armstrong really purchased chocolate just because he liked it, rather than because his desire for it is a desire for a part of social wealth, then his desire would have no commonality with the desires of those who do not like chocolate. Consequently, we would be unable to establish that consumers have common goals. But as we have seen, the desire for chocolate is a quantitatively and qualitatively multiplied desire. As such, it has the shared property of being a desire for wealth. The common desire for wealth establishes a dimension of community among citizens, which invokes the ethics of community and its egalitarian rules of distribution of part of national income.

\section{(E) CAN THere be Community in Market Economies with Dissident ENVIRONMENTALISTS AND SUSTAINABLE ECONOMISTS AROUND?}

The proposition that capital-based market systems have a dimension of community is apparently contradicted by the fact that these systems contain economic democrats, right- and left-wing libertarians, market socialists, devotees of sustainable economics, all advocating alternative economic arrangements: a system of self-owned and self-governing economic enterprises, unregulated capitalism, a system of collectively owned and self-managed firms, a system with highest attainable basic income, etc. Some proponents of these systems view them as categorically different from, and ethically superior to, capital-based market systems with egalitarian rules of distribution derived from the ethics of community. ${ }^{68}$ As they see it, the ethics of community for capital-based market systems does not provide principles of distributive justice that are generally valid for all economic systems or specifically valid for capital-based market systems. Some theorists doubt that community could be ascribed to systems fraught with this much dissensus. ${ }^{69}$

Disagreement between individuals in a capital-based market system regarding distributive rules may not rule out a dimension of community regarding some or all of the system's fundamentals. While economic actors may disagree over whether there should be liberal property or redistributory property, they may agree that the economy should be arranged so as to preserve

62 The Chocolate Market (note 58 above) at 20.

63 The Chocolate Market (note 58 above) at 68.

64 Lopez Chocolate (note 54 above) at 126

65 Lopez Chocolate (note 54 above) at 126.

66 The Chocolate Market (note 58 above) at 18.

67 Rees 'Bite-Sized Marketing' (note 55 above) at 127.

68 V Chibber 'Individualism, Community, and Distributive Justice' (2004) 13 The Good Society 62 at 62-66.

69 Armstrong 'Equality' (note 37 above) at 346 fn 23. 
and expand capital. As long as they agree on this relevant fundamental, a dimension of community can exist within capital-based market systems, and it can invoke the redistributory rules of the ethics of community. Even if the minority prefers traditional liberal property rights, the majority can cite the agreement on the preservation and expansion of capital as a communal basis for the egalitarian rules of distribution of the ethics of community.

Disagreement between individuals in capital-based market systems regarding private versus collective ownership of production precludes some forms of community among the members. But it does not rule out agreement on a relevant fundamental: that the system should be arranged so that capital is preserved and expanded, and wealth created and acquired. Community in regard to the preservation and maintenance of capital can, therefore, exist in a capital-based market systems, despite the lack of community with respect to whether there should be collective versus decentralized ownership of firms. And it can invoke the egalitarian distributive rules of the ethics of community.

Do differences between advocates of capital-based systems and sustainable economies preclude an element of economic community from the former systems? And therefore also preclude the ethics of economic community with their egalitarian rules of distribution? I don't think so.

Sustainable economics rejects growth economics and adopts steady-state economics. Its advocates define growth as 'an increase in the physical scale of the matter/energy throughput that sustains the economic activities of production and consumption commodities. ${ }^{70}$ If adherents of sustainable economics were right that economic growth could be defined as an increase in the amount of physical inputs and physical outputs, then a sustainable economy that eliminates this kind of increase would obviously be categorically different from a capital-based economy, where increases in physical inputs and outputs are ongoing. But economic growth cannot be reduced to increased use of physical inputs (raw materials and capital stock) and increased production of physical outputs. New generations of computers, refrigerators, televisions, and other electronic devices can have innovative features that add to their value, even though their production does not utilize as much matter and energy as previous generations did. Since the growth of capital consists essentially in the growth of value, the limitation of physical inputs and outputs that sustainable economics requires does not necessarily limit capital's growth. A sustainable development model is, at least in this fundamental respect, indistinguishable from a capital-based market system. Disagreements between the advocates of these alternatives systems do not bar the existence of community with respect to the preservation and expansion of value, so the communal basis exists for the ethics of community and its egalitarian rule of distribution.

As the natural resource constraint upon physical growth tightens, however, countries will have to try to shift from the mode of expansion of capital under capitalism to the mode of expansion of capital in the sustainable economy. Instead of expanding capital through expansion of physical inputs and outputs there will be an intensified drive to expand it through expanding value-without expansion of physical inputs and outputs. If, on the one hand, this works, then capital-based markets will be preserved. If, on the other hand, economic society cannot convert to the alternative mode of value expansion, then the economy will cease to be a value-growth system and will lose a basic feature of a capital-based market system (though it can still have another basic feature of a capital-based market, which I will mention in a moment). Community will not obtain between the advocates of sustainable and wealth-based

70 Herman Daly Beyond Growth (1996) at 31. 
economics with respect to continued expansion, and to this extent there will not be a basis on which to argue for the ethics of community with its egalitarian rules of distribution. There will, however, continue to be agreement with respect to the pursuit and acquisition of a portion of wealth, considered as a vast amount of wealth involving an immense accumulation of commodities, though not as a growing sum and possibly as a retreating sum. This degree and kind of community would also continue to justify egalitarian distribution proportionate to the extent of community.

The number of advocates of expansionary capital-based economics will probably dwindle under circumstances of severe resource constraints, just as support for capitalism waned after World War II in Europe, where a new consensus on the mixed economy arose. In this case, there would be community with respect to the mode of value creation in the sustainable economy, which would invoke egalitarian rules of community.

Suppose that capital-based market systems can successfully change to economic growth involving expansion of value without expansion of physical inputs and outputs. Then it would seem like the ethics of capital-based economic community would still be valid. The common goals of the members - preservation and expansion of capital and the creation and acquisition of wealth - would not have hit an insuperable barrier. People would continue to have a common interest in the preservation and expansion of capital, except that it would take the form of a common interest in the preservation and expansion of value rather than of physical inputs and outputs. The egalitarian rules of distribution would still be invoked, because community had been maintained.

In sum, there is a communal element in both sustainable economics and capital-based market systems. Indeed the former can be capital-based market systems and can have the dimension of community that the latter have. Under certain circumstances, however, they will cease to be species of capital-based systems. When resource constraints are very severe, sustainable economies will not be capital-based market systems, and they will lack at least some of the forms of community that reside in the latter systems. But they will have a different dimension of community, one that obtains with respect to the mode of value creation characteristic of a sustainable economy, and that dimension of community will invoke the rules of the ethics of community.

The ethics of community, therefore, seem general in their application to the various types of modern real world economies.

\section{(F) ON THE MarXist CRITIQUe of THE ETHICS OF COMMUNiTy FOR CAPITAL-BASED MARKETS}

In the judgment of some radical and liberal analysts, cooperative relations between owners and workers do not display an element of community, because these relations do not arise from free, uncoerced choices. Labour deals with capital on pain of starvation, not out of a community of interests. This line of critique seeks to undermine the communal thesis by refuting the premises on which it is based. But I do not think the attempt is successful. One of the premises of community is that labour and capital share an interest in preserving and expanding wealth and capital. Another is that labour has an interest in creating and consuming a share of social wealth. Neither one of these premises can be set aside by arguing that labour cooperates with capital on pain of starvation. To refute these premises, one would have to show labour could successfully pursue its interest in a share of social wealth without proceeding in accordance with the requirements for preserving and expanding capital. As far as I know, neo-Marxist and liberal 
arguments have not shown this, so the communal dimension remains well founded.

The argument that cooperation in capitalism is necessitous rather than volitional hinges on a neo-Marxist or classical political economic view of how capital provides for the needs of workers. On this view, capitalism affords the bare minimum for workers' needs, if that. But the classical model does not square with the facts, noted above, of the twenty-first century American economy. With thirty five million white collar workers receiving mean hourly earnings of 19 dollars, fifteen million workers in professional specialty and technical occupations with average earnings of 26.18 dollars, twenty three million blue collar workers with mean hourly earnings of 13.61 dollars, and fourteen million workers in state and local governments receiving mean hourly earnings of 20.56 dollars, workers in twenty-first century America share enough in the ends of association for the economy to have a substantial dimension of community, though not equally enough for the distributive ethics of community to be fully realized. ${ }^{71}$ The presence of an element of community makes the ethics of community applicable to capitalism to the extent that community exists within it. Because this ethics morally entails equalization, there should be an equalization of income proportionate to the extent of community present in the system.

Once the redistributive rules of ethical community are applied, they can reduce the antagonism in capital-labour relations. That antagonism is treatable by these external rules partly because the antagonism is not entirely intrinsic to these relations. And, to the extent that the antagonism is intrinsic, it can still be substantially overcome by external measures. The antagonism between labour and capital arises in part from an external source: liberal laws of property and contract which promote income inequality by giving legal authorization to almost any terms that capital and labour agree upon. It is therefore susceptible to reduction by redistributive measures which alter the external legal environment of business that currently authorizes highly unequal incomes.

Marxists in particular believe that external redistributive policies cannot significantly enhance community between labour and capital, because the antagonism springs from sources intrinsic to their relations rather than extrinsic to them. Under competitive market conditions, capitalistic owners who seek to maximize profits must minimize costs by, among other things, keeping wages down. For this reason, Marxists contend that wage conflict is built into capitallabour relations and that it is unalterable so long as private ownership of capital exists. Since the antagonism between workers and owners is a function of the private ownership and control of firms, Marxists contend that it cannot be overcome by governmental policies in regard to welfare or redistribution. While the antagonism between labour and capital does, as Marxists claim, have some internal causes within capitalism, the fact that the sources of wage conflict are internal does not put the antagonism beyond the ameliorative reach of redistributive policies. Redistributive measures can reach the inequality of incomes wherever it arises, inside or outside the economy. And, by allowing workers to share more fully in the ends of association, these measures are able to strengthen the bonds of association.

From the perspective of neo-Marxists and some liberals, wage conflict is inherent in capitalism, so it can not be eradicated or significantly reduced under capitalism, because there is a zero-sum relation between profit and wages. It is true that profits and wages are partially inversely related, but they are not entirely inversely related. A partially inverse relation between wages and profits precludes a fully communal relationship between labour and capital, but it

71 See National Compensation Survey: Occupational Wages in the United States, 2001. 
does not preclude a partially communal one. A dimension of community is, therefore, compatible with a partially inverse relationship between wages and profits. Profits are important for capital accumulation, and capital accumulation is an essential input to long-term growth, which in turn is one of the most important causes of rising standards of living. ${ }^{72}$ As Joel Mokyr puts it, 'To say ... that a country is rich is to say that it experienced economic growth in the past.' 73 Both workers and owners of capital can, therefore, have some common interest in profit maximization and cost minimization. This means that the opposition between workers and owners of capital as regards wages and profits is not thoroughgoing and that it can co-exist with an element of community. When one adds this aspect of community to other aspects that the system possesses, there are gathering bases for invoking an ethics of community and applying its egalitarian rules to the distribution of income in capital-based market systems.

Marxists also believe that antagonism is intrinsic because workers and owners hold different values and act from different motivational goals. And they think that these motivational differences give rise to conflicts that can only be eradicated or reduced by changing the basic form of ownership and control, not by promulgating redistributive measures. In a competitive environment, wealth-seeking capitalists organize the labour process so as 'to extract the maximum quantum of effort from workers.' 74 This inevitably pits capitalists against workers, who value 'leisure over work' and even 'shirk[] from it where possible. ${ }^{75}$ Though this might undermine the preservation of capital, workers do not care, because they are motivated by a 'different set of incentives.' 'Given the different set of incentives motivating labour and capital,' some Marxists argue that 'the employment relation comes to involve an irreducible element of conflict-not over distribution, but over autonomy and control. ${ }^{76}$ To focus on simple inequality of incomes is ignore other more important conflicts that are irresolvable within the context of capitalism. In the Marxist view there is, therefore, no community to speak of.

The fact that workers and owners differ about the appropriate pace and quantity of work does not mean, however, that they hold fundamentally different values. The view that workers value leisure over income is another feature of classical political economic and Marxist models, which posit that labour seeks subsistence rather than a share of wealth. The worker who values leisure over work does not seem, however, to be the worker that inhabits advanced capitalist economies. Workers integrated into the wealth-seeking ethos of the modern economy tend to value work over leisure or money-incomes over leisure. Shirking by workers does not mean that they seek subsistence rather than wealth. Executives for that matter are just as capable of shirking as workers are, yet no one adduces a desire for subsistence as an explanation for it. Shirking, whether by workers or owners, is instead symptomatic of an organizational pathology, which leads them to believe that a share of wealth can be had without working.

Since the modern worker shares the owner's desire for a share of wealth, and she is not motivated by utterly different incentives, her values cannot be sharply distinguished from those of owners of capital. The differences between thee goals of workers and owners do not, therefore, constitute an intrinsic source of conflict over ownership and control that is so thoroughgoing that all elements of community are vitiated from labour capital relations. And, broadening our account of points of conflict from simple inequality of income to ownership and control of

72 Philippe Aghion \& Peter Howitt Endogenous Growth Theory (1999) at 114.

73 Joel Mokyr The Lever of Riches (1990) at 3.

74 Chibber 'Individualism, Community, and Distributive Justice' (2004) 13 The Good Society 62 at 64 .

75 Chibber (note 74 above) at 64 .

76 Chibber (note 74 above) at 64 . 
firms has not, contrary to Marxist theory, revealed oppositions of interests so thoroughgoing that they preclude all significant elements of community.

The differences that Marxist and classical theory posits between the values of workers and owners may also not hold with respect to workers in developing countries. In countries of this sort with highly unequal distributions of income, workers sometimes appear to have a preference for leisure over monetary reward, but this may not be their real preference. In these economies poor workers do not have much capital to work with, so they can only expect to receive low payoffs from hard work. If redistribution were implemented, 'so that the payoffs are more equally shared,' Aghion and Howitt contend, the incentives of the poor will be raised and this will raise output. ${ }^{77}$

In sum, the element of community is not refuted by any supposedly thoroughgoing conflict over autonomy and control arising from irreducible differences between the values of workers and owners. This element of community continues to invoke the ethics of community with respect to capital-based market systems, requiring egalitarian redistribution of a portion of national income. 


\section{Bibliography}

A

Abel R A Time of Trouble: Law and Liberty in South Africa's State of Emergency (1992)

Abbott-Smith G A Manual Greek Lexicon of the New Testament (1977)

Acemoglu D 'Root Causes. A Historical Approach to Assessing the Role of Institutions in Economic Development' (2003) 40 Finance and Development 27

Ackermann L 'Equality and the South African Constitution: The Role of Dignity' (2000) 60 The Heidelberg Journal for International Law 537

Aghion P \& P Howitt Endogenous Growth Theory (1999)

Albertyn C 'Equality' in M H Cheadle, D M Davis and N R L Haysom (eds) South African Constitutional Law: The Bill of Rights (1990)

Albertyn C \& B Goldblatt 'Facing the Challenge of Transformation: Difficulties in the Development of an Indigenous Jurisprudence of Equality' (1998) 14 SAJHR 248

Altizer TJJ The Genesis of God - A Theological Genealogy (1993)

Archer M 'The Private Life of The Social Agent: What Difference Does It Make?' in J Cruickshank (ed) Critical Realism. The Difference it Makes (2003) 91

Armstrong C 'Equality, Community, and the Production of Value' 2004 European Journal of Political Theory 339

Aron J 'Growth and Institutions: A Review of Evidence' (2000) 15(1) The World Bank Observer 99

Ashcraft R 'Liberalism and the Problem of Poverty' (1992) 6 Crit Rev 493

Assmann J et al Gerechtigkeit: Richten und Retten in der abendländischen Tradition und ibren altorientalischen Ursprüngen (1998)

August KT The Quest for Being Public Church (2003) DTh thesis, University of Stellenbosch, Stellenbosch

\section{B}

Bachmann M 'Would Social Health Insurance Improve South African Health Care? What other Middle Income Countries Can Teach Us' (1994) 24 Transformation 26

Balderman I et al (eds) Menschenwürde: JBTh 15 (2001)

Balz H 'Die Gerechtigkeit der Gerechtfertigten: eine neutestamentliche Skizze' in P Dabrock et al (eds) Kriterien der Gerechtigkeit (2003) 45

Barberton C 'Progressive Realisation' of Socio-Economic Rights' (1999) 2 Economic and Social Rights Review 1

Barenberg M 'Democracy and Domination in the Law of Workplace Cooperation: From Bureaucratic to Flexible Production' (1994) $94 \mathrm{Col}$ LR 753

Baron M, P Pettit \& M Slote Three Methods of Ethics: A Debate (1999)

Barth K Church Dogmatics (1960)

Barth K Texte zur Barmer Theologischen Erklärung (1984)

Barth K The Humanity of God (1967)

Baumol WJ 'Entrepreneurship: Productive, Unproductive and Destructive' (1990) 89 Journal of Political Economy 893

Baur J (ed) Zum Thema Menschenrechte: theologische Versuche und Entwürfe (1977) 
Bebchuk L, J Fried \& D Walker 'Managerial Power and Rent Extraction in the Design of Executive Compensation' (2002) 69 University of Chicago LR 751

Bedford-Strohm H Vorrang für die Armen: auf dem Weg zu einer theologischen Theorie der Gerechtigkeit (1993)

Bell W Aid to Dependent Children (1965)

Bellah R et al Habits of the Heart. Individualism and Commitment in American Life (1985)

Bellah R et al The Good Society (1991)

Ben-Bassat A \& M Dahan 'Social Rights in the Constitution and in Practice' Hebrew U of Jerusalem School of Public Policy Working Paper No 05-03 May 2003

Benedict ML 'Laissez-Faire and Liberty: A Reevaluation of the Meaning and Origins of Laissez-Faire Constitutionalism' (1985) 3 Law \& History Review 293

Bennett T \& C Powell 'Aboriginal Title in South Africa Revisited' (1999) 15 SAJHR 449

Bennis P 'Talking Points: Iraq, the UN, \& US Corporations' (2003) Web publication by United for Peace and Justice http://unitedforpeace.org/article.php?id=2031

Berlin I 'Two Concepts of Liberty' in I Berlin (ed) Fours Essays on Liberty (1969) 118

Berger P (ed) The Desecularization of the World. Resurgent Religion and World Politics (1999)

Best TF and M Robra (eds) Ecclesiology and Ethics: Ecumenical Engagement, Moral Formation and the Nature of the Church (1997)

Best TF and M Robra 'Introduction' in TF Best and M Robra (eds) Ecclesiology and Ethics: Ecumenical Engagement, Moral Formation and The Nature of the Church (1997) vii

Bhaskar R 'On the Possibility of Social Scientific Knowledge and the Limits of Naturalism' in J Mepham

\& DH Rubin (eds) Issues in Marxist Philosophy vol 3: Epistemology, Science, Ideology (1979) 125

Biko S I Write What I Like (2004)

Bilchitz D 'Giving Socio-Economic Rights Teeth: The Minimum Core and its Importance' (2002) 118 SALJ 484

Birch B \& L Rasmussen Bible and Ethics in the Christian Life (1989)

Bix B Jurisprudence: Theory and Context (1996)

Bloch FS 'Cooperative Federalism and the Role of Litigation in the Development of Federal AFDC Eligibility Policy' (1979) Wis LR 1

Botha H 'Freedom and Constraint in Constitutional Adjudication' (2004) 20 SAJHR 249

Botha H, A van der Walt \& J van der Walt (eds) Rights and Democracy in a Transformative Constitution (2004)

Botha J \& P Naude Op Pad met Belhar: Goeie Nuus vir Gister, Vandag en Môre (1998)

Botman HR 'Human Dignity and Economic Globalization' in HR Botman \& K Sporre (eds) Building a Human Rights Culture: South African and Swedish Perspectives (2003) 20

Bosniak LS 'Critical Reflection on "Citizenship” as a Progressive Aspiration' in J Conaghan, RM Fischl

\& K Klare (eds) Labour Law in an Era of Globalization: Transformative Practices and Possibilities (2002) 339

Brady BV The Moral Bond of Community: Justice and Discourse in Christian Morality (1998)

Brand D \& S Russell Exploring the Core Content of Socio-Economic Rights: South African and International Perspectives (2002)

Brand D 'Introduction to Socio-Economic Rights in the South African Constitution' in D Brand \& CH Heyns (eds) Socio-Economic Rights in South Africa (2005) 1

Brand D 'The Proceduralisation of South African Socio-Economic Rights Jurisprudence, or "What are Socio-Economic Rights For?"' in H Botha, A van der Walt \& J van der Walt (eds) Rights and Democracy in a Transformative Constitution (2004) 33

Breitenberg EH 'To Tell the Truth: Will the Real Public Theology Please Stand Up?' (2003) 23 Journal of 
the Society of Christian Ethics 55

Brodsky G 'Gosselin v Quebec (Attorney General): Autonomy with a Vengeance' (2003) 15 Canadian Journal of Women and the Law 194

Brown S \& A Fölscher Taking Power in the Economy - Gains and Directions (2004)

Browning D A Fundamental Practical Theology. Descriptive and Strategic Proposals (1996)

Brunner E Dogmatics (1950)

Brunner E Gerechtigkeit: eine Lehre von den Grundgesetzen der Gesellschaftsordnung (1943)

Buchanan A 'The Right to a Decent Minimum of Health Care' (1984) 13(1) Philosophy and Public Affairs 55

Buchanan JM \& RA Musgrave Public Finance and Public Choice. Two Contrasting Visions of the State (2000)

Buchanan JM 'Politics without Romance' in JM Buchanan (ed) The Collected Works of James Buchanan. Volume I. The Logical Foundations of Constitutional Liberty (1999) 45

Buchanan R 'Border Crossings: NAFTA, Regulatory Restructuring, and the Politics of Place' (1995) 2 Indiana J of Global Legal Studies 371

Budlender D The People's Voices (1998)

Burgsmüller A \& R Weth (eds) Die Barmer Theologische Erklärung: Einführung und Dokumentation (1983)

Burke E 'Reflections on the Revolution in France' in E Burke (ed) On Taste; On the Sublime and Beautiful; Reflections on the French Revolution; A Letter to a Noble Lord (1937) 143

Busch E Die Barmer Thesen 1934 - 2004 (2004)

$\mathbf{C}$

Calitz E \& K Siebritz: 'Macroeconomic Stability and Developmental Expectations: Fiscal Consolidation in Post-Apartheid South Africa' (2003)

Cameron E 'Legal Chauvinism, Executive-Mindedness and Justice: L C Steyn's Impact on South African Law' (1982) 99 SALJ 38

Casper G 'Changing Concepts of Constitutionalism: 18th to 20th Century' (1989) S Ct Rev 311

Chanock M The Making of South African Legal Culture 1902-1936: Fear, Favour and Prejudice (2001)

Chapman A 'Core Obligations Related to the Right to Health and their Relevance for South Africa' (2002) in D Brand \& S Russell Exploring the Core Content of Socio-Economic Rights: South African and International Perspectives (2002) 35

Chetty K 'The Public Finance Implications of Recent Socio-Economic Rights Judgments' (2002) 6 Law, Democracy and Development 231

Chibber V 'Individualism, Community, and Distributive Justice' (2004) 13 The Good Society 62

Clark HB Serenity, Courage, and Wisdom: The Enduring Legacy of Reinhold Niebubr (1994)

Clements K Learning to Speak: The Church's Voice in Public Affairs (1995)

Cloete GD \& DJ Smit A Moment of Truth: The Confession of the Dutch Reformed Mission Church (1984)

Cloete JJN Administration of Health Services (1981)

Coase RH 'The Institutional Structure of Production' in RH Coase (ed) Essays on Economics and Economists (1994) 3

Cockrell A 'Rainbow Jurisprudence' (1996) 12 SAJHR 1

Cohen WJ 'The Social Security Act of 1935: Reflections Fifty Years Later' in The Report of the Committee on Economic Security of 1935 at 3 (50th Anniversary ed Natl Conf on Soc Welfare 1985)

Collier P \& JW Gunning 'Explaining African Economic Performance' (1999) 37 Journal of Economic Literature 64 
Commons JR Legal Foundations of Capitalism (1924)

Conaghan J 'Woman, Work and Family: A British Revolution' in J Conaghan, RM Fischl \& K Klare (eds) Labour Law in an Era of Globalization: Transformative Practices and Possibilities (2002) 53

Conaghan J, RM Fischl \& K Klare (eds) Labour Law in an Era of Globalization: Transformative Practices and Possibilities (2002)

Coons JE et al 'Educational Opportunity: A Workable Constitutional Test for State Financial Structures' (1969) 57 Cal LR 305

Corder H Judges at Work: The Role and Attitudes of the South African Appellate Judiciary, 1910-50 (1984)

Courage N 'WTO Agreement Improves Access to Life-Saving Drugs' The Lawyers Weekly 2003-09-26

Cover R Justice Accused: Antislavery and the Judicial Process (1975)

Cowen S ‘Can “Dignity” Guide South Africa's Equality Jurisprudence?’ (2001) 17 SAJHR 34

Cranston M 'Human Rights, Real and Supposed' in DD Raphael (ed) Political Theory and the Rights of Man (1967) 51

Crüsemann F 'Jahwes Gerechtigkeit im Alten Testament' (1976) 36 Evangelische Theologie 427

Cupitt D The Long-legged Fly (1987)

Currie DP 'Positive and Negative Constitutional Rights' (1986) 53 Univ of Chicago LR 864

Currie DP The Constitution of the Federal Republic of Germany (1994)

\section{D}

Dabrock P et al (eds) Kriterien der Gerechtigkeit: Festschrift für Christofer Frey zum 65. Geburtstag (2003)

Daly H Beyond Growth (1996)

Daniels N 'Health Care Needs and Distributive Justice' (1981) 10 Philosophy and Public Affairs 146

Daniels N 'A Reply to Stern Critics and a Remark on Health Care Rights' (1983) 8 Journal of Medicine and Philosophy 363

Davis DM 'The Case Against the Inclusion Of Socio-Economic Demands In a Bill of Rights Except as Directive Principles' (1992) 8 SAJHR 475

Davis DM 'Equality: The Majesty of Legoland Jurisprudence' (1999) 116 SALJ 398

Davis DM Democracy and Deliberation (1999)

Davis DM 'Elegy to Transformative Constitutionalism' in H Botha, AJ van der Walt \& J van der Walt (eds) Rights and Democracy in a Transformative Constitution (2004) 57

Davis DM 'Socio-Economic Rights in South Africa. The Record of the Constitutional Court after Ten Years' (2004) 5:5 ESR Review 3

Davis MF Brutal Need: Lawyers and The Welfare Rights Movement, 1960-1973 (1993)

De Beer C 'A Forward View of the Health Services in South Africa' (1976) 50 South African Medical Journal 431

De Beer C 'Explaining the Present: Why Health Services do not meet the Health Needs of the Population' in A Zwi \& WB Saunders (ed) Towards Health Care for All (1985) 59

Debreu G Theory of Value: An Axiomatic Analysis of Economic Equilibrium (1959)

De Buen Unna C 'Mexican Trade Unionism in a Time of Transition' in J Conaghan, RM Fischl \& K Klare (eds) Labour Law in an Era of Globalization: Transformative Practices and Possibilities (2002) 401

De Gruchy SM Not Liberation but Justice: An Analysis of Reinhold Niebubr's Understanding of Human Destiny in the Light of the Doctrine of the Atonement (1992) DTh thesis, University of the Western Cape, Bellville

De Gruchy J Christianity and Democracy. A Theology for a Just World Order (1995)

De Gruchy J 'African Theology: South Africa' in D Ford (ed) The Modern Theologians. An Introduction to Christian Theology in the Twentieth Century (1997) 445 
De Long JB \& A Shleifer 'Princes and Merchants: European City Growth before the Industrial Revolution' (1993) 36 Journal of Law and Economics 671

Derthick M The Influence of Federal Grants: Public Assistance in Massachusetts (1970)

De Vos P 'Grootboom, The Right of Access to Housing and Substantive Equality as Contextual Fairness' (2001) 17 SAJHR 258

De Waal J, I Currie \& MG Erasmus The Bill of Rights Handbook (4th ed) (2001)

Diamond J Guns, Germs and Steel. The Fates of Human Societies (1997)

Dicey AV Lectures on Law and Public Opinion in England During the Nineteenth Century (1905)

Dietsch P 'Review of Ross Zucker Democratic Distributive Justice' (2002) 14 The Review of Political Economy 397

Dollar D \& A Kraay 'Growth is Good for the Poor' (2001) World Bank Policy Research Working Paper Series 2587

Donnely J Universal Human Rights in Theory and Practice (1989)

Dorrington RE et al The Impact of HIV/AIDS on Adult Mortality in South Africa (2001)

Duchrow U 'Justice' in N Lossky et al (eds) Dictionary of the Ecumenical Movement (2002) 627

Dugard J 'The Judicial Process, Positivism and Civil Liberty' (1971) 88 SALJ 181

Dugard J Human Rights and the South African Legal Order (1978)

Dugard J 'Should Judges Resign? A Reply to Professor Wacks' (1984) 101 SALJ 286

Durkheim E Suicide. A study in Sociology (1952)

Durkheim E Professional Ethics and Civic Morals (1957)

Durkheim E The Rules of Sociological Method and Selected Texts on Sociology and its Method (1982)

Durkheim E The Division of Labour in Society (1984)

Durkheim E The Elementary Forms of Religious Life (1995)

Du Toit D (ed) Menseregte: Opstelle (1984)

Du Toit D Die Mens en sy Regte: Geloof en Praktyk in Suid-Afrika (1988)

$\mathrm{Du}$ Toit SF Ideas of Truth and Revelation in the Light of the Challenge of Postmodernism (1995) University of Oxford: DPhil Thesis

Du Toit SF Learning to Live Together: Practices of Social Reconciliation (2003)

Dworkin R Taking Rights Seriously (1977)

Dworkin R 'What Is Equality: Part 2: Equality of Resources' (1981)10 Philosophy and Public Affairs 283

Dworkin R 'Why We Are All Liberals' paper presented at the Program for the Study of Law, Philosophy

\& Social Theory NYU School of Law 19 October 1995

Dykstra C\& DC Bass 'A Theological Understanding of Christian Practices' in M Volf \& DC Bass Practicing Theology. Beliefs and Practices in Christian Life (2002) 13

Dyzenhaus D Hard Cases in Wicked Legal Systems: South African Law in the Perspective of Legal Philosophy (1991)

Dyzenhaus D Truth, Reconciliation and the Apartheid Legal Order (1998)

\section{$-\mathbf{E}$}

Easterly W The Elusive Quest for Growth (2001)

Edelman MW Lanterns: A Memoir of Mentors (1999)

Eggertsson T Economic Behaviour and Institutions (1990)

Elkin SL 'Notes on the Old Political Science for the Present Age' (2004) 1 The Good Society 4

Ellmann S In a Time of Trouble: Law and Liberty in South Africa's State of Emergency (1992)

Engelhardt HT 'Rights to Health Care: A Critical Appraisal' (1979) 4 Journal of Medicine and Philosophy 113

Etzioni A The Moral Dimension (1988) 


\section{$\mathbf{F}$}

Fabre C Social Rights under the Constitution: Government and the Decent Life (2000)

Falconer AD 'Pressing the Claims: Reflections in the Theological Basis of Human Rights' (1998) 48 Reformed World 50

Feldman D Civil Liberties and Human Rights in England and Wales (1993)

Feuerbach L The Essence of Christianity $\left(1989,1^{\text {st }}\right.$ ed 1841)

Fineman MLA 'Masking Dependency: The Political Role of Family Rhetoric' (1995) 81 Virginia LR 2181

Fischer J 'Jenseits reiner Normativität: Skizze einer theologisch-ethischen Annäherung and die Gerechtigkeitsthematik' in P Dabrock et al (eds) Kriterien der Gerechtigkeit (2003) 137

Forbath WE 'The Ambiguities of Free Labor: Labor and the Law in the Gilded Age' (1985) Wis LR 767 Forbath WE 'Habermas's Constitution: A History, Guide, and Critique' (1998) 23 L \& Soc Inquiry 969 Forbath WE 'Caste, Class, and Equal Citizenship' (1999) 98 Mich LR 1

Forbath WE ““Constitutional Welfare Rights”: A History, Critique and Reconstruction' (2001) 69 Fordham LR 1821

Forbath WE 'The New Deal Constitution in Exile' (2001) 51 Duke LJ 165

Forbath WE 'Lincoln, the Declaration, and the "Grisly, Undying Corpse of States' Rights": History, Memory, and Imagination in the Constitution of a Southern Liberal' (2004) 92 Georgetown LJ 709

Forbath WE 'Not So Simple Justice: Frank Michelman on Social Rights 1969-Present' (2004) 39 Tulsa LR 597

Forrester D Christian Justice and Public Policy (1997)

Forsyth C In Danger for their Talents: A Study of the Appellate Division of the Supreme Court of South Africa from 1950-80 (1985)

Fouts DE 'Policy-Making in the Supreme Court of Canada, 1950-1960' in G Schubert \& DJ Danelski (eds) Comparative Judicial Behavior: Cross-Cultural Studies of Political Decision-Making in the East and West (1969) 257

Frank J Law and the Modern Mind (1930)

Fraser N 'Talking about Needs: Interpretive Contests as Political Conflicts in Welfare-State Societies' (1989) 99 Ethics 291

Fraser N \& L Gordon 'A Genealogy of Dependency: Tracing a Keyword of the US Welfare State' (1994) 19 Signs: Journal of Women in Culture and Society 309

Fredman S 'Providing Equality: Substantive Equality and the Positive Duty to Provide' unpublished paper delivered at SAJHR Conference, 5 - 7 July 2004

Garner BA (ed) Black's Law Dictionary 7ed (1999)

Gauri V 'Social Rights and Economics. Claims to Health Care and Education in Developing Countries' (2003) World Bank Policy Research Paper 3006

Gearon L Human Rights \& Religion: A Reader (2002)

Gelderblom D Morality, Individual and Society: Emile Durkheim (2004)

Gewirth A 'Are there any Absolute Rights?' in J Waldron Theories of Rights (1984) 92

Giddens A Studies in Social and Political Theory (1977)

Gilkey LB On Niebuhr: A Theological Study (2001)

Glendon M 'Rights in Twentieth-Century Constitutions' (1992) 59 U Chi LR 519

Glendon M A World Made New: Eleanor Roosevelt and the Universal Declaration of Human Rights (2001)

Gloppen R 'Analyzing the Role of Courts in Social Transformation: Social Rights Litigation, Court Responsiveness and Capability' paper presented at the Centre for Applied Legal Studies Workshop on 
Human Rights, Democracy and Social Transformation: When do Rights Work? (November 2003)

Gloppen R, Rargarella \& E Skaar (eds) Democratization and the Judiciary: The Accountability Function of Courts in New Democracies (2004)

Goldberg AJ 'Equality and Governmental Action' (1964) 39 FNY U LR 205

Goldsmith AH et al 'The Psychological Impact of Unemployment and Joblessness' (1996) 25 J Socio-Eco 333

Goodin E, B Headey, R Muffels \& HJ Dirven The Real Worlds of Welfare Capitalism (1999)

Goyer KC 'HIV/AIDS in South African Prisons' http://www.iss.co.za/Pubs/Monographs/ No79/Chap1.html

Graham C \& S Pettinato Happiness and Hardship: Opportunity and Insecurity in New Market Economies (2002)

Gray JC Restraints on the Alienation of Property (1895)

Green W and J Neusner (eds) The Religion Factor. An Introduction to how Religion Matters (1996)

Griffen D Primordial Truth and Postmodern Theology (1989)

Grilli V, D Masciandaro et al 'Institutions and Policies' (1991) Economic Policy 341

Gustafson J 'An Analysis of Church and Society Social Ethical Writings' (1988) 40 Ecumenical Review 267

Gustafson J Varieties of Moral Discourse: Prophetic, Narrative, Ethical and Policy. The Stob Lectures of Calvin College and Seminary (1988)

Gustafson J 'Moral Discourse About Medicine: A Variety of Forms' (1990) Journal of Medicine and Philosophy 125

\section{H}

Habermas J 'Law as Medium and Law as Institution' in G Teubner (ed) Dilemmas of Law in the Welfare State (1986) 204

Habermas J The Philosophical Discourse of Modernity: Twelve Lectures (1987)

Habermas J The Structural Transformation of the Public Sphere: An Inquiry into a Category of Bourgeois Society (1989)

Habermas J Erläuterungen zur Diskursethik (1991)

Habermas J Faktizität und Geltung: Beiträge zur Diskurstheorie des Rechts und des demokratischen Rechtsstaats (1992)

Habermas J Between Facts and Norms (1996)

Habib A \& C Skinner 'The Poor Must Fend for Themselves' (04-08-2002) Sunday Times 14

Hall KL The Magic Mirror (1989)

Hall R 'Rural Land Restitution in South Africa' paper prepared for Programme for Land and Agrarian Studies (July 2003)

Hall R \& CI Jones 'Why do Some Countries Produce so Much More Output per Worker than Others' (1999) 114 Quarterly Journal of Economics 83

Handler JF \& Y Hasenfeld We the Poor People: Work, Poverty, and Welfare (1997)

Hardmeier C et al (eds) Freiheit und Recht: Festschrift für Frank Crüsemann zum 65. Geburtstag (2003)

Hart HLA The Concept of Law (1961)

Haspel M Protestantische Ethik vor der Herausforderung der Globalisierung (2004)

Hauerwas S Vision and Virtue: Essays in Christian Ethical Reflection (1974)

Hauerwas S Truthfulness and Tragedy: Further Investigations in Christian Ethics (1977)

Hauerwas S A Community of Character: Toward a Constructive Christian Social Ethic (1981)

Hauerwas S The Peaceable Kingdom. A Primer in Christian Ethics (1983)

Hauerwas S Christian Existence Today. Essays on Church, World and Living in Between (1995) 
Hauerwas S \& C Pinches Christians among the Virtues. Theological Conversations with Ancient and Modern Ethics (1997)

Hauerwas S \& S Wells (eds) The Blackwell Companion to Christian Ethics (2004)

Hayek FA The Constitution of Liberty (1960)

Hayek FA 'Individualism: True and False' in FA Hayek (ed) Individualism and Economic Order (1984) 1

Hayek FA 'The Meaning of Competition' in FA Hayek (ed) Individualism and Economic Order (1984) 92

Haysom N 'Constitutionalism, Majoritarian Democracy and Socio-Economic Rights' (1992) 2 SAJHR 451

Hegarty A \& S Leonard Human Rights. An Agenda for the $21^{\text {st }}$ Century (1999)

Hegel GWF The Philosophy of Right (1952)

Heller PS 'Wealth Creation and Social Justice: An IMF perspective' (2003) Paper Presented at the World Council of Churches/World Bank/IMF Meeting, February 2003

Hendriks H The Future of the Church, the Church of the Future (2004) Unpublished Inaugural lecture, University of Stellenbosch

Heywood A Politics (2002)

Heywood M 'Preventing Mother-to-Child HIV Transmission in South Africa: Background, Strategies and Outcomes of the Treatment Action Campaign Case Against the Minister of Health' (2003) 19 SAJHR 278

Hicks JR The Theory of Wages (1963)

Hoctor S 'Dignity, Criminal Law and the Bill of Rights' (2004) 121 SALJ 265

Hofstadter R Social Darwinism in American Thought (1955)

Honecker M Das Recht des Menschen: Einführung in die evangelische Sozialethik (1978)

Hont I \& M Ignatieff, Needs and Justice in the Wealth of Nations: An Introductory Essay, in Wealth and Virtue: The Shaping of Political Economy in the Scottish Enlightenment (1983)

Horne TA Property Rights and Poverty: Political Argument in Britain, 1605-1834 (1990)

Huber W \& HE Tödt Menschenrechte: Perspektiven einer menschlichen Welt (1977)

Huber W 'Human Rights: A Concept and its History' (1979) 124 Concilium 1

Huber W 'Beten und Tun des Gerechten' in W Huber \& I Tödt (eds) Ethik im Ernstfall: Dietrich Bonhoeffers Stellung zu den Juden und ibre Aktualitat (1982) 11

Huber W 'Menschenrechte' in Staatslexikon Bd. 3 (1987)

Huber W 'Recht im Horizont der Liebe' in Brandt et al (eds) Ein Richter, ein Bürger, ein Christ: Festschrift für Helmut Simon (1987) 1045

Huber W 'Justice, Peace and the Integrity of Creation: A Challenge for Ecumenical Theology' (1988) 24 Scriptura 1

Huber W 'Menschenrechte' in L Engel et al (eds) Hoffnung in der Krise: Dokumente einer christlichen Existenz in Südafrika zum 65 Geburtstag von Wolfram Kistner (1988) 298

Huber W 'Die Prediking oor Regverdigheid en Geregtigheid' in CW Burger et al (eds) Riglyne vir Prediking oor die Bergrede (1990) 15

Huber W 'Das Grundgesetz und die Menschenrechte' (1989) 33 Zeitschrift für Evangelische Ethik 82

Huber W 'Die Menschenrechte und das Grundgesetz: Theologische Überlegungen' in M Pfeiffer (ed) Auftrag Grundgesetz: Wirklichkeit und Perspektiven (1989) 190

Huber W 'Menschenrechte - Christenrechte' in Recht nach Gottes Wort: Menschenrechte und Grundrechte in Gesellschaft und Kirche (1989) 82

Huber W 'Die Würde des Menschen ist antastbar: Anfragen aus der Sicht der christlichen Ethik' (1990) 45 Universitas 852

Huber W Konflikt und Konsens: Studien zur Ethik der Verantwortung (1990)

Huber W 'Menschenrechte/Menschenwürde' in Theologische Realencyklopädie XXII (1992) 577 
Huber W 'Menschenrechte und biblisches Rechtsdenken: ein Versuch' (1993) 2 Neukirchener Theologische Zeitschrift: Kirche und Israel 144

Huber W Die tägliche Gewalt: gegen die Ausverkauf der Menschenwürde (1993)

Huber W 'Meschenwürde? Gewalt und Intimität als Unterhaltung' in W Wunden (ed) Öffentlichkeit und Kommunikationskultur (1994) 181

Huber W 'Gottesrecht und Menschenrechte in gesellschaftspolitischen Entwürfen' (1995) 32 epdDokumentation 55

Huber W 'Lebenswert und Lebensrecht' (1995)

Huber W 'Die Würde des Menschen ist antastbar: Anfragen aus der Sicht der christlichen Ethik' in S Abarbanell et al (eds) Fernsehzeit (1996) 185

Huber W Gerechtigkeit und Recht: Grundlinien Christlicher Rechtsethik (1996)

Huber W 'Recht als Beruf: Verantwortung für das Recht im Horizont der Gerechtigkeit' in U Neumann and L Schulz (eds) Verantwortung in Recht und Moral: Referate der Tagung der Deutschen Sektion der Internationalen Vereinigung für Rechts- und Sozialphilosophie (2000) 39

Huber W Rechtfertigung und Recht: über die christlichen Wurzeln der europäischen Rechtskultur (2001) Hunsinger G How to Read Karl Barth - The Shape of His Theology (1991)

Huntington S The Clash of Civilizations and the Remaking of Worldorder (1997)

Hütter R Evangelische Ethik als kirchliches Zeugnis: Interpretationen zu Schlüsselfragen theologischer Ethik in der Gegenwart (1993)

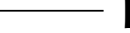

Iles K 'Limiting Socio-Economic Rights: Beyond the Internal Limitations Clauses' (2004) 20 SAJHR 448

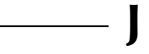

Jackman M 'Constitutional Rhetoric and Social Justice: Reflections on the Justiciability Debate' in J Bakan \& D Schneiderman (eds) Social Justice and the Constitution: Perspectives on a Social Union for Canada (1992) 17

Jeeves A 'Public Health and Epidemiology in the Era of South Africa's VD Pandemic of the 1930s and 1940s' paper read at AIDS in Context International Conference held at the University of the Witwatersrand 4-7 April 2001

Johanson B (ed) Human Rights in South Africa (1974)

Johanson B Human Rights and Repression in Southern Africa: The Apartheid Machine Grinds On (1989) John C 'Human Rights and the Churches: The New Challenges' (1998) 48 Reformed World 79

Johnsen DE 'Ronald Reagan and the Rehnquist Court on Congressional Power: Presidential Influences on Constitutional Change' (2003) 78 Ind LJ 363

Jones J Labor of Love, Labor of Sorrow: Black Women, Work, and the Family from Slavery to the Present (1985)

\section{K}

Kagan D, S Ozment \& FM Turner The Western Heritage to 1715 (2001)

Kant I 'On the Common Saying: "This May be True in Theory, But it Does not Apply in Practice"' in Hans Riess (ed) Kant's Political Writings (1970) 61

Kant I The Moral Law: Kant's Groundwork of the Metaphysic of Morals (1963)

Kapp C 'World Trade Organisation Reaches Agreement on Generic Medicines' (2003) 362 Lancet 807

Kasper W \& M E Streit Institutional Economics: Social Order and Public Policy (1998)

Keeton C 'A Turning Point for AIDS Treatment' Sunday Times 2003-08-10

Kegley CW Reinhold Niebuhr, his Religious, Social, and Political Thought (1984) 
Kennedy D A Critique of Adjudication (Fin de Siècle) (1997)

Keynes JM The General Theory of Employment, Interest, and Money (1964)

Kindra J 'AIDS: Ministers Revolt' Mail \& Guardian 2003-08-15 to 2003-08-21

Klaaren J 'An Institutional Interpretation of Socio-Economic Rights and Judicial Remedies after TAC' in $\mathrm{H}$ Botha, AJ van der Walt \& J van der Walt (eds) Rights and Democracy in a Transformative Constitution (2004) 105

Klare KE 'Judicial Deradicalization of the Wagner Act and the Origins of Modern Legal Consciousness' (1978) 62 Minnesota LR 1049

Klare KE 'Workplace Democracy and Market Reconstruction: An Agenda for Legal Reform'(1988) 38 Catholic University L Rev 1

Klare KE 'Legal Culture and Transformative Constitutionalism’ (1998) 14 SAJHR 146

Knack S 'Predation of Production? The Impact of Political, Legal and Social Institutions' in S Knack (ed) Democracy, Governance and Growth (2003) 1

Knack S \& P Keefer 'Institutions and Economic Performance: Cross Country Tests Using Alternative Institutional Measures' (1995) 7 Economics and Politics 207

Koopman N 'Tussen die Duiwel van Konstantinisme en die Diep Blou See van Sektarisme - Kerk en Staat Verhoudinge in Post-apartheid Suid-Afrika' (2001) 43 NGTT 135

Koopman N ' “... and the wronged...” A Basic and Neglected Conviction of (Reformed) Theology?' in P Coertzen (ed) 350 Years Reformed 1652-2002 (2002) 252

Koopman N 'Freedom of Religion and the Prophetic Role of the Church' (2002) 43 NGTT 237

Koopman N 'Some Comments About Public Theology Today' (2003) Journal of Theology for Southern Africa 1

Koopman N 'Defence in a Democracy. A Church Perspective on the Postapartheid Defence Review Process' in K Haglind (ed) Arms Trade. Final Report from the $2^{\text {nd }}$ Ecumenical Conference in Gothenburg (2004) 7

Koopman N 'The Role of Tradition in Moral Decisionmaking and Moral Consensus' (2004) 45 NGTT 838

Koopman N 'Let the Plight of the Poor be Heard. Prophetic Speaking about Poverty Today' (2004) 45 NGTT 440

Koopman N \& R Vosloo Die Ligtheid van die Lig. Morele Oriëntasie in 'n Postmoderne Tyd (2002)

Küng $\mathrm{H}$ (ed) Yes to a global ethic (1996)

Küng H \& KJ Kuschel (eds) A Global Ethic. The Declaration of the Parliament of World Religions (1993) Kymlicka W Liberalism, Community and Culture (1989)

Ladd-Taylor M Mother-Work: Women, Child Welfare, and the State, 1890-1930 (1994)

Landes D The Wealth and Poverty of Nations. Why Some are so Rich and Some so Poor (1998)

Landes D The Unbound Prometheus: Technological Change and Industrial Development in Western Europe from 1750 to the Present (2003)

Landman W 'Appropriate Health Care as a Human Right' in A Van Niekerk (ed) Health Care as Human Right (1993) 36

Lategan BC 'Taking the Third Public Seriously' in JW de Gruchy \& S Martin (eds) Religion and the Reconstruction of Civil Society (1995) 217

Lawrence SE The Poor in Court: The Legal Services Program and Supreme Court Decision Making (1990) Lebacqz K Six Theories of Justice: Perspectives from Philosophical and Theological Ethics (1986)

Lebacqz K Justice in an Unjust World: Foundations for a Christian Approach to Justice (1987)

Leech BE 'The Right of the HIV-positive Patient to Medical Care: An Analysis of Costs of Providing 
Medical Treatment' (1993) 9 SAJHR 39

Levine DP Economic Theory (1978)

Levine DP 'Poverty, Capabilities, and Freedom' (2003) 15 Review of Political Economy 101

Liebenberg S 'The Right to Social Assistance: The Implications of Grootboom for Policy Reform in South Africa' (2001) 17 SAJHR 232

Liebenberg S 'South Africa's Evolving Jurisprudence on Socio-Economic Rights: An Effective Tool in Challenging Poverty?' (2002) 6 Law, Democracy and Development 159

Liebenberg S 'The Interpretation of Socio-Economic Rights' in M Chaskalson et al Constitutional Law of South Africa (2nd edition 2004) chap 33

Lienemann W Gerechtigkeit (1995)

Lindblom CE Politics and Markets (1977)

Lister R ‘Citizenship: Towards a Feminist Synthesis’ (1997) 57 Feminist Rev 28

Locke J Two Treatises of Government 170 (1960)

Lopez R Chocolate: The Nature of Indulgence (2002)

Lovin R Christian Ethics. An Essential Guide (2000)

Lucas RJ 'Econometric Policy Evaluation: A Critique' in K Brunner \& Meltzer AH (ed) The Phillips Curve and Labour Markets (1976) 19

Lucas RJ 'Some Macroeconomics for the 21 ${ }^{\text {st }}$ Century' (2000) 14 Journal of Economic Perspectives 159 Lucas RJ Lectures on Growth Theory (2002)

Luhmann N Ausdifferenzierung des Rechts: Beiträge zur Rechtssoziologie und Rechtstheorie (1981)

Luhman N 'The Self-Reproduction of Law and its Limits' in G Teubner (ed) Dilemmas of Law in the Welfare State (1986) 111

Lukes S Émile Durkheim. His Life and Work: A Historical and Critical Study (1975)

\section{M}

McDonnell PJ ‘US Votes Could Sway Mexico's Next Election' (1999) 15 February Los Angeles Times A1 MacIntyre A Whose Justice? Which Rationality? (1988)

McIntyre DE \& RE Dorrington 'Trends in the Distribution of South African Health Care Expenditure' (1990) 78 SAMJ 125

Macneil I 'Economic Analysis of Contractual Relations' in P Burrows \& CG Veljanovski (eds) The Economic Approach to Law (1981) 61

Maddison A The World Economy: A Millennial Perspective (2002)

Maklem P 'Constitutional Ropes of Sand or Justiciable Guarantees? Social Rights in a New South African Constitution’ (1992) 141 Univ of Pennsylvania LR 1

Malan N 'Civil Society and the Right to have Access to Social Security in South Africa' (2004) Unpublished Research Paper, RAU: Johannesburg

Margolis J 'The Rights of Man' (1978) 4 Social Theory and Practice 423

Marshall TH 'On Citizenship and Social Class' in Class, Citizenship and Social Development (1964) 28

Marx K \& F Engels The Communist Manifesto (1848)

May J Poverty and Inequality in South Africa: Report Prepared for the Office of the Executive Deputy President and the Inter-Ministerial Committee for Poverty and Inequality (PIR Report) (1998)

Melnick RS Between the Lines: Interpreting Welfare Rights (1994)

Meyerson D Rights Limited (1997)

Minow M 'Just Education: An Essay for Frank Michelman' (2004) 39 Tulsa LR 547

Michel S Children's Interests/Mothers' Rights: The Shaping of America's Child Care Policy (1999)

Michelman FI 'Foreword: On Protecting the Poor through the Fourteenth Amendment' (1969) 83 Harv LR 7 
Michelman FI 'In Pursuit of “Constitutional Welfare Rights”: One View of Rawls' Theory of Justice' (1973) 121 U Pa LR 962

Michelman FI 'Welfare Rights in a Constitutional Democracy' (1979) 3 Wash Univ LQ 659

Michelman FI 'Justification (and Justifiability) of Law in a Contradictory World' in J R Pennock \& J W Chapman (eds) NOMOS XXVIII: Justification (1986) 71

Michelman FI 'Foreword: Traces of Self-Government' (1986) 100 Harv LR 4

Michelman FI 'Possession vs. Distribution' in the Constitutional Idea of Property' (1987) 72 Iowa LR 1319

Michelman FI 'Law’s Republic' (1988) 97 Yale LJ 1493

Michelman FI 'Conceptions of Democracy in American Constitutional Argument: Voting Rights' (1989) 41 Fla LR 443

Michelman FI 'Family Quarrel' (1996) 17 Cardozo LR 1163

Michelman FI 'Morality, Identity and 'Constitutional Patriotism” (1999) 76 Denv U LR 1009

Michelman FI " "Democracy-Based Resistance” to a Constitutional Right of Social Citizenship: A Comment on Forbath' (2001) 69 Fordham LR 1893

Michelman FI 'The Problem of Constitutional Interpretive Disagreement: Can "Discourse of Application" Help?' in M Aboulafai et al Habermas and Pragmatism (2002) 113

Miller AO (ed) A Christian Declaration on Human Rights: Theological Studies of the World Alliance of Reformed Churches (1977)

Mokyr J The Lever of Riches (1990)

Mollendorf D 'Reasoning about Resources: Soobramoney and the Future of Economic Rights Claims' (1998) 14 SAJHR 327

Moltmann J The Experiment Hope (1975)

Moltmann J On Human Dignity: Political Theology and Ethics (1984)

Moltmann J God for a Secular Society: The Public Relevance of Theology (1999)

Mongiovi G 'Distributive Justice: An Economist's Perspective' (2004) 13 The Good Society 45

Morton M \& F Morton Chocolate: An Illustrated History (1986)

Moskop J 'Rawslian Justice and a Human Rights to Health Care' (1983) 8(4) Journal of Medicine and Philosophy 329

Mostert H 'Liberty, Social Responsibility and Fairness in the Context of Constitutional Property Protection and Regulation' in H Botha, AJ van der Walt \& J van der Walt (eds) Rights and Democracy in a Transformative Constitution (2004) 131

Mudge LS The Church as Moral Community: Ecclesiology and Ethics in Ecumenical Debate (1998)

Mureinik E 'Beyond a Charter of Luxuries: Economic Rights in the Constitution' (1992) 8 SAJHR 464

\section{$\mathbf{N}$}

Nedelsky J 'Reconceiving Rights as Relationship' (1993) 1 Review of Constitutional Studies 1

Newman KS, No Shame in My Game: The Working Poor in the Inner City (1999)

Niebuhr H The Responsible Self. An Essay in Christian Moral Philosophy (1978)

North DC 'Transaction Costs, Institutions, and Economic History' (1984) 140 Journal of Institutional and Theoretical Economics 7

North DC Institutions, Institutional Change, and Economic Performance (1990)

North DC 'Institutions' (1991) 5 Journal of Economic Perspectives 97

North DC 'Five Propositions about Institutional Change' in J Knight \& I Sened (ed) Explaining Social Institutions (1995) 15

Novak WJ The People's Welfare: Law and Regulation in Nineteenth-Century America (1996)

Nozick R Anarchy, State, and Utopia (1974) 
Nussbaum MC 'Capabilities, Human Rights and the Universal Declaration' in B H Weston \& S P Marks (eds) The Future of International Human Rights (1999) 25

Nussbaum MC Women and Human Development - The Capabilities Approach (2000)

Nussbaum MC 'The Enduring Significance of John Rawls' (2001) The Chronicle of Higher Education B7

\section{$\mathbf{O}$}

O'Connor JS 'Gender, Class and Citizenship in the Comparative Analysis of Welfare State Regimes: Theoretical and Methodological Issues' (1993) 44 British J of Sociology 501

Olsen M The Rise and Decline of Nations: Economic Growth, Stagflation, and Social Rigidities (1982)

Olsen FE 'The Myth of State Intervention in the Family' (1985) 18 University of Michigan J of Law Reform 835

Olson M 'Big Bills left on the Sidewalk: Why Some Nations are Rich, and Others Poor' in S Knack (ed) Democracy, Governance and Growth (2003) 29

Orloff AS 'Gender and the Social Rights of Citizenship: The Comparative Analysis of Gender Relations and Welfare States’ (1993) 58 American Sociological Rev 303

Packard R White Plague, Black Labor: Tuberculosis and the Political Economy of Health and Disease in South Africa (1989)

Pavetti LD The Dynamics of Welfare and Work: Exploring the Process by Which Young Women Work Their Way Off Welfare (1993) unpublished PhD dissertation, JFK School of Government, Harvard University

Peters AAG 'Law as Critical Discussion' in G Teubner (ed) Dilemmas of Law in the Welfare State (1986) 250

Pieterse M 'Beyond the Welfare State: Globalisation of Neo-liberal Culture and the Constitutional Protection of Social and Economic Rights in South Africa' (2003) 14 Stellenbosch LR 3

Pieterse E \& M van Donk 'The Politics of Socio-Economic Rights in South Africa. Ten Years after Apartheid' (2004) 5:5 ESR Review 12

Pillay K 'Implementation of Grootboom: Implications for the Enforcement of Socio-Economic Rights' (2002) 6 Law, Democracy \& Development 255

Pizzigati S 'The Left and the Rich' Paper presented at the Global Left Forum, New York City (2005)

Pizzigati S Greed and Good (2005)

Pope SJ (ed) The Ethics of Aquinas (2002)

Popper KR The Logic of Science (1959)

Popper KR The Poverty of Historicism (1961)

Popper KR 'Towards a Rational Theory of Tradition' in KR Popper (ed) Conjectures and Refutations: The Growth of Scientific Knowledge (1992) 120

Posner RA Overcoming Law (1995)

Posner RA 'Values and Consequences: An Introduction to Economic Analysis of Law' (1998) Chicago Law \& Economics Working Paper no 53

Price M Health Policy and Planning (1986)

Price M 'Health Care as an Instrument of Apartheid Policy in South Africa' (1986) 1 Health Policy and Planning 158

Priest G \& W Klein 'The Selection of Disputes for Litigation' (1984) 13 J of Legal Studies 1 


\section{Q}

Quint PE 'The Constitutional Guarantees of Social Welfare in the Process of German Unification' (1999) 47 Am J Comp L 303

\section{$-\mathbf{R}$}

Radin MJ \& FI Michelman 'Pragmatist and Poststructuralist Critical Legal Practice' (1991) 139 U Pa LR 1019

Rasmussen LL Moral Fragments and Moral Community: A Proposal for Church in Society (1993)

Rawls J Political Liberalism (1996)

Rawls J 'Preface for the French Edition of A Theory of Justice' in Samuel Freeman (ed) Collected Papers (1999) 415

Rees RM 'Bite-Sized Marketing: Candy Bars' in A Szogyi (ed) Chocolate: Food of the Gods (1997) 125

Reich CA 'The "New Property" (1964) 73 Yale LJ 733

Reich CA 'Individual Rights and Social Welfare: The Emerging Legal Issues' (1965) 74 Yale LJ 1245

Reich CA 'The Global Drug Gap' (2000) 287 Science 1979

Resnik D 'Developing Drugs for the Developing World: An Economic, Legal, Moral and Political Dilemma' (2001) 1 Developing World Bioethics 11

Rhodes RP Health Care Politics, Policy and Distributive Justice (1992)

Richardson N 'Ethics of Character and Community' in C Villa-Vicencio and J de Gruchy (eds) Doing Ethics in Context. South African Perspectives (1994) 89

Robra M Ökumenische Sozialethik (1994)

Rodrik D, A Subramanian et al 'Institutions Rule: The Primacy of Institutions over Geography and Integration in Economic Development' (2002) NBER Working Paper 9305

Romer PM 'The Origins of Endogenous Growth' (1994) Journal of Economic Perspectives 8

Rorty R Philosophy and the Mirror of Nature (1980)

Rorty R Contingency, Irony, and Solidarity (1989)

Rorty R Truth and Progress (1998)

Roosevelt FD 'Objectives of the Administration' (June 8, 1934) in The Public Papers and Addresses of Franklin D Roosevelt (1938) vol 3291

Roux T 'Legitimating Transformation: Political Resource Allocation in the South African Constitutional Court' (2003) 10 Democratization 92

Ross T 'The Rhetoric of Poverty: Their Immorality, Our Helplessness' (1991) 79 Georgetown Law Journal 1499

\section{$-\mathbf{S}$}

Sable CF \& WH Simon 'Destabilisation Rights: How Public Law Litigation Succeeds' (2004) 117 Harvard LR 1016

Sachs A 'Enforcement of Social and Economic Rights' Speech at London School Economics Feb 272000 Sager LG 'Justice in Plain Clothes: Reflections on the Thinness of Constitutional Law' (1993) 88 Nw U LR 410

Sala-i-Martin X 'The World Distribution of Income' (2002) NBER Working Paper 8933

Samuelson PA 'Some Uneasiness with the Coase Theorem' (1993) 7 Japan and the World Economy 1

Sandel MJ Democracy's Discontent: America in Search of a Public Philosophy (1996)

Sandel MJ Liberalism and the Limits of Justice (1998)

Schachter O 'Human Dignity as a Normative Concept' (1983) 77 Am J of Int Law 848

Schachter O 'Human Dignity as a Value - Part I' (1999) 14 Public Law 682

Schachter O 'Human Dignity as a Foundational Value of our Constitutional Order' (2000) 16 SAJHR 193 
Schaeffer J 'WARC’s Historic Commitments to Justice and Human Rights' (1998) 48 Reformed World 63 Schauer F 'Judging in a Corner of the Law' (1988) 61 Southern California LR 1717

Schauer F Playing by the Rules: A Philosophical Examination of Rule-Based Decision-making in Law and in Life (1991)

Scheppele KL ‘A Realpolitik Theory of Social Rights’ (2004) 82 Tex LR 1921

Schultz V 'Life’s Work' (2000) 100 Col LR 1881

Sen A Choice, Welfare and Measurement (1982)

Sen A The Penalties of Unemployment (1997) Banca D’Italia Working Paper No 307

Sen A 'The Possibility of Social Choice' (1999) 89 American Economic Review 349

Sen A Development as Freedom (1999)

Sen A The Penalties of Unemployment (1997) Banca D’Italia Working Paper No 307

Sened I 'The Emergence of Individual Rights' in J Knight \& I Sened (ed) Explaining Social Institutions (1995) 161

Shapiro M \& A Stone Sweet On Law, Politics, and Judicialization (2002)

Singer JW 'The Player and the Cards: Nihilism and Legal Theory' (1984) 94 Yale LJ 1

Singer P (ed) A Companion to Ethics (2002)

Skocpol T Protecting Soldiers and Mothers: The Political Origins of Social Policy in the United States (1992)

Sloth-Nielsen J 'The Right to Social Services, the Right to Social Security, and the Primary Prevention of

Child Abuse in the Aftermath of Grootboom' (2001) 17 SAJHR 210

Smit DJ 'Die Droom van Bybelse Geregtigheid' (1985) 15 Scriptura 51

Smit DJ 'Paradigms of Radical Grace' in C Villa-Vicencio (eds) On Reading Karl Barth in South Africa (1988) 33

Smit DJ 'Die Bergrede en Christelike Etiek' in CW Burger et al (eds) Riglyne vir Prediking oor die Bergrede (1990) 34

Smit DJ 'Die Bergrede in die Geskiedenis' in CW Burger et al (eds) Riglyne vir Prediking oor die Bergrede (1990) 11

Smit DJ 'Oor die Prediking van Regverdiging en Reg' in BA Müller et al (eds) Riglyne vir Prediking oor Regverdiging en Reg. Woord teen die Lig III/3 (1993) 1

Smit DJ and JL De Villiers 'Hoe Christene in Suid-Afrika by Mekaar Verby Praat ... Oor Vier Morele Spreekwyses in die Suid-Afrikaanse Kerklike Konteks' (1994) 15 Skrif en Kerk 228

Smit DJ 'Oor die Unieke Openbare Rol van die Kerk' (1996) 36 Tydskrif vir Geesteswetenskappe 190

Smit DJ 'Oor die Kerk as 'n Unieke Samelewingsverband' (1996) 36 Tydskrif vir Geesteswetenskappe 119 Smit DJ 'Reformed Ethics and Economic Justice' (1996) 37 Nederduitse Gereformeerde Teologiese Tydskrif 438

Smit DJ 'Oor die Kerk as Unieke Samelewingsverband' (1996) Tydskrif vir Geesteswetenskappe 119

Smit DJ 'Oor die Unieke Openbare Rol van die Kerk' (1996) Tydskrif vir Geesteswetenskappe 190

Smit DJ 'Seeing Things Differently - On Prayer and Politics' in L Holness \& RK Wüstenberg (eds)

Theology in Dialogue: The Impact of the Arts, Humanities, and Science on Contemporary Religious

Thought: Essays in Honor of John W de Gruchy (2002) 271

Smit DJ 'Liberty/Freedom' in N Lossky et al (eds) Dictionary of the Ecumenical Movement (2002)

Smit DJ 'On Learning to See? A Reformed Perspective on the Church and the Poor' in P Couture \& BJ Miller-McLemore (eds) Suffering, Poverty, and HIV-AIDS (2003) 55

Smit DJ 'Oor die God wat Ons Roep' in Handelinge van die NGK in SA (Wes-en Suid-Kaapland) (2003) H99 Smit DJ 'Openbare Getuienis en Publieke Teologie Vandag?’ (2003) 82 Scriptura 39

Smit DJ 'Oor die Kerk en Maatskaplike Uitdagings in Ons Land' (2004) 45 Nederduitse Gereformeerde Teologiese Tydskrif 350 
Smit DJ 'The Impact of the Church in South Africa after the Collapse of the Apartheid Regime' in K Bediako et al (eds) A New Day Dawning: African Christians living the Gospel (2004) 128

Smit DJ 'Theologische Ansätze für kirchliches Engagement in Fragen der Globalisierung - Reformierte Perspektiven aus dem Südlichen Afrika' 2004 Ökumenische Rundschau 160

Smith A The Wealth of Nations (1937)

Smith A An Inquiry into the Nature and Causes of the Wealth of Nations (1950)

Smith JF 'Vote Denied to Mexicans Living Abroad' (1999) 2 July Los Angeles Times A1

Smith RKM Textbook in International Human Rights (2003)

Simitis S 'Juridification of Labor Relations' in G Teubner (ed) Juridification of Social Spheres (1987) 113

Soifer A 'The Paradox of Paternalism and Laissez-Faire Constitutionalism: United States Supreme Court, 1888-1921' (1987) 5 Law \& History Review 252

Spalter-Roth R Making Work Pay: The Real Employment Opportunities of Single Mothers Participating in the AFDC Program (1994)

Spragens T 'Review Essay: Justice, Consensus, and Boundaries: Assessing Political Liberalism’ (2003) 31 Political Theory 589

Stone RH Reinhold Niebubr: Prophet to Politicians (1981)

Streak J \& J Wehner 'Children's Socio-Economic Rights in the South African Constitution: Towards a Framework for Monitoring Implementation' in E Coetzee \& J Streak (eds) Monitoring Child SocioEconomic Rights in South Africa: Achievements and Challenges (2004) 50

Stern L 'Opportunity and Health Care: Criticims and Suggestions' (1983) 8(4) Journal of Medicine and Philosophy 339

Stewart RB \& CR Sunstein 'Public Programs and Private Rights' (1982) 95 Harv LR 1195

Steyn LC 'Regsbank en Regsfakulteit' (1967) 30 THRHR 101

Stiglitz JE 'Principal and Agent' in J Eatwell, M Milgate \& P Newman (eds) The New Palgrave Dictionary of Economics (1987) 966

Sunstein CR 'On Property and Constitutionalism' (1991) Chicago Law and Economics Working Paper no 3

Sunstein CR 'Social and Economic Rights? Lessons from South Africa' (2001) Chicago Law and Economics Working Paper no 124

Sunstein CR 'The Second Bill of Rights: The Last Great Speech of Franklin Delano Roosevelt and America's Unfinished Pursuit of Freedom' (prelim draft 26 July 2003)

Sunstein CR The Second Bill of Rights: FDR's Unfinished Revolution and Why We Need It More than Ever (2004)

\section{$-\mathbf{T}$}

Tanzi V 'The Changing Role of the State in the Economy' (1997) IMF Working Paper WP/97/114

Tanzi V 'The Role of the State and the Quality of the Public Sector' (2000) IMF Working Paper WP/00/36 Taylor MCE Erring: A Postmodern A/theology (1984)

Trengove W 'Judicial Remedies for Violations of Socio-Economic Rights' (1999) 1 ESR Rev 8

Teubner G 'The Transformation of Law in the Welfare State' in G Teubner (ed) Dilemmas of Law in the Welfare State (1986) 3

Teubner G 'Juridification Concepts, Aspects, Limits, Solutions' in G Teubner (ed) Juridification of Social Spheres (1987) 16

Toebes BCA The Right to Health as a Human Right in International Law (1999)

Torrance TF Karl Bath: An Introduction to his Early Theology, 1910-1931 (1960)

Townsend P et al The Black Report and the Health Divide (1990)

Tracy D The Analogical Imagination. Christian Theology and the Culture of Pluralism (1981) 
Tushnet M 'State Action, Social Welfare Rights, and the Judicial Role: Some Comparative Observations' (2002) 3 Chi J Intl L 435

Tushnet M 'Strong Rights, Weak Courts' (2004) 82 Tex LR 1895

\section{$-\mathbf{V}$}

Van Blerk A 'The Irony of Labels' (1982) 99 SALJ 365

Van Blerk A Judge and Be Judged (1988)

Van den Brink G Een Publieke Zaak. Theologie tussen Geloof en Wetenskap (2004)

Van der Berg S \& R Burger 'Social Delivery in South Africa' (2003) Stellenbosch Report prepared for the CDE Van der Westhuizen J 'The Human Rights Debate in South Africa' in K Nürnberger (ed) A Democratic Vision for South Africa. Political Realism and Christian Response (1991) 471

Van der Walt AJ 'A South African Reading of Frank Michelman's Theory of Social Justice' in H Botha, A van der Walt \& J van der Walt (eds) Rights and Democracy in a Transformative Constitution (2004) 163

Van Marle K 'Love, Law and the South African Community: Critical Reflections on "Suspect Intimacies” and "Immanent Subjectivity" in H Botha, A van der Walt \& J van der Walt (eds) Rights and Democracy in a Transformative Constitution (2004) 231

Van Marle K “No Last Word” - Reflections on the Imaginary Domain, Dignity and Intrinsic Worth' (2002) Stell LR 299

Van Marle K 'Revisiting the Politics of Post-Apartheid Constitutional Interpretation' (2003) TSAR 549

Van Marle K “The Capabilities Approach”, “The Imaginary Domain”, and "Asymmetrical Reciprocity": Feminist Perspectives on Equality and Justice’ (2003) 11 Feminist Legal Studies 255

Van Parijs P Real Freedom for All (1995)

Van Rensburg HCJ 'South African Health Care in Change' (1991) 22 SA Journal of Sociology 1

Van Rensburg HCJ Health Care in South Africa: Structure and Dynamics (1992)

Van Rensburg HCJ 'Health and Health Care in South Africa in Transition: A Macro Perspective' (1999) 31 Acta Academica 1

Van Rensburg HCJ \& SR Benatar 'The Legacy of Apartheid in Health and Health Care' (1993) 24 SA Journal of Sociology 99

Van Rensburg HCJ \& Fourie A 'Privatisation of South African Health Care: In Whose Interest?' (1988) 11 Curationis 1

Van Rensburg HCJ \& C Ngwena 'Health and Health Care in South Africa against an African Background' in WC Cockerham (ed) The Blackwell Companion to Medical Sociology (2001) 365

Villa-Vicencio C A Theology of Reconstruction - Nationbuilding and Human Rights (1992)

Voss G et al 'Menschenwürde neu Buchstabieren' (2000) 55 Una Sancta - Zeitschrift für ökumenische Begegnung 97

\section{W}

Wacks R 'Judges and Injustice' (1984) 101 SALJ 266

Waldron J Liberal Rights: Collected Papers 1981-1991 (1993)

Walshe P 'Christianity and the Anti-apartheid struggle: The Prophetic Voice within Divided Churches' in R Elphick \& R Davenport (eds) Christianity in South Africa. A Political, Social and Cultural History (1997) 383

Walzer M 'Philosophy and Democracy' (1981) 9 Pol Theory 379

Ward G (ed) The Postmodern God: A Theological Reader (1998)

Weingärtner E 'Human Rights' in N Lossky et al (eds) Dictionary of the Ecumenical Movement (2002) 
Welker M 'Security of Expectations' (1986) 66 Journal of Religion 237

Welker M 'Dynamiken der Rechtsentwicklung in den biblischen Überlieferungen' in A Aarnio (ed) Rechtsnorm und Rechtswirklichkeit: Festschrift für Werner Krawietz zum 60. Geburtstag (1993) 779

Welker M 'Moral, Recht und Ethos in evangelisch-theologischer Sicht' in W Härle \& R Preul (eds) Ethik und Recht (2002) 67

Wellman C 'The Proliferation of Rights: Moral Progress or Empty Rhetoric?' in L Gearon (ed) Human Rights \& Religion (2002) 368

Williams L 'The Ideology of Division: Behavior Modification Welfare Reform Proposals' (1992) 102 Yale L 719

Williams L Decades of Distortion: The Right's 30-Year Assault on Welfare (1997)

Williams L 'Welfare Law and Legal Entitlements: The Social Roots of Poverty' in D Kairys (ed) The Politics of Law: A Progressive Critique (1998) 569

Williamson OE 'Contract Analysis: The Transaction Cost Approach' in P Burrows \& CG Veljanovski (eds) The Economic Approach to Law (1981) 39

Wilson S 'Taming the Constitution: Rights and Reform in the South African Education System' (2004) 20 SAJHR 418

Wilson WJ When Work Disappears: The World of the New Urban Poor (1996)

Winfield RD The Just Economy (1990)

Witte J 'The Study of Law and Religion: An Apologia and Agenda' (1988) Ministry and Mission 14

Wogaman JP Christian Moral Judgment (1988)

Wogaman JP Christian Perspectives on Politics (2000)

$-\mathbf{Y}$

Yergin D \& J Stanislaw The Commanding Heights (1998)

Yoon YH, R Spalter-Roth \& M Baldwin Unemployment Insurance: Barriers to Access for Women and Part-Time Workers (1995)

Yuval- Davis N 'Women, Citizenship and Difference' (1997) 57 Feminist Rev 4

\section{$\mathbf{Z}$}

Zucker R Democratic Distributive Justice (2002)

Zucker R 'Democracy and Economic Justice' Paper presented at the annual meeting of the American Political Science Association 23 August 2003

Zucker R 'On the Future of the Justice Debates’ (2004) 13 The Good Society 67 


\section{Cases}

Alexkor Ltd and Another $v$ Richtersveld Community and Others 2004 (5) SA 460 (CC)

Atkinson $v$ Van Wyk and Another 1999 (1) SA 1080 (LCC)

August and Another $v$ Electoral Commission and Others 1999 (3) SA 1 (CC)

143,165

B $v$ Minister of Correctional Services 1997 (6) BCLR 789 (C)

194, 195

Baartman v Port Elizabeth Municipality 2004 (1) SA 560 (SCA)

Bergboerdery v Makgoro 2000 (4) SA 575 (LCC)

Bernstein v Bester 1996 (2) SA 751 (CC)

Brink $v$ Kitshoff NO 1996 (4) SA 197 (CC

Connors $v$ The United Kingdom 2005 (40) EHRR 189

Conradie $v$ Hanekom and Another 1999 (4) SA 491 (LCC)

221,222

Cooper v Laupheimer 316 F Supp 264 (ED Pa 1970)

Cruzan v Director, Missouri Department of Health et al 497 US 261 (1990)

28

Dandridge $v$ Williams 397 US 471 (1970)

$85,86,88,95$

Dawood $v$ Minister of Home Affairs; Shalabiv Minister of Home Affairs;

Thomas $v$ Minister of Home Affairs 2000 (3) SA 936 (CC)

142,143

Dandridge $v$ Williams 397 US 471 (1970)

DeShaney $v$ Winnebago County Dept of Social Services 489 US 189 (1989)

Douglas $v$ California 372 US 353 (1963)

Eldridge $v$ British Columbia (Attorney General) (1997) 151 DLR (4th) 577 (SC)

Ex parte Chairperson of the Constitutional Assembly 1996 (4) SA 744 (CC)

Ex parte Geldenhuys 1926 OPD 155

Ferreira v Levin NO 1996 (1) SA 984 (CC)

Fose $v$ Minister of Safety and Security 1997 (3) SA 786 (CC)

Gideon $v$ Wainwright 372 US 335 (1963)

Goldberg $v$ Kelly 397 US 254 (1970)

Gosselin v Quebec (Attorney General) 2002 SCC 84221 DLR (4th)
$9,12,79,82,83,84,85,242$ $141,151,152,153,155,156$,

$157,158,160$

Government of the Republic of South Africa v Grootboom 2001 (1) SA 46 (CC) 3, 18, 26, 27, 28, 31, 33, 35, 54, 143, 144, 148, 154, 155, 158, 159, 160, 161, 164, 165, 192, 193

Griffin v Illinois 351 US 12 (1956)

Hlatshwayo $v$ Hein 1999 (2) SA 834 (LCC)

Hagans $v$ Lavine 415 US 528 (1974)

Harksen $v$ Lane NO and Others 1998 (1) SA 300 (CC)

$143,144,153$

Harper $v$ Virginia Board of Elections 383 US 663 (1966)

8,87

Hoffman v SAA 2000 (11) BCLR 1211 (CC)

Holley $v$ Lavine 553 F2d 845 (2d Cir 1977)

In re Jobes 529 A2d 434 (NJ S Ct 1987)

In re Macleantown Residents Association: Re Certain Erven and Commonage in

Macleantown 1996 (4) SA 1272 (LCC)

206, 207

JA $v$ Riti 377 F Supp 1046 (DFNJ 1974)

Jackson $v$ City of Joliet 715 F 2d 1200 (7th Cir) (1983)

Jaftha $v$ Schoeman and Others; Van Rooyen $v$ Stoltz and Others 2005 (1) BCLR 78 (CC) 143, 160

Jooste $v$ Botha 2002 (2) BCLR 187 (T) 
Karabo and Others $v$ Kok and Others 1998 (1) SA 1014 (LCC)

King $v$ Smith 392 US (1968)

$163,164,166$

Khuzwayo v Dludla [2000] 4 All SA 329 (LCC)

$79,80,95$

Landbou Navorsingsraad $v$ Klaasen LCC Case 83R/01 (unreported 29 October 2001)

Lategan $v$ Koopman en Andere 1998 (3) SA 457 (LCC)

Law $v$ Canada (Minister of Employment and Immigration) (1999) 170 DLR (4th)

Lewis $v$ Martin 397 US 552 (1970)

Magodi and Others $v$ Van Rensburg [2001] 4 All SA 485 (LCC)

Mablangu and Another $v$ Van Eeden and Another [2000] 3 All SA 321 (LCC)

Mahlangu $v$ De Jager 1996 (3) SA 325 (LCC)

Mashavha $v$ President of the RSA \& Others 2004 (12) BCLR 1243 (CC)

Maryland $v$ Mathews 415 F Supp 1206 (DDC 1976)

Minister of Finance \& Another $v$ Van Heerden 2004 (11) BCLR 1125 (CC)

Minister of Health $v$ Treatment Action Campaign 2002 (5) SA 721 (CC)

30, 31, 32, 33, 53, 54, 151, 154, 155, 159, 160, 165, 192, 193, 194

Minister of Home Affairs and Others $v$ Watchenuka and Another 2004 (2)

BCLR 120 (SCA)

$150,151,153,154$

Minister of Land Affairs and Another $v$ Slamdien and Others [1999] 1 All SA 608 (LCC);

1999 (4) BCLR 413 (LCC)

208

Modderfontein Squatters $v$ Modderklip Boerdery (Pty) Ltd 2004 (6) SA 40 (SCA)

Muller $v$ Oregon 208 US 412 (1908)

National Coalition for Gay \& Lesbian Equality v Minister of Justice

and Others 1999 (1) SA 6 (CC)

Nevada Department of Human Resources v Hibbs 123 S Ct 1972 (2003)

$42,143,145,146,184$

Nhlabati $v$ Fick [2003] 2 All SA 323 (LCC)

Nkosi and Another v Bubrmann 2002 (1) SA 372 (SCA)

Ntai and Others $v$ Vereniging Town Council and Another 1953 (4) SA 579 (A)

Owens $v$ Roberts 377 F Supp 45 (MD Fla 1974)

211

Pitout $v$ Mbolane [2000] 2 All SA 377 (LCC)

Port Elizabeth Municipality v Various Occupiers 2005 (1) SA 217 (CC)3, 18, 27, 33, 34, 35, 150, 151

President of the Republic of South African and Another $v$ Hugo 1997 (4) SA 1 (CC)

Prince $v$ President of the Law Society of the Cape of Good Hope \& Others 2002 (2) SA 794 (CC) 148

Prinsloo $v$ Van der Linde 1997 (3) SA 1012 (CC)

$R v$ Cambridge Health Authority, ex parte B [1995] 2 All ER 129 (CA)

Richtersveld Community $v$ Alexkor Ltd and Another 2000 (1) SA 337 (LCC)

Rosado $v$ Wyman 397 US 397 416-17 (1970)

Rothstein $v$ Wyman 303 F Supp 339 (SD FNY 1969)

$S v$ Makwanyane \& Another 1995 (3) SA 391 (CC)

$S v$ Mamabolo (E TV and Others Intervening) 2001 (3) SA 409 (CC)

$143,145,149,150,196$

144

San Antonio Independent School District v Rodriguez 411 US 1 (1973)

85,88

Serole and Another v Pienaar 2000 (1) SA 328 (LCC)

205,222

Shapiro $v$ Thompson 394 US 618 (1969)

$79,81,82,87$

203, 205

Skhosana and Others $v$ Roos t/a Roos se Oord and Others 2000 (4) SA 561 (LCC)

Soobramoney $v$ Minister of Health, KwaZulu-Natal 1998 (1) SA 765 (CC)

$18,25,27,28,31$, 32, 55, 144, 148, 149, 150, 194, 196, 197 
The Social and Economic Rights Action Centre and the Centre for Economic and

Social Rights v Nigeria Communication No $155 / 96$ October 2001

(African Commission on Human and Peoples' Rights)

143,148

Tucker $v$ Toia 371 NE 2d 449 (NY 1977)

Van Lare $v$ Hurley 421 US 338 (1975)

Van Zyl NO v Maarman [2000] 4 All SA 212 (LCC) 203

Williams $v$ Dandridge 297 F Supp 450469 (D Md 1968) 


\section{Legislation and Policy Documents}

Advisory Council on Unemployment Compensation, Report and Recommendations

(Washington, DC: US Government Printing Office 1995)

African Charter of Human and People's Rights (1981)

Choice on Termination of Pregnancy Act 92 of 1996

Constitution of the Republic of South Africa Act 200 of 1993

$179,199,208$

Constitution of the Republic of South Africa Act 108 of 1996

$164,165,167,169,179,190,192$,

193, 203, 235

Constitucion Politica de los Estados Unidos Mexicanos, art 30 (amended 1996)

253

Convention on the Elimination of All Forms of Discrimination Against Women (1979) 183

Convention of the Rights of the Child (2002)

Department of Health National HIV and Syphilis Sero-Prevalence Survey of Women

Attending Ante-Natal Clinics in South Africa in 2001 (2003)

Department of Health Operational Plan for Comprehensive HIV and AIDS Care, Management and Treatment for South Africa (2003)

Dutch Reformed Church in Africa 'Transition and Poverty' (1990) 2/90 (Supplement)

DRCA Action Economic Justice in South Africa : A Pastoral Statement (1999)

Evangelical Church in Germany and the German Bishops' Conference For a Future

Founded on Solidarity and Justice: A Statement of the Evangelical Church in

Germany and the German Bishops' Conference on the Economic and Social Situation

in Germany (1997)

Extension of Security of Tenure Act 62 of 1997

203, 205, 210, 212, 213, 220, 221, 222, 223

Gluckman Commission Report of the National Health Services Commission (1944)

186,187

International Covenant on Economic, Social and Cultural Rights (1966)

$183,183,168,169,183$

Land Affairs General Amendment Act 51 of 2001

214

Land Reform (Labour Tenants) Act 3 of 1996

203

Land Restitution and Reform Laws Amendment Act 18 of 1999

206

MarketResearch.com Academic The Chocolate Market (2001) Web publication www.academic.marketresearch.com/product/print/default.asp

$283,284,285$

Medical Schemes Act 131 of 1998

Medical Research Council Changing Health in South Africa: Towards New

Perspectives in Research (1991)

188

Medicines and Related Substances Act 90 of 1997

National Compensation Survey: Occupational Wages in the United States, 2001

National Health Act 63 of 1977

National Health Act 61 of 2003

Natives Land Act 28 of 1913

Nelson Mandela Foundation/HSRC Report Emerging Voices: A Report on

Education in South African Rural Communities (2002)

Prevention of Illegal Eviction from and Unlawful Occupation of Land Act 19 of $1998 \quad 26,146$

Public Health Act 1919

79,185

Restitution of Land Rights Act 2 of 1994

$199,203,206,208,220,223,224$

RES Testimony on Human Rights (1983)

Social Assistance Act 59 of 1992 
Social Security Act 1935 (US)

Staff of House Committee on Ways and Means Background Material and

Data on Programs. Within the Jurisdiction of the Committee on Ways and Means (1996) 104th Cong 2d Sess

The Confession of Belhar (1986)

The Kairos Document: Challenge to the Church: a Theological Comment on the Political Crisis in South Africa (1985)

United Nations General Comment No 3 (Fifth session, 1990) The Nature of States Parties Obligations (art 2(1) of the Covenant), UN doc E/1991/23

United Nations General Comment (2003) Human Security Now, presented to the United Nations Secretary-General, Kofi Annan on 1 May 2003

United Nations General Assembly (1948) Universal Declaration of Human Rights adopted 10 December 1948

US Dept of Justice, Immigration and Naturalization Service, 1996 Statistical Yearbook of the Immigration and Naturalization Service (1997)

White Paper on Transformation of the Health System in South Africa (1997)

World Bank World Development Report 2002. Building Institutions for Markets (2002)

World Health Organisation Global Strategy for Health for All by the Year 2000 (1981) 


\section{Index}

Anti-paternalism

6,13

Children

$29,77,80,85$

Citizenship

$153,240,249,280$

Civic Republicanism

7, 74, 98, 100

Civil society / NGOs

$33,129,131,135,177,237$

Communitarianism

34,280

Critical theories

$6,199,227,230,239$

Depoliticisation

$18,21,25,36$

40,51

Development economics

$90,92,141,143,145,152,232$

Dignity-based theories

104

Directive principles

3, 242

Due process-based theories

108

Durkheim, Emile

Economic theory

$4,37,41,51,52,109,168,170,256,257,261,267,274,276,285,287$

Egalitarian vs libertarian theories

$180,256,270$

Equality-based theories

$2,69,87,144,153,256,260,261$

Fraser, Nancy

19

Fundamentalism

Hayek, Friedrich von

$43,51,171$

Health care

HIV/Aids

Homelessness and housing

26, 27, 29, 151, 165, 179, 193, 194, 196

$18,19,26,30,33,58,151,192,193,194,195$

26, 28, 33, 35, 58, 192, 199, 206, 208, 210

Institutional argument

$32,49,61,112,175,222$

Institutional capacity

$30,31,60,93,96,103$

Judicial review / overview

Justiciability

31, 32, 35, 49, 53, 154, 159, 160, 165 199, 206

93, 96, 103, 142

Klare, Karl

$17,49,218$

Labour rights / employment

$89,239,240,245,251$

Legal Realism

$6,8,11,12$

Michelman, Frank

$2,9,72,73,79,86,90,98$

Millennium Development Goals (UN)

Minimum / core rights

$30,85,86,155,158,160,166,168,169,183$

Morality-based theories

$57,61,115,120,261,276$ 
Needs-based theories

Negative vs positive rights

New Deal

New Institutional Economics

New Property

Normality assumption

Normative theories

Positive social science

Posner, Richard

Poverty

Progressive realization

Public choice theory

Public vs private

Race

Rawls, John

Reich, Charles

Rhetoric

Roosevelt, Franklin D

Sen, Amartya

Social citizenship

Social Darwinism

Sunstein, Cass

Theological theory

'Theory drag'

'Theory matters'

Transformative Constitutionalism
$2,86,154$

$7,48,49,108,111,149$

$15,73,76,84$

$38,43,44,49,112$

9,82

3,241

$39,226,276$

$37,38,39,41,52,53,54$

7,8

$9,15,19,21,60,79,241,260$

47

40,41

$32,61,65,114,240,245$

$77,78,188,189,208,210$

$74,86,90,124,171,180,258$

$2,9,12,15,82$

$24,25,28,33,36,244,254$

8,15

$60,67,172,174$

89, 97, 101, 103, 105, 240, 249, 276

6,9

$62,63,64,67,69,128,133,225$

$3,38,39,128,214,215,225,234$

$3,38,39,57,128,225,226$

17, 49, 50, 199, 214, 215, 218

$9,15,75,78,89$

War on Poverty

$239,241,246,252$ 
7 he bulk of the contributions in Theories of Social and Economic Justice originated in a research project initiated by the Stellenbosch Institute for

Advanced Study (STIAS) in 2002. STIAS hosted a workshop in July 2004 in which researchers from Law, Economics, Theology and Sociology participated, and some of the contributions at the workshop were subsequently reworked into chapters for this book. In addition, colleagues, both in South Africa and abroad, who had not participated in the workshop but whose recently published work on social and economic justice fitted in with the project extremely well, gave permission to re-publish their articles in the book.

The book is based on the idea that the attainment of greater social and economic justice, specifically in the South African context, is strongly influenced by the implications and the coherence of various theories of social and economic justice. Furthermore, it is argued that the promotion and protection of social and economic justice need to be approached from different theoretical perspectives when considering different practical circumstances, contexts and dilemmas. One theoretical size simply does not fit all, as far as social and economic justice is concerned. The range of theoretical approaches represented in this book - legal, economic, theological and sociological - is testimony to the truly cross- and multi-disciplinary nature of the contributions.

Apart from leading South African scholars in Law, Economics, Theology and Sociology, four contributions from American academics are included: Professors Gregory Alexander (Cornell Law School), William Forbath (University of Texas), Lucy Williams (Northeastern University), and Ross Zucker (Lander College).

AJ van der Walt is professor in the Faculty of Law at Stellenbosch University and author of Constitutional Property Clauses: A Comparative Analysis (1999) and Constitutional Property Law (2005). He is also a co-editor, with $\mathrm{H}$ Botha and J van der Walt, of Rights and Democracy in a Transformative Constitution (2004, AFRICAN SUN MeDIA).
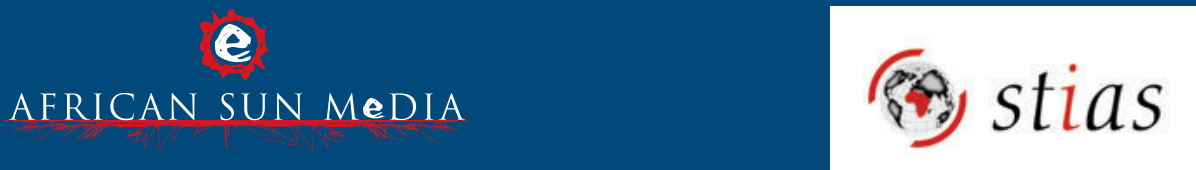